PNNL-18119

WTP-RPT-169, Rev 0

Prepared for the U.S. Department of Energy under Contract DE-AC05-76RL01830

\title{
Characterization, Leaching, and Filtration Testing for Tributyl Phosphate (TBP, Group 7) Actual Waste Sample Composites
}

$\begin{array}{llll}\text { MK Edwards } & \text { AM Casella } & \text { LK Jagoda } & \text { RW Shimskey } \\ \text { JM Billing } & \text { JV Crum } & \text { ED Jenson } & \text { LA Snow } \\ \text { DL Blanchard } & \text { RC Daniel } & \text { AE Kozelisky } & \text { RG Swoboda } \\ \text { EC Buck } & \text { KE Draper } & \text { PJ MacFarlan } & \\ \text { AJ Casella } & \text { SK Fiskum } & \text { RA Peterson } & \end{array}$

March 2009

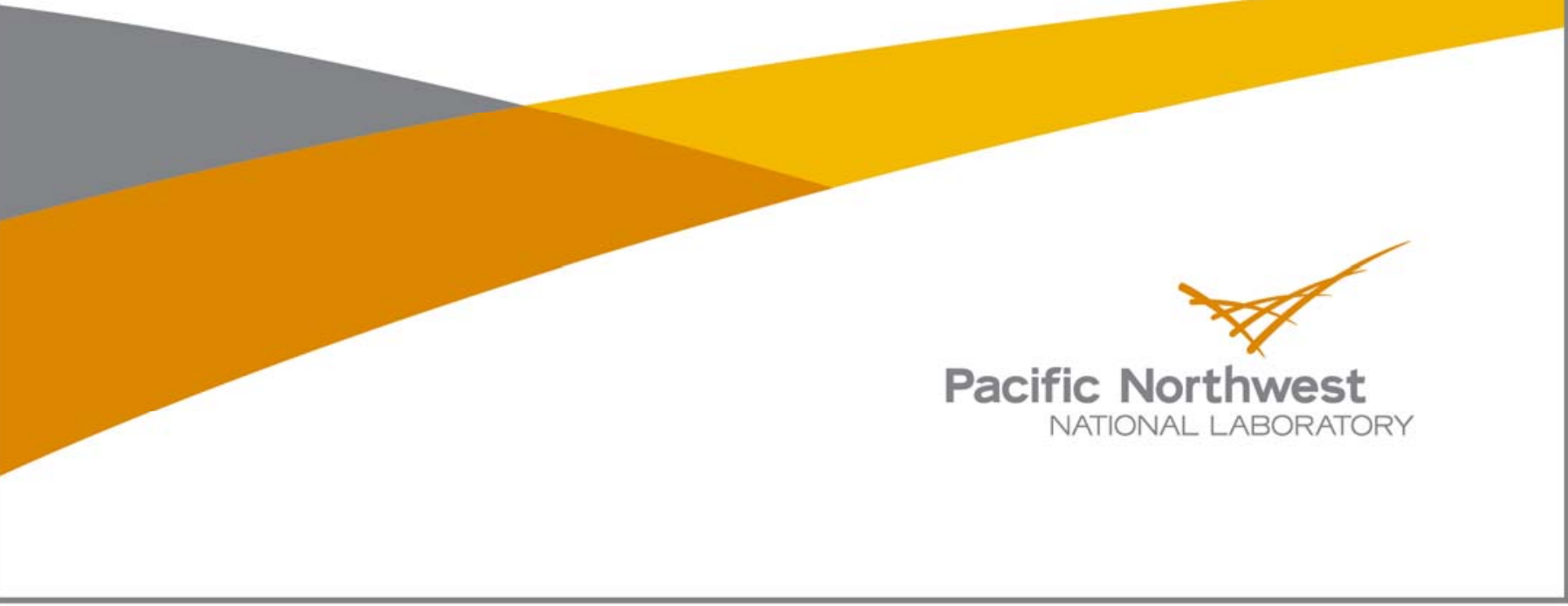




\section{DISCLAIMER}

This report was prepared as an account of work sponsored by an agency of the United States Government. Neither the United States Government nor any agency thereof, nor Battelle Memorial Institute, nor any of their employees, makes any warranty, express or implied, or assumes any legal liability or responsibility for the accuracy, completeness, or usefulness of any information, apparatus, product, or process disclosed, or represents that its use would not infringe privately owned rights. Reference herein to any specific commercial product, process, or service by trade name, trademark, manufacturer, or otherwise does not necessarily constitute or imply its endorsement, recommendation, or favoring by the United States Government or any agency thereof, or Battelle Memorial Institute. The views and opinions of authors expressed herein do not necessarily state or reflect those of the United States Government or any agency thereof.

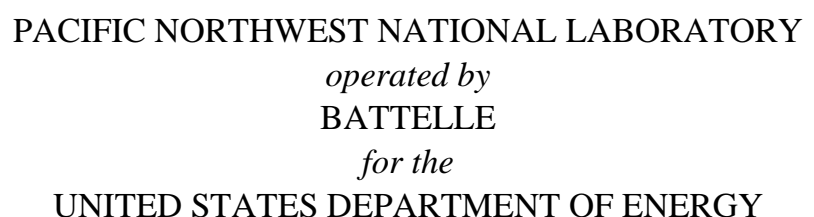
under Contract DE-AC05-76RL01830

Printed in the United States of America

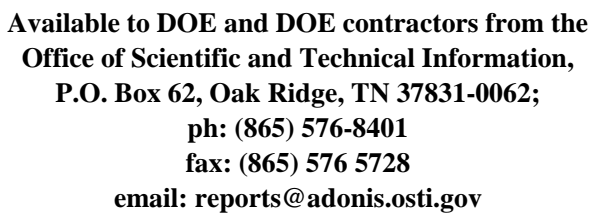

Available to the public from the National Technical Information Service, U.S. Department of Commerce, 5285 Port Royal Rd., Springfield, VA 22161 ph: (800) 553-6847 fax: (703) 605-6900

email: orders@nits.fedworld.gov online ordering: http://www.ntis.gov/ordering.htm 
PNNL-18119

WTP-RPT-169, Rev 0

\section{Characterization, Leaching, and Filtration Testing for Tributyl Phosphate (TBP, Group 7) Actual Waste Sample Composites}

$\begin{array}{llll}\text { MK Edwards } & \text { AM Casella } & \text { LK Jagoda } & \text { RW Shimskey } \\ \text { JM Billing } & \text { JV Crum } & \text { ED Jenson } & \text { LA Snow } \\ \text { DL Blanchard } & \text { RC Daniel } & \text { AE Kozelisky } & \text { RG Swoboda } \\ \text { EC Buck } & \text { KE Draper } & \text { PJ MacFarlan } & \\ \text { AJ Casella } & \text { SK Fiskum } & \text { RA Peterson } & \end{array}$

March 2009

Test Specification: 24590-PTF-TSP-RT-06-003, Rev. 1

Work Authorization: 019

Test Plan: TP-RPP-WTP-467, Rev. 1

Test Exceptions: None

R\&T Focus Area: Pretreatment

Test Scoping Statement: None

Pacific Northwest National Laboratory

Richland, Washington 99352 
WTP-RPT-169, Rev 0

\section{COMPLETENESS OF TESTING}

This report describes the results of work and testing specified by Test Specification 24590-PTF-TSP-RT-06-003, Rev. 1 and Test Plans TP-RPP-WTP-467, Rev. 1 7/31/07. The work and any associated testing followed the quality assurance requirements outlined in the Test Specification/Plan. The descriptions provided in this test report are an accurate account of both the conduct of the work and the data collected. Test plan results are reported. Also reported are any unusual or anomalous occurrences that are different from expected results. The test results and this report have been reviewed and verified.

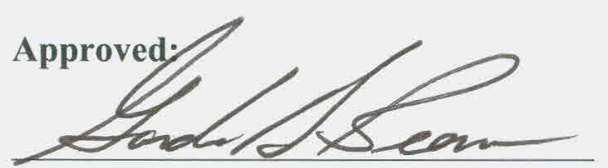

Gordon H. Beeman, Manager WTP R\&T Support Project

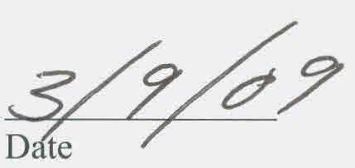




\section{Contents}

Abbreviation/Acronym List ..................................................................................................... XV

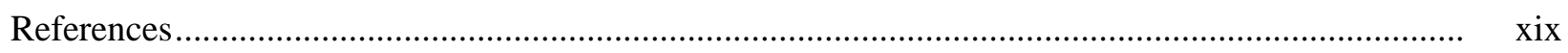

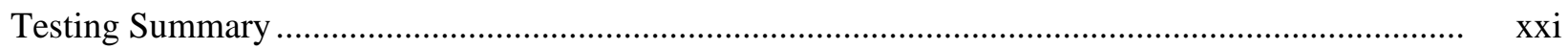

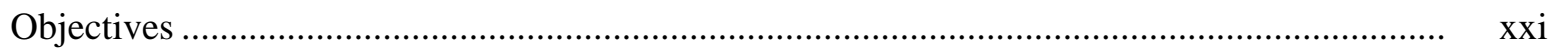

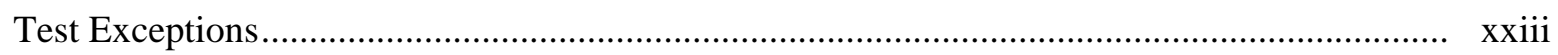

Results and Performance Against Success Criteria ............................................................... xxiii

Quality Requirements ................................................................................................. XxV

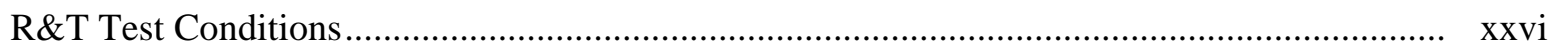

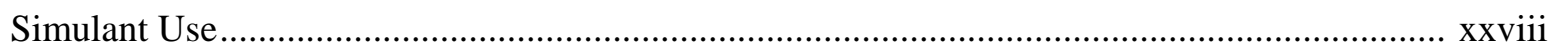

Discrepancies and Follow-on Tests ….................................................................................... xxviii

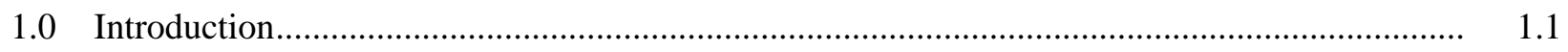

1.1 Tank Waste Pretreatment Operations at the WTP ....................................................... 1.1

1.2 Issues Identified by the External Flowsheet Review Team .......................................... 1.2

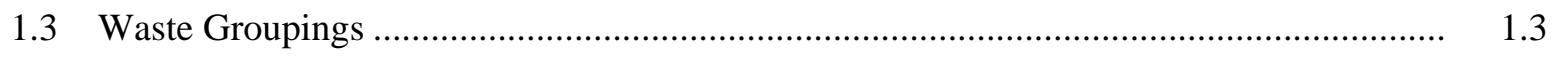

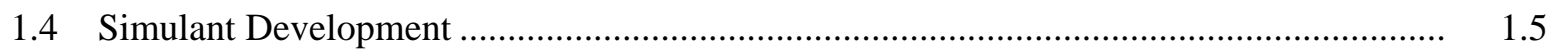

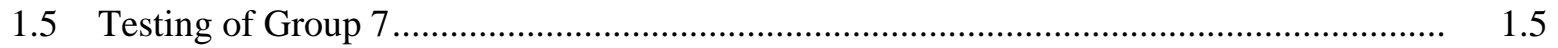

2.0 Test-Sample Selection, Compositing, and Homogenization ................................................ 2.1

2.1 Tributyl Phosphate Sludge Sample Selection............................................................... 2.1

2.2 Group 7 Sample Homogenization and Sub-sampling................................................... 2.5

3.0 Initial Characterization Results for Tributyl Phosphate Waste Sludge Group 7 ..................... 3.1

3.1 Physical Properties of the Composite Group 7 TBP Slurry ............................................. 3.3

3.2 Rheology of the Composite Group 7 TBP Slurry ....................................................... 3.6

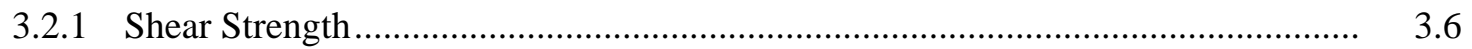

3.2.2 Flow Curve …......................................................................................... 3.7

3.3 Chemical and Radiochemical Composition of the Group 7 Slurry …................................ 3.10

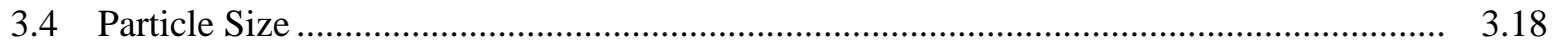

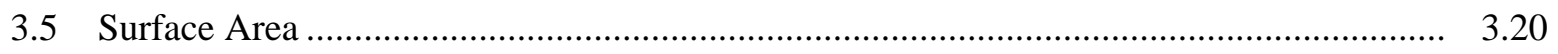

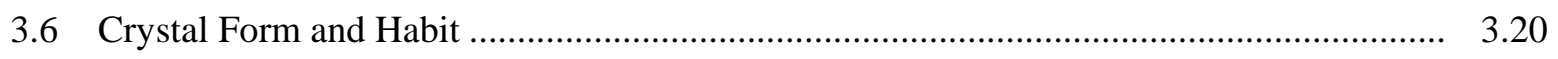

4.0 Group 7 Tributyl Phosphate Sludge Batch Parametric Leaching …...................................... 4.1

4.1 Group 7 Tributyl Phosphate Sludge Batch Parametric Leaching: Experimental............... 4.1

4.1.1 Initial Washing of the Group 7 Solids ................................................................ 4.1

4.1.2 Division of the Washed Group 7 Solids.................................................................. 4.2

4.1.3 Caustic Leaching of the Washed Group 7 Solids ............................................... 4.2 
4.1.4 Washing of Caustic Leached Group 7 Solids for Analysis.................................. 4.4

4.2 Group 7 Tributyl Phosphate Sludge Parametric Caustic-Leaching Test Results............... 4.5

4.2.1 Time, Temperature, and Hydroxide Effects on Aluminum Dissolution from the Group 7 Solids .......................................................................................... 4.5

4.2.2 Time, Temperature, and Hydroxide Effects on Phosphorus Dissolution from the Group 7 Solids

4.2.3 Time, Temperature, and Hydroxide Effects on Uranium Dissolution from the Group 7 Solids

4.2.4 Anions, Silicon, Cr, and Iron Leaching Behavior ............................................. 4.15

4.2.5 Assessment of Final Leaching Conditions .......................................................... 4.15

4.2.6 Comparison of Initial and Caustic-Leached and Washed Solids Properties........... 4.15

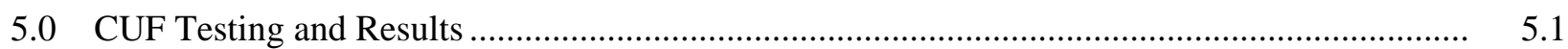

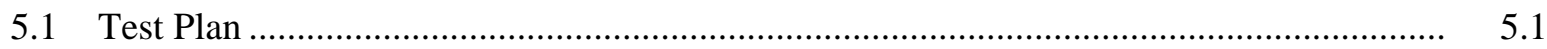

5.2 Low-Solids Slurry Characterization ......................................................................... 5.4

5.3 Filter-Flux Test Matrix and Initial Dewater …............................................................... 5.13

5.3.1 Low-Solids Test Matrix …............................................................................ 5.13

5.3.2 Group 7 Dewatering................................................................................ 5.18

5.3.3 Adding AY-102 and Pump Failure ............................................................... 5.20

5.3.4 Dewatering Group 7/AY-102 Slurry............................................................ 5.22

5.3.5 High-Solids Matrix ........................................................................................ 5.23

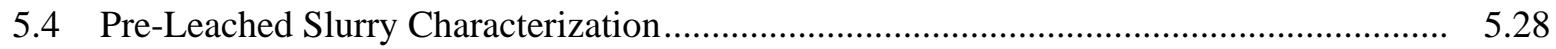

5.4.1 Physical-Property and Chemical-Characterization Measurements ......................... 5.28

5.4.2 Rheology of the AY-102 Slurry and High-Solids Slurry .................................... 5.32

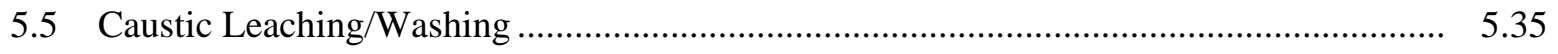

5.5.1 Caustic Batch Leaching Results.................................................................... 5.36

5.5.2 Caustic-Leach Dewatering ........................................................................ 5.41

5.5.3 Dewatered Leached Slurry Physical Characterization ........................................ 5.43

5.5.4 Caustic Batch Rinsing Results ....................................................................... 5.48

5.5.5 Dewatering Caustic-Wash Solutions ............................................................... 5.63

5.6 Final Filter Flux Test Matrix ..................................................................................... 5.65

5.7 Leached-Material Characterization.......................................................................... 5.70

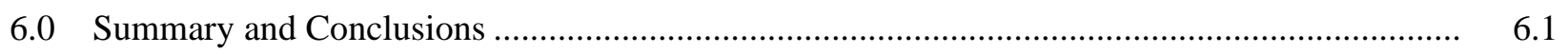

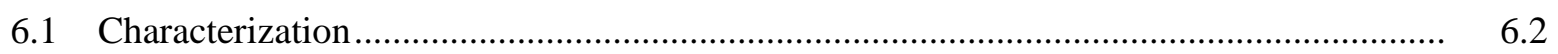

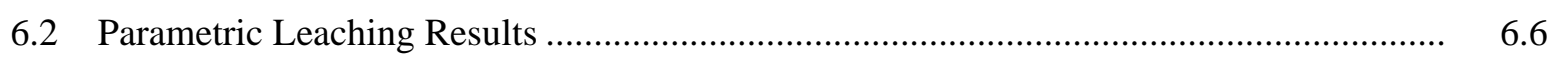

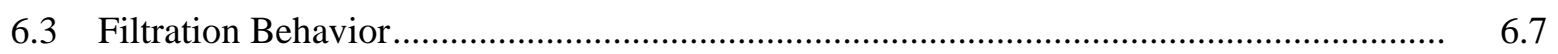

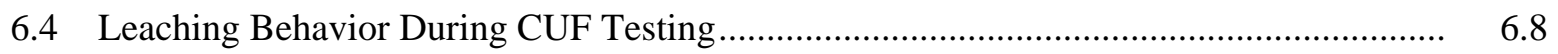




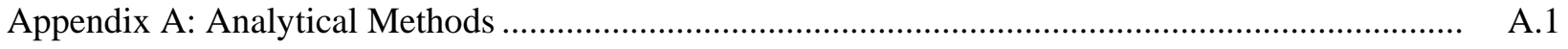

Appendix B: Physical Properties Determination and BET Methods .............................................. B.1

Appendix C: Crystal Form and Habit .............................................................................. C.1

Appendix D: Quality Assurance and Quality Control .............................................................. D. D.1

Appendix E: Group 7 Particle-Size Methods and Analysis (TDP-WTP-273).................................. E.1

Appendix F: Group 7 Rheology Methods and Analysis ................................................................... F.1

Appendix G: Group 7 Analytical Results from Parametric Leaching …....................................... G.1

Appendix H: CUF Filtration/Leaching Experimental Methods and Analyses .................................. H.1

Appendix I: Homogenization Methods ................................................................................... I.1

Appendix J: Group 7/AY-102 /CUF Analytical Results............................................................... J.1

Appendix K: Group 7 CUF Concurrence Letter ............................................................................. K.1 


\section{Figures}

1.1. Schematic Representation of the Processes to be Performed in the PTF

2.1. Estimated Tank Waste Composition of Selected Analytes for Group 7 Sludge Wastes in the Hanford Tank Farm (BBI Source) ................................................................................ 2.2

2.2. Selection Decision Process for TBP Sludge Samples ................................................................ 2.3

2.3. Representative Pictures of As-Received Group 7 Waste ....................................................... 2.6

2.4. Group 7 Sample with Visible Debris.................................................................................... 2.7

2.5. Composite Composition of Group 7 by Hanford Tank Waste ................................................. 2.9

2.6. Group 7 Confirmation of Successful Material Composite Based on Density and Settled Solids

3.1. Composite Group 7 Slurry Processing and Analysis Scheme ................................................ 3.2

3.2. Composited Group 7 Washed Solids Processing and Analysis Scheme .................................. 3.3

3.3. Group 7 TBP Solids Settling Test ................................................................................... 3.4

3.4. Flow Curve (shear stress versus shear rate) for the Group 7 Initial Characterization Slurry Sample at $25^{\circ} \mathrm{C}, 40^{\circ} \mathrm{C}$, and $60^{\circ} \mathrm{C}$. The second repeat measurement for $25^{\circ} \mathrm{C}$ is shown............ 3.7

3.5. Initial Flow-Curve Measurement of the Group 7 Initial Characterization Slurry at $25^{\circ} \mathrm{C}$ Highlighting Significant Flow-Curve Hysteresis

3.6. Down-Ramp Flow-Curve Data for the Group 7 Initial Characterization Slurry at $25^{\circ} \mathrm{C}$, $40^{\circ} \mathrm{C}$, and $60^{\circ} \mathrm{C}$.

3.7. Centrifuged Solids from Chemical Characterization Sample of Group 7 TBP Sludge.

3.8. Wash Sequence of Group 7 TBP Sludge Supporting Initial Characterization

3.9. Comparison of Group 7 TBP Sequential Wash Solutions

3.10. Third Wash after Ionic Strength Adjustment and Filtration.....

3.11. Selected Analyte Phase Distribution for Group 7 TBP Sludge .....

3.12. Volume Distribution Result for the Primary Group 7 Initial Characterization Sample as a Function of Pump Speed

3.13. Volume Distribution Result for the Duplicate Group 7 Initial Characterization Sample as a Function of Pump Speed

3.14. XRD Pattern of Washed Group 7 TBP Sludge with Rutile (TiO2) Internal Standard Background-Subtracted Pattern with Stick-Peak Identification

3.15. SEM Images of Washed Group 7 TBP Sludge with EDS Evaluation

3.16. SEM Images of Washed Group 7 TBP Sludge.

3.17. SEM Images with EDS Evaluation of Group 7 TBP Washed Sludge

3.18. SEM Imaging of Washed Group 7 TBP Sludge with EDS Analysis

3.19. TEM Analysis of an Iron Calcium Phosphate Phase and EDS Analysis of the Phase 
3.20. EDS Analysis of an Iron Phosphate Phase, Electron Diffraction of the Phase and a TEM Image

3.21. Electron Diffraction Pattern of U(VI) Phase in G7-S-WL

3.22. (a) Rotational Average Spectrum from Diffraction Pattern and (b) Compositional Analysis of U(VI) Phase.

3.23. TEM Image of Large Sodium Uranyl Phosphate Phase in G7 Tank Sludge.

4.1. Aluminum Heating Block and Shaker Table Used in Parametric Leaching Tests.....

4.2. Washing, Subdivision, and Analysis Scheme for the Group 7 Caustic-Leached Solids .

4.3. Aluminum Concentration and Percent Removed Versus Time at $40^{\circ} \mathrm{C}$ for Leaching of the Group 7 Washed Solids in 1 and $3 \mathrm{M} \mathrm{NaOH}$

4.4. Aluminum Concentration and Percent Removed Versus Time at $60^{\circ} \mathrm{C}$ for Leaching of the Group 7 Washed Solids in 0.25, 1, and $3 \mathrm{M} \mathrm{NaOH}$

4.5. Aluminum Concentration and Percent Removed Versus Time at $80^{\circ} \mathrm{C}$ for Leaching of the Group 7 Washed Solids in 0.25, 1, and $3 \mathrm{M} \mathrm{NaOH}$

4.6. Aluminum Concentration and Percent Dissolved in $0.25 \mathrm{M} \mathrm{NaOH}$

4.7. Aluminum Concentration and Percent Dissolved in $1 \mathrm{M} \mathrm{NaOH}$

4.8. Aluminum Concentration and Percent Dissolved in $3 \mathrm{M} \mathrm{NaOH}$

4.9. Phosphorus Concentration and Percent Removed Versus Time at $40^{\circ} \mathrm{C}$ for Leaching of the Group 7 Washed Solids in 1 and $3 \mathrm{M} \mathrm{NaOH}$

4.10. Phosphorus Concentration and Percent Removed Versus Time at $60^{\circ} \mathrm{C}$ for Leaching of the Group 7 Washed Solids in $0.25,1$, and $3 \mathrm{M} \mathrm{NaOH}$

4.11. Phosphorus Concentration and Percent Removed Versus Time at $80^{\circ} \mathrm{C}$ for Leaching of the Group 7 Washed Solids in 0.25 , 1, and $3 \mathrm{M} \mathrm{NaOH}$

4.12. Phosphorus Concentration and Percent Removed in $0.25 \mathrm{M} \mathrm{NaOH}$

4.13. Phosphorus Concentration and Percent Removed in $1 \mathrm{M} \mathrm{NaOH}$

4.14. Phosphorus Concentration and Percent Removed in $3 \mathrm{M} \mathrm{NaOH}$

4.15. Uranium Concentration and Percent Removed Versus Time at $60^{\circ} \mathrm{C}$ for Leaching of the Group 7 Washed Solids in 0.25 , 1, and $3 \mathrm{M} \mathrm{NaOH}$

4.16. Uranium Concentration and Percent Removed in $1 \mathrm{M} \mathrm{NaOH}$

4.17. Group 7 TBP Sludge Reduction in Solid Mass with Water Washing and Caustic Leaching.....

4.18. Volume Distribution Result for the Group 7 Caustic-Leached Sample as a Function of Pump Speed

4.19. Influence of Caustic-Leaching and Washing on Group 7 (TBP sludge) Solids PSD

4.20. XRD Pattern of Caustic-Leached Group 7 TBP Sludge with Rutile (TiO2) Internal Standard (a) Raw Data and (b) Background-Subtracted with Stick-Peak Identification.

4.21. SEM Images of Group 7 TBP Sludge Caustic Leached and Washed Solids (a) $15 \mathrm{kV}$, 2500×; (b) $15 \mathrm{kV}, 1500 \times$; (c) $15 \mathrm{kV}, 4000 \times$; (d) $15 \mathrm{kV}, 4000 \times$ 
4.22. SEM Image of Group 7 TBP Sludge Caustic Leached and Washed Solids with EDS Spectra (a) SEM Image; (b) EDS Spectra of Spot 3; (c) EDS Spectra of Spot 4

4.23. TEM Image of Group 7 TBP Sludge Caustic Leached and Washed Solids (a) TEM Image of an Agglomerate; (b) TEM Image Showing Various Phases; (c) EDS Analysis of a Uranium Phosphorus Phase in the Agglomerate Shown in (a); (d) SAED Image of the Uranium Phosphorus Phase.

4.24. TEM Analysis of a Sodium Aluminum Phosphate Phase in the Group 7 TBP Sludge Caustic Leached and Washed Solids (a) EDS Analysis; (b) SAED Image

4.25. TEM Images and Analysis of an Iron Phase in the Group 7 TBP Sludge Caustic Leached and Washed Solids (a) STEM-HAADF Image of a Particle; (b) EDS Analysis of an Iron Phase; (c) TEM Image of the Agglomerate.

4.26. Iron Oxide Phase Surrounded by Uranium-Bearing Particles in the Group 7 TBP Sludge Caustic-Leached and Washed Solids. (a) TEM Image; (b) SAED Image; (c) EDS Analysis..

4.27. TEM Images of Particles in the Group 7 TBP Sludge Caustic-Leached and Washed Solids ....

5.1. Group 7 / AY-102 Testing Flowchart.

5.2. Process Flow Diagram of Creating Low-Solids Slurry

5.3. PSD of CUF Group 7 Low-Solids Slurry as a Function of Pump Speed

5.4. Influence of Circulation in the CUF for Group 7 5.10

5.5. Flow Curves for Group 7 CUF Low Solids Slurry... 5.11

5.6. Filter-Flux Data for Low-Solids Matrix (Predicted UDS concentration of $4 \mathrm{wt} \%$ )....... 5.12

5.7. Filter Test Matrix for Group 7 Lows-Solids 5.15

5.8. Flux vs. TMP for Group 7 Low-Solids 5.16

5.9. Flux vs. AV for Group 7 Low-Solids 5.16

5.10. Flux vs. Median Process Time of Test Condition for Group 7 Low-Solids 5.16

5.11. Correlation Calculations of Average Flux as Function of TMP and Time (Predicted UDS of $4 \mathrm{wt} \%)$.

5.12. Process Flow for Dewatering Group 8 Slurry

5.13. Dewatering of Group 7 (4 to $12 \mathrm{wt} \%$ UDS) and the Blended Waste (12 to $26 \mathrm{wt} \%$ UDS) ...............

5.14. Process Flow of AY-102 Addition and Losses Created by Pump Failure.

5.15. Process Flow for Dewatering the Blended Waste Slurry (Group 7/AY-102)

5.16. Filter-Flux Data for Group 7-AY102 High-Solids Matrix (Measured as $26 \mathrm{wt} \%$ UDS) 5.22

5.17. Filter Test Matrix for Group 7-AY102 High-Solids 5.25

5.18. Flux vs. TMP for Group 7-AY102 High-Solids. 5.26

5.19. Flux vs. AV for Group 7-AY102 High-Solids 5.26

5.20. Flux vs. Median Process Time of Test for Group 7-AY102 High-Solids 5.26

5.21. Least Squares Fit to High-Solids Matrix Test Results to Linear Model (Measured UDS of $26 \mathrm{wt} \%)$ 5.26 
5.22. Process Flow Through the High-Solids Matrix

5.23. Flow Curves for the AY-102 Slurry 5.33

5.24. Flow Curves for the CUF High Solids Slurry 5.34

5.25. Process Flow for Caustic-Leach Preparation. 5.36

5.26. Process Flow for the Caustic Leach 5.37

5.27. Temperature Profile/Aluminum Leach Factor During Caustic Leaching 5.38

5.28. Concentration of Al, Cr, P, S, U and K during Caustic Leach of Group 3/4 Slurry...... 5.40

5.29. Process Flow of Dewatering Caustic Leached Slurry ..... 5.41

5.30. Dewatering Leached Blended Slurry (Group 7/AY102) at Standard Conditions 5.42

5.31. Sampling of Dewatered Caustic Leached Slurry 5.44

5.32. Flow Curves for Group 8 CUF Leached Dewatered Slurry .... 5.47

5.33. Process Flow of Batch Washing Operations 5.49

5.34. Total Aluminum in Group 7/AY-102 CUF Slurry 5.58

5.35. Total Chromium in Group 7/AY-102 CUF Slurry 5.59

5.36. Total Phosphorus in Group 7/AY-102 CUF Slurry..... 5.60

5.37. $\mathrm{Al}, \mathrm{Cr}$ and $\mathrm{P}$ removed from Dewatering and Washing the Group 7/AY-102 CUF Slurry After Caustic Leaching. 5.61

5.38. Free $\mathrm{OH}, \mathrm{Na}, \mathrm{Al}$, and $\mathrm{P}$ Molarity in Group 7/AY-102 CUF Slurry ...... 5.62

5.39. Filter Flux During Caustic Wash Steps and Comparison to Leach Dewatering Average Flux.. 5.64

5.40. Process Flow for Final Filter Slurry ................................................................................ 5.65

5.41. Filter Flux for the Washed Leached Filter Test Matrix (Measured UDS of 14 wt\%) ............... 5.67

5.42. Filter Test Matrix for Group 7-AY102 _...............................................................................

5.43. Flux vs. TMP for Group 7-AY102 Leached-Solids .............................................................. 5.68

5.44. Flux vs. AV for Group 7-AY102 Leached-Solids................................................................ 5.68

5.45. Flux vs. Median Process Time of Test .................................................................................. 5.68

5.46. Least-Squares-Fit of Leached Solid Test Matrix Results with Linear Model (Measured UDS of $14 \mathrm{wt} \%)$.

5.47. Radionuclides/Total Solids in Group 7/AY-102 CUF Slurry, Adjusted for Sampling ............. 5.74

5.48. Anions in the Group 7/AY-102 Slurry Supernate .............................................................. 5.75

5.49. XRD Scan Result for the Leached and Washed Solids from the CUF Experiments................. 5.77

5.50. SEM of Leached and Washed Particle ............................................................................. 5.78

5.51. SEM 2 of Leached and Washed Particle ............................................................................... 5.78

5.52. Flow Curves for the Group 7 Leached, Washed Slurry ..................................................... 5.80

6.1. Comparison of Slurry Composition Before and After Caustic Leaching and Washing ............. 6.10 


\section{Tables}

Table

Caption

Page

S.1. $\quad$ Test Objectives for Test Plan TP-RPP-WTP-467 ............................................................... x.. xi

S.2. Results and Performance Against Success Criteria for TP-RPP-WTP-467 ............................ xxiii

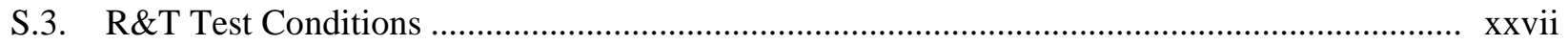

1.1. Water-Insoluble Component Mass (Metric Tons) Inventory as Function of Waste Type ......... $\quad 1.4$

1.2. Projected Distribution of Water-Insoluble Components in the Tank Waste Groupings ............ 1.4

2.1. Selection of TBP Sludge Tanks......................................................................................... 2.4

2.2. Group 7, 222S TBP Samples .................................................................................... 2.5

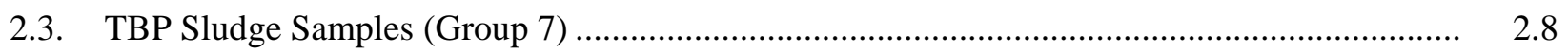

2.4. Group 7 Subsample Mass Density and Settling Data......................................................... 2.10

3.1. Physical-Property Measurements of Homogenized Group 7 TBP Slurry ................................. 3.5

3.2. Supplemental Physical Properties from Chemical Characterization Samples............................ 3.6

3.3. Shear Strength of Group 7 Initial Characterization Settled Solids at Ambient Hot-Cell

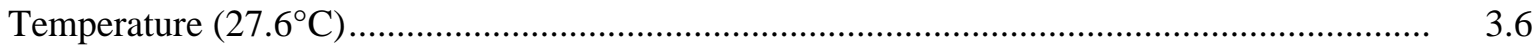

3.4. Results of Fitting Analysis for Rheology of the Group 7 Initial Characterization Slurry .......... 3.10

3.5. Radionuclide Characterization of the Group 7 TBP Sludge................................................... 3.13

3.6. Chemical Characterization of the Group 7 TBP Sludge........................................................... 3.14

3.7. Phase Distribution of Selected Analytes in Group 7 TBP Sludge........................................... 3.17

3.8. Particle-Size Analysis Percentile Results from Primary Group 7 Initial Characterization

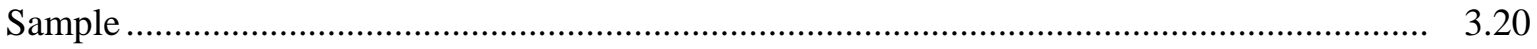

3.9. EDS Analysis of Iron Phosphate Phase ....................................................................... 3.29

4.1. Group 7 Caustic Leaching Conditions.............................................................................. 4.2

4.2. Group 7 TBP Sludge Leaching Final (24 hr) Aqueous Phase Conditions................................ 4.15

4.3. Group 7 Solids Wash Solution Composition and Density ................................................... 4.16

4.4. Group 7 TBP Sludge Leached Solids Composition and Leach Factors (Dry Mass Basis) ........ 4.16

4.5. Group 7 TBP Sludge Aluminum and Phosphorus Leach Factors ........................................... 4.19

4.6. Particle-Size Analysis Percentile Results from the Group 7 Caustic-Leached Sample.............. 4.21

4.7. Cumulative Undersize Percentiles Showing the Influence of Caustic-Leaching and Washing on the PSD of Group 7 (TBP sludge) Solids at Measurement Condition 1 (3000 RPM).

4.8. Normalized Weight Percents for Various Analytes Found by EDS of SEM Images for

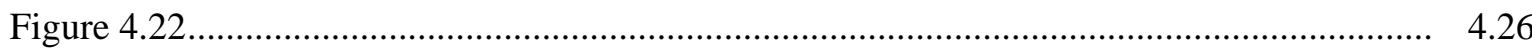

5.1. Mass Balance Overview of Group 7 Low-Solids Slurry ........................................................ 5.5

5.2. Simulant Addition to Group 7 Composite ............................................................................. 5.6 
5.3. Low-Solids Inventory and Composition (including permeate hold-up).................................. 5.6

5.4. Group 7 Low-Solids Supernate Opportunistic Composition................................................... 5.9

5.5. Particle Size Analysis Percentile Results for Group 7 Low-Solids Matrix .............................. 5.10

5.6. Cumulative Undersize Percentiles Showing the Influence of Circulation in the CUF on Group 7 PSD at Measurement Condition 1 to 3000 RPM................................................... 5.11

5.7. Results of Fitting Analysis for Group 7 CUF Low Solids Matrix.......................................... 5.12

5.8. Select Apparent Viscosities for the Low Solids Slurry ........................................................

5.9. Average Operating Conditions and Permeate Flux for Low-Solids Matrix Test ...................... 5.14

5.10. Mass Balance Overview of Dewatering .......................................................................... 5.18

5.11. Physical Properties of the Blended Group 7/AY102 Slurry Before Dewatering ...................... 5.20

5.12. Mass Balance Overview of Dewatering, AY-102 Addition ................................................... 5.21

5.13. Mass Balance Overview for the Dewatering of the Blended Slurry to $26 \mathrm{wt} \%$....................... 5.22

5.14. Average Operating Conditions and Permeate Flux for High-Solids Matrix Test..................... 5.24

5.15. High-Solids Slurry Physical-Property Measurements (inside slurry loop) .............................. 5.29

5.16. High-Solids Slurry Inventory and Composition ............................................................... 5.29

5.17. Group 7/AY102 High-Solids Slurry Composition Based on ICP-OES/Radionuclide

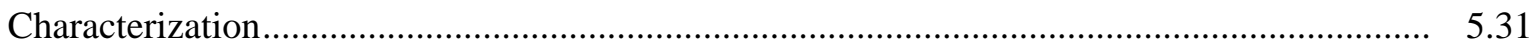

5.18. Results of Fitting Analysis for AY-102 Slurry ................................................................... 5.33

5.19. Results of Fitting Analysis for the CUF High Solids Rheology Matrix ................................... 5.34

5.20. Select Apparent Viscosities for the High-Solids Slurry …........................................................ 5.35

5.21. Concentration of Major Analyte Components of Filtered Caustic Leach Samples, Corrected for Sample Evaporation ....

5.22. Comparison of Slurry Supernate Attributes to Filter Flux ...................................................... 5.43

5.23. Dewatered Caustic Leached Slurry Physical-Property Measurements...................................... 5.44

5.24. Group 7 Caustic leached, Dewatered Slurry Inventory and Composition................................ 5.44

5.25. Dewatered Leached Slurry Composition and Solid Leach Factor Calculations........................ 5.46

5.26. Results of Fitting Analysis for the Group 7 CUF Leached Dewatered Slurry ......................... 5.48

5.27. Select Apparent Viscosities for the Leached Dewatered Slurry .............................................. 5.48

5.28. Group 7/AY-102 Caustic leached Slurry Inventory and Composition after the First Wash ...... 5.50

5.29. Group 7/AY-102 Caustic leached Slurry Inventory and Composition after the Second Wash.. 5.51

5.30. Group 7/AY-102 Caustic leached Slurry Inventory and Composition after the Third Wash..... 5.52

5.31. Group 7/AY-102 Caustic leached Slurry Inventory and Composition after the Fourth Wash... 5.53

5.32. Caustic Wash Solutions Radionuclide and Opportunistic Compositions ................................ 5.55

5.33. Comparison of Washed Slurry Supernate Attributes to Filter Flux ....................................... 5.63

5.34. Average Flux Values for Rinsed Leached Group 7 Solids.................................................... 5.66

5.35. Final Leached and Washed Slurry Physical-Property Measurements ..................................... 5.70 
5.36. Final Leached, Washed Dewatered Slurry Composition (Including Permeate Hold-up).

5.37. Washed Caustic-Leached Slurry Composition and Solid-Leach-Factor Calculations 5.73

5.38. Results of Fitting Analysis for the Group 7 Leached, Washed Slurry 5.80

5.39. Select Apparent Viscosities for the Leached Washed Slurry 5.81

5.40. Rheology at Different Points During the CUF Testing 5.83

6.1. Initial Radionuclide Content in Group 7 ...

6.2. Initial ICP Metals Content in Group 7

6.3. Summary of Group 7 Filtration Results

6.4. Composition of Caustic-Leached Group 7 Solids with Leach Factors of Selected Analytes (3 $\mathrm{M} \mathrm{NaOH}, 40^{\circ} \mathrm{C}, 24 \mathrm{~h}$ )

6.5. Caustic Leaching Summary of Group 7 Slurry 


\section{Abbreviation/Acronym List}

\begin{tabular}{|c|c|}
\hline AEA & alpha energy analysis \\
\hline ASO & Analytical Support Organization \\
\hline ASR & Analytical Service Request \\
\hline ASTM & American Society for Testing and Materials \\
\hline AV & axial velocity \\
\hline BBI & Best Basis Inventory \\
\hline BET & (Brunauer, Emmett, and Teller) surface area analysis technique \\
\hline BNI & Bechtel National, Incorporated \\
\hline BS & blank spike \\
\hline CC & corrected concentration \\
\hline CCD & charge coupled device \\
\hline CCN & corporate correspondence number (BNI) \\
\hline CS & centrifuged solids \\
\hline CUF & crossflow ultrafiltration testing apparatus (containing $2 \mathrm{ft}$ cell unit filter) \\
\hline DACS & data acquisition collection system \\
\hline DI & deionized (water) \\
\hline DOE & U.S. Department of Energy \\
\hline ED & electron diffraction \\
\hline EDS & energy-dispersive spectroscopy \\
\hline EELS & electron energy-loss spectroscopy \\
\hline EFRT & External Flowsheet Review Team \\
\hline fps & feet per second \\
\hline EQL & estimated quantitation limit \\
\hline FTIR & Fourier transform infrared \\
\hline GEA & gamma energy analysis \\
\hline HAADF & High Angle Annular Dark-Field Detector \\
\hline HDPE & high-density polypropylene \\
\hline $\mathrm{HF}$ & hydrofluoric acid \\
\hline HLRF & High-Level Radiochemistry Facility \\
\hline *HLW & high-level waste \\
\hline IC & ion chromatography \\
\hline ICDD & International Centre for Diffraction Data \\
\hline ICP-OES & inductively coupled plasma-optical emission spectroscopy \\
\hline ICSD & Inorganic Crystal Structure Database \\
\hline $\mathrm{KOH}$ & potassium hydroxide \\
\hline KPA & kinetic phosphorescence analysis \\
\hline LAW & low activity waste \\
\hline LCS & laboratory control sample \\
\hline
\end{tabular}




\begin{tabular}{|c|c|}
\hline LEPS & Low-Energy Photon Spectroscopy \\
\hline MDL & minimum detection limit \\
\hline MRQ & minimum reportable quantity \\
\hline MS & matrix spike \\
\hline M\&TE & measuring and test equipment \\
\hline NIST & National Institute of Science and Technology \\
\hline OES & optical emission spectroscopy \\
\hline ORP & Office of River Protection \\
\hline PB & preparation blank \\
\hline PNNL & Pacific Northwest National Laboratory \\
\hline PSD & particle-size distribution \\
\hline PTF & Pretreatment Facility \\
\hline psid & pounds per square inch differential \\
\hline psig & pounds per square inch gauge \\
\hline QA & quality assurance \\
\hline QAM & Quality Assurance Manual \\
\hline QAPjP & quality assurance project plan \\
\hline QARD & Quality Assurance Requirements and Descriptions \\
\hline QC & quality control \\
\hline REDOX & reduction-oxidation \\
\hline RPD & relative percent difference \\
\hline RPL & Radiochemical Processing Laboratory \\
\hline RPP-WTP & River Protection Project - Waste Treatment Plant Support Program \\
\hline RSD & relative standard deviation \\
\hline $\mathrm{R} \& \mathrm{~T}$ & research and technology \\
\hline SAL & Shielded Analytical Laboratory \\
\hline SEM & scanning electron microscopy \\
\hline TBP & tributyl phosphate \\
\hline TEM & transmission electron microscopy \\
\hline TIC & total inorganic carbon \\
\hline TMP & transmembrane pressure \\
\hline TOC & total organic carbon \\
\hline TRU & transuranics \\
\hline SBMS & Standards Based Management System \\
\hline SEM & scanning electron microscopy \\
\hline STEM & scanning transmission electron microscopy \\
\hline TEM/ED & transmission electron microscopy \\
\hline TP & test plan \\
\hline TWINS & Tank-Waste Information Network System \\
\hline UDS & undissolved solids \\
\hline
\end{tabular}


UFP

WCS

WTP

XRD ultrafiltration process

wet centrifuged solids

Waste Treatment and Immobilization Plant

$\mathrm{X}$-ray diffraction 

WTP-RPT-169, Rev 0

\section{References}

Barnes HA, and NQ Dzuy. 2001. "Rotating Vane Rheometry - A Review.” Journal of Non-Newtonian Fluid Mechanics 98(1): 1-14.

Coleman CJ, MS Hay, KB Martin. 2003. Compositing and Characterization of Samples from Hanford Tank 241-AY-102/C-106. WSRC-TR-2003-00205 Rev 0, Westinghouse Savannah River Company, Aiken, SC.

Cleveland JM. 1970. The Chemistry of Plutonium, Gordon and Breach Science Publishers, New York; pp. 500-503.

de Barry Barnett E and CL Wilson. 1953. Inorganic Chemistry: A Text-Book for Advanced Students, Longmans Green and Co, London; p. 202.

Fiskum SK, EC Buck, RC Daniel, K Draper, MK Edwards, TL Hubler, LK Jagoda, ED Jenson, GJ Lumetta, BK McNamara, RA Peterson, SI Sinkov, and LA Snow. 2008. Characterization and Leach Testing for REDOX Sludge and S-Saltcake Actual Waste Sample Composites. PNNL-17368 (WTP-RPT157), Pacific Northwest National Laboratory, Richland, WA.

Krupka KM, WJ Deutch, MJ Lindberg, KJ Cantrell, NJ Hess, HT Schaef, BW Arey. 2004. Hanford Tanks 241-AY-102 and 241-BX-101: Sludge Composition and Contaminant Release Data. PNNL14614, Pacific Northwest National Laboratory, Richland, WA.

Li H, J Addai-Mensah, JC Thomas, and AR Gerson. 2005. “The Influence of Al(III) Supersaturation and $\mathrm{NaOH}$ Concentration on the Rate of Crystallization of $\mathrm{Al}(\mathrm{OH})_{3}$ Precursor Particles From Sodium Aluminate Solutions,” J. Colloid and Interface Science, 286:511-519.

Lumetta GJ. 2008. Mechanism of Phosphorus Removal from Hanford Tank Sludge by Caustic Leaching, PNNL-17257, Pacific Northwest National Laboratory, Richland, Washington.

Lumetta GJ and BM Rapko. 1999. "Removal of Chromium from Hanford Tank Sludges.” Sep. Sci. Technol. 34:1495-1506.

Lumetta GJ, KJ Carson, LP Darnell, LR Greenwood, FV Hoopes, RL Sell, SI Sinkov, CZ Soderquist, MW Urie, JJ Wagner. 2001. Caustic Leaching of Hanford Tank S-110 Sludge, PNNL-13702, Pacific Northwest National Laboratory, Richland, Washington.

Lumetta GJ, LP Darnell, PA Garza, LR Greenwood, BM Oliver, DE Rinehart, DR Sanders, CZ Soderquist, T Trang-Le, MW Urie, JJ Wagner. 2002. Caustic Leaching of Hanford Tank T-110 Sludge, PNNL-13956, Pacific Northwest National Laboratory, Richland, Washington.

Lumetta, GJ, EC Buck, RC Daniel, K Draper, MK Edwards, SK Fiskum, LK Jagoda, ED Jenson, AE KOzelisky, PJ MacFarlan, RA Peterson, RW Shimskey, SI Sinkov, and LA Snow. 2008.

Characterization, Leaching, and Filtration Testing for Bismuth Phosphate Sludge (Group 1) and Bismuth Phosphate Saltcake (Group 2) Actual Waste Sample Composites. WTP-RPT-166, Pacific Northwest National Laboratory, Richland, WA. 
Lumetta GJ, BM Rapko, J Liu, DJ Temer, and RD Hunt. 1998. Washing and Caustic Leaching of Hanford Tank Sludges: Results of FY 1998 Studies, PNNL-12026, Pacific Northwest National Laboratory, Richland, Washington.

Malvern Instruments Ltd. 1997. Sample Dispersion and Refractive Index Guide. MAN 0079, Version 3.1. Worcestershire, England.

Rapko BM. 1998. Oxidative Alkaline Dissolution of Chromium from Hanford Tank Sludges: Results of FY 98 Studies. PNNL-11908, Pacific Northwest National Laboratory, Richland, WA.

Rapko BM and JD Vienna. 2002. Selective Leaching of Chromium from Hanford Tank Sludge 241-U108. PNNL-14019, Pacific Northwest National Laboratory, Richland, WA.

Rapko BM, JD Vienna, SI Sinkov, J Kim, and AJ Cisar. 2002. Alkaline Leaching of Key, NonRadioactive Components from Simulants and Hanford Tank Sludge 241-S-110: Results of FY 01 Studies. PNNL-14018, Pacific Northwest National Laboratory, Richland, WA.

Rapko, BM, JGH Geeting, SI Sinkov, and JD Vienna. 2004. Oxidative-Alkaline Leaching of Washed 241-SY-102 and 241-SX-101 Tank Sludges. PNWD-3512 (WTP-RPT-117), Battelle-Pacific Northwest Division, Richland, WA. (WTP Doc. No. 24590-101-TSA-W000-0004-99-00012 Rev 00A.)

Rapko BM, GJ Lumetta, JD Vienna, and SK Fiskum. 2005. Oxidative Alkaline Leaching of SX-101 and SY-102 and Its Impact on Immobilized High Level Waste. PNWD-3600 (WTP-RPT-137), BattellePacific Northwest Division, Richland, WA. (WTP Doc. No. 24590-101-TSA-W000-0004-168-00002 Rev 00A.)

Rector DR, and BC Bunker. 1995. Effect of Colloidal Aggregation on the Sedimentation and Rheological Properties of Tank Waste. PNL-10761, Pacific Northwest Laboratory, Richland, WA.

Shimskey RW. April, 2008. HLW Filtration and Caustic Leaching of Group 7 / AY-102 Composite Waste, TI-RPP-WTP-624.

Shimskey RW, JM Billing, EC Buck, AJ Casella, JV Crum, RC Daniel, K Draper, MK Edwards, RT Hallen, AE Kozelisky, PJ MacFarlan, RA Peterson, RG Swoboda. 2008. Filtration and Leach Testing for PUREX Cladding Sludge and REDOX Cladding Sludge Actual Waste Sample Composites. WTPRPT-181, Pacific Northwest National Laboratory, Richland, WA.

Shimskey RW, JM Billing, EC Buck, RC Daniel, K Draper, MK Edwards, JGH Geeting, RT Hallen, ED Jenson, AE Kozelisky, PJ MacFarlan, RA Peterson, LA Snow, RG Swoboda. 2008. Filtration and Leach Testing for REDOX Sludge and S-Saltcake Actual Waste Sample Composites. WTP-RPT-172, Pacific Northwest National Laboratory, Richland, WA. 


\section{Testing Summary}

A testing program evaluating actual tank waste was developed in response to Task 4 from the M-12 External Flowsheet Review Team (EFRT) issue response plan. The bulk water-insoluble solid wastes that are anticipated to be delivered to the Waste Treatment and Immobilization Plant (WTP) were identified according to type such that the actual waste testing could be targeted to the relevant categories. Eight broad waste groupings were defined. Samples available from the 222S archive were identified and obtained for testing. The actual waste-testing program included homogenizing the samples by group, characterizing the solids and aqueous phases, and performing parametric leaching tests.

The tributyl phosphate sludge (TBP, Group 7) is the subject of this report. The Group 7 waste was anticipated to be high in phosphorus as well as aluminum in the form of gibbsite. Both are believed to exist in sufficient quantities in the Group 7 waste to address leaching behavior. Thus, the focus of the Group 7 testing was on the removal of both $\mathrm{P}$ and Al. The waste-type definition, archived sample conditions, homogenization activities, characterization (physical, chemical, radioisotope, and crystal habit), and caustic leaching behavior as functions of time, temperature, and hydroxide concentration are discussed in this report. Testing was conducted according to TP-RPP-WTP-467.

\section{Objectives}

The test objectives are summarized in Table S.1 along with a discussion of how the objectives were met. Several objectives (in gray shading lighter than header shading) did not specifically apply to the scope provided in this report; they will be reported in companion reports as indicated in the controlling test plan.

Table S.1. Test Objectives for Test Plan TP-RPP-WTP-467

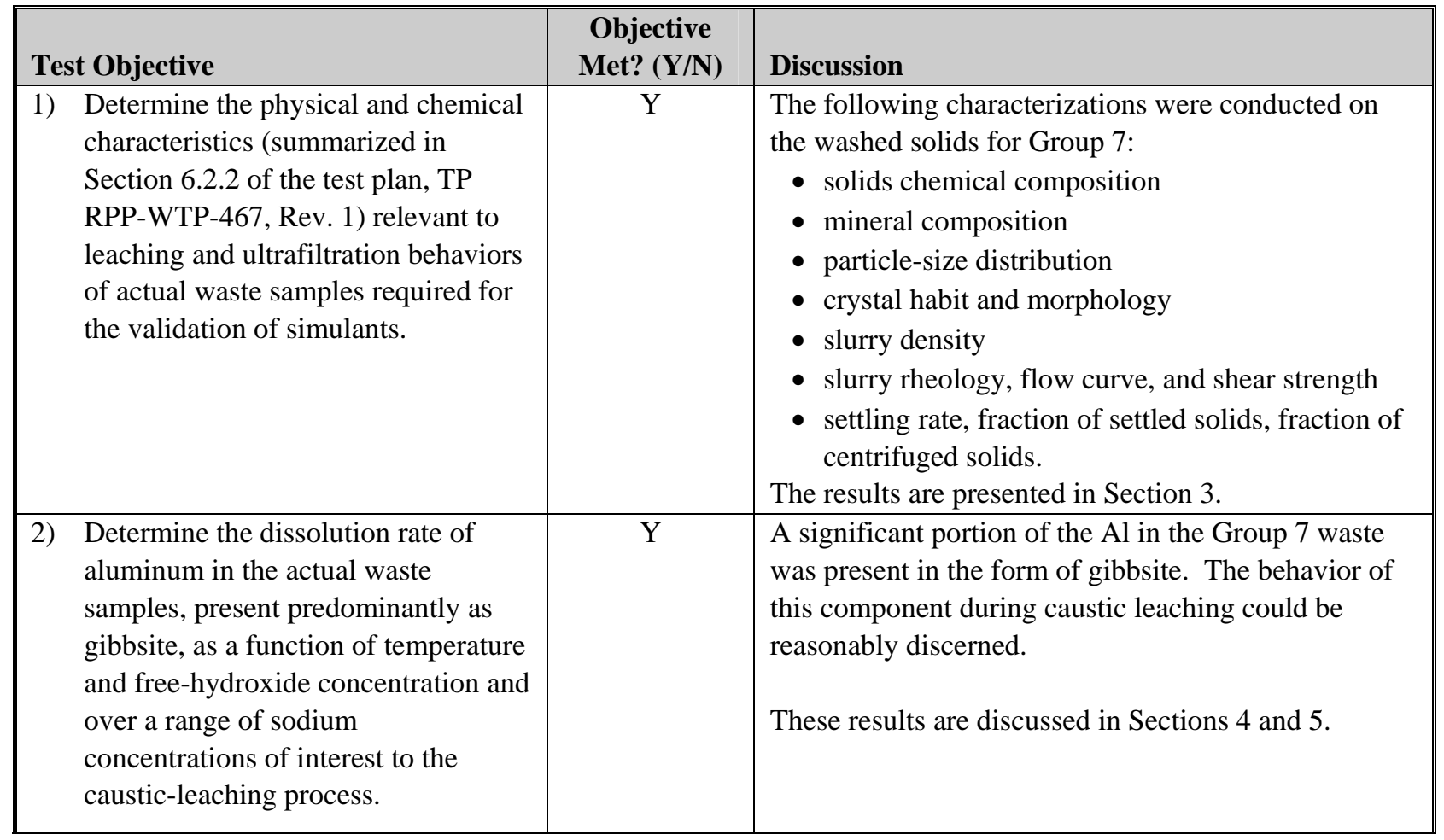


WTP-RPT-169, Rev 0

Table S.1 (Contd)

\begin{tabular}{|c|c|c|}
\hline Test Objective & $\begin{array}{c}\text { Objective } \\
\text { Met? (Y/N) }\end{array}$ & Discussion \\
\hline $\begin{array}{l}\text { 3) Determine the dissolution rate of } \\
\text { aluminum in the actual waste } \\
\text { samples, present predominantly as } \\
\text { boehmite, as a function of } \\
\text { temperature and free-hydroxide } \\
\text { concentration and over a range of } \\
\text { sodium concentrations of interest to } \\
\text { the caustic-leaching process. }\end{array}$ & NA & $\begin{array}{l}\text { Group } 7 \text { was not expected to contain significant } \\
\text { quantities of boehmite, and characterization found this } \\
\text { to be the case. }\end{array}$ \\
\hline $\begin{array}{l}\text { Determine the dissolution rate of } \\
\text { chromium and the extent of } \\
\text { dissolution of plutonium and other } \\
\text { safety-related constituents ( } \mathrm{U}, \mathrm{Fe} \text {, } \\
\mathrm{Mn}, \mathrm{Ni} \text {, and } \mathrm{Zn} \text { ) in the actual waste } \\
\text { samples as functions of temperature } \\
\text { and over a range of } \mathrm{NaOH} \\
\text { concentrations of interest for } \\
\text { oxidative leaching. (The } \mathrm{NaMnO} \\
\text { dosage will be predetermined for the } \\
\text { oxidation of the chromium in the } \\
\text { waste solids.) }\end{array}$ & NA & $\begin{array}{l}\text { Oxidative leaching was not an objective of the } \\
\text { Group } 7 \text { testing because it was not anticipated to be a } \\
\text { high-Cr waste. }\end{array}$ \\
\hline $\begin{array}{l}\text { 5) Determine the dissolution/reaction } \\
\text { rate of phosphates in the actual waste } \\
\text { samples as a function of temperature } \\
\text { and over a range of } \mathrm{NaOH} \\
\text { concentrations of interest for the } \\
\text { caustic leaching process as well as } \\
\text { the extent of dissolution during post- } \\
\text { leaching wash. }\end{array}$ & $\mathrm{Y}$ & $\begin{array}{l}\text { Group } 7 \text { contained a significant amount of P. The P } \\
\text { behavior for the Group } 7 \text { composite during caustic } \\
\text { leaching was characterized as a function of time, } \\
\text { temperature, and free-hydroxide concentration. } \\
\text { The P removal results can be found in Sections 3, 4, } \\
\text { and } 5 \text {. }\end{array}$ \\
\hline $\begin{array}{l}\text { 6) Determine the ultrafiltration flux } \\
\text { before and after caustic and oxidative } \\
\text { leaching over the operating range of } \\
\text { solids concentrations during the } \\
\text { leaching processes at } 25^{\circ} \mathrm{C} \text { when } \\
\text { sufficient actual waste sample is } \\
\text { available for testing the filtration } \\
\text { behavior. }\end{array}$ & $\mathrm{Y}$ & $\begin{array}{l}\text { Ultrafiltration (CUF) testing was performed on the } \\
\text { Group } 7 \text { solids. The CUF testing was performed } \\
\text { before leaching using slurries with both low- and } \\
\text { high-solids contents. The high-solids slurry was } \\
\text { obtained by blending wastes from AY-102 with the } \\
\text { Group } 7 \text { slurry. Further CUF testing was performed } \\
\text { after caustic leaching. During these tests, the } \\
\text { ultrafiltration flux was determined as a function of } \\
\text { transmembrane pressure and axial velocity. The CUF } \\
\text { tests were conducted at ambient temperature. There } \\
\text { was no oxidative leach performed on this waste type; } \\
\text { therefore, there was no CUF testing done on post } \\
\text { oxidative-leach materials. } \\
\text { All the CUF testing results are discussed in Section } 5 \text {. }\end{array}$ \\
\hline
\end{tabular}


Table S.1 (Contd)

\begin{tabular}{|l|c|l||}
\hline Test Objective & $\begin{array}{c}\text { Objective } \\
\text { Met? (Y/N) }\end{array}$ & Discussion \\
\hline 7) $\begin{array}{l}\text { Scanning electron microscopy } \\
\text { (SEM), transmission electron }\end{array}$ & Y & $\begin{array}{l}\text { SEM, TEM, EDS, and XRD were performed on the } \\
\text { microscopy (TEM), energy } \\
\text { dispersive spectroscopy (EDS), and } \\
\text { X-ray diffraction (XRD) will be used } \\
\text { to determine the primary mineral } \\
\text { forms present for Al, Cr, and P and } \\
\text { provide information to enable the } \\
\text { correlation of these mineral forms to } \\
\text { dissolution behavior. }\end{array}$ \\
\hline
\end{tabular}

\section{Test Exceptions}

No test exceptions applied to this work.

\section{Results and Performance Against Success Criteria}

The test plan delineated several success criteria, which are listed in Table S.2. Selected criteria were relevant to the test scope included in this report; the other criteria that are outside of the reported scope are shaded.

Table S.2. Results and Performance Against Success Criteria for TP-RPP-WTP-467

\section{List Success Criteria}

1) A summary (letter report format) of the available information (including published literature) is provided on the characteristics (both known characteristics and those needed to be determined) relevant to leaching and filtration behaviors of the tank farm waste groupings identified for testing.

2) The physical and chemical characteristics for each of the actual waste-sample composites selected for testing are provided (including a format in conformance with the presentation protocols [24590-WTP-GPG-RTD-001]). The relevant physical and chemical characteristics are elaborated in Test Conditions, Section 6.0, of the test plan, TP RPP-WTP-467, Rev. 1.

\section{Explain How the Tests Did or Did Not} Meet the Success Criteria

Letter report number RPP-WTP-07-705 (GJ Lumetta and RT Hallen, WTP-RPT-151, Review of Caustic Leaching Testing With Hanford Tank Waste Sludges), which addressed this success criterion, was delivered to BNI-WTP on 1/24/2007.

All physical and chemical characterization testing as defined in the test plan was completed. This included extensive physical and chemical characterization of the homogenized slurry materials and extensive chemical characterization of selected leach solids. The analytical results for each test group are reported in the appropriate report sections. TEM was not performed on the postleach CUF samples because of high dose rates after adding AY-102 tank waste.

The dissolution of the gibbsite fraction of the Group 7 washed solids was evaluated by measuring the $\mathrm{Al}$ in the leaching solution as a function of time $(0,1,2,4$, 8 , and $24 \mathrm{~h}$ ). The effects of free-hydroxide concentration and temperature were assessed. Testing was conducted at 
Table S.2 (Contd)

\begin{tabular}{|c|c|c|}
\hline \multicolumn{2}{|c|}{ List Success Criteria } & $\begin{array}{l}\text { Explain How the Tests Did or Did Not } \\
\text { Meet the Success Criteria } \\
\text { three free-hydroxide concentrations }(0.25,1 \text {, and } 3 \mathrm{M}) \\
\text { and at three temperatures }\left(40,60 \text {, and } 80^{\circ} \mathrm{C}\right) \text {. One test } \\
\left.\text { condition ( } 3 \mathrm{M} \text { free hydroxide at } 40^{\circ} \mathrm{C}\right) \text { was conducted } \\
\text { in triplicate to assess overall test precision. }\end{array}$ \\
\hline & results are provided. & $\begin{array}{l}\text { three free-hydroxide concentrations }(0.25,1 \text {, and } 3 \mathrm{M} \text { ) } \\
\text { and at three temperatures }\left(40,60 \text {, and } 80^{\circ} \mathrm{C}\right) \text {. One test } \\
\left.\text { condition ( } 3 \mathrm{M} \text { free hydroxide at } 40^{\circ} \mathrm{C}\right) \text { was conducted } \\
\text { in triplicate to assess overall test precision. } \\
\text { The dissolution of the gibbsite fraction of the Group } 7 \\
\text { solids was slow at } 40^{\circ} \mathrm{C} \text {, with a large rise in the amount } \\
\text { dissolved occurring between } 8 \text { and } 24 \text { hours. A steady } \\
\text { state was reached at } 60^{\circ} \mathrm{C} \text { in } 1 \text { and } 3 \mathrm{M} \mathrm{NaOH} \text { after } 4 \\
\text { hours and at } 80^{\circ} \mathrm{C} \text { in } 1 \text { and } 3 \mathrm{M} \mathrm{NaOH} \text { after } 2 \text { hours. } \\
\text { The steady-state Al concentrations in these experiments } \\
\text { represented } 80 \text { to } 90 \% \text { Al dissolution, suggesting that } 10 \\
\text { to } 20 \% \text { of the Al in the Group } 7 \text { solids was present as a } \\
\text { caustic-insoluble aluminum compound, perhaps zeolite } \\
\text { as identified by XRD. Detailed results are presented in } \\
\text { Section } 4.0 \text {. }\end{array}$ \\
\hline & $\begin{array}{l}\text { The dissolution rate and the extent of dissolution of } \\
\text { aluminum present predominantly as boehmite in } \\
\text { actual waste solids are determined as a function of } \\
\text { temperature, free-hydroxide, and sodium } \\
\text { concentrations. The associated uncertainties in test } \\
\text { results are provided. }\end{array}$ & $\begin{array}{l}\text { Not applicable. The Group } 7 \text { sample did not have } \\
\text { significant amounts of boehmite. }\end{array}$ \\
\hline & $\begin{array}{l}\text { The dissolution rate and the extent of dissolution of } \\
\text { chromium in the actual waste solids are determined } \\
\text { as a function of temperature and over a range of } \\
\text { NaOH concentrations of interest to oxidative } \\
\text { leaching. The } \mathrm{NaMnO}_{4} \text { dosage will be } \\
\text { predetermined for the oxidation of the chromium in } \\
\text { the waste solids. The associated uncertainties in } \\
\text { the test results are provided. }\end{array}$ & $\begin{array}{l}\text { Not applicable. The Group } 7 \text { sample did not have } \\
\text { significant amounts of chromium. }\end{array}$ \\
\hline & $\begin{array}{l}\text { The dissolution rate and the extent of dissolution of } \\
\text { phosphates in the actual waste solids are } \\
\text { determined as a function of temperature and } \mathrm{NaOH} \\
\text { concentration along with the uncertainty in these } \\
\text { estimates. }\end{array}$ & $\begin{array}{l}\text { Phosphorus removal from the Group } 7 \text { washed solids } \\
\text { was evaluated by measuring the P in the leaching } \\
\text { solution as a function of time }(0,1,2,4,8 \text {, and } 24 \mathrm{~h}) \text {. } \\
\text { The effects of free-hydroxide concentration and } \\
\text { temperature were assessed. Testing was conducted at } \\
\text { three free-hydroxide concentrations }(0.25,1 \text {, and } 3 \mathrm{M}) \\
\left.\text { and at three temperatures ( } 40,60 \text {, and } 80^{\circ} \mathrm{C}\right) \text {. One test } \\
\left.\text { condition ( } 3 \mathrm{M} \text { free hydroxide at } 40^{\circ} \mathrm{C}\right) \text { was conducted } \\
\text { in triplicate to assess overall test precision. } \\
\text { The P removal from the Group } 7 \text { solids was rapid, with } \\
\text { steady state reached within } 1 \mathrm{~h} \text { under all conditions } \\
\text { examined. Approximately } 85 \text { to } 95 \% \text { of the P was } \\
\text { removed at all conditions examined. Detailed results are } \\
\text { presented in Section } 4.0 \text {. }\end{array}$ \\
\hline & $\begin{array}{l}\text { The ultrafiltration flux before and after caustic and, } \\
\text { as applicable, oxidative leaching (reconcentration, }\end{array}$ & $\begin{array}{l}\text { The following variables were examined for the Group } 7 \\
\text { waste slurry where the focus was measuring the filter }\end{array}$ \\
\hline
\end{tabular}


Table S.2 (Contd)

\begin{tabular}{|c|c|c|}
\hline \multicolumn{2}{|c|}{ List Success Criteria } & $\begin{array}{l}\text { Explain How the Tests Did or Did Not } \\
\text { Meet the Success Criteria }\end{array}$ \\
\hline & $\begin{array}{l}\text { if sufficient solids are available) over the operating } \\
\text { range of solids concentrations with the actual waste } \\
\text { samples at } 25^{\circ} \mathrm{C} \text { is defined when available sample } \\
\text { size is adequate for the testing. }\end{array}$ & $\begin{array}{l}\text { flux before and after leaching at } 25^{\circ} \mathrm{C} \text { : } \\
\text { - Transmembrane pressure } \\
\text { - Axial velocity } \\
\text { - Undissolved solids concentration } \\
\text { - Differences due to changes in the slurry during } \\
\text { caustic leaching and rinses of waste solids. } \\
\text { The results of this testing are summarized in Section } 5 \text {. }\end{array}$ \\
\hline & $\begin{array}{l}\text { Determination of the primary mineral forms } \\
\text { present for } \mathrm{Al}, \mathrm{Cr} \text {, and } \mathrm{P} \text { and a qualitative } \\
\text { correlation of the dissolution behavior of these } \\
\text { waste elements to the mineral forms identified. }\end{array}$ & $\begin{array}{l}\text { As mainly determined by XRD, the Group } 7 \text { solids } \\
\text { contained gibbsite, } \mathrm{Al}(\mathrm{OH})_{3} \text {; threadgoldite, } \\
\mathrm{Al}\left(\mathrm{UO}_{2}\right)_{2}\left(\mathrm{PO}_{4}\right)_{2}(\mathrm{OH})\left(\mathrm{H}_{2} \mathrm{O}\right)_{8} ; \text { zeolite, } \mathrm{NaAlSiO}_{4}\left(\mathrm{H}_{2} \mathrm{O}\right)_{1.1} \text {; } \\
\text { sodium iron phosphate, } \mathrm{Na}_{7}\left(\mathrm{FeP}_{2} \mathrm{O}_{7}\right)_{4} \mathrm{PO}_{4} \text {; and } \\
\text { lepidocrocite, } \mathrm{FeO}(\mathrm{OH}) \text {. The } \mathrm{Al} \text { removal behavior } \\
\text { during caustic leaching can be correlated with this } \\
\text { observation, assuming that } 60 \text { to } 70 \% \text { of the } \mathrm{Al} \text { is } \\
\text { gibbsite, and the remaining is an insoluble } \mathrm{Al} \\
\text { compound, perhaps zeolite. The only P-containing } \\
\text { compound identified by XRD in the caustic-leached and } \\
\text { washed solids was nabaphite, } \mathrm{NaBa}\left(\mathrm{PO}_{4}\right)\left(\mathrm{H}_{2} \mathrm{O}\right)_{9} \text {. It is } \\
\text { also likely that part of the undissolved } \mathrm{P} \text { exists as the } \\
\text { sodium iron phosphate that was identified in the } \\
\text { unleached solids. Because of the low concentrations of } \\
\text { Cr found in this waste grouping, Cr mineral forms were } \\
\text { not identified. }\end{array}$ \\
\hline
\end{tabular}

\section{Quality Requirements}

Pacific Northwest National Laboratory (PNNL) is operated for the U.S. Department of Energy (DOE) by Battelle under Contract DE-AC05-76RL01830. PNNL implements a Quality Assurance Program that is based upon the requirements as defined in DOE Order 414.1C, "Quality Assurance," and 10 CFR 830, "Energy/Nuclear Safety Management,” Subpart A—“Quality Assurance Requirements.” PNNL has chosen to implement the requirements of DOE Order 414.1C and 10 CFR 830, Subpart A by integrating them into the laboratory's management systems and daily operating processes. The procedures necessary to implement the requirements are documented through the laboratory's Standards-Based Management System (SBMS).

PNNL implemented the RPP-WTP quality requirements by performing work in accordance with the River Protection Project - Waste Treatment Plant Support Program (RPP-WTP) Quality Assurance Plan (RPPWTP-QA-001, QAP). Work was performed to the quality requirements of NQA-1-1989 Part I, "Basic and Supplementary Requirements,” NQA-2a-1990, Part 2.7, and DOE/RW-0333P, Rev 13, Quality Assurance Requirements and Descriptions (QARD). These quality requirements were implemented through the River Protection Project - Waste Treatment Plant Support Program (RPP-WTP) Quality Assurance Manual (RPP-WTP-QA-003, QAM). The analytical requirements were implemented through RPP-WTP's Statement of Work (RPP-WTP-QA-005) with the Radiochemical Processing Laboratory (RPL) Analytical Service Operations (ASO). 
A matrix that cross-references the NQA-1, NQA-2a, and QARD requirements with the procedures for RPP-WTP work was provided in the test plan TP-RPP-WTP-467. It included justification for those requirements not implemented.

Experiments that were not method-specific were performed in accordance with RPP-WTP's procedures QA-RPP-WTP-1101 "Scientific Investigations" and QA-RPP-WTP-1201 “Calibration and Control of Measuring and Testing Equipment” so that sufficient data were taken with properly calibrated measuring and test equipment (M\&TE) to obtain quality results.

RPP-WTP addressed internal verification and validation activities by conducting an Independent Technical Review of the final data report in accordance with RPP-WTP's procedure QA-RPP-WTP-604. This review verified that the reported results were traceable, that inferences and conclusions were soundly based, and the reported work satisfied the Test Plan objectives. This review procedure is part of PNNL's RPP-WTP Quality Assurance Manual.

\section{R\&T Test Conditions}

The R\&T test conditions, as defined in the BNI Test Specification, ${ }^{(a)}$ are summarized in Table S.3.

(a) PS Sundar. Nov. 2006. Characterization and Small Scale Testing of Hanford Wastes to Support the Development and Demonstration of Leaching and Ultrafiltration Pretreatment Processes. 24590-PTF-TSPRT-06-003, Rev. 1. 
Table S.3. R\&T Test Conditions

\begin{tabular}{|l|l|}
\hline List R\&T Test Conditions & Were Test Conditions Followed? \\
\hline $\begin{array}{l}\text { 1) Selection of actual wastes for testing: the waste } \\
\text { samples selected for testing will be from the } \\
\text { groupings identified in the resolution of Issue M4. }\end{array}$ & $\begin{array}{l}\text { Yes. One of the eight waste groupings identified in } \\
\text { resolution to Issue M4 were tested: Group 7 } \\
\text { (tributyl phosphate, TBP). }\end{array}$ \\
\hline $\begin{array}{l}\text { 2) Physical and chemical characterization properties } \\
\text { shall be stated and carried out according to the }\end{array}$ & $\begin{array}{l}\text { Yes. Physical characterizations, including specific } \\
\text { gravity (density), settling rate, rheology, volume- } \\
\text { percent settled solids, and volume-percent } \\
\text { centrifuged solids were determined for both test } \\
\text { groups according to the requirements document. }\end{array}$ \\
& $\begin{array}{l}\text { Chemical characterization was conducted on the } \\
\text { supernatant (water used to dissolve and slurry the } \\
\text { solids into a workable homogenized composite) on } \\
\text { the solids rinsed with three contacts of 1:1 volume } \\
\text { ratios of 0.01 M NaOH and on the rinse solution } \\
\text { composite. }\end{array}$ \\
\hline $\begin{array}{l}\text { 3) Actual determinations of waste leach kinetics } \\
\text { will be carried out in well-mixed conditions. A test } \\
\text { matrix will be forwarded to the research and } \\
\text { technology (R\&T) M12 Issue manager for } \\
\text { concurrence before testing. Residual leached and } \\
\text { washed solids will be characterized. }\end{array}$ & $\begin{array}{l}\text { Yes. Test matrices for the Group 7 waste sample } \\
\text { were forwarded to, and approved by, the R\&T M12 } \\
\text { Issue Manager (BNI). The actual test conditions are } \\
\text { given in Section 4.0 and were compliant with the } \\
\text { test matrices. }\end{array}$ \\
\hline 4) Testing for filtration behavior will be performed. & $\begin{array}{l}\text { Yes. Cross-flow filtration testing was performed on } \\
\text { the Group 7 solids. CUF testing matrices were } \\
\text { applied to a low-solids slurry, a high-solids slurry, } \\
\text { and post-caustic leaching. Rheology and particle- } \\
\text { size distribution measurements were made before } \\
\text { and after the various process steps. }\end{array}$ \\
\hline
\end{tabular}




\section{Simulant Use}

The bulk of the testing used actual Hanford tank wastes. However, due to the limitations in the quantity of supernate present, a simulant of the Group 7 supernate fraction was prepared and used to dilute the feed to allow testing at lower solids concentrations.

\section{Discrepancies and Follow-on Tests}

TEM, BET, and particle size measurements were not performed on CUF samples after the addition of AY-102. Dose rates of samples pulled from the hot cells afterwards were too high to be handled for theses analyses which are prepared in radiological fume hoods. Procedures were in place to prepare XRD and SEM slides in the hot cells so these measurements were able to be performed. 
WTP-RPT-169, Rev 0

\subsection{Introduction}

This is one in a series of reports that define the characterization, parametric leaching, and filtration testing of actual Hanford tank wastes in support of the Hanford Tank Waste Treatment and Immobilization Plant (WTP) pretreatment process development and demonstration. The tests reported here were conducted according to TP-RPP-WTP-467 ${ }^{(\mathrm{a})}$ and were written in response to Bechtel National, Incorporated (BNI) Test Specification 24590-PTF-TSP-RT-06-003 Rev. 1. ${ }^{\text {(b) }}$ This report focuses on the tributyl phosphate (TBP) tank waste, which is referred to as Group 7 in this report.

\subsection{Tank Waste Pretreatment Operations at the WTP}

Figure 1.1 provides a schematic illustration of the primary functions to be performed in the WTP. Initially, the low-activity waste (LAW) liquid stream will be removed from the high-level waste (HLW) solids phase by ultrafiltration in the Pretreatment Facility (PTF). The concentrated HLW solids will be pretreated using caustic and, in some cases, oxidative leaching processes to dissolve and remove materials (aluminum, chromium, phosphates, and sulfates) that would otherwise limit HLW loading in the immobilized waste glass. The current plant design calls for the pretreatment leaching processes to be carried out in the ultrafiltration feed vessels. During pretreatment, the concentrated HLW solids will be caustic leached, washed, and in the case of high Cr wastes, oxidatively leached and washed once more. The caustic leaching will be conducted to solubilize the aluminum, phosphorus, and sulfur in the HLW solids; the oxidative leaching will be conducted to oxidize the chromium [from $\mathrm{Cr}(\mathrm{III})$ to $\mathrm{Cr}(\mathrm{VI})$ ] using a sodium permanganate $\left(\mathrm{NaMnO}_{4}\right)$ solution and dissolve the chromate in a mild caustic solution. The HLW solids will be re-concentrated after each leach and wash operation in the ultrafilter.

The current design of the PTF was based on aluminum dissolution results from earlier small, bench-scale, caustic-leaching tests that were supplied to BNI by the U.S. Department of Energy's (DOE's) Office of River Protection (ORP). Only a limited number of small bench-scale oxidative leaching tests using two selected actual waste tank samples (SX-101 and SY-102) with the preferred oxidant $\mathrm{NaMnO}_{4}$ were carried out to estimate the oxidant dosage and the efficacy of the oxidative leaching process (Rapko et al. 2004; Rapko et al. 2005), but a number of previous studies demonstrated the technical feasibility of the oxidative leaching process (Rapko 1998; Lumetta and Rapko 1999; Rapko and Vienna 2002; Rapko et al. 2002). The testing with actual radioactive wastes has been generally limited to small-scale testing (typically 1 to $10 \mathrm{~g}$ ) because of limited sample availability and personnel safety associated with sample handling.

(a) SK Fiskum, TP-RPP-WTP-467, Rev. 0, 2/2/07 and Rev. 1 7/31/07, Characterization and Small Scale Testing of Hanford Wastes to Support the Development and Demonstration of Leaching and Ultrafiltration Pretreatment Processes.

(b) PS Sundar. 2006. 24590-PTF-TSP-RT-06-003 Rev. 1, Characterization and Small Scale Testing of Hanford Wastes to Support the Development and Demonstration of Leaching and Ultrafiltration Pretreatment Processes. 
WTP-RPT-169, Rev 0

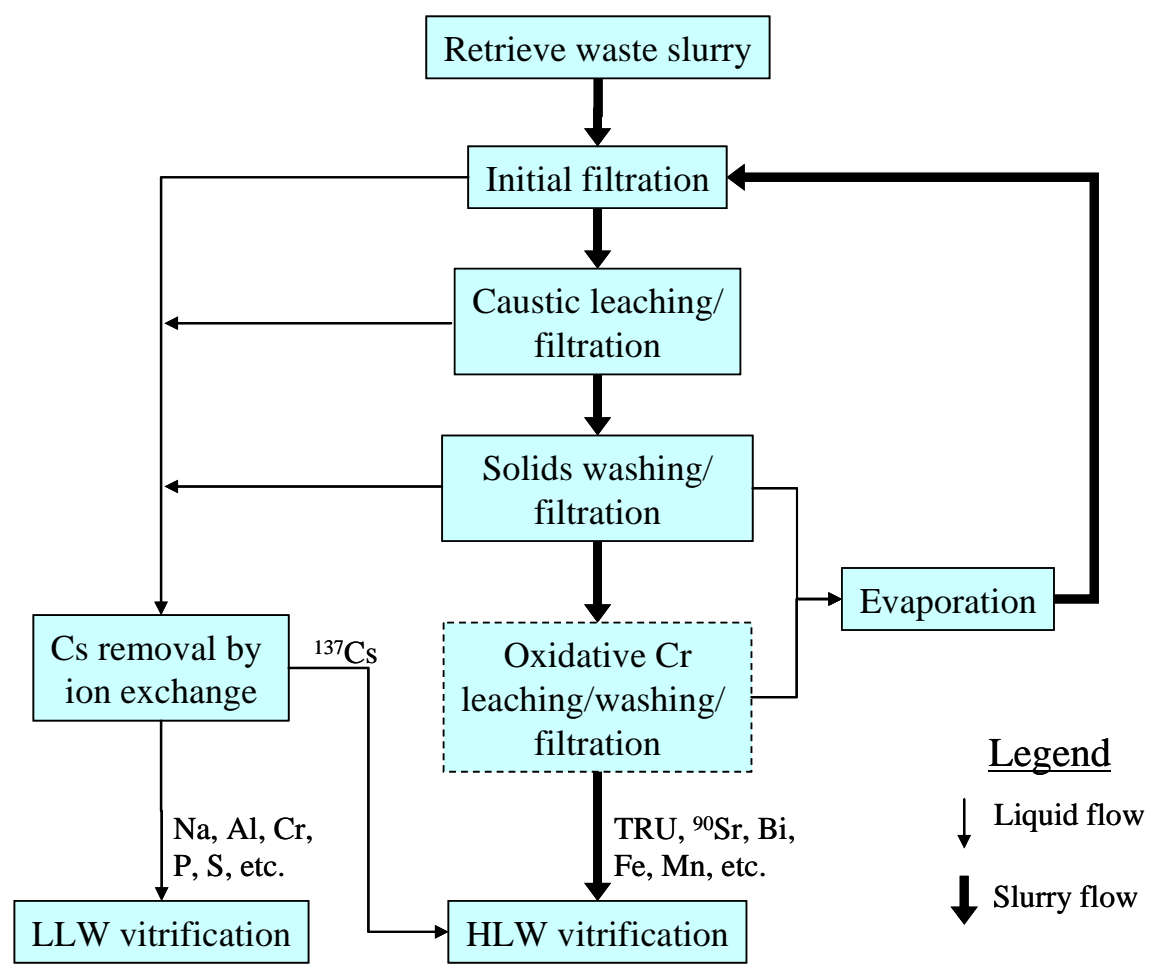

Figure 1.1. Schematic Representation of the Processes to be Performed in the PTF (Note: This is for illustrative purposes only; it is not meant to be a comprehensive view of the functions performed within the WTP.)

\subsection{Issues Identified by the External Flowsheet Review Team}

A team of experts from industry, national laboratories, and universities (referred to as the External Flowsheet Review Team or EFRT) was assembled by BNI in October of 2005 to conduct an in-depth review of the process flowsheet supporting the design of the WTP. The EFRT identified several issues from the critical review of the process flowsheet, ${ }^{(\mathrm{a}, \mathrm{b})}$ including

- Issue M4: The WTP has not demonstrated that its design is sufficiently flexible to reliably process all of the Hanford tank farm wastes at the design throughputs.

- Issue M12: Neither the caustic-leaching nor the oxidative-leaching process has been demonstrated at greater than bench scale. The small-scale experiments are capable of defining the leaching chemistry. However, they are limited in their capability to predict the effectiveness of these processes without a scale-up demonstration.

(a) WTP Doc. No. 24590-WTP-PL-ENG-06-0008, Rev 0, "Hanford Waste Treatment and Immobilization Plant (WTP) Project Response Plan for Resolution of Issues Identified by the Comprehensive Review of the WTP Flowsheet and Throughput.” L. Lucas, March 2006.

(b) WTP Project Doc. No. CCN 132846 "Comprehensive Review of the Hanford Waste Treatment Plant Flowsheet and Throughput - Assessment Conducted by an Independent Team of External Experts.” March 2006, chartered by the Hanford Waste Treatment and Immobilization Plant Project at the Direction of the U.S. Department of Energy, Office of Environmental Management, Washington DC. 
- Issue M13: For wastes requiring leaching, a combination of inadequate filter flux and area will likely limit throughput to the HLW or LAW vitrification facilities.

The work scope defined in TP-RPP-WTP-467 represented the initial portion of the actual waste-testing portion of Task 4 from the M-12 EFRT issue response plan. ${ }^{(a)}$ The actual tank waste testing work interfaced with responses developed to resolve EFRT Issue M4. In this case, a family of waste groupings representing the behavior of $\sim 75 \%$ of the tank-farm inventory was developed to assist in designing subsequent tests that will assess the adequacy of the overall flowsheet design in treating the tank-farm wastes. These waste groupings were the basis for selecting actual wastes for the current scope of testing.

Additional EFRT-defined issues were identified that likely will also benefit from the actual waste testing reported herein, including:

- Issue M1: Piping that transports slurries will plug unless it is properly designed to minimize this risk. This design approach has not been followed consistently, which will lead to frequent shutdowns due to line plugging.

- Issue M2: Large, dense particles will accelerate erosive wear in mixing vessels. The effects of such particles on vessel life must be re-evaluated.

- Issue M3: Issues were identified related to mixing-system designs that will result in insufficient mixing and/or extended mixing times. These issues include a design basis that discounts the effects of large particles and of rapidly settling Newtonian slurries. There is also insufficient testing of the selected designs.

- Issue M6: Many of the process operating limits have not been defined. Further testing is required to define process limits for WTP unit operations. Without this more complete understanding of each process, it will be difficult or impossible to define a practical operating range for each unit operation.

\subsection{Waste Groupings}

The available information regarding tank history and tank waste characterization was analyzed. This analysis revealed eight groupings of waste tanks that represent $~ 75 \%$ of the inventory of those components most significant with respect to leaching in the WTP; i.e., Al, Cr, phosphate, and sulfate (Fiskum et al. 2008). Table 1.1 (Fiskum et al. 2008) provides a summary of the calculated waterinsoluble quantities of each component for each major waste group studied. Table 1.2 (Fiskum et al. 2008) summarizes the selected eight waste groups along with the estimated fractions (with respect to the entire tank farm inventory) of selected components contained in each one. To support the actual waste testing, samples were obtained from the archives at the Hanford 222S Laboratory. Composites of these archived samples were made to obtain the most representative samples of each group as practical.

(a) SM Barnes, and R Voke, September 2006, 24590-WTP-PL-ENG-06-0024 Rev. 0, "Issue Response Plan for Implementation of External Flowsheet Review Team (EFRT) Recommendations - M12: Undemonstrated Leaching Process." 
WTP-RPT-169, Rev 0

Table 1.1. Water-Insoluble Component Mass (Metric Tons) Inventory as Function of Waste Type

\begin{tabular}{|lrrrrrrc||}
\hline \multicolumn{1}{c}{ Waste Type } & Al & Cr & \multicolumn{1}{c}{ F } & Fe & Oxalate & Phosphate & Sulfate \\
\hline Total & 4,871 & 365 & 226 & 1,252 & 884 & 1,304 & 149 \\
\hline Saltcake Category & & & & & & & \\
\hline A & 32 & 35 & 16 & 26 & 166 & 25 & 19 \\
B & 80 & 3 & 45 & 26 & 7 & 37 & 21 \\
BY & 237 & 46 & 52 & 41 & 269 & 145 & 28 \\
R & 170 & 11 & $<0.1$ & 4 & 6 & 1 & 0.3 \\
S & 366 & 166 & 1 & 47 & 242 & 58 & 20 \\
T & 384 & 20 & 2 & 65 & 59 & 151 & 35 \\
Balance of salt cake & 7 & 1 & $<0.1$ & 1 & 5 & 4 & 0.4 \\
\hline Sludge Category & & & & & & & \\
\hline Bismuth phosphate & 218 & 14 & 51 & 280 & 4 & 473 & 11 \\
CWP & 815 & 3 & 3 & 57 & 9 & 25 & 1 \\
CWR & 471 & 4 & $<0.1$ & 17 & 4 & 2 & $<0.1$ \\
REDOX & 1,433 & 23 & 0.1 & 53 & 25 & 9 & 1 \\
TBP & 41 & 1 & 1 & 92 & 1 & 228 & 5 \\
FeCN & 54 & 3 & 1 & 93 & 7 & 84 & 1 \\
Balance of sludge & 562 & 36 & 53 & 450 & 77 & 64 & 8 \\
\hline
\end{tabular}

Table 1.2. Projected Distribution of Water-Insoluble Components in the Tank Waste Groupings

\begin{tabular}{|c|c|c|c|c|c|c|c|c|}
\hline $\begin{array}{l}\text { Group } \\
\text { ID }\end{array}$ & Type & $\begin{array}{c}\mathrm{Al} \\
(\%)\end{array}$ & $\begin{array}{l}\mathbf{C r} \\
(\%)\end{array}$ & $\begin{array}{c}F \\
(\%)\end{array}$ & $\begin{array}{c}\mathrm{Fe} \\
(\%)\end{array}$ & $\begin{array}{c}\text { Oxalate } \\
(\%)\end{array}$ & $\begin{array}{c}\text { Phosphate } \\
(\%)\end{array}$ & $\begin{array}{c}\text { Sulfate } \\
(\%)\end{array}$ \\
\hline 1 & Bi Phosphate sludge & 4 & 4 & 22 & 22 & 0.5 & 36 & 7 \\
\hline 2 & $\begin{array}{l}\text { Bi Phosphate saltcake } \\
(\mathrm{BY}, \mathrm{T})\end{array}$ & 13 & 18 & 24 & 8 & 37 & 23 & 42 \\
\hline 3 & $\begin{array}{l}\text { CWP, PUREX } \\
\text { Cladding Waste sludge }\end{array}$ & 17 & 1 & 1.3 & 5 & 1 & 2 & 0.4 \\
\hline 4 & $\begin{array}{l}\text { CWR, REDOX } \\
\text { Cladding Waste sludge }\end{array}$ & 10 & 1 & $<0.1$ & 1 & 0.4 & 0.1 & $<0.1$ \\
\hline 5 & REDOX sludge & 29 & 6 & 0.1 & 4 & 3 & 1 & 0.4 \\
\hline 6 & S - Saltcake (S) & 8 & 46 & 0.6 & 4 & 27 & 4 & 14 \\
\hline 7 & TBP Waste sludge & 1 & 0.4 & 0.5 & 7 & 0.1 & 17 & 3 \\
\hline \multirow[t]{2}{*}{8} & FeCN Waste sludge & 1 & 1 & 0.4 & 7 & 1 & 6 & 1 \\
\hline & Balance & 17 & 24 & 51 & 41 & 30 & 10 & 32 \\
\hline
\end{tabular}




\subsection{Simulant Development}

BNI plans to carry out process development and scale-up testing to demonstrate the design effectiveness of both the caustic- and the oxidative-leaching processes over the entire applicable range of Hanford tank farm wastes. ${ }^{\text {(a) }}$ Scale-up testing will require substantial volumes of feed. Therefore, the development of simulants that mimic the chemical, leaching, and ultrafiltration behaviors over the range observed for actual waste groups is necessary to the process development and demonstration. The leaching and filtration performance data obtained from the actual waste testing will serve as benchmarks for defining the simulant characteristics and behaviors and as a basis for revising the parameters used in evaluating WTP process performance using the appropriate process models.

\subsection{Testing of Group 7}

The characterization, parametric leaching, and filtration/leaching testing of the TBP sludge waste (Group 7) is the subject of this report. The phosphate behavior is of particular interest, as this is the major component targeted to be removed by caustic leaching (Table 1.2). Aluminum is also of interest.

The waste-type definition, sample identification, archived sample conditions, and homogenization activities are discussed in this report. The caustic-leaching experiments and results are described for the Group 7 solids. The physical, chemical, radioisotope, and crystal morphology characterization in the waste before and after leach processing are also discussed. A single bench scale leaching and filtration test, using a crossflow filtration testing apparatus, was performed in a hot cell using the remainder of the Group 7 solids in combination with archived tank waste samples from 241-AY-102. The leaching and filtration results from this test are described and presented.

The results from these tests will refine the knowledge base of the tank waste chemical and mineralogical characteristics. Parametric leach testing will provide the leaching kinetics of gibbsite and phosphorus and support follow-on leach and filtration testing.

(a) WTP Doc. No. 24590-WTP-PL-ENG-06-0008, Rev 0, "Hanford Waste Treatment and Immobilization Plant (WTP) Project Response Plan for Resolution of Issues Identified by the Comprehensive Review of the WTP Flowsheet and Throughput.” L Lucas, March 2006. 
WTP-RPT-169, Rev 0

\subsection{Test-Sample Selection, Compositing, and Homogenization}

This section describes the rationale for selecting TBP sludge (Group 7) test materials from the Hanford tank waste sample archive located in the 222S building of the Hanford Site. Retrieving new sample materials from the tanks was deemed to be prohibitively expensive and time intensive and therefore was not considered. Also described is the homogenization and sub-sampling of Group7 composite samples.

\subsection{Tributyl Phosphate Sludge Sample Selection}

TBP tank waste sludge samples with high phosphate content were targeted to construct the Group 7 composite. As part of the uranium recovery process, a solution of TBP in an organic diluent was used to extract uranium from bismuth phosphate sludges. The TBP sludge refers to the waste generated during this extraction process. The Tank-Waste Information Network System (TWINS) database ${ }^{(a)}$ was queried to identify the tanks containing at least $95 \%$ of this TBP sludge as defined by the Best Basis Inventory (BBI). Only samples from 222S listed with a sludge/solid matrix were used. These tank wastes were queried in $\mathrm{BBI}^{(\mathrm{a})}$ for the major inorganic components (phosphate, sulfate, $\mathrm{Bi}, \mathrm{Al}, \mathrm{Fe}, \mathrm{Cr}, \mathrm{Mn}, \mathrm{Si}$, and $\mathrm{U}$ ) in the solid and sludge phases. Figure 2.1 shows the relative mass distributions of these analytes (note that major elemental and anionic contributions from $\mathrm{Na}$, nitrate, nitrite, and oxalate are excluded from the data in Figure 2.1).

The decision process flowchart for selecting tank waste samples from the sample archive is summarized in Figure 2.2. The 222S archive sample inventory ${ }^{(\mathrm{b})}$ was searched for sludge samples from the tanks identified as containing TBP waste (Figure 2.2). The samples were then cross-referenced to the TWINS database to determine if analytical data from the specific samples were available; samples identified as containing at least 95\% TBP sludge were carried forward in the selection process. The final list of samples was submitted to CH2MHill personnel ${ }^{(\mathrm{c})}$ to verify that: 1 ) the samples represented the TBP sludge waste stream based on the tank strata, core segment, and corresponding characterization results, and 2) the samples were not held for other activities and could be released from the archive.

(a) The TWINS database and the BBI are DOE-owned resources.

(b) Personal communication of the inventory database, file "Vials May18," provided from P Brackenbury, Bechtel, June 2006.

(c) David Place and Bruce Higley, Process Engineers, Process Analysis Organization, CH2MHill. 


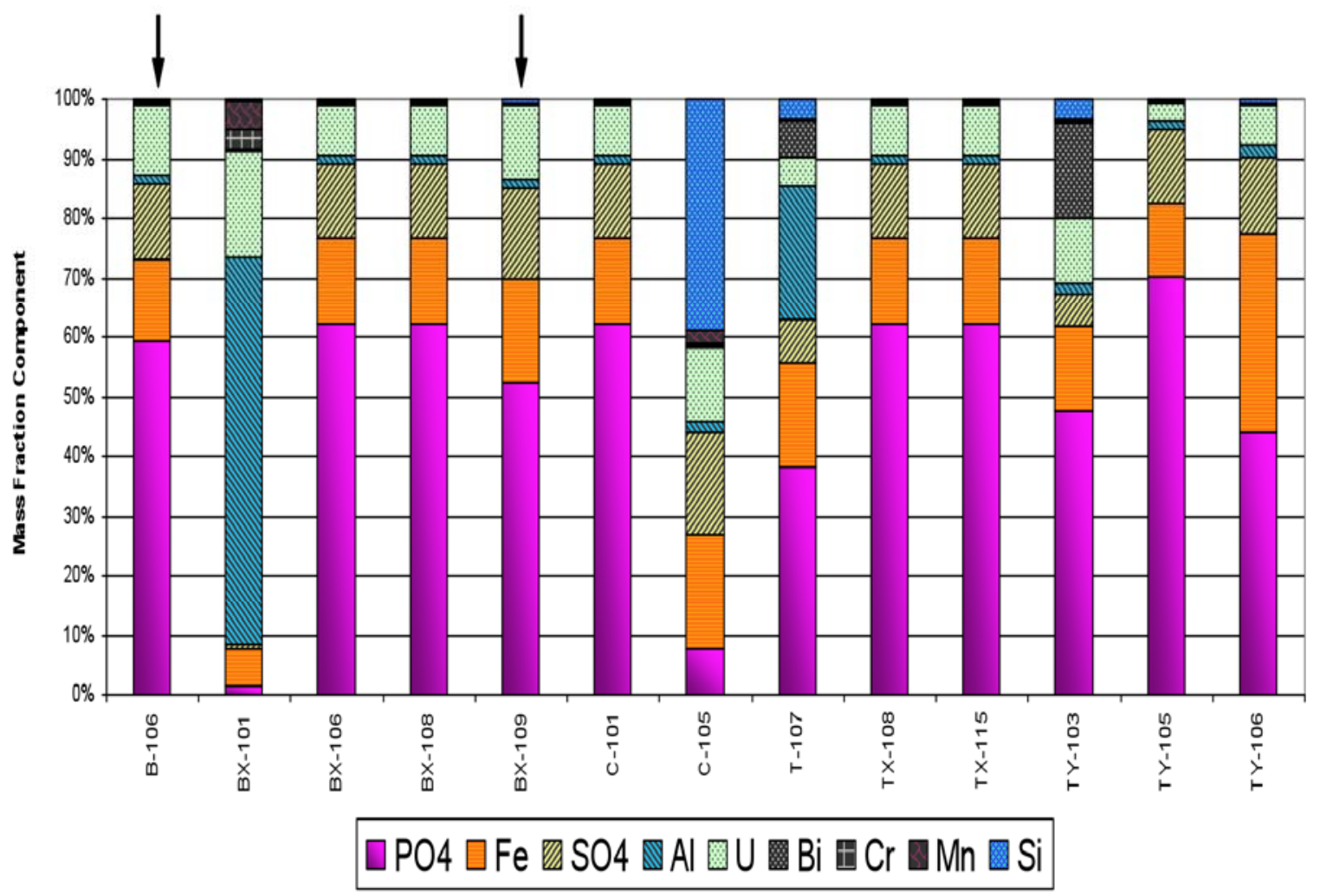

Figure 2.1. Estimated Tank Waste Composition of Selected Analytes for Group 7 Sludge Wastes in the Hanford Tank Farm (BBI Source). Note: arrows point to the tanks actually used to prepare the composite; BX-109 dominated the composite mass (see text). 
WTP-RPT-169, Rev 0

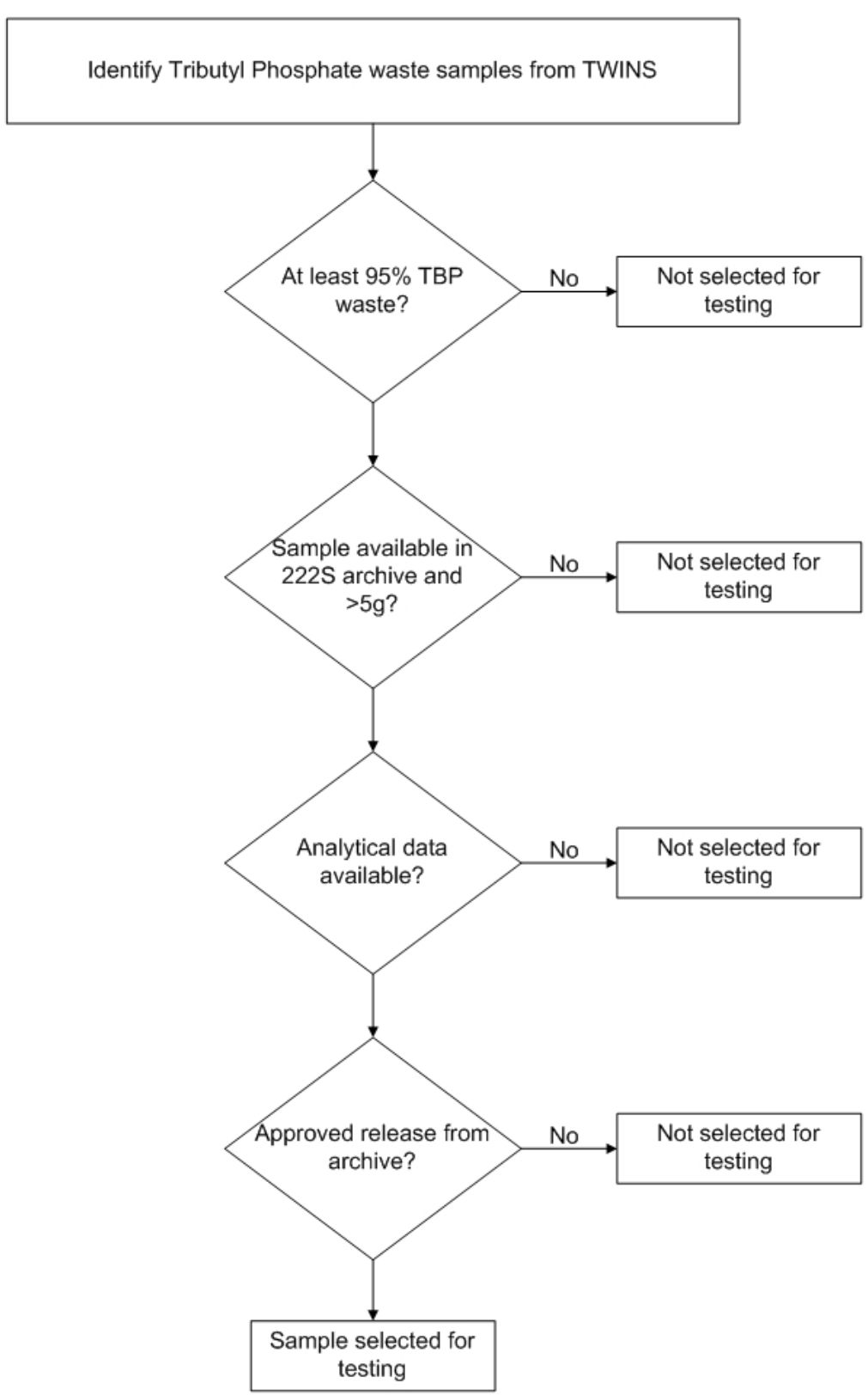

Figure 2.2. Selection Decision Process for TBP Sludge Samples

Table 2.1 summarizes the tank sources evaluated and shows whether the tank met or failed the selection criteria. Samples highlighted in bold in the table were those determined to meet all of the selection criteria.

Table 2.2 summarizes the individual samples (sample date, tank ID, sample core, and segment) from the archive that met the selection criteria. These samples had been in storage at 222-S for $\sim 12$ to 15 years. The long storage time could potentially cause the sample characteristics to be altered relative to the asretrieved sample condition through aging and drying. But, as stated previously, obtaining fresh core samples from the Hanford waste tanks was outside the scope of the project budget and schedule. Also 
shown in Table 2.2 are the anticipated sample masses assumed available based on the archive inventory in 2002. A total of $1.9 \mathrm{~kg}$ of TPB sludge was assumed to be available and sufficient for the complete testing scope.

The sample set was heavily represented by one tank, BX-109. The potential impact of the Group 7 composite representation primarily by BX-109 was evaluated. As seen in Figure 2.1, aside from three waste tank samples that were deemed unrepresentative of the waste type, gross deviations in the elemental compositions within the remainder of tank waste samples were relatively minor. It was concluded that BX-109 would be reasonably representative of the group.

Table 2.1. Selection of TBP Sludge Tanks

\begin{tabular}{|c|c|c|c|}
\hline Tank & Volume TBP Sludge, $k L$ & Total Sludge Volume, kL & Ratio TBP Sludge: Total Sludge \\
\hline 241-B-106 & 297 & 301 & 0.987 \\
\hline $241-B X-101^{(a)}$ & 59 & 59 & 1 \\
\hline $241-\mathrm{BX}-106^{(\mathrm{b})}$ & 20 & 20 & 1 \\
\hline $241-B X-108^{(a)}$ & 81 & 81 & 1 \\
\hline 241-BX-109 & 730 & 730 & 1 \\
\hline $241-C-101^{(a)}$ & 125 & 125 & 1 \\
\hline $241-C-105^{(\mathrm{c})}$ & 50 & 50 & 1 \\
\hline $241-T-107^{(\mathrm{c})}$ & 64 & 64 & 1 \\
\hline $241-T X-108^{(a)}$ & 15 & 15 & 1 \\
\hline $241-T X-115^{(a)}$ & 30 & 30 & 1 \\
\hline $241-T Y-103^{(a)}$ & 220 & 220 & 1 \\
\hline $241-T Y-105^{(a)}$ & 874 & 874 & 1 \\
\hline $241-T Y-106^{(c)}$ & 15 & 15 & 1 \\
\hline \multicolumn{4}{|c|}{$\begin{array}{l}\text { (a) Sample not listed in } 222 \mathrm{~S} \text { inventory. } \\
\text { (b) Available samples were }<20 \mathrm{~g} \text {. } \\
\text { (c) Available sample material is not representative of the waste type. } \\
\text { Samples from bolded/shaded tanks are represented in Table } 2.2\end{array}$} \\
\hline
\end{tabular}


Table 2.2. Group 7, 222S TBP Samples

\begin{tabular}{|c|c|c|c|c|c|c|c|c|}
\hline Date & Location & Box & Jar \# & Tank & Core & Segment & Matrix & $\begin{array}{c}\text { Net } \\
\text { Weight } \\
\text { (g) }\end{array}$ \\
\hline 9/3/1997 & 11A1B & 97 & 13516 & BX-109 & 85 & 1 & Sludge & 25.02 \\
\hline 7/24/1995 & 11A1A & 22 & 7424 & B-106 & 94 & 2 & Sludge & 43.54 \\
\hline 9/3/1997 & 11A1B & 97 & 13517 & BX-109 & 84 & 1 & Sludge & 43.64 \\
\hline $2 / 6 / 2002$ & 11A1B & 93 & 19302 & BX-109 & 84 & 3 & Sludge & 44 \\
\hline 9/11/1997 & 11A1B & 129 & 11840 & BX-109 & 84 & 4 & Sludge & 44.7 \\
\hline 9/4/1997 & 11A1B & 97 & 13523 & BX-109 & 84 & 4 & Sludge & 47.34 \\
\hline 9/12/1997 & 11A1A & 35 & 13473 & BX-109 & 85 & 1 & Sludge & 48.75 \\
\hline 9/4/1997 & 11A1B & 97 & 13522 & BX-109 & 85 & 4 & Sludge & 48.93 \\
\hline 4/20/1995 & 11A1A & 31 & 6935 & BX-109 & 84 & 2 & Sludge & 49.03 \\
\hline 4/20/1995 & 11A1A & 38 & 6907 & BX-109 & 84 & 2 & Sludge & 50.27 \\
\hline 4/18/1995 & 11A1A & 38 & 6927 & BX-109 & 85 & 2 & Sludge & 50.45 \\
\hline 7/24/1995 & 11A1A & 56 & 7417 & B-106 & 93 & 2 & Sludge & 50.49 \\
\hline 7/26/1995 & 11A1B & 129 & 7372 & BX-109 & 84 & Comp & Sludge & 50.7 \\
\hline 4/20/1995 & 11A1A & 31 & 6932 & BX-109 & 84 & 4 & Sludge & 51.65 \\
\hline 4/20/1995 & 11A1A & 31 & 6933 & BX-109 & 84 & 4 & Sludge & 52.08 \\
\hline $4 / 19 / 1995$ & 11A1A & 31 & 6931 & BX-109 & 84 & 3 & Sludge & 52.55 \\
\hline 4/21/1995 & 11A1A & 34 & 7158 & BX-109 & 85 & 4 & Sludge & 53.19 \\
\hline 4/20/1995 & 11A1A & 31 & 6934 & BX-109 & 84 & 1 & Sludge & 53.25 \\
\hline 4/18/1995 & 11A1A & 31 & 6921 & BX-109 & 85 & 1 & Sludge & 54.6 \\
\hline 4/21/1995 & 11A1A & 34 & 7154 & BX-109 & 85 & 3 & Sludge & 54.97 \\
\hline 4/19/1995 & 11A1A & 31 & 6930 & BX-109 & 84 & 3 & Sludge & 55.15 \\
\hline 4/21/1995 & 11A1A & 34 & 7157 & BX-109 & 85 & 4 & Sludge & 55.51 \\
\hline 4/18/1995 & 11A1A & 31 & 6922 & BX-109 & 85 & 2 & Sludge & 56.56 \\
\hline $4 / 21 / 1995$ & 11A1A & 34 & 7153 & BX-109 & 85 & 3 & Sludge & 57.89 \\
\hline 3/1/1996 & 11A1B & 104 & 9346 & BX-109 & 85 & 3 & Sludge & 64.68 \\
\hline $8 / 16 / 1999$ & 11A2 & 17 & 16916 & BX-109 & 85 & 2 & Sludge & 66.1 \\
\hline $5 / 17 / 1996$ & 11A1B & 62 & 10116 & BX-109 & 85 & 2R2 & Sludge & 69.5 \\
\hline 9/3/1997 & 11A1B & 97 & 13515 & BX-109 & 84 & 2 & Sludge & 70.59 \\
\hline 9/3/1997 & 11A1B & 102 & 13092 & BX-109 & 84 & 3 & Sludge & 72.5 \\
\hline 8/13/1999 & 11A2 & 17 & 16913 & B-106 & 93 & $1-2$ & Sludge & 78.6 \\
\hline $3 / 1 / 1996$ & 11A1B & 104 & 9334 & BX-109 & 85 & 3 & Sludge & 81.74 \\
\hline 9/26/1997 & 11A1B & 94 & 13445 & BX-109 & 85 & Comp & Sludge & 82.81 \\
\hline 8/3/1995 & 11A2 & Floor & 7378 & BX-109 & 84 & Comp & Sludge & 132.7 \\
\hline \multicolumn{8}{|c|}{ Total Sample Net Weight (g) } & 1913 \\
\hline
\end{tabular}

\subsection{Group 7 Sample Homogenization and Sub-sampling}

For a detailed description of homogenization methods please refer to Appendix I.

Thirty-three archived Group 7 samples (3 from Tank B-106 and 30 from BX-109) were shipped from the 222-S laboratory. Advanced Technologies and Laboratories International (ATL) provided masses for 
these archived samples in the shipping letter report. Many of the samples had dried out during the time spent in archived storage. Photographs (Figure 2.3), as-received weights, and detailed sample descriptions were all recorded in TI-RPP-WTP-515. The sample material fell into the following general categories:

\section{a. Dry powdery sample}

b. Dry solid sample; added water to soak sample so it could be broken up and removed from the jar for addition to the homogenizer.

c. Semi-solid; sample was added to homogenizer without soaking sample with water first.

d. Clearly visible supernate liquid in jar.

e. Sample with visible debris (deteriorated polypropylene [blue] lids were replaced on some samples at 222S facility by heavier [green] thermoset lids-Figure 2.4.)
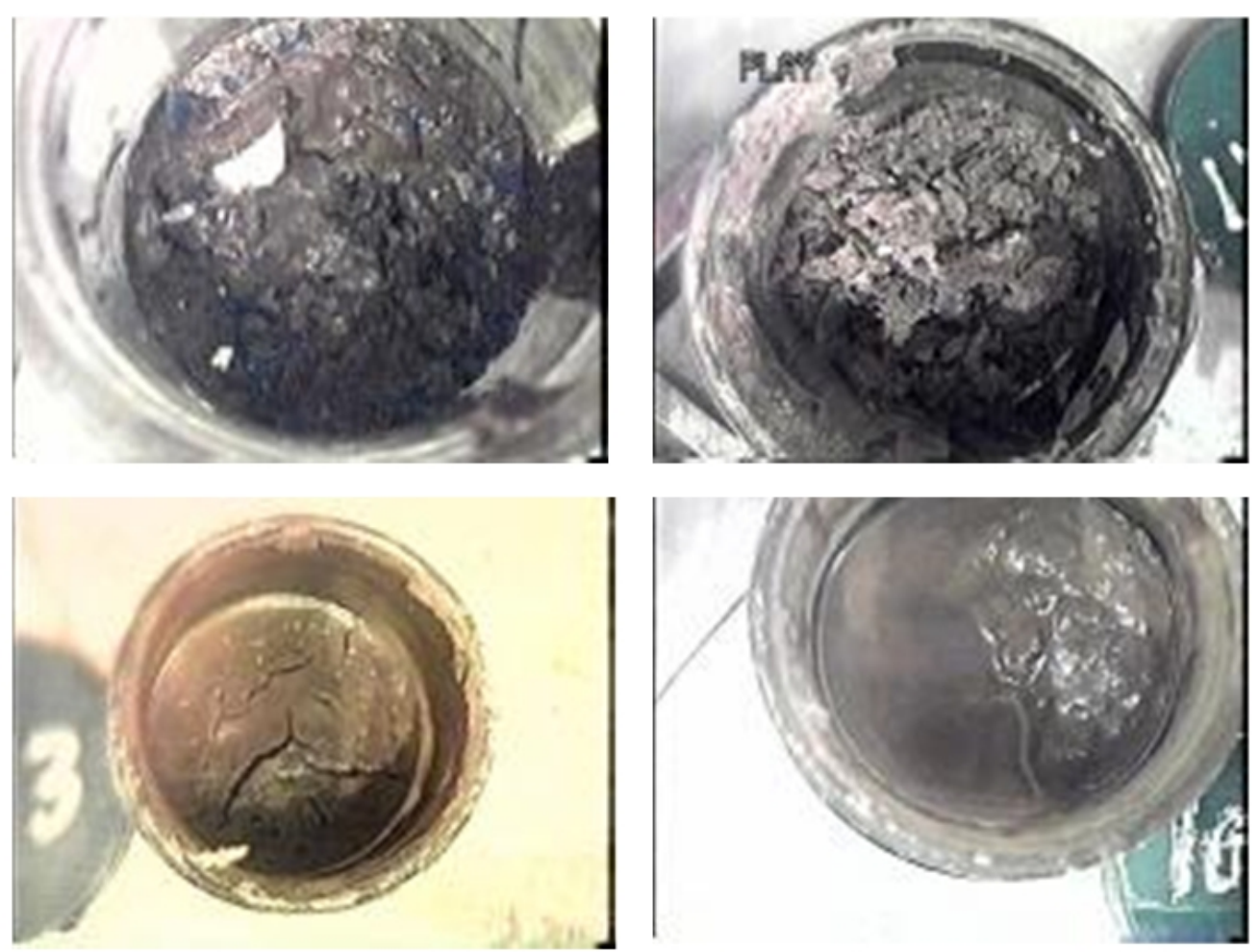

Figure 2.3. Representative Pictures of As-Received Group 7 Waste 


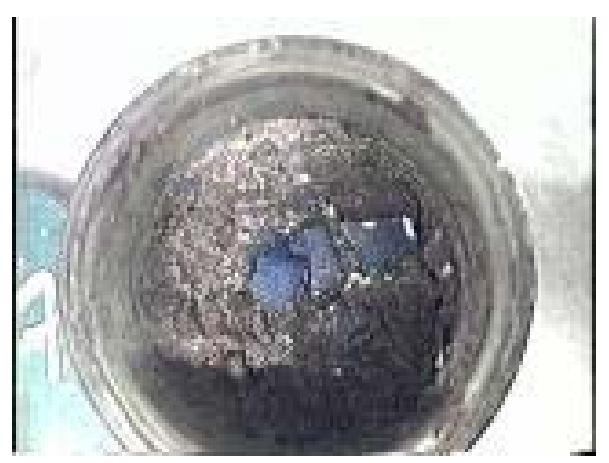

Figure 2.4. Group 7 Sample with Visible Debris

Table 2.3 lists the individual samples added to the composite sample, along with gross mass (expected and found), the mass of the empty container, and the net mass of waste transferred to the homogenizer. Samples that appeared to be fine solids were added first and easily passed through the sieve. If foreign material, such as pieces of broken caps, were present, those were picked out with stainless steel tweezers and weighed when possible (there were very few instances of this for these samples). For wet samples, the solids were removed from the sample jar by a process of scraping and rinsing with DI water using a squirt bottle. In this fashion, nearly all residues were removed from the sample jars. These samples were originally placed in secondary containment and removed from their smaller jars into larger jars to minimize evaporative losses that sitting in the larger tank might have allowed over the several days required to empty the smaller jars.

Solids and semi-solids were forced through the sieve using DI water, rubber spatulas, and a stainless steel mashing tool that also was used in breaking up some chunks of solid materials so they could pass though the sieve. To the maximum extent possible, all sample materials were placed into the homogenizer; there was very little loss of actual sample due to splattering or spillage. Water was used conservatively during the entire process of removing the samples from the jars so as to have enough water to remove all sample residues and come close to the desired total solution added to reach the desired Na concentration.

After all of the recoverable sample materials were transferred to the homogenizer tank, the sample jars were allowed to dry, and they were then reweighed. These values were used to calculate sample recovery and actual amount of sample added to the homogenizer (Table 2.3). A few jars had significant differences between the expected gross mass and the as-found gross mass. These larger differences are probably due to loss of water from the sample over time during storage at $222 \mathrm{~S}$ and/or sample loss in shipping. The jar lids tend to become brittle in the radiological environment over time, so some of these likely cracked, and the water evaporated. Some tare masses were based on vials with blue lids; lids had been replaced with green lids for shipping. The mass difference associated with the change in lids was $\sim 4.6 \mathrm{~g}$ and this was taken into account for the samples this applied to. New lids were placed on the jars before shipping. 
Table 2.3. TBP Sludge Samples (Group 7)

\begin{tabular}{|c|c|c|c|c|c|c|}
\hline $\begin{array}{l}\text { Hanford } \\
\text { Tank ID }\end{array}$ & 222-S ID & $\begin{array}{c}\text { 222S } \\
\text { Expected } \\
\text { Gross } \\
\text { Mass (g) } \\
\end{array}$ & $\begin{array}{c}\text { PNNL } \\
\text { As-found } \\
\text { Gross } \\
\text { Mass (g) }\end{array}$ & $\begin{array}{c}\text { Jar and } \\
\text { Lid Condition }\end{array}$ & $\begin{array}{c}\text { PNNL } \\
\text { Empty } \\
\text { Container } \\
\text { Mass (g) } \\
\end{array}$ & $\begin{array}{c}\text { PNNL } \\
\text { Mass } \\
\text { Transferred } \\
\text { (g) } \\
\end{array}$ \\
\hline B-106 & 7417 & 75 & 74.76 & Good & 26.81 & 47.95 \\
\hline B-106 & 7424 & 63.9 & 64.53 & Good & 27.26 & 37.27 \\
\hline B-106 & 16913 & 121.4 & 124.46 & Good & 92.60 & 31.86 \\
\hline BX-109 & 6907 & 70.3 & 69.62 & Good & 29.02 & 40.60 \\
\hline BX-109 & 6921 & 79.8 & 80.24 & Good & 27.58 & 52.66 \\
\hline BX-109 & 6922 & 81.5 & 80.70 & Good & 29.75 & 50.95 \\
\hline BX-109 & 6927 & 66.5 & 66.00 & Good & 29.07 & 36.93 \\
\hline BX-109 & 6930 & 79.9 & 79.83 & Good & 30.68 & 49.15 \\
\hline BX-109 & 6931 & 58.9 & 58.36 & Good & 26.19 & 32.17 \\
\hline BX-109 & 6932 & 76.4 & 76.58 & Good & 29.51 & 47.07 \\
\hline BX-109 & 6933 & 76.4 & 76.16 & Good & 27.56 & 48.60 \\
\hline BX-109 & 6934 & 74.8 & 73.11 & Good & 27.03 & 46.08 \\
\hline BX-109 & 6935 & 73.9 & 72.30 & Good & 26.41 & 45.89 \\
\hline BX-109 & 7153 & 82.8 & 82.46 & Good & 26.71 & 55.75 \\
\hline BX-109 & 7154 & 80 & 80.52 & Good & 26.37 & 54.15 \\
\hline BX-109 & 7157 & 79.4 & 78.26 & Good & 29.62 & 48.64 \\
\hline BX-109 & 7158 & 76.8 & 73.98 & Good & 28.38 & 45.60 \\
\hline BX-109 & 7372 & 168.8 & 167.44 & Good & 134.18 & 33.26 \\
\hline BX-109 & 7378 & 200.1 & 206.48 & Good & 131.03 & 75.45 \\
\hline BX-109 & 9334 & 137.4 & 137.25 & Good & 92.37 & 44.88 \\
\hline BX-109 & 9346 & 133.7 & 133.06 & Good & 92.2 & 40.86 \\
\hline BX-109 & 10116 & 152.9 & 152.77 & Good & 95.65 & 57.12 \\
\hline BX-109 & 11840 & 155.3 & 163.76 & Good & 130.25 & 33.51 \\
\hline BX-109 & 13092 & 148.9 & 141.23 & Good & 96.92 & 44.31 \\
\hline BX-109 & 13445 & 144.3 & 145.72 & Good & 92.15 & 53.57 \\
\hline BX-109 & 13473 & 128.8 & 129.07 & Good & 90.22 & 38.85 \\
\hline BX-109 & 13515 & 157.2 & 160.20 & Good & 96.13 & 64.07 \\
\hline BX-109 & 13516 & 111.4 & 116.16 & Good & 94.79 & 21.37 \\
\hline BX-109 & 13517 & 129.5 & 134.75 & Good & 94.68 & 40.07 \\
\hline BX-109 & 13522 & 117.6 & 120.92 & Good & 94.87 & 26.05 \\
\hline BX-109 & 13523 & 133.8 & 136.35 & na & 95.74 & 40.61 \\
\hline BX-109 & 16916 & 146.2 & 146.01 & na & 92.97 & 53.04 \\
\hline BX-109 & 19302 & 126.9 & 133.46 & na & 92.64 & 40.82 \\
\hline Totals & --- & 3610.5 & 3636.50 & --- & 2157.34 & 1479.16 \\
\hline
\end{tabular}


A total of $91.8 \%$ of the received mass was recovered from the sample jars and put into the composite. The received mass was calculated by subtracting the 222S-supplied tare weights for the sample jars from the total mass measured in HLRF before transferring the sample materials. The final tank composite based on the mass balance was primarily made of BX-109 tank waste as can be seen in Figure 2.5.

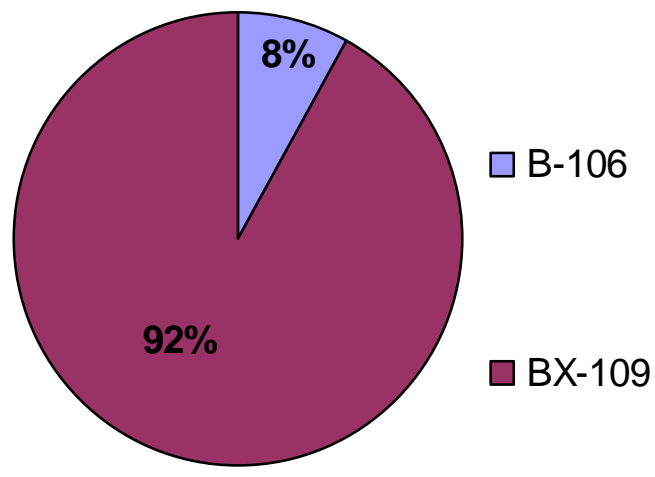

Figure 2.5. Composite Composition of Group 7 by Hanford Tank Waste

After all samples had been added to the homogenizer tank, and all equipment (spatula, sieve, mashing tool) had been rinsed free of sample, the sieve screen was removed. A total of $779.7 \mathrm{~g}$ of DI water was added during the compositing process. A mechanical stirrer with stainless steel impeller was lowered into the tank, the fitted lid was placed on the tank, and the material was mixed thoroughly. The temperature in the hot cell was $35^{\circ} \mathrm{C}$ at the start of mixing. The goal of this step was to homogenize the sample using as little force as possible. The stirrer speed was slowly increased until the solids were mobilized. The positions and arrangements for the height of the mixer relative to the support rod and impeller were predetermined during the preliminary non-radioactive testing, and the proper alignments were marked onto the impeller and support rod correctly aligned. While operating the vessel agitator, material was extracted from the collection port at the bottom of the tank and returned through the top of the vessel so that all the material was mixed well.

The total mixing time for the Group 7 composite slurry was 1 hour before sub-sampling began. Subsampling took 40 minutes, and the mixer continued to mix during this time. The consistency of the Group 7 composite was viscous and remained that way throughout all the subsamples. The sub-samples were removed in a specific order to pre-determined target volumes. Pre-weighed and labeled jars and centrifuge tubes were staged in collection vessels in the order provided in Table 2.4.

At the start of sub-sampling, while operating the vessel agitator, one sub-sample of sufficient size (minimum of $100 \mathrm{~mL}$ ) was extracted through the sample valve into TI515-G7-AR-J1 to clear material from the lowest portion of the vessel. This was then added back to the mixing vessel before sub-sampling began. The homogenized Group 7 samples settled slowly, requiring 13 days to settle completely. For compositing to be considered successful, the sample density and settled solids data standard deviation had to be less than $\pm 5 \%$, and there had to be no statistically significant trend in settled solids and density variation due to subsample removal order. Figure 2.6 shows that composting was successful. 
WTP-RPT-169, Rev 0

Table 2.4. Group 7 Subsample Mass Density and Settling Data

\begin{tabular}{|l|c|c|c|c|c|c||}
\hline $\begin{array}{l}\text { Sample ID in Order of } \\
\text { Collection }\end{array}$ & $\begin{array}{c}\text { Target } \\
\text { Collection } \\
\text { Volume, } \mathbf{m L}\end{array}$ & $\begin{array}{c}\text { Sample Net } \\
\text { Wt, g }\end{array}$ & $\begin{array}{c}\text { Total Slurry } \\
\text { Volume, } \mathbf{m L}\end{array}$ & $\begin{array}{c}\text { Settled } \\
\text { Solids } \\
\text { Volume, mL }\end{array}$ & $\begin{array}{c}\text { Gross } \\
\text { Slurry } \\
\text { Density }\end{array}$ & $\begin{array}{c}\text { \%Vol } \\
\text { Settled } \\
\text { Solids }\end{array}$ \\
\hline TI515-G7-AR-J1 & $300-400$ & 483.398 & 385 & 245 & 1.26 & 63.6 \\
\hline TI515-G7-AR-J2 & $300-400$ & 451.141 & 360 & 225 & 1.25 & 62.5 \\
\hline TI515-G7-AR-J3 & $300-400$ & 433.9 & 345 & 215 & 1.26 & 62.3 \\
\hline TI515-G7-AR-J4 & $300-400$ & 458.215 & 365 & 225 & 1.26 & 61.6 \\
\hline TI515-G7-AR-S1 & $10-15$ & 11.805 & 9.0 & 5.7 & 1.31 & 63.3 \\
\hline TI515-G7-AR-S2 & $10-15$ & 12.094 & 9.4 & 6.0 & 1.29 & 63.8 \\
\hline TI515-G7-AR-S3 & $10-15$ & 10.465 & 8.1 & 5.4 & 1.29 & 67.5 \\
\hline TI515-G7-AR-RH1 & 50 & 88.565 & 70 & 45 & 1.27 & 64.3 \\
\hline TI515-G7-AR-C1 & 25 & 21.831 & 17 & 11 & 1.28 & 64.7 \\
\hline TI515-G7-AR-C2 & 25 & 27.168 & 21.5 & 14 & 1.26 & 65.1 \\
\hline TI515-G7-AR-Arch1 & 10 & 22.716 & 20 & 13.0 & 1.14 & 65.0 \\
\hline TI515-G7-AR-P1 & 150 & 130.711 & 115 & 55 & 1.14 & 47.8 \\
\hline
\end{tabular}

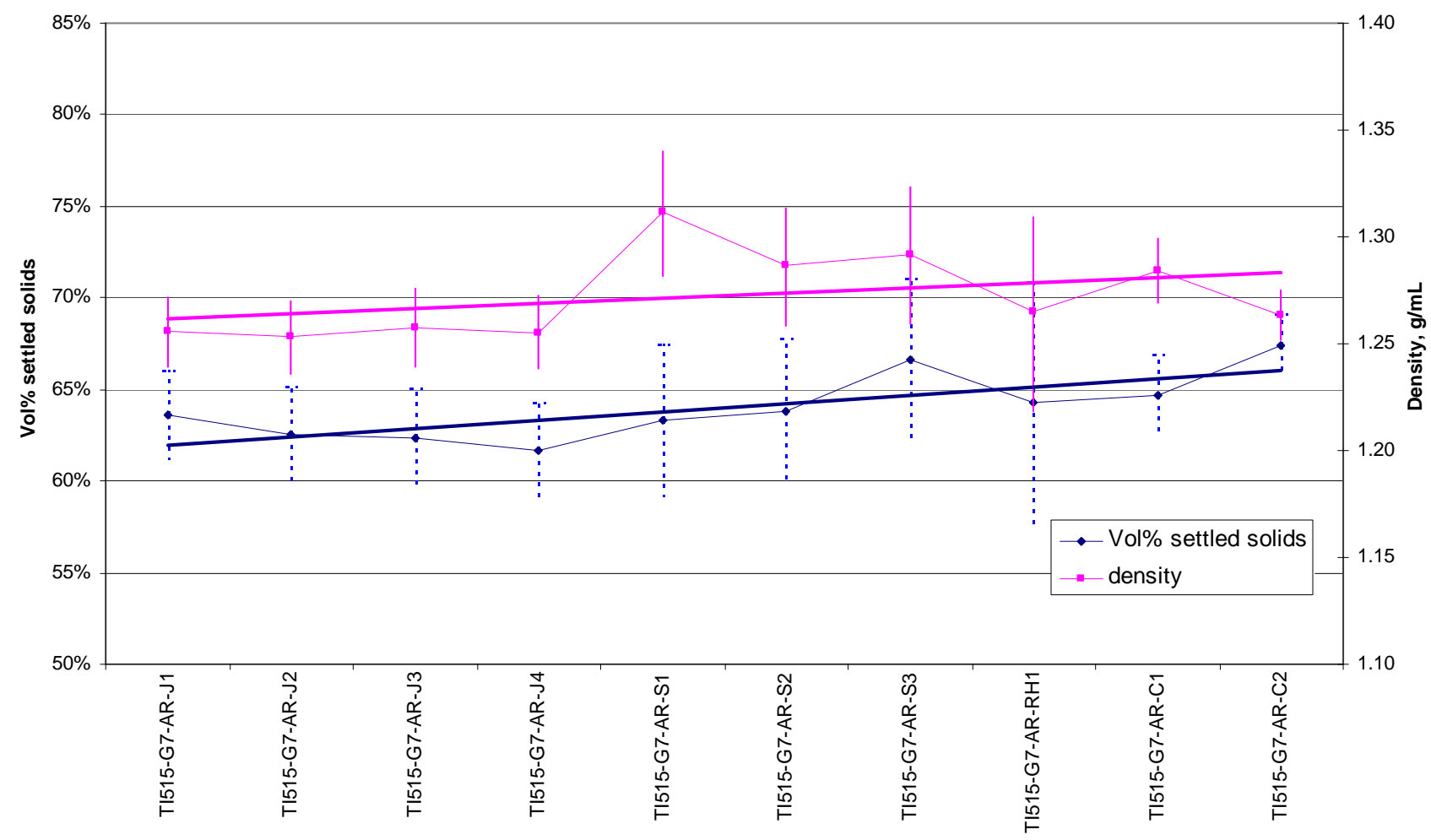

Figure 2.6. Group 7 Confirmation of Successful Material Composite Based on Density and Settled Solids 


\subsection{Initial Characterization Results for Tributyl Phosphate Waste Sludge Group 7}

This section reports on and discusses the initial characterization results for the Group 7 tributyl phosphate (TBP) sludge slurry composite, supernatant, and washed solids. The initial characterization activities included physical-property testing and chemical analysis as shown in Figure 3.1 ${ }^{\text {(a) }}$ and Figure 3.2. The supernatant results represent the equilibrated aqueous phase in contact with the solids; the solids characterization results were obtained after washing with $0.01 \mathrm{M} \mathrm{NaOH}$. Solids washing was considered crucial to better understand the nature of the solids, free of complications associated with supernatant entrainment. The solids wash solutions were separately collected in the three step-wise increments (as opposed to a total wash composite) to better evaluate the phosphate mobilization during the wash steps.

(a) The physical property testing was conducted according to TI-RPP-WTP-515, Tributyl Phosphate Sludge Hanford Tank Waste Sample Compositing, Homogenization, and Sub-Division, R. Swoboda, 12/5/07; the solids washing and sample handling was conducted according to TI-RPP-WTP-576, Initial Characterization of Group 7 Tank Waste: TBP Sludge, S Fiskum, 1/21/08. 


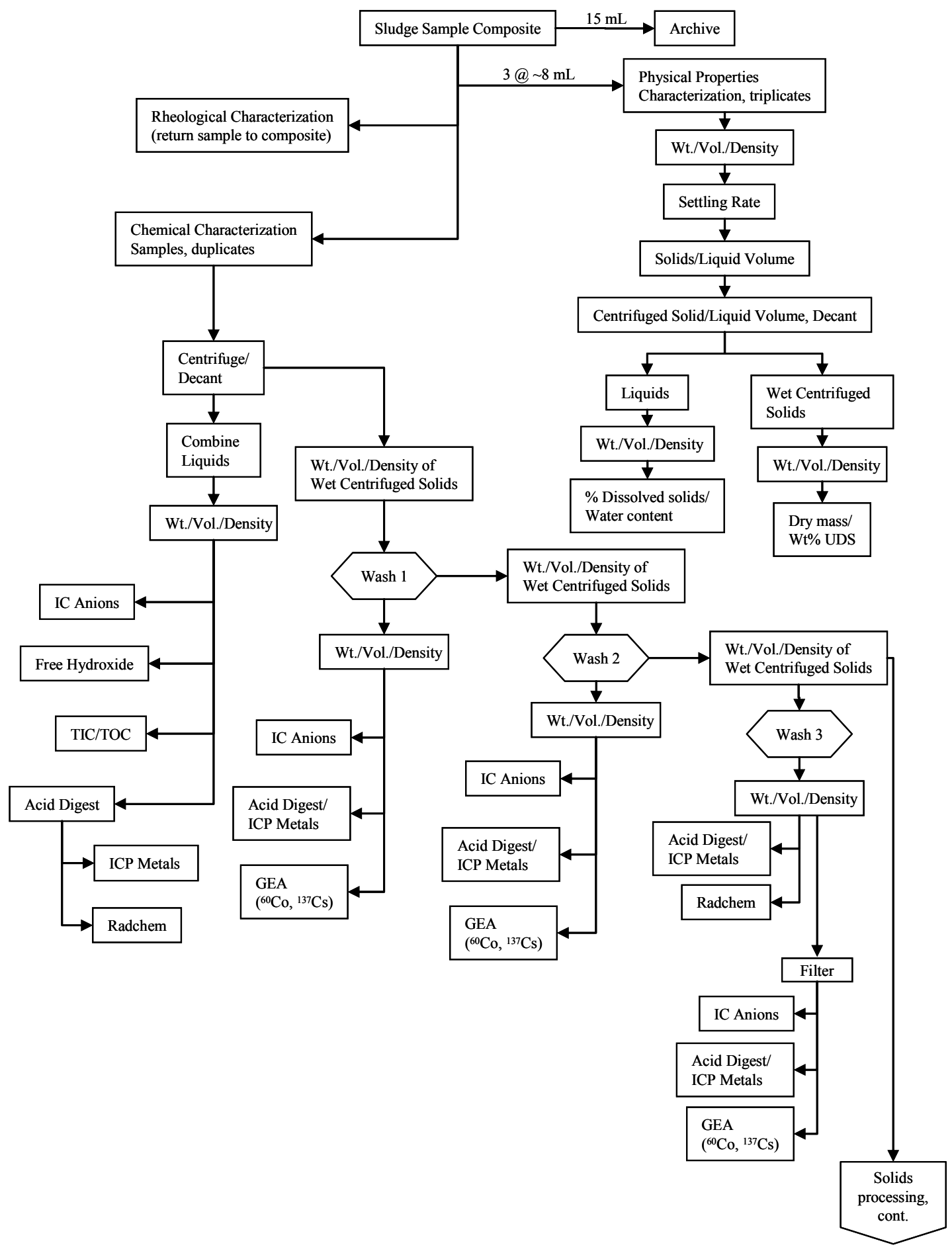

Figure 3.1. Composite Group 7 Slurry Processing and Analysis Scheme

Acronyms used in Figure 3.1:

GEA gamma energy analysis

IC ion chromatography

ICP inductively coupled plasma
TIC total inorganic carbon

TOC total organic carbon

UDS undissolved solids 
WTP-RPT-169, Rev 0

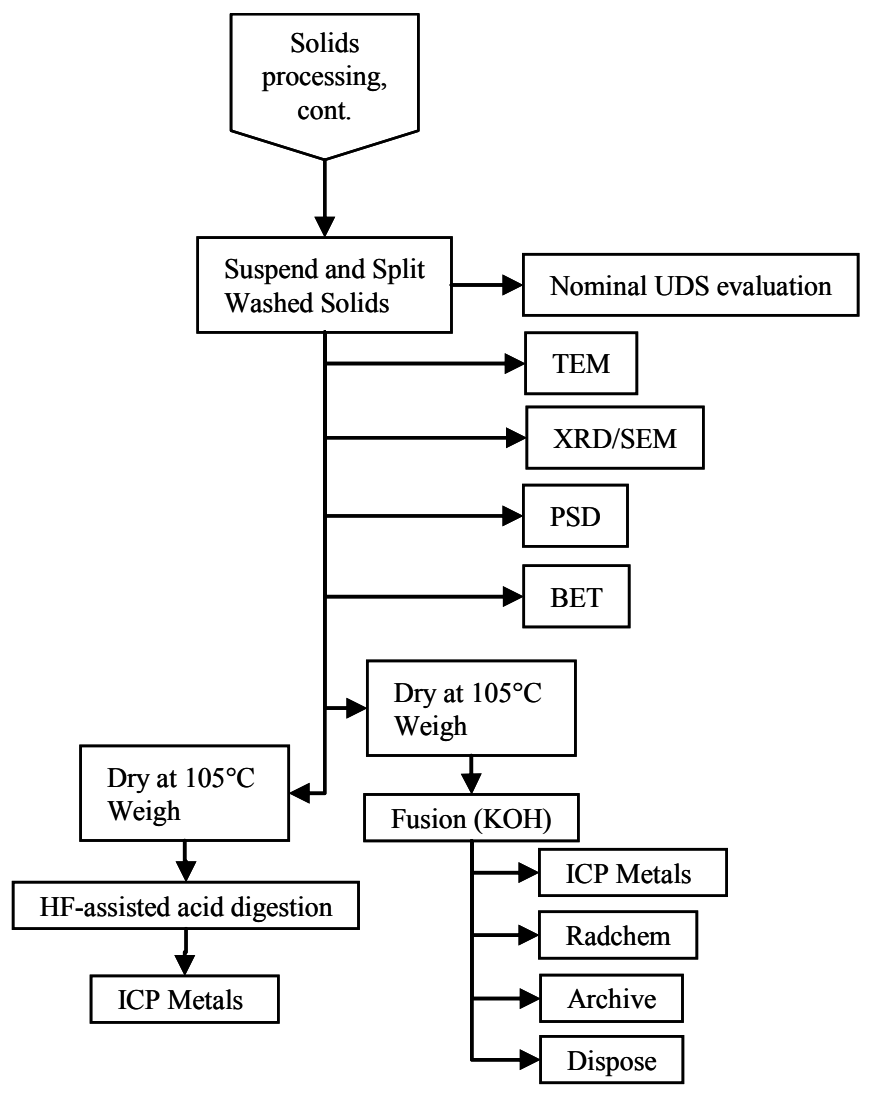

Figure 3.2. Composited Group 7 Washed Solids Processing and Analysis Scheme

Acronyms used in Figure 3.2:

BET Brunauer, Emmett, and Teller

HF Hydrofluoric Acid Digestion

ICP inductively coupled plasma

$\mathrm{KOH}$ potassium hydroxide (fusion)

PSD particle-size distribution
SEM scanning electron microscopy

TEM transmission electron microscopy

UDS undissolved solids

XRD X-ray diffraction

\subsection{Physical Properties of the Composite Group 7 TBP Slurry}

The settling curves of the triplicate samples of Group 7 composited solids are shown in Figure 3.3. Results are shown in two ways: 1) volume-percent settled solids as a function of time and 2) height of settled solids as a function of time. The settling curves for S2 and S3 appeared coincident whereas S1 appeared to settle slightly faster. Overall settling proceeded rather slowly, requiring nominally $50 \mathrm{~h}$ to reach a constant settled volume. 
a)

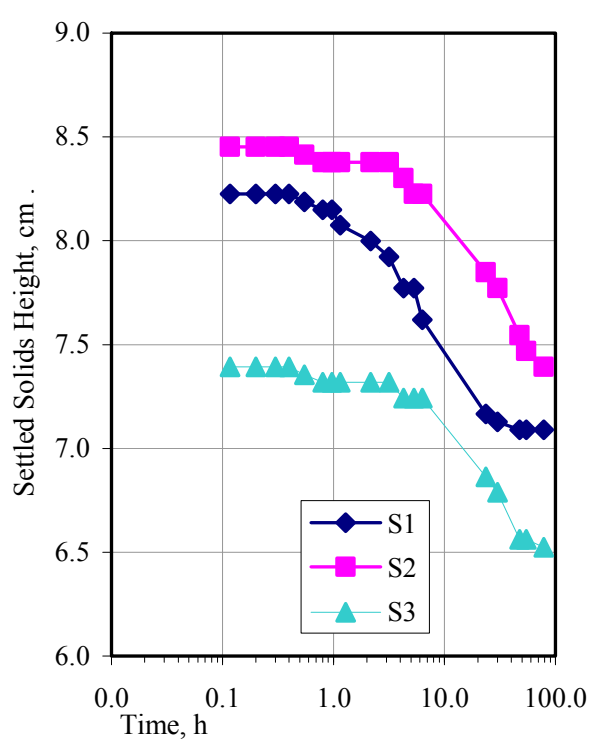

b)

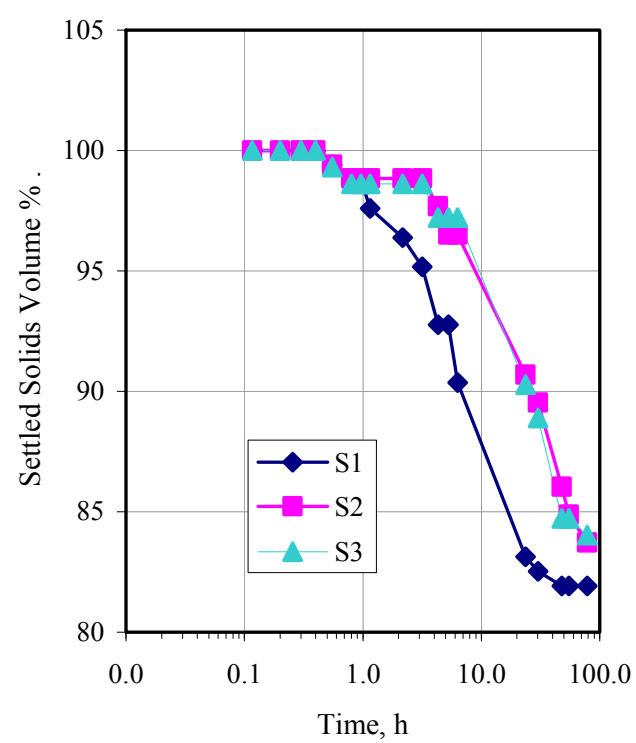

Figure 3.3. Group 7 TBP Solids Settling Test

Physical-property results for the TBP Group 7 sludge are summarized in Table 3.1 along with the propagated $1-\sigma$ errors, averages, and relative standard deviations. Good precision was obtained for the sample set. Density and vol\% values associated with this testing were limited to 2 significant figures because of the small sample size $(<10 \mathrm{~mL})$ and volume measure uncertainty in the graduated centrifuge tubes and cylinders $(\sim 0.2 \mathrm{~mL})$; the third significant figure is shown for indication only. Supernatant density was also determined to more significant figures as part of the chemical analysis processing. 
WTP-RPT-169, Rev 0

Table 3.1. Physical-Property Measurements of Homogenized Group 7 TBP Slurry

\begin{tabular}{|c|c|c|c|c|c|c|}
\hline Description & AR-S1 & AR-S2 & AR-S3 & $\begin{array}{l}\text { Nominal } \\
1 \sigma \text { error }\end{array}$ & Avg. & $\operatorname{RSD}^{(a)}(\%)$ \\
\hline \multicolumn{7}{|c|}{ Bulk Sample } \\
\hline Sample Size (mL) & 8.0 & 8.3 & 7.0 & 0.2 & na & na \\
\hline Sample Size (g) & 10.975 & 11.523 & 9.704 & 0.003 & na & na \\
\hline Density $(\mathrm{g} / \mathrm{mL})^{(\mathrm{b})}$ & 1.37 & 1.40 & 1.39 & 0.036 & 1.38 & 0.90 \\
\hline Total Solids (wt\%) & 37.2 & 37.1 & 33.3 & 0.034 & 35.8 & 6.2 \\
\hline Total Undissolved Solids (wt\%) & 11.6 & 11.7 & 6.7 & 0.045 & 10.0 & 28 \\
\hline \multicolumn{7}{|c|}{ Settled Solids } \\
\hline Density $(\mathrm{g} / \mathrm{mL})^{(\mathrm{b})}$ & 1.35 & 1.37 & 1.34 & 0.04 & 1.35 & 1.0 \\
\hline $\mathrm{Vol}^{(\mathrm{b})}$ & 85.0 & 85.7 & 86.4 & 3.3 & 85.7 & 0.83 \\
\hline $\mathrm{Wt} \%$ & 86.8 & 87.5 & 88.2 & 3.1 & 87.5 & 0.78 \\
\hline Total Undissolved Solids (wt\%) & 13.3 & 13.1 & 7.6 & 0.48 & 11.4 & 28 \\
\hline \multicolumn{7}{|c|}{ Wet Centrifuged Solids } \\
\hline Density $(\mathrm{g} / \mathrm{mL})^{(\mathrm{b})}$ & 1.46 & 1.53 & 1.73 & 0.084 & 1.57 & 8.6 \\
\hline $\mathrm{Vol}^{(\mathrm{b})}$ & 43.8 & 42.4 & 45.7 & 2.7 & 44.0 & 3.8 \\
\hline $\mathrm{Wt} \%$ & 48.3 & 48.4 & 59.7 & 0.03 & 52.1 & 13 \\
\hline Total Undissolved Solids (wt\%) & 22.9 & 23.2 & 12.8 & 1.5 & 19.6 & 30 \\
\hline Total Solids (wt\%) & 45.8 & 45.8 & 36.9 & 0.05 & 42.8 & 12 \\
\hline \multicolumn{7}{|c|}{ Supernatant } \\
\hline Density $(\mathrm{g} / \mathrm{mL})^{(\mathrm{b})}$ & 1.21 & 1.20 & 1.21 & 0.03 & 1.21 & 0.39 \\
\hline Total Dissolved Solids (wt\%) & 28.8 & 28.4 & 28.8 & 0.05 & 28.7 & 0.72 \\
\hline Water Content $(\mathrm{g} / \mathrm{g})$ & 0.712 & 0.716 & 0.712 & 0.001 & 0.713 & 0.29 \\
\hline \multicolumn{7}{|c|}{$\begin{array}{l}\text { (a) } \mathrm{RSD}=\text { relative standard deviation } \\
\text { (b) The density and vol\% values are only valid to two significant figures since the volume measures were determined } \\
\text { to two significant figures; the third significant figure is provided for indication only. }\end{array}$} \\
\hline
\end{tabular}

The two 20 -mL samples taken for chemical characterization were evaluated for density, wt $\%$, and vol $\%$ centrifuged solids as part of the initial phase separation providing supplemental physical-property results. Results are summarized in Table 3.2. In this case, the wt $\%$ and vol $\%$ wet centrifuged solids were lower than the values observed with the physical-property testing samples (AR-S1, -S2, and -S3) whereas all density measures were equivalent to those observed from the physical-property testing. This is possibly due to sampling. The S3 sample appears to be outside the bounds of expected error-when S1 and S2 alone are compared to the $\mathrm{C}$ samples, the values are much more precise. 
Table 3.2. Supplemental Physical Properties from Chemical Characterization Samples

\begin{tabular}{|c|c|c|c|c|c|c|}
\hline Description & AR-C1 & AR-C2 & $\begin{array}{l}\text { Nominal } \\
1 \sigma \text { error }\end{array}$ & Avg. & $\begin{array}{c}\mathbf{R P D}^{(\mathbf{a})} \\
(\%)\end{array}$ & $\begin{array}{c}\text { Comparison to } \\
\text { Table } 3.1 \\
\text { Results } \\
\end{array}$ \\
\hline Sample Size $(\mathrm{mL})^{(\mathrm{b})}$ & 17.0 & 20.5 & 1.0 & na & na & na \\
\hline Sample Size (g) & 21.691 & 26.704 & 0.003 & na & na & na \\
\hline Bulk Density $(\mathrm{g} / \mathrm{mL})^{(\mathrm{b})}$ & 1.28 & 1.30 & 0.07 & 1.29 & 2.1 & $-6.5 \%$ \\
\hline $\begin{array}{l}\text { Wet Centrifuged Solids } \\
\text { Density }(\mathrm{g} / \mathrm{mL})^{(\mathrm{b})}\end{array}$ & 1.45 & 1.61 & 0.11 & 1.53 & 11 & $-2.6 \%$ \\
\hline Vol\% Centrifuged Solids ${ }^{(b)}$ & 41.2 & 36.6 & 3.4 & 38.9 & 12 & $-12 \%$ \\
\hline $\mathrm{Wt} \%$ Centrifuged Solids & 46.665 & 45.270 & 0.004 & 46.0 & 3.0 & $-12 \%$ \\
\hline Supernatant Density $(\mathrm{g} / \mathrm{mL})$ & \multicolumn{2}{|c|}{1.211} & 0.0026 & na & na & equivalent \\
\hline \multicolumn{7}{|c|}{$\begin{array}{l}\text { (a) RPD = relative percent difference } \\
\text { (b) The density and vol\% values are only valid to two significant figures since the volume measures were } \\
\text { determined to two significant figures; the third significant figure is provided for indication only. } \\
\text { Bolded values indicated differences exceeding the uncertainties. }\end{array}$} \\
\hline
\end{tabular}

\subsection{Rheology of the Composite Group 7 TBP Slurry}

The rheology of select Hanford tank waste samples was characterized at the Radiochemical Processing Laboratory (RPL). Detailed rheology reports as well as rheology experimental methods can be found in Appendix F.

\subsubsection{Shear Strength}

The result for Group 7 initial characterization shear-strength testing is shown in Table 3.3. The single measurement for settled solids at 72 hours of settling time indicates a shear strength of $23 \mathrm{~Pa}$. Because the vane immersion requirements could not be met, the measured value of $23 \mathrm{~Pa}$ is to be treated an orderof-magnitude estimate. .

Table 3.3. Shear Strength of Group 7 Initial Characterization Settled Solids at Ambient Hot-Cell Temperature $\left(27.6^{\circ} \mathrm{C}\right)$

\begin{tabular}{||c|c|c||}
\hline $\begin{array}{c}\text { Test Sample } \\
\text { Settling Time } \\
{[\mathbf{h}]}\end{array}$ & $\begin{array}{c}\text { Shear Strength } \\
{[\mathbf{P a}]}\end{array}$ \\
\hline TI515-G7-AR-RH1 & 72 & 23 \\
\hline
\end{tabular}

The degree to which the measured shear strength for Group 7 settled solids is affected by limited immersion is difficult to ascertain. It can be speculated that proximity of the top of the vane to the surface of the settled solids lowers the measured shear strength because the vane no longer has to shear settled solids above the top of the blades (i.e., the upper rotational surface). In contrast, the proximity of the vane and floor of the test container likely increases the measured value of shear strength through frictional contact and stress chain formation between vane, solid slurry particles, and the container floor. 
Because of the limitations of the current test for shear strength, the value of $23 \mathrm{~Pa}$ measured for the shear strength of the Group 7 settled solids should be viewed with caution. The measurement is likely affected by competing effects of proximity of the vane to the surface of the settled solids and to the floor of the container and, as such, it should be treated only as an order-of-magnitude estimate.

\subsubsection{Flow Curve}

Figure 3.4 shows the results of flow-curve testing for the Group 7 initial characterization slurry sample. The measured flow curves indicate non-Newtonian slurry behavior, with the slurry showing finite yield stress, shearing-thinning, and significant hysteresis.

Flow-curve hysteresis is illustrated more clearly in Figure 3.5, which shows flow-curve data for the initial measurement at $25^{\circ} \mathrm{C}$. As indicated by the figure, the up-ramp stress response is significantly higher than the down-ramp stress response and shows a higher degree of shear-thinning behavior. The nature of hysteresis is similar during the repeat measurement at $25^{\circ} \mathrm{C}$ and during the single measurement at $40^{\circ} \mathrm{C}$. Although the flow-curve data at $60^{\circ} \mathrm{C}$ show hysteresis, the difference between the up- and down-ramp curves is significantly less than at the lower temperatures. The exact cause of hysteresis in the current measurements is difficult to ascertain from flow-curve data alone. However, because the hysteresis is characterized by a transient decrease in stress response over the course of the measurement, it can be speculated that hysteresis results from either shear-induced solids structure changes (i.e., sample thixotropy) or solids settling out of the measurement gap.

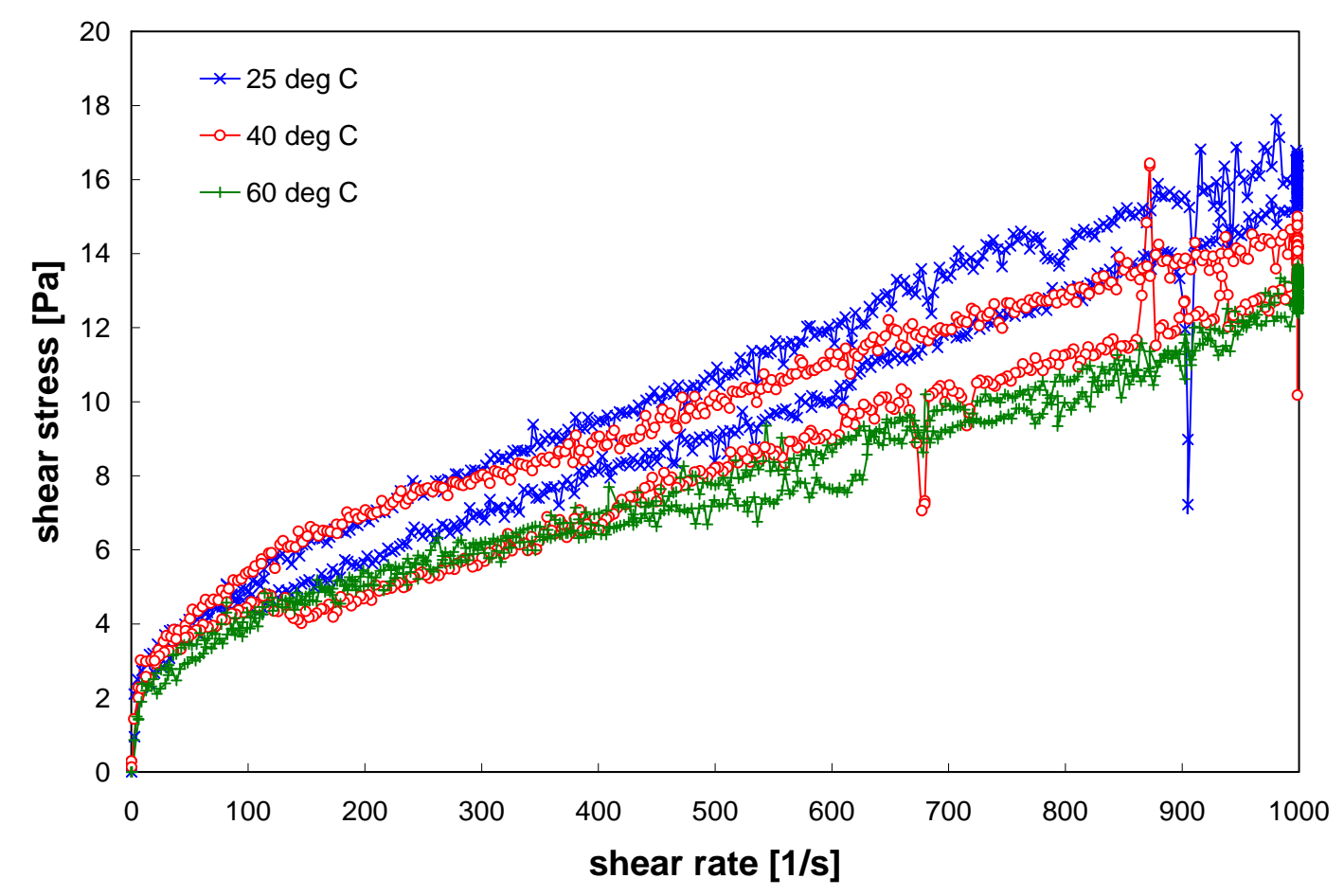

Figure 3.4. Flow Curve (shear stress versus shear rate) for the Group 7 Initial Characterization Slurry Sample at $25^{\circ} \mathrm{C}, 40^{\circ} \mathrm{C}$, and $60^{\circ} \mathrm{C}$. The second repeat measurement for $25^{\circ} \mathrm{C}$ is shown. 


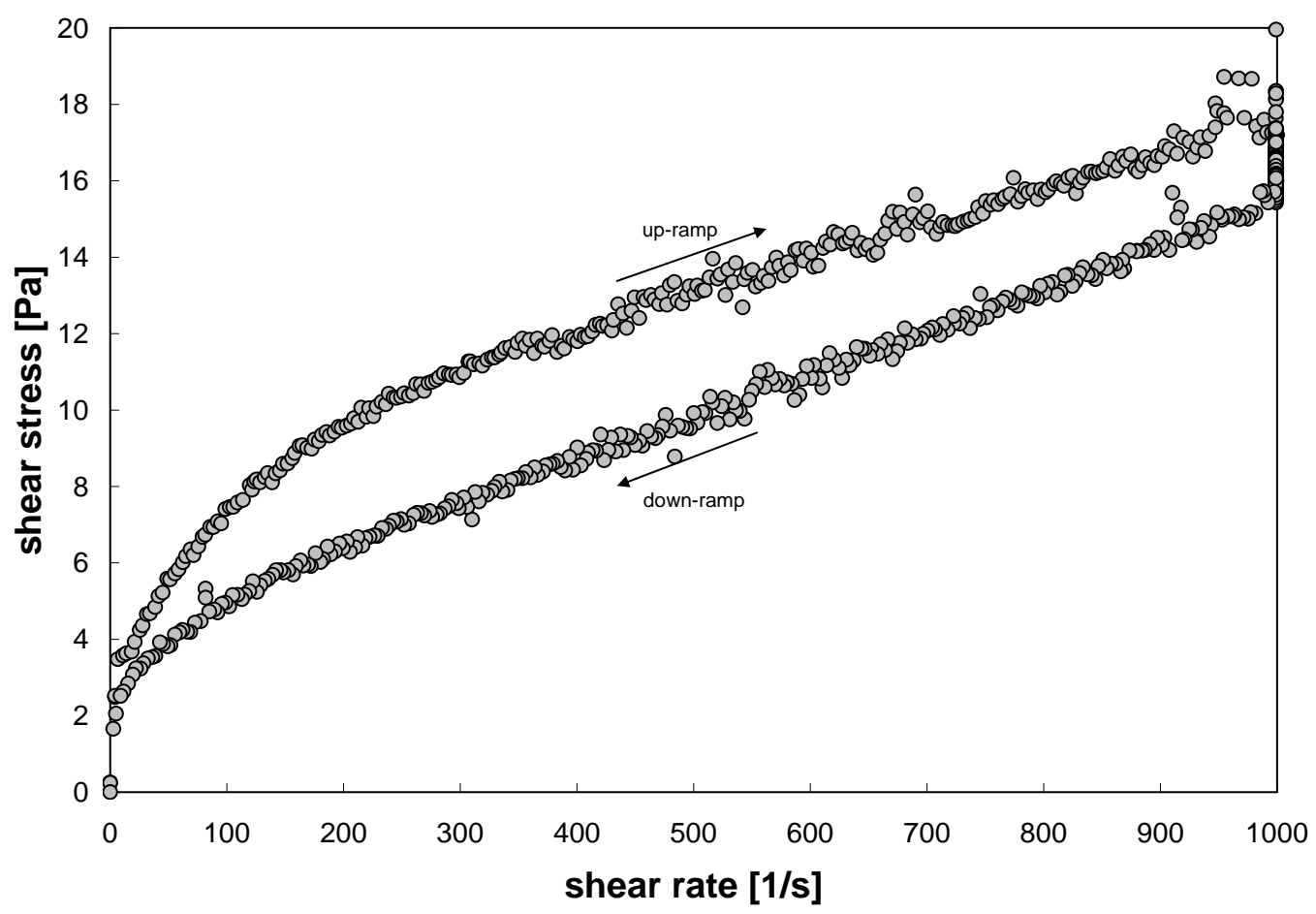

Figure 3.5. Initial Flow-Curve Measurement of the Group 7 Initial Characterization Slurry at $25^{\circ} \mathrm{C}$ Highlighting Significant Flow-Curve Hysteresis

Significant data overlap between the different temperature results from measurement hysteresis. As such, it is difficult to clearly determine how temperature influences the flow-curve data. Despite this difficulty, some observations can be based on rough visual inspection of the data. First, all flow-curve data indicate the slurry yield stress falls between 2 and $4 \mathrm{~Pa}$. Based on a rough average of upper and lower data bounds at each temperature, it appears that the stress response of the fluid (i.e., the slurry consistency) decreases with increasing temperature.

The measured flow-curve data were fit to both Bingham-Plastic and Casson constitutive equations to obtain a quantitative description of flow behavior. Because of the significant hysteresis, it was not feasible to derive an averaged set of flow-curve parameters by fitting both up- and down-ramp flow-curve data simultaneously. Instead, flow-curve fits were limited to down-ramp data alone (shown in Figure 3.6). Up-ramp data were excluded based on the assumption that hysteresis likely results from transient breakdown of slurry structure and that the well-mixed flow behavior is most closely represented by the down-ramp flow-curve data. For Bingham-Plastic fitting analysis, data fits were restricted to a shear-rate range of 100 to $1000 \mathrm{~s}^{-1}$ at $25^{\circ} \mathrm{C}$ and $40^{\circ} \mathrm{C}$ and of 100 to $800 \mathrm{~s}^{-1}$ at $60^{\circ} \mathrm{C}$. The lower bound excludes the non-linear region that occurs over 0 to $100 \mathrm{~s}^{-1}$ from the Bingham fitting analysis because this model cannot account for curvature. The $800 \mathrm{~s}^{-1}$ upper bound excludes $60^{\circ} \mathrm{C}$ data potentially affected by unstable flow. Unstable flow is evidenced by a sharp and unexpected increase in slope of the up-ramp data. While this slope change appears to be absent from the down-ramp data, the shear-rate limt of $800 \mathrm{~s}^{-1}$ is maintained as a precautionary measure. 


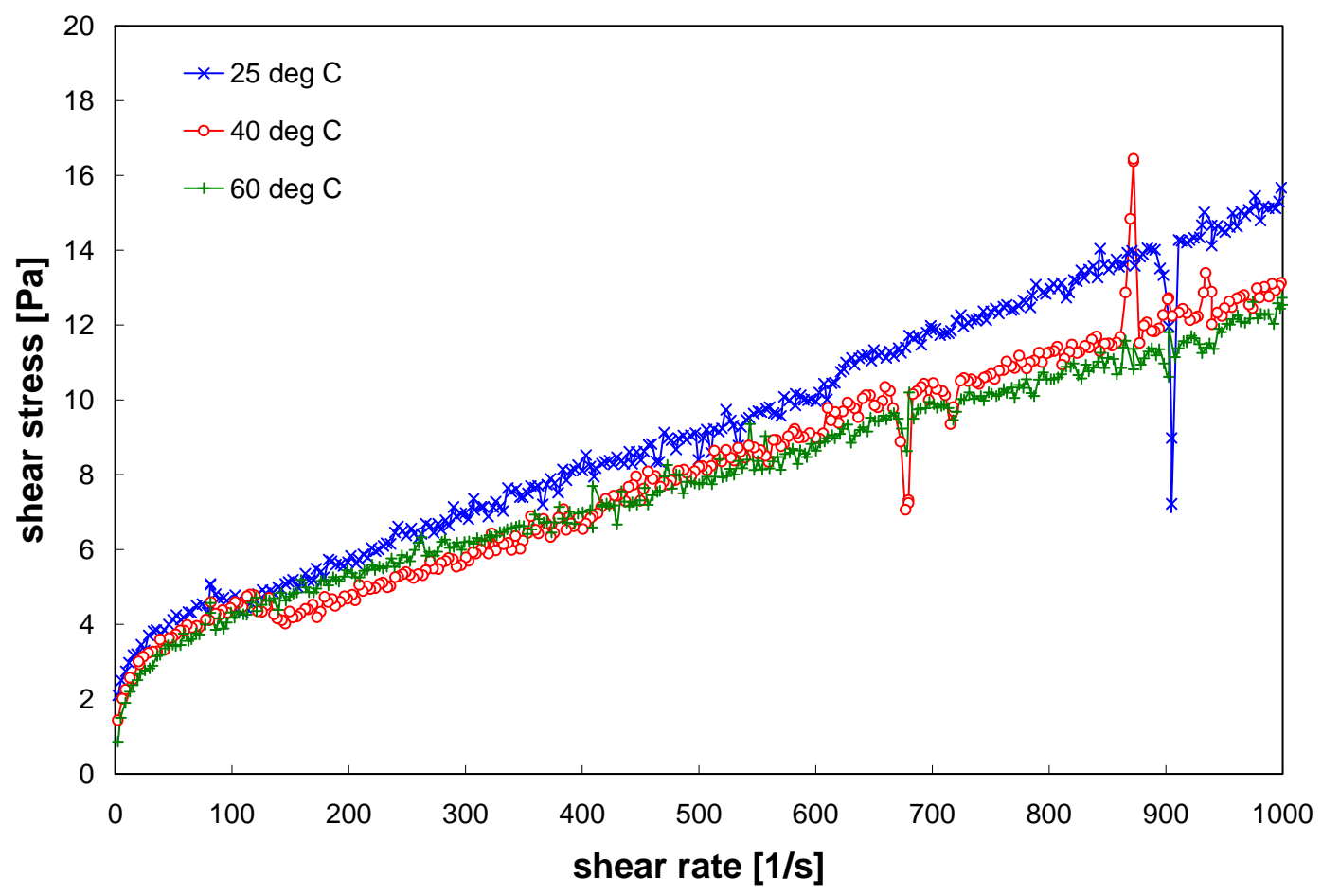

Figure 3.6. Down-Ramp Flow-Curve Data for the Group 7 Initial Characterization Slurry at $25^{\circ} \mathrm{C}, 40^{\circ} \mathrm{C}$, and $60^{\circ} \mathrm{C}$. The second repeat measurement for $25^{\circ} \mathrm{C}$ is shown.

Table 3.4 summarizes the best-fit Bingham-Plastic and Casson parameters for the Group 7 initial characterization slurry. The Bingham-Plastic parameters indicate a slurry yield stress and consistency that range from 2.8 to $4.1 \mathrm{~Pa}$ and 8.9 to $12 \mathrm{mPa} \cdot \mathrm{s}$, respectively. Likewise, the Casson model indicates a yield stress and consistency that range from 1.3 to $1.9 \mathrm{~Pa}$ and 4.4 to $6.6 \mathrm{mPa} \cdot \mathrm{s}$. The lower consistency and yield stress provided by the Casson fits is simply a result of model curvature.

The fitting results in Table 3.4 do not provide much insight into how slurry yield stress and consistency behave as a function of temperature. Although Bingham-Plastic yield stress varies over a significant range of 2.8 to $4.1 \mathrm{~Pa}$, its variation does not track with temperature. Yield-stress reproducibility is poor, as indicated by the significant difference of $0.8 \mathrm{~Pa}$ in initial and repeat measurements at $25^{\circ} \mathrm{C}(4.1$ and 3.3 Pa, respectively). Similar yield stress issues are observed with the Casson fits.

Slurry consistency does not vary significantly for the repeat measurements at $25^{\circ} \mathrm{C}$ and the measurement $40^{\circ} \mathrm{C}$. Bingham-Plastic and Casson consistencies range from 11 to 12 and 6.0 to $6.6 \mathrm{mPa} \cdot \mathrm{s}$, respectively. Because both ranges cover less than the expected limit of instrument accuracy of $10 \%$, it is unlikely that there is variation between slurry consistency at $25^{\circ} \mathrm{C}$ and $40^{\circ} \mathrm{C}$. On the other hand, Bingham-Plastic consistency drops from 11 to $8.9 \mathrm{mPa} \cdot \mathrm{s}$ as slurry temperature is raised from $40^{\circ} \mathrm{C}$ to $60^{\circ} \mathrm{C}$. Although this is a significant decrease, it is difficult to state that this decrease would continue at higher temperatures with confidence given the variation in the yield-stress results. Overall, the fitting results do not indicate strong temperature trends because it is difficult to distinguish measurement-to-measurement variation from changes induced by increased temperature. It is speculated that the significant flow-curve hysteresis is the source of measurement-to-measurement variation. 
Table 3.4. Results of Fitting Analysis for Rheology of the Group 7 Initial Characterization Slurry. All model parameters are based on down-ramp data only.

\begin{tabular}{||c|c|c|c|c|c||}
\hline \multirow{3}{*}{ Model } & $\begin{array}{c}\text { Temperature } \\
{\left[{ }^{\circ} \mathbf{C}\right]}\end{array}$ & Range & $\begin{array}{c}\text { Yield Stress } \\
{[\mathbf{P a}]}\end{array}$ & $\begin{array}{c}\text { Viscosity } \\
{[\mathbf{m P a} \cdot \mathbf{s}]}\end{array}$ & $\mathbf{R}$ \\
\hline $\begin{array}{c}\text { Bingham-Plastic } \\
\text { (Flow Curve) }\end{array}$ & $25(1$ of 2$)$ & $100-1000 \mathrm{~s}^{-1}$ & 4.1 & 11 & 1.00 \\
\cline { 2 - 6 } & $25(2$ of 2$)$ & $100-1000 \mathrm{~s}^{-1}$ & 3.3 & 12 & 0.98 \\
\cline { 2 - 6 } & 40 & $100-1000 \mathrm{~s}^{-1}$ & 2.8 & 11 & 0.98 \\
\cline { 2 - 6 } & 60 & $100-800 \mathrm{~s}^{-1}$ & 3.5 & 8.9 & 0.99 \\
\hline \multirow{3}{*}{$\begin{array}{c}\text { Casson } \\
\text { Flow Curve) }\end{array}$} & $25(1$ of 2$)$ & $0-1000 \mathrm{~s}^{-1}$ & 1.9 & 6.3 & 1.00 \\
\cline { 2 - 6 } & $25(2$ of 2$)$ & $0-1000 \mathrm{~s} \mathrm{~s}^{-1}$ & 1.6 & 6.6 & 0.98 \\
\cline { 2 - 7 } & 40 & $0-1000 \mathrm{~s}^{-1}$ & 1.3 & 6.0 & 0.98 \\
\cline { 2 - 7 } & 60 & $0-800 \mathrm{~s}^{-1}$ & 1.8 & 4.4 & 0.99 \\
\hline
\end{tabular}

\subsection{Chemical and Radiochemical Composition of the Group 7 Slurry}

One of the two characterization samples is shown in Figure 3.7 following centrifuging. The centrifuged solids appeared generally uniform from top to bottom and were colored dark brown-red with a pale yellow supernatant. The supernatant density was determined to be $1.211 \mathrm{~g} / \mathrm{mL}\left(\mathrm{T}=27^{\circ} \mathrm{C}\right)$ based on the average masses of four $1-\mathrm{mL}$ volume deliveries.

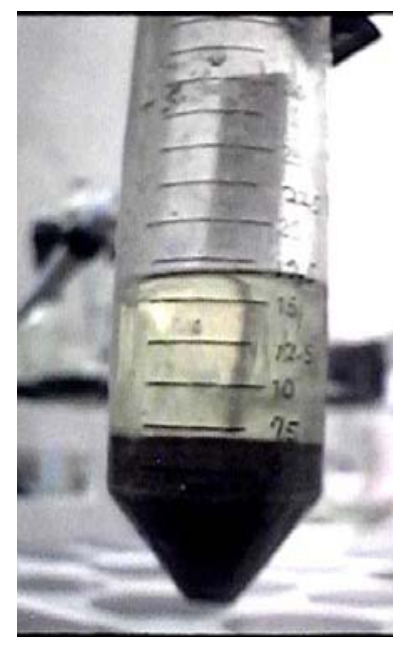

Figure 3.7. Centrifuged Solids from Chemical Characterization Sample of Group 7 TBP Sludge

The specific washing scheme for the TBP sludge is provided in Figure 3.8. The centrifuged solids (CS) volumes were estimated based on the centrifuge-tube graduations. With each successive washing step, the CS volume appeared to slightly increase; however, given the measurement uncertainty, this observation is not definitive. The hydroxide concentration in the final washing solution was $\sim 0.01 \mathrm{M}$. The final washing solution appeared to cause a dispersion of a small amount of material. The supernatant 
and sequential wash solutions are shown in Figure 3.9 to illustrate the dispersion. The solids suspension was attributed to the low ionic strength of the final aqueous phase.

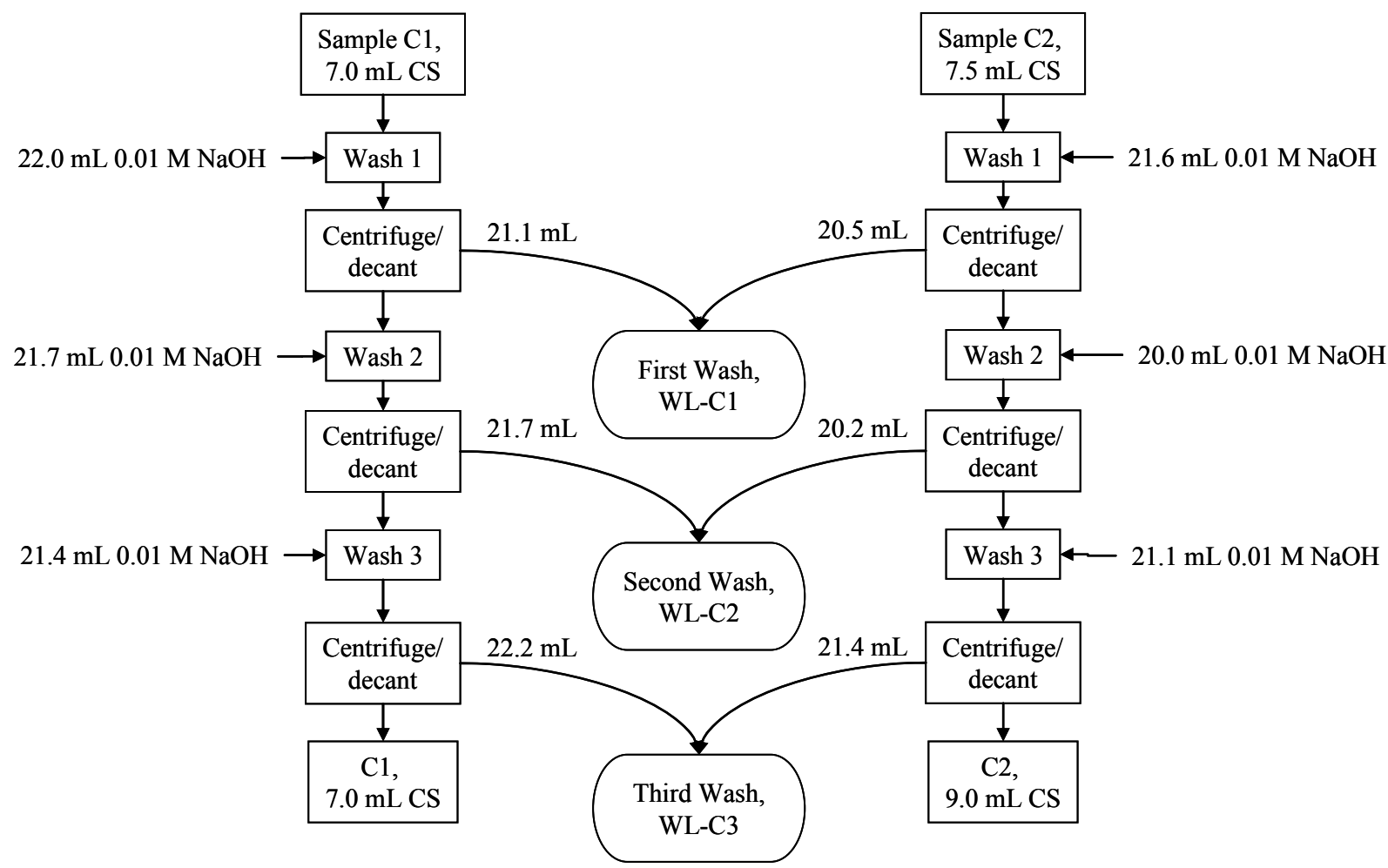

Figure 3.8. Wash Sequence of Group 7 TBP Sludge Supporting Initial Characterization

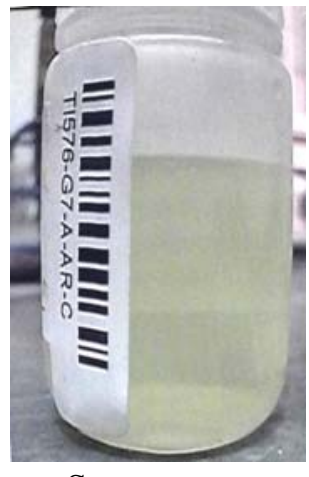

Supernatant

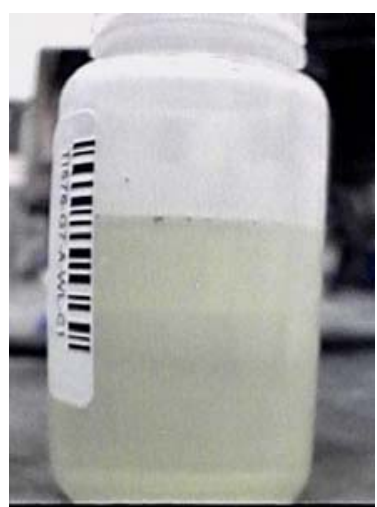

First wash

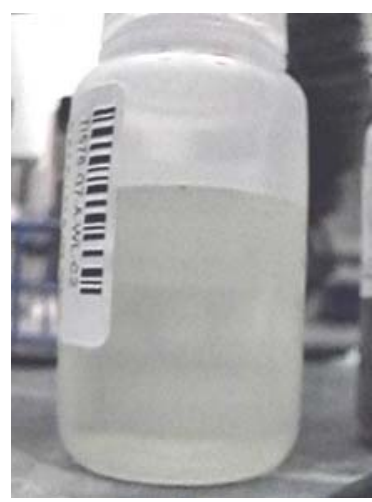

Second wash

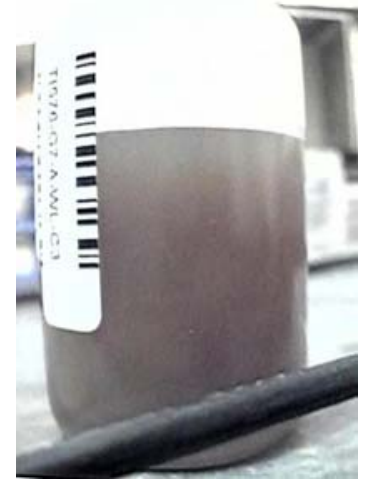

Third wash

Figure 3.9. Comparison of Group 7 TBP Sequential Wash Solutions

The effect of ionic-strength adjustment on the third wash (WL-C3) solids dispersion was tested. Small, 1-mL aliquots of the mixed composite were contacted with $\mathrm{NaOH}$ and $\mathrm{NaNO}_{3}$ added in sufficient amounts to result in 0.2-M solutions. In both cases, the Fe floc settled within $24 \mathrm{~h}$, whereas the parent material did not settle. A 5 -mL aliquot was filtered through a 0.2 -micrometer pore size HT Tuffryn ${ }^{\circledR}$ (polysuflone membrane) syringe filter (part number 4496, Gelman Sciences, Ann Arbor, MI). The filter 
quickly plugged from rust-colored fines indicative of $\mathrm{Fe}(\mathrm{OH})_{3}$; the filtrate was virtually colorless. The beta-gamma activity was also greatly diminished in the filtrate relative to the starting material.

Figure 3.10 shows the 24 -h equilibrated result of the matrix-adjusted material, filtrate, and starting material. The filtrate was analyzed for anions, free hydroxide, and inductively coupled plasma-optical emission spectrometry (ICP-OES) metals; the unfiltered solution (with floc) was analyzed for ICP-OES metals and radionuclides.

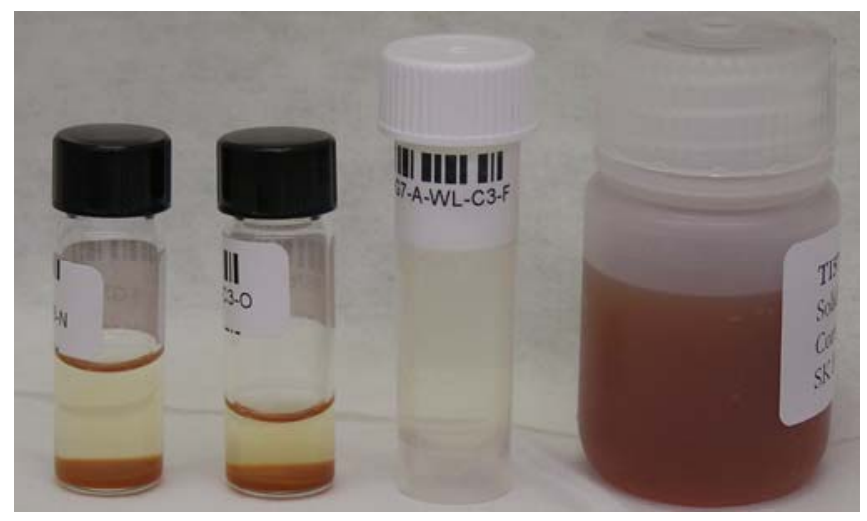

Figure 3.10. Third Wash after Ionic Strength Adjustment and Filtration

Treatments from Left to Right: $0.2 \mathrm{M} \mathrm{NaNO}_{3} ; 0.2 \mathrm{M} \mathrm{NaOH}$; Filtrate; Starting Material

The average radioanalytical results for the supernatant, three wash solutions, third filtered wash solution, and washed solids are provided in Table 3.5 along with the applicable relative percent differences (RPD, measure of precision) between duplicate results. The concentrations of the gross-beta results and the sum of beta emitters, ${ }^{137} \mathrm{Cs}$ and ${ }^{90} \mathrm{Sr}$ (in secular equilibrium with ${ }^{90} \mathrm{Y}$ ), were essentially equivalent (ratio close to 1.0). The reasonably good agreement between these values indicated that no other major source of beta activity was present. Similarly, the gross-alpha activity was reasonably close to the summation of alpha emitters $\left({ }^{238} \mathrm{Pu},{ }^{239+240} \mathrm{Pu}\right.$, and detected $\left.{ }^{241} \mathrm{Am}\right)$, indicating that no other significant source of alpha activity was present.

The chemical compositions of the Group 7 TBP supernatant, composite wash solution, and washed solids are provided in Table 3.6. Results for both solids preparation methods (fusion and HF-assisted acid digestion) are shown. The analysis results from the solids prepared by the HF-assisted acid digestion method were $\sim 15 \%$ greater than the results from the fusion preparation method. This difference is just within the uncertainty stated for the preparation and analysis methods $( \pm 15 \%)$.

The supernatant salt concentrations were generally very low relative to those observed in other tank waste preparations. The free hydroxide was less than the requested analytical detection limit of $0.1 \mathrm{M}$. The supernatant was primarily sodium salts (nitrate, nitrite, sulfate, and phosphate). The anionic and cationic charge balance was evaluated for the supernatant, resulting in a $9.1 \%$ difference, well within analytical uncertainties. 
Table 3.5. Radionuclide Characterization of the Group 7 TBP Sludge

\begin{tabular}{|c|c|c|c|c|c|c|c|c|}
\hline & Supernatant & & Wash 1 & Wash 2 & $\begin{array}{l}\text { Filtered } \\
\text { Wash } 3 \\
\end{array}$ & $\begin{array}{c}\text { Wash } 3 \\
\text { with Floc } \\
\end{array}$ & \multicolumn{2}{|c|}{ Washed solids $^{(a)}$} \\
\hline Sample ID> & $08-01145^{(b)}$ & & 08-01146 & 08-01147 & 08-01148 & 08-01149 & \multicolumn{2}{|c|}{ 08-01150 } \\
\hline Analyte & $\mu \mathrm{Ci} / \mathbf{m L}$ & RPD & $\mu \mathrm{Ci} / \mathbf{m L}$ & $\mu \mathrm{Ci} / \mathrm{mL}$ & $\mu \mathrm{Ci} / \mathbf{m L}$ & $\mu \mathrm{Ci} / \mathbf{m L}$ & $\mu \mathrm{Ci} / \mathrm{g}$ & RPD \\
\hline${ }^{137} \mathrm{Cs}$ & $4.56 \mathrm{E}+0$ & 1.3 & $7.18 \mathrm{E}-1$ & $1.88 \mathrm{E}-1$ & $7.66 \mathrm{E}-2$ & $1.25 \mathrm{E}-1$ & $3.64 \mathrm{E}+1$ & 7.7 \\
\hline${ }^{60} \mathrm{Co}$ & $<8 . \mathrm{E}-5$ & na & $2.14 \mathrm{E}-5$ & $7.22 \mathrm{E}-6$ & $3.00 \mathrm{E}-6$ & $<8 \mathrm{E}-5$ & $2.11 \mathrm{E}-2$ & 0.95 \\
\hline${ }^{241} \mathrm{Am}$ & $<4$.E-3 & na & $<2 . \mathrm{E}-4$ & $<1 \mathrm{E}-4$ & $<2 \mathrm{E}-5$ & $<3 \mathrm{E}-4$ & [8.7E-2] & na \\
\hline${ }^{238} \mathrm{Pu}$ & [3.9E-6] & [59] & \multirow{9}{*}{\multicolumn{3}{|c|}{$\mathrm{n} / \mathrm{a}$}} & $9.68 \mathrm{E}-6$ & $5.63 \mathrm{E}-3$ & 3.7 \\
\hline${ }^{239+240} \mathrm{Pu}$ & $1.21 \mathrm{E}-4$ & 0.83 & & & & $6.24 \mathrm{E}-4$ & $1.95 \mathrm{E}-1$ & 7.2 \\
\hline Gross alpha & $<3$.E-4 & na & & & & $8.12 \mathrm{E}-4$ & $3.00 \mathrm{E}-1$ & 8.0 \\
\hline Gross beta & $4.59 \mathrm{E}+0$ & 1.3 & & & & $1.97 \mathrm{E}+0$ & $1.57 \mathrm{E}+3$ & 7.0 \\
\hline${ }^{90} \mathrm{Sr}$ & $1.00 \mathrm{E}-2$ & 5.5 & & & & $8.81 \mathrm{E}-1$ & $7.41 \mathrm{E}+2$ & 7.6 \\
\hline Alpha sum & $1.24 \mathrm{E}-4$ & 1.0 & & & & $6.34 \mathrm{E}-4$ & $2.44 \mathrm{E}-1$ & 30 \\
\hline$\alpha$ gross $/$ sum & na & na & & & & 1.28 & 1.23 & na \\
\hline Beta sum & $4.58 \mathrm{E}+0$ & 1.3 & & & & $1.89 \mathrm{E}+0$ & $1.52 \mathrm{E}+3$ & 7.6 \\
\hline$\beta$ gross/sum & 1.00 & na & & & & 1.04 & 1.03 & na \\
\hline \multicolumn{9}{|l|}{ Opportunistic } \\
\hline${ }^{154} \mathrm{Eu}$ & $<2$.E-4 & na & $<1$.E-5 & $<7$. E-6 & $<9$.E-6 & $<2$.E-4 & $5.90 \mathrm{E}-2$ & 19 \\
\hline${ }^{155} \mathrm{Eu}$ & $<2 . \mathrm{E}-3$ & na & $<2 . \mathrm{E}-4$ & $<8$. E-5 & $<4$. E-5 & $<4$.E-4 & $<5 \mathrm{E}-2$ & na \\
\hline $\begin{array}{l}\text { (a) Analyte } \\
\text { (b) This san } \\
\text { Notes: } \\
\text { ASR } 8108 \\
\text { Reference dat } \\
\text { na= not appli }\end{array}$ & $\begin{array}{l}\text { November } 5,2 \\
\text { le; } \mathrm{n} / \mathrm{a}=\text { not an }\end{array}$ & $\begin{array}{l}\text { Ilculated } \\
\text { I to be ru }\end{array}$ & $\begin{array}{l}\text { a dry-mass } b \\
\text { a duplicate; } t\end{array}$ & $\begin{array}{l}\text { erefore, an R } \\
\text { esis. }\end{array}$ & was not calc & ated. & & \\
\hline
\end{tabular}

For most components, the wash solutions represented simply dilutions of the supernatant. The ratios of $\mathrm{P}$, phosphate, and fluoride concentrations in the wash solutions relative to the supernatant were higher than the corresponding nitrate concentration ratio, indicating that some phosphate and fluoride were dissolved from the solids phase during washing. This indicated that water-soluble phosphate and fluoride solids were present in the unwashed solids phase. As washing progressed, the dissolved salt (electrolyte) concentrations dropped below the threshold that would limit flocculent dispersions. Concentrations of Al, $\mathrm{Fe}$, and $\mathrm{Sr}$ were observed to increase with each wash cycle. Filtration of the third wash solution resulted in large $(70 \times)$ decreases of the $\mathrm{Fe}$ and $\mathrm{Sr}$ concentrations, indicating that the colloidal particles were mostly $>0.2 \mu \mathrm{m}$ (filter pore size was $0.2 \mu \mathrm{m}$ ). In contrast, the filtrate $\mathrm{Al}$ concentration only decreased by $40 \%$. Clearly, a fraction of the $\mathrm{Al}$ was also dissolved during the washing process.

The washed water-insoluble solids were dominated by Fe (15 wt\%), $\mathrm{Na}(14 \mathrm{wt} \%)$, and $\mathrm{P}$ and $\mathrm{U}(12 \mathrm{wt} \%$ each) (dry mass basis). 
Table 3.6. Chemical Characterization of the Group 7 TBP Sludge

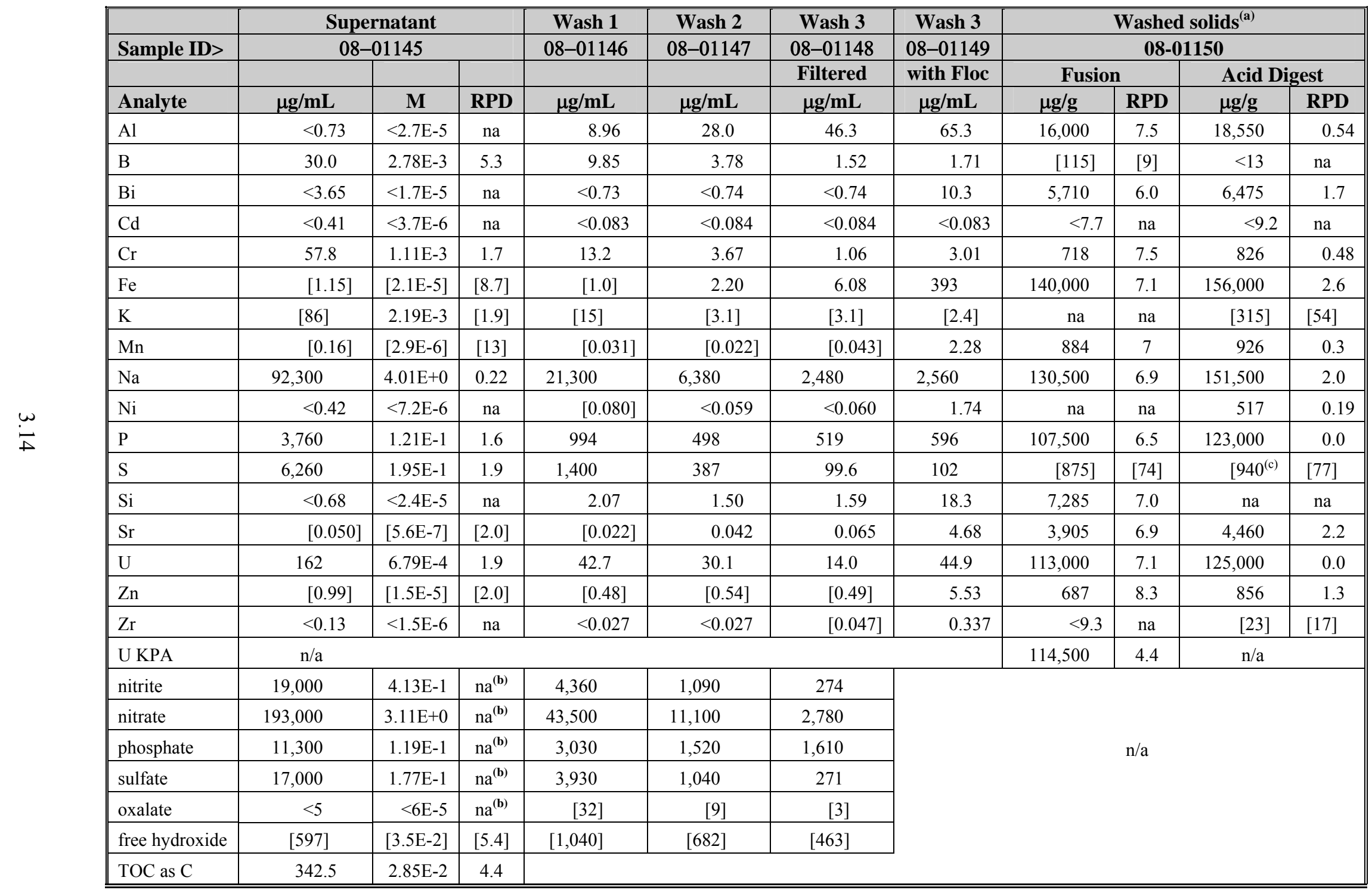


Table 3.6 (Contd)

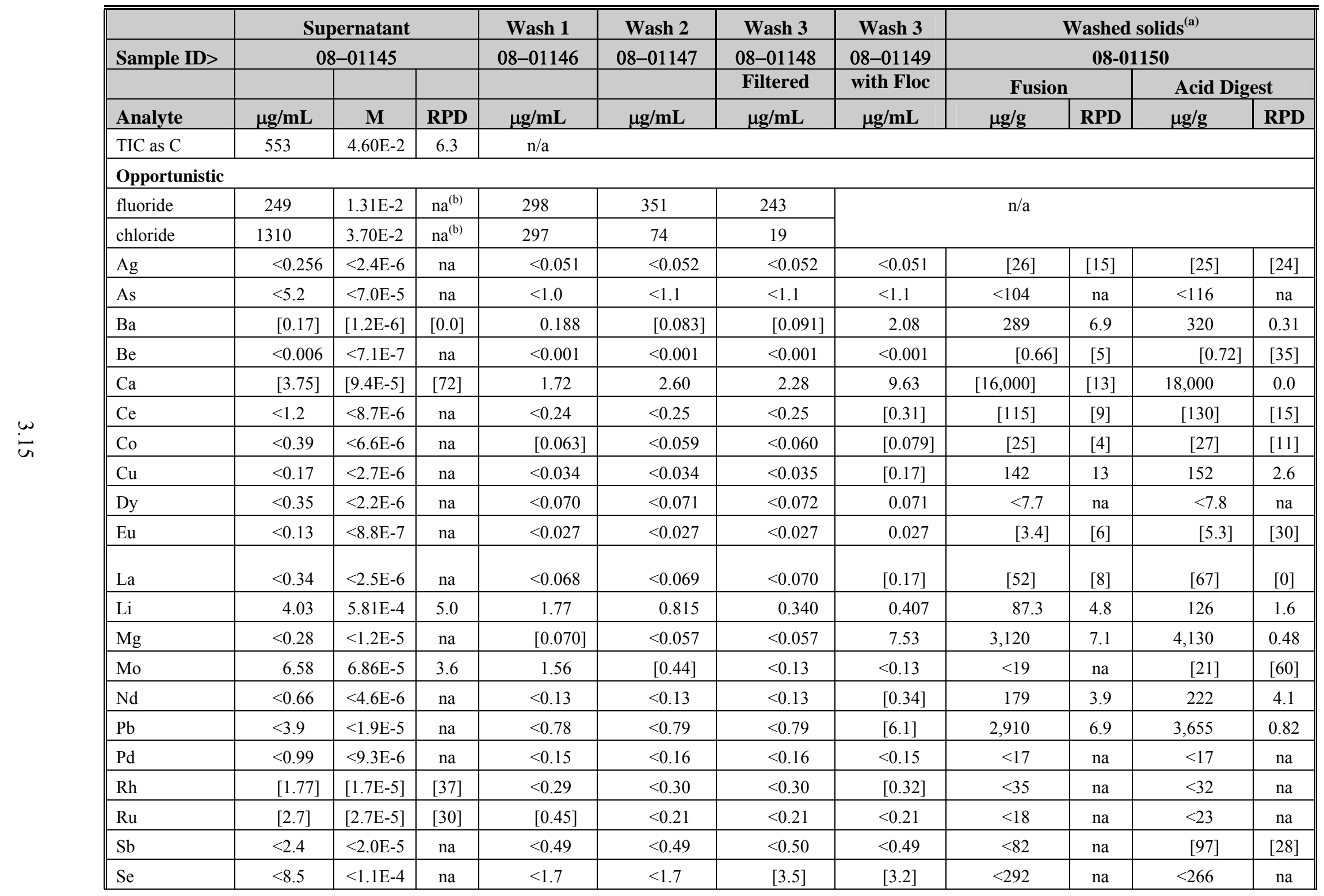


Table 3.6 (Contd)

\begin{tabular}{|c|c|c|c|c|c|c|c|c|c|c|c|}
\hline \multirow{4}{*}{$\begin{array}{l}\text { Sample ID> } \\
\text { Analyte }\end{array}$} & \multicolumn{3}{|c|}{ Supernatant } & \multirow{4}{*}{$\begin{array}{c}\text { Wash } 1 \\
08-01146 \\
\mu \mathrm{g} / \mathrm{mL} \\
\end{array}$} & \multirow{4}{*}{$\begin{array}{c}\text { Wash } 2 \\
08-01147 \\
\mu \mathrm{g} / \mathrm{mL} \\
\end{array}$} & \multirow{4}{*}{$\begin{array}{c}\text { Wash } 3 \\
08-01148 \\
\text { Filtered } \\
\mu \mathrm{g} / \mathrm{mL} \\
\end{array}$} & \multirow{4}{*}{$\begin{array}{c}\text { Wash } 3 \\
08-01149 \\
\text { with Floc } \\
\mu \mathrm{g} / \mathrm{mL} \\
\end{array}$} & \multicolumn{4}{|c|}{ Washed solids $^{(a)}$} \\
\hline & \multicolumn{3}{|c|}{ 08-01145 } & & & & & \multicolumn{4}{|c|}{ 08-01150 } \\
\hline & & & & & & & & \multicolumn{2}{|c|}{ Fusion } & \multicolumn{2}{|c|}{ Acid Digest } \\
\hline & $\mu \mathrm{g} / \mathrm{mL}$ & $\mathbf{M}$ & RPD & & & & & $\mu \mathrm{g} / \mathrm{g}$ & RPD & $\mu \mathrm{g} / \mathrm{g}$ & RPD \\
\hline Sn & [4.02] & [3.4E-5] & [39] & {$[0.87]$} & {$[0.79]$} & $<0.67$ & $<0.66$ & $<66$ & na & $<90$ & na \\
\hline $\mathrm{Ta}$ & $<2.1$ & $<1.1 \mathrm{E}-5$ & na & $<0.41$ & $<0.42$ & $<0.42$ & $<0.42$ & $<61$ & na & $<46$ & na \\
\hline $\mathrm{Te}$ & $<3.2$ & $<2.5 \mathrm{E}-5$ & na & $<0.63$ & $<0.64$ & $<0.65$ & $<0.64$ & {$[82]$} & {$[38]$} & $<70$ & na \\
\hline Th & $<1.2$ & $<5.1 \mathrm{E}-6$ & na & $<0.24$ & $<0.24$ & $<0.24$ & $<0.24$ & $<22$ & na & $<26$ & na \\
\hline $\mathrm{Ti}$ & $<0.052$ & $<1.1 \mathrm{E}-6$ & na & $<0.010$ & $<0.011$ & $<0.011$ & 0.422 & 371 & 7.0 & 407 & 0.49 \\
\hline $\mathrm{Tl}$ & {$[7.5]$} & [3.7E-5] & {$[35]$} & [1.9] & {$[2.5]$} & {$[1.1]$} & $<0.93$ & $<80$ & na & $<164$ & na \\
\hline $\mathrm{V}$ & $<0.090$ & $<1.8 \mathrm{E}-6$ & na & {$[0.062]$} & [0.049] & {$[0.058]$} & {$[0.075]$} & $<8.5$ & na & $<2.0$ & na \\
\hline $\mathrm{W}$ & {$[2.79]$} & [1.5E-5] & [36] & $<0.46$ & $<0.47$ & $<0.47$ & $<0.47$ & $<56$ & na & $<51$ & na \\
\hline $\mathrm{Y}$ & $<0.054$ & $<6.0 \mathrm{E}-7$ & na & $<0.011$ & $<0.011$ & $<0.011$ & {$[0.062]$} & 29.7 & 5.1 & 36.7 & 3.8 \\
\hline
\end{tabular}

(a) Analyte concentrations are calculated on a dry-mass basis.

(b) Sample 08-01145 was analyzed in duplicate for this analytical batch with RPDs $\leq 1.1 \%$

(c) The laboratory control sample (LCS) sulfur recovery was high at $144 \%$, indicating that the sample result might be biased high.

Notes:

ASR 8108.

Analyte uncertainties were typically within $\pm 15 \%$; results in brackets indicate that the analyte concentrations were greater than the minimum detection limit (MDL) and less than the estimated quantitation limit (EQL), and uncertainties were $>15 \%$.

Opportunistic analytes are reported for information only; quality control (QC) requirements did not apply to these analytes.

na $=$ not applicable, sample was not analyzed in duplicate or the analyte was $<$ MDL.

$\mathrm{n} / \mathrm{a}=$ not analyzed, analysis was not required. 
Analyte water-wash factors were calculated from the mass distribution in the combined supernatant and wash solutions relative to the total analyte mass according to Equation 3.1.

$$
F_{i}=\frac{S_{i}+W_{i}}{S_{i}+W_{i}+U D S_{i}}
$$

where $\quad F_{i}=$ analyte fraction removed during washing

$\mathrm{S}_{\mathrm{i}}=$ analyte mass in supernatant fraction

$\mathrm{W}_{\mathrm{i}}=$ analyte mass in wash solution

$\mathrm{UDS}_{\mathrm{i}}=$ analyte mass in the undissolved solids.

The fractional distributions of selected analytes in the supernatant, combined wash, and solids phases are shown in Table 3.7 and Figure 3.11. According to TWINS data, a large portion $(>90 \%)$ of the $\mathrm{Na}$ and $\mathrm{S}$ should partition to the aqueous phase. While this was the case with $\mathrm{S}$ for the tested Group 7 waste, the $\mathrm{Na}$ only partitioned $80 \%$ into the aqueous phase. Washing removed much smaller amounts of $\mathrm{Cr}(30 \mathrm{wt} \%)$, $\mathrm{Al}(3.4 \mathrm{wt} \%)$, and $\mathrm{P}(19.5 \mathrm{wt} \%)$. The water-wash factors obtained from the current testing were compared with the weighted mean of the water-wash factors obtained from the TWINS database. The weighting factors were calculated from the relative masses of tank wastes that were used to create the composite. The experimentally obtained $\mathrm{Al}, \mathrm{Na}, \mathrm{Cr}$, and $\mathrm{S}$ wash factors agreed fairly well with the TWINS water-wash factors. The experimentally obtained $\mathrm{P}$ wash factor was significantly lower than the TWINS factor. Direct cross comparison of these water-wash factors with those in the TWINS database may be confounded by the sample selection process; only available TBP sludge samples in the $222 \mathrm{~S}$ archive were selected for processing, and these had aged $\sim 10 \mathrm{y}$.

Table 3.7. Phase Distribution of Selected Analytes in Group 7 TBP Sludge

\begin{tabular}{|c|c|c|c|c|c|}
\hline Analyte & $\begin{array}{c}\text { Supernatant } \\
\text { wt } \%\end{array}$ & $\begin{array}{c}\text { Combined Wash } \\
\text { Solution } \\
\text { wt \% }\end{array}$ & $\begin{array}{c}\text { Water-Wash } \\
\text { Factor } \\
\text { wt } \%\end{array}$ & $\begin{array}{c}\text { TWINS Water- } \\
\text { Wash Factor }^{(a)} \\
\text { wt \% }\end{array}$ & $\begin{array}{l}\text { Solids } \\
\text { wt \% }\end{array}$ \\
\hline $\mathrm{Cr}$ & 19 & 11 & 30 & 23.4 & 70 \\
\hline $\mathrm{Al}$ & $<0.01$ & 3.4 & 3.4 & 9.2 & 97 \\
\hline $\mathrm{Na}$ & 49 & 31 & 80 & 91.8 & 20 \\
\hline $\mathrm{P}$ & 9.5 & 10 & 19.5 & $73.7^{(\mathrm{b})}$ & 80 \\
\hline S & 62 & 36 & {$[98]$} & $96.0^{(\mathrm{c})}$ & {$[2.5]$} \\
\hline $\begin{array}{l}\text { (a) The w: } \\
\text { Basis I } \\
\\
\text { (b) Report } \\
\text { (b) Report } \\
\text { (c) Report } \\
\text { Results in }\end{array}$ & $\begin{array}{l}\text { r-wash factors rep } \\
\text { entory (BBI) in th } \\
\text { in TWINS as pho } \\
\text { in TWINS as sul } \\
\text { ackets indicate }\end{array}$ & $\begin{array}{l}\text { sent the weighted me } \\
\text { Tank Waste Informat } \\
\text { phate; phosphorous w } \\
\text { te; sulfur water wash } \mathrm{f} \\
\text { at the analyte conce }\end{array}$ & $\begin{array}{l}\text { of the five repres } \\
\text { Network System } \\
\text { factor was not a } \\
\text { tor was not availa } \\
\text { ations were }>\mathrm{M}\end{array}$ & $\begin{array}{l}\text { d tank-waste source } \\
\text { WINS) database (se } \\
\text { able. } \\
\text { and <EQL. }\end{array}$ & $\begin{array}{l}\text { om the Bes } \\
\text { date }\end{array}$ \\
\hline
\end{tabular}




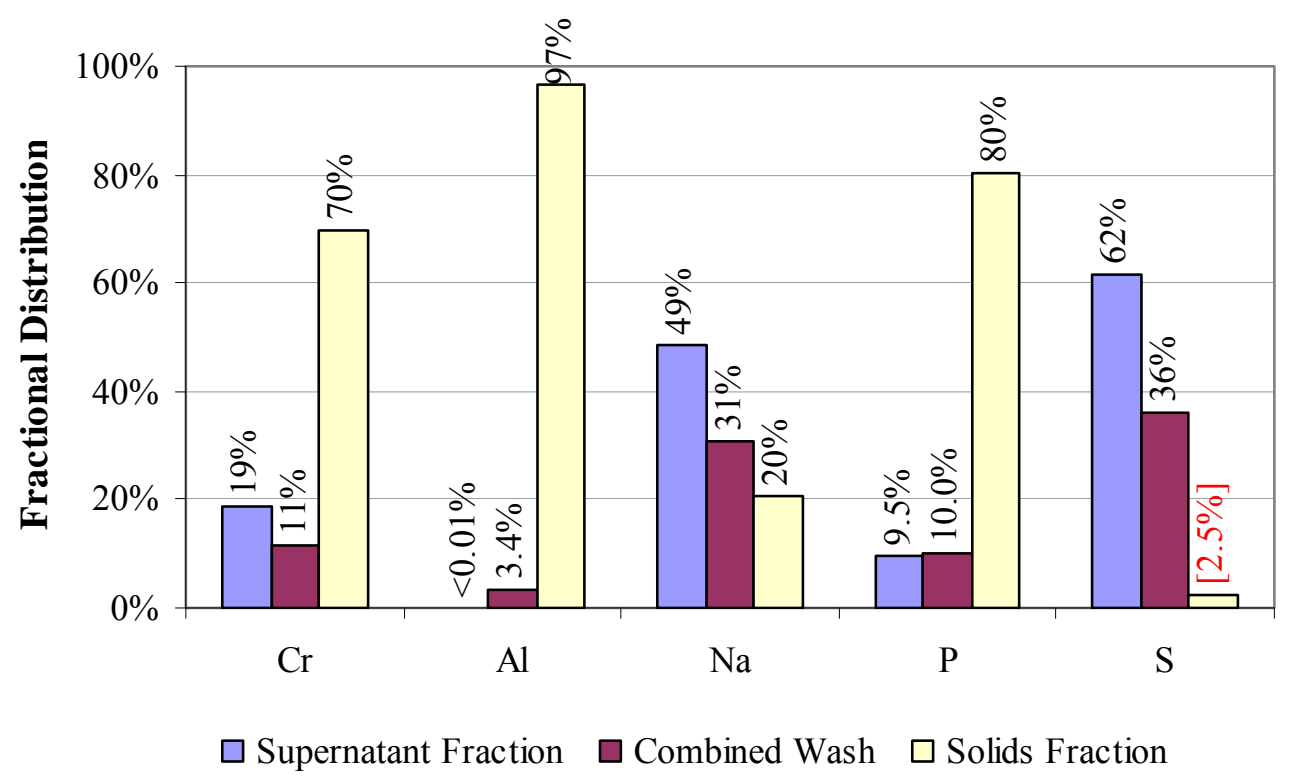

Figure 3.11. Selected Analyte Phase Distribution for Group 7 TBP Sludge

\subsection{Particle Size}

Figure 3.12, Figure 3.13 and Table 3.8 present the results of Group 7 initial characterization particle-size analysis as a function of test condition. Figure 3.12 and Figure 3.13 show the differential volume population distribution for the Group 7 initial characterization sample and allow a qualitative examination of the PSD behavior with respect to pump speed. Table 3.8 is a summary of the measured oversize diameter percentiles (by volume/weight) for the primary sample that present cumulative oversize diameters corresponding to the $10^{\text {th }}, 50^{\text {th }}$, and $90^{\text {th }}$ volume/weight percentiles, hereafter referred to as $\mathrm{d}(10), \mathrm{d}(50)$, and $\mathrm{d}(90)$, respectively.

Figure 3.12 shows the PSD for the primary Group 7 initial characterization sample as a function of pump speed. The sample displayed a multi-modal distribution at all pump speeds. At 2000 RPM, the distribution ranges from 0.2 to $750 \mu \mathrm{m}$ with peak maxima around $0.7,7.5,84$, and $475 \mu \mathrm{m}$. At $3000 \mathrm{RPM}$, the distribution ranges from 0.2 to $500 \mu \mathrm{m}$ and displays peak maxima around $0.7,7.5$, and $75 \mu \mathrm{m}$. At $4000 \mathrm{RPM}$, the distribution ranges from 0.2 to $200 \mu \mathrm{m}$ and contains peak maxima around 0.7 , 7.5 , and $60 \mu \mathrm{m}$. Overall, the higher pump speeds show an increasing population of particles or agglomerates $>20 \mu \mathrm{m}$. The $475-\mu \mathrm{m}$ peak seen at 2000 RPM may be an artifact of scattering signal interpretation by the Malvern software or possible flocculates in the solution that are sheared apart at higher pump speeds. The sample appears to have numerous large particles, agglomerates, or flocculates, which may result in poor reproducibility in sampling due to settling of the larger particles solids.

Figure 3.13 shows the PSD for the duplicate Group 7 initial characterization sample as a function of pump speed. This distribution shows a range of 0.2 to $150 \mu \mathrm{m}$ with the exception of a $475-\mu \mathrm{m}$ peak at 2000 RPM. As this $475-\mu \mathrm{m}$ peak is observed in both the primary and duplicate sample only at 2000 RPM, it is probable that it corresponds to flocculates that are sheared apart at higher pump speeds. In the duplicate sample, a primary peak is present around $6 \mu \mathrm{m}$, and a shoulder exists around $0.75 \mu \mathrm{m}$ at 
all pump speeds. At 4000 RPM, an additional small peak is seen around $60 \mu \mathrm{m}$, and at 3000 and 2000 RPM, either a small peak or a shoulder is present around $75 \mu \mathrm{m}$. Again, the varying distribution may indicate poor sampling due to settling of larger particles that are difficult-to-suspend.

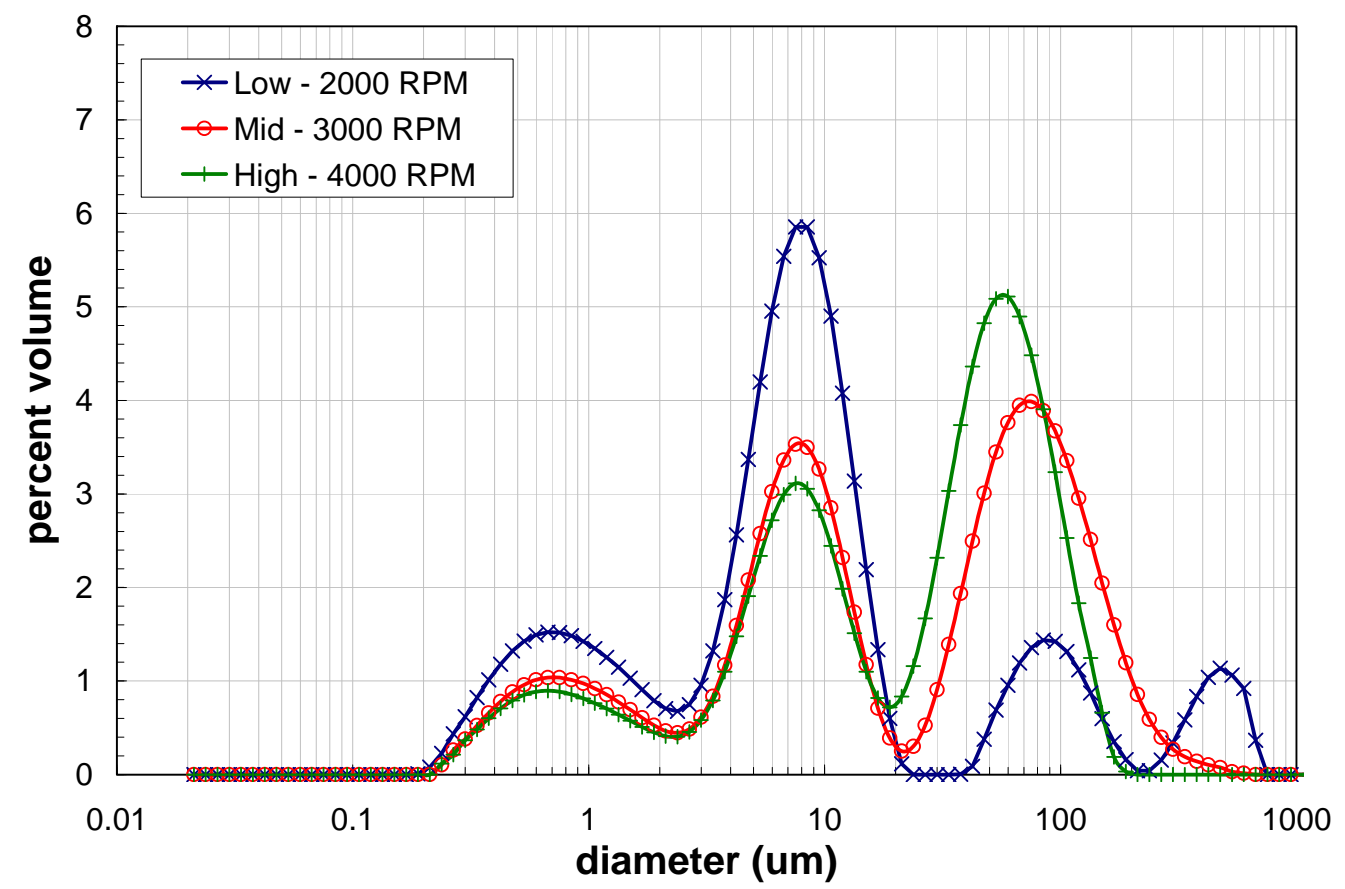

Figure 3.12. Volume Distribution Result for the Primary Group 7 Initial Characterization Sample as a Function of Pump Speed

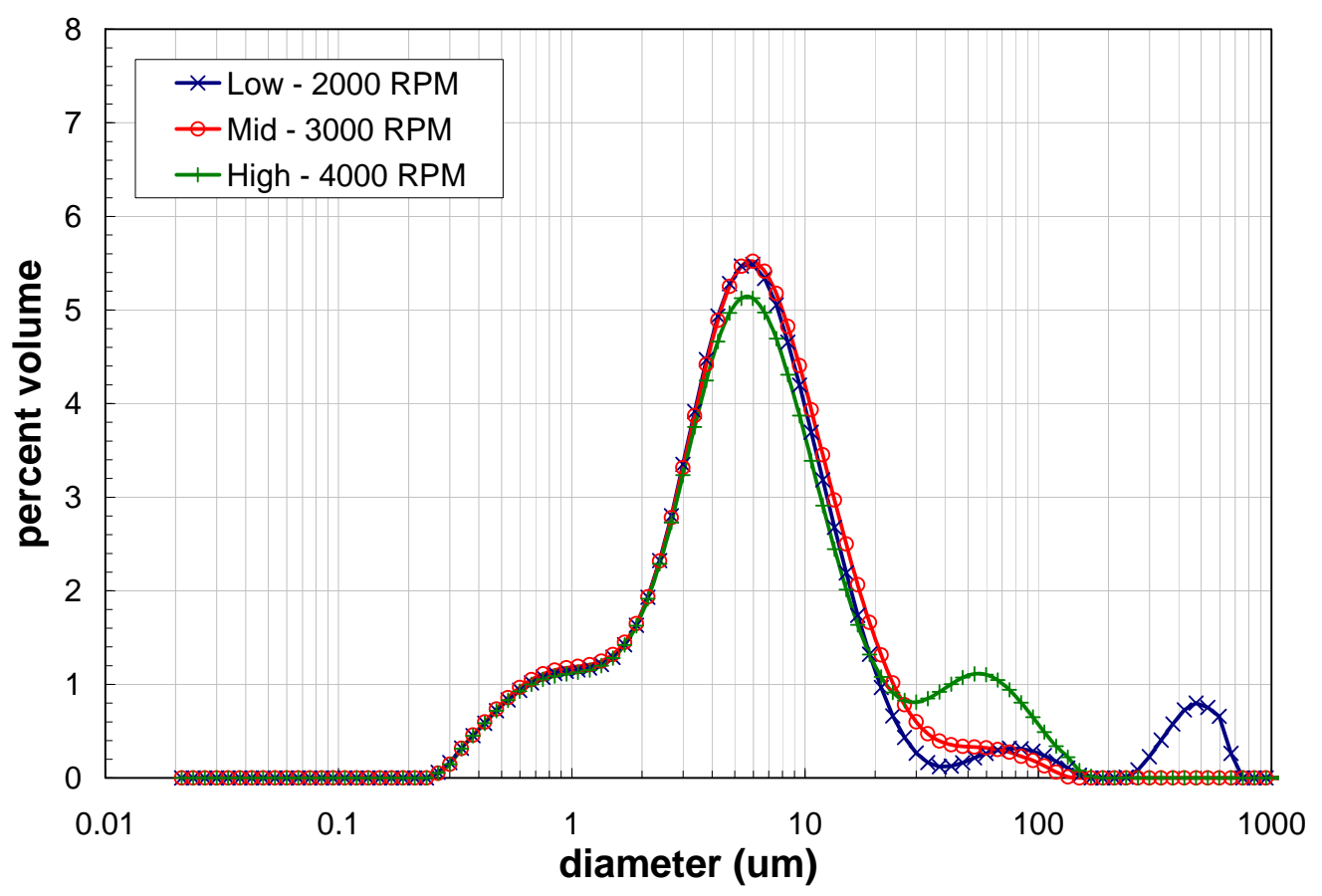

Figure 3.13. Volume Distribution Result for the Duplicate Group 7 Initial Characterization Sample as a Function of Pump Speed 
Table 3.8 shows select cumulative oversize percentiles for the primary and duplicate Group 7 particle dispersions. Using the primary results as a reference, the behavior of Group 7 initial characterization particle size as a function of pump speed can be quantitatively evaluated. Specifically, the following observations can be made:

- In general, the $\mathrm{d}(10)$ falls between 0.70 and $1.3 \mu \mathrm{m}$, the $\mathrm{d}(50)$ between 7.4 and $31 \mu \mathrm{m}$, and the $\mathrm{d}(90)$ between 89 and $130 \mu \mathrm{m}$

- The listed diameter percentiles appear to be highly sensitive to changes in pump speed. Increases in pump speed appear to result in increases in the $\mathrm{d}(50)$. For example, increasing the pump speed from 2000 to 4000 RPM increases the mean particle diameter from 9.8 to $31 \mu \mathrm{m}$. This is an increase of $68 \%$, which is above the instrument limit of accuracy (10\%) and is significant and not merely random noise or measurement error.

Table 3.8. Particle-Size Analysis Percentile Results from Primary Group 7 Initial Characterization Sample

\begin{tabular}{||c|c|c|c|c|c||}
\hline $\begin{array}{c}\text { Measurement } \\
\text { Condition }\end{array}$ & Pump Speed & Sonication & $\begin{array}{c}\mathbf{d}(\mathbf{1 0}) \\
{[\boldsymbol{\mu m}]}\end{array}$ & $\begin{array}{c}\mathbf{d}(\mathbf{5 0}) \\
{[\boldsymbol{\mu m}]}\end{array}$ & $\begin{array}{c}\mathbf{d}(\mathbf{9 0}) \\
{[\boldsymbol{\mu m}]}\end{array}$ \\
\hline 1 & 3000 & $\mathrm{n} / \mathrm{a}$ & 1.0 & 19 & 130 \\
\hline 1 & 3000 & $\mathrm{n} / \mathrm{a}$ & 1.1 & 5.5 & 17 \\
\hline 2 & 4000 & $\mathrm{n} / \mathrm{a}$ & 1.3 & 31 & 89 \\
\hline 2 & 4000 & $\mathrm{n} / \mathrm{a}$ & 1.2 & 5.8 & 35 \\
\hline 3 & 2000 & $\mathrm{n} / \mathrm{a}$ & 0.87 & 9.8 & 120 \\
\hline 3 & 2000 & $\mathrm{n} / \mathrm{a}$ & 1.2 & 5.9 & 66 \\
\hline 4 & 2000 & $\mathrm{n} / \mathrm{a}$ & 0.70 & 7.4 & 110 \\
\hline 4 & 2000 & $\mathrm{n} / \mathrm{a}$ & 1.2 & 5.5 & 19 \\
\hline
\end{tabular}

\subsection{Surface Area}

Duplicate samples $(0.176 \mathrm{~g}$ and $0.158 \mathrm{~g})$ tested for surface area resulted in $66.1 \pm 0.14 \mathrm{~m}^{2} / \mathrm{g}$. The overall experimental uncertainty was estimated to be $\pm 5 \%$.

\subsection{Crystal Form and Habit}

XRD sample analysis was carried out by PNNL's Radiochemical Science and Engineering Group. The XRD instrument used was the Scintag PAD V X-ray Diffractometer. Phase identification was done with the JADE search match routines (version 6.0, Materials Data Inc.) with comparison to the International Centre for Diffraction Data (ICDD) database PDF-2 release 1999, which includes the Inorganic Crystal Structure Database (ICSD) (maintained by Fachinformationszentrum [FIZ], Karlsruhe, Germany). In general, the patterns contain a very large number of peaks along with significant peak overlapping in areas (Figure 3.14). The phases identified were not good matches to the measured XRD patterns, indicating that the pattern contains phases that are likely somewhat different than the patterns available in the database. Phases identified were:

- Rutile, $\mathrm{TiO}_{2}$ (internal standard)

- Zeolite, $\mathrm{NaAlSiO}_{4}\left(\mathrm{H}_{2} \mathrm{O}\right)_{1.1}$ 
- Threadgoldite, $\mathrm{Al}\left(\mathrm{UO}_{2}\right)_{2}\left(\mathrm{PO}_{4}\right)_{2}(\mathrm{OH})\left(\mathrm{H}_{2} \mathrm{O}\right)_{8}$

- Sodium Iron Phosphate, $\mathrm{Na}_{7}\left(\mathrm{FeP}_{2} \mathrm{O}_{7}\right)_{4} \mathrm{PO}_{4}$

- Lepidocrocite, $\mathrm{FeO}(\mathrm{OH})$

- Humboldtine, $\mathrm{C}_{2} \mathrm{FeO}_{4} \cdot 2 \mathrm{H}_{2} \mathrm{O}$

- Iron (III) phosphate oxide, $\mathrm{Fe}_{2} \mathrm{PO}_{5}$

- Dioxouranium(VI) bis(dihydrogenphosphate(I)) hydrate, $\left(\mathrm{UO}_{2}\right)\left(\mathrm{H}_{2} \mathrm{PO}_{2}\right)_{2}\left(\mathrm{H}_{2} \mathrm{O}\right)$

- Sodium Uranyl Phosphate, $\mathrm{Na}_{6}\left(\mathrm{UO}_{2}\right)_{2}\left(\mathrm{PO}_{4}\right)_{4}$

- Gibbsite, $\mathrm{Al}(\mathrm{OH})_{3}$. 


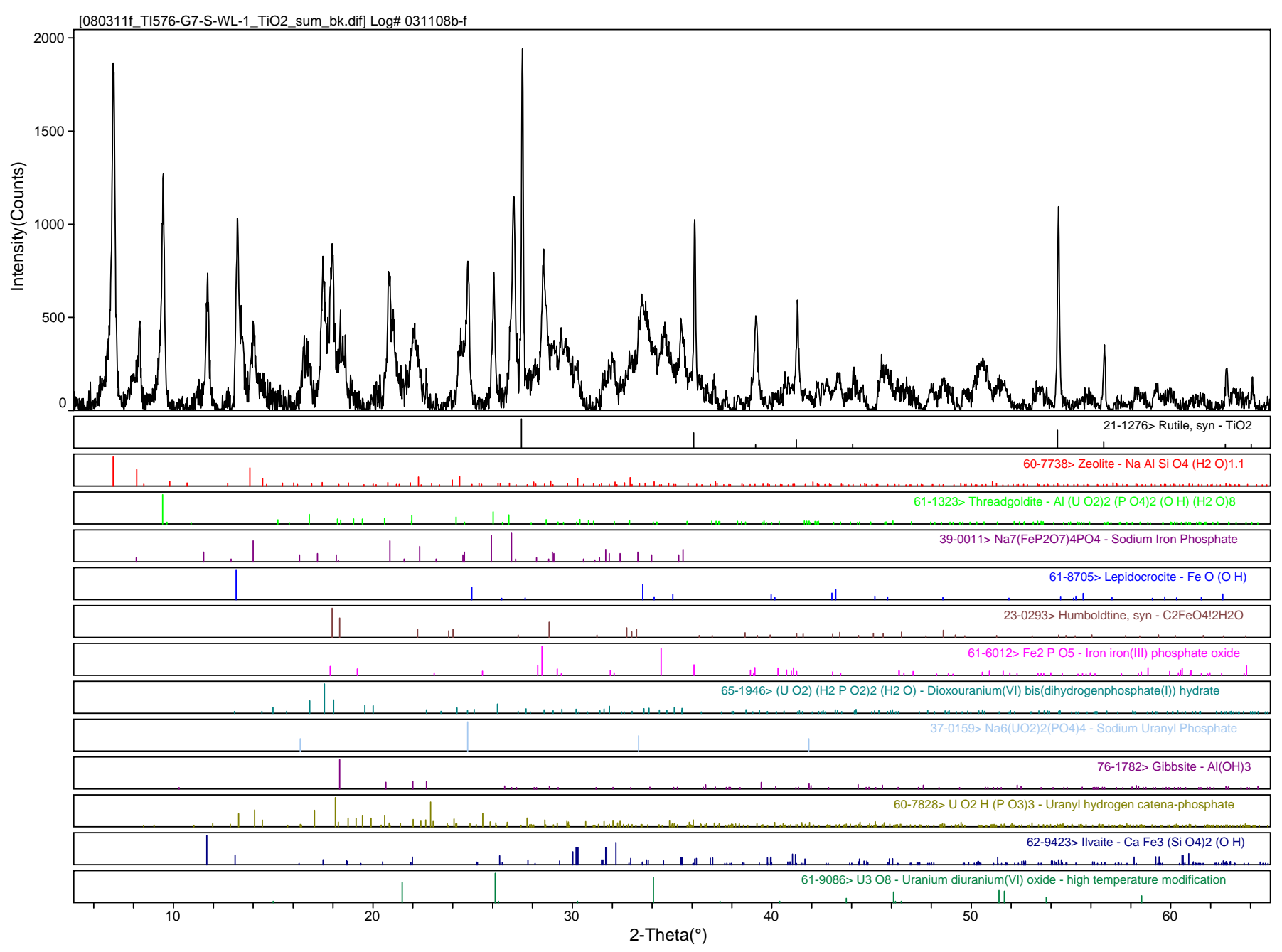

Figure 3.14. XRD Pattern of Washed Group 7 TBP Sludge with Rutile $\left(\mathrm{TiO}_{2}\right)$ Internal Standard Background-Subtracted Pattern with Stick-Figure Peak Identification 
Several SEM images of the washed Group 7 solids are shown in Figure 3.15 through Figure 3.18. The washed TBP sludge particles tended to agglomerate. A significant population of platy particles appeared to agglomerate in a spherical structure (see Figure 3.16 and Figure 3.17a) with a complex chemical composition including $\mathrm{O}, \mathrm{Na}, \mathrm{Al}, \mathrm{P}, \mathrm{Ca}$, and Fe. Spot 2 in Figure 3.17b shows a relatively large, platy structure with flat faces in the xyz planes of similar composition, except it contains U. Possible gibbsitelike structures appear in Figure 3.17b, spots 1 and 5, and Figure 3.18 Spot 3 with only Al and O identified by energy-dispersive spectroscopy (EDS) examination. 

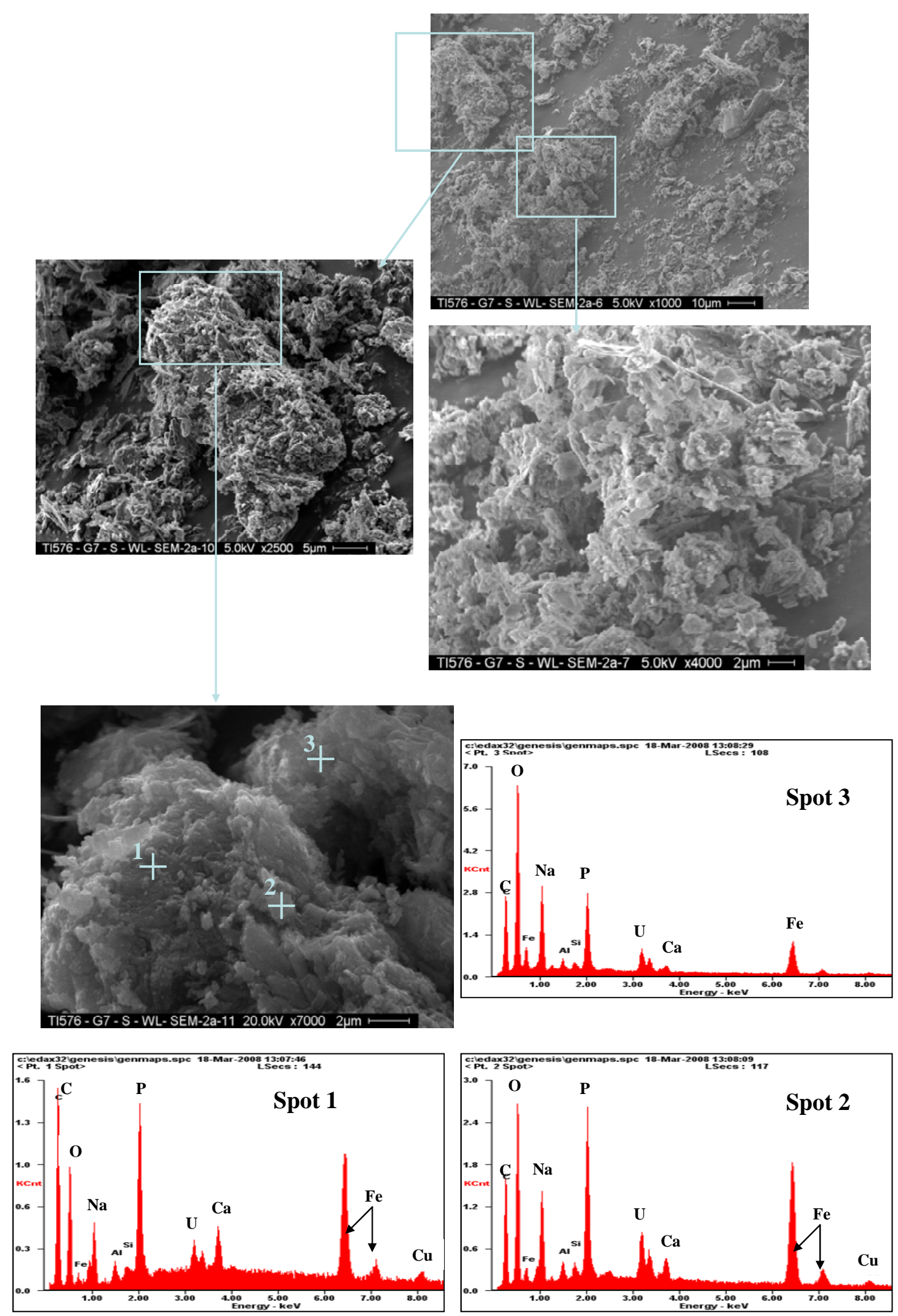

Figure 3.15. SEM Images of Washed Group 7 TBP Sludge with EDS Evaluation 

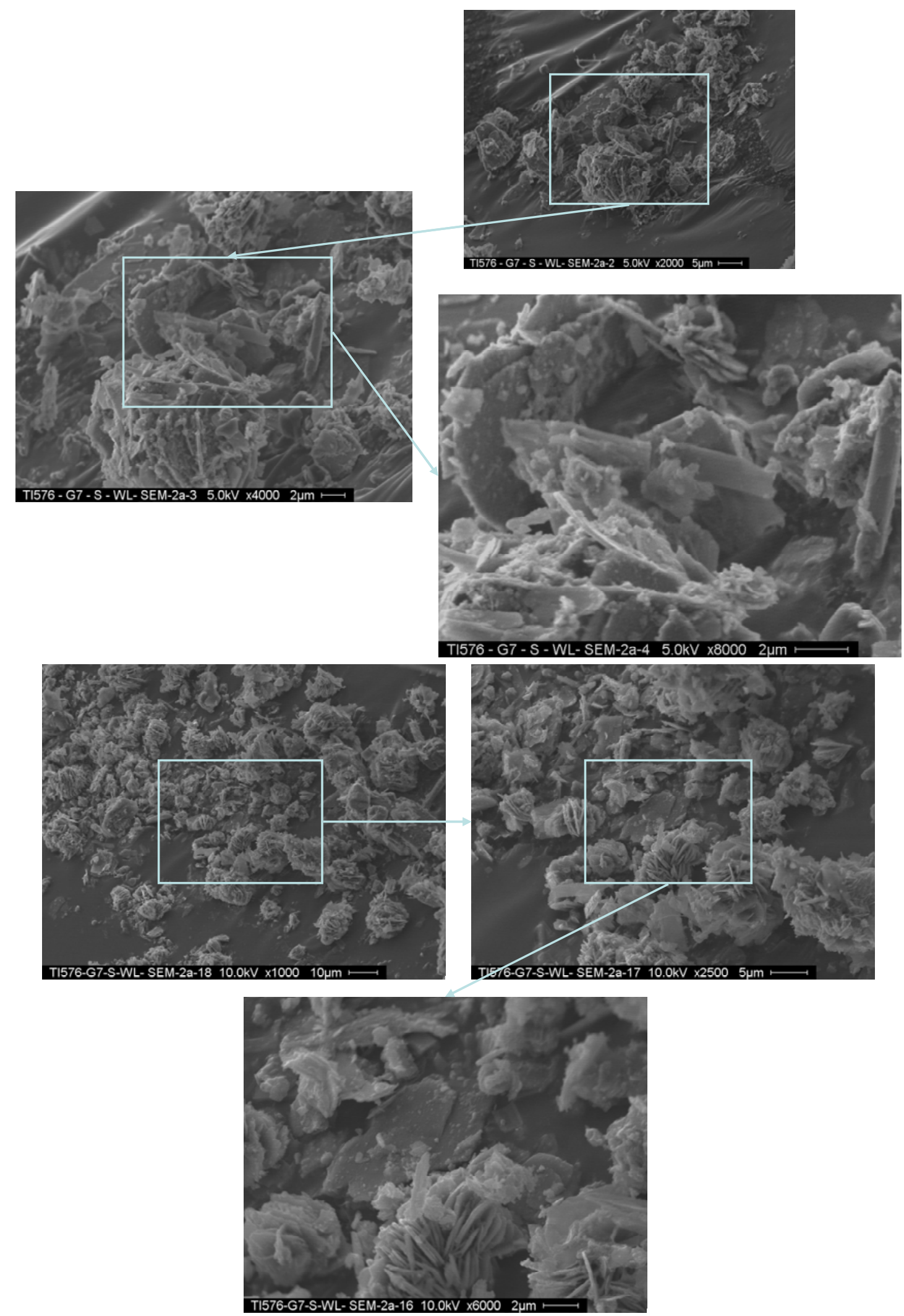

Figure 3.16. SEM Images of Washed Group 7 TBP Sludge 

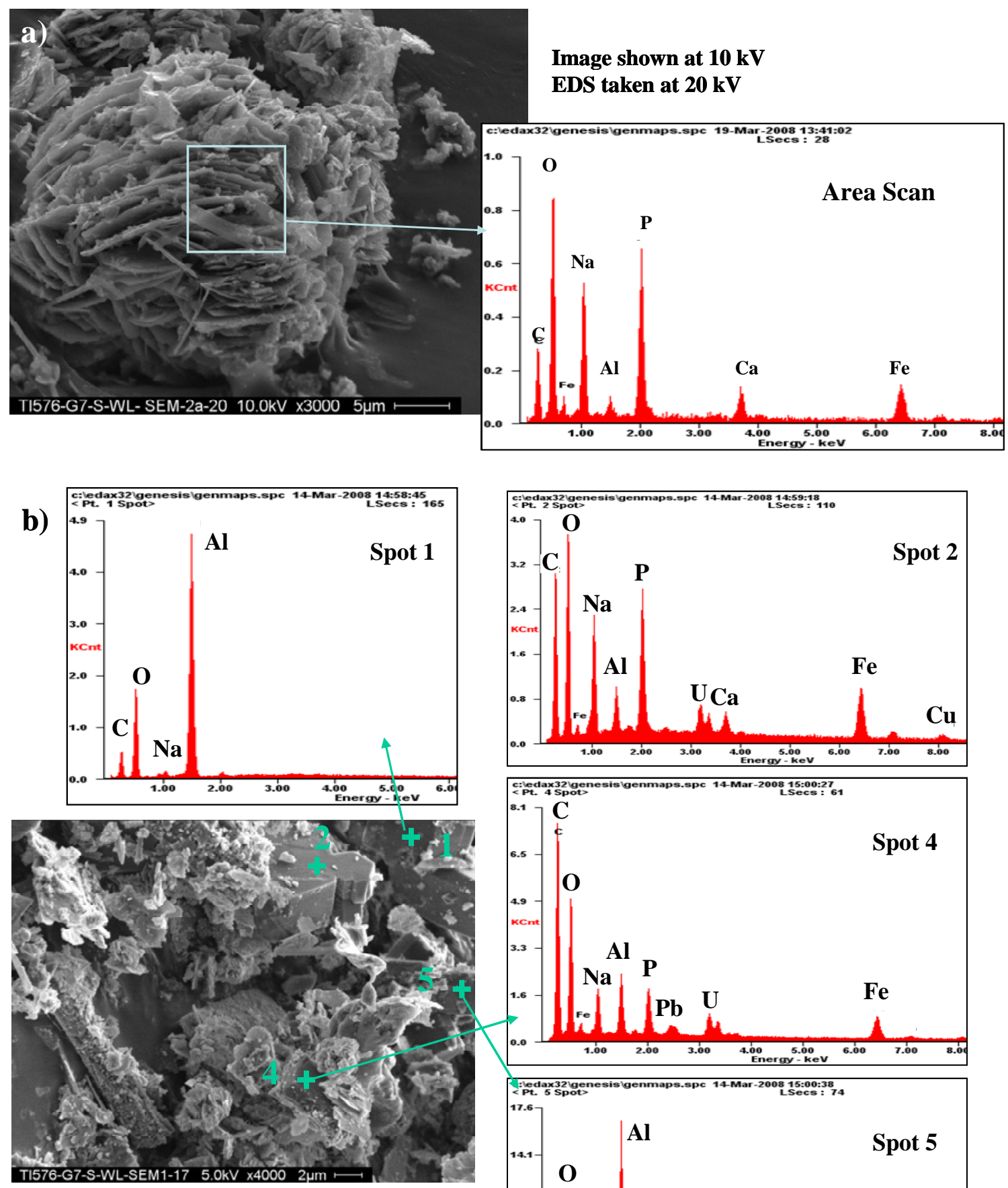

Image shown at $5 \mathrm{kV}$ for clarity EDS taken at $20 \mathrm{kV}$
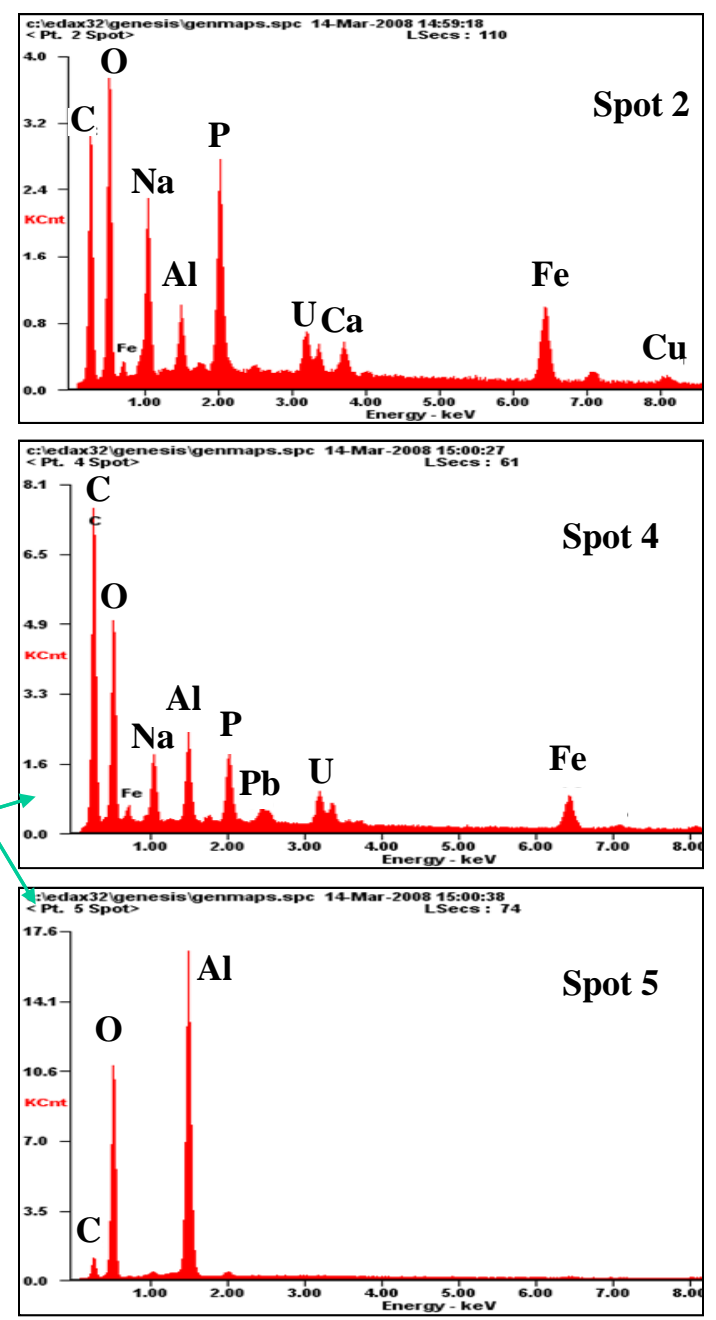

Figure 3.17. SEM Images with EDS Evaluation of Group 7 TBP Washed Sludge 


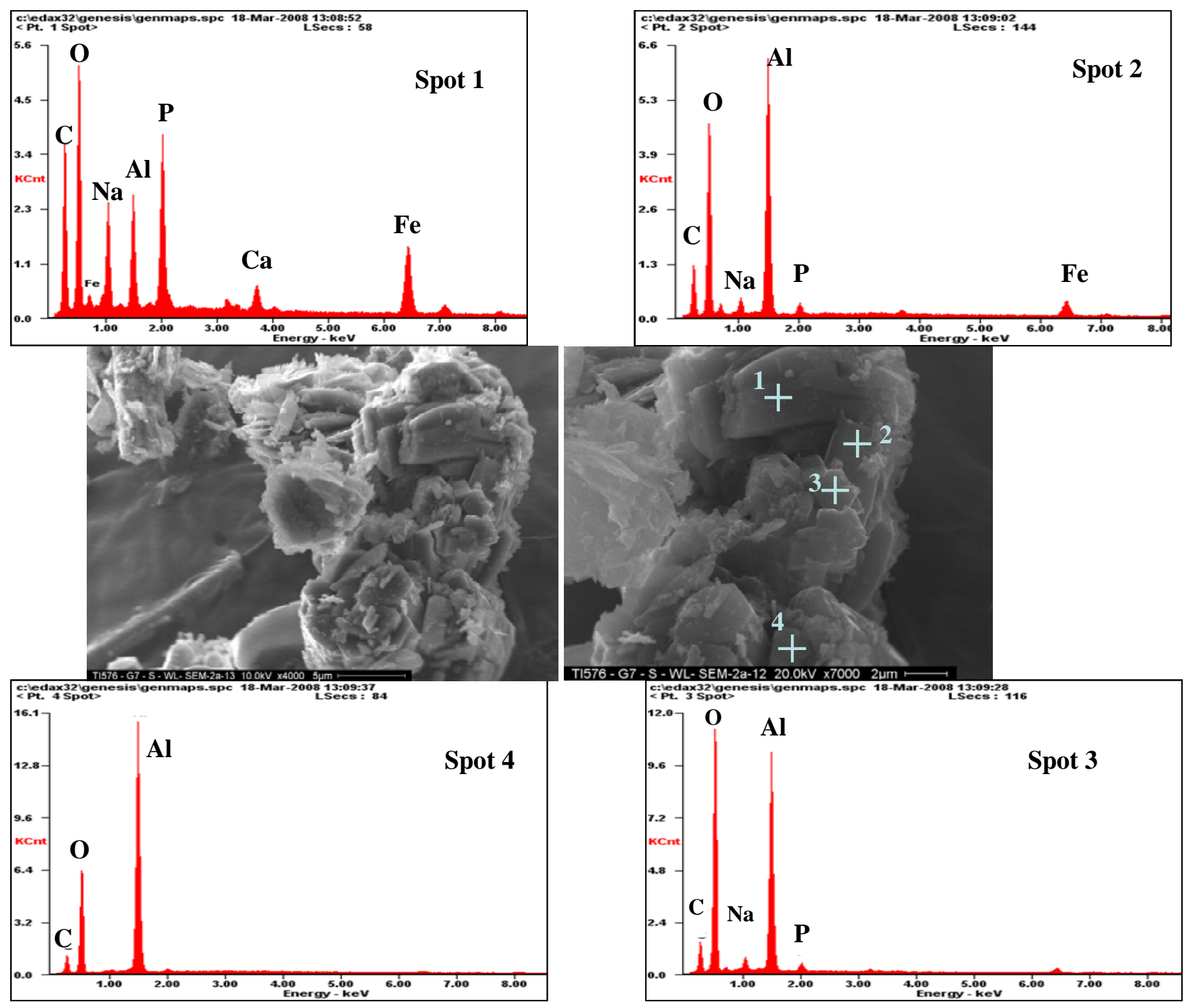

Figure 3.18. SEM Imaging of Washed Group 7 TBP Sludge with EDS Analysis 
TEM images were obtained and the dominant surface area phase in the G7 sample was an iron calcium phosphate (see Figure 3.19). This phase occurred as a finely divided phase that was attached tenaciously to larger crystals that were iron and uranium rich. Large iron bearing particles were also found (see Figure 3.20). In Table 3.9, the compositional analysis of this phase is described. The major elements were $\mathrm{Na}, \mathrm{Fe}$, and $\mathrm{P}$.

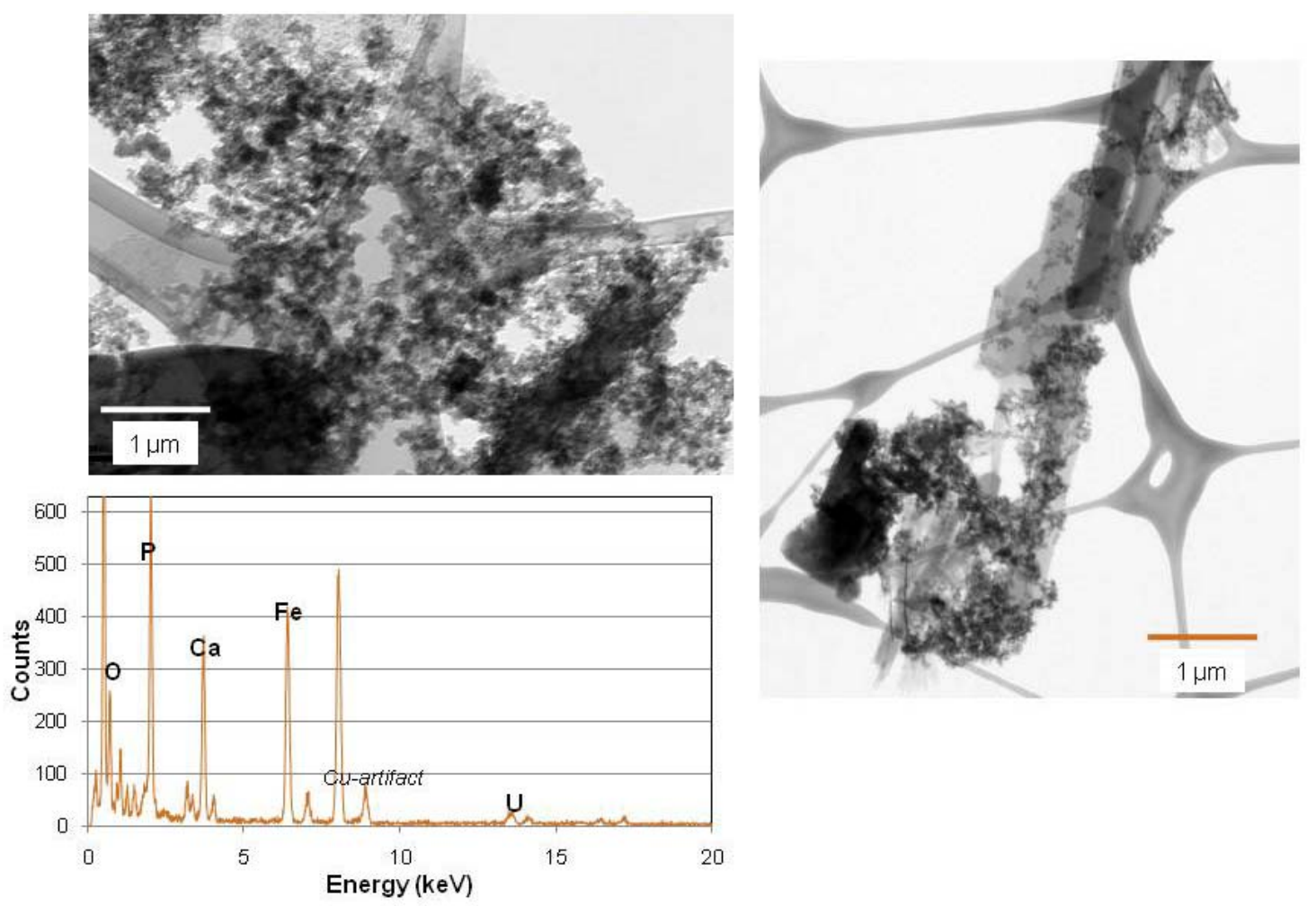

Figure 3.19. TEM Analysis of an Iron Calcium Phosphate Phase and EDS Analysis of the Phase 


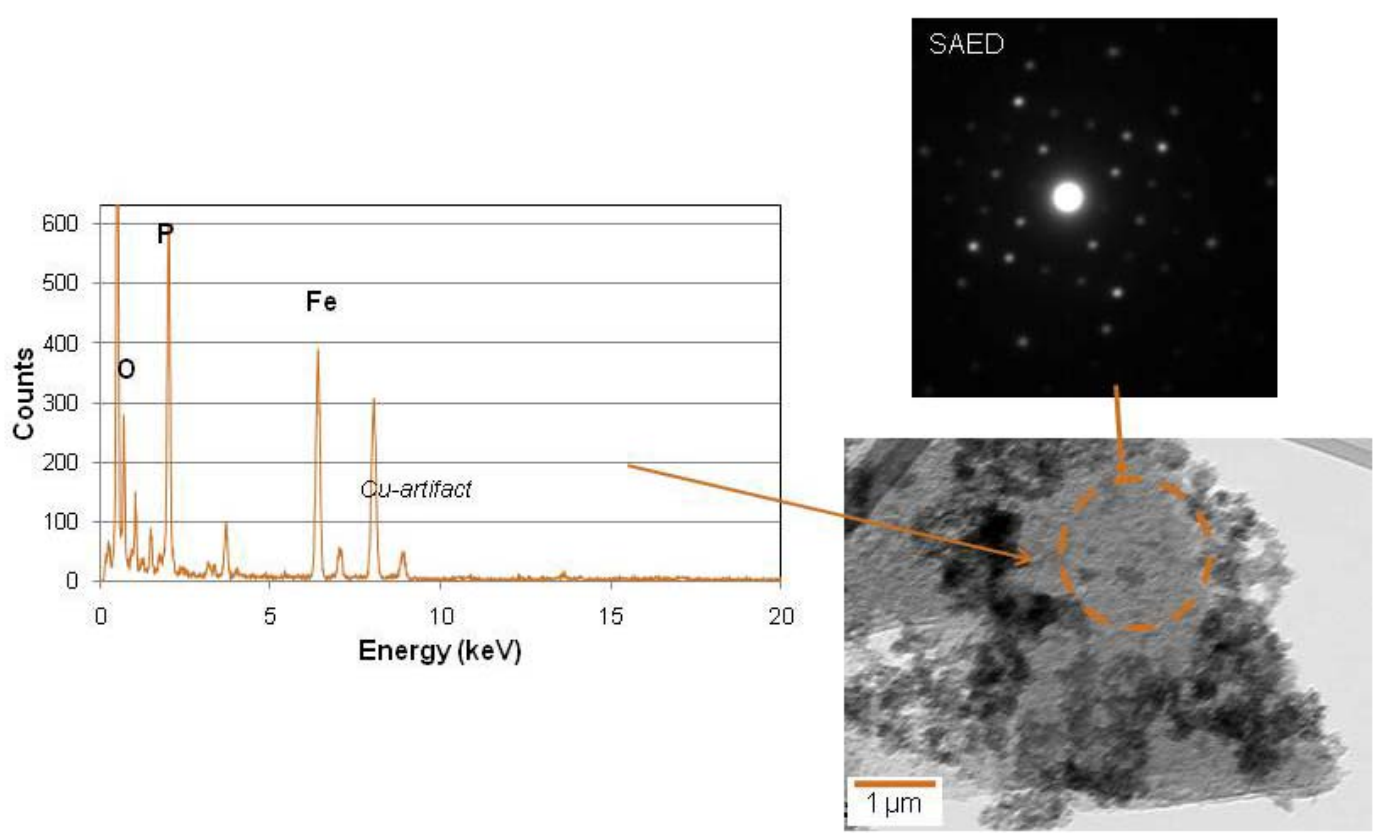

Figure 3.20 EDS analysis of an iron phosphate phase, electron diffraction of the phase and a TEM image.

The compositional analysis of the phase (Table 3.9) indicates, assuming that the phase is a phosphate, that the formula is $\mathrm{NaFe}_{2-3}\left(\mathrm{PO}_{4}\right)_{4-5}$. The iron phosphates, kidwellite $\left[\mathrm{Na}\left(\mathrm{Fe}^{3+}, \mathrm{Cu}\right)_{9+\mathrm{x}}\left(\mathrm{PO}_{4}\right)_{6}(\mathrm{OH})_{11} \cdot 3\left(\mathrm{H}_{2} \mathrm{O}\right)\right]$ and cyrilovite $\left[\mathrm{NaFe}_{3}^{3+}\left(\mathrm{PO}_{4}\right)_{2}(\mathrm{OH})_{4} \cdot 2\left(\mathrm{H}_{2} \mathrm{O}\right)\right]$, have been reported in nature in occurrence with autunites and other uranyl phosphates. Natrodufrenite $\left[\mathrm{Na}\left(\mathrm{Fe}^{3+}, \mathrm{Fe}^{2+}\right)\left(\mathrm{Fe}^{3+}, \mathrm{Al}\right)_{5}\left(\mathrm{PO}_{4}\right)_{4}(\mathrm{O})_{6} \cdot 2\left(\mathrm{H}_{2} \mathrm{O}\right)\right]$ and ercitite $\left[\mathrm{Na}\left(\mathrm{Mn}^{3+}, \mathrm{Fe}^{3+}\right)\left(\mathrm{PO}_{4}\right)(\mathrm{OH})_{2} \cdot\left(\mathrm{H}_{2} \mathrm{O}\right)\right]$ are formed under low-temperature hydrothermal conditions that can be similar to the environments found in the Hanford sludges. For example, cancrinite and the uranyl phosphates are known to form in laboratory tests under low-temperature and high-pH hydrothermal conditions. The best match in terms of diffraction, formation conditions, and composition is ercitite.

Table 3.9. EDS Analysis of Iron Phosphate Phase

\begin{tabular}{|c|c|c|c||}
\hline Element & Weight \% & Atomic \% & Uncertainty \% \\
\hline $\mathrm{Na}(\mathrm{K})$ & 6.55 & 10.99 & 0.185 \\
\hline $\mathrm{Mg}(\mathrm{K})$ & 1.48 & 2.36 & 0.106 \\
\hline $\mathrm{Al}(\mathrm{K})$ & 3.85 & 5.51 & 0.141 \\
\hline $\mathrm{P}(\mathrm{K})$ & 38.04 & 47.38 & 0.419 \\
\hline $\mathrm{Ca}(\mathrm{K})$ & 5.54 & 5.33 & 0.175 \\
\hline $\mathrm{Fe}(\mathrm{K})$ & 38.65 & 26.70 & 0.462 \\
\hline $\mathrm{Sr}(\mathrm{K})$ & 2.75 & 1.21 & 0.172 \\
\hline $\mathrm{U}(\mathrm{L})$ & 3.14 & 0.51 & 0.538 \\
\hline
\end{tabular}

Large crystals of a uranium phosphate were common in the sample. The particles were several micrometers in length and up to 1 to $2 \mu \mathrm{m}$ across. The particles were electron transparent, suggesting that they were $<50$ to $100 \mathrm{~nm}$ thick (consistent with the PSD measurements). A few small precipitates were found on the surface of the acicular (needlelike; mineral growth in long and slender crystals) crystals. An 
EDS probe was used to determine the exact composition of the phase. Sodium was visible but would be removed rapidly by condensing down the probe even slightly. Electron diffraction on the platy axis revealed a well-formed slightly distorted rectangular lattice (Figure 3.21). The crystal went amorphous under the electron beam after a few minutes of intense irradiation. Figure 3.21 shows a clear diffraction pattern of the phase, Figure 3.22a is a rotational average of the diffraction pattern, and Figure 3.22b is an EDS analysis of the phase. Based on the ease of amorphization, the composition, and the shape of the crystal, it was clear that the phase was a uranyl phosphate. There are many varieties of uranyl phosphates in nature; autunite and meta-autunite are the most common. At least three uranyl phosphate phases were suggested by the XRD analysis (see above). Figure 3.23 shows a prime example of a large single crystal of uranyl phosphate in the Group 7 sludge.

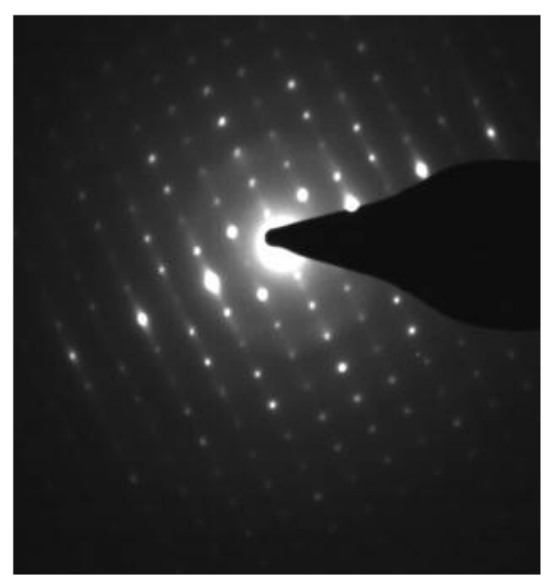

Figure 3.21. Electron Diffraction Pattern of U(VI) Phase in G7-S-WL
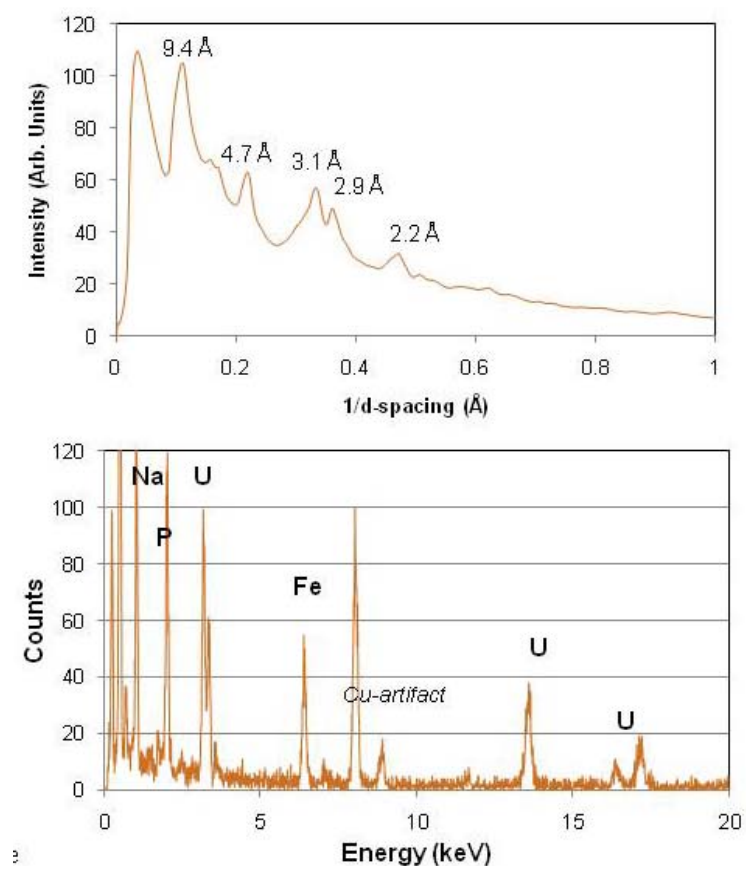

Figure 3.22. (a) Rotational Average Spectrum from Diffraction Pattern and (b) Compositional Analysis of U(VI) Phase 


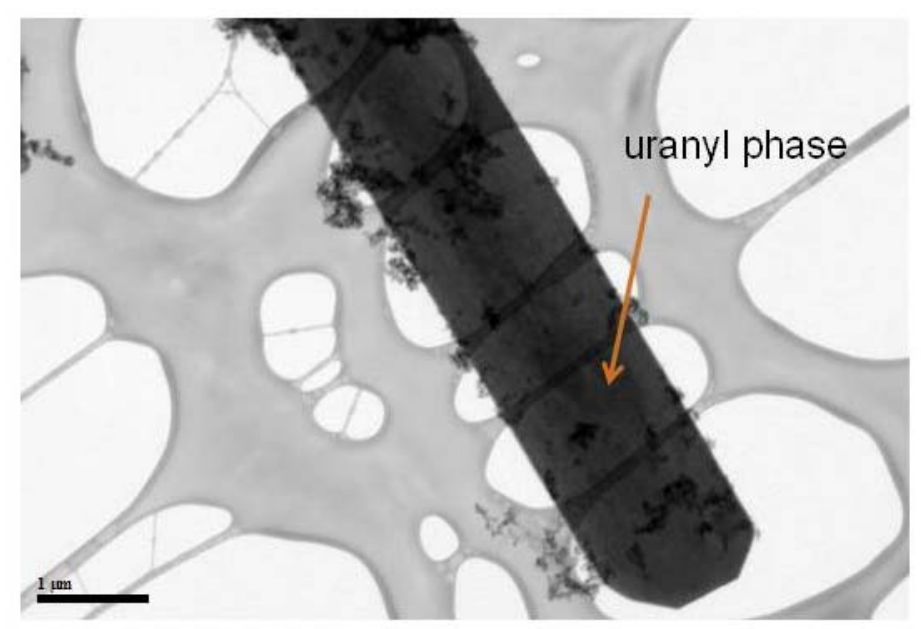

Figure 3.23. TEM Image of Large Sodium Uranyl Phosphate Phase in G7 Tank Sludge 
WTP-RPT-169, Rev 0

\subsection{Group 7 Tributyl Phosphate Sludge Batch Parametric Leaching}

This section reports on and discusses the parametric leach testing and leaching results for the Group 7 TBP sludge slurry composite.

\subsection{Group 7 Tributyl Phosphate Sludge Batch Parametric Leaching: Experimental}

Parametric caustic leaching tests were performed on the Group 7 TBP sludge sample to determine the behavior of aluminum and phosphate during leaching at different conditions. The composite Group 7 sample material was rinsed with $0.01 \mathrm{M} \mathrm{NaOH}$, subdivided, and subjected to a parametric test matrix for caustic leach testing as discussed in the following sections.

\subsubsection{Initial Washing of the Group 7 Solids}

The Group 7 composite sample was mixed with an overhead stirrer fitted with a bladed stainless steel impeller. A 98.4-g aliquot was removed with a large transfer pipette and transferred to a 200-mL centrifuge bottle. At a concentration of $0.123 \mathrm{~g}$ dry water-insoluble solids per gram of slurry, the 98.4-g slurry contained $12.1 \mathrm{~g}$ of water-insoluble solids. The slurry aliquot was centrifuged at $\sim 2500 \mathrm{RPM}$ $(1200 \mathrm{G})$ for $15 \mathrm{~min}$, and then the supernatant liquid was removed. The volume of centrifuged solids was estimated to be $\sim 15 \mathrm{~mL}$ based on volume graduations on the sample bottle. Approximately $45 \mathrm{~mL}$ ( $3 \times$ the centrifuged solids volume) of $0.01 \mathrm{M} \mathrm{NaOH}$ was added to wash the solids. The slurry was placed on a vortex mixer to loosen the solids and then shaken for 15 minutes on a shaker table. The slurry was centrifuged at $\sim 1200 \mathrm{G}$ for $15 \mathrm{~min}$, and then the supernatant liquid was removed. The washing steps were repeated twice for a total of three washes. The third wash was centrifuged for 65 minutes because the wash liquid had floating solids. After 65 minutes, there were still floating solids, so $0.5 \mathrm{~mL}$ of $19 \mathrm{M}$ $\mathrm{NaOH}$ was added. The slurry was mixed gently and centrifuged for an additional 15 minutes at $1200 \mathrm{G}$. At this point, the solution was clear and nearly colorless.

The washed solids were thinned by adding $80.6 \mathrm{~g}$ of deionized (DI) water to conduct the sample subdivision. While mixing this slurry with an overhead mixer, the sample bottle was knocked over. Approximately ${ }^{2} / 3$ of the sample was lost, leaving $31.4 \mathrm{~g}$ of slurry. Since the sample had been mixing for 10 minutes before the sample loss, it was assumed that the sample was reasonably well mixed, and it was calculated that the $31.4 \mathrm{~g}$ of slurry contained $\sim 3.5 \mathrm{~g}$ of UDS.

To make up for the lost sample, a new 73.3-g aliquot of the sample was removed with a large transfer pipette and transferred to a $200-\mathrm{mL}$ centrifuge bottle. At a concentration of $0.123 \mathrm{~g}$ dry water-insoluble solids per gram of slurry, the 73.3-g slurry contained $9.0 \mathrm{~g}$ of water-insoluble solids. The slurry aliquot was centrifuged at 2500 RPM $(1200 \mathrm{G})$ for $15 \mathrm{~min}$, and then the supernatant liquid was removed. The solids were washed in the same manner as described above. Again, floating solids were observed during the third wash that did not settle after centrifuging for 75 minutes. In this case, approximately $5 \mathrm{~g}$ of the wash solution was left on the solids. 


\subsubsection{Division of the Washed Group 7 Solids}

To conduct a successful sample subdivision, the two bottles containing washed centrifuged solids needed to be combined, and the total sample needed to be thinned. DI water $(\sim 50 \mathrm{~mL})$ was added to the solids in the first wash vessel. The slurry was mixed by shaking by hand and the contents transferred to the second wash vessel. At this point, the first vessel was clean. Then DI water was added to the $100-\mathrm{mL}$ mark on the second wash vessel, for a total of about $84 \mathrm{~g}$ of DI water in the solids.

An overhead mixer equipped with a three-bladed stainless steel impeller was used to homogenize the thinned slurry. Ten $\sim 9.4$-g slurry samples were transferred to 125-mL high-density polyethylene (HDPE) bottles with a large disposable polyethylene pipette. Each sample contained $\sim 1 \mathrm{~g}$ UDS. The samples were removed from the hot cell for follow-on processing at the fume-hood workstation.

One additional sample (623-G7-WL-Solids) containing approximately 10.0 g of slurry was transferred to a 60-mL HDPE bottle. A portion of this sample was submitted for a $\mathrm{KOH}$ fusion and the following subsequent analyses: ICP-OES metals, GEA, Pu, total alpha, total beta, ${ }^{90} \mathrm{Sr}$, and U by kinetic phosphorescence analysis (KPA). These analyses were performed to establish the starting composition of the washed solids.

\subsubsection{Caustic Leaching of the Washed Group 7 Solids}

The leaching test matrix for each of the 10 samples is summarized in Table 4.1. The test matrix evaluated the effects of free-hydroxide concentration $(0.25$ to $3 \mathrm{M} \mathrm{NaOH})$ and temperature ( 40 to $80^{\circ} \mathrm{C}$ ) on gibbsite and phosphorus leaching kinetics.

Table 4.1. Group 7 Caustic Leaching Conditions

\begin{tabular}{|c|c|c|c|c|c|}
\hline & \multicolumn{2}{|c|}{ Free OH, M } & \multicolumn{2}{|c|}{$\mathrm{Na}, \mathrm{M}$} & \multirow{2}{*}{$\begin{array}{c}\text { Temperature, } \\
{ }^{\circ} \mathbf{C}^{(\mathbf{b})}\end{array}$} \\
\hline Bottle ID & Target & Measured $^{(a)}$ & Target & Measured $^{(a)}$ & \\
\hline G7-40-1 & 1 & 1.02 & 1 & 1.10 & 40 \\
\hline G7-40-3a & 3 & 3.12 & 3 & 3.21 & 40 \\
\hline G7-40-3b & 3 & 3.00 & 3 & 3.04 & 40 \\
\hline G7-40-3c & 3 & 3.19 & 3 & 3.17 & 40 \\
\hline G7-60-0.25 & 0.25 & 0.24 & 0.25 & 0.28 & 60 \\
\hline G7-60-1 & 1 & 1.01 & 1 & 1.01 & 60 \\
\hline G7-60-3 & 3 & 3.02 & 3 & 3.00 & 60 \\
\hline G7-80-0.25 & 0.25 & 0.25 & 0.25 & 0.30 & 80 \\
\hline G7-80-1 & 1 & 1.05 & 1 & 1.04 & 80 \\
\hline G7-80-3 & 3 & 3.05 & 3 & 2.95 & 80 \\
\hline \multicolumn{6}{|c|}{$\begin{array}{l}\text { (a) The measured analyte concentrations represent the concentration obtained aft } \\
\text { time. } \\
\text { (b) The temperature uncertainty was } \pm 2.5^{\circ} \mathrm{C} \text {. } \\
\text { Note: All analyte concentrations were measured at ambient }\left(\sim 21^{\circ} \mathrm{C}\right) \text { temperature. } \\
\text { Analytical Service Request (ASR): } 8144\end{array}$} \\
\hline
\end{tabular}

The $\mathrm{NaOH}$ concentration in each leaching mixture was adjusted to support the test matrix. Sodium hydroxide was added to each aliquot of the washed solids slurry. For the four samples run at $40^{\circ} \mathrm{C}, 19 \mathrm{M}$ sodium hydroxide was used and added in the following amounts: $5.3 \mathrm{~mL}$ to yield $1 \mathrm{M} \mathrm{NaOH}$, and 15.8 
$\mathrm{mL}$ to yield $3 \mathrm{M} \mathrm{NaOH}$. For the samples run at 60 and $80^{\circ} \mathrm{C}, 10 \mathrm{M}$ sodium hydroxide was used and added in the following amounts: $2.5 \mathrm{~mL}$ to yield $0.25 \mathrm{M} \mathrm{NaOH}, 10.0 \mathrm{~mL}$ to yield $1 \mathrm{M} \mathrm{NaOH}$, and $30.0 \mathrm{~mL}$ to yield $3 \mathrm{M} \mathrm{NaOH}$. The leaching mixtures were then diluted to a final volume of $100 \mathrm{~mL}$ (with an estimated uncertainty of $2 \mathrm{~mL}$ ) with DI water. (The $100-\mathrm{mL}$ volume had been pre-marked on each sample bottle.) The contact time with the concentrated $\mathrm{NaOH}$ was brief ( $<5 \mathrm{~min})$. The sample bottles were weighed after each addition of reagents $(\mathrm{NaOH}$ and water). Each leaching vessel was closed with a cap equipped with a tube condenser. The condenser was used to eliminate pressurization and minimize water loss while at the same time minimizing the spread of contamination.

The sample slurries were transferred to a temperature-controlled shaker table. The temperature was controlled with an aluminum heating block (J-KEM Scientific, Inc.) equipped with a Type T thermocouple. The temperature of the sample solution was not monitored during this process. The heating block was supported on a J-KEM BTS-3500 digital bench-top shaker (Figure 4.1). The shaking speed was digitally controlled to 200 RPM; based on visual inspection, the solids were well suspended in solution. The samples were grouped according to the leaching temperature, and one group was leachtested at a time. The heating block was pre-heated to the appropriate temperature before leach testing.

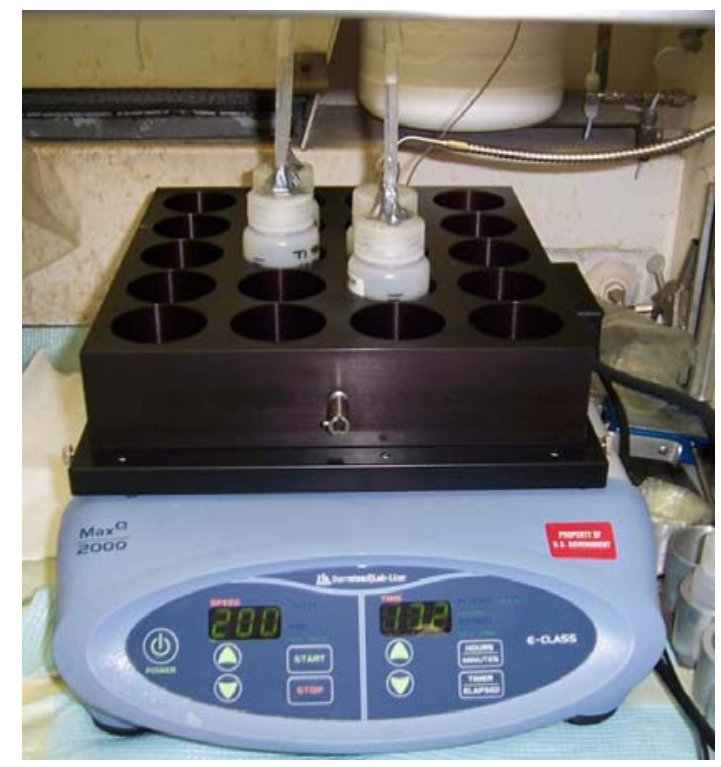

Figure 4.1. Aluminum Heating Block and Shaker Table Used in Parametric Leaching Tests

The leaching mixtures were shaken at temperature for 24 hours, and solution samples were withdrawn at 0 (taken before insertion into heating block), 1, 2, 4, 8, and 24 hours. At each sampling time, the shaker was stopped, and the solids were allowed to settle for $\sim 5$ to $10 \mathrm{~min}$, resulting in sufficient clarification of the aqueous portion to support sampling without removing any solids. Approximately $1.5 \mathrm{~mL}$ of the clarified leachate solution was withdrawn with a transfer pipette and filtered through a $0.45-\mu \mathrm{m}$ pore size nylon syringe filter; the syringe filter and the syringe had been pre-heated in an oven to the sample temperature $\left(40,60\right.$, or $80^{\circ} \mathrm{C}$ ) before filtering in an effort to minimize temperature changes impacting the sample. One $0.5-\mathrm{mL}$ sample of filtered solution was acidified with $15 \mathrm{~mL}$ of $0.3 \mathrm{M} \mathrm{HNO}_{3}$ for analysis by ICP-OES; another 0.5-mL sample of filtered solution was removed for analysis by IC. The remaining filtered solution was returned to the leaching vessel, and the leaching process was continued. The new 
liquid level was marked after each sample was taken. Evaporation was minimal during the course of the experiment, but when evaporation was observed, DI water was added to restore the volume to the previously marked liquid level. After 24 hours, additional leachate samples were taken to determine the free-hydroxide ion concentration and gamma-emitting isotopes by GEA.

After the final samples were taken at temperature, the slurries were removed from the mixing/heating block and cooled to ambient $\left(\sim 22^{\circ} \mathrm{C}\right)$ temperature. The slurries were centrifuged, and the leachate was decanted. $^{\text {(a) }}$

The equilibrium concentration values for free hydroxide and sodium are shown in Table 4.1 and were based on results from the samples taken at 24 hours.

\subsubsection{Washing of Caustic Leached Group 7 Solids for Analysis}

The solids from the triplicate samples (G7-40-3a, -3b, and -3c, leached at $40^{\circ} \mathrm{C}$ in $3 \mathrm{M} \mathrm{NaOH}$, and each consisting of $\sim 2.4 \mathrm{~g}$ centrifuged slurry) were prepared for characterization as shown in Figure 4.2. One of the solids samples was slurried in $\sim 15 \mathrm{~mL}$ of $0.01 \mathrm{M} \mathrm{NaOH}$ and divided between the remaining two solids samples. The leaching bottle was then rinsed with $10 \mathrm{~mL}$ of $0.01 \mathrm{M} \mathrm{NaOH}$, and the wash was split between the remaining two solids samples. The solids were mixed on a shaker table for 15 minutes. The slurry was centrifuged for $5 \mathrm{~min}$ and the supernatant removed. Dilute sodium hydroxide solution ( $0.01 \mathrm{M} ; 15 \mathrm{~mL}$ ) was added to each of the solids, the compacted solids were broken up with a disposable pipette, and the two slurry samples were mixed on a shaker table for 15 minutes. The two slurry samples were centrifuged for $5 \mathrm{~min}$ and the supernatant removed. The wash steps were repeated once more for a total of three washes. Additional $0.01 \mathrm{M} \mathrm{NaOH}$ was used to move the solids from one of the bottles to combine all solids in one bottle. The sample was centrifuged for 5 min and the supernatant removed. After the final wash, the solids were slurried in $~ 2 \mathrm{~mL}$ of DI water and sub-divided for analysis by PSD, XRD, TEM, SEM, a surface area measurement with BET, and a $\mathrm{KOH}$ fusion with subsequent analysis for ICP-OES metals, GEA, Pu, total alpha, total beta, ${ }^{90} \mathrm{Sr}$, and U by KPA.

(a) The contact dose rates of the leached solids were too high to safely conduct transfer to volume-graduated centrifuge tubes to assess the volume of centrifuged solids. 


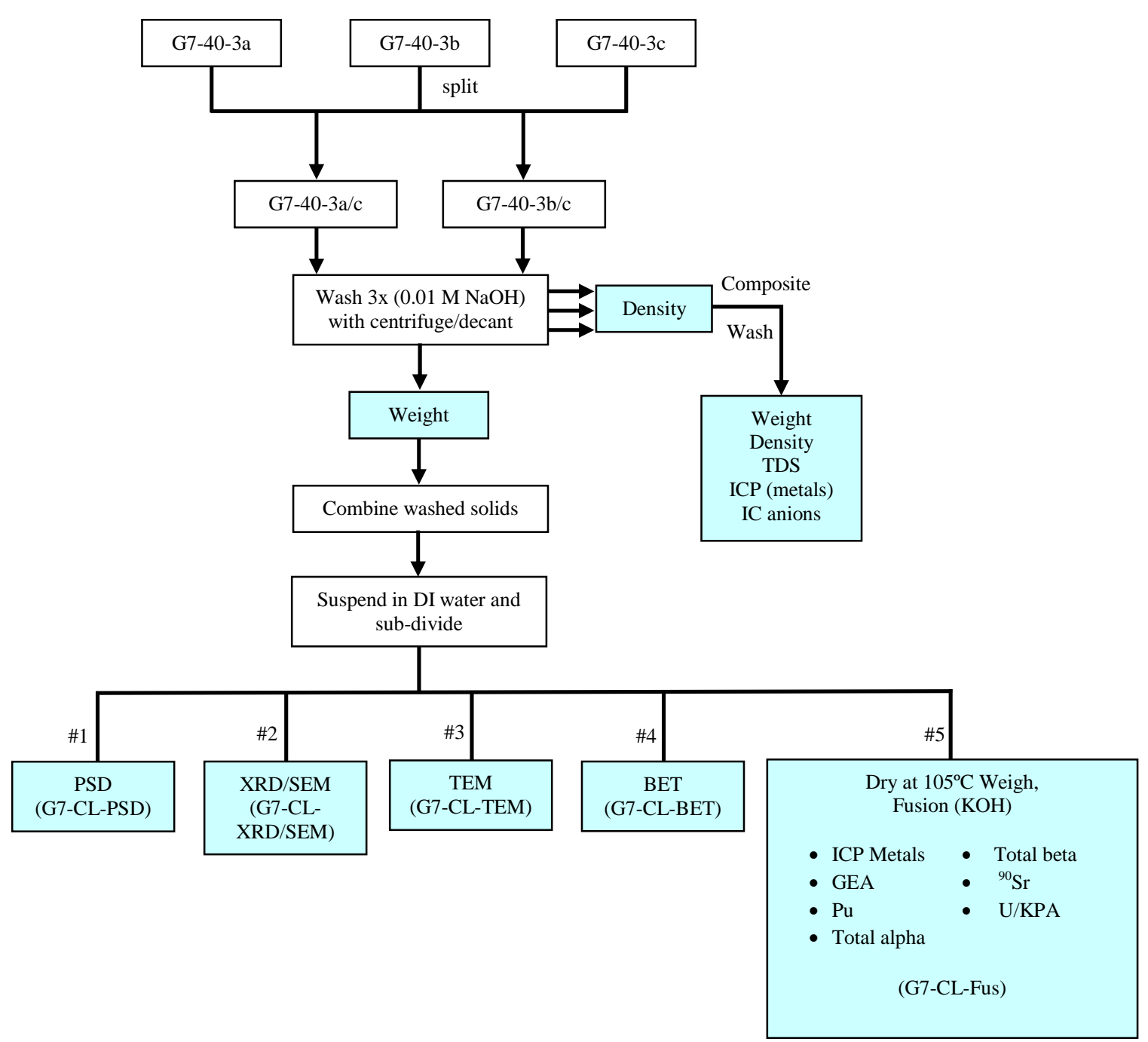

Figure 4.2. Washing, Subdivision, and Analysis Scheme for the Group 7 Caustic-Leached Solids

\subsection{Group 7 Tributyl Phosphate Sludge Parametric Caustic-Leaching Test Results}

The Group 7 waste was anticipated to be high in phosphorus as well as aluminum in the form of gibbsite. Therefore, the parametric leach testing of this waste sample was directed toward understanding gibbsite and phosphorus dissolution in the actual tank waste to understand and subsequently match the dissolution properties to a simulant material. The parametric leaching results and residual solids composition are discussed in the following sections. Data for the figures in this section can be found in Appendix G.

\subsubsection{Time, Temperature, and Hydroxide Effects on Aluminum Dissolution from the Group 7 Solids}

The rate and extent of $\mathrm{Al}$ removal from the washed Group 7 solids were investigated as a function of time, temperature, and free-hydroxide concentration. As indicated in Section 3, the aluminum appears to be a mix of gibbsite and an aluminum-bearing phosphate phase. The aluminum leaching data at 40,60 , 
and $80^{\circ} \mathrm{C}$ at varying free-hydroxide concentrations are plotted in Figure 4.3 through Figure 4.5, respectively. A measure of experimental precision is shown by the triplicate tests conducted at $3 \mathrm{M}$ free hydroxide and at $40^{\circ} \mathrm{C}$ in Figure 4.3. The scatter in the data was within the analytical characterization uncertainty of $\pm 15 \%$.

At the higher temperatures $\left(60\right.$ and $80^{\circ} \mathrm{C}$ ), aluminum dissolution reached a steady-state value. At $40^{\circ} \mathrm{C}$, the amount of $\mathrm{Al}$ dissolved continued increasing throughout the entire sampling period. At $60^{\circ} \mathrm{C}$, the $\mathrm{Al}$ dissolution reached a steady-state value between 4 and 8 hours, except in the case of $1 \mathrm{M} \mathrm{NaOH}$, which had a significant rise in the $\mathrm{Al}$ concentration between 8 and 24 hours, and reached nearly the same final $\mathrm{Al}$ concentration as the sample in $3 \mathrm{M} \mathrm{NaOH}$. The sample in $0.25 \mathrm{M} \mathrm{NaOH}$ only reached $\sim 60 \%$ dissolved $\mathrm{Al}$, much less than the values obtained in 1 and $3 \mathrm{M} \mathrm{NaOH}$. At $80^{\circ} \mathrm{C}$, for the two highest hydroxide concentrations, steady-state was reached between 2 and 4 hours. Between 80 and $90 \%$ of the $\mathrm{Al}$ was dissolved at the higher temperatures, suggesting that a small amount of a caustic-insoluble $\mathrm{Al}$ compound was present, perhaps zeolite as identified by XRD.

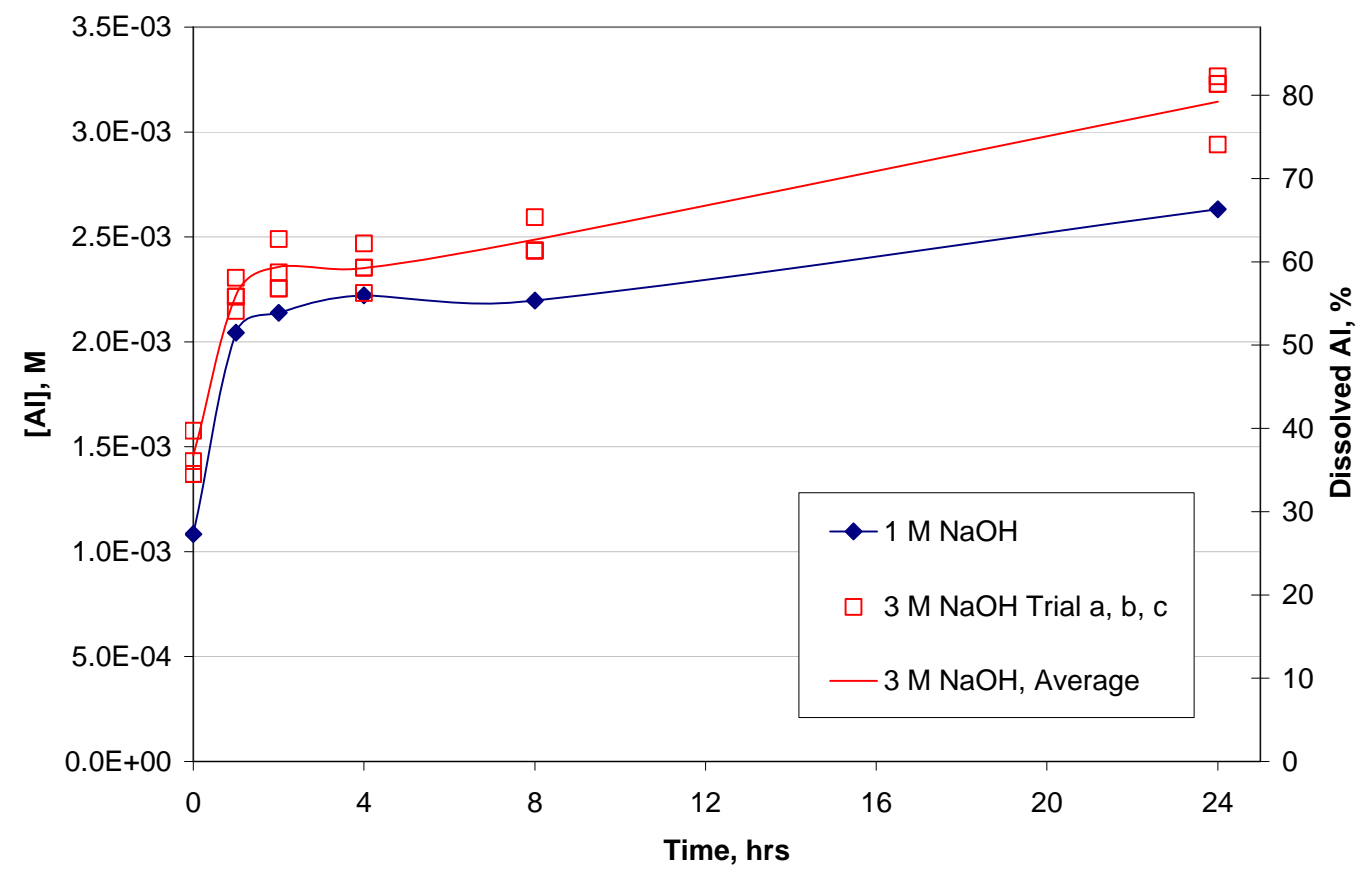

Figure 4.3. Aluminum Concentration and Percent Removed Versus Time at $40^{\circ} \mathrm{C}$ for Leaching of the Group 7 Washed Solids in 1 and $3 \mathrm{M} \mathrm{NaOH}$ 
WTP-RPT-169, Rev 0

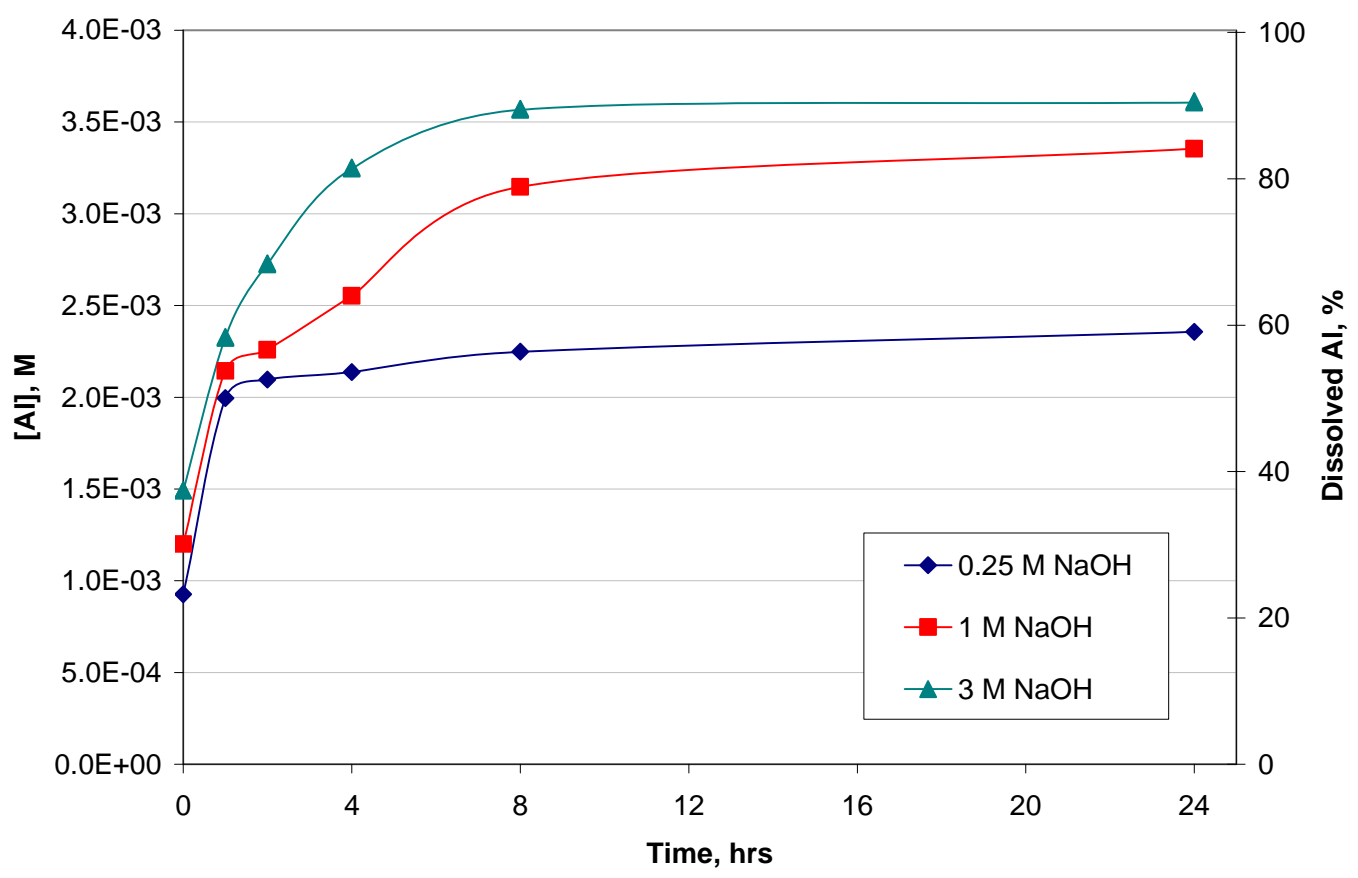

Figure 4.4. Aluminum Concentration and Percent Removed Versus Time at $60^{\circ} \mathrm{C}$ for Leaching of the Group 7 Washed Solids in 0.25, 1, and $3 \mathrm{M} \mathrm{NaOH}$

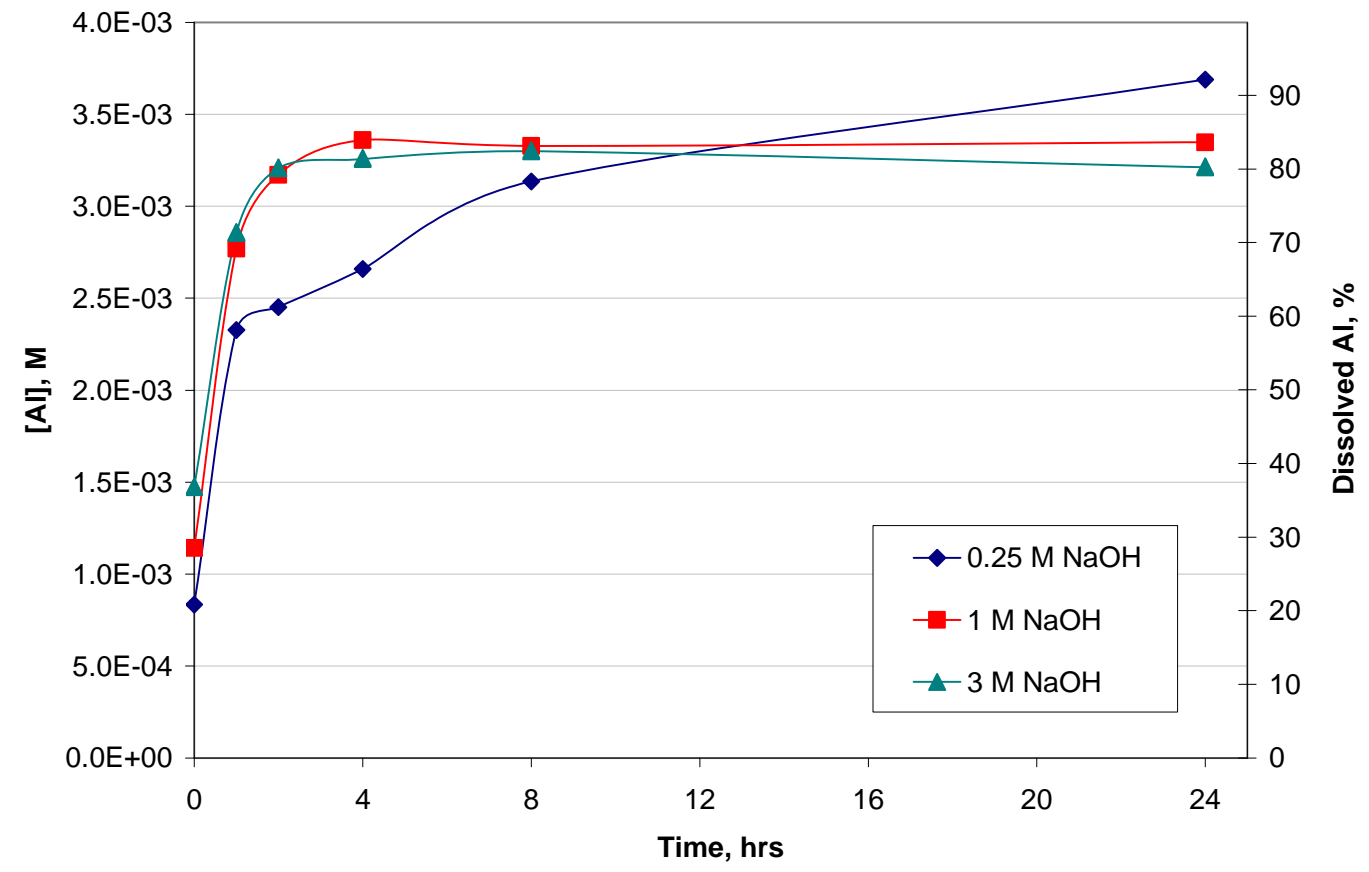

Figure 4.5. Aluminum Concentration and Percent Removed Versus Time at $80^{\circ} \mathrm{C}$ for Leaching of the Group 7 Washed Solids in 0.25 , 1, and $3 \mathrm{M} \mathrm{NaOH}$ 
The same data are re-plotted in Figure 4.6 through Figure 4.8 to show the effect of temperature at constant free-hydroxide concentrations of $0.25,1$, and $3 \mathrm{M} \mathrm{NaOH}$, respectively.

The temperature had a large effect on the gibbsite dissolution rate at lower hydroxide concentrations. In $0.25 \mathrm{M} \mathrm{NaOH}$, the reaction at $60^{\circ} \mathrm{C}$ was slower and much less $\mathrm{Al}$ was removed than at $80^{\circ} \mathrm{C}$, reaching $\sim 60$ and $90 \% \mathrm{Al}$ dissolution, respectively. In $1 \mathrm{M} \mathrm{NaOH}$, approximately the same Al dissolution was achieved at the two higher temperatures, with the dissolution at $40^{\circ} \mathrm{C}$ being $\sim 20 \%$ less. In $3 \mathrm{M} \mathrm{NaOH}$, the samples at all three temperatures reached nearly the same final value ( $\sim 0$ to $90 \%$ ). Note that during all of these tests, there appeared to be two forms of aluminum dissolving. In all these tests, roughly $50 \%$ of the aluminum dissolved rapidly. This initial dissolution was likely due to the dissolution of an aluminum phosphate phase. Subsequently, an additional 30 to $40 \%$ of the aluminum (likely gibbsite) dissolved with extended time. As expected, the data are consistent with faster dissolution at higher temperatures and hydroxide concentrations.

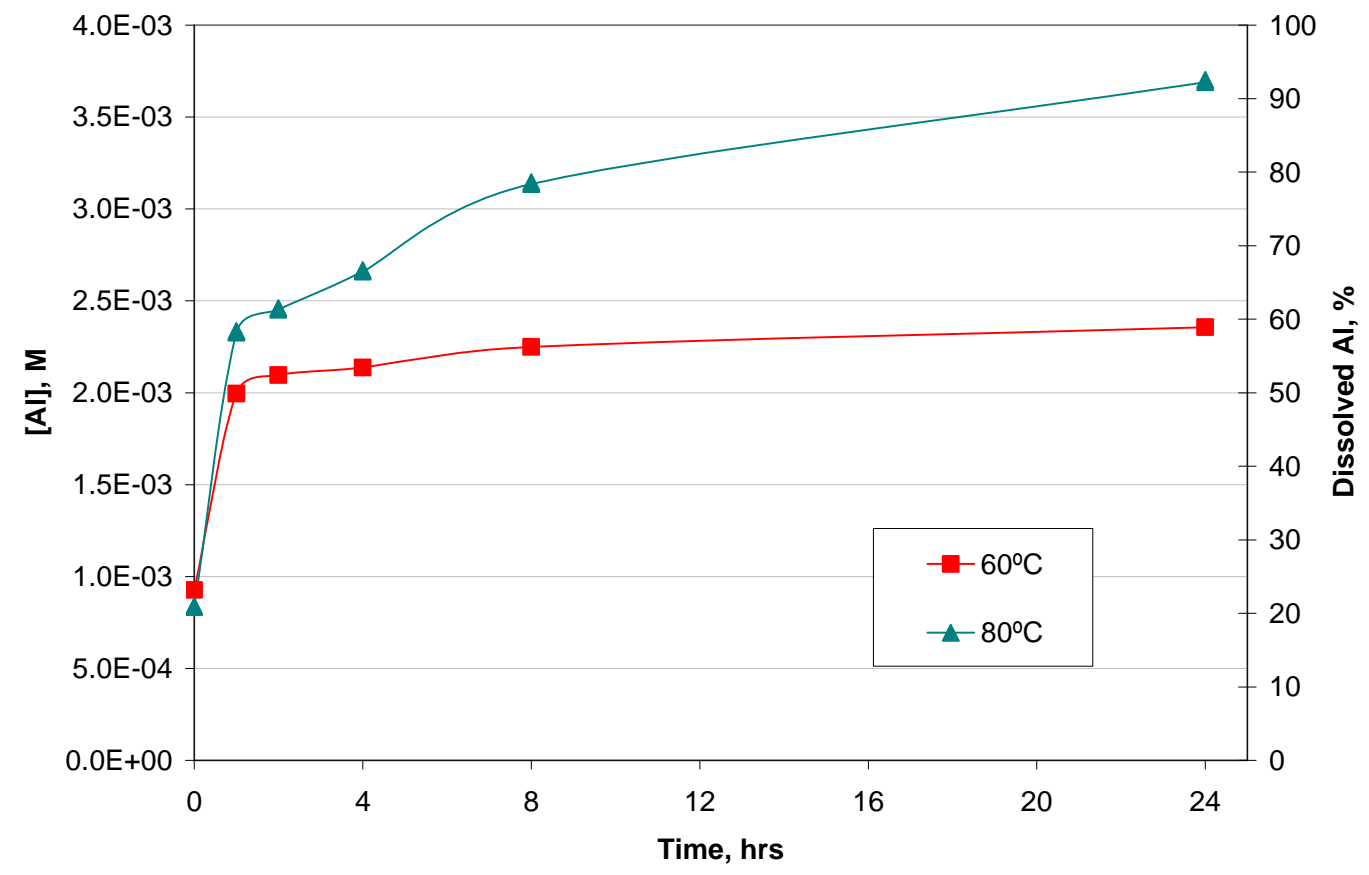

Figure 4.6. Aluminum Concentration and Percent Dissolved in $0.25 \mathrm{M} \mathrm{NaOH}$ 
WTP-RPT-169, Rev 0

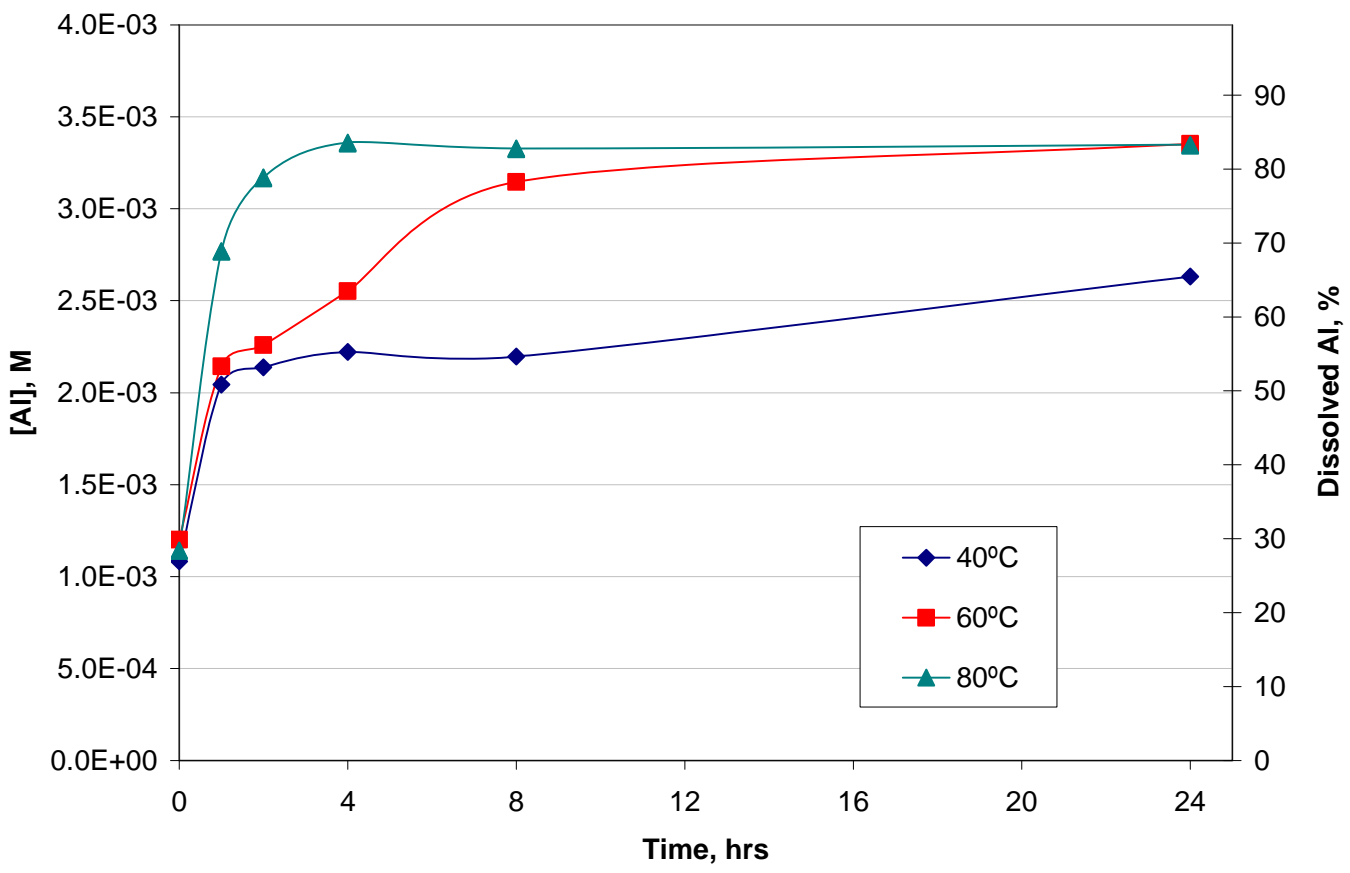

Figure 4.7. Aluminum Concentration and Percent Dissolved in $1 \mathrm{M} \mathrm{NaOH}$

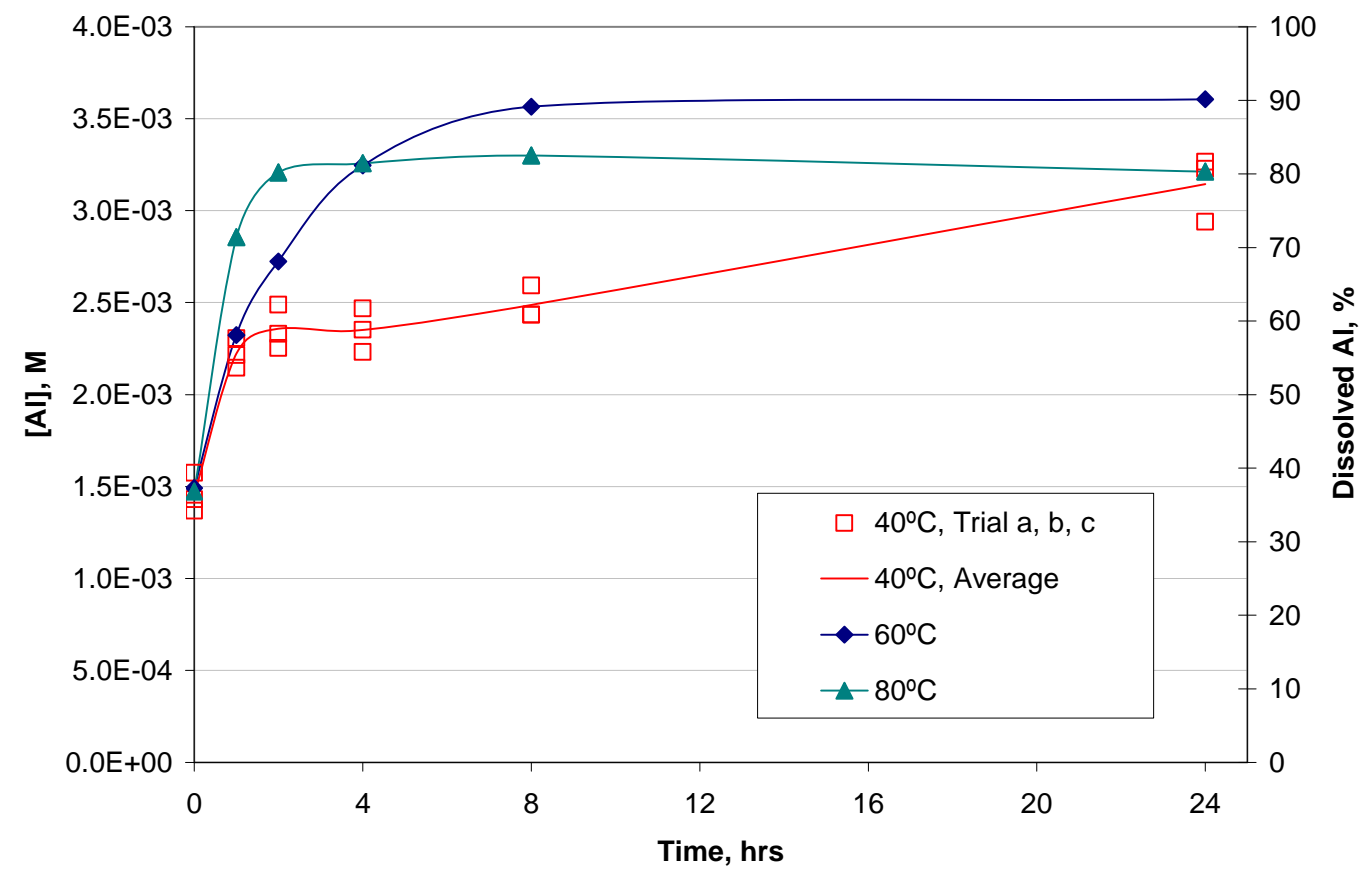

Figure 4.8. Aluminum Concentration and Percent Dissolved in $3 \mathrm{M} \mathrm{NaOH}$ 
WTP-RPT-169, Rev 0

\subsubsection{Time, Temperature, and Hydroxide Effects on Phosphorus Dissolution from the Group 7 Solids}

The rate and extent of P removal from the washed Group 7 solids were investigated as a function of time, temperature, and free-hydroxide concentration. The phosphorus leaching data at 40,60 , and $80^{\circ} \mathrm{C}$ at varying free-hydroxide concentrations are plotted in Figure 4.9 through Figure 4.11, respectively. A measure of experimental precision is shown by the triplicate tests conducted at $3 \mathrm{M}$ free hydroxide and at $40^{\circ} \mathrm{C}$ in Figure 4.9. The scatter in the data was within the analytical characterization uncertainty of $\pm 15 \%$.

Under all conditions, there was rapid transfer of $\mathrm{P}$ to the liquid phase. Even before heating was applied (i.e., at $\mathrm{t}=0$ ), $\sim 50$ to $80 \%$ of the $\mathrm{P}$ was removed from the solid phase. In this respect, the $\mathrm{P}$ behavior was similar to what was observed for the bismuth phosphate sludge (Lumetta et al. 2008). The amount of $\mathrm{P}$ removed before the application of heat was dependent on the hydroxide concentration, with $~ 52 \%$ of the P removed in $0.25 \mathrm{M} \mathrm{NaOH}, 61$ to $69 \%$ of the $\mathrm{P}$ removed in $1 \mathrm{M} \mathrm{NaOH}$, and 71 to $82 \%$ of the $\mathrm{P}$ removed in $3 \mathrm{M} \mathrm{NaOH}$. For all temperatures at all hydroxide concentrations, a steady-state value of $\mathrm{P}$ dissolution was reached in the first hour, with nearly complete P dissolution obtained for all conditions (85 to 95\%). Hydroxide concentration had virtually no effect on the P dissolution once heating was applied. Within the experimental uncertainty, the same amount of $\mathrm{P}$ was dissolved in samples run in $0.25 \mathrm{M} \mathrm{NaOH}$ as in samples run in $3 \mathrm{M} \mathrm{NaOH}$.

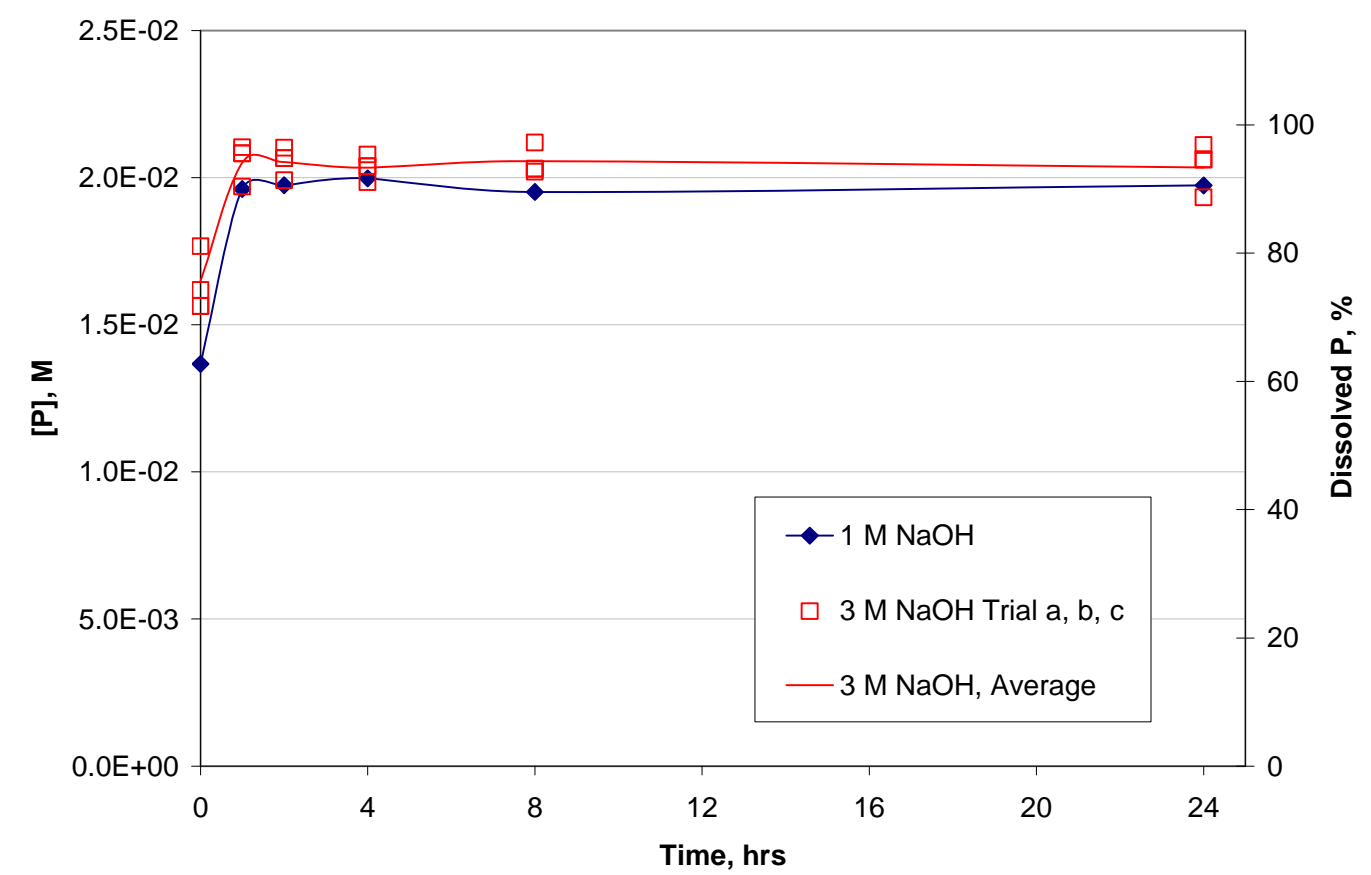

Figure 4.9. Phosphorus Concentration and Percent Removed Versus Time at $40^{\circ} \mathrm{C}$ for Leaching of the Group 7 Washed Solids in 1 and $3 \mathrm{M} \mathrm{NaOH}$ 
WTP-RPT-169, Rev 0

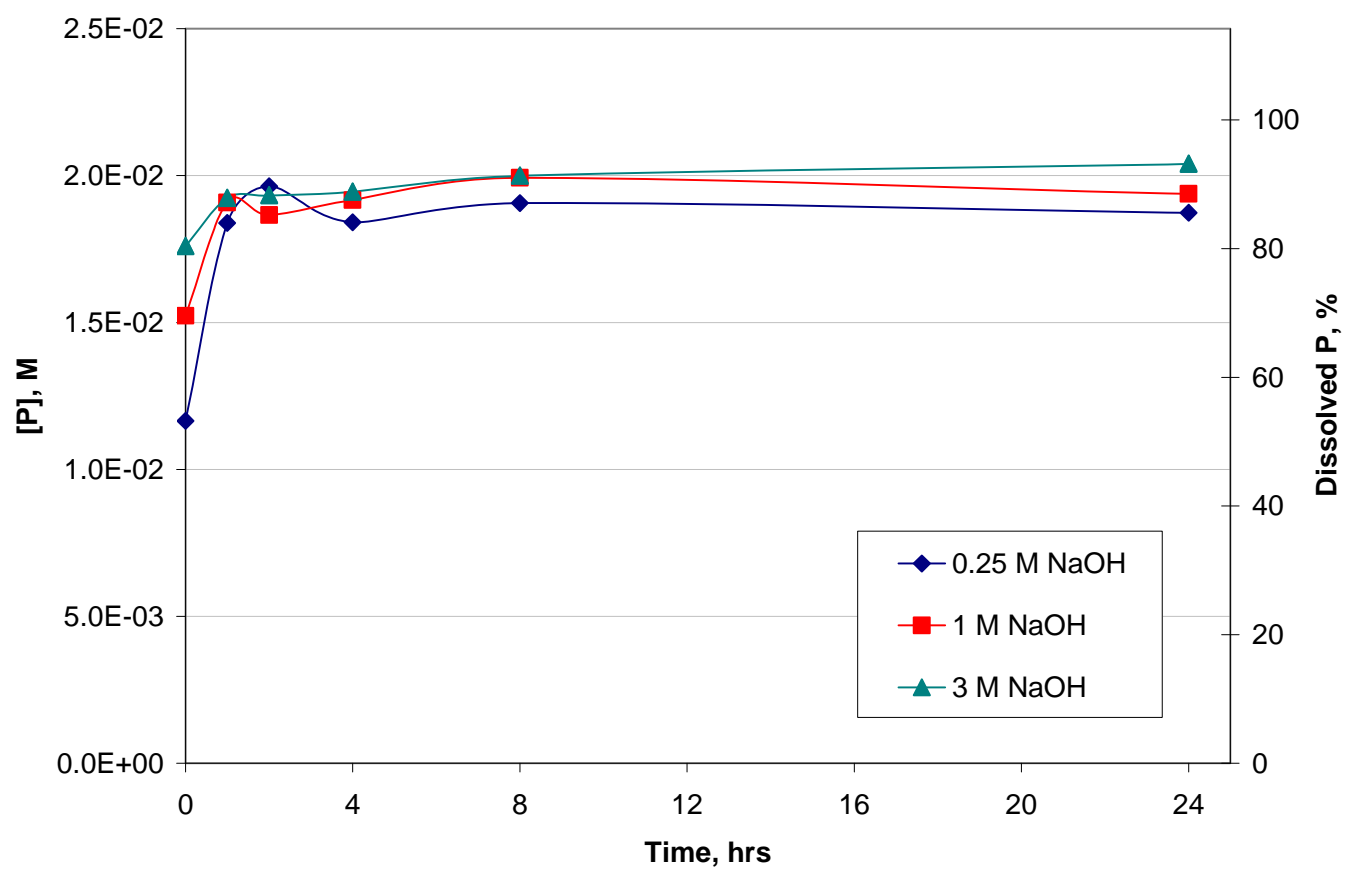

Figure 4.10. Phosphorus Concentration and Percent Removed Versus Time at $60^{\circ} \mathrm{C}$ for Leaching of the Group 7 Washed Solids in $0.25,1$, and $3 \mathrm{M} \mathrm{NaOH}$

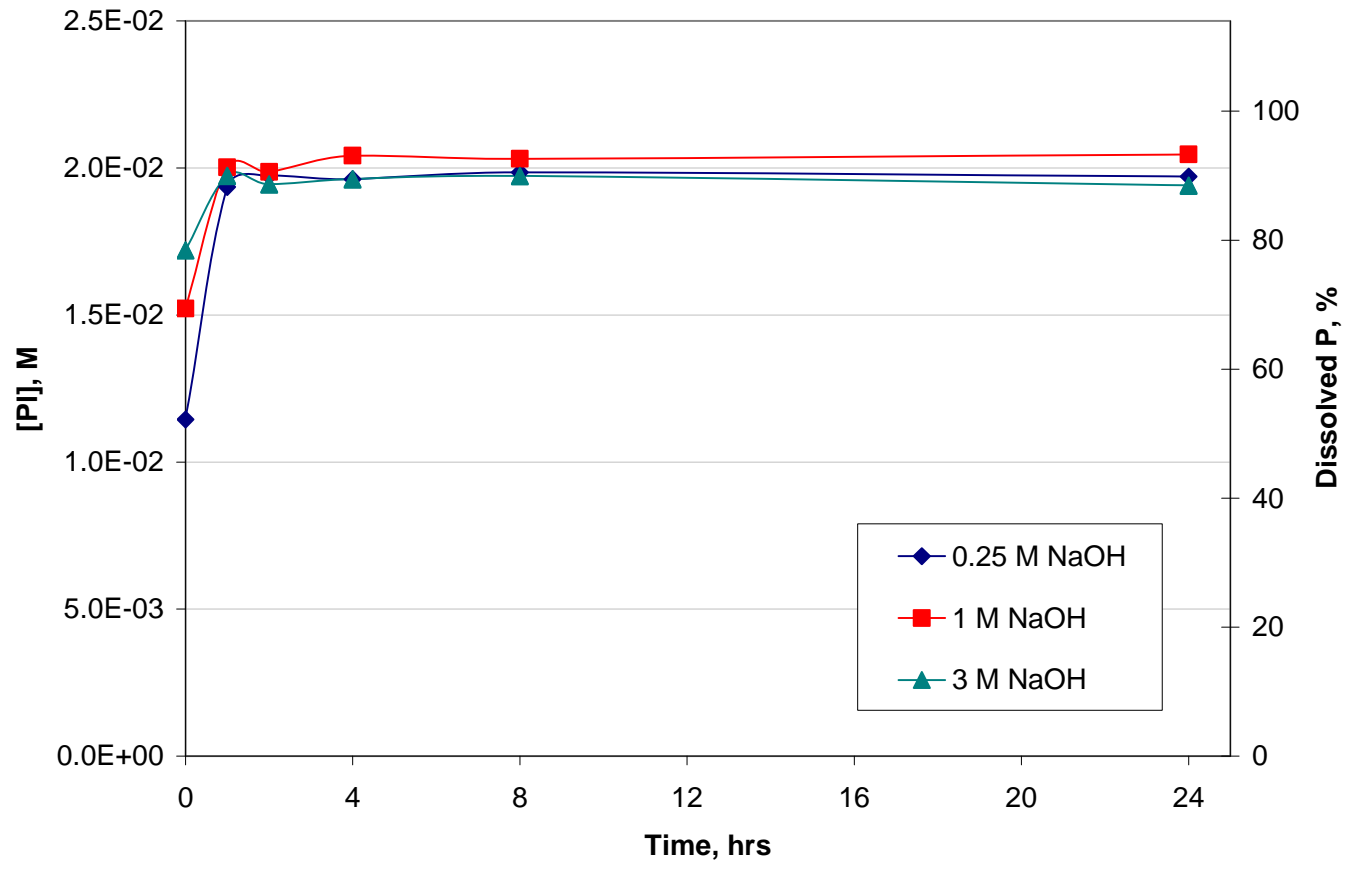

Figure 4.11. Phosphorus Concentration and Percent Removed Versus Time at $80^{\circ} \mathrm{C}$ for Leaching of the Group 7 Washed Solids in 0.25, 1, and $3 \mathrm{M} \mathrm{NaOH}$ 
The same data are re-plotted in Figure 4.12 through Figure 4.14 to show the effect of temperature at constant free-hydroxide concentrations of $0.25,1$, and $3 \mathrm{M} \mathrm{NaOH}$, respectively. The temperature had little influence on the P leaching kinetics. Rapid P removal was observed in all cases, typically with a steady-state value being achieved within 1 hour.

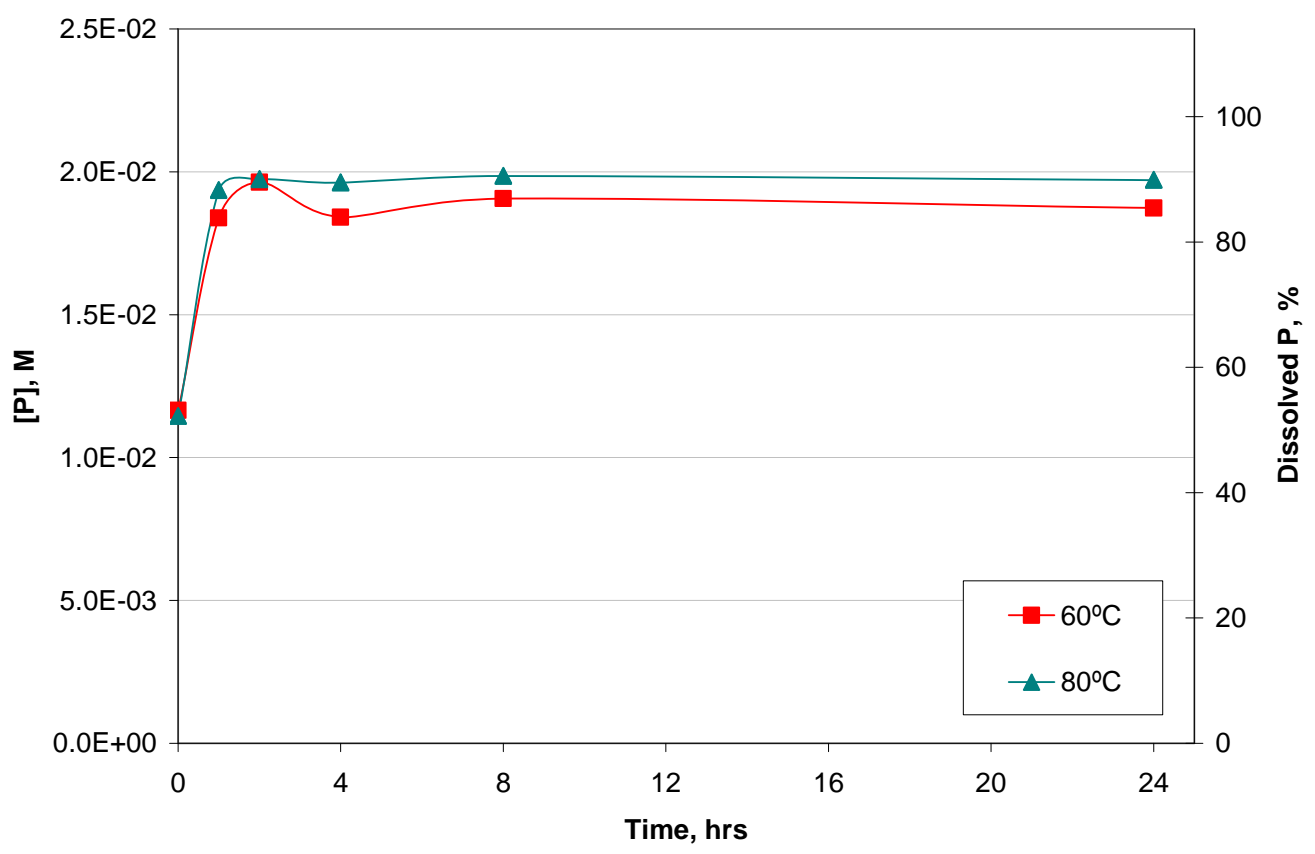

Figure 4.12. Phosphorus Concentration and Percent Removed in $0.25 \mathrm{M} \mathrm{NaOH}$

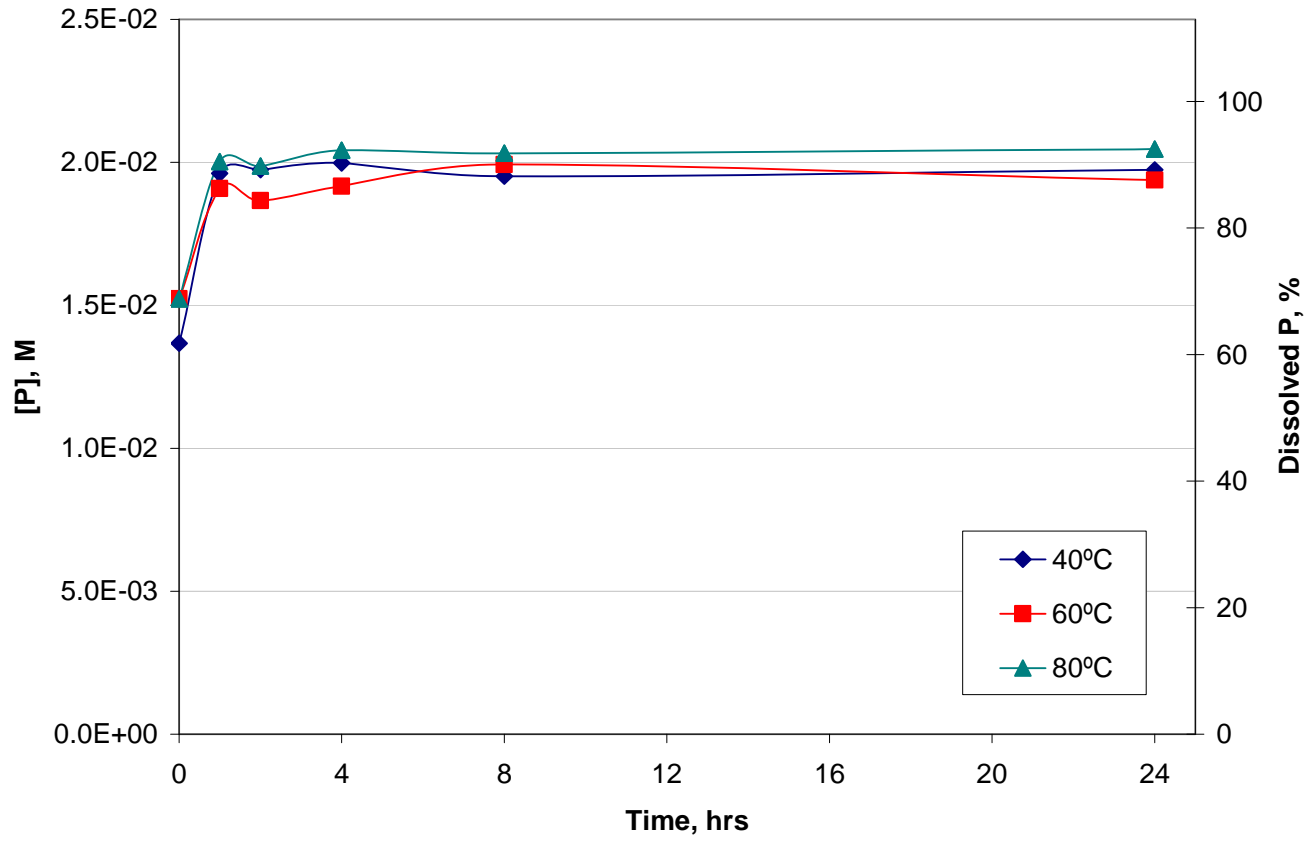

Figure 4.13. Phosphorus Concentration and Percent Removed in $1 \mathrm{M} \mathrm{NaOH}$ 


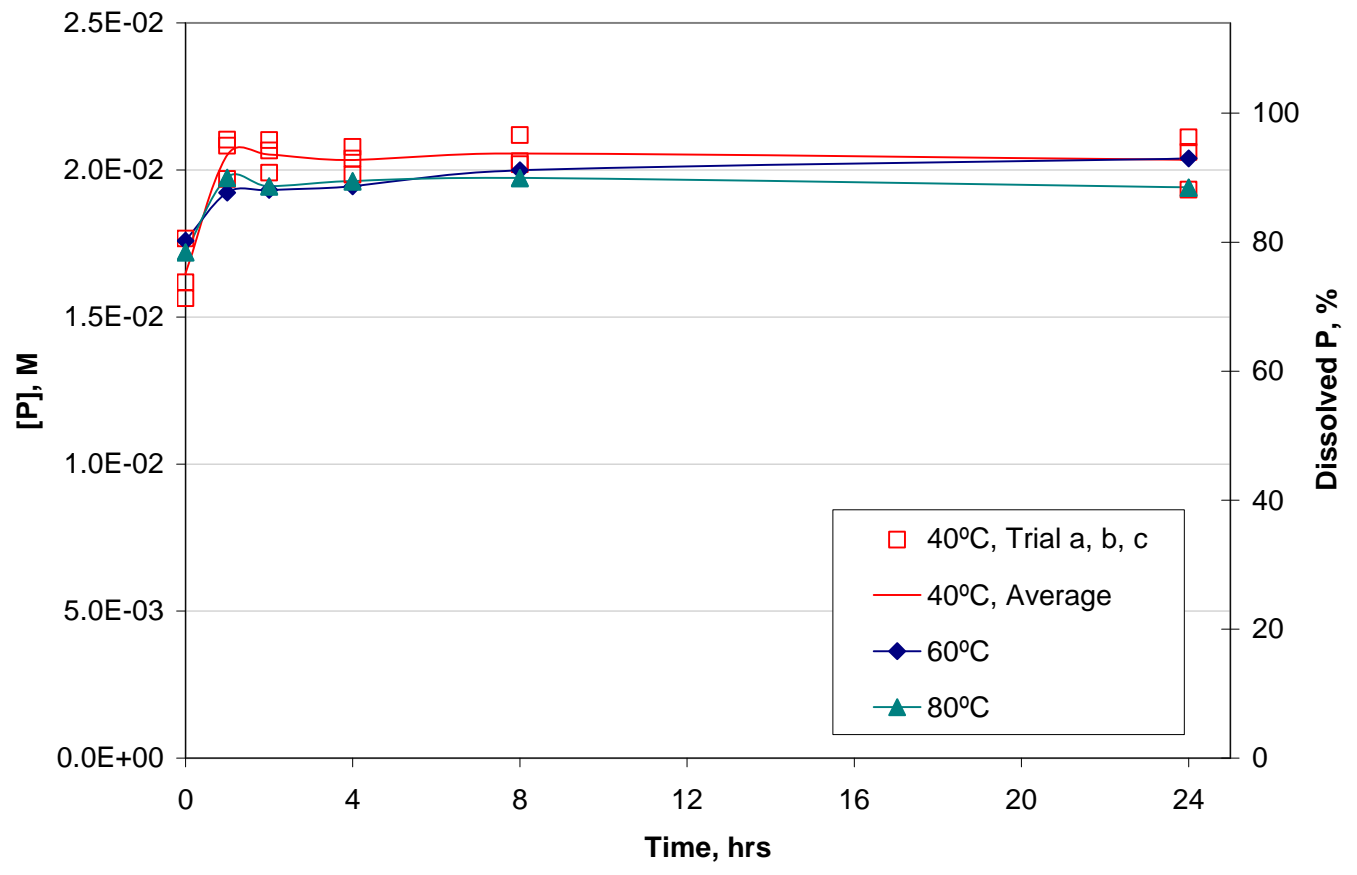

Figure 4.14. Phosphorus Concentration and Percent Removed in $3 \mathrm{M} \mathrm{NaOH}$

\subsubsection{Time, Temperature, and Hydroxide Effects on Uranium Dissolution from the Group 7 Solids}

Figure 4.15 and Figure 4.16 show the effect of $\mathrm{NaOH}$ concentration and temperature on the behavior of uranium under caustic-leaching conditions. Under all conditions, there was an initial rapid transfer of $\mathrm{U}$ to the liquid phase. Before heating was applied (i.e., at $\mathrm{t}=0$ ), 50 to $100 \%$ of the $\mathrm{U}$ was observed to be in the liquid phase. As heat was applied, the uranium re-precipitated, leaving only 12 to $20 \%$ in solution. 
WTP-RPT-169, Rev 0

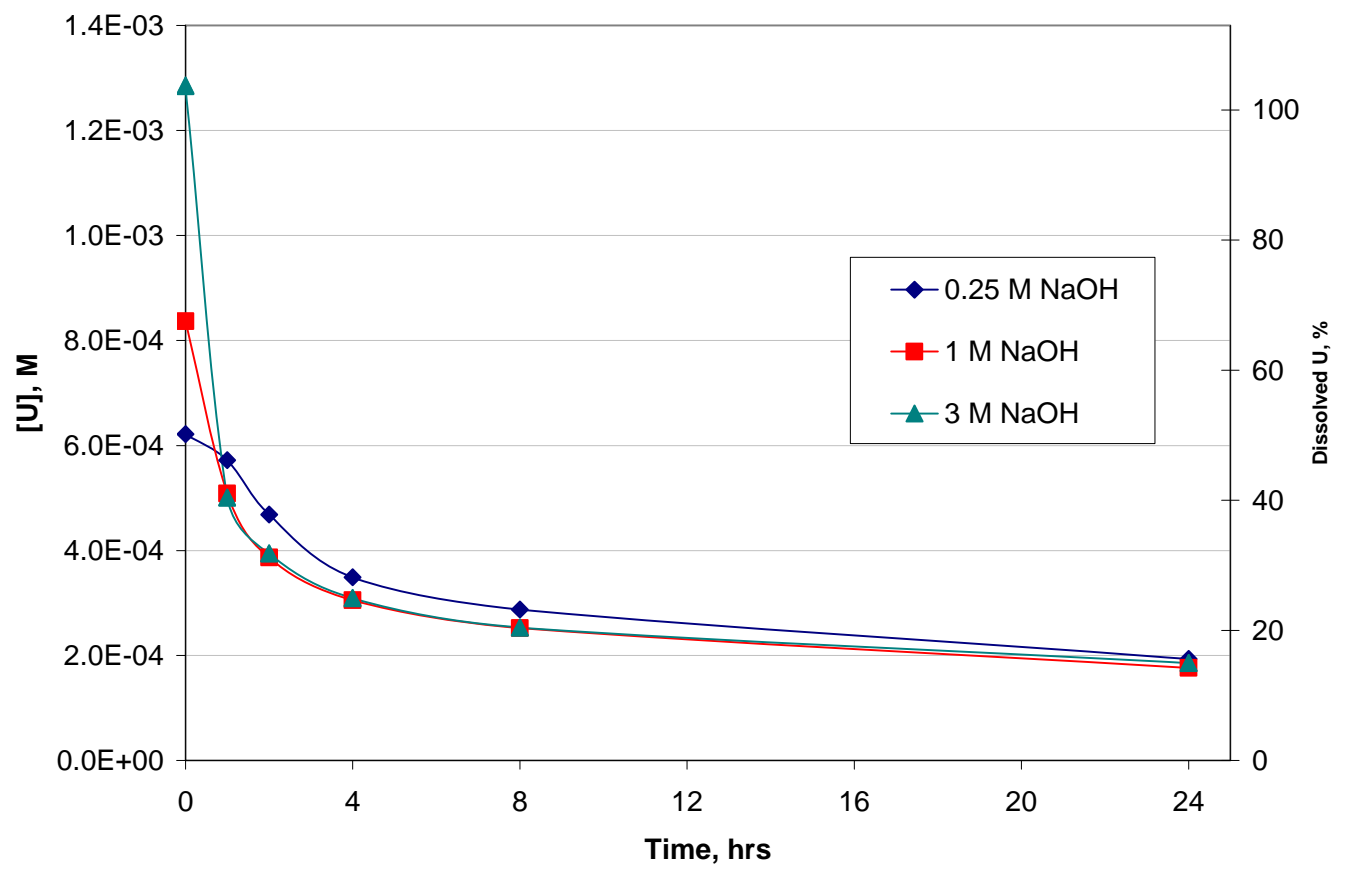

Figure 4.15. Uranium Concentration and Percent Removed Versus Time at $60^{\circ} \mathrm{C}$ for Leaching of the Group 7 Washed Solids in 0.25, 1, and $3 \mathrm{M} \mathrm{NaOH}$

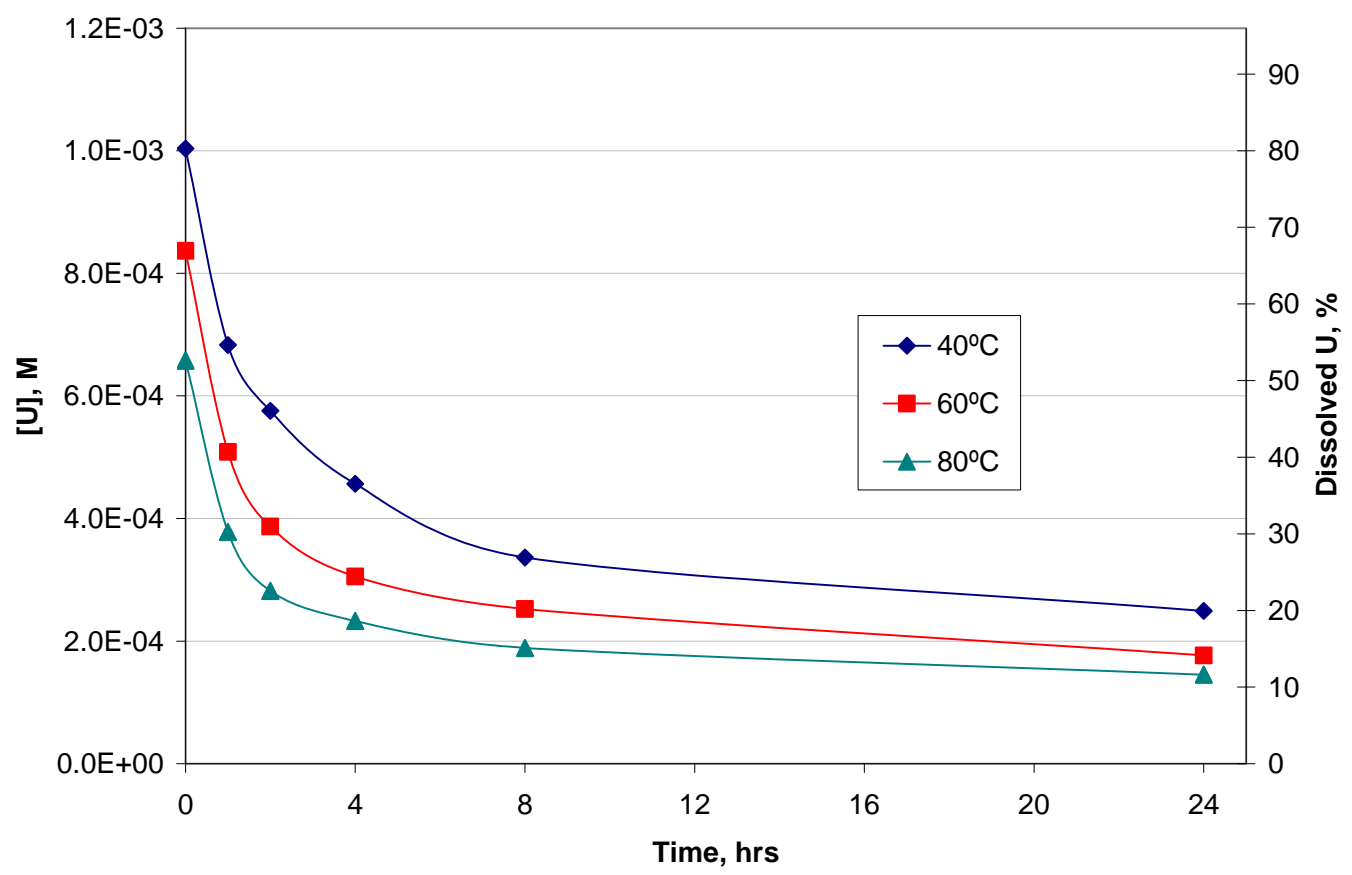

Figure 4.16. Uranium Concentration and Percent Removed in $1 \mathrm{M} \mathrm{NaOH}$ 


\subsubsection{Anions, Silicon, $\mathrm{Cr}$, and Iron Leaching Behavior}

The concentrations of $\mathrm{Cr}, \mathrm{Fe}$, and $\mathrm{Si}$ were measured by ICP-OES. The anionic compositions were also assessed at each sampling period. The Cr concentrations were generally low (on the order of $10^{-5} \mathrm{M}$ ), but appear to generally increase with increasing leaching time. The $\mathrm{Fe}, \mathrm{Si}$, and anion data were generally above the EQL. The Fe, Si, and anion concentrations (fluoride, nitrite, nitrate, and sulfate) in the leachate did not significantly change during the leach testing. The results are summarized in Appendix G.

\subsubsection{Assessment of Final Leaching Conditions}

A summary of the final (24-h) leaching solution chemistry and physical parameters is shown in Table 4.2. The final free-hydroxide and sodium concentrations were at the targeted values within the uncertainty of the analytical methods ( $\pm 15 \%)$. The calculated percentage of phosphorus that was removed at each leaching condition is also shown. Appendix G provides a compilation of the concentrations of $\mathrm{Al}, \mathrm{Cr}, \mathrm{Fe}$, $\mathrm{Na}, \mathrm{P}, \mathrm{Si}$, U, fluoride, nitrite, nitrate, phosphate, and sulfate in the final leaching solutions. The GEA results for ${ }^{60} \mathrm{Co}$ and ${ }^{241} \mathrm{Am}$ were $<\mathrm{MDL}$; the GEA results are also provided in Appendix G.

Table 4.2. Group 7 TBP Sludge Leaching Final (24 hr) Aqueous Phase Conditions

\begin{tabular}{|c|c|c|c|c|c|c|}
\hline $\begin{array}{c}\text { Temp., } \\
{ }^{\circ} \mathrm{C}\end{array}$ & $\begin{array}{c}\text { Density, } \\
\text { g/mL }\end{array}$ & $\begin{array}{c}\text { Free OH, } \\
\text { M }\end{array}$ & $\begin{array}{l}\mathrm{Na}, \\
\mathrm{M}\end{array}$ & $\begin{array}{l}\text { Al, } \\
\text { M }\end{array}$ & $\begin{array}{l}\text { P, } \\
\text { M }\end{array}$ & $\begin{array}{c}\text { Wt \% P } \\
\text { Removed }\end{array}$ \\
\hline 40 & 1.05 & 1.02 & 1.10 & 2.63E-03 & 1.97E-02 & 89.0 \\
\hline 40 trial a & 1.14 & 3.12 & 3.21 & $3.27 \mathrm{E}-03$ & $2.11 \mathrm{E}-02$ & 87.7 \\
\hline 40 trial b & 1.14 & 3.00 & 3.04 & $2.94 \mathrm{E}-03$ & 1.93E-02 & 88.3 \\
\hline 40 trial c & 1.14 & 3.19 & 3.17 & 3.23E-03 & 2.06E-02 & 94.6 \\
\hline 60 & 1.02 & 0.24 & 0.28 & 2.36E-03 & $1.87 \mathrm{E}-02$ & 85.5 \\
\hline 60 & 1.05 & 1.01 & 1.01 & 3.35E-03 & $1.94 \mathrm{E}-02$ & 88.5 \\
\hline 60 & 1.13 & 3.02 & 3.00 & 3.61E-03 & 2.04E-02 & 93.3 \\
\hline 80 & 1.02 & 0.25 & 0.30 & 3.69E-03 & $1.97 \mathrm{E}-02$ & 90.0 \\
\hline 80 & 1.05 & 1.05 & 1.04 & 3.35E-03 & 2.05E-02 & 92.5 \\
\hline 80 & 1.13 & 3.05 & 2.95 & $3.21 \mathrm{E}-03$ & 1.94E-02 & 88.4 \\
\hline
\end{tabular}

\subsubsection{Comparison of Initial and Caustic-Leached and Washed Solids Properties}

The Group 7 solids that had been caustic leached at $40^{\circ} \mathrm{C}$ in $3 \mathrm{M} \mathrm{NaOH}$ for 24 hours were combined and washed in preparation for analysis. The wash solution composition and the washed solids chemical, radiochemical, particle size, and crystal habit are discussed.

\subsubsection{Leached-Solids Wash Solution}

After the third washing of the caustic-leached Group 7 solids, the wet centrifuged solids mass was $4.5 \mathrm{~g}$. The densities of the three sequential wash solutions were $1.023 \mathrm{~g} / \mathrm{mL}, 1.003 \mathrm{~g} / \mathrm{mL}$, and $1.003 \mathrm{~g} / \mathrm{mL}$, respectively. The composite wash-solution (126.8 mL volume) density, ICP metals, and anion composition are shown in Table 4.3. 
The analysis of the wash solution by ICP-OES for metal content indicated the presence of primarily Na, $\mathrm{Al}$, and Si. There was no evidence of additional dissolution of these species during the washing process.

Table 4.3. Group 7 Solids Wash Solution Composition and Density

\begin{tabular}{|c|c|c|c|c|c||}
\hline Analyte & $\mu \mathbf{g} / \mathbf{m L}$ & Analyte & $\mu \mathbf{g} / \mathbf{m L}$ & Density Measurement & $\mathbf{g} / \mathbf{m L}$ \\
\hline $\mathrm{Al}$ & 5.45 & $\mathrm{Si}$ & $<0.85$ & Density & 1.007 \\
\cline { 1 - 4 } $\mathrm{Cr}$ & {$[0.28]$} & nitrate & {$[5.10]$} & & \\
\cline { 1 - 3 } $\mathrm{Na}$ & 3,665 & phosphate & 126 & & \\
\cline { 1 - 4 } $\mathrm{P}$ & {$[39.4]$} & sulfate & {$[7.40]$} & & \\
\hline
\end{tabular}

\subsubsection{Chemical and Radiochemical Composition}

The initial composition of washed solids (before caustic leaching) is provided in Table 4.4 along with selected results from the initial characterization study. The solids composition after leaching in $3 \mathrm{M}$ $\mathrm{NaOH}$ at $40^{\circ} \mathrm{C}$ for 24 hours and washing is also shown in Table 4.4. Both the initial solids for characterization and the "before leaching" material had been extensively washed, i.e., little or no salt entrainment was expected (except for $\mathrm{NaOH}$ from the washing liquid). The composition of the initial characterization sample was generally consistent with that for the "before leaching" material.

Table 4.4. Group 7 TBP Sludge Leached Solids Composition and Leach Factors (Dry Mass Basis)

\begin{tabular}{|c|c|c|c|c|}
\hline Analyte & $\begin{array}{c}\text { Avg. Initial } \\
\text { Charac. } \\
\mu g / g \\
\text { (ASR 8108) }\end{array}$ & $\begin{array}{c}\text { Avg. Before } \\
\text { Leaching, } \\
\mu g / g \\
\text { (ASR 8144) }\end{array}$ & $\begin{array}{c}\text { Avg. After } \\
\text { Leaching, } \\
\mu g / g \\
\text { (ASR 8144) }\end{array}$ & $\begin{array}{c}\text { Observed } \\
\text { Leach } \\
\text { Factor }\end{array}$ \\
\hline $\mathrm{Al}$ & 16,000 & 15,100 & {$[6,550]$} & 0.79 \\
\hline B & [115] & $<33.7$ & $<31.452$ & -- \\
\hline $\mathrm{Bi}$ & 5,710 & 7,095 & 13,950 & -- \\
\hline $\mathrm{Cd}$ & $<7.7$ & [43] & [66] & 0.25 \\
\hline $\mathrm{Fe}$ & 140,000 & 165,500 & 331,000 & -- \\
\hline $\mathrm{Mn}$ & 884 & 990 & 1,975 & -- \\
\hline $\mathrm{Na}$ & 130,500 & 150,000 & {$[32,500]$} & 0.89 \\
\hline $\mathrm{P}$ & 107,500 & 124,000 & 18,400 & 0.93 \\
\hline $\mathrm{S}$ & [875] & $<1,353$ & $<1347.953$ & -- \\
\hline $\mathrm{Si}$ & 7,285 & 9,680 & {$[8,250]$} & 0.58 \\
\hline $\mathrm{Sr}$ & 3,905 & 4,670 & 9,165 & -- \\
\hline $\mathrm{U}$ & 113,000 & 125,500 & 217,500 & 0.15 \\
\hline $\mathrm{Zn}$ & 687 & 905 & 749 & 0.59 \\
\hline $\mathrm{Zr}$ & $<9.3$ & [30] & [120] & -- \\
\hline U KPA & 114,500 & 134,157 & 227,641 & 0.17 \\
\hline${ }^{60} \mathrm{Co}$ & $2.11 \mathrm{E}-2$ & 1.65E-02 & $4.65 \mathrm{E}-02$ & -- \\
\hline${ }^{90} \mathrm{Sr}$ & $7.41 \mathrm{E}+2$ & $9.36 \mathrm{E}+02$ & 1863.46 & -- \\
\hline${ }^{137} \mathrm{Cs}$ & $3.64 \mathrm{E}+1$ & $4.83 \mathrm{E}+01$ & $1.10 \mathrm{E}+00$ & 0.99 \\
\hline${ }^{154} \mathrm{Eu}$ & $5.90 \mathrm{E}-2$ & 7.07E-02 & $1.40 \mathrm{E}-01$ & 0.03 \\
\hline${ }^{155} \mathrm{Eu}$ & $<5 \mathrm{E}-2$ & 7.58E-02 & 8.89E-02 & 0.42 \\
\hline${ }^{238} \mathrm{Pu}$ & $5.63 \mathrm{E}-3$ & 4.49E-03 & 1.09E-02 & -- \\
\hline
\end{tabular}


WTP-RPT-169, Rev 0

Table 4.4 (contd)

\begin{tabular}{|c|c|c|c|c|}
\hline Analyte & $\begin{array}{c}\text { Avg. Initial } \\
\text { Charac. } \\
\mu g / g \\
\text { (ASR 8108) }\end{array}$ & $\begin{array}{l}\text { Avg. Before } \\
\text { Leaching, } \\
\mu \mathrm{g} / \mathrm{g} \\
\text { (ASR 8144) }\end{array}$ & $\begin{array}{l}\text { Avg. After } \\
\text { Leaching, } \\
\mu g / g \\
\text { (ASR 8144) }\end{array}$ & $\begin{array}{c}\text { Observed } \\
\text { Leach } \\
\text { Factor }\end{array}$ \\
\hline${ }^{239+240} \mathrm{Pu}$ & $1.95 \mathrm{E}-1$ & $2.51 \mathrm{E}-01$ & $5.00 \mathrm{E}-01$ & -- \\
\hline${ }^{241} \mathrm{Am}$ & $8.68 \mathrm{E}-2$ & $<1$.E-1 & $2.32 \mathrm{E}-01$ & -- \\
\hline total alpha & $3.00 \mathrm{E}-1$ & $4.57 \mathrm{E}-01$ & $1.04 \mathrm{E}+00$ & -- \\
\hline total beta & $1.57 \mathrm{E}+3$ & $1.95 \mathrm{E}+03$ & $3.72 \mathrm{E}+03$ & -- \\
\hline \multicolumn{5}{|l|}{ Opportunistic } \\
\hline $\mathrm{Ag}$ & {$[26]$} & $<5.922$ & $<6.127$ & -- \\
\hline As & $<104$ & $<153.968$ & $<159.304$ & -- \\
\hline $\mathrm{Ba}$ & 289 & 358 & 726 & -- \\
\hline $\mathrm{Be}$ & {$[0.66]$} & {$[0.38]$} & {$[0.39]$} & 0.50 \\
\hline $\mathrm{Ca}$ & {$[16,000]$} & {$[18,000]$} & {$[37,000]$} & -- \\
\hline $\mathrm{Ce}$ & [115] & [93] & [235] & -- \\
\hline Co & [25] & [30] & [60] & -- \\
\hline $\mathrm{Cr}$ & 718 & 829 & 1,370 & 0.19 \\
\hline $\mathrm{Cu}$ & 142 & 287 & 315 & 0.46 \\
\hline Dy & $<7.7$ & $<11.449$ & $<11.686$ & -- \\
\hline $\mathrm{Eu}$ & {$[3.4]$} & $<1.461$ & [2.5] & -- \\
\hline $\mathrm{K}$ & na & na & na & na \\
\hline $\mathrm{La}$ & {$[52]$} & [88] & 181 & -- \\
\hline $\mathrm{Li}$ & 87.3 & 113 & 135 & 0.41 \\
\hline $\mathrm{Mg}$ & 3,120 & 3,630 & 7,030 & 0.05 \\
\hline Mo & $<19$ & $<28.425$ & $<29.410$ & -- \\
\hline $\mathrm{Nd}$ & 179 & [103] & {$[170]$} & 0.19 \\
\hline $\mathrm{Pb}$ & 2,910 & 3,505 & 6,425 & 0.10 \\
\hline $\mathrm{Pd}$ & $<17$ & $<25.267$ & $<26.142$ & -- \\
\hline $\mathrm{Rh}$ & $<35$ & $<51.323$ & $<53.101$ & -- \\
\hline $\mathrm{Ru}$ & $<18$ & {$[120]$} & [210] & 0.14 \\
\hline $\mathrm{Sb}$ & $<82$ & $<122.385$ & $<126.626$ & -- \\
\hline Se & $<292$ & $<434.269$ & $<449.318$ & -- \\
\hline Sn & $<66$ & $<98.698$ & $<102.118$ & -- \\
\hline $\mathrm{Ta}$ & $<61$ & $<78.958$ & $<81.694$ & -- \\
\hline $\mathrm{Te}$ & [82] & $<102.645$ & $<106.202$ & -- \\
\hline Th & $<22$ & [215] & 519 & -- \\
\hline $\mathrm{Ti}$ & 371 & 379 & 849 & -- \\
\hline $\mathrm{Tl}$ & $<80$ & $<118.437$ & $<122.541$ & -- \\
\hline $\mathrm{V}$ & $<8.5$ & [22] & [16] & 0.64 \\
\hline $\mathrm{W}$ & $<56$ & $<82.906$ & $<85.779$ & -- \\
\hline $\mathrm{Y}$ & 29.7 & 32.8 & 64.4 & 0.04 \\
\hline $\begin{array}{l}\text { Radionuclide ref } \\
\text { Radionuclide ref }\end{array}$ & $\begin{array}{l}\text { date for ASR } \\
\text { date for ASR } \varepsilon\end{array}$ & $\begin{array}{l}\text { 8: November 5, } \\
\text { 4: April 9, } 2008\end{array}$ & & \\
\hline
\end{tabular}


As a comparison, two methods of determining the percent leached were performed. Method 1 used the concentration of the analytes in the final leachate solutions and the concentration in the final leached solids. Method 2 used the concentrations in the initial and final solids and the "concentration factor" method.

For the first method, the mass of residual solids in each of the three samples treated at $40^{\circ} \mathrm{C}$ in $3 \mathrm{M} \mathrm{NaOH}$ was first determined. These three solids samples were combined, washed, and then slurried in water. A sample of this slurry was dried to determine the wt\% UDS. The total mass of solids was determined from the slurry mass and wt\% UDS. This number was then divided by three to obtain the average mass of dried solids in each of the three samples of leached solids. This mass was then multiplied by the concentration of each component in the final solids to determine the mass (in $\mu \mathrm{g}$ ) of the component in each leached sample. The leach factor was then calculated by dividing the mass of the component in the leachate solution $\left(\mathrm{W}_{\mathrm{L}}\right)$ by the total mass of the component in each sample, calculated from the mass of each in the final solids and leachate solution (sum of $\mathrm{W}_{\mathrm{L}}$ and weight in the final samples [ $\left.\mathrm{W}_{\mathrm{FS}}\right]$ ) as shown in Equation 4.1.

$$
L F_{\text {triplicate_samples }}=\left(\frac{W_{L}}{W_{L}+W_{F S}}\right)
$$

The average leach factor from the three samples was calculated. The average of the concentration of each component in the final leachates from the triplicate runs was divided by the average leach factor of the triplicate samples to obtain an average corrected concentration (CC) that corresponds to the concentration that would be obtained if $100 \%$ of the sample had dissolved. The weight of each component in the leachate solutions is divided by the average corrected concentration to determine the leach factors as shown in Equation 4.2.

$$
L F_{1}=\left(\frac{W_{L}}{C C}\right)
$$

The second method is the same that was previously reported in Fiskum et al. (2008). The analysis of the leachate solutions showed that $\mathrm{Bi}, \mathrm{Fe}, \mathrm{Mn}, \mathrm{Sr},{ }^{154} \mathrm{Eu},{ }^{241} \mathrm{Am},{ }^{90} \mathrm{Sr},{ }^{239+240} \mathrm{Pu}$, and ${ }^{238} \mathrm{Pu}$ were not dissolved by caustic leaching. The relative concentration factor (CF) of these analytes averaged 2.04 in the final leached solids, based on the ratio of the analyte concentrations after leaching to the analyte concentrations before leaching. This term was used to determine the specific analyte leach factors according to Equation 4.3:

$$
L F_{2}=1-\left(\frac{C_{L}}{C_{W} \times 2.04}\right)
$$

where $\mathrm{LF}_{2}$ is the caustic-leach factor, $\mathrm{C}_{\mathrm{L}}$ is the leached analyte concentration, and $\mathrm{C}_{\mathrm{W}}$ is the washed analyte concentration.

Results from the two methods are given in Table 4.5. For most of the samples, the CF method gave larger values of fraction removed, on the order of 10 to $15 \%$ higher values. All values of percent leached 
plotted in this section and shown in Table 4.2 and Table 4.4 were calculated using method two, the "CF" method.

Extended (24-hr) leach times did not mobilize Sr, Mn, or Pu to the aqueous phase. Consistent with previous leaching tests with Hanford sludge solids, most (99\%) of the ${ }^{137} \mathrm{Cs}$ was dissolved and would be routed to the LAW PTF.

Approximately $47 \%$ of the metals mass dissolved with a 24-hr leach time. As shown in Figure 4.17, in this case, iron and uranium were the predominant residual metals, and iron would be expected to become the limiting component of the HLW glass loading.

Table 4.5. Group 7 TBP Sludge Aluminum and Phosphorus Leach Factors

\begin{tabular}{|c|c|c|c|c|c|c|}
\hline \multirow{2}{*}{$\begin{array}{l}\text { Temp., } \\
{ }^{\circ} \mathrm{C}\end{array}$} & \multirow{2}{*}{$\begin{array}{c}\text { Free } \mathbf{O H} \text {, } \\
\mathbf{M}\end{array}$} & \multirow{2}{*}{$\begin{array}{c}\mathrm{Na}, \\
\mathrm{M}\end{array}$} & \multicolumn{2}{|c|}{$\begin{array}{l}\text { Fraction Removed } \\
\text { Based on final } \\
\text { solids/leachate } \\
\text { solution (Method 1) }\end{array}$} & \multicolumn{2}{|c|}{$\begin{array}{l}\text { Fraction Removed } \\
\text { Based on initial/final } \\
\text { solids } \\
\text { (“concentration } \\
\text { factor” method; } \\
\text { Method 2) }\end{array}$} \\
\hline & & & Al & $\mathbf{P}$ & Al & $\mathbf{P}$ \\
\hline 40 & 1.02 & 1.10 & 0.55 & 0.83 & 0.65 & 0.89 \\
\hline 40 trial a & 3.12 & 3.21 & 0.84 & 0.93 & 0.75 & 0.88 \\
\hline 40 trial b & 3.00 & 3.04 & 0.83 & 0.93 & 0.74 & 0.88 \\
\hline 40 trial c & 3.19 & 3.17 & 0.84 & 0.93 & 0.81 & 0.95 \\
\hline 60 & 0.24 & 0.28 & 0.50 & 0.80 & 0.59 & 0.86 \\
\hline 60 & 1.01 & 1.01 & 0.71 & 0.82 & 0.84 & 0.88 \\
\hline 60 & 3.02 & 3.00 & 0.76 & 0.87 & 0.91 & 0.93 \\
\hline 80 & 0.25 & 0.30 & 0.78 & 0.84 & 0.93 & 0.90 \\
\hline 80 & 1.05 & 1.04 & 0.70 & 0.86 & 0.83 & 0.93 \\
\hline 80 & 3.05 & 2.95 & 0.67 & 0.82 & 0.80 & 0.88 \\
\hline
\end{tabular}




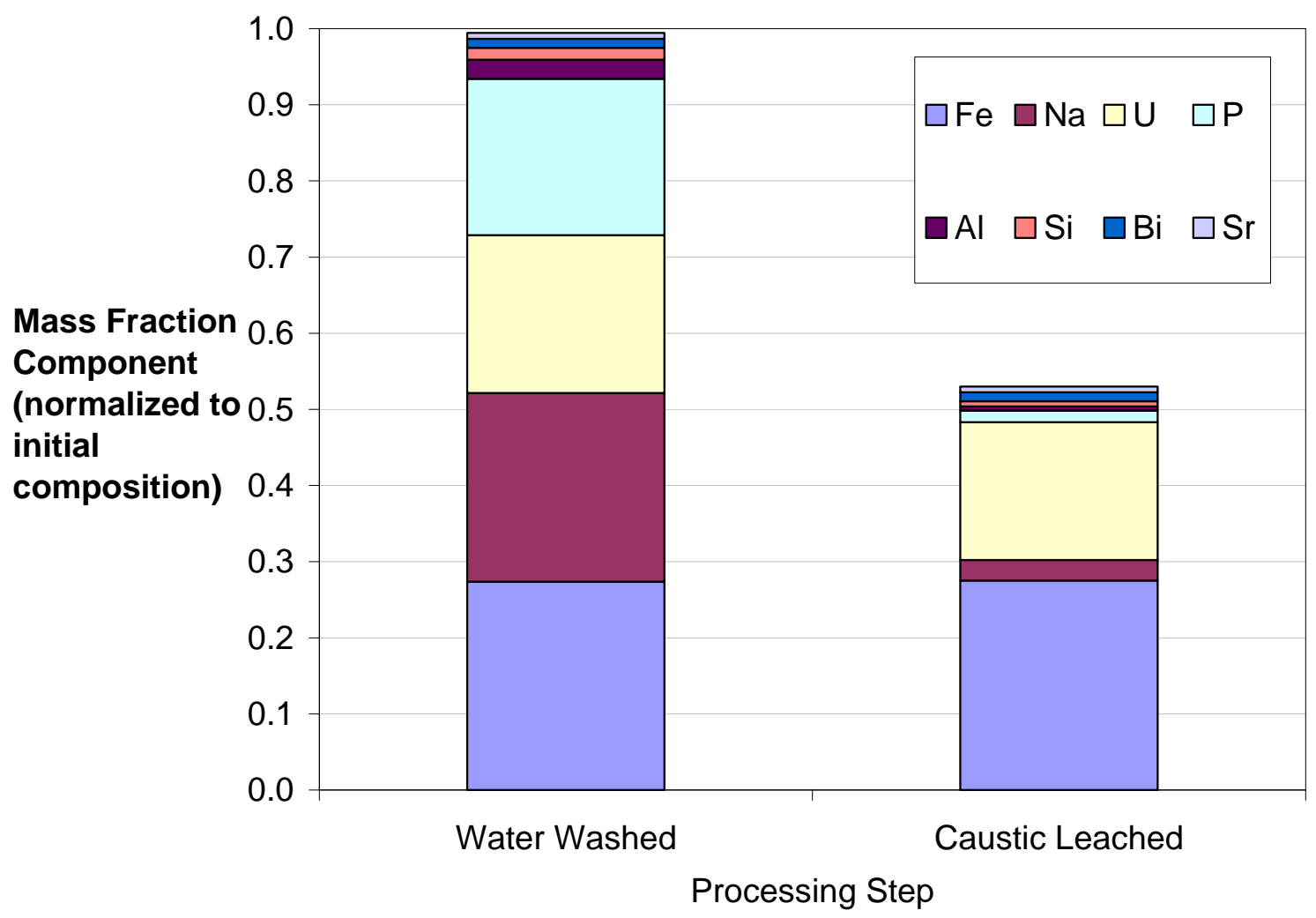

Figure 4.17. Group 7 TBP Sludge Reduction in Solid Mass with Water Washing and Caustic Leaching

\subsubsection{Particle-Size Distribution}

PSD measurements were performed on a sample of the caustic-leached solids (sample ID 623-G7-CLPSD). Table 4.6 gives a summary of the measured oversize diameter percentiles (by volume/weight) for this sample as a function of test condition. Here, the $d(10)$ ranges from 0.57 to $0.72 \mu \mathrm{m}$, the $d(50)$ ranges from 2.1 to $2.9 \mu \mathrm{m}$, and the $\mathrm{d}(90)$ ranges from 10 to $93 \mu \mathrm{m}$. More extensive percentile results are provided in Appendix E.

Figure 4.18 shows the PSD for the Group 7 caustic-leached sample as a function of pump speed. All of the pump speeds show a multi-modal distribution with peak maxima around 1.2 and $8 \mu \mathrm{m}$. At $2000 \mathrm{RPM}$, the range is 0.24 to $20 \mu \mathrm{m}$, although at higher pump speeds, a broader range exists. At $3000 \mathrm{RPM}$, the range is 0.24 to $300, \mu \mathrm{m}$ and an additional peak is seen around $135 \mu \mathrm{m}$. At $4000 \mathrm{RPM}$, the range is 0.24 to $200 \mu \mathrm{m}$, and again an additional peak is observed, although its maximum is around $70 \mu \mathrm{m}$. This larger diameter peak most likely indicates the presence of larger particles or agglomerates that are suspended by faster pump speeds. As this peak shifts to smaller particle diameters at 4000 RPM, this may also indicate shear-induced breakage of agglomerates, which would account for the relative increase in the 4- to 10 - $\mu \mathrm{m}$ peak observed. 


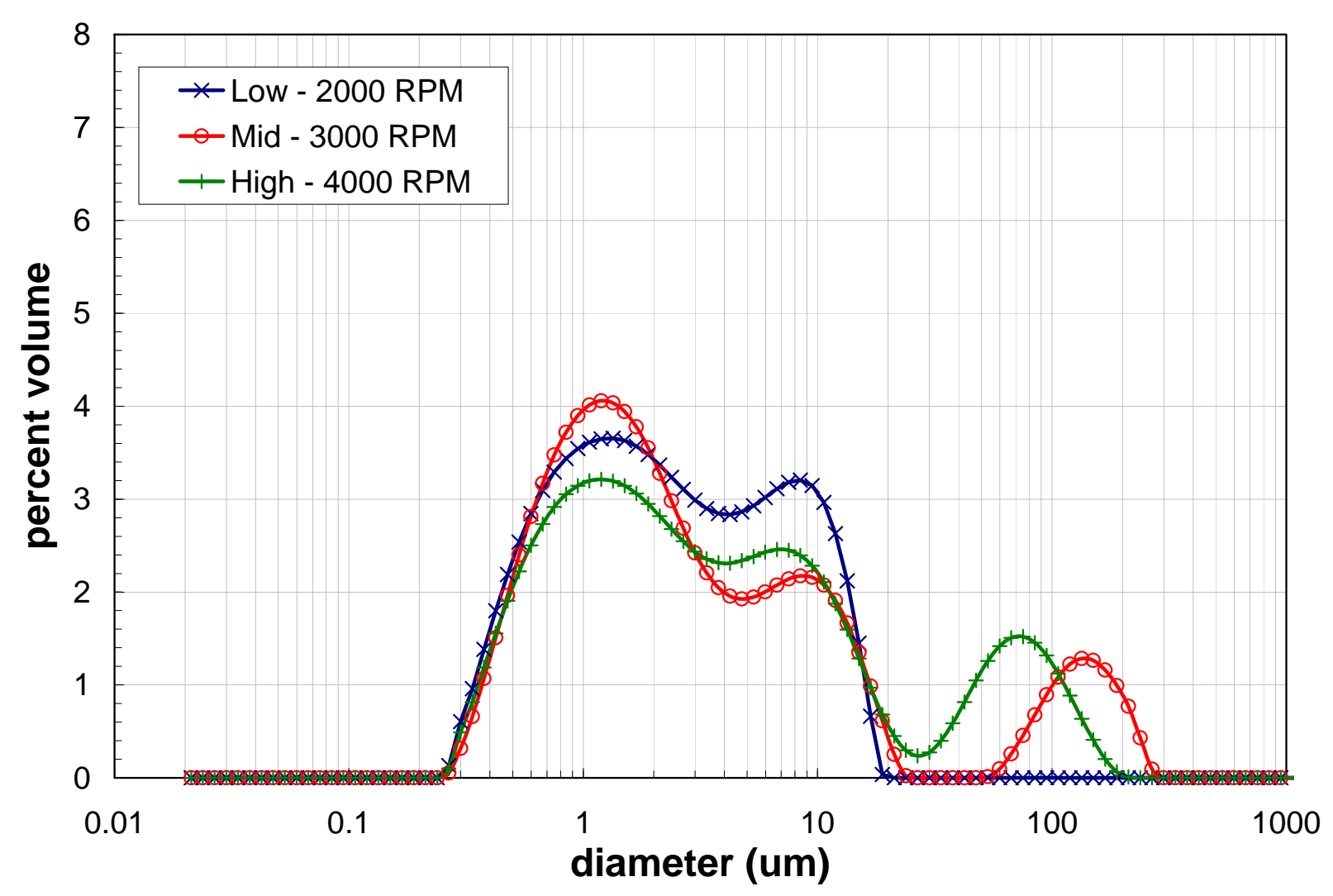

Figure 4.18. Volume Distribution Result for the Group 7 Caustic-Leached Sample as a Function of Pump Speed

Table 4.6 shows select cumulative oversize percentiles for the Group 7 caustic-leached sample particle dispersion. Using these results as a reference, the behavior of Group 7 caustic-leached particle size as a function of pump speed can be quantitatively evaluated. Specifically, the following observations can be made:

- In general, the $\mathrm{d}(10)$ falls between 0.57 and $0.72 \mu \mathrm{m}$, the $\mathrm{d}(50)$ between 2.1 and $2.9 \mu \mathrm{m}$, and the $\mathrm{d}(90)$ between 10 and $93 \mu \mathrm{m}$.

- The listed diameter percentiles appear to be sensitive to changes in pump speeds. Increases in flow rate appear to result in increases in the mean diameter [i.e., the d(50)]. For an increase from 3000 to 4000 RPM, the mean particle diameter increases from 2.1 to $2.9 \mu \mathrm{m}$. This is an increase of $\sim 38 \%$ and is significant relative to the accuracy of the instrument.

Table 4.6. Particle-Size Analysis Percentile Results from the Group 7 Caustic-Leached Sample

\begin{tabular}{||c|c|c|c|c|c||}
\hline $\begin{array}{c}\text { Measurement } \\
\text { Condition }\end{array}$ & Pump Speed & Sonication & $\begin{array}{c}\mathbf{d}(\mathbf{1 0}) \\
{[\boldsymbol{\mu m}]}\end{array}$ & $\begin{array}{c}\mathbf{d}(\mathbf{5 0 )} \\
{[\mathbf{\mu m}]}\end{array}$ & $\begin{array}{c}\mathbf{d}(\mathbf{9 0}) \\
{[\boldsymbol{\mu m}]}\end{array}$ \\
\hline 1 & 3000 & $\mathrm{n} / \mathrm{a}$ & 0.61 & 2.1 & 78 \\
\hline 2 & 4000 & $\mathrm{n} / \mathrm{a}$ & 0.61 & 2.9 & 59 \\
\hline 3 & 2000 & $\mathrm{n} / \mathrm{a}$ & 0.72 & 2.7 & 93 \\
\hline 4 & 2000 & $\mathrm{n} / \mathrm{a}$ & 0.57 & 2.2 & 10 \\
\hline
\end{tabular}


The particle-size analysis of the caustic-leached Group 7 sample displays multi-modal PSDs ranging from 0.24 to $300 \mu \mathrm{m}$. Higher pump speeds result in an additional peak consisting of particles $>20 \mu \mathrm{m}$. This may indicate the presence of larger difficult-to-suspend particles, which may result in irreproducible sampling due to settling.

The influence of caustic-leaching and washing on the Group 7 (TBP sludge) solids can be evaluated by comparing PSDs for the source material (i.e., for initial characterization sample TI576-G7-S-WL-PSD) to the caustic-leached and washed Group 7 parametric testing PSD sample (623-G7-CL-PSD). The PSD measurement for the primary initial characterization sample is used for this comparison. Comparison of the percentiles and distributions of the initial sample (presented in Section 3.4) and the caustic-leached sample can highlight the effects of chemical treatment on the Group 7 waste PSD. Caution must be used when directly comparing PSDs, however, because these PSDs include both primary particles and particle agglomerates. The structure of the agglomerates fractions depends on 1) physical conditions such as the analyzer pump speed and 2) chemical conditions such as particle interaction potentials and sample history.

One expected outcome of caustic leaching is a decrease in particle size as a result of solids dissolution. However, removing the leachable solid species may reveal the size distribution of particles only minimally represented in the initial sample. In addition, changes in the dominant particle-surface chemistry can yield increased particle agglomeration, which in turn results in increases in the apparent particle size. In addition to chemical effects, the mechanical force needed to pump the dispersion can also shear particle agglomerates (as well as influence the volume of agglomerates suspended). As such, the apparent PSD of a material may also vary with pump speed. Comparisons will be made at measurement condition 1 (3000 RPM).

Table 4.7 and Figure 4.19 show changes that occur to the Group 7 solids PSD as a result of causticleaching and washing. Figure 4.19 shows that both the initial characterization and parametric testing (caustic-leached) samples are tri-modal with peak maxima located around similar particle diameters. The most noticeable difference is the shift to lower particle diameters after caustic-leaching and washing. The reduction in particle size is likely a result of either dissolution of material from the particle surface or agglomerate breakage.

Table 4.7. Cumulative Undersize Percentiles Showing the Influence of Caustic-Leaching and Washing on the PSD of Group 7 (TBP sludge) Solids at Measurement Condition 1 (3000 RPM)

\begin{tabular}{||l|c|c|c||}
\hline \multicolumn{1}{|c|}{ Sample } & $\begin{array}{c}\mathbf{d}(\mathbf{1 0}) \\
{[\mu \mathbf{m}]}\end{array}$ & $\begin{array}{c}\mathbf{d}(\mathbf{5 0}) \\
{[\mu \mathrm{m}]}\end{array}$ & $\begin{array}{c}\mathbf{d}(\mathbf{9 0}) \\
{[\boldsymbol{\mu m}]}\end{array}$ \\
\hline Group 7 Initial Characterization (TI576-G7-S-WL-PSD-1) & 1.0 & 19 & 130 \\
\hline Group 7 Parametric Testing (TI623-G7-CL-PSD) & 0.61 & 2.1 & 78 \\
\hline
\end{tabular}




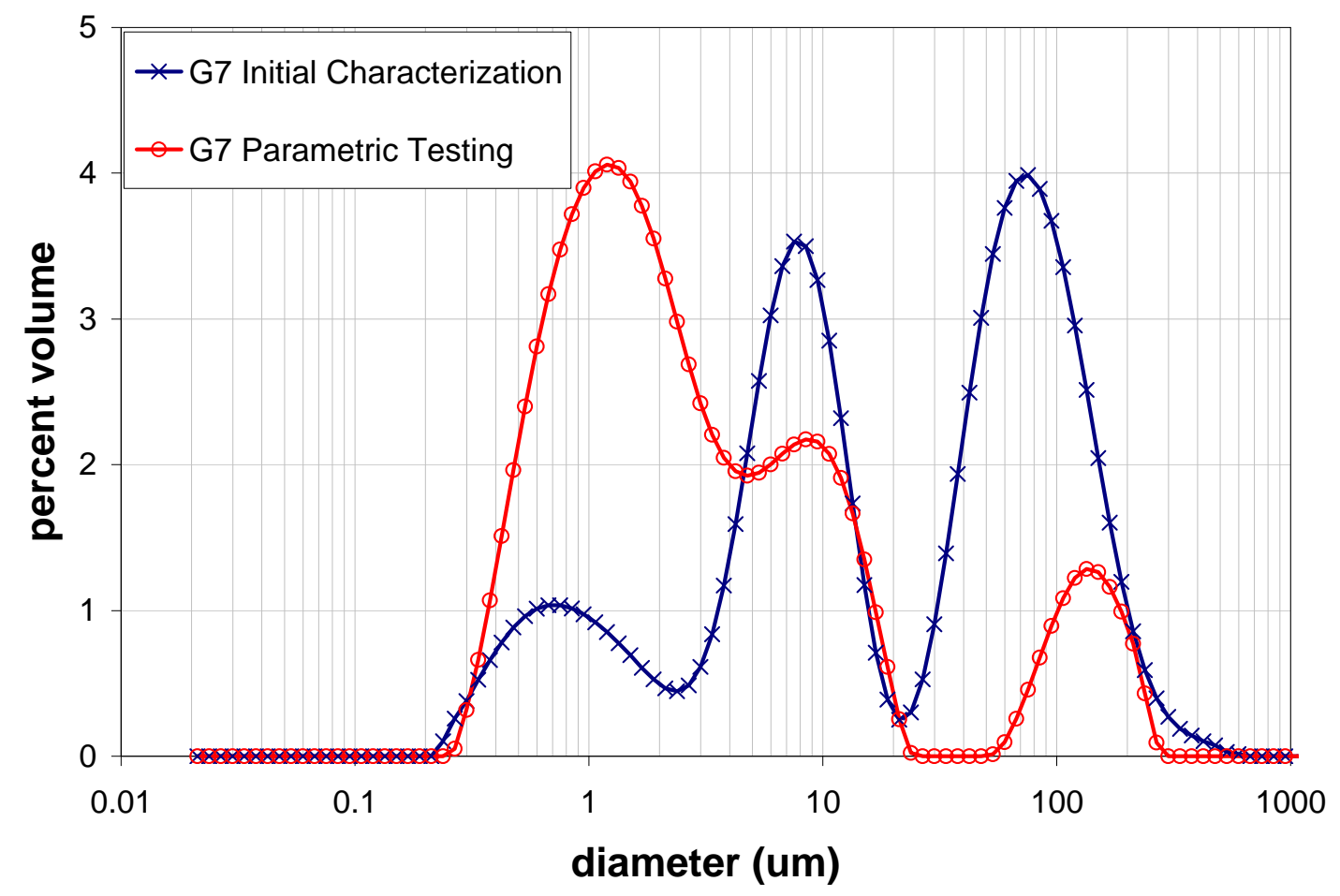

Figure 4.19. Influence of Caustic-Leaching and Washing on Group 7 (TBP sludge) Solids PSD. PSDs were taken at measurement condition 1 (3000 RPM).

\subsubsection{Crystal Form and Habit}

The following sections summarize the mineral-phase evaluation of the leached and washed solids.

\subsection{XRD}

The XRD pattern of the leached and washed solids (sample ID 585-G7-CL-XRD) is provided in Figure 4.20a; the background-subtracted XRD pattern with stick-figure phase identification is shown in Figure 4.20b.

Rutile, $\mathrm{TiO}_{2}$, was used as an internal standard for 2-theta calibration. Identification was done on 2-theta calibrated data. This material is predominantly amorphous as indicated by the very broad peak system from about 12 to 37 degrees 2-theta. Sodium uranium oxide hydrate $\left[\mathrm{Na}_{2} \mathrm{U}_{2} \mathrm{O}_{7} \cdot 6 \mathrm{H}_{2} \mathrm{O}\right]$ was a good fit to all peaks but one in the pattern. The peak at $25.4^{\circ}$ 2-theta has a significant intensity mismatch. Becquerelite $\left[\mathrm{Ca}\left(\mathrm{UO}_{2}\right)_{6} \mathrm{O}_{4}(\mathrm{OH})_{6}\left(\mathrm{H}_{2} \mathrm{O}\right)_{8}\right]$ and nabaphite $\left[\mathrm{NaBa}\left(\mathrm{PO}_{4}\right)\left(\mathrm{H}_{2} \mathrm{O}\right)_{9}\right]$ are good fits to the data. Clarkeite $\left[\mathrm{Na}\left(\mathrm{UO}_{2}\right) \mathrm{O}(\mathrm{OH})\right]$ is a good fit to the broad peaks at $\sim 15^{\circ}, 27^{\circ}$, and $36^{\circ}$ 2-theta in the pattern. Broad peaks indicate that this phase has an extremely small crystallite size $(\sim 10 \mathrm{~nm})$. Calcium nitrate $\left[\mathrm{Ca}\left(\mathrm{NO}_{3}\right)_{2}\right]$ is a possible fit to minor peaks unaccounted for in the pattern, although it is unlikely that calcium nitrate was present in the washed sample, as it is water-soluble. 
(a)

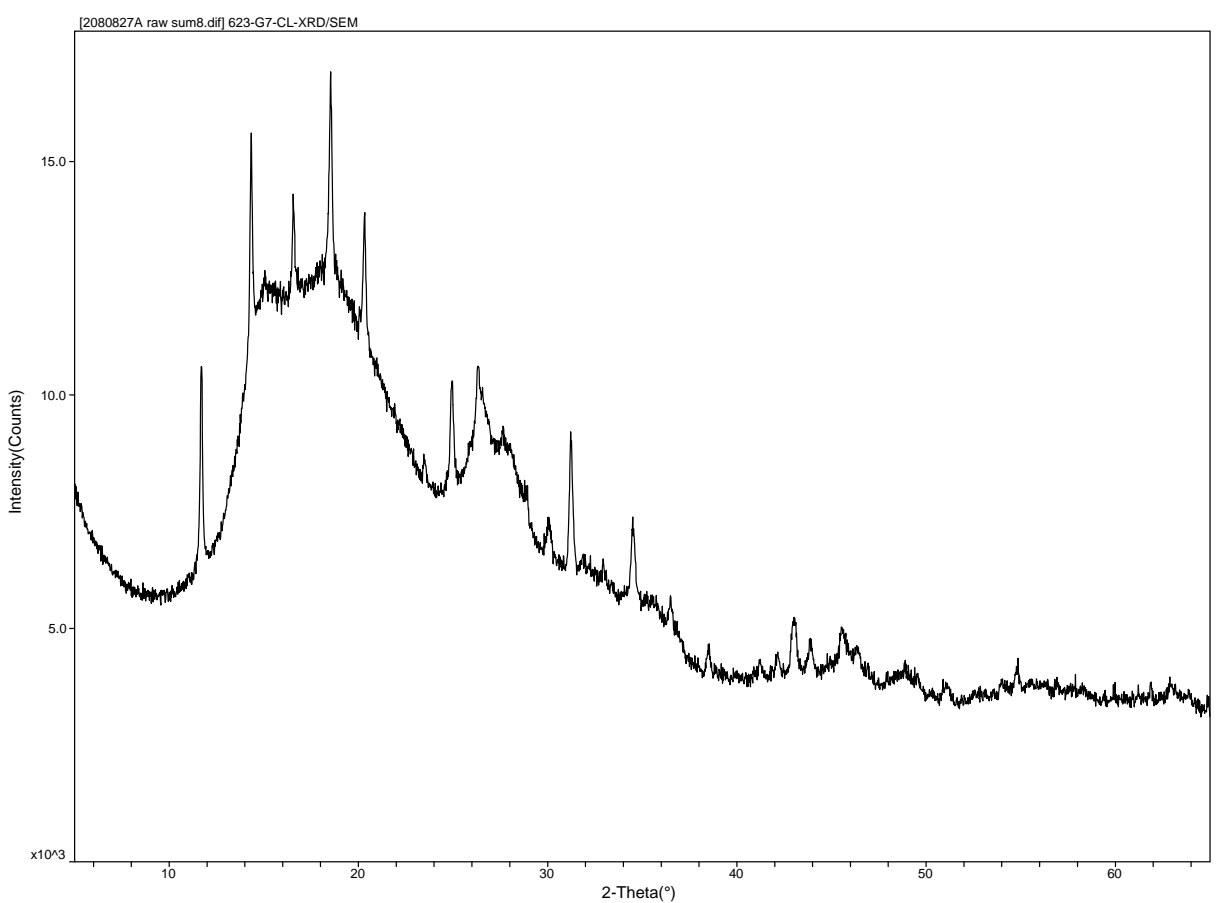

(b)

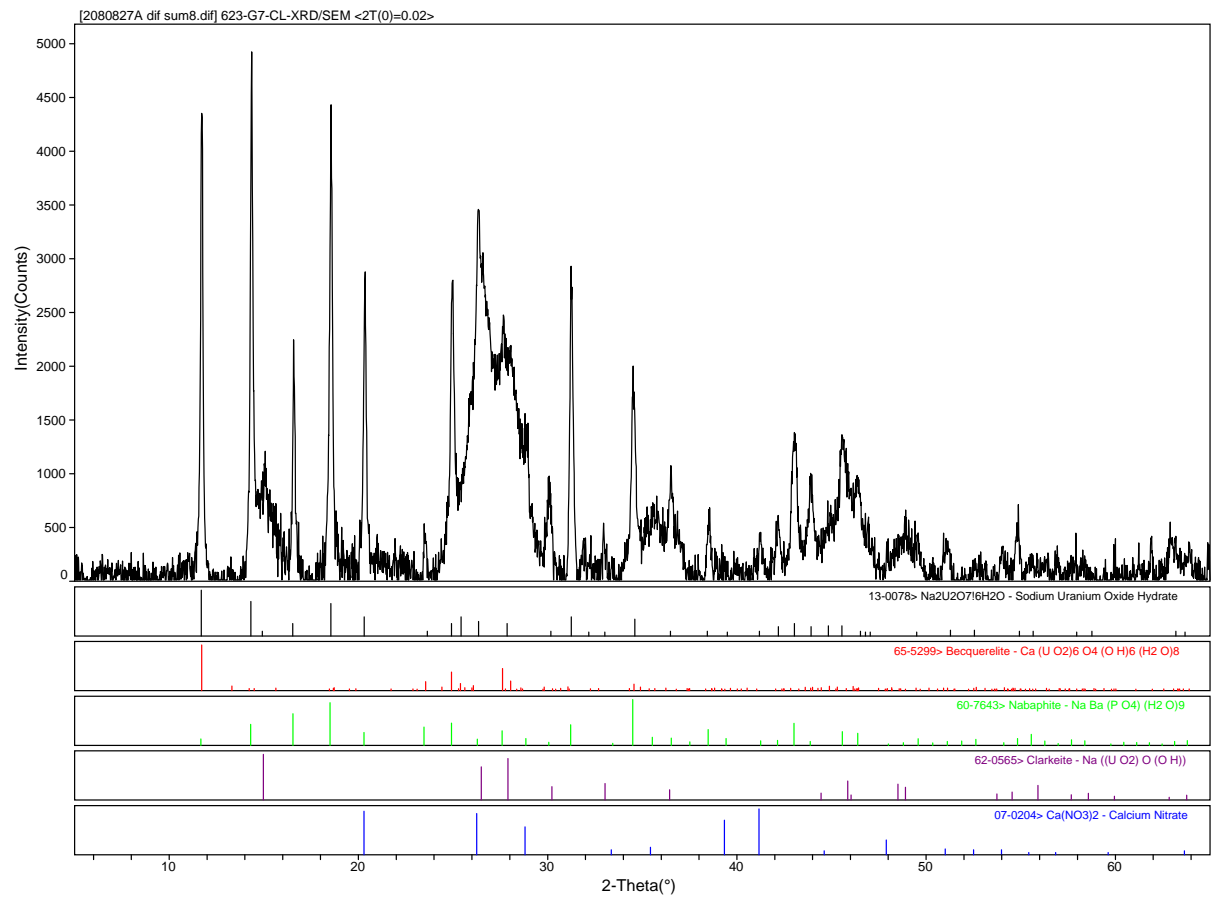

Figure 4.20. XRD Pattern of Caustic-Leached Group 7 TBP Sludge with Rutile $\left(\mathrm{TiO}_{2}\right)$ Internal Standard (a) Raw Data and (b) Background-Subtracted with Stick-Figure Peak Identification 


\subsection{SEM and TEM}

Several SEM images are shown in Figure 4.21. Particles seen in these images are typically on the order of 10 to $40 \mu \mathrm{m}$.

(a)

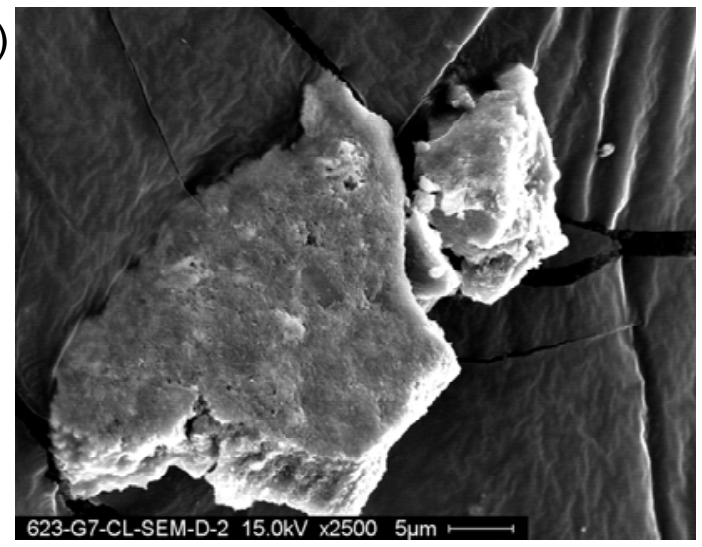

(c)

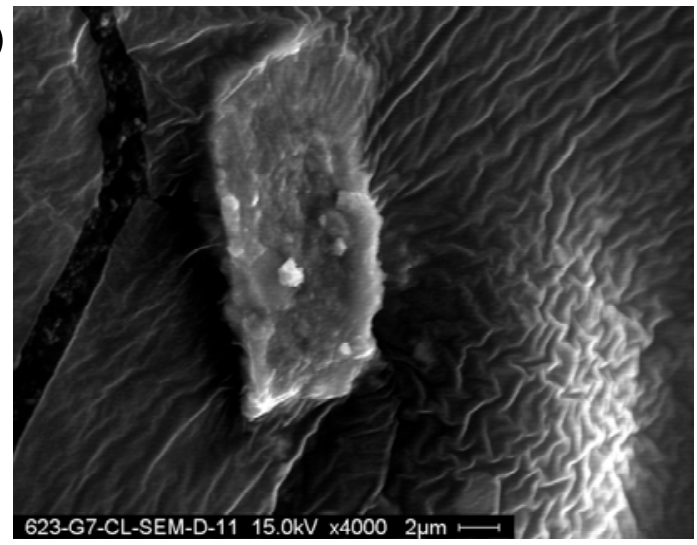

(b)

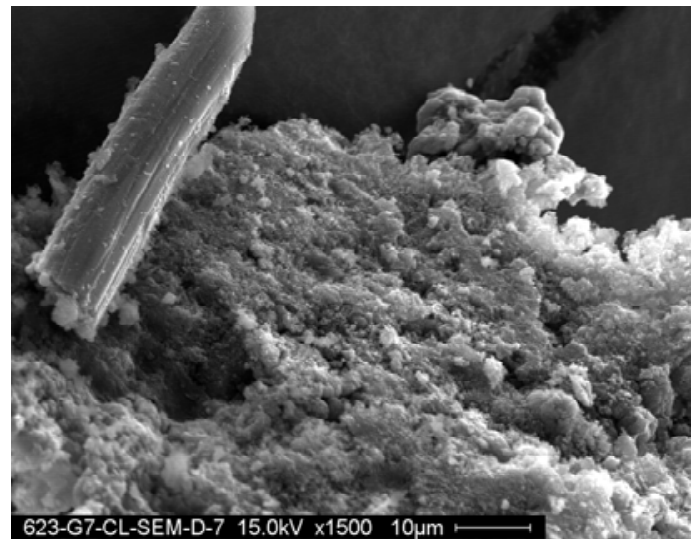

(d)

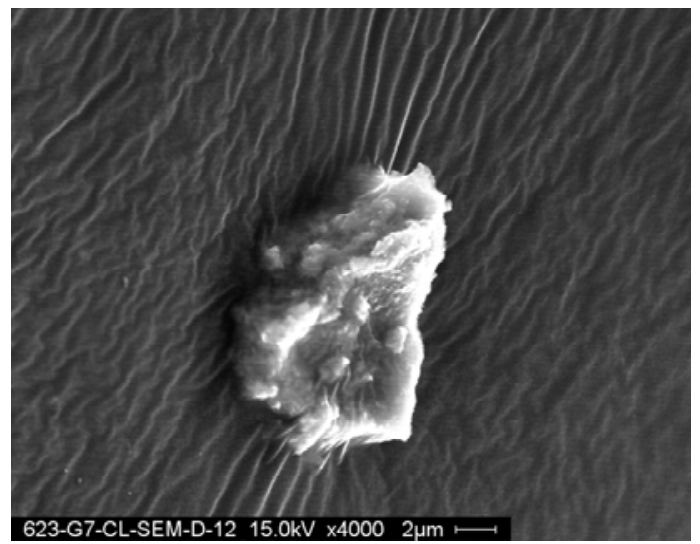

Figure 4.21. SEM Images of Group 7 TBP Sludge Caustic Leached and Washed Solids (a) $15 \mathrm{kV}$, $2500 \times$; (b) $15 \mathrm{kV}, 1500 \times$; (c) $15 \mathrm{kV}, 4000 \times$; (d) $15 \mathrm{kV}, 4000 \times$

Figure 4.22 shows an SEM image along with EDS spectra of two particles. The elemental analysis shows a large amount of oxygen and carbon, which is an artifact of the sample preparation (carbon is sputtered onto the sample to eliminate problems with charging). If this is removed, and the other constituents are normalized, the weight percentages shown in Table 4.8 for each analysis are obtained. The particle at spot 3 in Figure 4.21 consists mainly of Fe as well as a small amount of U. The particle at spot 4 in Figure 4.21 is more representative of the average of the 17 spots that were examined by SEM EDS, showing high amounts of $\mathrm{Fe}$, fairly high amounts of $\mathrm{U}$, and smaller concentrations of other analytes. This is in agreement with the ICP results from the residual solids, which showed that the residual solids are $33 \% \mathrm{Fe}$ and $21.8 \% \mathrm{U}$. 
(a)

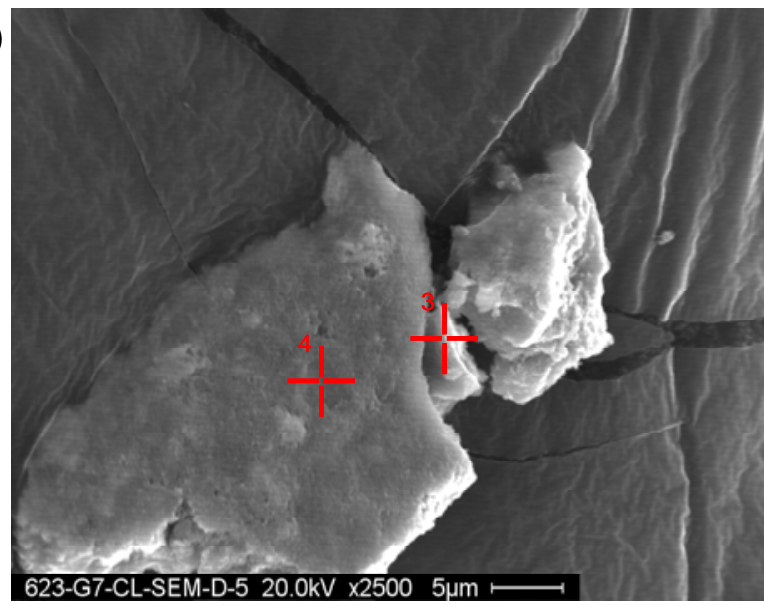

(b)

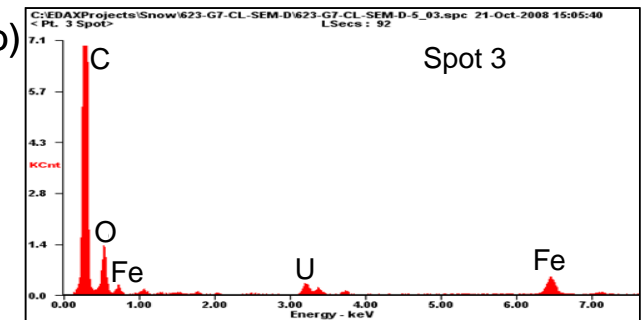

(c)

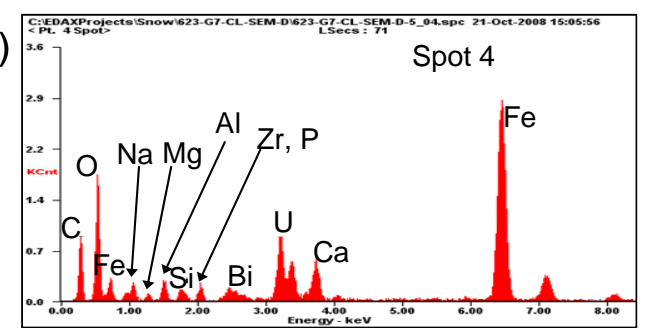

Figure 4.22. SEM Image of Group 7 TBP Sludge Caustic Leached and Washed Solids with EDS Spectra (a) SEM Image; (b) EDS Spectra of Spot 3; (c) EDS Spectra of Spot 4

Table 4.8. Normalized Weight Percents for Various Analytes Found by EDS of SEM Images for Figure 4.22

\begin{tabular}{||c|c|c|}
\hline \multirow{2}{*}{ Element } & \multicolumn{2}{|c|}{$\begin{array}{c}\text { Normalized Weight } \\
\text { Percent }\end{array}$} \\
\cline { 2 - 3 } & Spot 3 & Spot 4 \\
\hline $\mathrm{Fe}$ & 95.5 & 65.5 \\
\hline $\mathrm{Cu}$ & 0 & 6.85 \\
\hline $\mathrm{Na}$ & 0 & 1.86 \\
\hline $\mathrm{Mg}$ & 0 & 3.84 \\
\hline $\mathrm{Al}$ & 0 & 1.72 \\
\hline $\mathrm{Si}$ & 0 & 1.63 \\
\hline $\mathrm{P}$ & 0 & 0.35 \\
\hline $\mathrm{Zr}$ & 0 & 3.40 \\
\hline $\mathrm{Bi}$ & 0 & 12.67 \\
\hline $\mathrm{U}$ & 4.1 & 2.21 \\
\hline
\end{tabular}

As discussed in section 4.1.3, there was an apparent initial dissolution of the uranium compounds followed by a re-precipitation. Examination of the caustic-leached solids by TEM showed that the uranium phosphate phases in the caustic-leached sample were considerably smaller than those observed in the initial characterization sample. Figure 4.23 shows two TEM images of agglomerate phases in the caustic-leached and washed solids, as well as an EDS and selected area electron diffraction (SAED) analysis of the uranium phosphorus phase; any evidence of crystallinity in the phases was absent, and there was clear evidence that the original uranium phosphate phase dissolved and the uranium phase reprecipitated. This can be seen by comparing the uranium phases seen in Figure 4.23 to the sodium uranyl phosphate crystals in the initial characterization sample as seen in Figure 3.23.

In nature, uranyl phosphates and the often isostructural uranyl arsenates constitute nearly 70 of the known $200 \mathrm{U}(\mathrm{VI})$ mineral phases. The autunite group have the general composition $\mathrm{A}\left(\mathrm{UO}_{2} \mathrm{PO}_{4}\right)_{2} \cdot \mathrm{nH}_{2} \mathrm{O}$ where $\mathrm{A}$ 
is typically a divalent cation, and $\mathrm{n}$ represents the hydration number. The structure of autunite results in perfect (001) basal cleavage. In the sludge sample, the individual crystals were several microns in length but electron transparent along the c-axis. The caustic-leaching process dissolved these large crystals; however, uranium phosphates were still present. Sandino and Bruno (1992) demonstrated that uranyl phosphate complexation dominates when the total concentration ratio $\left[\mathrm{PO}_{4}{ }^{3-}\right]_{\mathrm{T}} /\left[\mathrm{CO}_{3}{ }^{2-}\right]_{\mathrm{T}}$ is $>0.1$ between pH 6 and 9. Hence, although treatment conditions permitted the dissolution of the uranyl phosphate, it is likely that the phase re-preciptiated.

(a)

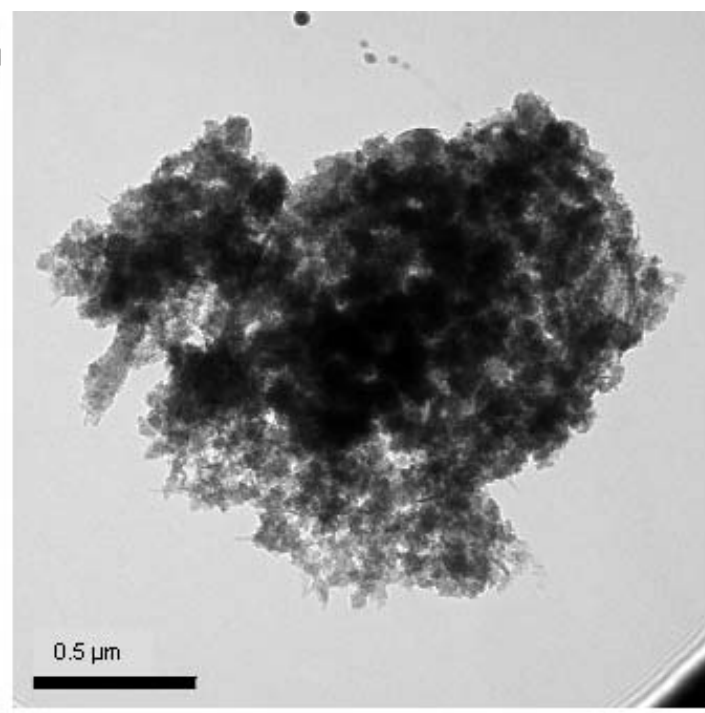

(c)

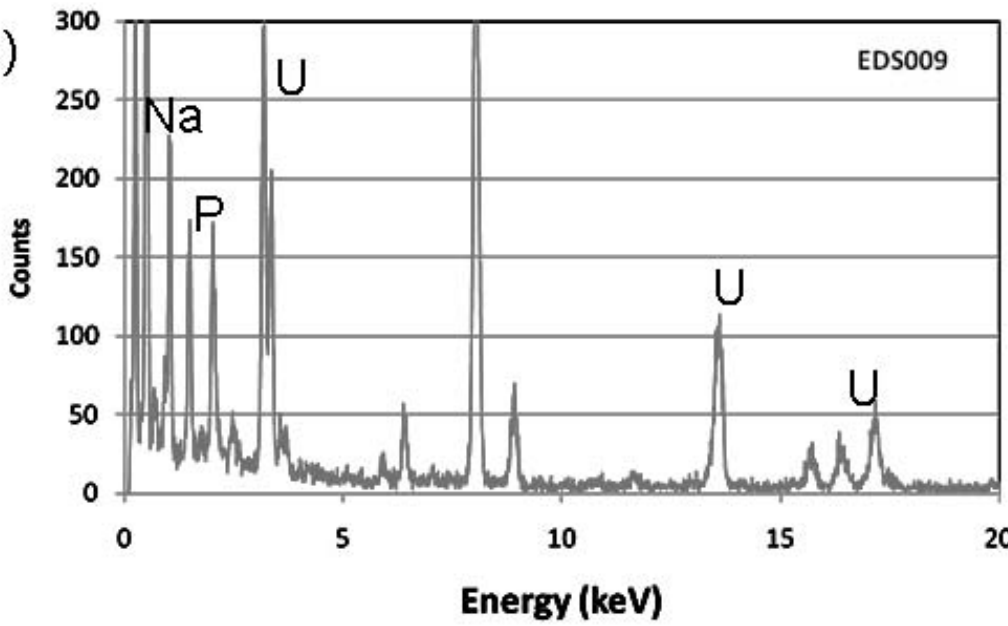

(b)

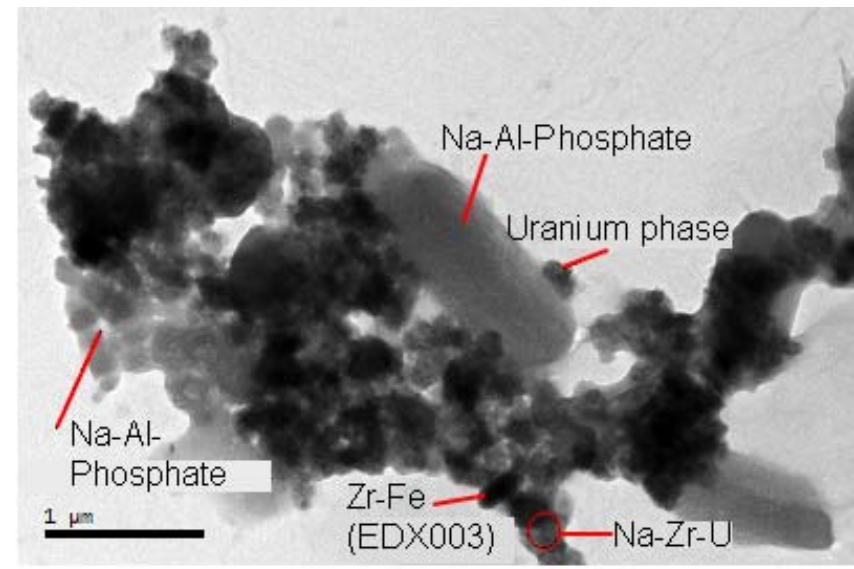

(d)

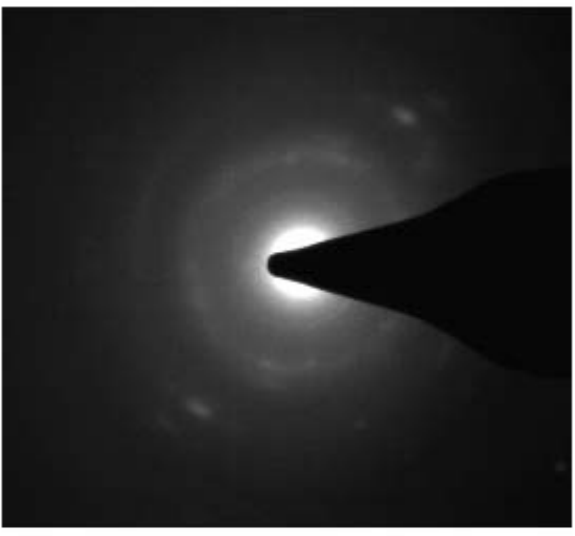

Figure 4.23. TEM Image of Group 7 TBP Sludge Caustic Leached and Washed Solids (a) TEM Image of an Agglomerate; (b) TEM Image Showing Various Phases; (c) EDS Analysis of a Uranium Phosphorus Phase in the Agglomerate Shown in (a); (d) SAED Image of the Uranium Phosphorus Phase

A crystalline sodium alumino-phosphate was also found in the sample, as seen in Figure 4.23b. The EDS and SAED analysis of this crystal is given in Figure 4.24. 
(a)

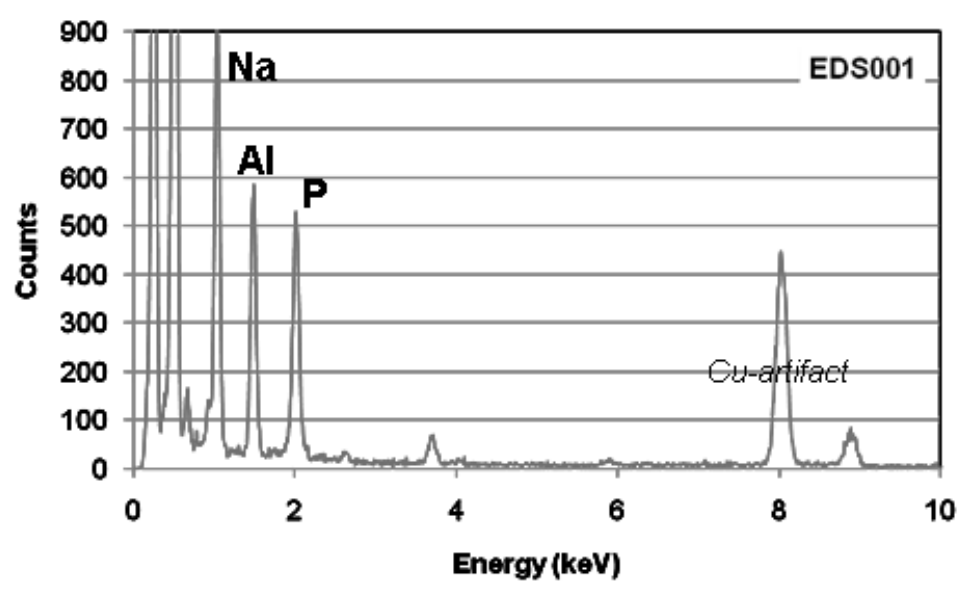

(b)

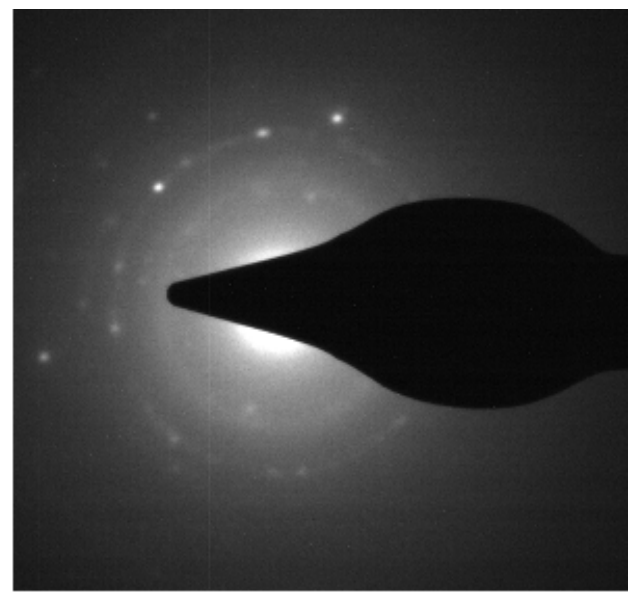

Figure 4.24. TEM Analysis of a Sodium Aluminum Phosphate Phase in the Group 7 TBP Sludge Caustic Leached and Washed Solids (a) EDS Analysis; (b) SAED Image

Iron phases were also seen. Figure 4.25 shows STEM-HAADF and TEM images as well as an EDS analysis of an iron phase. Figure 4.26 shows a large iron particle; the electron diffraction of this particle was consistent with hematite. This particle was exceptionally large compared to the other phases observed in this sample. 
(a)

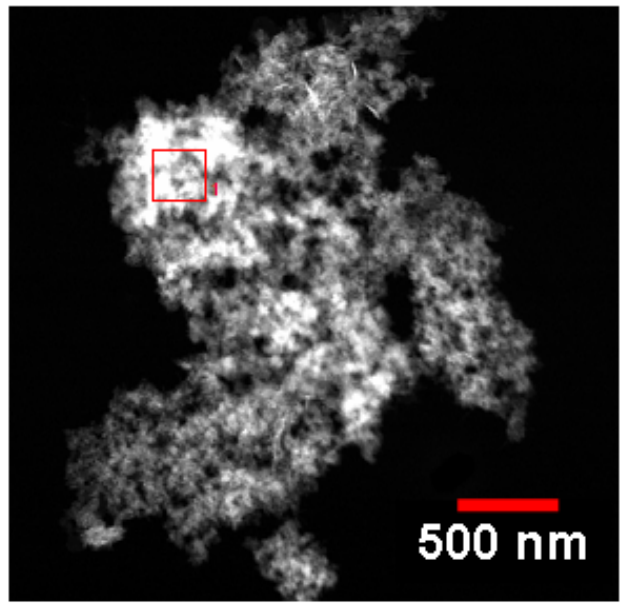

(b)

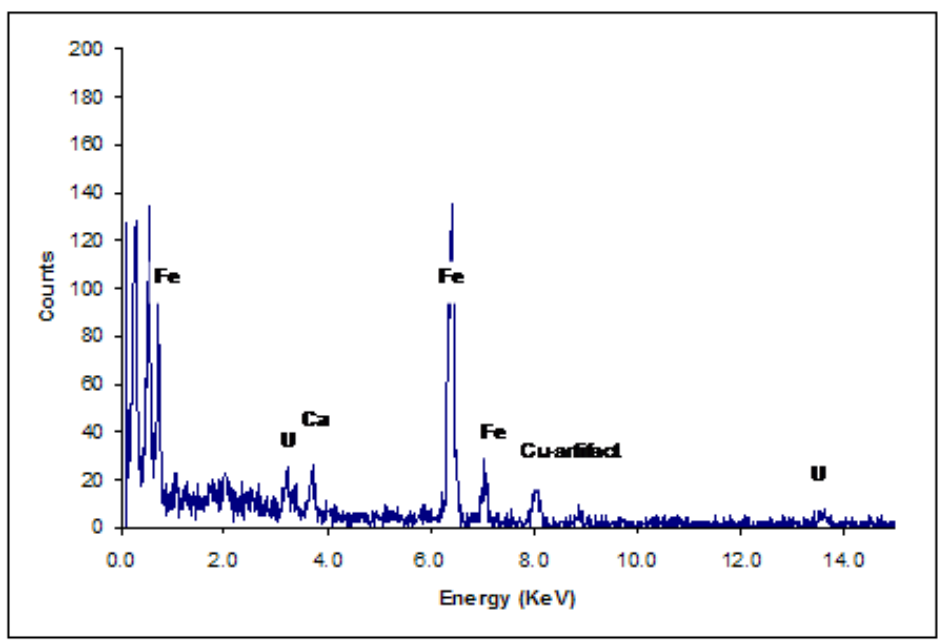

(c)

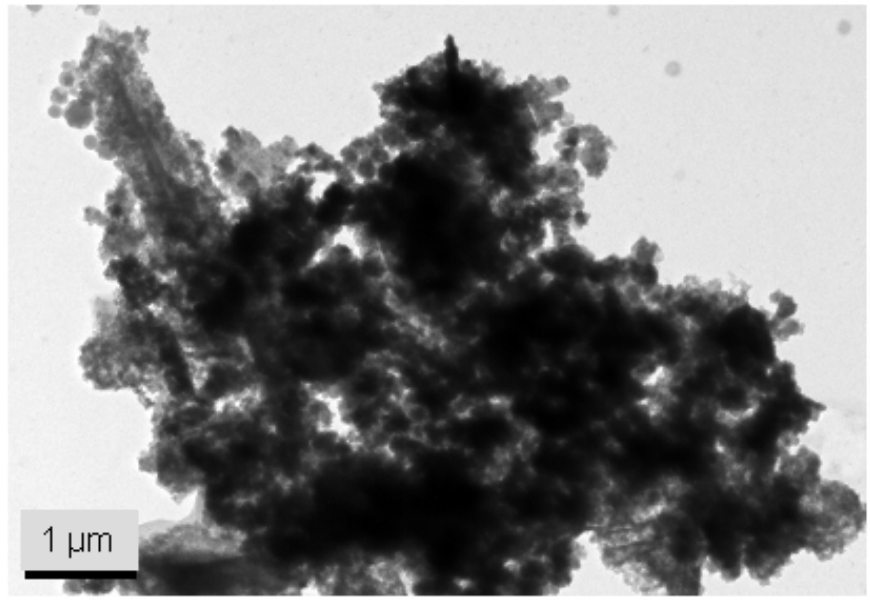

Figure 4.25. TEM Images and Analysis of an Iron Phase in the Group 7 TBP Sludge Caustic Leached and Washed Solids (a) STEM-HAADF Image of a Particle; (b) EDS Analysis of an Iron Phase; (c) TEM Image of the Agglomerate 

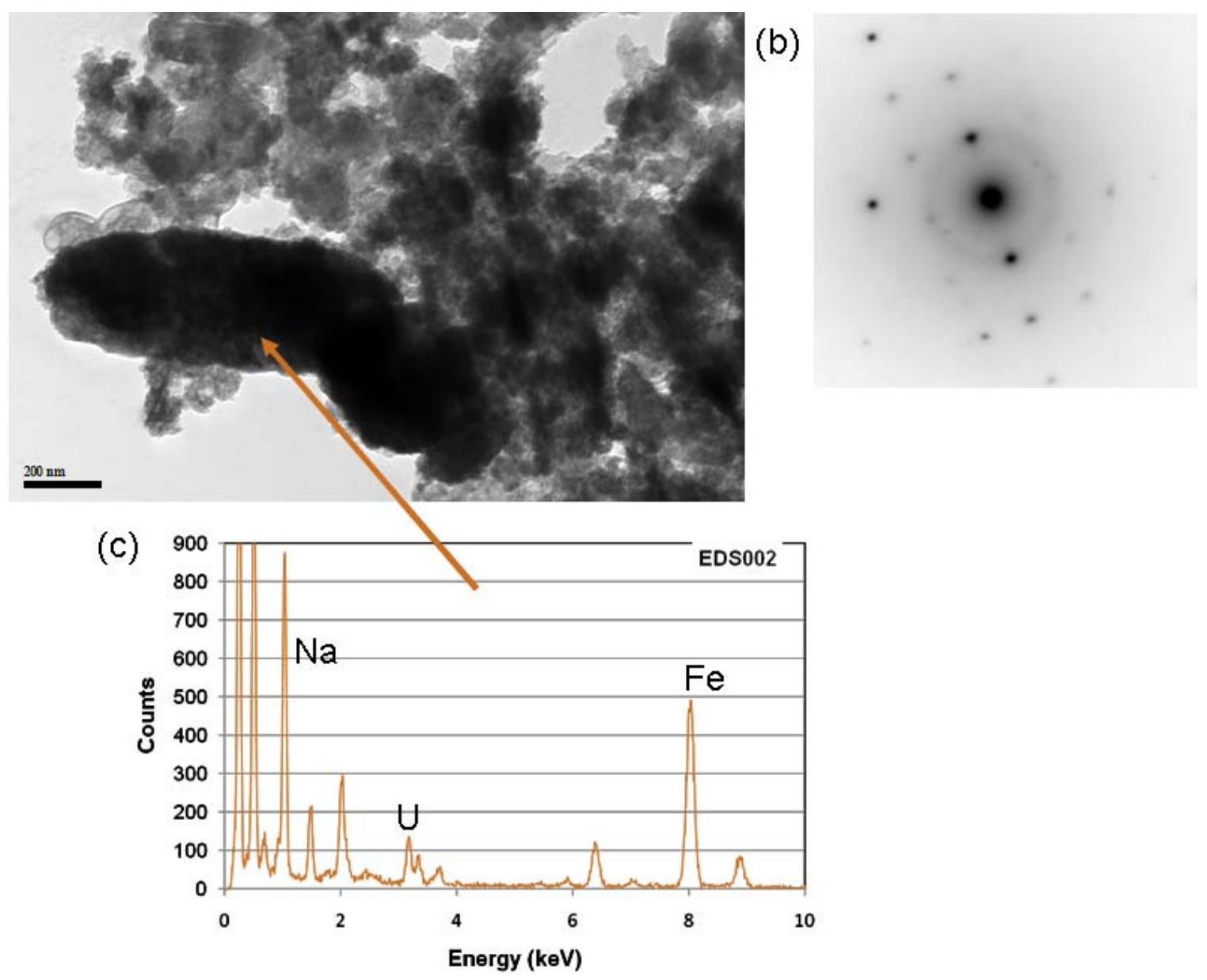

Figure 4.26. Iron Oxide Phase Surrounded by Uranium-Bearing Particles in the Group 7 TBP Sludge Caustic-Leached and Washed Solids. (a) TEM Image; (b) SAED Image; (c) EDS Analysis

Various other phases were also found in the samples as shown in Figure 4.27. 
(a)

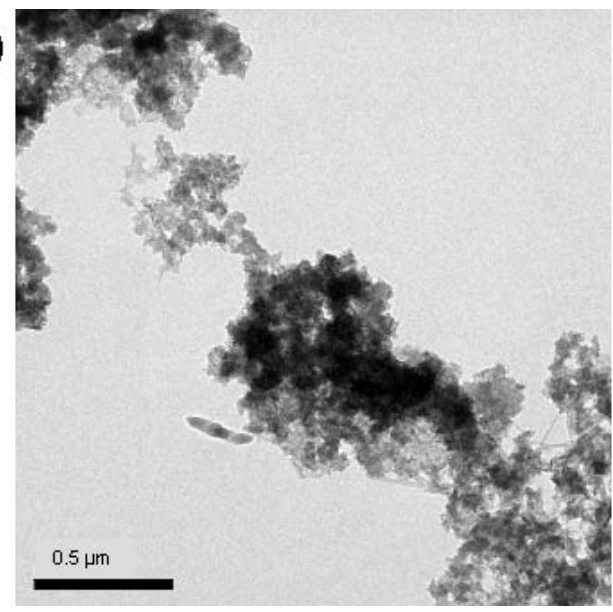

(b)

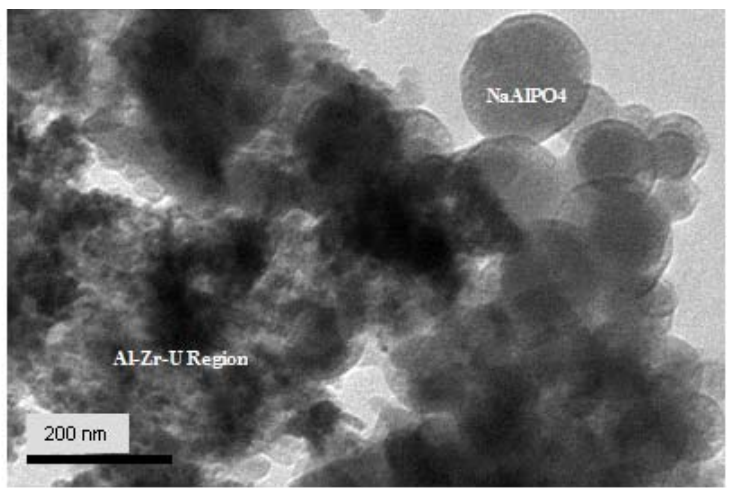

Figure 4.27. TEM Images of Particles in the Group 7 TBP Sludge Caustic-Leached and Washed Solids. (a) TEM Image of an Agglomerate Phase; (b) TEM Image Showing Regions Rich in Sodium, Aluminum, and Phosphorus, and Al-Bearing Phases

\subsubsection{Surface Area by BET}

A BET measurement was conducted on the caustic leached and washed solids, resulting in a surface area of $248 \mathrm{~m}^{2} / \mathrm{g}$. This shows an increase in relative surface area following caustic leaching from the value of $66 \mathrm{~m}^{2} / \mathrm{g}$ found for the initial washed solids. 
WTP-RPT-169, Rev 0

\subsection{CUF Testing and Results}

This section describes the filtration/leaching tests performed using the CUF for the TBP waste sludge composite referred to as the Group 7 waste sample performed under TI-RPP-WTP-624 ${ }^{\text {(a) }}$ and subsequent results. The UDS inventory of the Group 7 waste slurry was not enough to generate 20 -wt\% slurry in the CUF by itself, and therefore the slurry was blended with archive samples from HLW Tank 241-AY-102. This blending of wastes was approved by BNI in response to letter request WTP/RPP-MOA-PNNL00216.

\subsection{Test Plan}

Figure 5.1 outlines the testing that was performed, which is reported in this section. The goals of this test were to:

- Evaluate the filtration of the TBP sludge waste composite

- Blend with samples from Tank 241-AY-102 and evaluate the change in filtration

- Evaluate the effectiveness of caustic leaching on removing aluminum from the blended waste

- Evaluate the filtration of the washed leached solids.

The first half of the testing was to perform filtration studies on the Group 7 waste sample and understand its dewatering behavior, as outlined in the first column of Figure 5.1. The waste was to be initially evaluated at a target UDS concentration of $4 \mathrm{wt} \%$, which is the expected solids concentration entering the WTP-Pretreatment UFP2 vessel. To accomplish this, approximately $1.4 \mathrm{~L}$ of Group 7 composite material (measured at $10 \mathrm{wt} \%$ UDS) was diluted with $2.0 \mathrm{~L}$ of a simulated supernate solution (based on the Group 7 slurry supernate composition) to a final volume of $3.5 \mathrm{~L}$. Once the slurry was homogenized, a test matrix was performed as described in Appendix $\mathrm{H}$ to determine the filtration behavior of the waste at a low UDS concentration. After completion of the test matrix, the waste sample was dewatered to the minimum operating volume in the slurry recirculation loop at a predicted concentration of $13 \mathrm{wt} \%$ UDS.

The target concentration for the dewatering of waste slurry was $20 \mathrm{wt} \%$ UDS. However, this required approximately 300 grams of solid to be present in the initial slurry sample, and only 180 grams was present. As done in previous testing, another waste sample was added to the waste at this point to increase the mass of solids. Archived samples from Tank 241-AY-102 were selected to be added to the slurry to increase the solids mass. These archived samples were considered a neutral category waste, which did not fix any of the specific waste groups, but could be added to supplement any of the waste groups for CUF testing. Examination of the composition of the AY-102 from past studies performed at Savannah River (Coleman, 2003) and PNNL (Krupka 2004) showed the following similarities and differences in the wastes:

(a) Conducted according to TI-RPP-WTP-624, HLW Filtration and Caustic Leaching of Group 7 / AY-102 Composite Waste, R Shimskey, April, 2008. 
WTP-RPT-169, Rev 0
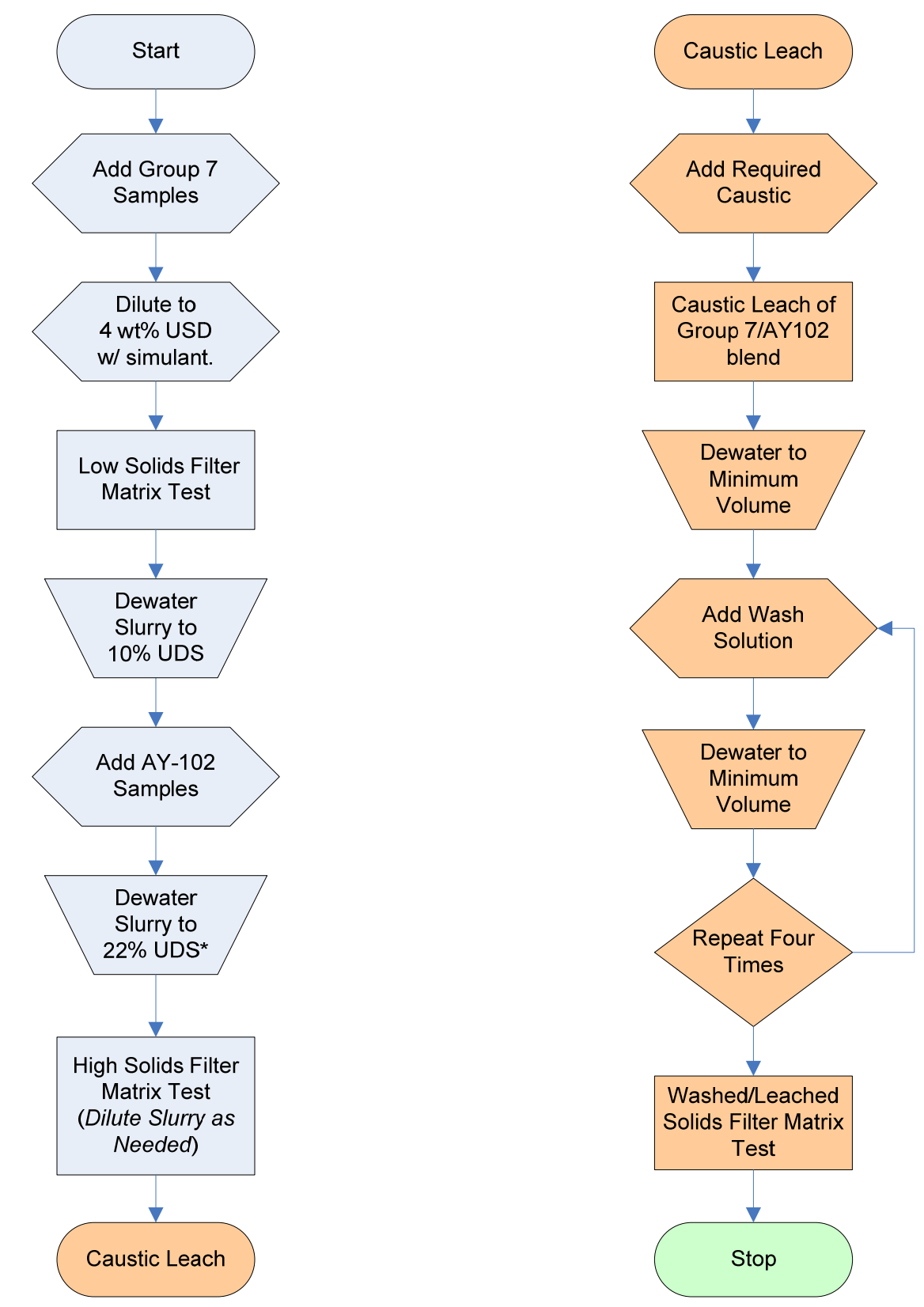

${ }^{*}$ Concentration value is target

Figure 5.1. Group 7 / AY-102 Testing Flowchart

- Both the Group 7 composite and the AY-102 archive tank sample contained insoluble aluminum (in the form of gibbsite), which had the potential to be removed by caustic leaching. However, a majority of the aluminum inventory came from AY-102.

- The quantity of phosphorus in the AY102 was not significant, so a majority of the phosphorus present in the composite waste was to be from Group 7.

- Both wastes contained similar quantities of iron. 
- The TRU inventory in the AY-102 samples was greater than 100 times higher than that present in the Group 7 waste.

The AY-102 slurry was added to the CUF and diluted with additional supernate to maintain the slurry UDS concentration at $\sim 11 \mathrm{wt} \%$. After the slurry was homogenized again, it was dewatered to minimum volume and target UDS concentration. At this point, another test matrix was performed to evaluate the change in the filtration behavior after concentrating the waste slurry.

The second half of the testing was to evaluate the caustic-leaching behavior of the Group 7/AY-102 blended waste slurry, as outlined in the right column of Figure 5.1. After completing the high-solidsconcentration filtration test matrix, the sample was drained from the CUF piping and placed back into the slurry reservoir after isolating the tank from the filtration piping. At this point, a known volume and concentration of $\mathrm{NaOH}$ was blended with the concentrated slurry to increase the leach volume to 3.4 liters. The caustic addition was based on the following preparations:

- Approximately 20 grams of aluminum was present in the combined slurry-4 grams from the 180 grams of insoluble Group 7 solids and $16 \mathrm{~g}$ from the 220 grams of insoluble 241-AY-102 solids.

- A leach factor of $100 \%$ for the 20 grams of aluminum present was used to verify that the final freehydroxide concentration was high enough to maintain Al solubility ${ }^{(a)}$ after the leach solution cooled to room temperature. The final molar ratio of free hydroxide to aluminum was predicted to be 10 to 1 .

- After calculating the free-hydroxide concentration needed to maintain Al solubility after cooling, the required addition of $\mathrm{NaOH}$ was calculated. This mass was to be added as a 19-M NaOH solution.

- Once the volume of dewatered slurry and $19 \mathrm{M} \mathrm{NaOH}$ was known, the volume of water to be added to the leach solution representing the leach volume increase due to condensation from heating via steam injection was calculated.

- Because this was a hot-cell operation, only one solution addition was desired. Therefore, the 19-M $\mathrm{NaOH}$ addition and water addition for steam condensate were combined into one solution. The final solution became 1.4 liters of $5.3 \mathrm{M} \mathrm{NaOH}$.

- The expected sodium concentration during the leach was planned to be $4.5 \mathrm{M}$ while the final freehydroxide concentration was $2.7 \mathrm{M}$.

- The consumption of hydroxide by phosphorus was considered to be negligible for this test

This caustic solution was used to rinse additional solids in the CUF piping before isolating the slurry reservoir tank for leaching operations. After rinsing the CUF slurry piping with the caustic addition, the drained slurry, supernate, and caustic addition solution were added to the isolated slurry reservoir tank with the overhead mixer operating. Because leaching for phosphorus and aluminum in the form of gibbsite does not require leaching beyond $60^{\circ} \mathrm{C}$, the process for the leach deviated from the historic baseline conditions as follows:

- The leach slurry was heated from $25^{\circ} \mathrm{C}$ to $60^{\circ} \mathrm{C}\left(+5^{\circ} /-10^{\circ} \mathrm{C}\right)$ over a 2.5 -hour period.

- The leach slurry temperature was held at $60^{\circ} \mathrm{C}$ for 8 hours.

(a) Solubility of aluminum and hydroxide taken from data reported by Huixin Li, et al., in The Influence of Al(III) Supersaturation and $\mathrm{NaOH}$ Concentration on the Rate of Crystallization of $\mathrm{Al}(\mathrm{OH})_{3}$ Precursor Particles From Sodium Aluminate Solutions, Journal of Colloid and Interface Science (2005, Vol. 286, pg. 511-519). 
- The leach slurry was cooled to $25^{\circ} \mathrm{C}$ over 5.6 hours.

During the 8-h leaching period, the slurry was sampled and filtered to measure changes in the supernate composition to track the dissolution rate of aluminum and phosphorus. After the leaching slurry had cooled to ambient temperature, it was dewatered to the minimum operating volume of the circulation pump. Four equal-volume caustic wash solutions (1.2 liters) were then added to the leached slurry. To prevent aluminum from precipitating during washing, additional caustic was added to each wash solution to prevent the free-hydroxide concentration from falling too low to maintain aluminum solubility. The concentration of $\mathrm{NaOH}$ in each wash was:

- $0.5 \mathrm{M}$ for the first rinse solution

- $0.1 \mathrm{M}$ for the second rinse solution

- $0.05 \mathrm{M}$ for the third rinse solution

- $0.01 \mathrm{M}$ for the fourth rinse solution.

After 20 to 30 minutes of mixing the slurry with each rinse solution, the slurry was dewatered. A final test matrix was performed on the washed leached slurry to compare with the filter behavior of the preleached slurry.

During testing, slurry and supernate samples were periodically collected to track the solids content in the waste slurry and to track the chemical composition of the slurry to perform mass balance calculations to evaluate the effectiveness of the process in separating LAW waste components from the HLW components in the waste sample. Details of the analyses performed and planning for this test scheme can be found in Appendices $\mathrm{H}$.

\subsection{Low-Solids Slurry Characterization}

Figure 5.2 and Table 5.1 outline the activities and materials added to the CUF to produce the low-solids slurry. Initially, $1.79 \mathrm{~kg}$ of the TBP sludge (at $10 \mathrm{wt} \% \mathrm{UDS}$ ) was added to the slurry reservoir. These waste samples were taken from the Group 7 characterization/homogenization study (described in Section 3). To dilute the waste slurry to $\sim 4 \mathrm{wt} \%$ UDS for the low-solids matrix test, $2.42 \mathrm{~kg}$ of a simulant supernate was added to the reservoir and blended with the actual waste samples. The composition of the simulant (shown in Table 5.2) was based on results of supernate characterization performed on the homogenized Group 7 waste (see Section 3).

Once the actual waste samples and simulant were blended in the slurry reservoir tank, the slurry was circulated through the CUF with permeate from the ultra filter recycling back to the slurry reservoir. The hold-up of slurry supernate in the filter and permeate loop was $\sim 200 \mathrm{~mL}$. Slurry samples were collected for chemical and physical characterization inside the slurry circulation loop. These samples were inadvertently destroyed during replacement of a broken pump, so no physical-property data are available for the initial slurry. The chemical and radiological composition of the waste slurry is summarized in Table 5.3 and the supernate opportunistic composition in Table 5.4. The composition is based on the characterization of the starting material, the known composition of the simulant added, and changes due to slurry sampling. Results are expressed as the total amount of components in the CUF slurry (mass balance) and include the supernate present in the permeate loop. 


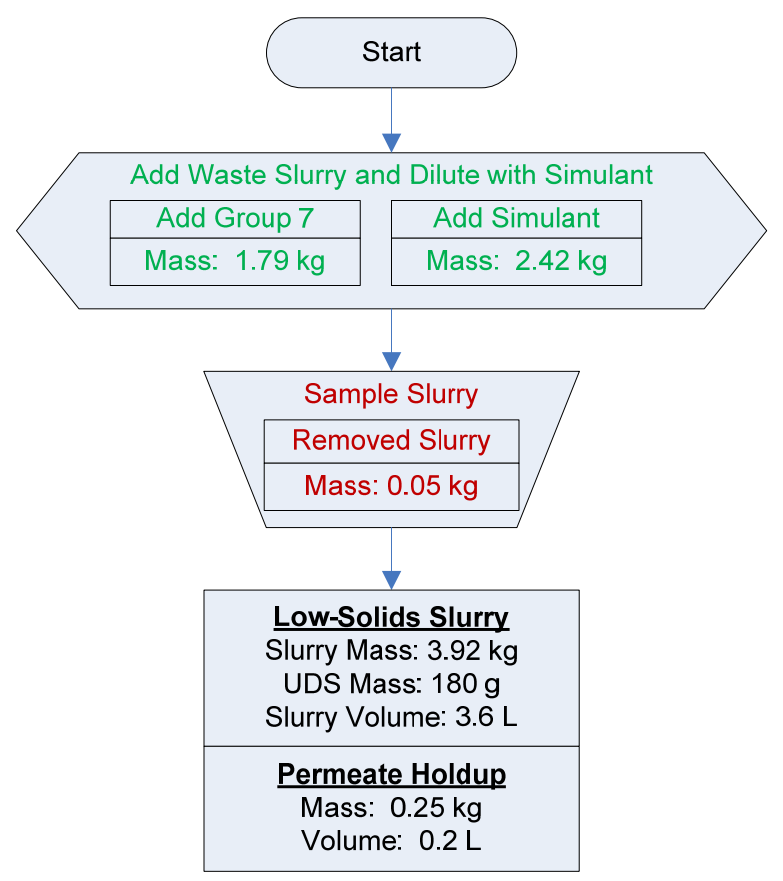

Figure 5.2. Process Flow Diagram of Creating Low-Solids Slurry

Table 5.1. Mass Balance Overview of Group 7 Low-Solids Slurry

\begin{tabular}{||l|c|c|c|c|c||}
\hline \multicolumn{1}{|c|}{ Step } & $\begin{array}{c}\text { Change in } \\
\text { Mass } \\
\text { (g) }\end{array}$ & $\begin{array}{c}\text { Total } \\
\text { Mass } \\
\text { (g) }\end{array}$ & $\begin{array}{c}\text { Estimated } \\
\text { Solid } \\
\text { Mass } \\
(\mathbf{g})\end{array}$ & $\begin{array}{c}\text { Slurry } \\
\text { Circulating } \\
\text { Mass (g) }\end{array}$ & $\begin{array}{c}\text { Estimated } \\
\text { Slurry } \\
\text { UDS } \\
\text { (wt\%) }\end{array}$ \\
\hline Add Group 7 Slurry & +1790 & 1790 & 180 & & \\
\hline $\begin{array}{l}\text { Add Simulated } \\
\text { Supernate }\end{array}$ & +2420 & 4210 & 180 & & \\
\hline Initial Slurry & 0 & 4210 & 180 & 3970 & 4.3 \\
\hline $\begin{array}{l}\text { Slurry Sample Loss/ } \\
\text { Low-Solids Slurry }\end{array}$ & -50 & 4160 & 180 & 3920 & 4.3 \\
\hline \hline
\end{tabular}


Table 5.2. Simulant Addition to Group 7 Composite

\begin{tabular}{|c|c|c|c|c|c|}
\hline \multirow[b]{2}{*}{ Cations } & \multicolumn{2}{|c|}{$\begin{array}{c}\text { Simulant Addition } \\
(2.00 \mathrm{~L})\end{array}$} & \multicolumn{2}{|c|}{$\begin{array}{c}\text { Actual Slurry Waste \& } \\
\text { Simulant } \\
(4.21 \mathrm{~kg}) \\
\end{array}$} & \multirow{2}{*}{$\begin{array}{c}\begin{array}{c}\% \text { slurry due } \\
\text { to simulant }\end{array} \\
w t \% \\
\end{array}$} \\
\hline & $\mathrm{mg} / \mathrm{L}$ & mg & $\mathrm{mg} / \mathrm{g}$ & mg & \\
\hline $\mathrm{Na}$ & 99,000 & 198,000 & 83.2 & 350,000 & 57 \\
\hline \multicolumn{6}{|l|}{ Metals } \\
\hline $\mathrm{Al}$ & 0 & 0 & 0.94 & 3,980 & 0 \\
\hline $\mathrm{Cr}$ & 0 & 0 & 0.06 & 250 & 0 \\
\hline $\mathrm{P}$ & 3,720 & 7,430 & 9,300 & 39,100 & 19 \\
\hline \multicolumn{6}{|l|}{ Anions } \\
\hline $\mathrm{C}_{2} \mathrm{O}_{4}$ & 0 & 0 & 0.02 & 63.3 & 0 \\
\hline $\mathrm{NO}_{2}$ & 18,400 & 36,800 & 14.5 & 60,800 & 60 \\
\hline $\mathrm{NO}_{3}$ & 180,000 & 359,000 & 143 & 603,000 & 60 \\
\hline $\mathrm{SO}_{4}$ & 17,300 & 34,500 & 13.4 & 56,300 & 61 \\
\hline $\mathrm{PO}_{4}$ & 11,400 & 22,800 & 9.86 & 41,500 & 55 \\
\hline
\end{tabular}

Table 5.3. Low-Solids Inventory and Composition (including permeate hold-up)

\begin{tabular}{|c|c|c|c|c|c|}
\hline & Slurry $^{(a)}$ & \multicolumn{2}{|c|}{ Liquid Fraction $^{(b)}$} & \multicolumn{2}{|c|}{ Solids Fraction $^{(\mathrm{c})}$} \\
\hline Mass (kg) & 4.17 & \multicolumn{2}{|c|}{3.99} & \multicolumn{2}{|c|}{0.18} \\
\hline Wt\% of Slurry & $100 \%$ & \multicolumn{2}{|c|}{$95.7 \%$} & \multicolumn{2}{|c|}{$4.3 \%$} \\
\hline Metal & g & g & $\mu \mathrm{g} / \mathrm{ml}$ & g & $\mu \mathrm{g} / \mathrm{g}$ \\
\hline Al & $3.9 \mathrm{E}+00$ & $5.0 \mathrm{E}-01$ & $1.6 \mathrm{E}+02$ & $3.4 \mathrm{E}+00$ & $1.9 \mathrm{E}+04$ \\
\hline B & $7.2 \mathrm{E}-02$ & $6.6 \mathrm{E}-02$ & $2.0 \mathrm{E}+01$ & $6.4 \mathrm{E}-03$ & $3.6 \mathrm{E}+01$ \\
\hline $\mathbf{B i}$ & $1.3 \mathrm{E}+00$ & $<1 . \mathrm{E}-2$ & $<4 . \mathrm{E}+0$ & $1.3 \mathrm{E}+00$ & $7.6 \mathrm{E}+03$ \\
\hline $\mathrm{Ca}$ & $3.7 \mathrm{E}+00$ & $3.2 \mathrm{E}-02$ & $1.0 \mathrm{E}+01$ & $3.7 \mathrm{E}+00$ & $2.1 \mathrm{E}+04$ \\
\hline Cd & $1.1 \mathrm{E}-03$ & $4.7 \mathrm{E}-03$ & $1.5 \mathrm{E}+00$ & $\mathrm{n} / \mathrm{a}^{(\mathrm{d})}$ & $\mathrm{n} / \mathrm{a}^{(\mathrm{d}}$ \\
\hline $\mathrm{Cr}$ & $2.4 \mathrm{E}-01$ & $7.6 \mathrm{E}-02$ & $2.3 \mathrm{E}+01$ & $1.7 \mathrm{E}-01$ & $9.5 \mathrm{E}+02$ \\
\hline $\mathbf{F e}$ & $3.3 \mathrm{E}+01$ & $2.1 \mathrm{E}-03$ & $6.6 \mathrm{E}-01$ & $3.3 \mathrm{E}+01$ & $1.9 \mathrm{E}+05$ \\
\hline $\mathbf{K}$ & $1.7 \mathrm{E}-01$ & $4.4 \mathrm{E}-01$ & $1.4 \mathrm{E}+02$ & $\mathrm{n} / \mathrm{a}^{(\mathrm{d})}$ & $\mathrm{n} / \mathrm{a}^{(\mathrm{d}}$ \\
\hline Mn & $2.0 \mathrm{E}-01$ & 5.3E-04 & $1.7 \mathrm{E}-01$ & $2.0 \mathrm{E}-01$ & $1.1 \mathrm{E}+03$ \\
\hline $\mathrm{Na}$ & $3.5 \mathrm{E}+02$ & $3.0 \mathrm{E}+02$ & $9.2 \mathrm{E}+04$ & $5.0 \mathrm{E}+01$ & $2.8 \mathrm{E}+05$ \\
\hline $\mathbf{N i}$ & $1.2 \mathrm{E}-01$ & $<9 . \mathrm{E}-4$ & $<3 . \mathrm{E}-1$ & $1.2 \mathrm{E}-01$ & $6.5 \mathrm{E}+02$ \\
\hline $\mathbf{P}$ & $3.9 \mathrm{E}+01$ & $1.5 \mathrm{E}+01$ & $4.5 \mathrm{E}+03$ & $2.4 \mathrm{E}+01$ & $1.4 \mathrm{E}+05$ \\
\hline $\mathrm{s}$ & $1.9 \mathrm{E}+01$ & $1.9 \mathrm{E}+01$ & $5.9 \mathrm{E}+03$ & 3.2E-01 & $1.8 \mathrm{E}+03$ \\
\hline $\mathrm{Si}$ & $1.6 \mathrm{E}+00$ & $<2 . \mathrm{E}-3$ & $<7 . \mathrm{E}-1$ & $1.6 \mathrm{E}+00$ & $9.2 \mathrm{E}+03$ \\
\hline $\mathrm{Sr}$ & $9.2 \mathrm{E}-01$ & $3.5 \mathrm{E}-04$ & $1.1 \mathrm{E}-01$ & 9.2E-01 & $5.2 \mathrm{E}+03$ \\
\hline $\mathbf{Z n}$ & $1.8 \mathrm{E}-01$ & $3.2 \mathrm{E}-03$ & $1.0 \mathrm{E}+00$ & $1.8 \mathrm{E}-01$ & $9.9 \mathrm{E}+02$ \\
\hline $\mathrm{Zr}$ & $5.6 \mathrm{E}-03$ & $5.2 \mathrm{E}-04$ & $1.6 \mathrm{E}-01$ & $5.0 \mathrm{E}-03$ & $2.8 \mathrm{E}+01$ \\
\hline $\mathbf{U}$ & $2.6 \mathrm{E}+01$ & $4.4 \mathrm{E}-01$ & $1.4 \mathrm{E}+02$ & $2.6 \mathrm{E}+01$ & $1.5 \mathrm{E}+05$ \\
\hline
\end{tabular}


WTP-RPT-169, Rev 0

Table 5.3 (Contd)

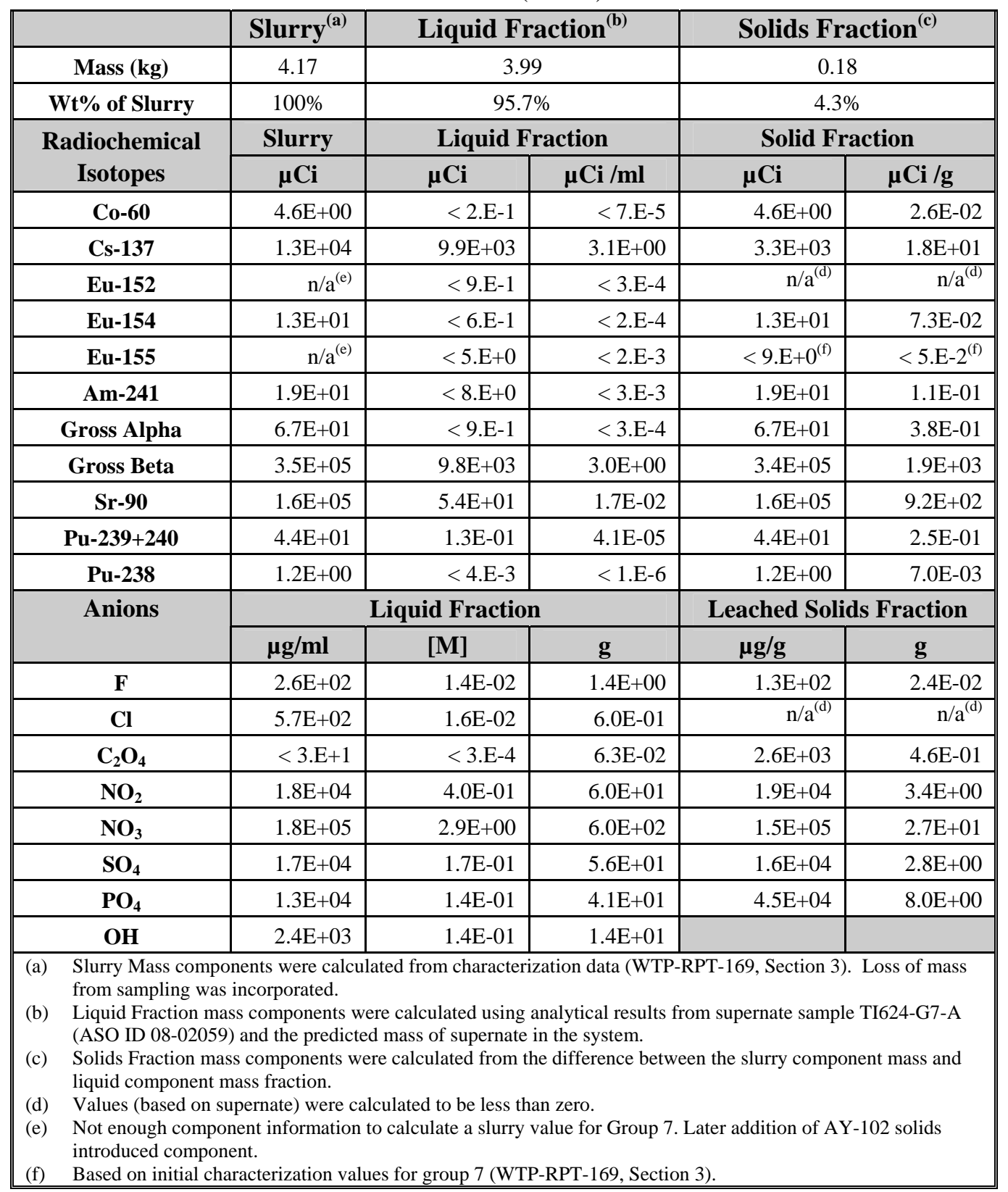

Particle-size measurements were performed on the slurry sample taken before the filtration testing. Table 5.5 shows select cumulative undersize percentiles for the low-solids slurry. Here the $d(10)$ ranges between 28 and $38 \mu \mathrm{m}$, the d(50) between 81 and $240 \mu \mathrm{m}$, and the $\mathrm{d}(90)$ between 150 and $510 \mu \mathrm{m}$. With regard to pump-speed effects, the $\mathrm{d}(50)$ and $\mathrm{d}(90)$ percentiles show a significant increase in size at 4000 RPM, indicating the presence of large, difficult-to-suspend particles.

Figure 5.3 shows the PSD for the Group 7 low-solids matrix as a function of pump speed. The sample shows a broad bi-modal distribution. At 2000 RPM, the distribution ranges from 1 to $500 \mu \mathrm{m}$ with peak maxima at 190 and $30 \mu \mathrm{m}$. At $3000 \mathrm{RPM}$, the range is from 0.3 to $300 \mu \mathrm{m}$ with peak maxima at 90 and $12 \mu \mathrm{m}$. At $4000 \mathrm{RPM}$, the distribution ranges from 0.6 to $750 \mu \mathrm{m}$ with peak maxima at 330 and $50 \mu \mathrm{m}$. 
As the pump speed increases from 3000 to 4000 RPM, there are more large particles or agglomerates that may be difficult-to-suspend; this may account for the extended range at $4000 \mathrm{RPM}$. These particles suspended at 4000 RPM may be slow settling relative to the measurement time and may contribute to the larger particle diameters at 2000 RPM in comparison with the distribution at 3000 RPM. Overall, the distribution shows that the majority of particles and/or agglomerates are $>20 \mu \mathrm{m}$, and their distribution is dependent upon pump speed. 
Table 5.4. Group 7 Low-Solids Supernate Opportunistic Composition

\begin{tabular}{|c|c|}
\hline \multirow{3}{*}{$\begin{array}{l}\text { Opportunistic } \\
\text { Analytes }\end{array}$} & \multirow{2}{*}{$\begin{array}{c}\text { Supernate } \\
\text { Measured }^{(a)}\end{array}$} \\
\hline & \\
\hline & $\mu \mathrm{g} / \mathrm{mL}$ \\
\hline Ag & $<2.6 \mathrm{E}-1$ \\
\hline As & $<6.3 \mathrm{E}+0$ \\
\hline Ba & [0.17] \\
\hline Be & $<6.3 \mathrm{E}-3$ \\
\hline Ca & [10.0] \\
\hline $\mathrm{Ce}$ & $<1.2 \mathrm{E}+0$ \\
\hline Co & $<2.9 \mathrm{E}-1$ \\
\hline $\mathrm{Cu}$ & $<1.7 \mathrm{E}-1$ \\
\hline Dy & $<3.5 \mathrm{E}-1$ \\
\hline Eu & $<1.3 \mathrm{E}-1$ \\
\hline La & $<3.4 \mathrm{E}-1$ \\
\hline $\mathbf{L i}$ & 3.76 \\
\hline Mg & $<2.8 \mathrm{E}-1$ \\
\hline Mo & [2.9] \\
\hline Nd & $<2.1 \mathrm{E}+0$ \\
\hline $\mathbf{P b}$ & $<3.9 \mathrm{E}+0$ \\
\hline Pd & $<7.7 \mathrm{E}-1$ \\
\hline Rh & [1.8] \\
\hline Ru & [1.1] \\
\hline Sb & $<2.4 \mathrm{E}+0$ \\
\hline Se & [14] \\
\hline Sn & $<3.3 \mathrm{E}+0$ \\
\hline Ta & $<2.1 \mathrm{E}+0$ \\
\hline Te & $<3.2 \mathrm{E}+0$ \\
\hline Th & $<1.2 \mathrm{E}+0$ \\
\hline Ti & $<5.2 \mathrm{E}-2$ \\
\hline Tl & $<4.6 \mathrm{E}+0$ \\
\hline $\mathbf{V}$ & [0.35] \\
\hline $\mathbf{W}$ & [3.15] \\
\hline $\mathbf{Y}$ & $<5.3 \mathrm{E}-2$ \\
\hline $\begin{array}{l}\text { (a) Supernatant me } \\
\text { ID 08-02059); } \\
\text { Analyte uncertaintie } \\
\text { indicate that the ana } \\
\text { detection limit (MD } \\
\text { (EQL), and uncertai } \\
\text { Opportunistic analy } \\
\text { (QC) requirements c }\end{array}$ & $\begin{array}{l}\text { mple TI624-G7-A (RPL } \\
2007 . \\
\% \text {; results in brackets } \\
\text { ater than the method } \\
\text { ed quantitation limit } \\
\text { ion only; quality control } \\
\text { es. }\end{array}$ \\
\hline
\end{tabular}


Table 5.5. Particle Size Analysis Percentile Results for Group 7 Low-Solids Matrix

\begin{tabular}{||c|c|c|c|c|c||}
\hline $\begin{array}{c}\text { Measurement } \\
\text { Condition }\end{array}$ & Pump Speed & Sonication & $\begin{array}{c}\mathbf{d}(\mathbf{1 0}) \\
{[\boldsymbol{\mu m}]}\end{array}$ & $\begin{array}{c}\mathbf{d}(\mathbf{5 0}) \\
{[\boldsymbol{\mu m}]}\end{array}$ & $\begin{array}{c}\mathbf{d}(\mathbf{9 0}) \\
{[\boldsymbol{\mu m}]}\end{array}$ \\
\hline 1 & 3000 & $\mathrm{n} / \mathrm{a}$ & 28 & 81 & 150 \\
\hline 2 & 4000 & $\mathrm{n} / \mathrm{a}$ & 38 & 240 & 510 \\
\hline 3 & 2000 & $\mathrm{n} / \mathrm{a}$ & 38 & 190 & 350 \\
\hline 4 & 2000 & $\mathrm{n} / \mathrm{a}$ & 31 & 170 & 290 \\
\hline
\end{tabular}

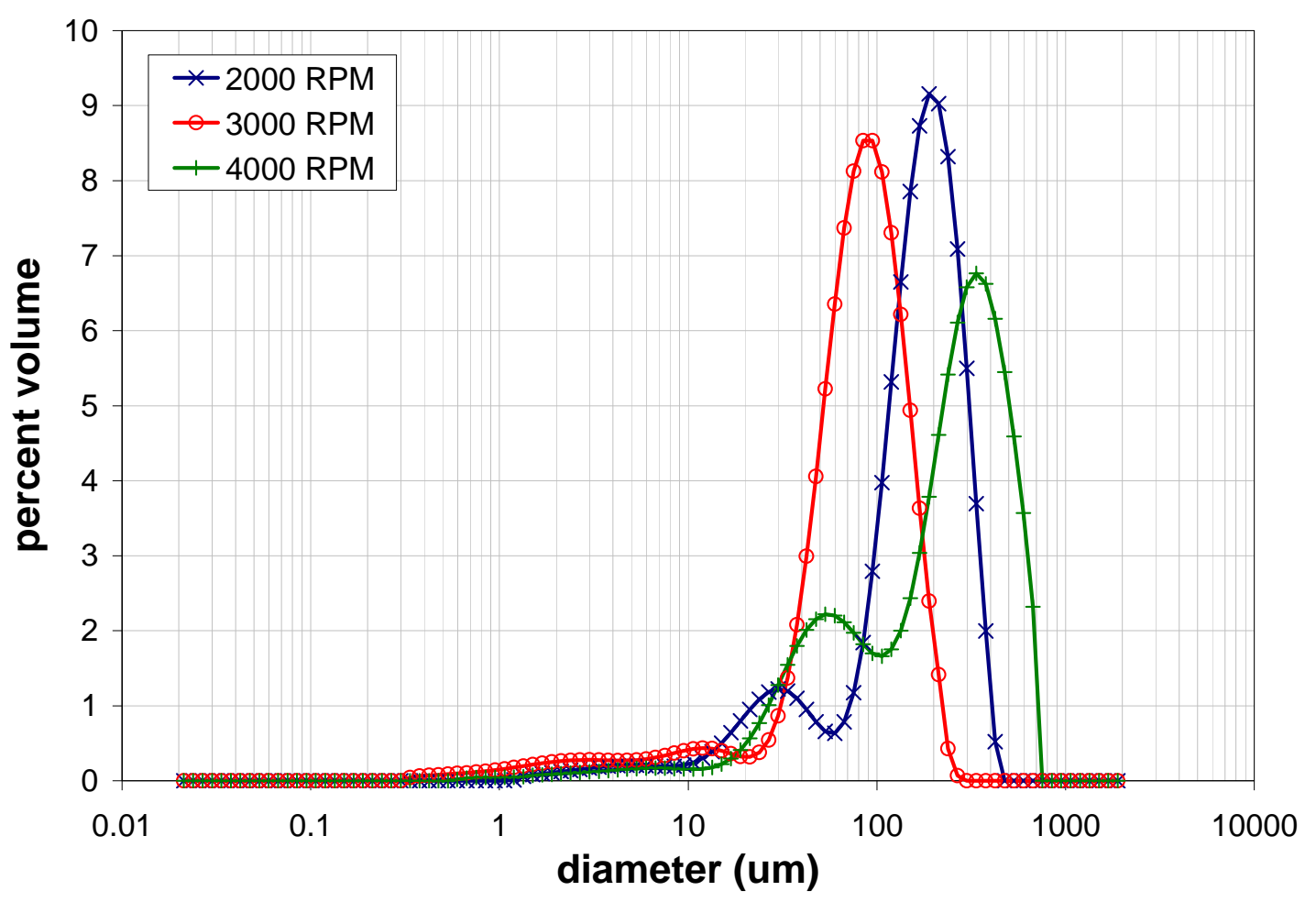

Figure 5.3. PSD of CUF Group 7 Low-Solids Slurry as a Function of Pump Speed

Table 5.6 and Figure 5.4 show the influence of circulation in the CUF on the PSD of Group 7 waste solids. Here, select cumulative undersize percentiles and the PSD for the initial characterization are compared to low-solids matrix slurry. Both samples show a similar PSD range of 0.2 to $400 \mu \mathrm{m}$ with a primary peak maximum between 70 to $90 \mu \mathrm{m}$. The major difference observed in the low-solids matrix slurry is a large shift in the population to the primary peak diameter. This shift may likely be due to transient effects, such as shear-induced agglomeration or flocculation occurring in the PSD analyzer, resulting in a significant relative increase in 20 - to $300-\mu \mathrm{m}$ particles. This shift may also indicate a variation in composition because of sampling difficulties due to large difficult-to-suspend particles. These larger particles also present a complication since they are near the upper limit of the instrument's particle suspension capability and cannot be suspended reliably. The impact of poor suspension on the measured volume particles in this size range is difficult to quantify, as it depends on the settling rate of particles in the instrument flow cell. In addition, preparation and analysis steps for CUF PSD samples typically involve dilution and resuspension. As such, there is significant potential for dissolution, reprecipitation, and ripening. 
Table 5.6. Cumulative Undersize Percentiles Showing the Influence of Circulation in the CUF on Group 7 PSD at Measurement Condition 1 to 3000 RPM

\begin{tabular}{||l|c|c|c||}
\hline \multicolumn{1}{|c|}{ Sample } & $\begin{array}{c}\mathbf{d}(\mathbf{1 0}) \\
{[\boldsymbol{\mu m}]}\end{array}$ & $\begin{array}{c}\mathbf{d}(\mathbf{5 0}) \\
{[\boldsymbol{\mu m}]}\end{array}$ & $\begin{array}{c}\mathbf{d}(\mathbf{9 0}) \\
{[\boldsymbol{\mu m}]}\end{array}$ \\
\hline Group 7 Initial Characterization (TI576-G7-S-WL-PSD-1) & 1.0 & 19 & 130 \\
\hline Group 7 Low Solids Matrix Slurry (TI624-G7-3-PSD) & 28 & 81 & 150 \\
\hline
\end{tabular}

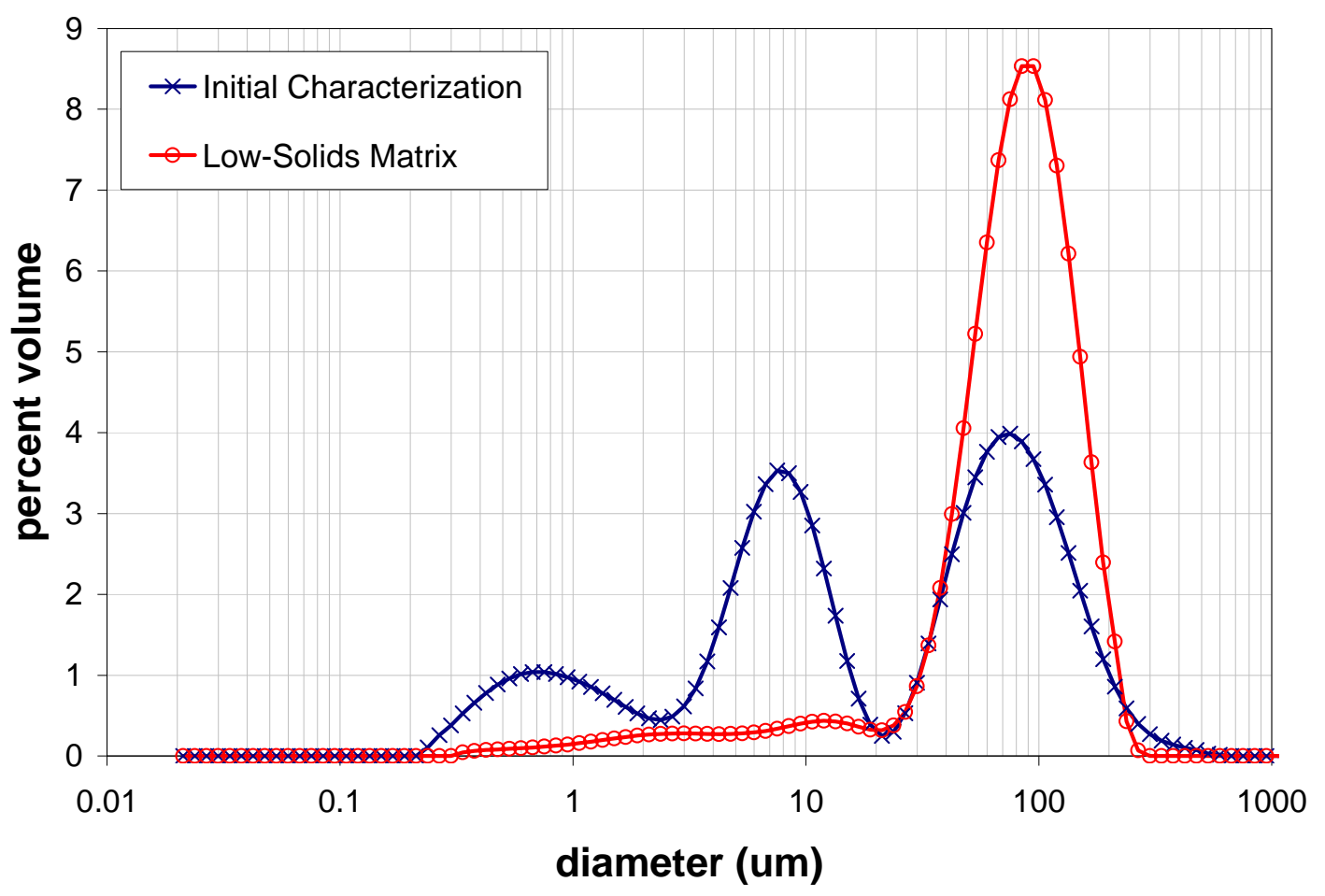

Figure 5.4. Influence of Circulation in the CUF for Group 7. All PSDs were taken at measurement condition 1 to 3000 RPM.

Rheology measurements of the low-solids slurry were taken before the filtration test as well. Figure 5.5 shows the results of flow-curve testing for the low-solids slurry. The measured flow curves indicate nonNewtonian slurry behavior, with the slurry showing finite yield stress, shearing-thinning, and possible hysteresis. The exact cause of possible hysteresis in the current measurements is difficult to ascertain from flow-curve data alone. However, because the hysteresis is characterized by a transient decrease in stress response over the course of the measurement, it can be speculated that hysteresis results from either shear-induced solids structure changes (i.e., sample thixotropy) or solids settling out of the measurement gap.

Flow-curve data at $25^{\circ} \mathrm{C}, 40^{\circ} \mathrm{C}$, and $60^{\circ} \mathrm{C}$ were fit to both Bingham-Plastic and Casson models. Table 5.7 summarizes the best-fit model parameters for the low-solids slurry. Since the data were not influenced by Taylor vortex formation, the full range of shear rates $\left(0\right.$ to $\left.500 \mathrm{~s}^{-1}\right)$ is employed in the Casson fitting analysis. Bingham-Plastic analysis cannot account for slurry shear thinning, and as a result, its fitting analysis is limited to 100 to $500 \mathrm{~s}^{-1}$ to avoid bias introduced by slurry shear thinning at low shear rates. 
Both models provide reasonable fits of the data, although the Casson model provides a better description of the flow curve (especially over 0 to $100 \mathrm{~s}^{-1}$ ).

Apparent viscosities at 33, 100, 500, and $1000 \mathrm{~s}^{-1}$ were derived from each measurement. For each temperature, the 33,100 , and $500 \mathrm{~s}^{-1}$ reference viscosities were determined from the average of both upramp and down-ramp flow-curve data. The apparent viscosity at $1000 \mathrm{~s}^{-1}$ is derived from the averaging of all apparent viscosity measurements during constant rotation at $1000 \mathrm{~s}^{-1}$. As a point of comparison, apparent viscosities were also calculated using the Bingham-Plastic and Casson fitting parameters in Table 5.7. The results of these analyses are provided in Table 5.8.

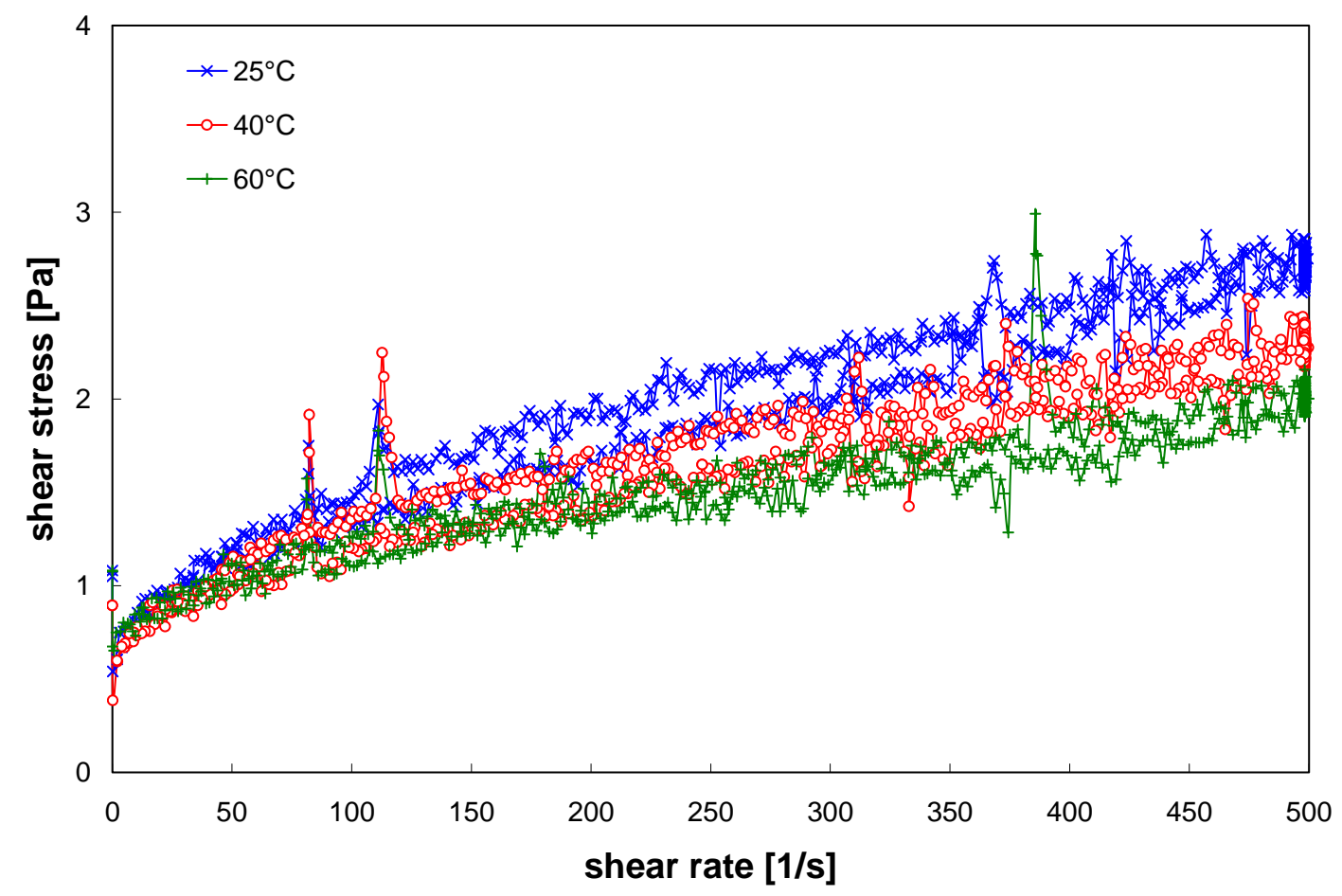

Figure 5.5. Flow Curves for Group 7 CUF Low Solids Slurry

Table 5.7. Results of Fitting Analysis for Group 7 CUF Low Solids Matrix

\begin{tabular}{|c|c|c|c|c|c|}
\hline Model & Temperature $\left[{ }^{\circ} \mathrm{C}\right]$ & Range & $\begin{array}{c}\text { Yield } \\
\text { Stress [Pa] }\end{array}$ & $\begin{array}{c}\text { Consistency } \\
\text { [mPa·s] }\end{array}$ & $\mathbf{R}$ \\
\hline \multirow{4}{*}{$\begin{array}{l}\text { Bingham- } \\
\text { Plastic }\end{array}$} & $25(1$ of 2$)$ & $100-500 \mathrm{~s}^{-1}$ & 1.3 & 3.1 & 0.96 \\
\hline & 25 (2 of 2$)$ & $100-500 \mathrm{~s}^{-1}$ & 1.2 & 3.1 & 0.97 \\
\hline & 40 & $100-500 \mathrm{~s}^{-1}$ & 1.1 & 2.4 & 0.94 \\
\hline & 60 & $100-500 \mathrm{~s}^{-1}$ & 1.0 & 1.9 & 0.92 \\
\hline \multirow[t]{4}{*}{ Casson } & 25 (1 of 2$)$ & $0-500 \mathrm{~s}^{-1}$ & 0.7 & 1.3 & 0.98 \\
\hline & 25 (2 of 2$)$ & $0-500 \mathrm{~s}^{-1}$ & 0.7 & 1.4 & 0.98 \\
\hline & 40 & $0-500 \mathrm{~s}^{-1}$ & 0.7 & 1.0 & 0.97 \\
\hline & 60 & $0-500 \mathrm{~s}^{-1}$ & 0.7 & 0.7 & 0.95 \\
\hline
\end{tabular}


Table 5.8. Select Apparent Viscosities for the Low Solids Slurry

\begin{tabular}{|c|c|c|c|c|c|}
\hline \multirow[b]{2}{*}{ Source } & \multirow{2}{*}{$\begin{array}{c}\text { Temperature } \\
{\left[{ }^{\circ} \mathrm{C}\right]} \\
\end{array}$} & \multicolumn{4}{|c|}{ Apparent Viscosity [mPa·s] } \\
\hline & & @ $33 \mathrm{~s}^{-1}$ & @ $100 \mathrm{~s}^{-1}$ & @ $500 \mathrm{~s}^{-1}$ & @ $1000 \mathrm{~s}^{-1}$ \\
\hline \multirow[t]{4}{*}{ Measured } & 25 (1 of 2$)$ & 34 & 15 & 6.6 & $\mathrm{n} / \mathrm{a} *$ \\
\hline & 25 (2 of 2$)$ & 31 & 14 & 5.5 & $\mathrm{n} / \mathrm{a}^{*}$ \\
\hline & 40 & 27 & 13 & 4.2 & $\mathrm{n} / \mathrm{a}^{*}$ \\
\hline & 60 & 29 & 12 & 4.4 & $\mathrm{n} / \mathrm{a}^{*}$ \\
\hline \multirow[t]{4}{*}{ Bingham-Plastic } & 25 (1 of 2$)$ & 41 & 16 & 5.6 & 4.3 \\
\hline & 25 (2 of 2$)$ & 39 & 15 & 5.5 & 4.3 \\
\hline & 40 & 35 & 13 & 4.6 & 3.5 \\
\hline & 60 & 33 & 12 & 4.0 & 3.0 \\
\hline \multirow[t]{4}{*}{ Casson } & 25 (1 of 2$)$ & 35 & 15 & 5.6 & 4.0 \\
\hline & $25(2$ of 2$)$ & 32 & 14 & 5.4 & 4.0 \\
\hline & 40 & 29 & 13 & 4.5 & 3.2 \\
\hline & 60 & 29 & 12 & 4.0 & 2.7 \\
\hline
\end{tabular}

\subsection{Filter-Flux Test Matrix and Initial Dewater}

This section describes the filtration testing performed using the Group 7 composite and AY-102 tank sample before leaching, as shown in the left column of Figure 5.1. The following tests were performed.

- Filtration testing of the composite Group 7 waste slurry at a low-solids concentration as described in Appendix H. Testing compares the effects of transmembrane pressure (TMP), axial velocity (AV), and operation time on filter flux.

- Dewatering of the waste slurry to a higher UDS concentration using a constant TMP and AV to understand the impact of solids concentration on filtration performance, and to provide data that can be compared to previous testing of other wastes.

- Adding the AY-102 archive tank waste samples to the Group 7 (TBP) sample in the system to achieve the high solids concentration of about $20 \mathrm{wt} \%$ in the dewatered slurry.

- Dewatering the blended waste using a constant TMP and AV to compare to dewatering of the Group 7 before the AY-102 addition and increase the UDS concentration to $20 \mathrm{wt} \%$.

- Filtration testing of the slurry at a high-solids concentration. Like before, testing compares the effects of TMP, AV, and operation time on filter flux.

\subsubsection{Low-Solids Test Matrix}

After all the slurry samples were collected, and the rheology sample was returned to the CUF, the lowsolids matrix test was performed. The average filter flux and process parameter for each filtration test in the matrix is reported in Table 5.9. The measured filter flux over the course of the test matrix is shown in Figure 5.6 where $t=0$ is defined as the starting point of the test matrix. The average TMP and AV from each test condition are plotted against the target values for each test in Figure 5.7.

The average filter flux from each test condition (Table 5.9) was plotted against TMP, AV, and the median operational time of the test condition to qualitatively gauge their impact. The filter flux was found to be directly proportional to the TMP (Figure 5.8). The plot for AV (Figure 5.9) contains a large amount of 
scatter and does not show a significant relationship between the filter flux and the AV. The plot for filter flux over time (Figure 5.10) has a slightly downward but significant trend. Comparing test conditions 1 and 11 at the standard conditions (TMP $=40 \mathrm{psid}, \mathrm{AV}=13 \mathrm{ft} / \mathrm{s}$ ) demonstrates that the filter flux drops from 0.028 to $0.018 \mathrm{GPM} / \mathrm{ft}^{2}$ which is a $36 \%$ decrease over the course of the 16 -hour test. This indicates that the filter membrane was fouling and that filter resistance was not at steady state during this test.

The effects of TMP, AV, and relative processing time on filter flux was quantified by modeling of the data using a least-squares-fit method. Process time reflects the average time for the given process conditions since the start of testing. This variable is intended to assess the fouling of the filter that occurs through the duration of testing. A linear-fit equation with an $\mathrm{R}^{2}$ correlation of 0.98 was developed using TMP and processing time as variables (Figure 5.11). The model also showed that processing time had a measureable negative effect on flux, demonstrating that filter resistance was slightly increasing over time by some fouling mechanism occurring with the waste. Axial velocity was shown to have no significant impact on the filter flux from this analysis.

Use of this model was limited to comparing TMP and AV impacts on filter flux during this test and how filter behavior changed later. During development of the linear model, a positive offset was created. Therefore, the model does not predict a zero filter flux when the TMP is zero, demonstrating that the input to these models must be bound by the range of TMP used in this filter test, shown in Table 5.9. The use of the model should also be limited to when the test matrix occurred because the filter resistance was not at steady state, and the parameters developed in these models would be expected to change past the 16-hour period that this model predicts.

Table 5.9. Average Operating Conditions and Permeate Flux for Low-Solids Matrix Test

\begin{tabular}{|c|c|c|c|c|c|c|c|}
\hline $\begin{array}{c}\text { Design } \\
\text { Test } \\
\text { Condition } \\
\end{array}$ & $\begin{array}{c}\text { Median } \\
\text { Operation } \\
\text { Time of } \\
\text { Test }^{\text {(a) }} \\
\text { (hr:mm) } \\
\end{array}$ & $\begin{array}{c}\text { Slurry } \\
\text { Temp }^{(b)} \\
\left({ }^{\circ} \mathbf{C}\right)\end{array}$ & $\begin{array}{l}\mathrm{TMP}^{(\mathrm{c})} \\
\text { (psid) }\end{array}$ & $\begin{array}{c}\text { Axial } \\
\text { Velocity } \\
(\mathrm{ft} / \mathrm{s}) \\
\end{array}$ & $\begin{array}{l}\text { Permeate } \\
\text { Flowrate } \\
\text { (mL/min) }\end{array}$ & $\begin{array}{c}\text { Corrected } \\
\text { Permeate } \\
\text { Flux } \\
\left(\mathrm{GPM} / \mathrm{ft}^{2}\right) \\
\end{array}$ & $\begin{array}{c}\text { Axial } \\
\text { Pressure } \\
\text { Drop }^{(\mathrm{c})} \\
\text { (psid/ft) }^{\text {pre }}\end{array}$ \\
\hline 1 & $1: 41$ & 23.5 & 41.0 & 13.1 & 26.3 & 0.028 & 2.0 \\
\hline 2 & $3: 48$ & 23.4 & 31.1 & 11.0 & 20.0 & 0.021 & 1.7 \\
\hline 3 & $5: 02$ & 23.7 & 31.0 & 14.9 & 18.3 & 0.019 & 2.3 \\
\hline 4 & $6: 25$ & 23.5 & 49.8 & 15.2 & 24.8 & 0.026 & 2.4 \\
\hline 5 & $7: 43$ & 24.2 & 50.4 & 11.0 & 25.5 & 0.026 & 1.8 \\
\hline 6 & $8: 54$ & 24.4 & 41.2 & 13.0 & 19.9 & 0.020 & 2.0 \\
\hline 7 & $10: 12$ & 24.2 & 40.8 & 8.8 & 20.1 & 0.021 & 1.5 \\
\hline 8 & $11: 36$ & 24.6 & 40.4 & 17.1 & 17.8 & 0.018 & 2.6 \\
\hline 9 & $12: 52$ & 24.5 & 22.3 & 12.9 & 10.2 & 0.010 & 1.9 \\
\hline 10 & 14:06 & 24.8 & 62.5 & 13.2 & 26.6 & 0.027 & 2.0 \\
\hline 11 & $15: 11$ & 24.4 & 40.9 & 12.8 & 17.6 & 0.018 & 1.9 \\
\hline \multicolumn{8}{|c|}{$\begin{array}{l}\text { (a) Median operation time refers to the midpoint in processing time of the specific filtration test condition } \\
\text { relative to the start time of the test }(\mathrm{T}=0) \text {. Time periods between test conditions were excluded. } \\
\text { (b) Thermocouple accuracy } \pm 2^{\circ} \mathrm{C} \text {. } \\
\text { (c) Pressure transducer accuracy } \pm 1 \text { psig. }\end{array}$} \\
\hline
\end{tabular}




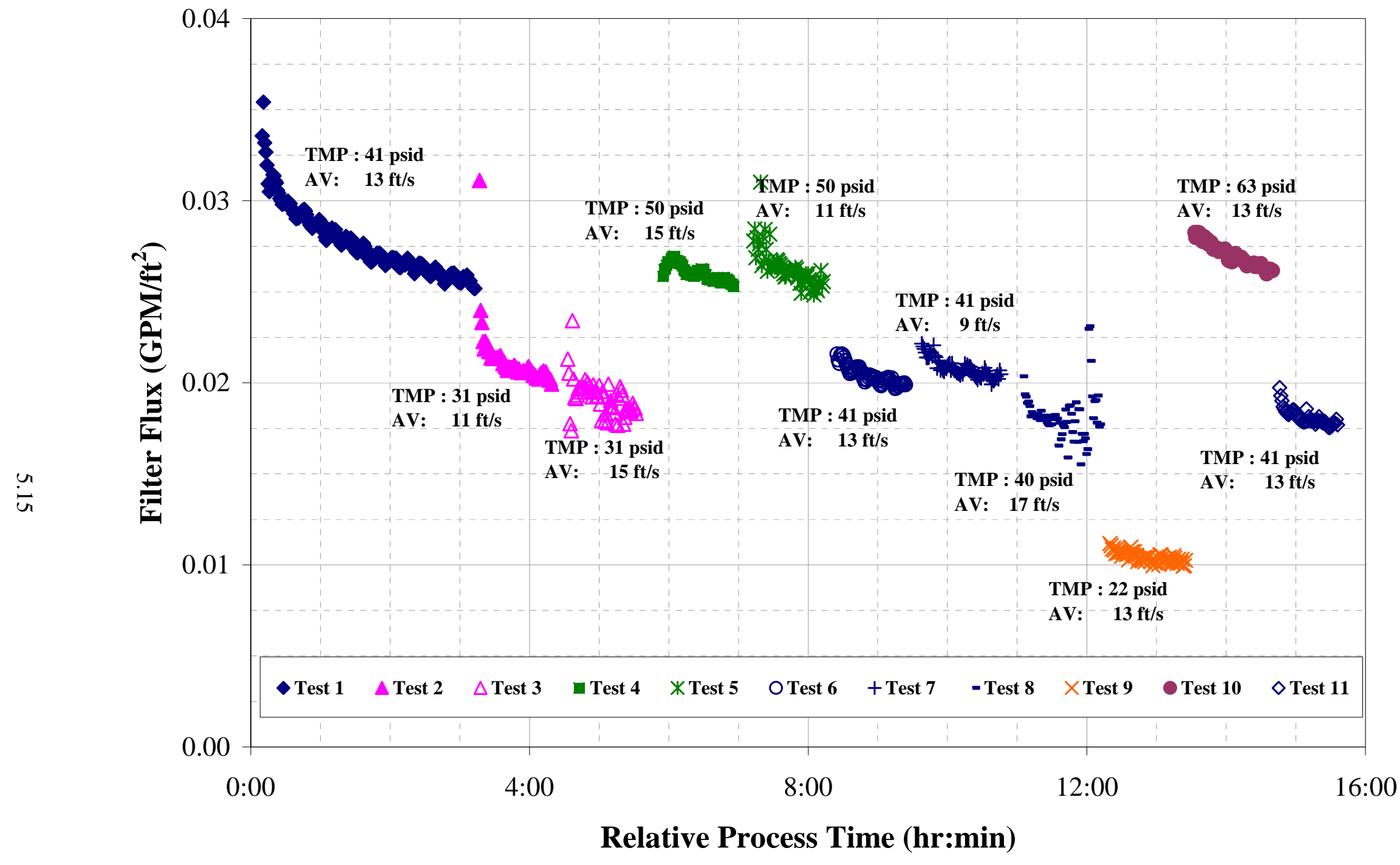

Figure 5.6. Filter-Flux Data for Low-Solids Matrix (Predicted UDS concentration of 4 wt\%) 


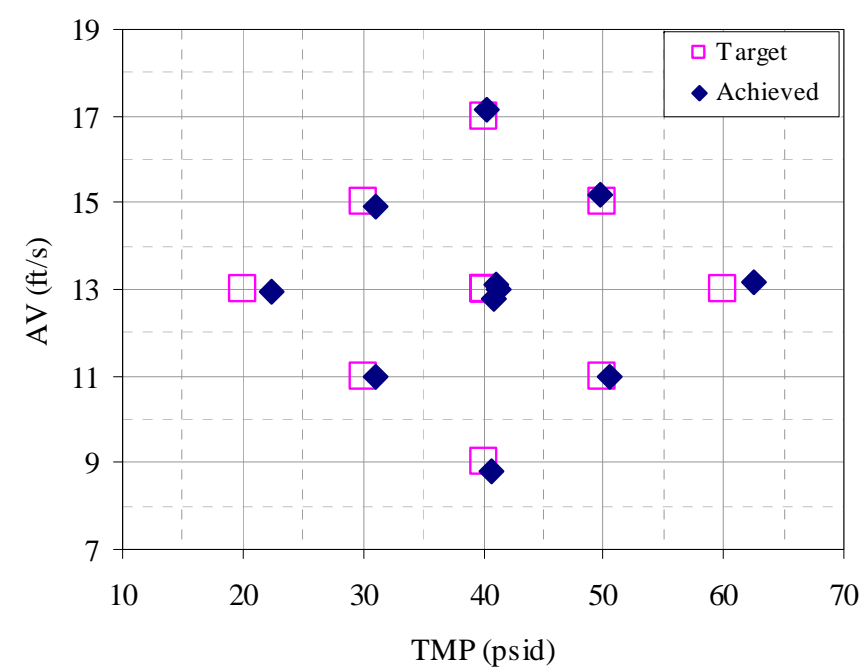

Figure 5.7. Filter Test Matrix for Group 7 Lows-Solids

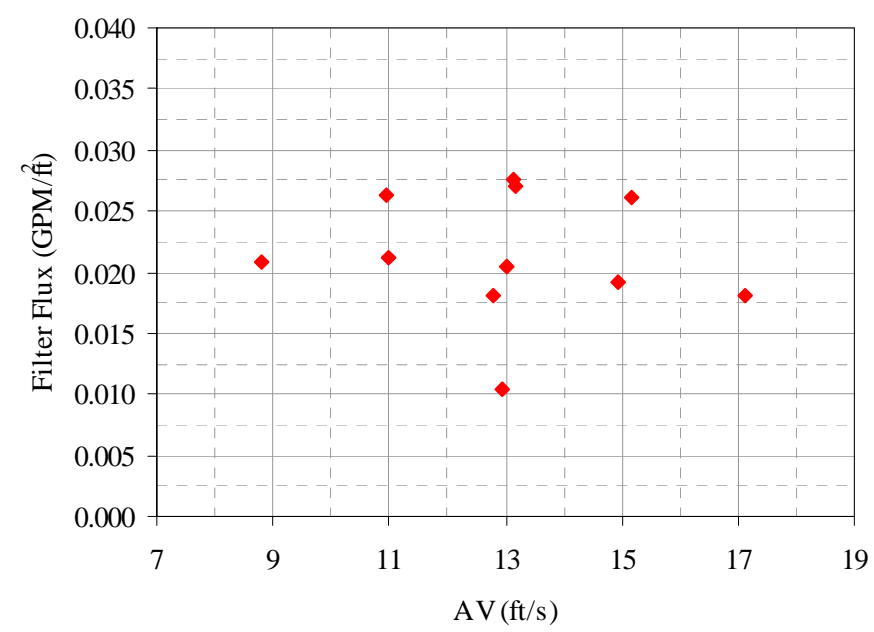

Figure 5.9. Flux vs. AV for Group 7 Low-Solids

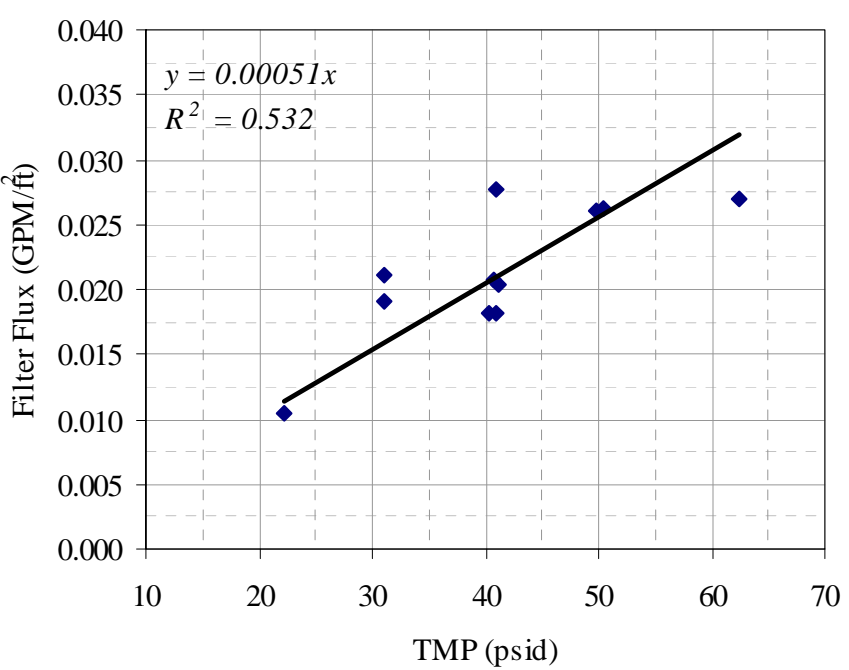

Figure 5.8. Flux vs. TMP for Group 7 Low-Solids

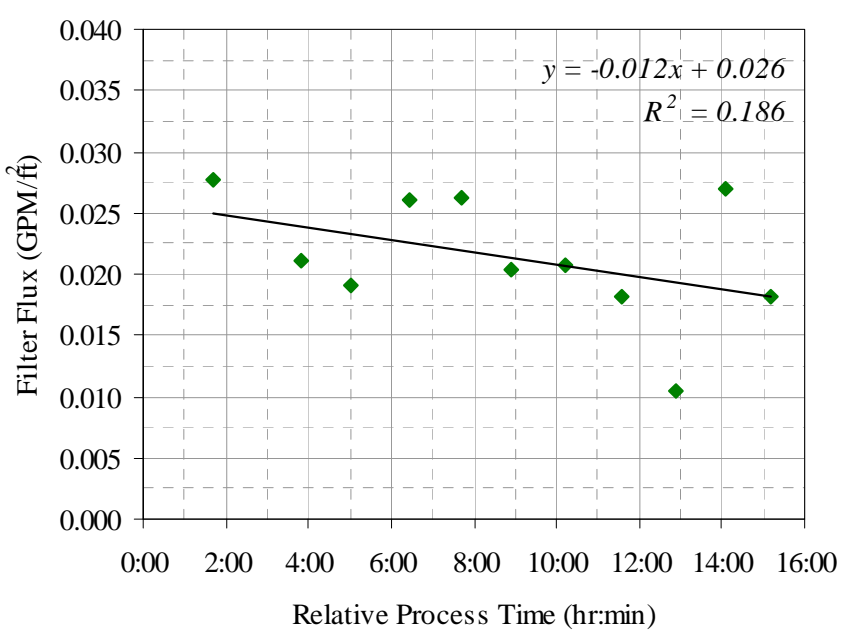

Figure 5.10. Flux vs. Median Process Time of Test Condition for Group 7 Low-Solids 


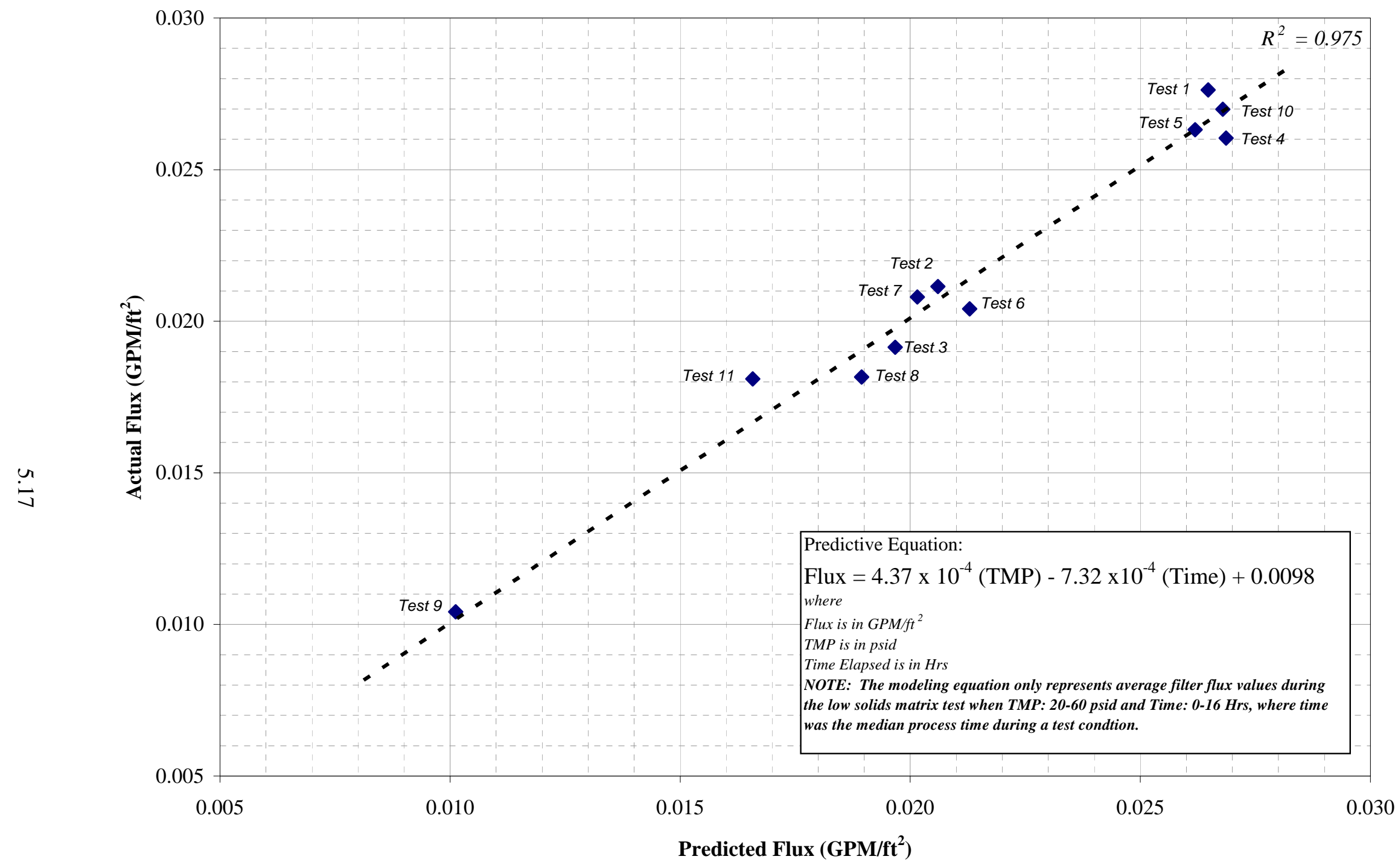

Figure 5.11. Correlation Calculations of Average Flux as Function of TMP and Time (Predicted UDS of 4 wt\%) 


\subsubsection{Group 7 Dewatering}

The Group 7 sample was dewatered after the low-solids test to a target UDS of 13 wt\%. An overview of the test activities and mass balance is shown in Figure 5.12 and Table 5.10. Filter-flux results are charted against relative processing time in Figure 5.13. Approximately $2 \mathrm{~L}$ of filtered supernate was removed from the slurry over the course of 110 minutes, increasing the slurry UDS concentration to $12 \mathrm{wt} \%$ inside the CUF slurry circulation loop. Over the course of the dewatering, the filter flux rate decreased from 0.019 to $0.017 \mathrm{GPM} / \mathrm{ft}^{2}$. A spike in the filter flux was observed from 25 to 30 minutes into the dewatering. Examining axial-velocity data during this time shows noticeable variation, indicating a problem with the pump, such as cavitation. Despite the increase in the filter flux measured, the TMP decreased from 42 to 40 psid, and the AV decreased from 13.0 to $12.5 \mathrm{ft} / \mathrm{s}$. After 15 minutes, the TMP and AV returned to the original settings without any adjustments. If air bubbles were entrained into the slurry, this would explain the variation seen in the filter permeate flow and changes in the pumping behavior during this time frame. Examination of the raw data over this time range revealed that the variability in the averaged flux data is due to highly erratic readings from the mass flowmeter. Such readings are indicative of air bubbles periodically passing through the meter.

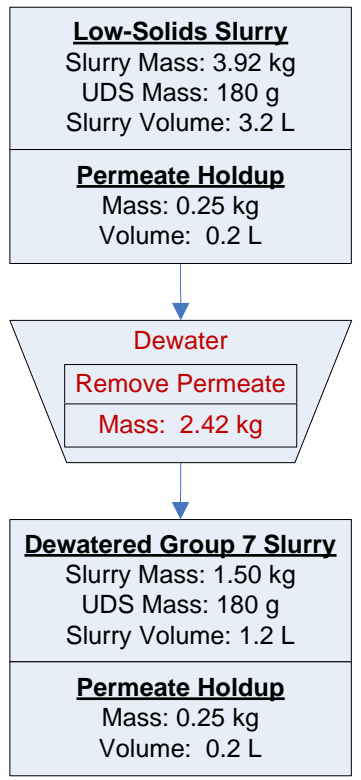

Figure 5.12. Process Flow for Dewatering Group 8 Slurry

Table 5.10. Mass Balance Overview of Dewatering

\begin{tabular}{||l|c|c|c|c|c|}
\hline \multicolumn{1}{|c|}{ Step } & $\begin{array}{c}\text { Change in } \\
\text { Mass } \\
(\mathbf{g})\end{array}$ & $\begin{array}{c}\text { Total } \\
\text { Mass } \\
\mathbf{( g )}\end{array}$ & $\begin{array}{c}\text { Estimated } \\
\text { Solid Mass } \\
\mathbf{( g )}\end{array}$ & $\begin{array}{c}\text { Slurry } \\
\text { Circulating } \\
\text { Mass (g) }\end{array}$ & $\begin{array}{c}\text { Estimated } \\
\text { Slurry UDS } \\
\text { (wt\%) }\end{array}$ \\
\hline Low-Solids Slurry & & 4160 & 180 & 3920 & $4.3 \mathrm{wt} \%$ \\
\hline Dewatered Slurry & -2420 & 1750 & 180 & 1500 & $12 \mathrm{wt} \%$ \\
\hline
\end{tabular}




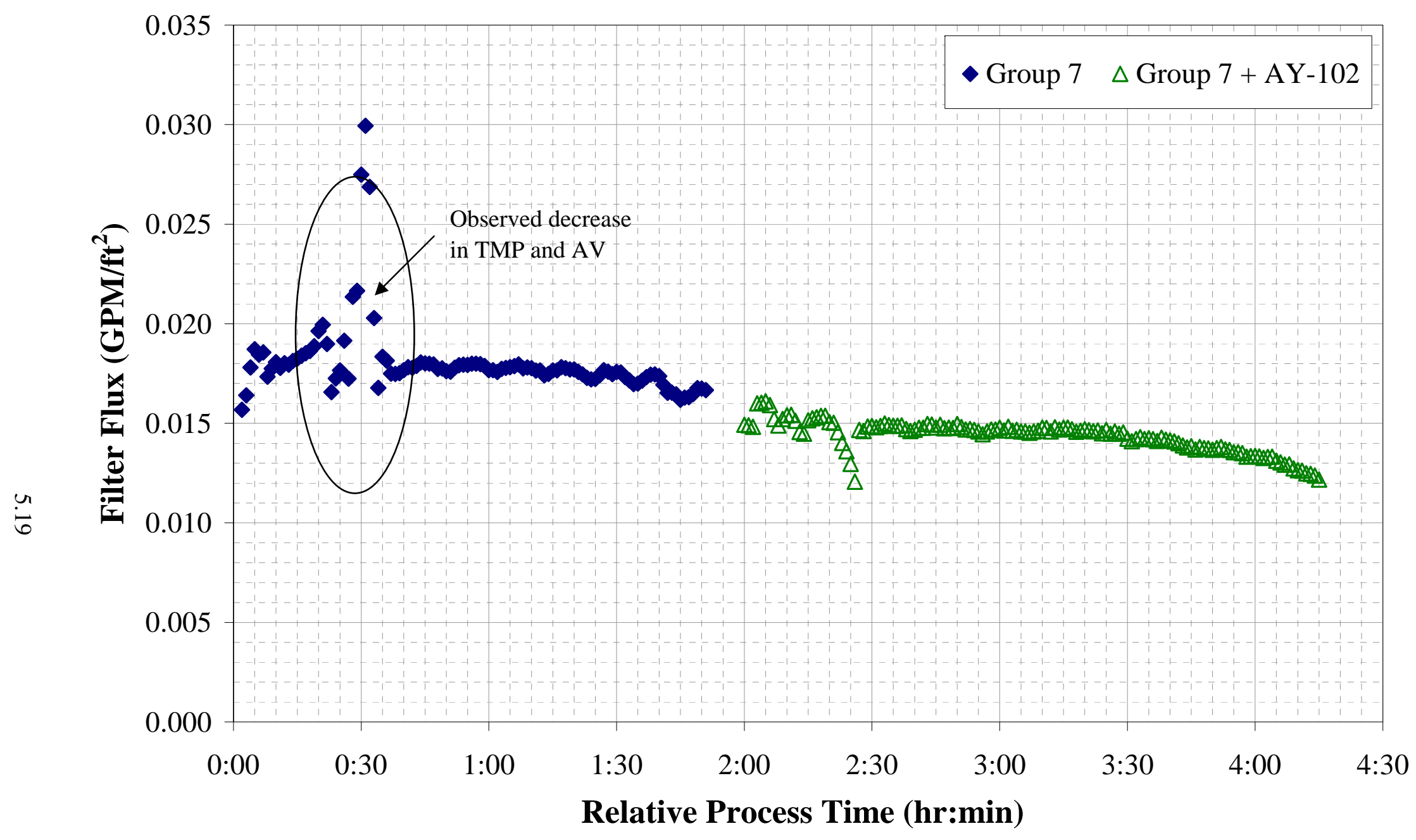

Figure 5.13. Dewatering of Group 7 (4 to 12 wt\% UDS) and the Blended Waste (12 to $26 \mathrm{wt} \%$ UDS) 


\subsubsection{Adding AY-102 and Pump Failure}

AY-102 was added to the Group 7 sample in the system after the low solids filtration matrix test was completed to boost the solids content of the sample, as discussed in Sec. 5.1. Physical-property measurements performed on the combined slurry are shown in Table 5.11. The mass balance for the addition is shown in Figure 5.14 and Table 5.12.

After the samples of the AY102 were added to the CUF, the pump froze before the blended waste sample could be dewatered. Despite initial success in cleaning and restarting the pump, it soon froze again, and the main seal failed. The pump head was removed, and a magnetic stir bar was discovered inside, most likely from adding one of the AY-102 samples. The system was drained, the pump replaced, and the sample returned to the system. Permeate collected in the previous step was used during cleaning operations to recover a majority of the slurry solids.

When the slurry was returned, the mass of the returned slurry was measured to account for losses that occurred from the pump failure and draining of the slurry out of the CUF. Physical-property measurements indicated that initial estimates of the UDS concentration of the archived AY-102 slurry were lower than believed. Despite the losses created from the pump failure, the inventory of solids in the CUF at this point was believed to be 460 grams at this point in the process, based on the final results of physical-property testing (Table 5.11). The waste solids ratio between AY-102 to Group 7 was estimated as 2:1.

Table 5.11. Physical Properties of the Blended Group 7/AY102 Slurry Before Dewatering

\begin{tabular}{|r|c||}
\hline Slurry Density (g/mL) & 1.28 \\
\hline Supernate Density (g/mL) & 1.24 \\
\hline Settled Solids (Vol \%) & $48 \%$ \\
\hline Centrifuged UDS (Wt \%) & $55 \%$ \\
\hline Total Solids (Wt \%) & $33 \%$ \\
\hline Dissolved Solids (Wt \%) & $24 \%$ \\
\hline UDS (Wt \%) & $12 \%$ \\
\hline
\end{tabular}


WTP-RPT-169, Rev 0

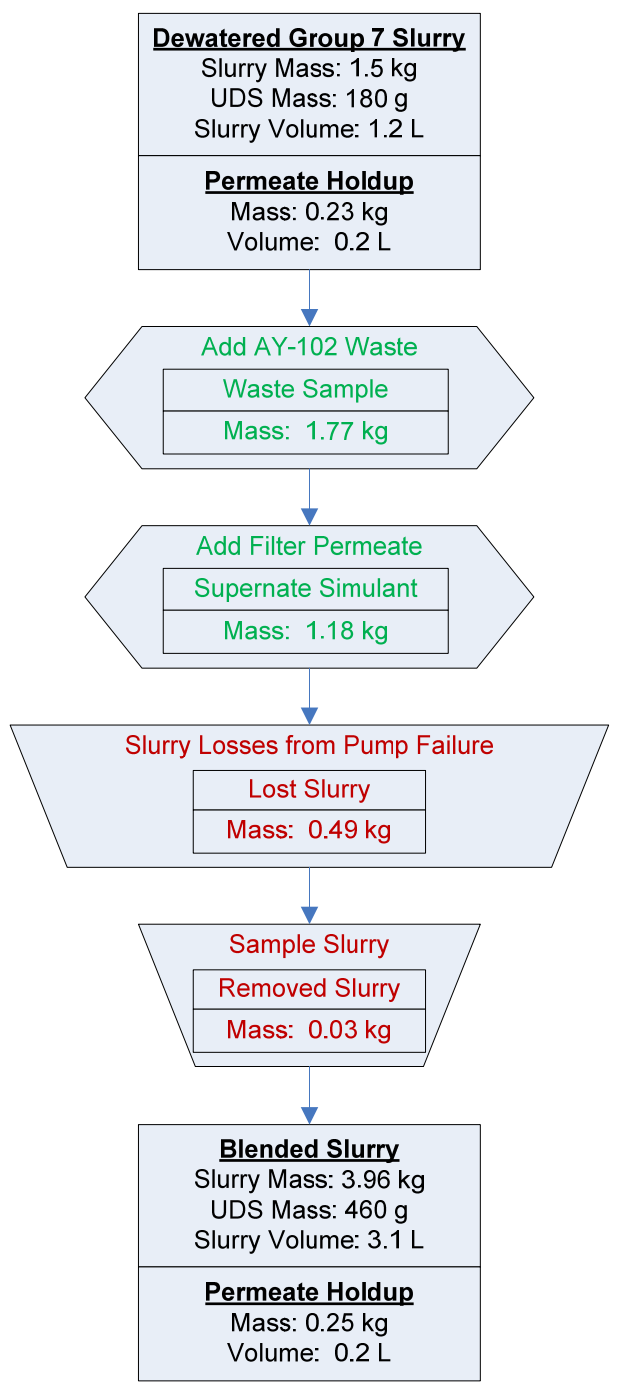

Figure 5.14. Process Flow of AY-102 Addition and Losses Created by Pump Failure

Table 5.12. Mass Balance Overview of Dewatering, AY-102 Addition

\begin{tabular}{|l|c|c|c|c|c|c||}
\hline \multicolumn{1}{|c|}{ Step } & $\begin{array}{c}\text { Change in } \\
\text { Mass } \\
\mathbf{( g )}\end{array}$ & $\begin{array}{c}\text { Total } \\
\text { Mass } \\
\mathbf{( g )}\end{array}$ & $\begin{array}{c}\text { Estimated } \\
\text { Solid } \\
\text { Mass } \\
\mathbf{( g )}\end{array}$ & $\begin{array}{c}\text { Slurry } \\
\text { Circulating } \\
\text { Mass (g) }\end{array}$ & $\begin{array}{c}\text { Estimated } \\
\text { Slurry } \\
\text { UDS } \\
\text { (wt \%) }\end{array}$ & $\begin{array}{c}\text { Measured } \\
\text { Slurry } \\
\text { UDS } \\
\text { (wt\%) }\end{array}$ \\
\hline $\begin{array}{l}\text { Initial dewatering } \\
\text { (Incl. Sample) }\end{array}$ & 1750 & 180 & 1500 & $12 \mathrm{wt} \%$ & \\
\hline Add AY-102 & +1770 & 3520 & & 3270 & & \\
\hline Add permeate & +1180 & 4700 & & 4450 & & \\
\hline $\begin{array}{l}\text { Mass Loss from } \\
\text { Leakage and Transfers }\end{array}$ & -460 & 4240 & & 3990 & & $11.6 \mathrm{wt} \%$ \\
\hline Sampling & -30 & 4210 & $\mathbf{4 6 0}$ & 3960 & & \\
\hline \hline
\end{tabular}




\subsubsection{Dewatering Group 7IAY-102 Slurry}

The blend slurry was dewatered to a UDS concentration of $26 \mathrm{wt} \%$. An overview of the mass balance is shown in Figure 5.15 and Table 5.13. The measured filter flux is compared to the initial dewatering of the Group 7 waste in Figure 5.13. Comparing the flux before and after the AY102 test shows that the measured flux at the end of the Group 7 dewatering was similar to the start of the blended slurry dewatering. Over the course of 2 hours, the flux ranged from 0.016 to $0.012 \mathrm{GPM} / \mathrm{ft}^{2}$, and $1.8 \mathrm{~L}$ of permeate was collected. Overall, the flux was stable over most of the duration of the dewatering operations. The exception to this occurred about 20 minutes into dewatering of the blended slurry, when the pump speed decreased by by $10 \%$ unexpectedly for about five minutes. During this time, the TMP decreased from 40 psid to 33 psid, which correlated to a decrease in the permeate flow. Without any adjustments, the pump speed returned to normal after five minutes, and dewatering continued at the standard conditions. Physical-property measurements of the slurry afterwards showed that the centrifuge UDS concentration of the blended slurry was 55 to $58 \mathrm{wt} \%$. This indicates that the slurry was capable of being dewatered perhaps even higher than $26 \mathrm{wt} \%$ before the slurry UDS concentration began to limit filter flux. The filter flux began to decrease slightly during the last 30 minutes, indicating that the slurry was beginning to approach a region where the UDS concentration, and not transmembrane pressure, was the dominant filtration parameter.

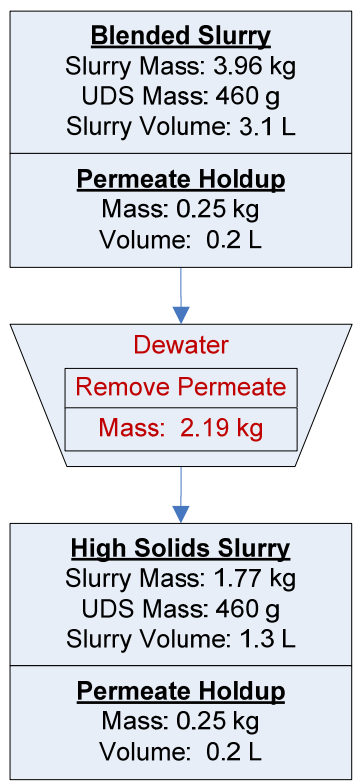

Figure 5.15. Process Flow for Dewatering the Blended Waste Slurry (Group 7/AY-102)

Table 5.13. Mass Balance Overview for the Dewatering of the Blended Slurry to $26 \mathrm{wt} \%$

\begin{tabular}{||l|c|c|c|c|c|c||}
\hline \multicolumn{1}{|c|}{ Step } & $\begin{array}{c}\text { Change in } \\
\text { Mass } \\
(\mathbf{g})\end{array}$ & $\begin{array}{c}\text { Total } \\
\text { Mass } \\
(\mathbf{g})\end{array}$ & $\begin{array}{c}\text { Estimated } \\
\text { Solid } \\
\text { Mass } \\
\mathbf{( g )}\end{array}$ & $\begin{array}{c}\text { Slurry } \\
\text { Circulating } \\
\text { Mass (g) }\end{array}$ & $\begin{array}{c}\text { Estimated } \\
\text { Slurry } \\
\text { UDS } \\
\text { (wt\%) }\end{array}$ & $\begin{array}{c}\text { Measured } \\
\text { Slurry } \\
\text { UDS } \\
\text { (wt \%) }\end{array}$ \\
\hline Blended Slurry & & 4210 & 460 & 3960 & & $11.6 \mathrm{wt} \%$ \\
\hline $\begin{array}{l}\text { Dewatered Slurry } \\
\text { (High-Solids Slurry) }\end{array}$ & -2190 & 2020 & 460 & 1770 & $26 \mathrm{wt} \%$ & $26 \mathrm{wt} \%$ \\
\hline \hline
\end{tabular}




\subsubsection{High-Solids Matrix}

After dewatering, the high-solids matrix test was started. Figure 5.16 displays the complete permeate flux data for each step with respect to the relative processing time. The average filter flux ranged from 0.007 to $0.015 \mathrm{GPM} / \mathrm{ft}^{2}$, with a value near $0.012 \mathrm{GPM} / \mathrm{ft}^{2}$ for the standard filtration condition of TMP $=40 \mathrm{psid}$ and $A V=13 \mathrm{ft} / \mathrm{s}$. Table 5.14 contains the average operating conditions and filter flux for each step of the high-solids matrix. The average TMP and AV from each test condition are plotted against the target values for each test in Figure 5.17.

The average filter flux from each test condition was plotted against TMP, AV, and the median operational time of the test condition to qualitatively gauge their impact, as shown in Figure 5.18 through Figure 5.20. The median operation time for the test condition was used to assess if fouling of the filter was significant during the test, which would shift the results of the test matrix. Filter flux was found to be directly proportional to TMP (Figure 5.18), with a $\mathrm{R}^{2}$ correlation of 0.64. The plot for AV (Figure 5.19) also showed that filter flux was proportional to AV. While the $\mathrm{R}^{2}$ correlation for the trend in Figure 5.19 was only 0.049 , it still suggests some dependence of the flux on the AV. The plot for filter flux over time (Figure 5.20) does not show a significant relationship. Comparing test conditions 1, 6, and 11 at the standard conditions (TMP $=40 \mathrm{psid}, \mathrm{AV}=13 \mathrm{ft} / \mathrm{s}$ ) demonstrates little difference in the average filter flux.

Modeling the data using a least-squares-fit method was then used to quantify the effects of TMP, AV, and relative processing time on filter flux. Process time reflects the average time for the given process conditions since the start of testing. This variable is intended to assess the fouling of the filter that occurs through the duration of testing. While the individual correlations of AV and TMP to flux were not very good, a linear fit equation combining both TMP and AV effects was developed with an $\mathrm{R}^{2}$ correlation of 0.89 (Figure 5.21). This indicates that after dewatering, the slurry filtration behavior was influenced by both the filter medium resistance and the filter cake resistance. As seen from Figure 5.20, the process time was found not to have any significant impact. As seen in previous testing, fouling effects over time tend to decay over time, reaching a steady-state condition.

The use of this model was limited to comparing TMP and AV impacts on filter flux during this test and how the filter behavior changed after dewatering. During development of the linear model, a negative offset was created. Therefore, the model does not predict a zero filter flux when the TMP is zero, demonstrating that the input to these models must be bound by the range of TMP used in this filter test, shown in Table 5.14. The use of the model should also be limited to when the test matrix occurred. While changes in the filter resistance appeared to be not significant over the course of this test, a 16-hour filter matrix test cannot predict fouling influences impacting long-term operations of the CUF. 
Table 5.14. Average Operating Conditions and Permeate Flux for High-Solids Matrix Test

\begin{tabular}{|c|c|c|c|c|c|c|c|}
\hline $\begin{array}{c}\text { Design } \\
\text { Test } \\
\text { Condition } \\
\end{array}$ & $\begin{array}{c}\text { Median } \\
\text { Operation } \\
\text { Time of } \\
\text { Test }^{\text {(a) }} \\
\text { (hr:mm) } \\
\end{array}$ & $\begin{array}{c}\text { Slurry } \\
\text { Temp }^{(b)} \\
\left({ }^{\circ} \mathrm{C}\right)\end{array}$ & $\begin{array}{l}\operatorname{TMP}^{(c)} \\
\text { (psid) }\end{array}$ & $\begin{array}{c}\text { Axial } \\
\text { Velocity } \\
\text { (ft/s) }\end{array}$ & $\begin{array}{l}\text { Permeate } \\
\text { Flowrate } \\
\text { (mL/min) }\end{array}$ & $\begin{array}{c}\text { Corrected } \\
\text { Permeate } \\
\text { Flux } \\
\left(\mathrm{GPM} / \mathbf{f t}^{2}\right) \\
\end{array}$ & $\begin{array}{c}\text { Axial } \\
\text { Pressure } \\
\text { Drop }^{(c)} \\
\text { (psid/ft) }^{\text {pot }}\end{array}$ \\
\hline 1 & $1: 42$ & 23.0 & 39.8 & 12.9 & 10.8 & 0.012 & 2.2 \\
\hline 2 & $3: 59$ & 22.7 & 30.2 & 11.0 & 9.2 & 0.010 & 1.8 \\
\hline 3 & $5: 16$ & 23.9 & 29.9 & 15.1 & 9.4 & 0.010 & 2.3 \\
\hline 4 & $6: 37$ & 29.7 & 50.7 & 14.2 & 17.1 & 0.015 & 2.4 \\
\hline 5 & $7: 48$ & 23.0 & 50.7 & 11.0 & 11.6 & 0.012 & 1.9 \\
\hline 6 & 9:01 & 24.6 & 40.5 & 13.1 & 12.3 & 0.013 & 2.1 \\
\hline 7 & $10: 15$ & 22.3 & 40.1 & 8.9 & 8.5 & 0.009 & 1.8 \\
\hline 8 & $11: 36$ & 27.0 & 41.0 & 14.3 & 12.9 & 0.012 & 2.3 \\
\hline 9 & $12: 50$ & 24.4 & 21.6 & 13.3 & 6.7 & 0.007 & 2.0 \\
\hline 10 & $14: 12$ & 28.2 & 61.9 & 12.5 & 16.1 & 0.015 & 2.2 \\
\hline 11 & $15: 41$ & 26.1 & 39.8 & 12.9 & 11.3 & 0.011 & 2.1 \\
\hline \multicolumn{8}{|c|}{$\begin{array}{l}\text { (a) Median operation time refers to the midpoint in processing time of the specific filtration test condition } \\
\text { relative to the start time of the test }(\mathrm{T}=0) \text {. Time periods between test conditions were excluded. } \\
\text { (b) Thermocouple accuracy } \pm 2^{\circ} \mathrm{C} \text {. }\end{array}$} \\
\hline
\end{tabular}




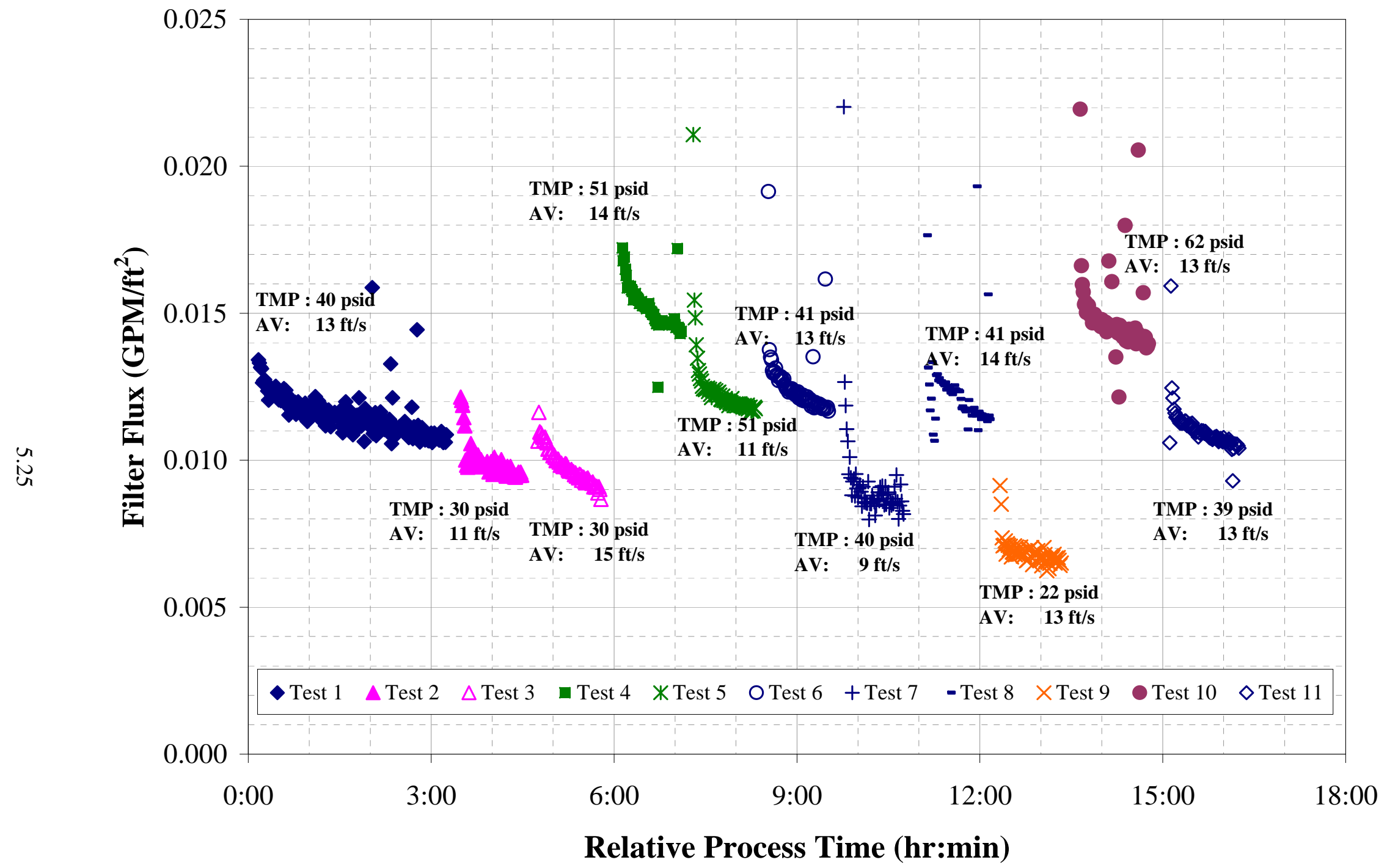

Figure 5.16. Filter-Flux Data for Group 7-AY102 High-Solids Matrix (Measured as 26 wt\% UDS) 


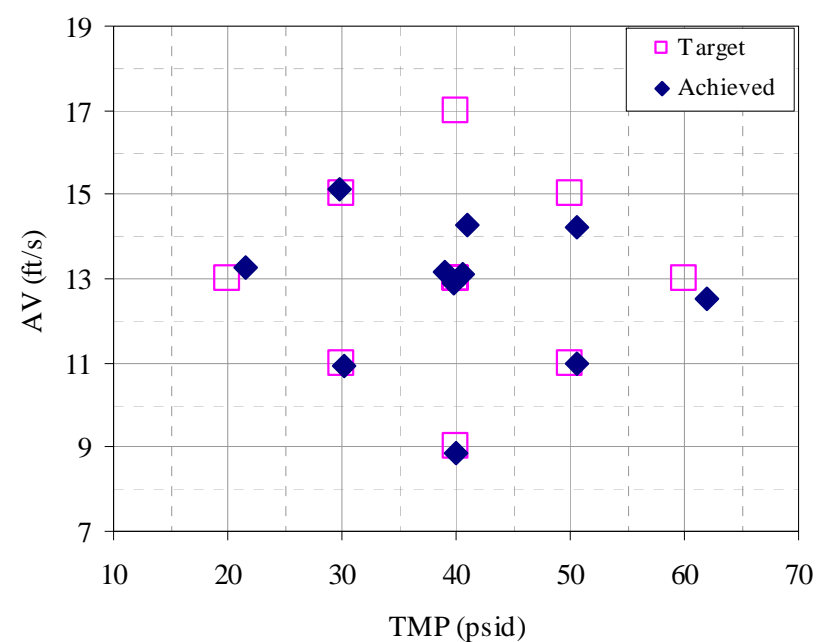

Figure 5.17. Filter Test Matrix for Group 7-AY102 High-

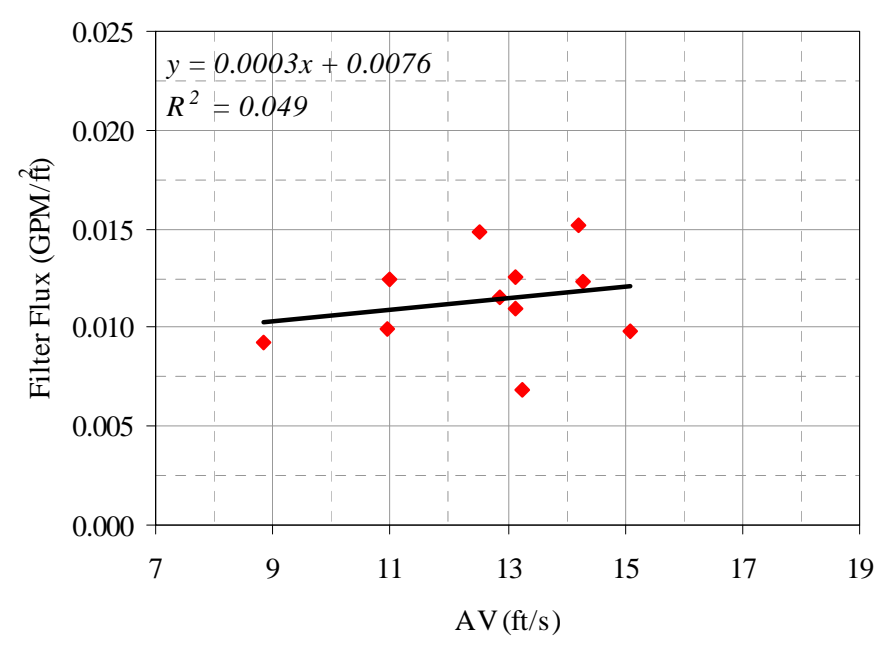

Figure 5.19. Flux vs. AV for Group 7-AY102 High-Solids

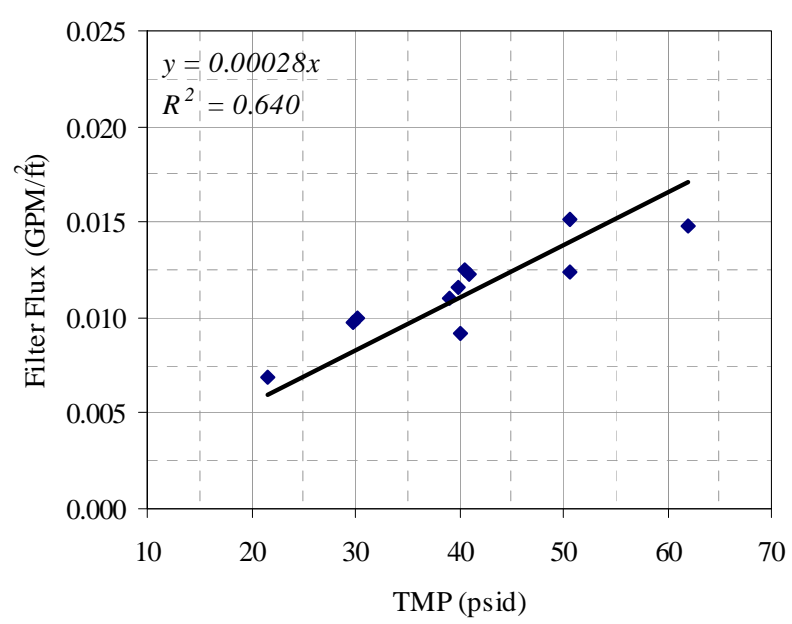

Figure 5.18. Flux vs. TMP for Group 7-AY102 High-Solids

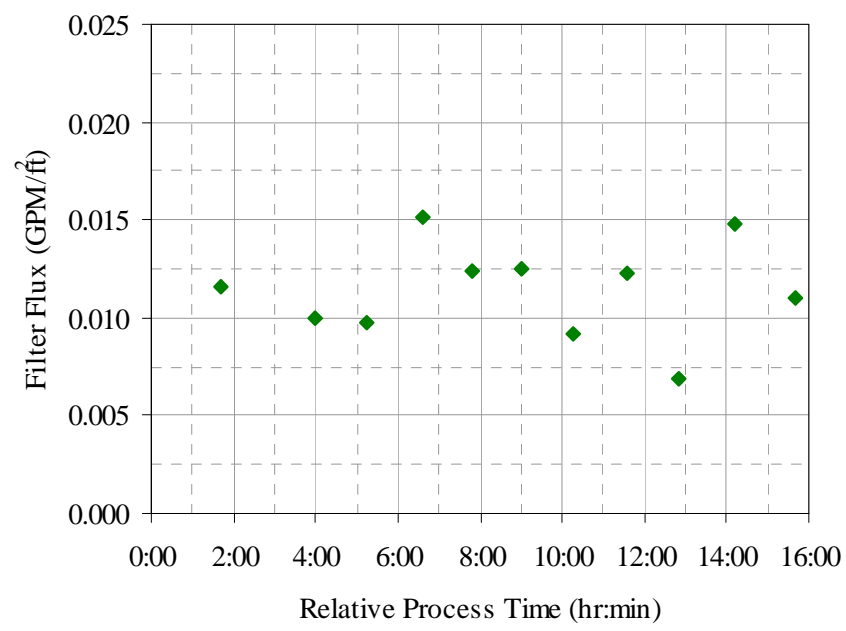

Figure 5.20. Flux vs. Median Process Time of Test for Group 7-AY102 High-Solids 


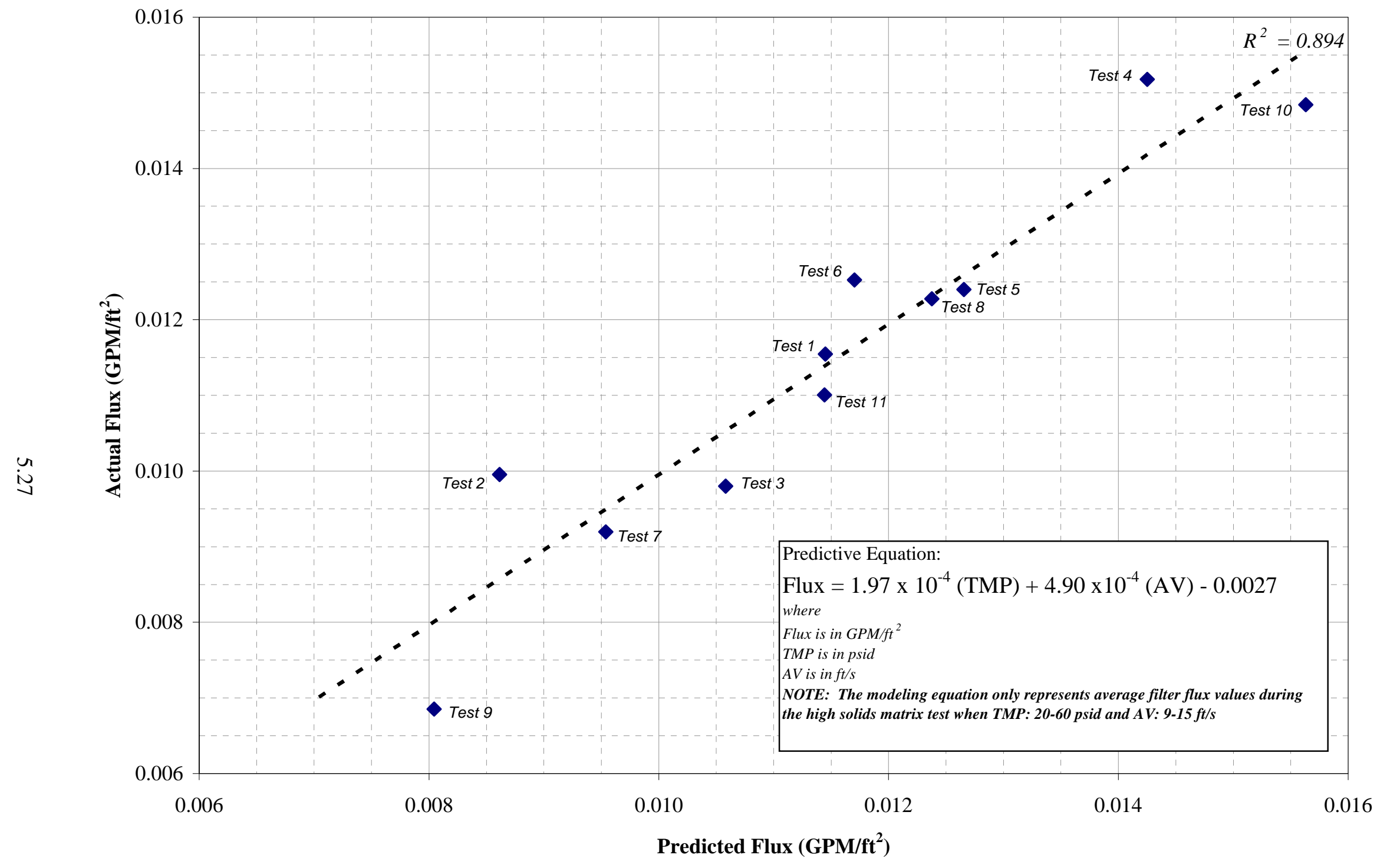

Figure 5.21. Least Squares Fit to High-Solids Matrix Test Results to Linear Model (Measured UDS of 26 wt\%) 


\subsection{Pre-Leached Slurry Characterization}

\subsubsection{Physical-Property and Chemical-Characterization Measurements}

At the completion of the high-solids test matrix, the slurry in the recirculation loop was sampled for physical and chemical analysis (Figure 5.22). Results from the physical-property measurements of the slurry samples are shown in Table 5.15, which correlate with the predicted concentration calculated from Table 5.13. The high-solids slurry wet-composition (including permeate hold-up) before caustic leaching is shown in Table 5.16. The slurry composition in terms of supernate and solid composition is provided in Table 5.17.

Comparing the low-solids slurry to the high solids slurry shows that adding the AY-102 sample resulted in significant increases in all radionuclides and in $\mathrm{Al}, \mathrm{Cr}, \mathrm{Fe}, \mathrm{Mn}, \mathrm{Si}$, and $\mathrm{C}_{2} \mathrm{O}_{4}$. These species were presumably high in the AY-102 sample, and since they are usually found in the solids (with the exception of ${ }^{137} \mathrm{Cs}$ ), they would not be reduced by the dewatering step. Al added from the AY-102 sample was expected to be in the form of gibbsite, dawsonite, and cancrinite [Krupka 2004]. The exception, ${ }^{137} \mathrm{Cs}$, shows unusual behavior. The majority of the ${ }^{137} \mathrm{Cs}$ in the Group 7 slurry before adding the AY-102 sample was found in the supernate (75\%). Only 7\% was found in the supernate after the AY-102 addition, suggesting that the AY-102 solids contain an insoluble Cs species.

The following species typically found in the supernatant were observed to decrease after AY-102 addition and dewatering: $\mathrm{Na}, \mathrm{P}$, and all anions other than $\mathrm{C}_{2} \mathrm{O}_{4}$. Uranium, though normally found in the solids, was also observed to decrease after AY-102 addition and dewatering. In the Group 7 slurry, before adding the AY-102 sample, 2\% of the total U mass was found in the supernate. After AY-102 addition, $46 \%$ was found in the supernate after dewatering. The dewatering operation removed $39 \mathrm{wt} \%$ of the U inventory of the slurry because of the large fraction of uranium that became soluble after the addition was made. An increase in the $\mathrm{P}$ concentration in the supernate was also observed, which was unexpected because the AY102 supernate had a lower P concentration than the Group 7 slurry [Coleman, 2003]. This indicated that some $\mathrm{P}$ in the insoluble solids (such as phosphate) dissolved into the slurry supernate.,

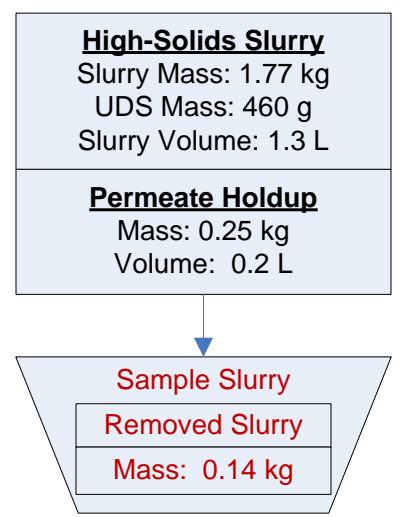

Figure 5.22. Process Flow Through the High-Solids Matrix 
Table 5.15. High-Solids Slurry Physical-Property Measurements (inside slurry loop)

\begin{tabular}{|r|c||}
\hline Slurry Density (g/mL) & 1.45 \\
\hline Supernate Density (g/mL) & 1.35 \\
\hline Settled Solids (Vol \%) & $95 \%$ \\
\hline Centrifuged UDS (Wt \%) & $58 \%$ \\
\hline Total Solids (Wt \%) & $44 \%$ \\
\hline Dissolved Solids (Wt\%) & $24 \%$ \\
\hline UDS (Wt\%) & $26 \%$ \\
\hline
\end{tabular}

Table 5.16. High-Solids Slurry Inventory and Composition

\begin{tabular}{|c|c|c|c|c|c|}
\hline & Slurry $^{(a)}$ & \multicolumn{2}{|c|}{ Liquid Fraction $^{(\mathbf{b})}$} & \multicolumn{2}{|c|}{ Solids Fraction ${ }^{(c)}$} \\
\hline Mass (kg) & 2.02 & \multicolumn{2}{|c|}{1.57} & \multicolumn{2}{|c|}{0.46} \\
\hline Wt\% of Slurry & $100 \%$ & \multicolumn{2}{|c|}{$77.4 \%$} & \multicolumn{2}{|c|}{$22.6 \%$} \\
\hline Metal & g & $\mathbf{g}$ & $\mu \mathrm{g} / \mathrm{ml}$ & g & $\mu g / g$ \\
\hline Al & $3.3 \mathrm{E}+01$ & $1.3 \mathrm{E}-02$ & $1.1 \mathrm{E}+01$ & $3.3 \mathrm{E}+01$ & $7.2 \mathrm{E}+04$ \\
\hline B & 2.9E-02 & $2.4 \mathrm{E}-02$ & $2.1 \mathrm{E}+01$ & 5.5E-03 & $1.2 \mathrm{E}+01$ \\
\hline $\mathbf{B i}$ & 8.3E-01 & $<4$.E-3 & $<4 . \mathrm{E}+0$ & 8.3E-01 & $1.8 \mathrm{E}+03$ \\
\hline $\mathbf{C a}$ & $4.7 \mathrm{E}+00$ & $1.9 \mathrm{E}-02$ & $1.6 \mathrm{E}+01$ & $4.7 \mathrm{E}+00$ & $1.0 \mathrm{E}+04$ \\
\hline Cd & $9.8 \mathrm{E}-02$ & 1.5E-03 & $1.3 \mathrm{E}+00$ & 9.7E-02 & $2.1 \mathrm{E}+02$ \\
\hline $\mathrm{Cr}$ & $1.3 \mathrm{E}+00$ & 5.2E-02 & $4.5 \mathrm{E}+01$ & $1.3 \mathrm{E}+00$ & $2.7 \mathrm{E}+03$ \\
\hline $\mathbf{F e}$ & $7.2 \mathrm{E}+01$ & $2.1 \mathrm{E}-03$ & $1.8 \mathrm{E}+00$ & $7.2 \mathrm{E}+01$ & $1.6 \mathrm{E}+05$ \\
\hline $\mathbf{K}$ & 4.4E-01 & $3.5 \mathrm{E}-01$ & $3.0 \mathrm{E}+02$ & 8.5E-02 & $1.9 \mathrm{E}+02$ \\
\hline Mn & $1.1 \mathrm{E}+01$ & 2.5E-04 & 2.2E-01 & $1.1 \mathrm{E}+01$ & $2.3 \mathrm{E}+04$ \\
\hline $\mathrm{Na}$ & $1.4 \mathrm{E}+02$ & $1.0 \mathrm{E}+02$ & $8.6 \mathrm{E}+04$ & $4.0 \mathrm{E}+01$ & $8.6 \mathrm{E}+04$ \\
\hline $\mathbf{N i}$ & $1.8 \mathrm{E}+00$ & $<3$. E-4 & $<3 . \mathrm{E}-1$ & $1.8 \mathrm{E}+00$ & $4.0 \mathrm{E}+03$ \\
\hline $\mathbf{P}$ & $1.9 \mathrm{E}+01$ & $5.7 \mathrm{E}+00$ & $5.0 \mathrm{E}+03$ & $1.3 \mathrm{E}+01$ & $2.9 \mathrm{E}+04$ \\
\hline $\mathrm{S}$ & $5.4 \mathrm{E}+00$ & $5.1 \mathrm{E}+00$ & $4.4 \mathrm{E}+03$ & 2.9E-01 & $6.3 E+02$ \\
\hline Si & $1.8 \mathrm{E}+01$ & $2.0 \mathrm{E}-03$ & $1.7 \mathrm{E}+00$ & $1.8 \mathrm{E}+01$ & $3.9 \mathrm{E}+04$ \\
\hline $\mathrm{Sr}$ & 7.1E-01 & $2.4 \mathrm{E}-04$ & 2.1E-01 & 7.1E-01 & $1.5 \mathrm{E}+03$ \\
\hline Zn & $2.0 \mathrm{E}-01$ & $1.0 \mathrm{E}-03$ & 8.8E-01 & $2.0 \mathrm{E}-01$ & $4.4 \mathrm{E}+02$ \\
\hline $\mathrm{Zr}$ & $1.7 \mathrm{E}+00$ & 1.5E-03 & $1.3 \mathrm{E}+00$ & $1.7 \mathrm{E}+00$ & $3.7 \mathrm{E}+03$ \\
\hline $\mathbf{U}$ & $1.1 \mathrm{E}+01$ & $4.4 \mathrm{E}+00$ & $3.8 \mathrm{E}+03$ & $6.1 \mathrm{E}+00$ & $1.3 \mathrm{E}+04$ \\
\hline \multirow{2}{*}{$\begin{array}{c}\text { Radiochemical } \\
\text { Isotopes }\end{array}$} & Slurry & \multicolumn{2}{|c|}{ Liquid Fraction } & \multicolumn{2}{|c|}{ Solid Fraction } \\
\hline & $\mu \mathrm{Ci}$ & $\mu \mathrm{Ci}$ & $\mu \mathrm{Ci} / \mathrm{ml}$ & $\mu \mathrm{Ci}$ & $\mu \mathrm{Ci} / \mathrm{g}$ \\
\hline Co-60 & $7.8 \mathrm{E}+01$ & $7.6 \mathrm{E}-01$ & $6.6 \mathrm{E}-04$ & $7.7 \mathrm{E}+01$ & $1.7 \mathrm{E}-01$ \\
\hline Cs-137 & $1.7 \mathrm{E}+05$ & $1.1 \mathrm{E}+04$ & $9.5 \mathrm{E}+00$ & $1.6 \mathrm{E}+05$ & $3.6 \mathrm{E}+02$ \\
\hline Eu-152 & $1.0 \mathrm{E}+02$ & $<5 . \mathrm{E}-1$ & $<4 . \mathrm{E}-4$ & $1.0 \mathrm{E}+02$ & 2.3E-01 \\
\hline Eu-154 & $2.6 \mathrm{E}+03$ & $<4$.E-1 & $<3$. E-4 & $2.6 \mathrm{E}+03$ & $5.6 \mathrm{E}+00$ \\
\hline Eu-155 & $1.2 \mathrm{E}+03$ & $<4 . \mathrm{E}+0$ & $<3 . \mathrm{E}-3$ & $1.2 \mathrm{E}+03$ & $2.5 \mathrm{E}+00$ \\
\hline Am-241 & $4.2 \mathrm{E}+03$ & $<4 . \mathrm{E}+0$ & $<3$. E-3 & $4.2 \mathrm{E}+03$ & $9.3 \mathrm{E}+00$ \\
\hline Gross Alpha & $6.2 E+03$ & $2.4 \mathrm{E}+01$ & 2.0E-02 & $6.2 \mathrm{E}+03$ & $1.3 \mathrm{E}+01$ \\
\hline Gross Beta & $7.2 \mathrm{E}+06$ & $1.1 \mathrm{E}+04$ & $9.5 \mathrm{E}+00$ & $7.2 \mathrm{E}+06$ & $1.6 \mathrm{E}+04$ \\
\hline Sr-90 & $3.7 \mathrm{E}+06$ & $3.3 E+02$ & $2.8 \mathrm{E}-01$ & $3.7 \mathrm{E}+06$ & $8.1 \mathrm{E}+03$ \\
\hline
\end{tabular}


WTP-RPT-169, Rev 0

Table 5.16 (Contd)

\begin{tabular}{||c|r|r|r|r|r||}
\hline Pu-239+240 & $1.6 \mathrm{E}+03$ & $2.6 \mathrm{E}+01$ & $2.2 \mathrm{E}-02$ & $1.5 \mathrm{E}+03$ & $3.4 \mathrm{E}+00$ \\
\hline Pu-238 & $2.5 \mathrm{E}+02$ & $3.7 \mathrm{E}+00$ & $3.2 \mathrm{E}-03$ & $2.5 \mathrm{E}+02$ & $5.4 \mathrm{E}-01$ \\
\hline \multirow{2}{*}{ Anions } & \multicolumn{3}{|c|}{ Liquid Fraction } & \multicolumn{2}{c||}{ Leached Solids Fraction } \\
\cline { 2 - 6 } & $\boldsymbol{\mu g} / \mathbf{m l}$ & $\mathbf{I M}]$ & $\mathbf{g}$ & $\boldsymbol{\mu} \mathbf{g} / \mathbf{g}$ & $\mathbf{g}$ \\
\hline $\mathbf{F}$ & $4.4 \mathrm{E}+02$ & $2.3 \mathrm{E}-02$ & $5.0 \mathrm{E}-01$ & $1.3 \mathrm{E}+02$ & $6.1 \mathrm{E}-02$ \\
\hline $\mathbf{C l}$ & $4.6 \mathrm{E}+02$ & $1.3 \mathrm{E}-02$ & $5.3 \mathrm{E}-01$ & $0.0 \mathrm{E}+00$ & $0.0 \mathrm{E}+00$ \\
\hline $\mathbf{C}_{\mathbf{2}} \mathbf{O}_{\mathbf{4}}$ & $1.7 \mathrm{E}+03$ & $2.0 \mathrm{E}-02$ & $2.0 \mathrm{E}+00$ & $2.6 \mathrm{E}+03$ & $1.2 \mathrm{E}+00$ \\
\hline $\mathbf{N O}_{2}$ & $1.4 \mathrm{E}+04$ & $3.1 \mathrm{E}-01$ & $1.6 \mathrm{E}+01$ & $1.9 \mathrm{E}+04$ & $8.6 \mathrm{E}+00$ \\
\hline $\mathbf{N O}_{3}$ & $1.2 \mathrm{E}+05$ & $2.0 \mathrm{E}+00$ & $1.4 \mathrm{E}+02$ & $1.5 \mathrm{E}+05$ & $7.0 \mathrm{E}+01$ \\
\hline $\mathbf{S O}_{4}$ & $1.2 \mathrm{E}+04$ & $1.3 \mathrm{E}-01$ & $1.4 \mathrm{E}+01$ & $1.6 \mathrm{E}+04$ & $7.3 \mathrm{E}+00$ \\
\hline $\mathbf{P O}_{4}$ & $1.5 \mathrm{E}+04$ & $1.6 \mathrm{E}-01$ & $1.7 \mathrm{E}+01$ & $4.5 \mathrm{E}+04$ & $2.1 \mathrm{E}+01$ \\
\hline $\mathbf{O H}$ & $1.9 \mathrm{E}+03$ & $1.1 \mathrm{E}-01$ & $2.2 \mathrm{E}+00$ & & \\
\hline $\mathbf{O}$
\end{tabular}

(a) Slurry Mass components were calculated from characterization data (WTP-RPT-169, Section 3). Loss of mass from sampling was incorporated.

(b) Liquid Fraction mass components were calculated using analytical results from supernate sample TI624-G7-B (ASO ID 08-02060) and the predicted mass of supernate in the system.

(c) Solids Fraction mass components were calculated from the difference between the slurry component mass and liquid component mass fraction. 
Table 5.17. Group 7/AY102 High-Solids Slurry Composition Based on ICP-OES/Radionuclide Characterization

\begin{tabular}{|c|c|c|c|}
\hline $\begin{array}{c}\text { ICP-OES } \\
\text { Analytes }\end{array}$ & $\begin{array}{c}\text { Dry Slurry } \\
(\mu \mathrm{g} / \mathrm{g})\end{array}$ & $\begin{array}{c}\text { Supernate }^{(b)} \\
(\mu \mathrm{g} / \mathrm{mL})\end{array}$ & $\begin{array}{c}\text { Dry Solids }^{(c)} \\
(\mu \mathrm{g} / \mathrm{g})\end{array}$ \\
\hline $\mathrm{Al}$ & 42,000 & 11 & 72,000 \\
\hline $\mathrm{B}$ & [23] & 20.5 & -- \\
\hline $\mathrm{Bi}$ & 1,040 & -- & 1,800 \\
\hline $\mathrm{Cd}$ & 113 & [1.3] & 190 \\
\hline $\mathrm{Cr}$ & 1,630 & 44.7 & 2,700 \\
\hline $\mathrm{Fe}$ & 91,200 & {$[1.8]$} & 156,000 \\
\hline Mn & 13,500 & {$[0.220]$} & 23,000 \\
\hline $\mathrm{Na}$ & 153,000 & 86,000 & 60,000 \\
\hline $\mathrm{Ni}$ & 2,440 & -- & 4,200 \\
\hline $\mathrm{P}$ & 22,500 & 4,960 & 27,000 \\
\hline $\mathrm{S}$ & 5,320 & 4,390 & -- \\
\hline $\mathrm{Sr}$ & 892 & 0.205 & 1,500 \\
\hline $\mathrm{U}$ & 12,400 & 3,840 & 12,000 \\
\hline $\mathrm{Zn}$ & 270 & {$[.88]$} & 460 \\
\hline $\mathrm{Zr}$ & 2,280 & [1.3] & 3,900 \\
\hline $\mathrm{Ag}$ & 67.6 & 10.9 & 90 \\
\hline$B a$ & 580.0 & [.19] & 990 \\
\hline $\mathrm{Be}$ & 0.787 & {$[.0064]$} & 1.3 \\
\hline $\mathrm{Ca}$ & 6,330 & 16.1 & 11,000 \\
\hline $\mathrm{Ce}$ & 633 & -- & 1,100 \\
\hline $\mathrm{Cu}$ & 209 & -- & 360 \\
\hline$L a$ & 725 & -- & 1,200 \\
\hline $\mathrm{Li}$ & 87 & 3.65 & 140 \\
\hline$M g$ & 1,690 & -- & 2,900 \\
\hline Mo & [17] & [5.0] & [20] \\
\hline Nd & 1,060 & -- & 1,800 \\
\hline $\mathrm{Pb}$ & 3,930 & [5.2] & 6,700 \\
\hline$R u$ & 217 & [9.6] & 350 \\
\hline$T h$ & 486 & $\begin{array}{l}- \\
\end{array}$ & 830 \\
\hline $\mathrm{Ti}$ & 199 & -- & 340 \\
\hline$V$ & 16.9 & [0.590] & 30 \\
\hline$W$ & 232 & [12] & 370 \\
\hline$Y$ & 94.0 & [0.069] & 160 \\
\hline $\mathrm{Si}$ & 23,200 & {$[1.7]$} & 40,000 \\
\hline Radionuclides & Dry Slurry $(\mu \mathrm{Ci} / g)$ & Supernate $(\mu \mathrm{Ci} / \mathrm{mL})$ & Dry Solids $(\mu \mathrm{Ci} / \mathrm{g})$ \\
\hline${ }^{60} \mathrm{Co}$ & $1.01 \mathrm{E}-1$ & $6.56 \mathrm{E}-4$ & $1.7 \mathrm{E}-1$ \\
\hline${ }^{137} \mathrm{Cs}$ & $2.25 \mathrm{E}+2$ & $9.51 \mathrm{E}+0$ & $3.6 \mathrm{E}+2$ \\
\hline${ }^{154} \mathrm{Eu}$ & $3.37 \mathrm{E}+0$ & $<3 . \mathrm{E}-4$ & $5.8 \mathrm{E}+0$ \\
\hline${ }^{155} \mathrm{Eu}$ & $1.49 \mathrm{E}+0$ & $<3$. E-3 & $2.5 \mathrm{E}+0$ \\
\hline${ }^{241} \mathrm{Am}$ & $5.49 \mathrm{E}+0$ & $<3$. E-3 & $9.4 \mathrm{E}+0$ \\
\hline${ }^{90} \mathrm{Sr}$ & $4.83 \mathrm{E}+3$ & $2.83 \mathrm{E}-1$ & $8.3 \mathrm{E}+3$ \\
\hline${ }^{239 / 240} \mathrm{Pu}$ & $1.99 \mathrm{E}+0$ & $2.22 \mathrm{E}-2$ & $3.3 \mathrm{E}+0$ \\
\hline${ }^{238} \mathrm{Pu}$ & 3.32E-1 & $3.21 \mathrm{E}-3$ & $5.6 \mathrm{E}-1$ \\
\hline \multicolumn{4}{|c|}{$\begin{array}{l}\text { (a) Test sample TI624-G7-6, ASO ID 08-2074 } \\
\text { (b) Test sample TI624-G7-B, ASO ID 08-2060 } \\
\text { (c) Calculated using results from TI624-G7-6 and TI624-G7-B. } \\
\text { Analyte uncertainties were typically within } \pm 15 \% \text {; results in brackets indicate that the analyte } \\
\text { concentrations were greater than the method detection limit (MDL) and less than the estimated } \\
\text { quantitation limit (EQL), and uncertainties were }>15 \% \text {. Opportunistic analytes (in italics) ware } \\
\text { reported for information only; quality control (QC) requirements did not apply to these analytes. }\end{array}$} \\
\hline
\end{tabular}




\subsubsection{Rheology of the AY-102 Slurry and High-Solids Slurry}

Rheology measurements were done on the AY-102 source material before introduction into the CUF. Figure 5.23 shows the results of flow-curve testing for the AY-102 slurry sample. The results of the measurement indicate that the flow behavior is Newtonian. Flow-curve data show a linear stress response over shear rates from zero up to 400 or $500 \mathrm{~s}^{-1}$. At higher shear rates (generally $500 \mathrm{~s}^{-1}$ and above), flowcurve data show an increase in the slope of the stress response curve. This increase is likely a result of Taylor vortex formation onset (i.e., unstable/turbulent flow), which renders the affected data unusable.

The flow curves are relatively free of hysteresis. Specifically, the up- and down-ramp data generally agree with the instrument limits of accuracy ( 0.5 Pa). Any difference can easily be attributed to rotor inertial effects. The lack of hysteresis suggests that the measurements are not significantly affected by shearing or settling of the sample. It should be noted that lack of hysteresis does not necessarily mean that these effects are absent because any changes could have taken place during the shearing step or before analysis took place.

Given the $\pm 0.4 \mathrm{~Pa}$ typical stress variation in measurement data, the best description of the current flow behavior that can be concluded based on the current measurement data is Newtonian. As such, Newtonian viscosity was derived for each flow-curve measurement. Data believed to be influenced by Taylor vortex formation are excluded from the fits. The shear-rate range for all fits is limited to the ranges specified in Table 5.18. Rotor inertial effects and measurement noise sometimes caused downramp stress data to fall below zero.

Table 5.18 summarizes the best-fit Newtonian parameters for the AY-102 slurry. The results indicate a Newtonian viscosity that generally falls between 1.8 and $4.1 \mathrm{mPa} \cdot \mathrm{s}$, depending on temperature. Increased temperature yields a decrease in the slurry viscosity, likely as a result of suspending phase viscosity decrease. The initial and replicate viscosity measurements at $25^{\circ} \mathrm{C}$ show agreement with a discrepancy of $\sim 5 \%$, which is below the accuracy level of the measurement. 


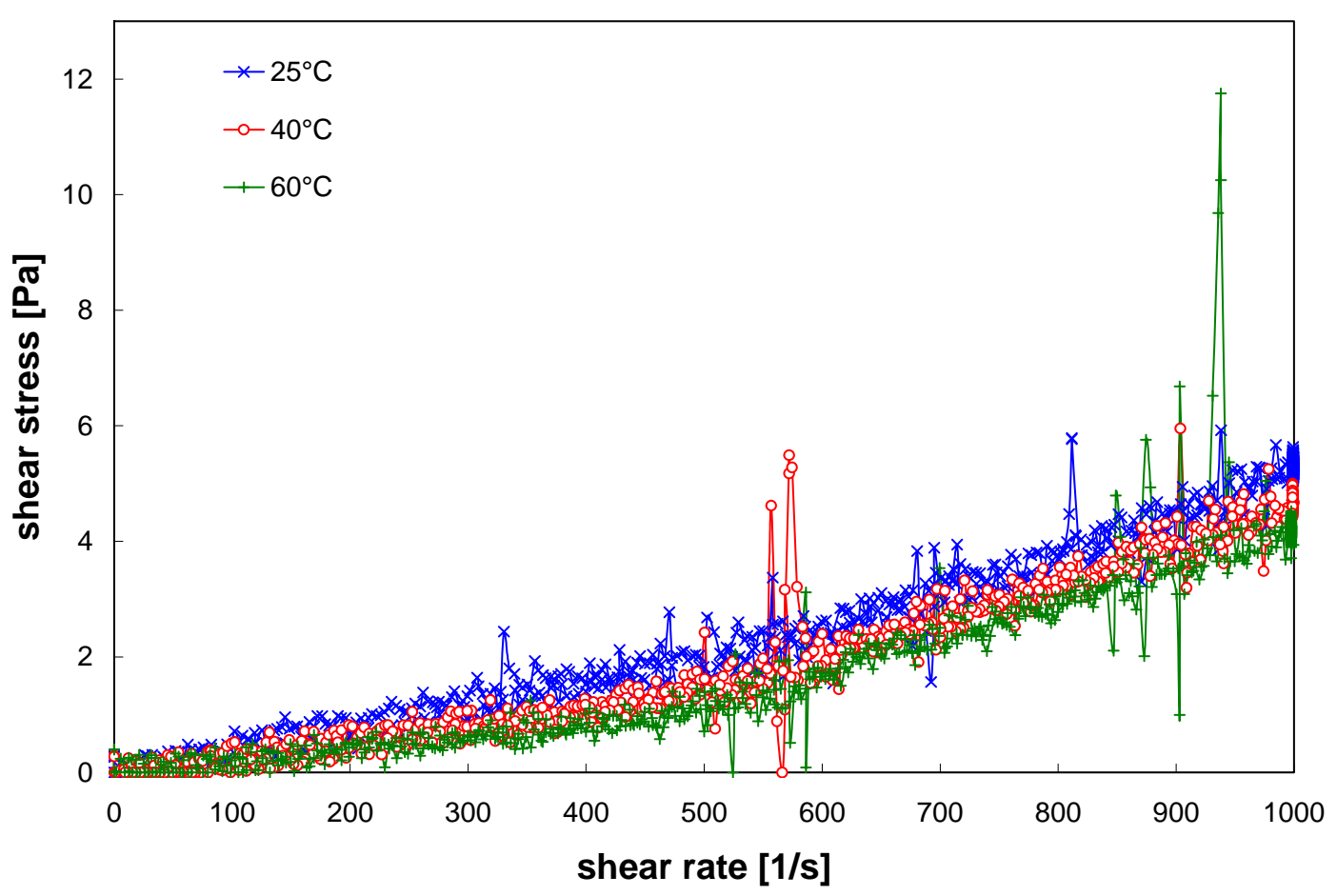

Figure 5.23. Flow Curves for the AY-102 Slurry

Table 5.18. Results of Fitting Analysis for AY-102 Slurry

\begin{tabular}{||c|c|c|c|c||}
\hline \multirow{3}{*}{ Model } & Temperature [ $\left.{ }^{\circ} \mathbf{C}\right]$ & Range & $\begin{array}{c}\text { Viscosity } \\
\text { [mPa·s] }\end{array}$ & $\mathbf{R}$ \\
\hline \multirow{2}{*}{$\begin{array}{c}\text { Newtonian } \\
\text { (Flow Curve) }\end{array}$} & $25(1$ of 2$)$ & $0-500 \mathrm{~s}^{-1}$ & 3.9 & 0.96 \\
\cline { 2 - 5 } & $25(2$ of 2$)$ & $0-500 \mathrm{~s}^{-1}(\mathrm{a})$ & 4.1 & 0.96 \\
\cline { 2 - 5 } & 40 & $0-400 \mathrm{~s}^{-1}(\mathrm{a})$ & 2.7 & 0.95 \\
\cline { 2 - 5 } & 60 & $0-400 \mathrm{~s}^{-1}(\mathrm{a})$ & 1.8 & 0.85 \\
\hline
\end{tabular}

Figure 5.24 shows the results of flow-curve testing for the high-solids slurry. The flow behavior is nonNewtonian. Flow-curve data indicate that the dewatered slurry has a finite yield stress of approximately 3 to $5 \mathrm{~Pa}$ and that the slurry is shear thinning. Flow-curve hysteresis is minor and can be attributed to rotor inertial effects alone. The lack of hysteresis suggests that the internal structure of the slurry (such as particle agglomerates) is stable with respect to shear or that any changes in structure occur quickly and are complete at the end of the 3-minute shearing step performed immediately before flow-curve measurement. With regard to data anomalies, the curves are free of any slope discontinuities that could be associated with Taylor vortex formation.

Flow-curve data at $25^{\circ} \mathrm{C}, 40^{\circ} \mathrm{C}$, and $60^{\circ} \mathrm{C}$ were fit to both Bingham-Plastic and Casson models.

Table 5.19 summarizes the best-fit model parameters for the high-solids slurry. Since the data were not influenced by Taylor vortex formation, the full range of shear rates ( 0 to $\left.1000 \mathrm{~s}^{-1}\right)$ is employed in the Casson fitting analysis. Bingham-Plastic analysis cannot account for slurry shear thinning, and as a result, its fitting analysis is limited to 100 to $1000 \mathrm{~s}^{-1}$ to avoid bias introduced by slurry shear thinning at low shear rates. Both models provide reasonable fits of the data, although the Casson model provides a 
better description of the flow curve (especially over 0 to $100 \mathrm{~s}^{-1}$ ). On the other hand, although the Bingham-Plastic cannot capture slurry shear thinning below $100 \mathrm{~s}^{-1}$, it better captures the flow-curve linearity at higher shear rates.

Apparent viscosities at 33, 100, 500, and $1000 \mathrm{~s}^{-1}$ were derived from each measurement. For each temperature, the 33, 100, and $500 \mathrm{~s}^{-1}$ reference viscosities were determined from the average both upramp and down-ramp flow-curve data. The apparent viscosity at $1000 \mathrm{~s}^{-1}$ is derived from the average of all apparent viscosity measurements during constant rotation at $1000 \mathrm{~s}^{-1}$. As a point of comparison, apparent viscosities were also calculated using the Bingham-Plastic and Casson fitting parameters in Table 5.19. The results of these analyses are provided in Table 5.20.

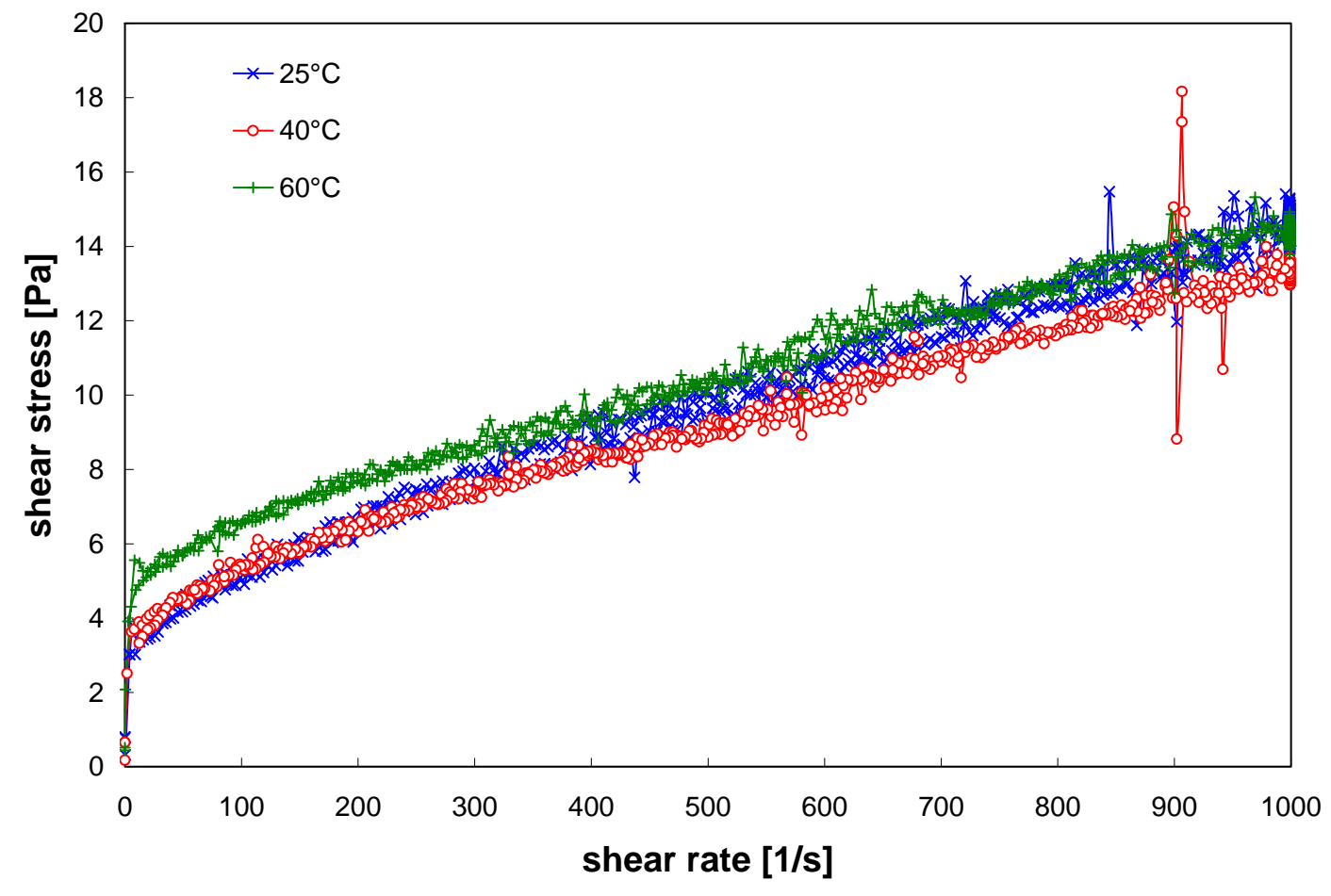

Figure 5.24. Flow Curves for the CUF High Solids Slurry

Table 5.19. Results of Fitting Analysis for the CUF High Solids Rheology Matrix

\begin{tabular}{|c|c|c|c|c|c|}
\hline Model & Temperature $\left[{ }^{\circ} \mathrm{C}\right]$ & Range & $\begin{array}{c}\text { Yield Stress } \\
{[\mathrm{Pa}]}\end{array}$ & $\begin{array}{c}\text { Consistency } \\
{[\mathrm{mPa} \cdot \mathrm{s}]}\end{array}$ & $\mathbf{R}$ \\
\hline \multirow[t]{4}{*}{ Bingham-Plastic } & $25(1$ of 2$)$ & $100-1000 \mathrm{~s}^{-1}$ & 5.2 & 10 & 0.98 \\
\hline & 25 (2 of 2$)$ & $100-1000 \mathrm{~s}^{-1}$ & 4.6 & 10 & 0.99 \\
\hline & 40 & $100-1000 \mathrm{~s}^{-1}$ & 4.8 & $\begin{array}{l}8.6 \\
\end{array}$ & 0.99 \\
\hline & 60 & $100-1000 \mathrm{~s}^{-1}$ & 6.1 & 8.3 & 0.99 \\
\hline \multirow[t]{4}{*}{ Casson } & 25 (1 of 2$)$ & $0-1000 \mathrm{~s}^{-1}$ & 2.6 & 5.3 & 0.98 \\
\hline & 25 (2 of 2$)$ & $0-1000 \mathrm{~s}^{-1}$ & 2.3 & 5.2 & 0.99 \\
\hline & 40 & $0-1000 \mathrm{~s}^{-1}$ & 2.6 & 4.1 & 0.99 \\
\hline & 60 & $0-1000 \mathrm{~s}^{-1}$ & 3.7 & 3.4 & 0.99 \\
\hline
\end{tabular}


Table 5.20. Select Apparent Viscosities for the High-Solids Slurry

\begin{tabular}{|c|c|c|c|c|c|}
\hline \multirow[b]{2}{*}{ Source } & \multirow{2}{*}{$\begin{array}{c}\text { Temperature } \\
{\left[{ }^{\circ} \mathrm{C}\right]} \\
\end{array}$} & \multicolumn{4}{|c|}{ Apparent Viscosity [mPa·s] } \\
\hline & & @ $33 \mathrm{~s}^{-1}$ & @ $100 \mathrm{~s}^{-1}$ & @ $500 \mathrm{~s}^{-1}$ & @ $1000 \mathrm{~s}^{-1}$ \\
\hline \multirow[t]{4}{*}{ Measured } & 25 (1 of 2$)$ & 130 & 54 & 21 & 15 \\
\hline & 25 (2 of 2$)$ & 120 & 52 & 19 & 15 \\
\hline & 40 & 130 & 54 & 18 & 13 \\
\hline & 60 & 170 & 66 & 20 & 14 \\
\hline \multirow[t]{4}{*}{ Bingham-Plastic } & 25 (1 of 2$)$ & 170 & 62 & 21 & 15 \\
\hline & 25 (2 of 2$)$ & 150 & 56 & 19 & 15 \\
\hline & 40 & 160 & 57 & 18 & 13 \\
\hline & 60 & 190 & 70 & 21 & 14 \\
\hline \multirow[t]{4}{*}{ Casson } & 25 (1 of 2$)$ & 130 & 55 & 21 & 15 \\
\hline & $25(2$ of 2$)$ & 110 & 50 & 20 & 15 \\
\hline & 40 & 120 & 51 & 19 & 13 \\
\hline & 60 & 160 & 64 & 21 & 14 \\
\hline
\end{tabular}

\subsection{Caustic Leaching/Washing}

After completing the filtration and rheological testing of the high-solids slurry, the slurry was drained from the system and prepared for caustic leaching, as outlined in Figure 5.25. The slurry loop was rinsed using part of the caustic addition for the leach and additional permeate that was remaining in the backpulse chamber. After the slurry and caustic additions were recovered from the system, the slurry reservoir was isolated from the slurry loop. At these points, all the recovered slurry, permeate, and caustic solutions were placed into the reservoir for caustic leaching, as outlined in the right column of Figure 5.1. It is estimated that $0.1 \mathrm{~kg}$ of material was lost due to transfer operations.

The activities involved in this process were:

- Batch caustic leaching of the slurry for removing aluminum, and phosphorus from UDS in the slurry.

- Dewatering the leached slurry.

- Batch washing of the caustic-leached slurry and dewatering of the diluted supernate afterwards. Five total wash solutions were added to the slurry to remove aluminum and phosphrous from the slurry. 
WTP-RPT-169, Rev 0

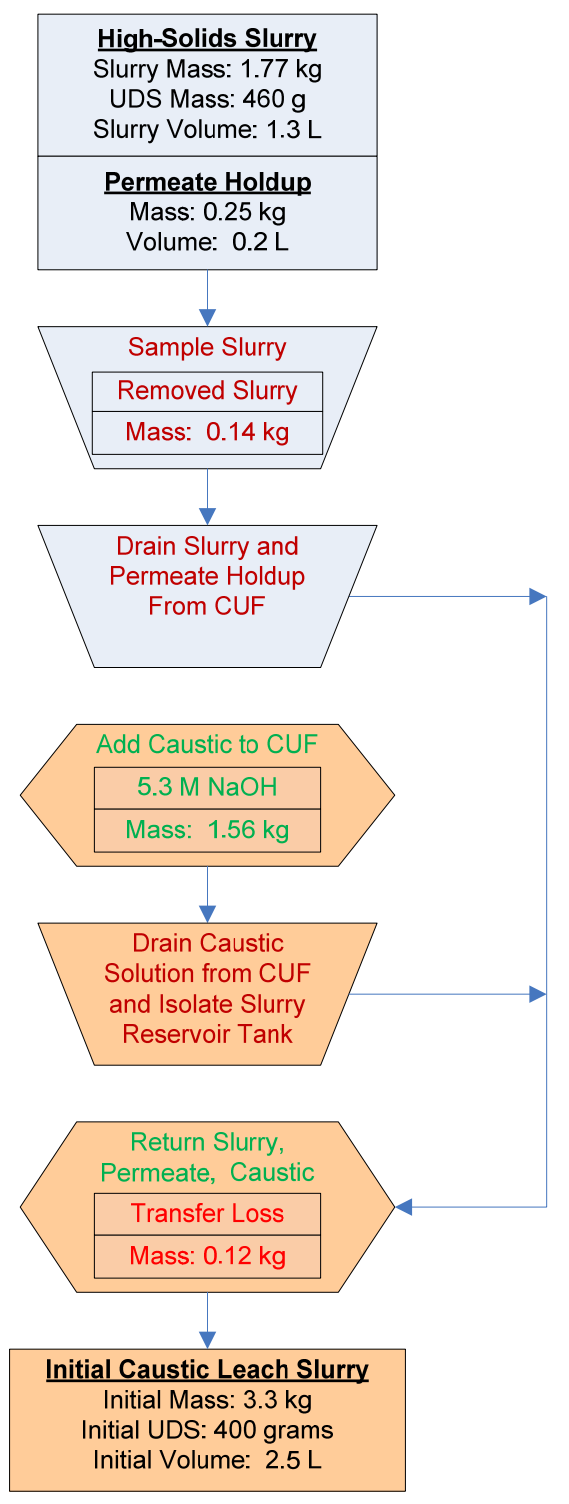

Figure 5.25. Process Flow for Caustic-Leach Preparation

\subsubsection{Caustic Batch Leaching Results}

After the slurry, permeate, and caustic were placed in the slurry reservoir, the lid for the slurry reservoir was placed on the tank, and the over-head mixer was started (Figure 5.26). The heat controller was then started to begin elevating the slurry temperature to $60^{\circ} \mathrm{C}\left(-10 /+5^{\circ} \mathrm{C}\right)$ over a 2.5 -hour period. After the heat ramp was completed, the temperature controller maintained the slurry temperature at $60^{\circ} \mathrm{C}$ for 8 hours, and then the slurry was allowed to cool to the hot-cell ambient temperature over another 5.6-hour period (Figure 5.27). As seen in previous testing, the slurry temperature was slightly higher than the cell ambient temperature at the end of the cooling ramp (slurry temperature $\sim 35^{\circ} \mathrm{C}$ versus the cell ambient temperature $\sim 30^{\circ}$ ). The slurry temperature was later decreased to $25^{\circ} \mathrm{C}$ once it was circulated through the slurry loop heat exchanger before dewatering. The mixer was turned off during sampling operations to prevent contact issues with the pipette. Afterwards, it was observed that temperature spikes in the slurry 
were occurring after the mixer was turned back on. Because the thermocouple controlling the heat controller is at the bottom of the tank while the heating jacket is on the side walls, it is believed that the controller was applying heat to the tank because the thermocouple would drop in temperature after the mixer was turned off. While one of the temperature spikes exceeded $10^{\circ} \mathrm{C}$, the duration of the temperature spikes are less than 10 minutes. The level of the leach solution was periodically checked during the leaching process. Unlike previous testing that was performed at $100^{\circ} \mathrm{C}$, no significant change in the leach slurry volume was observed.

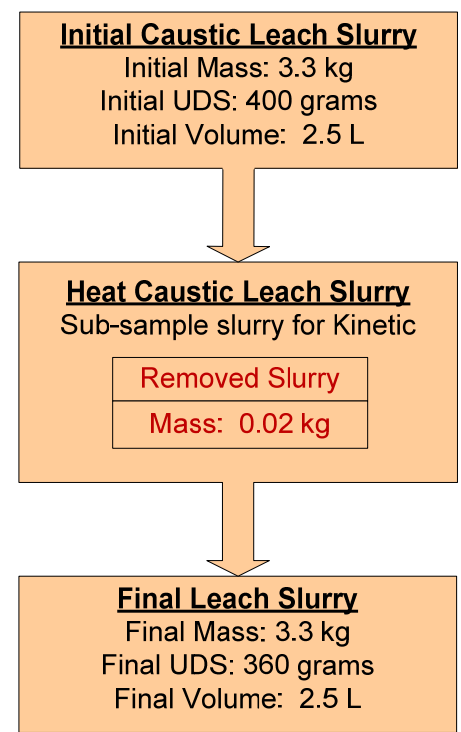

Figure 5.26. Process Flow for the Caustic Leach

The slurry was sampled once during the heat ramp and four times during the 8-hour soak at $60^{\circ} \mathrm{C}$

(Table 5.21). ICP analysis of the supernate filtered from these samples shows that although only $57 \mathrm{wt} \%$ of the solid aluminum dissolved, most of the dissolution occurred during the temperature ramp (Figure 5.27). Nineteen percent of the $\mathrm{Al}$ had dissolved in 3 hours into the temperature ramp when the slurry was $37^{\circ} \mathrm{C}$. This represents $34 \mathrm{wt} \%$ of the total solid aluminum that would dissolve by the end of the leach. Forty-one weight percent of the $\mathrm{Al}$ had dissolved when the slurry reached the target leach temperature, $60^{\circ} \mathrm{C}$. This represents $72 \mathrm{wt} \%$ of the total solids that would dissolve. After 2 hours at the target leaching temperature, the dissolution was effectively complete, with $56 \mathrm{wt} \%$ dissolved. The rapid reaction rate observed was indicative of gibbsite dissolution, while the extent of reaction implied that a significant fraction of aluminum was present in an insoluble form, like cancrinite. Figure 5.28 shows the concentrations of the major analytes during the evolution of the heat ramp and caustic leach.

The $\mathrm{Al}$ and $\mathrm{Cr}$ concentrations increase rapidly and level off. Phosphorus, potassium, and sulfur concentrations remain steady throughout the leach. Interestingly, the uranium concentration in the supernate decreases by a factor of 100 during the leach. 


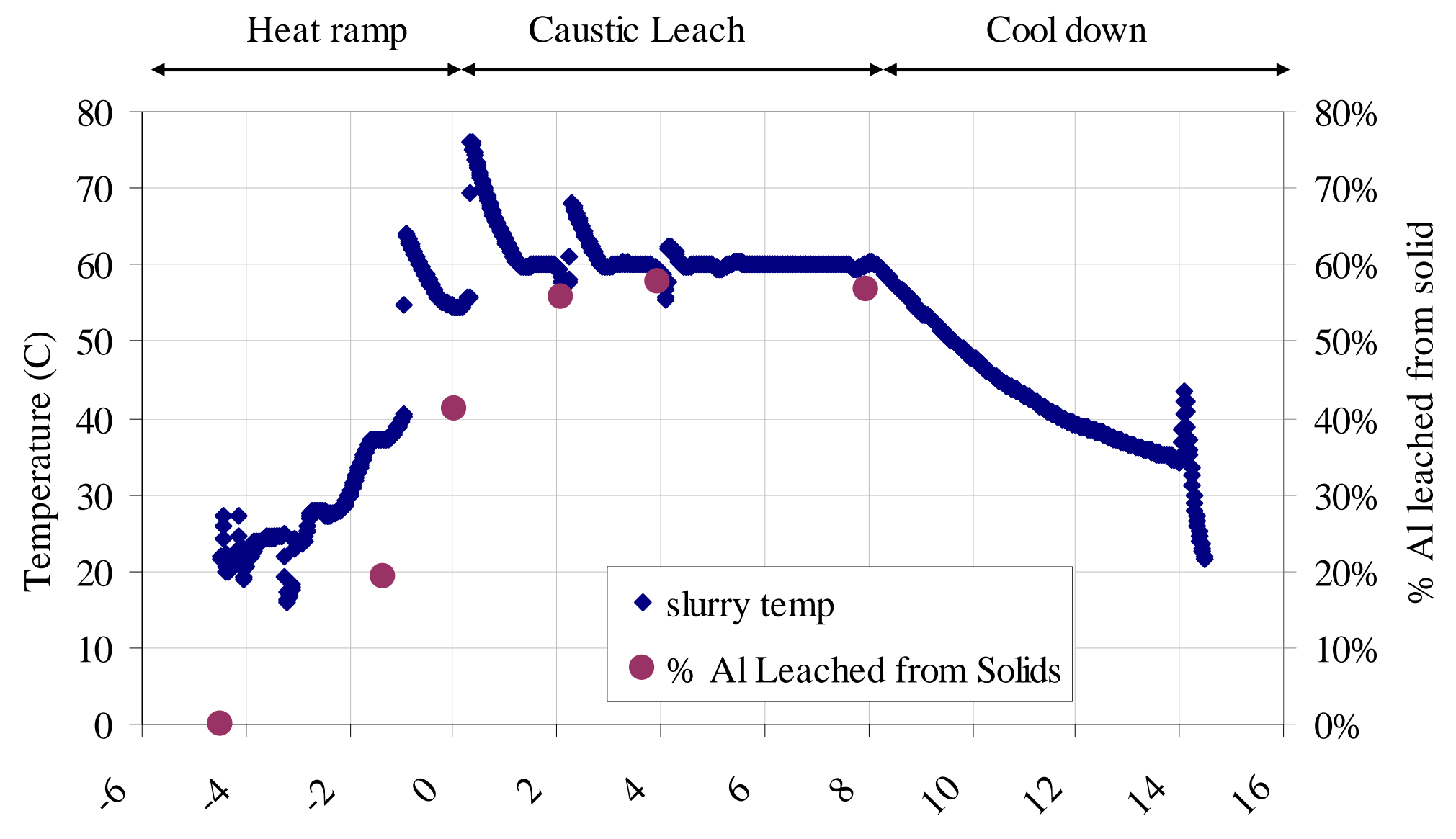

Elapsed Time of Caustic in Hours

Time at 0 is start of leach at $60^{\circ} \mathrm{C}$

Figure 5.27. Temperature Profile/Aluminum Leach Factor During Caustic Leaching 
Table 5.21. Concentration of Major Analyte Components of Filtered Caustic Leach Samples, Corrected for Sample Evaporation

\begin{tabular}{|c|c|c|c|c|c|c|}
\hline & $\begin{array}{l}\text { Start of heat } \\
\text { up }^{(\mathrm{a})}\left(22^{\circ} \mathrm{C}\right)\end{array}$ & $\begin{array}{r}3 \text { hour heat up } \\
\left(37^{\circ} \mathrm{C}\right)\end{array}$ & $\begin{array}{r}0 \text { hour leach }{ }^{(\mathrm{c})} \\
\left(55^{\circ} \mathrm{C}\right)\end{array}$ & $\begin{array}{r}2 \text { hour leach }{ }^{(\mathrm{d})} \\
\left(58^{\circ} \mathrm{C}\right)\end{array}$ & $\begin{array}{r}4 \text { hour leach }{ }^{(\mathrm{e})} \\
\left(59^{\circ} \mathrm{C}\right)\end{array}$ & $\begin{array}{r}8 \text { hour leach }{ }^{(\mathrm{t})} \\
\left(60^{\circ} \mathrm{C}\right)\end{array}$ \\
\hline & $\mu \mathrm{g} / \mathrm{ml}$ & $\mu \mathrm{g} / \mathrm{ml}$ & $\mu \mathrm{g} / \mathrm{ml}$ & $\mu \mathrm{g} / \mathrm{ml}$ & $\mu \mathrm{g} / \mathrm{ml}$ & $\mu \mathrm{g} / \mathrm{ml}$ \\
\hline Al & $5.5 \mathrm{E}+00$ & $2.5 \mathrm{E}+03$ & $5.2 \mathrm{E}+03$ & $7.2 \mathrm{E}+03$ & $7.4 \mathrm{E}+03$ & $7.3 \mathrm{E}+03$ \\
\hline B & $9.9 \mathrm{E}+00$ & $1.0 \mathrm{E}+01$ & $1.1 \mathrm{E}+01$ & $1.2 \mathrm{E}+01$ & $1.1 \mathrm{E}+01$ & $1.1 \mathrm{E}+01$ \\
\hline Bi & $<2 . \mathrm{E}+0$ & $<4 . \mathrm{E}+0$ & $<4$.E +0 & $<4 . \mathrm{E}+0$ & $<4 . \mathrm{E}+0$ & $3.2 \mathrm{E}+00$ \\
\hline Ca & $7.8 \mathrm{E}+00$ & $4.4 \mathrm{E}+00$ & $4.7 \mathrm{E}+00$ & $5.0 \mathrm{E}+00$ & $1.4 \mathrm{E}+01$ & $1.9 \mathrm{E}+00$ \\
\hline Cd & 6.3E-01 & $1.4 \mathrm{E}+00$ & $1.4 \mathrm{E}+00$ & $1.4 \mathrm{E}+00$ & $1.5 \mathrm{E}+00$ & $1.2 \mathrm{E}+00$ \\
\hline $\mathrm{Cr}$ & $2.2 \mathrm{E}+01$ & $5.7 \mathrm{E}+01$ & $8.3 \mathrm{E}+01$ & $1.0 \mathrm{E}+02$ & $1.1 \mathrm{E}+02$ & $1.1 \mathrm{E}+02$ \\
\hline $\mathbf{F e}$ & 8.7E-01 & $2.5 \mathrm{E}+01$ & $3.7 \mathrm{E}+01$ & $3.3 \mathrm{E}+01$ & $8.1 \mathrm{E}+01$ & $5.9 \mathrm{E}+00$ \\
\hline $\mathbf{K}$ & $1.5 \mathrm{E}+02$ & $2.7 \mathrm{E}+02$ & $2.9 \mathrm{E}+02$ & $2.7 \mathrm{E}+02$ & $2.7 \mathrm{E}+02$ & $2.8 \mathrm{E}+02$ \\
\hline Mn & $1.1 \mathrm{E}-01$ & $2.8 \mathrm{E}+00$ & $4.6 \mathrm{E}+00$ & $4.4 \mathrm{E}+00$ & $1.2 \mathrm{E}+01$ & 3.1E-01 \\
\hline $\mathrm{Na}$ & $4.2 \mathrm{E}+04$ & $1.1 \mathrm{E}+05$ & $1.1 \mathrm{E}+05$ & $1.1 \mathrm{E}+05$ & $1.1 \mathrm{E}+05$ & $1.1 \mathrm{E}+05$ \\
\hline $\mathbf{N i}$ & $<1 . \mathrm{E}-1$ & $4.9 \mathrm{E}-01$ & 6.3E-01 & 5.3E-01 & $2.0 \mathrm{E}+00$ & $<2 . \mathrm{E}-1$ \\
\hline $\mathbf{P}$ & $2.4 \mathrm{E}+03$ & $1.5 \mathrm{E}+03$ & $1.7 \mathrm{E}+03$ & $1.6 \mathrm{E}+03$ & $1.5 \mathrm{E}+03$ & $1.1 \mathrm{E}+03$ \\
\hline S & $2.1 \mathrm{E}+03$ & $2.3 \mathrm{E}+03$ & $2.3 \mathrm{E}+03$ & $2.4 \mathrm{E}+03$ & $2.3 \mathrm{E}+03$ & $2.2 \mathrm{E}+03$ \\
\hline Si & $8.2 \mathrm{E}-01$ & $1.3 \mathrm{E}+02$ & $1.1 \mathrm{E}+02$ & $7.5 \mathrm{E}+01$ & $7.3 \mathrm{E}+01$ & $6.0 \mathrm{E}+01$ \\
\hline Sr & $9.9 \mathrm{E}-02$ & 2.4E-01 & 3.5E-01 & 3.4E-01 & 7.7E-01 & $6.4 \mathrm{E}-02$ \\
\hline $\mathbf{U}$ & $1.9 \mathrm{E}+03$ & $1.5 \mathrm{E}+02$ & $8.1 \mathrm{E}+01$ & $5.0 \mathrm{E}+01$ & $4.7 \mathrm{E}+01$ & $2.8 \mathrm{E}+01$ \\
\hline Zn & 4.2E-01 & $1.8 \mathrm{E}+01$ & $1.9 \mathrm{E}+01$ & $1.7 \mathrm{E}+01$ & $1.6 \mathrm{E}+01$ & $1.3 \mathrm{E}+01$ \\
\hline \multirow[t]{2}{*}{$\mathrm{Zr}$} & 6.3E-01 & 4.4E-01 & 7.7E-01 & 5.7E-01 & $1.4 \mathrm{E}+00$ & $<1$.E-1 \\
\hline & [M] & [M] & [M] & [M] & [M] & [M] \\
\hline OH & 0.05 & 2.6 & 2.4 & 2.4 & 2.2 & 1.9 \\
\hline
\end{tabular}

(a) Predicted concentrations from mixing caustic addition (5.3M) with slurry supernate. Composition of supernate based on sample TI624-G7A, ASO ID 08-02059.

(b) Composition based on sample TI624-G7-C1, ASO ID 08-02064. Values divided by 1.02 to account for evaporative loss of sample.

(c) Composition based on sample TI624-G7-C2, ASO ID 08-02065. Values divided by 1.03 to account for evaporative loss of sample.

(d) Composition based on sample TI624-G7-C3, ASO ID 08-02066. Values divided by 0.99 to account for evaporative loss of sample.

(e) Composition based on sample TI624-G7-C4, ASO ID 08-02067. Values divided by 0.97 to account for evaporative loss of sample.

(f) Composition based on sample TI624-G7-C5, ASO ID 08-02068. Values divided by 0.82 to account for evaporative loss of sample. 


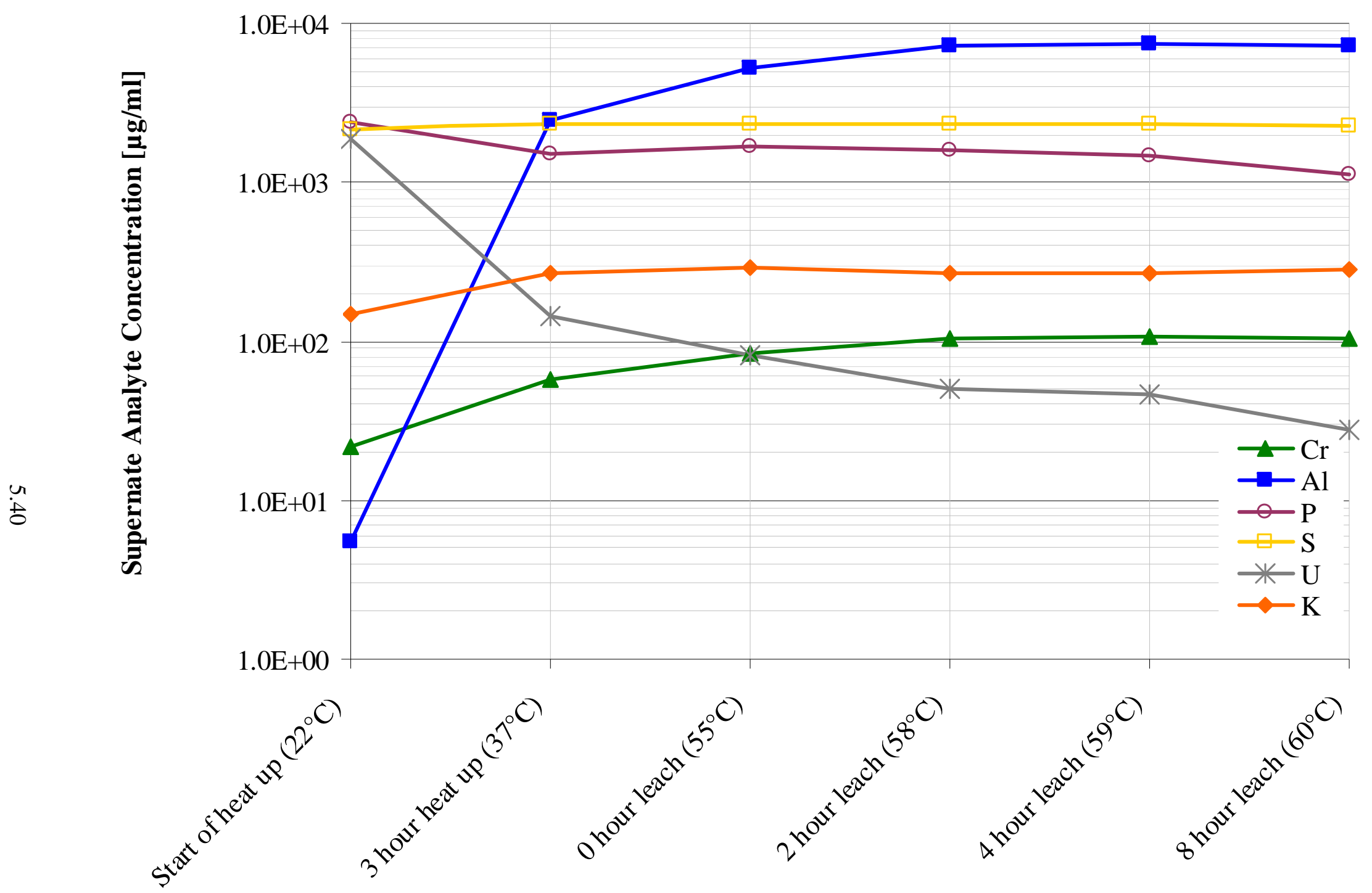

Figure 5.28. Concentration of $\mathrm{Al}, \mathrm{Cr}, \mathrm{P}, \mathrm{S}, \mathrm{U}$ and $\mathrm{K}$ during Caustic Leach of Group 3/4 Slurry 


\subsubsection{Caustic-Leach Dewatering}

After the temperature controller's cooling ramp cycle was completed, the slurry was allowed to circulate through the slurry reservoir loop and cooled to $25^{\circ} \mathrm{C}$ before dewatering. It was allowed to circulate at this temperature for about 30 minutes to verify that the slurry supernate was at thermal equilibrium. Afterwards, the slurry was dewatered at standard conditions (Figure 5.29). The caustic-leached slurry was dewatered from a total system volume of $\sim 2.5 \mathrm{~L}$ to $\sim 1.7 \mathrm{~L}$ over 2 hours. The slurry would have been dewatered further, but the systems-level measuring device was malfunctioning, and so initial estimates of the slurry volume were incorrect. A total of $1.04 \mathrm{~kg}$ of permeate was collected during the dewatering step. Figure 5.30 is a plot of the permeate flux for the dewatering step. The permeate flux decreased from 0.007 to $0.006 \mathrm{GPM} / \mathrm{ft}^{2}$ over the first 60 minutes, but then stayed relatively constant afterwards. While the flux is lower when compared to the slurry before caustic leaching, it resulted from increases in the sodium and free-hydroxide concentration in the slurry supernate from the caustic addition, which caused an increase in the supernate viscosity (see Table 5.22). The magnitude of change in the filter flux is in proportion to the change in the supernate viscosity, as predicted by the Darcy equation.

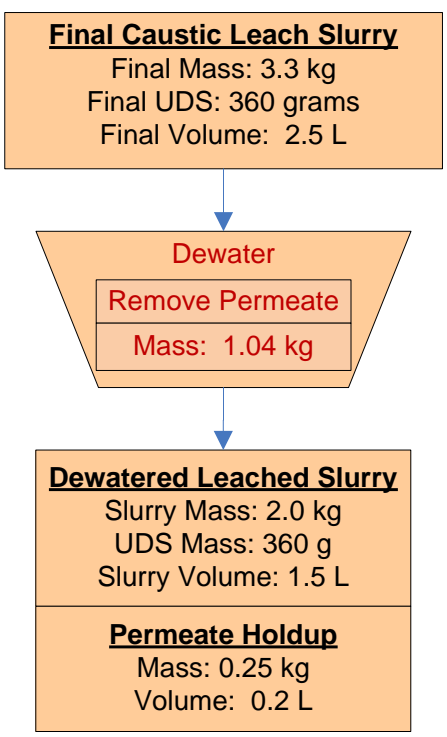

Figure 5.29. Process Flow of Dewatering Caustic Leached Slurry 


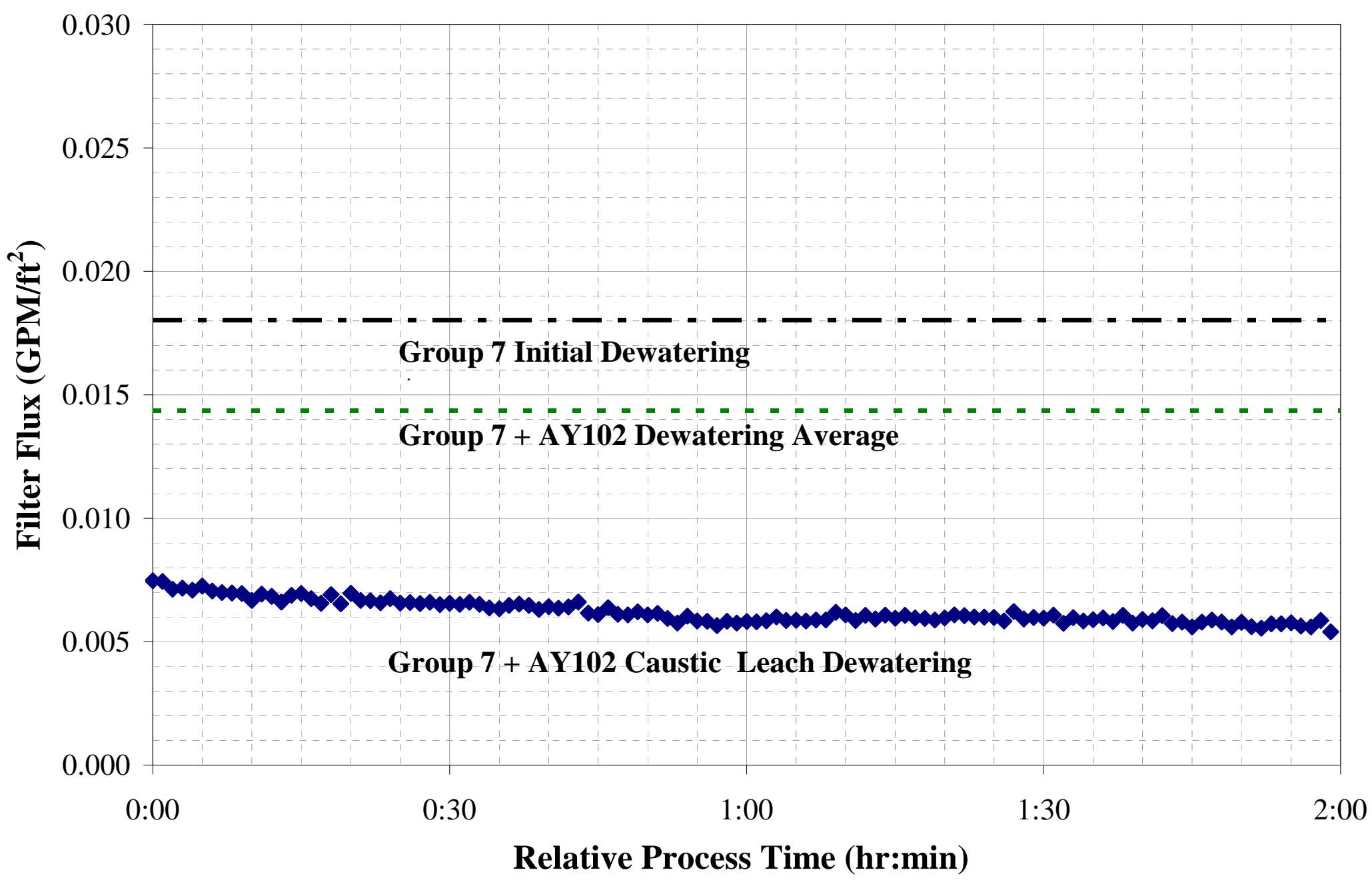

Figure 5.30. Dewatering Leached Blended Slurry (Group 7/AY102) at Standard Conditions 
WTP-RPT-169, Rev 0

Table 5.22. Comparison of Slurry Supernate Attributes to Filter Flux

\begin{tabular}{|c|c|c|c|c|c|}
\hline Supernate Sample & $\begin{array}{l}\text { Viscosity } \\
\text { at } 25^{\circ} \mathrm{C} \\
(\mathrm{mPa} \cdot \mathrm{s})\end{array}$ & $\begin{array}{c}{[\mathrm{Na}]} \\
(\mathrm{M})\end{array}$ & $\begin{array}{c}{[\mathrm{OH}]} \\
(\mathbf{M})\end{array}$ & $\begin{array}{l}\text { [Al] } \\
\text { (M) }\end{array}$ & $\begin{array}{c}\text { Nominal Flux at } \\
\text { Standard Conditions } \\
\left(\mathrm{GPM} / \mathrm{ft}^{2}\right)\end{array}$ \\
\hline High-Solids Slurry & 1.8 & 3.74 & 0.11 & $4.2 \mathrm{E}-4$ & 0.014 \\
\hline Leach Permeate & 3.1 & 4.70 & 2.26 & 2.7E-1 & 0.006 \\
\hline
\end{tabular}

\subsubsection{Dewatered Leached Slurry Physical Characterization}

After dewatering the leached slurry, the slurry was sampled for physical and chemical analysis (Figure 5.31). The results of physical-property measurements of the leached, dewatered material are shown in Table 5.23. The total slurry composition, based on mass balance calculations resulting from the removed mass of the dewatered leach permeate, is shown in Table 5.24. The composition of both the slurry and supernate at this point is shown in Table 5.25. Using chemical characterization data of the high solids slurry in Table 5.25, solid leach factors were calculated for each of the analytes listed, using iron and zirconium as baseline components (i.e., assuming these components do not dissolved during caustic leaching) to predict concentration factors.

As predicted by the filtered supernate analysis, the solids leach factor for aluminum was found to be about $50 \%$. The leach factor for phosphorus was calculated to be a negative value, which indicates that increases in the sodium concentration precipitated phosphate initially present in the un-leached slurry supernate and is suppressing the release of water-soluble phosphate present in the solids at this point in the process. The leach factor for this analyte was re-examined after washing (Section 5.5.4, Section 5.6), and much higher values were found after the sodium in the supernate was decreased. These observations would be consistent with the formation of solid $\mathrm{Na}_{3} \mathrm{PO}_{4} \cdot 12 \mathrm{H}_{2} \mathrm{O}$ at high sodium concentration, which becomes readily soluble as the Na concentration decreases during washing.

Before leaching, a large portion of uranium was found to be soluble in the slurry supernate. Leaching decreased the concentration of $U$ in the slurry from $3,800 \mu \mathrm{g} / \mathrm{mL}$ to $50 \mu \mathrm{g} / \mathrm{mL}$. It is predicted that the increase in the hydroxide concentration caused this portion in the slurry to precipitate as a hydroxide or oxide. The solids leach factor calculated for this term was found to be -0.8 , which also indicates an increase in the solids uranium content of the slurry. While cesium shows a decrease in the overall inventory, this was due to removal of cesium in the aqueous phase of the supernate. Examining the leach factors shows that a majority of the cesium is present in the solids phase and is not removed by caustic leaching, much like the transuranic elements. 


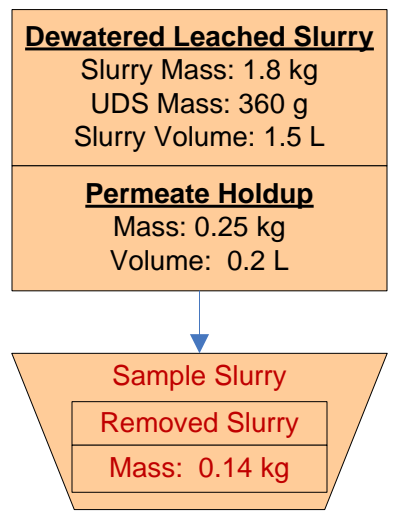

Figure 5.31. Sampling of Dewatered Caustic Leached Slurry

Table 5.23. Dewatered Caustic Leached Slurry Physical-Property Measurements (inside circulation loop)

\begin{tabular}{|r|c|}
\hline Slurry Density (g/mL) & 1.46 \\
\hline Supernate Density (g/mL) & 1.33 \\
\hline Settled Solids (Vol \%) & $95 \%$ \\
\hline Centrifuged UDS (Wt \%) & $43 \%$ \\
\hline Total Solids (Wt \%) & $35 \%$ \\
\hline Dissolved Solids (Wt \%) & $19 \%$ \\
\hline UDS (Wt \%) & $20 \%$ \\
\hline \hline
\end{tabular}

Table 5.24. Group 7 Caustic leached, Dewatered Slurry Inventory and Composition

\begin{tabular}{|c|c|c|c|c|c|}
\hline & Slurry $^{(\mathbf{a})}$ & \multicolumn{2}{|c|}{ Liquid Fraction $^{(b)}$} & \multicolumn{2}{|c|}{ Solids Fraction ${ }^{(\mathrm{c})}$} \\
\hline Mass (kg) & 2.12 & \multicolumn{2}{|c|}{1.79} & \multicolumn{2}{|c|}{0.33} \\
\hline Wt\% of Slurry & $100 \%$ & \multicolumn{2}{|c|}{$84.3 \%$} & \multicolumn{2}{|c|}{$15.7 \%$} \\
\hline Metal & g & g & $\mu \mathrm{g} / \mathrm{ml}$ & g & $\mu \mathrm{g} / \mathrm{g}$ \\
\hline Al & $2.2 \mathrm{E}+01$ & $1.1 \mathrm{E}+01$ & $7.4 \mathrm{E}+03$ & $1.1 \mathrm{E}+01$ & $3.4 \mathrm{E}+04$ \\
\hline B & $1.0 \mathrm{E}-02$ & 2.5E-02 & $1.8 \mathrm{E}+01$ & $\mathrm{n} / \mathrm{a}^{(\mathrm{d})}$ & $\mathrm{n} / \mathrm{a}^{(\mathrm{d})}$ \\
\hline $\mathbf{B i}$ & $6.8 \mathrm{E}-01$ & $<5$. E-3 & $<4 . \mathrm{E}+0$ & $6.8 \mathrm{E}-01$ & $2.1 \mathrm{E}+03$ \\
\hline Ca & $3.9 \mathrm{E}+00$ & 4.1E-03 & $2.9 \mathrm{E}+00$ & $3.9 \mathrm{E}+00$ & $1.2 \mathrm{E}+04$ \\
\hline Cd & 8.0E-02 & 2.0E-03 & $1.4 \mathrm{E}+00$ & 7.8E-02 & $2.4 \mathrm{E}+02$ \\
\hline $\mathrm{Cr}$ & 9.9E-01 & 1.6E-01 & $1.1 \mathrm{E}+02$ & 8.3E-01 & $2.5 \mathrm{E}+03$ \\
\hline $\mathbf{F e}$ & $6.0 \mathrm{E}+01$ & 8.9E-03 & $6.2 \mathrm{E}+00$ & $6.0 \mathrm{E}+01$ & $1.8 \mathrm{E}+05$ \\
\hline $\mathbf{K}$ & $1.2 \mathrm{E}-01$ & 4.1E-01 & $2.9 \mathrm{E}+02$ & $\mathrm{n} / \mathrm{a}^{(\mathrm{d})}$ & $\mathrm{n} / \mathrm{a}^{(\mathrm{d})}$ \\
\hline Mn & $8.7 \mathrm{E}+00$ & 2.1E-04 & $1.5 \mathrm{E}-01$ & $8.7 \mathrm{E}+00$ & $2.6 \mathrm{E}+04$ \\
\hline $\mathrm{Na}$ & $1.8 \mathrm{E}+02$ & $1.5 \mathrm{E}+02$ & $1.1 \mathrm{E}+05$ & $2.8 \mathrm{E}+01$ & $8.4 \mathrm{E}+04$ \\
\hline $\mathrm{Ni}$ & $1.5 \mathrm{E}+00$ & $<4$. E-4 & $<3$. E-1 & $1.5 \mathrm{E}+00$ & $4.5 \mathrm{E}+03$ \\
\hline $\mathbf{P}$ & $1.5 \mathrm{E}+01$ & $2.1 \mathrm{E}+00$ & $1.5 \mathrm{E}+03$ & $1.2 \mathrm{E}+01$ & $3.7 \mathrm{E}+04$ \\
\hline $\mathrm{S}$ & $2.7 \mathrm{E}+00$ & $3.3 \mathrm{E}+00$ & $2.3 \mathrm{E}+03$ & $\mathrm{n} / \mathrm{a}^{(\mathrm{d})}$ & $\mathrm{n} / \mathrm{a}^{(\mathrm{d})}$ \\
\hline Si & $1.5 \mathrm{E}+01$ & 7.2E-02 & $5.0 \mathrm{E}+01$ & $1.5 \mathrm{E}+01$ & $4.5 E+04$ \\
\hline $\mathrm{Sr}$ & 5.8E-01 & 1.6E-05 & $1.1 \mathrm{E}-02$ & 5.8E-01 & $1.8 \mathrm{E}+03$ \\
\hline
\end{tabular}


WTP-RPT-169, Rev 0

Table 5.24 (Contd)

\begin{tabular}{|c|c|c|c|c|c|}
\hline & Slurry $^{(\mathbf{a})}$ & \multicolumn{2}{|c|}{ "Liquid Fraction ${ }^{(b)}$} & \multicolumn{2}{|c|}{ Solids Fraction $^{(\mathrm{c})}$} \\
\hline Mass (kg) & 2.12 & \multicolumn{2}{|c|}{1.79} & \multicolumn{2}{|c|}{0.33} \\
\hline Wt\% of Slurry & $100 \%$ & \multicolumn{2}{|c|}{$84.3 \%$} & \multicolumn{2}{|c|}{$15.7 \%$} \\
\hline Metal & g & g & $\mu \mathrm{g} / \mathrm{ml}$ & g & $\mu g / g$ \\
\hline Zn & $1.6 \mathrm{E}-01$ & $1.8 \mathrm{E}-02$ & $1.2 \mathrm{E}+01$ & $1.4 \mathrm{E}-01$ & $4.2 \mathrm{E}+02$ \\
\hline $\mathbf{Z r}$ & $1.4 \mathrm{E}+00$ & $4.4 \mathrm{E}-04$ & 3.1E-01 & $1.4 \mathrm{E}+00$ & $4.2 \mathrm{E}+03$ \\
\hline $\mathbf{U}$ & $8.7 \mathrm{E}+00$ & 7.4E-02 & $5.2 \mathrm{E}+01$ & $8.6 \mathrm{E}+00$ & $2.6 \mathrm{E}+04$ \\
\hline \multirow{2}{*}{$\begin{array}{c}\text { Radiochemical } \\
\text { Isotopes }\end{array}$} & Slurry & \multicolumn{2}{|c|}{ Liquid Fraction } & \multicolumn{2}{|c|}{ Solid Fraction } \\
\hline & $\mu \mathrm{Ci}$ & $\mu \mathrm{Ci}$ & $\mu \mathrm{Ci} / \mathrm{ml}$ & $\mu \mathrm{Ci}$ & $\mu \mathrm{Ci} / \mathrm{g}$ \\
\hline Co-60 & $6.5 \mathrm{E}+01$ & 3.6E-01 & 2.5E-04 & $6.4 \mathrm{E}+01$ & 1.9E-01 \\
\hline Cs-137 & $1.4 \mathrm{E}+05$ & $1.7 \mathrm{E}+04$ & $1.2 \mathrm{E}+01$ & $1.2 \mathrm{E}+05$ & $3.6 \mathrm{E}+02$ \\
\hline Eu-152 & $8.7 \mathrm{E}+01$ & $<4$.E-1 & $<3$. E-4 & $8.7 \mathrm{E}+01$ & 2.6E-01 \\
\hline Eu-154 & $2.1 \mathrm{E}+03$ & $<3 . \mathrm{E}-1$ & $<2$.E-4 & $2.1 \mathrm{E}+03$ & $6.5 \mathrm{E}+00$ \\
\hline Eu-155 & $9.7 \mathrm{E}+02$ & $<5 . \mathrm{E}+0$ & $<3 . \mathrm{E}-3$ & $9.7 \mathrm{E}+02$ & $2.9 \mathrm{E}+00$ \\
\hline Am-241 & $3.5 \mathrm{E}+03$ & $<1 . \mathrm{E}+1$ & $<9$. E-3 & $3.5 \mathrm{E}+03$ & $1.1 \mathrm{E}+01$ \\
\hline Gross Alpha & $5.2 \mathrm{E}+03$ & $2.5 \mathrm{E}+00$ & $1.7 \mathrm{E}-03$ & $5.2 \mathrm{E}+03$ & $1.6 \mathrm{E}+01$ \\
\hline Gross Beta & $6.0 \mathrm{E}+06$ & $1.4 \mathrm{E}+04$ & $9.9 \mathrm{E}+00$ & $6.0 \mathrm{E}+06$ & $1.8 \mathrm{E}+04$ \\
\hline Sr-90 & $3.1 \mathrm{E}+06$ & $3.4 \mathrm{E}+00$ & $2.4 \mathrm{E}-03$ & $3.1 \mathrm{E}+06$ & $9.5 \mathrm{E}+03$ \\
\hline $\mathrm{Pu}-239+240$ & $1.3 \mathrm{E}+03$ & $3.2 \mathrm{E}+00$ & 2.3E-03 & $1.3 \mathrm{E}+03$ & $4.0 \mathrm{E}+00$ \\
\hline Pu-238 & $2.1 \mathrm{E}+02$ & 4.4E-01 & 3.1E-04 & $2.1 \mathrm{E}+02$ & $6.2 \mathrm{E}-01$ \\
\hline \multirow[t]{2}{*}{ Anions } & \multicolumn{3}{|c|}{ Liquid Fraction } & \multicolumn{2}{|c|}{ Leached Solids Fraction } \\
\hline & $\mu \mathrm{g} / \mathrm{ml}$ & [M] & g & $\mu \mathrm{g} / \mathrm{g}$ & g \\
\hline $\mathbf{F}$ & $1.7 \mathrm{E}+02$ & 8.9E-03 & 2.6E-01 & $5.7 \mathrm{E}+02$ & 2.0E-01 \\
\hline Cl & $1.6 \mathrm{E}+03$ & 4.5E-02 & $2.4 \mathrm{E}+00$ & $2.7 \mathrm{E}+03$ & 9.3E-01 \\
\hline $\mathrm{C}_{2} \mathrm{O}_{4}$ & $9.0 \mathrm{E}+02$ & $1.0 \mathrm{E}-02$ & $1.4 \mathrm{E}+00$ & $2.6 \mathrm{E}+03$ & 9.0E-01 \\
\hline $\mathrm{NO}_{2}$ & $7.6 \mathrm{E}+03$ & 1.6E-01 & $1.1 \mathrm{E}+01$ & $1.4 \mathrm{E}+04$ & $5.1 \mathrm{E}+00$ \\
\hline $\mathrm{NO}_{3}$ & $6.5 \mathrm{E}+04$ & $1.0 \mathrm{E}+00$ & $9.8 \mathrm{E}+01$ & $1.1 \mathrm{E}+05$ & $4.0 \mathrm{E}+01$ \\
\hline $\mathrm{SO}_{4}$ & $6.5 \mathrm{E}+03$ & $6.8 \mathrm{E}-02$ & $9.8 \mathrm{E}+00$ & $1.2 \mathrm{E}+04$ & $4.2 \mathrm{E}+00$ \\
\hline $\mathrm{PO}_{4}$ & $4.6 \mathrm{E}+03$ & 4.9E-02 & $7.0 \mathrm{E}+00$ & $6.6 \mathrm{E}+04$ & $2.3 \mathrm{E}+01$ \\
\hline $\mathbf{O H}$ & $3.8 \mathrm{E}+04$ & $2.3 \mathrm{E}+00$ & $5.8 \mathrm{E}+01$ & & \\
\hline \multicolumn{6}{|c|}{$\begin{array}{l}\text { Slurry Mass components were calculated from characterization data (WTP-RPT-169, Section 3). Loss of mass } \\
\text { from sampling was incorporated. } \\
\text { Liquid Fraction mass components were calculated using analytical results from supernate sample TI624-G7-D } \\
\text { (ASO ID 08-02061) and the predicted mass of supernate in the system. } \\
\text { Solids Fraction mass components were calculated from the difference between the slurry component mass and } \\
\text { liquid component mass fraction. } \\
\text { Values (based on supernate) were calculated to be less than zero. }\end{array}$} \\
\hline
\end{tabular}


Table 5.25. Dewatered Leached Slurry Composition and Solid Leach Factor Calculations

\begin{tabular}{|c|c|c|c|c|c|}
\hline $\begin{array}{c}\text { Slurry Prep } \\
\text { Method }\end{array}$ & Analyte & $\begin{array}{c}\text { Dry Slurry } \\
(\mu \mathrm{g} / \mathrm{g})\end{array}$ & $\begin{array}{c}\text { Supernate }^{(b)} \\
(\mu g / m L)\end{array}$ & $\begin{array}{c}\text { Dry Solids }^{(\mathrm{c})} \\
(\mu \mathrm{g} / \mathrm{g})\end{array}$ & $\begin{array}{c}\text { Solids } \\
\text { Leach Factor }^{(d)}\end{array}$ \\
\hline \multirow{33}{*}{ 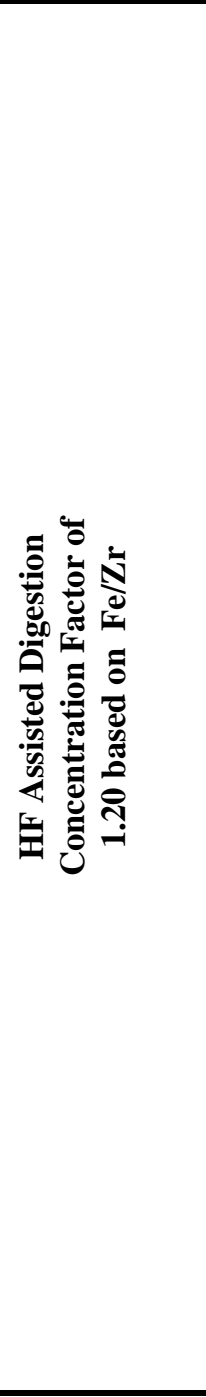 } & $\mathrm{Al}$ & 36,800 & 7,370 & 42,000 & 0.51 \\
\hline & $\mathrm{B}$ & [23] & 17.5 & $-[12]$ & -0.14 \\
\hline & $\mathrm{Bi}$ & 1,240 & -- & 2,200 & -0.02 \\
\hline & $\mathrm{Cd}$ & 132 & [1.4] & 230 & 0.01 \\
\hline & $\mathrm{Cr}$ & 1,750 & 110 & 2,700 & 0.15 \\
\hline & $\mathrm{Fe}$ & 107,000 & 6.24 & 190,000 & \\
\hline & $\mathrm{Mn}$ & 15,800 & {$[0.15]$} & 28,000 & 0.00 \\
\hline & $\mathrm{Na}$ & 249,000 & 108,000 & 110,000 & -0.58 \\
\hline & $\mathrm{Ni}$ & 2,900 & -- & 5,100 & -0.01 \\
\hline & $\mathrm{P}$ & 25,300 & [1500] & 40,000 & -0.24 \\
\hline & $\mathrm{S}$ & 4,480 & 2,310 & 940 & 1.64 \\
\hline & $\mathrm{Sr}$ & 1050.0 & {$[0.011]$} & 1,800 & 0.00 \\
\hline & $\mathrm{U}$ & 15,100 & 51.70 & 26,000 & -0.80 \\
\hline & $\mathrm{Zn}$ & 313 & 12.3 & 510 & 0.07 \\
\hline & $\mathrm{Zr}$ & 2,670 & [.31] & 4,700 & \\
\hline & $A g$ & 47.0 & 5.34 & 66 & 0.39 \\
\hline & $B a$ & 680 & {$[0.16]$} & 1,200 & 0.00 \\
\hline & $B e$ & [0.94] & [0.022] & [1.6] & 0.01 \\
\hline & $\mathrm{Ca}$ & 7,390 & [2.9] & 13,000 & 0.00 \\
\hline & $\mathrm{Ce}$ & 751 & -- & 1,300 & -0.01 \\
\hline & $\mathrm{Cu}$ & 247 & [1.1] & 430 & 0.00 \\
\hline & $L a$ & 862 & -- & 1,500 & -0.01 \\
\hline & $L i$ & 98.9 & 1.84 & 170 & 0.01 \\
\hline & Mg & 1,990 & -- & 3,500 & 0.00 \\
\hline & Mo & [19] & [2.7] & [25] & -0.21 \\
\hline & $N d$ & 1,280 & -- & 2,200 & -0.03 \\
\hline & $P b$ & 4,590 & [5.7] & 8,000 & 0.00 \\
\hline & $R u$ & 243 & [6.0] & 410 & 0.03 \\
\hline & Th & 579 & -- & 1,000 & -0.02 \\
\hline & $\mathrm{Ti}$ & 234.0 & -- & 410 & 0.00 \\
\hline & $V$ & 19.30 & 0.980 & 31 & 0.07 \\
\hline & $W$ & 273 & [15] & 430 & 0.02 \\
\hline & $\boldsymbol{Y}$ & 111 & -- & 190 & -0.01 \\
\hline \multirow{11}{*}{ 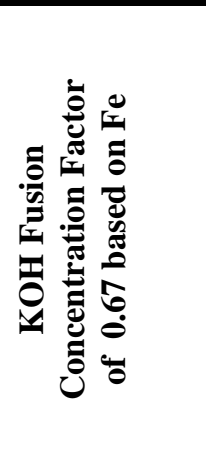 } & $\mathrm{Fe}$ & 64,600 & 6.24 & 110,000 & \\
\hline & $\mathrm{Si}$ & {$[16,300]$} & $\begin{array}{r}50.0 \\
\end{array}$ & {$[28,000]$} & -0.06 \\
\hline & Radionuclide & Dry Slurry $(\mu \mathrm{Ci} / \mathrm{g})$ & Supernate $(\mu \mathrm{Ci} / \mathrm{mL})$ & Dry Solids $(\mu \mathrm{Ci} / \mathrm{g})$ & \\
\hline & ${ }^{60} \mathrm{Co}$ & $8.28 \mathrm{E}-2$ & $2.49 \mathrm{E}-4$ & $1.4 \mathrm{E}-1$ & -0.24 \\
\hline & ${ }^{137} \mathrm{Cs}$ & $1.81 \mathrm{E}+2$ & $1.17 \mathrm{E}+1$ & $2.8 \mathrm{E}+2$ & -0.15 \\
\hline & ${ }^{154} \mathrm{Eu}$ & $1.05 \mathrm{E}-1$ & $<3 . E-4$ & $1.8 \mathrm{E}-1$ & -0.22 \\
\hline & ${ }^{155} \mathrm{Eu}$ & $2.72 \mathrm{E}+0$ & $<2$.E-4 & $4.8 \mathrm{E}+0$ & -0.14 \\
\hline & ${ }^{241} \mathrm{Am}$ & $1.12 \mathrm{E}+0$ & $<3$. E-3 & $2.0 \mathrm{E}+0$ & -0.34 \\
\hline & ${ }^{90} \mathrm{Sr}$ & $4.86 \mathrm{E}+0$ & $<9 . \mathrm{E}-3$ & $8.5 \mathrm{E}+0$ & 0.06 \\
\hline & ${ }^{239+240} \mathrm{Pu}$ & $3.00 \mathrm{E}+3$ & $2.40 \mathrm{E}-3$ & $5.3 \mathrm{E}+3$ & -0.09 \\
\hline & ${ }^{238} \mathrm{Pu}$ & $1.41 \mathrm{E}+0$ & $2.27 \mathrm{E}-3$ & $2.5 \mathrm{E}+0$ & -0.34 \\
\hline \\
\hline \multicolumn{6}{|c|}{$\begin{array}{ll}\text { (a) } & \text { Test sample TI624-G7-9, ASO ID 08-2075 } \\
& \text { (b) }\end{array}$} \\
\hline \multicolumn{6}{|c|}{$\begin{array}{l}\text { Test sample TI624-G8-D, ASO ID 08-2061 } \\
\text { Calculated using results in from TI624-G7-9 and TI624-G7-D. }\end{array}$} \\
\hline \multicolumn{6}{|c|}{$\begin{array}{l}\text { (d) Calculated using the concentration factor in the first column and b } \\
\text { concentration. }\end{array}$} \\
\hline
\end{tabular}


The slurry was also sub-sampled for rheological measurement. Figure 5.32 shows the results of flowcurve testing for the leached dewatered slurry. The flow behavior is non-Newtonian. Flow-curve data indicate that the dewatered slurry has a finite yield stress of approximately 1 to $3 \mathrm{~Pa}$ and that the slurry is shear thinning. Flow-curve hysteresis is minor and can be attributed to rotor inertial effects alone. The lack of hysteresis suggests that the internal structure of the slurry (such as particle agglomerates) is stable with respect to shear or that any changes in structure occur quickly and are complete at the end of the 3-minute shearing step performed immediately before flow-curve measurement. With regard to data anomalies, the curves are free of any slope discontinuities that could be associated with Taylor vortex formation.

Flow-curve data at $25^{\circ} \mathrm{C}, 40^{\circ} \mathrm{C}$, and $60^{\circ} \mathrm{C}$ were fit to both Bingham-Plastic and Casson models.

Table 5.26 summarizes the best-fit model parameters for the leached dewatered slurry. Since the data were not influenced by Taylor vortex formation, the full range of shear rates ( 0 to $\left.1000 \mathrm{~s}^{-1}\right)$ is employed in the Casson fitting analysis. Bingham-Plastic analysis cannot account for slurry shear thinning, and as a result, its fitting analysis is limited to 100 to $1000 \mathrm{~s}^{-1}$ to avoid bias introduced by slurry shear thinning at low-shear rates. Both models provide reasonable fits of the data.

Apparent viscosities at 33, 100, 500, and $1000 \mathrm{~s}^{-1}$ were derived from each measurement. For each temperature, the 33, 100, and $500 \mathrm{~s}^{-1}$ reference viscosities were determined from the average of both upramp and down-ramp flow-curve data. The apparent viscosity at $1000 \mathrm{~s}^{-1}$ is derived from the averaging of all apparent viscosity measurements during constant rotation at $1000 \mathrm{~s}^{-1}$. As a point of comparison, apparent viscosities were also calculated using the Bingham-Plastic and Casson fitting parameters in Table 5.26. The results of these analyses are provided in Table 5.27.

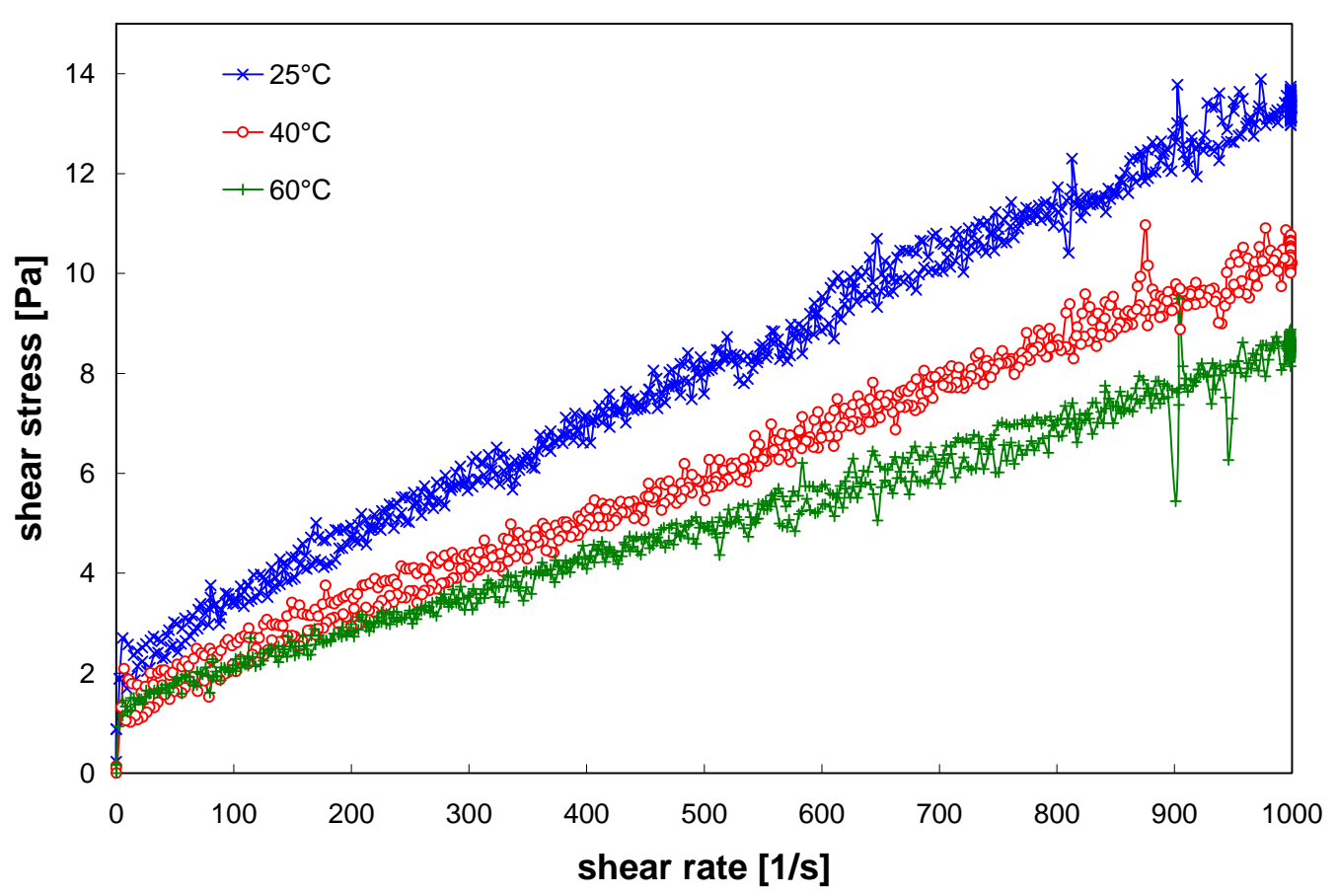

Figure 5.32. Flow Curves for Group 8 CUF Leached Dewatered Slurry 
WTP-RPT-169, Rev 0

Table 5.26. Results of Fitting Analysis for the Group 7 CUF Leached Dewatered Slurry

\begin{tabular}{|c|c|c|c|c|c|}
\hline Model & Temperature $\left[{ }^{\circ} \mathrm{C}\right]$ & Range & $\begin{array}{c}\text { Yield Stress } \\
{[\mathrm{Pa}]}\end{array}$ & $\begin{array}{c}\text { Consistency } \\
\text { [mPa·s] }\end{array}$ & $\mathbf{R}$ \\
\hline \multirow[t]{4}{*}{ Bingham-Plastic } & $25(1$ of 2$)$ & $100-1000 \mathrm{~s}^{-1}$ & 2.5 & 11 & 1.00 \\
\hline & 25 (2 of 2$)$ & $100-1000 \mathrm{~s}^{-1}$ & 2.6 & 11 & 1.00 \\
\hline & 40 & $100-1000 \mathrm{~s}^{-1}$ & 1.5 & 8.9 & 1.00 \\
\hline & 60 & $100-1000 \mathrm{~s}^{-1}$ & 1.4 & 7.1 & 0.99 \\
\hline \multirow[t]{4}{*}{ Casson } & 25 (1 of 2$)$ & $0-1000 \mathrm{~s}^{-1}$ & 0.83 & 7.4 & 1.00 \\
\hline & 25 (2 of 2$)$ & $0-1000 \mathrm{~s}^{-1}$ & 1.0 & 7.2 & 1.00 \\
\hline & 40 & $0-1000 \mathrm{~s}^{-1}$ & 0.45 & 6.5 & 1.00 \\
\hline & 60 & $0-1000 \mathrm{~s}^{-1}$ & 0.45 & 5.0 & 0.99 \\
\hline
\end{tabular}

Table 5.27. Select Apparent Viscosities for the Leached Dewatered Slurry

\begin{tabular}{|c|c|c|c|c|c|}
\hline \multirow[b]{2}{*}{ Source } & \multirow{2}{*}{$\begin{array}{c}\text { Temperature } \\
{\left[{ }^{\circ} \mathrm{C}\right]}\end{array}$} & \multicolumn{4}{|c|}{ Apparent Viscosity [mPa·s] } \\
\hline & & (a) $33 \mathrm{~s}^{-1}$ & (@) $100 \mathrm{~s}^{-1}$ & (a) $500 \mathrm{~s}^{-1}$ & @ $1000 \mathrm{~s}^{-1}$ \\
\hline \multirow[t]{4}{*}{ Measured } & 25 (1 of 2$)$ & 59 & 31 & 16 & 13 \\
\hline & 25 (2 of 2$)$ & 78 & 34 & 16 & 13 \\
\hline & 40 & 48 & 23 & 11 & 10 \\
\hline & 60 & 49 & 22 & 9.8 & 8.6 \\
\hline \multirow[t]{4}{*}{ Bingham-Plastic } & 25 (1 of 2$)$ & 87 & 36 & 16 & 13 \\
\hline & 25 (2 of 2$)$ & 90 & 37 & 16 & 13 \\
\hline & 40 & 55 & 24 & 12 & 10 \\
\hline & 60 & 49 & 21 & 10 & 8.5 \\
\hline \multirow[t]{4}{*}{ Casson } & 25 (1 of 2$)$ & 60 & 31 & 16 & 13 \\
\hline & 25 (2 of 2$)$ & 65 & 33 & 16 & 13 \\
\hline & 40 & 39 & 22 & 12 & 10 \\
\hline & 60 & 35 & 19 & 10 & 8.4 \\
\hline
\end{tabular}

\subsubsection{Caustic Batch Rinsing Results}

After slurry sampling, the slurry was washed four times with decreasing concentrations of sodium hydroxide, as shown in Figure 5.33. The volume of each wash solution was 1.2 liters, approximately the same volume of supernate present in the system after dewatering from caustic leaching. After each solution was added, the slurry was re-circulated in the CUF for $~ 30$ minutes while filter permeate was recycled back to the slurry reservoir. The slurry was then dewatered at standard conditions to return the slurry back to its original volume. To prevent damage to the pump, the final dewatering was stopped at 1 liter because cavitation was occurring. Grab samples of the filtered permeate were collected half-way between each dewatering step to assess the composition of the filtrate. The results were used to predict the slurry inventory and composition at each wash step, shown in Table 5.28 through Table 5.31. The measured concentration of free hydroxide, radionuclides, and opportunistic ICP-OES analytes for each filtered wash solution is provided in Table 5.32. 


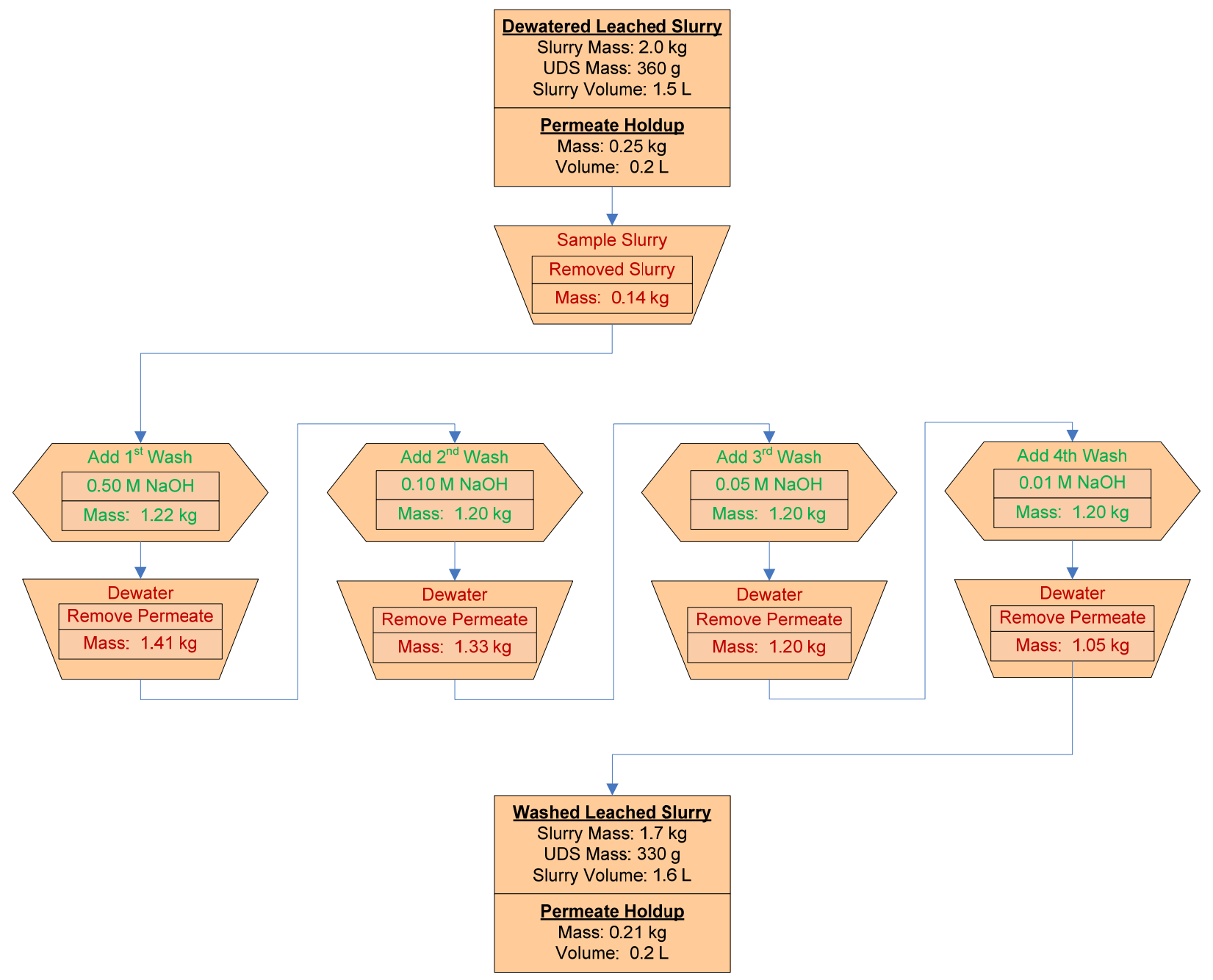

Figure 5.33. Process Flow of Batch Washing Operations 
Table 5.28. Group 7/AY-102 Caustic leached Slurry Inventory and Composition after the First Wash

\begin{tabular}{|c|c|c|c|c|c|}
\hline & Slurry $^{(a)}$ & \multicolumn{2}{|c|}{ Liquid Fraction $^{(b)}$} & \multicolumn{2}{|c|}{ Solids Fraction $^{(c)}$} \\
\hline Mass (kg) & 1.92 & & 1.60 & & 0.32 \\
\hline Wt\% of Slurry & $100 \%$ & & $83.3 \%$ & & $16.7 \%$ \\
\hline Metal & g & g & $\mu \mathrm{g} / \mathrm{ml}$ & g & $\mu g / g$ \\
\hline Al & $1.7 \mathrm{E}+01$ & $5.5 \mathrm{E}+00$ & $4.0 \mathrm{E}+03$ & $1.1 \mathrm{E}+01$ & $3.6 \mathrm{E}+04$ \\
\hline B & $2.2 \mathrm{E}-03$ & 8.8E-03 & $6.4 \mathrm{E}+00$ & $\mathrm{n} / \mathrm{a}^{(\mathrm{d})}$ & $\mathrm{n} / \mathrm{a}^{(\mathrm{d})}$ \\
\hline $\mathbf{B i}$ & $6.8 \mathrm{E}-01$ & $<5$.E-3 & $<4 . \mathrm{E}+0$ & $6.8 \mathrm{E}-01$ & $2.1 \mathrm{E}+03$ \\
\hline Ca & $3.9 \mathrm{E}+00$ & 3.7E-03 & $2.7 \mathrm{E}+00$ & $3.9 \mathrm{E}+00$ & $1.2 \mathrm{E}+04$ \\
\hline Cd & 7.9E-02 & $1.7 \mathrm{E}-03$ & $1.2 \mathrm{E}+00$ & 7.7E-02 & $2.4 \mathrm{E}+02$ \\
\hline $\mathrm{Cr}$ & $9.1 \mathrm{E}-01$ & $8.4 \mathrm{E}-02$ & $6.1 \mathrm{E}+01$ & 8.3E-01 & $2.6 \mathrm{E}+03$ \\
\hline $\mathbf{F e}$ & $6.0 \mathrm{E}+01$ & 2.9E-03 & $2.1 \mathrm{E}+00$ & $6.0 \mathrm{E}+01$ & $1.9 \mathrm{E}+05$ \\
\hline $\mathbf{K}$ & $2.0 \mathrm{E}-01$ & $2.0 \mathrm{E}-01$ & $1.4 \mathrm{E}+02$ & $\mathrm{n} / \mathrm{a}^{(\mathrm{d})}$ & $\mathrm{n} / \mathrm{a}^{(\mathrm{d})}$ \\
\hline Mn & $8.7 \mathrm{E}+00$ & 1.7E-04 & $1.2 \mathrm{E}-01$ & $8.7 \mathrm{E}+00$ & $2.7 \mathrm{E}+04$ \\
\hline $\mathrm{Na}$ & $1.1 \mathrm{E}+02$ & $9.3 \mathrm{E}+01$ & $6.8 \mathrm{E}+04$ & $2.1 \mathrm{E}+01$ & $6.7 \mathrm{E}+04$ \\
\hline $\mathrm{Ni}$ & $1.5 \mathrm{E}+00$ & $<4 . \mathrm{E}-4$ & $<3$. E-1 & $1.5 \mathrm{E}+00$ & $4.6 \mathrm{E}+03$ \\
\hline $\mathbf{P}$ & $1.1 \mathrm{E}+01$ & $3.6 \mathrm{E}+00$ & $2.6 \mathrm{E}+03$ & $7.8 \mathrm{E}+00$ & $2.4 \mathrm{E}+04$ \\
\hline $\mathbf{S}$ & $1.2 \mathrm{E}+00$ & $1.7 \mathrm{E}+00$ & $1.2 \mathrm{E}+03$ & $\mathrm{n} / \mathrm{a}^{(\mathrm{d})}$ & $n / a^{(d)}$ \\
\hline Si & $1.5 \mathrm{E}+01$ & 4.0E-02 & $2.9 \mathrm{E}+01$ & $1.5 \mathrm{E}+01$ & $4.6 \mathrm{E}+04$ \\
\hline Sr & $5.8 \mathrm{E}-01$ & $<1$.E-5 & $<1 . \mathrm{E}-2$ & $5.8 \mathrm{E}-01$ & $1.8 \mathrm{E}+03$ \\
\hline Zn & $1.5 \mathrm{E}-01$ & 6.7E-03 & $4.9 \mathrm{E}+00$ & $1.4 \mathrm{E}-01$ & $4.5 \mathrm{E}+02$ \\
\hline $\mathbf{Z r}$ & $1.4 \mathrm{E}+00$ & 4.4E-04 & 3.2E-01 & $1.4 \mathrm{E}+00$ & $4.3 \mathrm{E}+03$ \\
\hline $\mathbf{U}$ & $8.7 \mathrm{E}+00$ & 5.6E-02 & $4.1 \mathrm{E}+01$ & $8.6 \mathrm{E}+00$ & $2.7 \mathrm{E}+04$ \\
\hline \multirow[t]{2}{*}{ Anions } & \multicolumn{3}{|c|}{ Liquid Fraction } & & \\
\hline & $\mu \mathrm{g} / \mathrm{ml}$ & [M] & g & & \\
\hline $\mathbf{O H}$ & $2.5 \mathrm{E}+04$ & $1.5 \mathrm{E}+00$ & $3.5 \mathrm{E}+01$ & & \\
\hline \multicolumn{6}{|l|}{$\begin{array}{ll}\text { (b) Liquid Fract } \\
& \text { G4-E (ASO } \\
\text { (c) Solids Fract } \\
\text { and liquid ce } \\
\text { (d) Values (base }\end{array}$} \\
\hline
\end{tabular}


Table 5.29. Group 7/AY-102 Caustic leached Slurry Inventory and Composition after the Second Wash

\begin{tabular}{|c|c|c|c|c|c|}
\hline & Slurry $^{(a)}$ & \multicolumn{2}{|c|}{ Liquid Fraction $^{(\mathbf{b})}$} & \multicolumn{2}{|c|}{ Solids Fraction ${ }^{(\mathrm{c})}$} \\
\hline Mass (kg) & 1.79 & & 1.49 & & 0.30 \\
\hline Wt\% of Slurry & $100 \%$ & & $83.3 \%$ & & $16.7 \%$ \\
\hline Metal & g & g & $\mu \mathrm{g} / \mathrm{ml}$ & g & $\mu g / g$ \\
\hline Al & $1.5 \mathrm{E}+01$ & $2.5 \mathrm{E}+00$ & $1.9 \mathrm{E}+03$ & $1.2 \mathrm{E}+01$ & $4.1 \mathrm{E}+04$ \\
\hline B & 4.4E-03 & 4.4E-03 & $3.3 \mathrm{E}+00$ & $n / a^{(d)}$ & $\mathrm{n} / \mathrm{a}^{(\mathrm{d})}$ \\
\hline $\mathbf{B i}$ & $6.8 \mathrm{E}-01$ & $<5$. E-3 & $<4 . \mathrm{E}+0$ & $6.8 \mathrm{E}-01$ & $2.3 \mathrm{E}+03$ \\
\hline Ca & $3.9 \mathrm{E}+00$ & 3.2E-03 & $2.4 \mathrm{E}+00$ & $3.9 \mathrm{E}+00$ & $1.3 \mathrm{E}+04$ \\
\hline Cd & 7.7E-02 & $1.6 \mathrm{E}-03$ & $1.2 \mathrm{E}+00$ & 7.6E-02 & $2.5 \mathrm{E}+02$ \\
\hline $\mathrm{Cr}$ & 8.8E-01 & 3.8E-02 & $2.9 \mathrm{E}+01$ & $8.4 \mathrm{E}-01$ & $2.8 \mathrm{E}+03$ \\
\hline $\mathbf{F e}$ & $6.0 \mathrm{E}+01$ & $1.8 \mathrm{E}-03$ & $1.3 \mathrm{E}+00$ & $6.0 \mathrm{E}+01$ & $2.0 \mathrm{E}+05$ \\
\hline $\mathbf{K}$ & $1.0 \mathrm{E}-01$ & $1.0 \mathrm{E}-01$ & $7.4 \mathrm{E}+01$ & $\mathrm{n} / \mathrm{a}^{(\mathrm{d})}$ & $\mathrm{n} / \mathrm{a}^{(\mathrm{d})}$ \\
\hline Mn & $8.7 \mathrm{E}+00$ & 9.6E-05 & 7.1E-02 & $8.7 \mathrm{E}+00$ & $2.9 \mathrm{E}+04$ \\
\hline $\mathrm{Na}$ & $7.2 \mathrm{E}+01$ & $5.0 \mathrm{E}+01$ & $3.7 \mathrm{E}+04$ & $2.3 \mathrm{E}+01$ & $7.5 \mathrm{E}+04$ \\
\hline $\mathrm{Ni}$ & $1.5 \mathrm{E}+00$ & $<4$.E-4 & $<3$. E-1 & $1.5 \mathrm{E}+00$ & $4.9 \mathrm{E}+03$ \\
\hline $\mathbf{P}$ & $7.5 \mathrm{E}+00$ & $4.3 \mathrm{E}+00$ & $3.2 \mathrm{E}+03$ & $3.2 \mathrm{E}+00$ & $1.1 \mathrm{E}+04$ \\
\hline $\mathbf{S}$ & $5.0 \mathrm{E}-01$ & 7.6E-01 & $5.7 \mathrm{E}+02$ & $n / a^{(d)}$ & $\mathrm{n} / \mathrm{a}^{(\mathrm{d})}$ \\
\hline Si & $1.5 \mathrm{E}+01$ & $2.0 \mathrm{E}-02$ & $1.5 \mathrm{E}+01$ & $1.5 \mathrm{E}+01$ & $4.9 \mathrm{E}+04$ \\
\hline $\mathrm{Sr}$ & $5.8 \mathrm{E}-01$ & $1.5 \mathrm{E}-05$ & $1.1 \mathrm{E}-02$ & 5.8E-01 & $1.9 \mathrm{E}+03$ \\
\hline Zn & $1.5 \mathrm{E}-01$ & 2.6E-03 & $1.9 \mathrm{E}+00$ & $1.4 \mathrm{E}-01$ & $4.8 \mathrm{E}+02$ \\
\hline $\mathrm{Zr}$ & $1.4 \mathrm{E}+00$ & 2.2E-04 & $1.6 \mathrm{E}-01$ & $1.4 \mathrm{E}+00$ & $4.6 \mathrm{E}+03$ \\
\hline $\mathbf{U}$ & $8.6 \mathrm{E}+00$ & 3.6E-02 & $2.7 \mathrm{E}+01$ & $8.6 \mathrm{E}+00$ & $2.9 \mathrm{E}+04$ \\
\hline \multirow[t]{2}{*}{ Anions } & \multicolumn{3}{|c|}{ Liquid Fraction } & & \\
\hline & $\mu \mathrm{g} / \mathrm{ml}$ & [M] & g & & \\
\hline OH & $1.3 \mathrm{E}+04$ & 7.7E-01 & $1.8 \mathrm{E}+01$ & & \\
\hline \multicolumn{6}{|l|}{$\begin{array}{l}\text { (b) Liquid Frac } \\
\text { G4-F (ASO } \\
\text { (c) Solids Frac }\end{array}$} \\
\hline
\end{tabular}


Table 5.30. Group 7/AY-102 Caustic leached Slurry Inventory and Composition after the Third Wash

\begin{tabular}{|c|c|c|c|c|c|}
\hline & Slurry $^{(a)}$ & \multicolumn{2}{|c|}{ Liquid Fraction $^{(\mathbf{b})}$} & \multicolumn{2}{|c|}{ Solids Fraction ${ }^{(\mathrm{c})}$} \\
\hline Mass (kg) & 1.74 & & 1.44 & & 0.30 \\
\hline Wt\% of Slurry & $100 \%$ & & $82.8 \%$ & & $17.2 \%$ \\
\hline Metal & g & g & $\mu \mathrm{g} / \mathrm{ml}$ & g & $\mu g / g$ \\
\hline Al & $1.4 \mathrm{E}+01$ & $1.2 \mathrm{E}+00$ & $8.7 \mathrm{E}+02$ & $1.3 \mathrm{E}+01$ & $4.2 \mathrm{E}+04$ \\
\hline B & $-3.5 \mathrm{E}-03$ & 2.0E-03 & $1.5 \mathrm{E}+00$ & $\mathrm{n} / \mathrm{a}^{(\mathrm{d})}$ & $\mathrm{n} / \mathrm{a}^{(\mathrm{d})}$ \\
\hline $\mathbf{B i}$ & $6.8 \mathrm{E}-01$ & $3.2 \mathrm{E}-03$ & $2.4 \mathrm{E}+00$ & $6.8 \mathrm{E}-01$ & $2.3 \mathrm{E}+03$ \\
\hline Ca & $3.9 \mathrm{E}+00$ & $1.3 \mathrm{E}-03$ & 9.5E-01 & $3.9 \mathrm{E}+00$ & $1.3 \mathrm{E}+04$ \\
\hline Cd & 7.7E-02 & 3.5E-04 & 2.6E-01 & 7.7E-02 & $2.6 \mathrm{E}+02$ \\
\hline $\mathrm{Cr}$ & 8.6E-01 & $1.9 \mathrm{E}-02$ & $1.4 \mathrm{E}+01$ & 8.4E-01 & $2.8 \mathrm{E}+03$ \\
\hline $\mathbf{F e}$ & $6.0 \mathrm{E}+01$ & 5.0E-04 & 3.7E-01 & $6.0 \mathrm{E}+01$ & $2.0 \mathrm{E}+05$ \\
\hline $\mathbf{K}$ & $-2.0 \mathrm{E}-01$ & 6.6E-02 & $4.9 \mathrm{E}+01$ & $\mathrm{n} / \mathrm{a}^{(\mathrm{d})}$ & $n / a^{(d)}$ \\
\hline Mn & $8.7 \mathrm{E}+00$ & 5.4E-05 & 4.0E-02 & $8.7 \mathrm{E}+00$ & $2.9 \mathrm{E}+04$ \\
\hline $\mathrm{Na}$ & $5.3 \mathrm{E}+01$ & $2.4 \mathrm{E}+01$ & $1.8 \mathrm{E}+04$ & $2.9 \mathrm{E}+01$ & $9.8 \mathrm{E}+04$ \\
\hline $\mathrm{Ni}$ & $1.5 \mathrm{E}+00$ & $<$ 8.E-5 & $<6 . \mathrm{E}-2$ & $1.5 \mathrm{E}+00$ & $4.9 \mathrm{E}+03$ \\
\hline $\mathbf{P}$ & $5.8 \mathrm{E}+00$ & $2.0 \mathrm{E}+00$ & $1.5 \mathrm{E}+03$ & $3.8 \mathrm{E}+00$ & $1.3 \mathrm{E}+04$ \\
\hline $\mathbf{S}$ & 1.9E-01 & 3.6E-01 & $2.7 \mathrm{E}+02$ & $\mathrm{n} / \mathrm{a}^{(\mathrm{d})}$ & $\mathrm{n} / \mathrm{a}^{(\mathrm{d})}$ \\
\hline Si & $1.5 \mathrm{E}+01$ & $1.6 \mathrm{E}-02$ & $1.2 \mathrm{E}+01$ & $1.5 \mathrm{E}+01$ & $4.9 \mathrm{E}+04$ \\
\hline $\mathrm{Sr}$ & 5.8E-01 & 6.6E-06 & 4.9E-03 & 5.8E-01 & $1.9 \mathrm{E}+03$ \\
\hline Zn & 1.5E-01 & 8.8E-04 & 6.5E-01 & 1.5E-01 & $4.9 \mathrm{E}+02$ \\
\hline $\mathrm{Zr}$ & $1.4 \mathrm{E}+00$ & 4.6E-05 & $3.4 \mathrm{E}-02$ & $1.4 \mathrm{E}+00$ & $4.6 \mathrm{E}+03$ \\
\hline $\mathbf{U}$ & $8.6 \mathrm{E}+00$ & 2.2E-02 & $1.7 \mathrm{E}+01$ & $8.6 \mathrm{E}+00$ & $2.9 \mathrm{E}+04$ \\
\hline \multirow[t]{2}{*}{ Anions } & \multicolumn{3}{|c|}{ Liquid Fraction } & & \\
\hline & $\mu \mathrm{g} / \mathrm{ml}$ & [M] & g & & \\
\hline $\mathbf{O H}$ & $6.6 \mathrm{E}+03$ & 3.9E-01 & $8.9 \mathrm{E}+00$ & & \\
\hline $\begin{array}{ll}\text { (a) } & \text { Slurry Mas } \\
& \text { mass from } \\
\text { (b) Liquid Fra } & \text { G4-G (ASC } \\
& \text { Solids Frac } \\
\text { (c) } & \text { and liquid } \\
\text { (d) } & \text { Values (ba }\end{array}$ & $\begin{array}{l}\text { omponents were } \\
\text { apling was incor } \\
\text { n mass compone } \\
\text { 08-02071) and } \\
\text { a mass compone } \\
\text { aponent mass fra } \\
\text { on supernate) w }\end{array}$ & $\begin{array}{l}\text { ulated from cha } \\
\text { ted. } \\
\text { were calculated } \\
\text { predicted mass } \\
\text { vere calculated } \\
\text {. } \\
\text { alculated to be }\end{array}$ & $\begin{array}{l}\text { ization data ( } \\
\text { analytical re } \\
\text { ernate in the } \\
\text { he difference } \\
\text { tan zero. }\end{array}$ & $\begin{array}{l}\text { RPT-169, Sect } \\
\text { om supernate } \\
\text { en the slurry c }\end{array}$ & $\begin{array}{l}\text { Loss of } \\
\text { TI624- } \\
\text { nent mass }\end{array}$ \\
\hline
\end{tabular}


Table 5.31. Group 7/AY-102 Caustic leached Slurry Inventory and Composition after the Fourth Wash

\begin{tabular}{|c|c|c|c|c|c|}
\hline & Slurry $^{(a)}$ & \multicolumn{2}{|c|}{ Liquid Fraction $^{(b)}$} & \multicolumn{2}{|c|}{ Solids Fraction $^{(\mathrm{c})}$} \\
\hline Mass (kg) & 2.34 & \multicolumn{2}{|c|}{2.04} & \multicolumn{2}{|c|}{0.30} \\
\hline Wt\% of Slurry & $100 \%$ & \multicolumn{2}{|c|}{$87.2 \%$} & \multicolumn{2}{|c|}{$12.8 \%$} \\
\hline Metal & g & g & $\mu \mathrm{g} / \mathrm{ml}$ & g & $\mu g / g$ \\
\hline Al & $1.3 \mathrm{E}+01$ & 8.6E-01 & $4.4 \mathrm{E}+02$ & $1.3 \mathrm{E}+01$ & $4.2 \mathrm{E}+04$ \\
\hline B & 2.9E-03 & 2.9E-03 & $1.5 \mathrm{E}+00$ & $\mathrm{n} / \mathrm{a}^{(\mathrm{d})}$ & $\mathrm{n} / \mathrm{a}^{(\mathrm{d})}$ \\
\hline $\mathbf{B i}$ & 6.8E-01 & 5.3E-03 & $2.7 \mathrm{E}+00$ & 6.7E-01 & $2.2 \mathrm{E}+03$ \\
\hline $\mathbf{C a}$ & $3.9 \mathrm{E}+00$ & $2.2 \mathrm{E}-03$ & $1.1 \mathrm{E}+00$ & $3.9 \mathrm{E}+00$ & $1.3 \mathrm{E}+04$ \\
\hline Cd & 7.7E-02 & 5.1E-04 & 2.6E-01 & 7.6E-02 & $2.5 \mathrm{E}+02$ \\
\hline $\mathrm{Cr}$ & 8.6E-01 & $1.4 \mathrm{E}-02$ & $7.0 \mathrm{E}+00$ & 8.5E-01 & $2.8 \mathrm{E}+03$ \\
\hline $\mathbf{F e}$ & $6.0 \mathrm{E}+01$ & 7.3E-04 & 3.7E-01 & $6.0 \mathrm{E}+01$ & $2.0 \mathrm{E}+05$ \\
\hline $\mathbf{K}$ & $6.4 \mathrm{E}-02$ & $6.4 \mathrm{E}-02$ & $3.3 \mathrm{E}+01$ & $\mathrm{n} / \mathrm{a}^{(\mathrm{d})}$ & $\mathrm{n} / \mathrm{a}^{(\mathrm{d})}$ \\
\hline Mn & $8.7 \mathrm{E}+00$ & $6.1 \mathrm{E}-05$ & 3.1E-02 & $8.7 \mathrm{E}+00$ & $2.9 \mathrm{E}+04$ \\
\hline $\mathrm{Na}$ & $4.8 \mathrm{E}+01$ & $1.7 \mathrm{E}+01$ & $8.8 \mathrm{E}+03$ & $3.1 \mathrm{E}+01$ & $1.0 \mathrm{E}+05$ \\
\hline $\mathrm{Ni}$ & $1.5 \mathrm{E}+00$ & $<1 . \mathrm{E}-4$ & $<6 . \mathrm{E}-2$ & $1.5 \mathrm{E}+00$ & $4.9 \mathrm{E}+03$ \\
\hline $\mathbf{P}$ & $5.4 \mathrm{E}+00$ & $1.4 \mathrm{E}+00$ & $7.3 \mathrm{E}+02$ & $4.0 \mathrm{E}+00$ & $1.3 \mathrm{E}+04$ \\
\hline $\mathrm{S}$ & $1.2 \mathrm{E}-01$ & 2.5E-01 & $1.3 \mathrm{E}+02$ & $\mathrm{n} / \mathrm{a}^{(\mathrm{d})}$ & $\mathrm{n} / \mathrm{a}^{(\mathrm{d})}$ \\
\hline $\mathrm{Si}$ & $1.5 \mathrm{E}+01$ & 1.6E-02 & $8.4 \mathrm{E}+00$ & $1.5 \mathrm{E}+01$ & $4.9 \mathrm{E}+04$ \\
\hline $\mathrm{Sr}$ & 5.8E-01 & 8.2E-06 & 4.2E-03 & 5.8E-01 & $1.9 \mathrm{E}+03$ \\
\hline Zn & $1.5 \mathrm{E}-01$ & $1.6 \mathrm{E}-03$ & 7.9E-01 & 1.4E-01 & $4.8 \mathrm{E}+02$ \\
\hline $\mathrm{Zr}$ & $1.4 \mathrm{E}+00$ & $<5$. E-5 & $<3 . \mathrm{E}-2$ & $1.4 \mathrm{E}+00$ & $4.6 \mathrm{E}+03$ \\
\hline $\mathbf{U}$ & $8.6 \mathrm{E}+00$ & 2.2E-02 & $1.1 \mathrm{E}+01$ & $8.6 \mathrm{E}+00$ & $2.9 \mathrm{E}+04$ \\
\hline \multirow{2}{*}{$\begin{array}{c}\text { Radiochemical } \\
\text { Isotopes }\end{array}$} & Slurry & \multicolumn{2}{|c|}{ Liquid Fraction } & \multicolumn{2}{|c|}{ Solid Fraction } \\
\hline & $\mu \mathrm{Ci}$ & $\mu \mathrm{Ci}$ & $\mu \mathrm{Ci} / \mathrm{ml}$ & $\mu \mathrm{Ci}$ & $\mu \mathrm{Ci} / \mathrm{g}$ \\
\hline Co-60 & $6.5 \mathrm{E}+01$ & $<1 . \mathrm{E}-1$ & $<7$. E-5 & $6.5 \mathrm{E}+01$ & 2.2E-01 \\
\hline Cs-137 & $1.2 \mathrm{E}+05$ & $1.3 \mathrm{E}+03$ & $6.8 \mathrm{E}-01$ & $1.2 \mathrm{E}+05$ & $4.1 \mathrm{E}+02$ \\
\hline Eu-152 & $8.7 \mathrm{E}+01$ & $<5 . \mathrm{E}-1$ & $<3 . \mathrm{E}-4$ & $8.7 \mathrm{E}+01$ & 2.9E-01 \\
\hline Eu-154 & $2.1 \mathrm{E}+03$ & $<3 . \mathrm{E}-1$ & $<2$.E-4 & $2.1 \mathrm{E}+03$ & $7.1 \mathrm{E}+00$ \\
\hline Eu-155 & $9.7 \mathrm{E}+02$ & $<2$.E +0 & $<8 . \mathrm{E}-4$ & $9.7 \mathrm{E}+02$ & $3.2 \mathrm{E}+00$ \\
\hline Am-241 & $3.5 \mathrm{E}+03$ & $<3 . \mathrm{E}+0$ & $<2$.E-3 & $3.5 \mathrm{E}+03$ & $1.2 \mathrm{E}+01$ \\
\hline Gross Alpha & $5.2 \mathrm{E}+03$ & $1.2 \mathrm{E}+00$ & $6.1 \mathrm{E}-04$ & $5.2 \mathrm{E}+03$ & $1.7 \mathrm{E}+01$ \\
\hline Gross Beta & $6.0 \mathrm{E}+06$ & $1.4 \mathrm{E}+03$ & 7.1E-01 & $6.0 \mathrm{E}+06$ & $2.0 \mathrm{E}+04$ \\
\hline Sr-90 & $3.1 \mathrm{E}+06$ & $2.5 \mathrm{E}+00$ & 1.3E-03 & $3.1 \mathrm{E}+06$ & $1.0 \mathrm{E}+04$ \\
\hline $\mathrm{Pu}-239+240$ & $1.3 \mathrm{E}+03$ & 7.0E-01 & 3.6E-04 & $1.3 \mathrm{E}+03$ & $4.4 \mathrm{E}+00$ \\
\hline Pu-238 & $2.1 \mathrm{E}+02$ & 9.3E-02 & 4.7E-05 & $2.1 \mathrm{E}+02$ & 6.9E-01 \\
\hline \multirow[t]{2}{*}{ Anions } & \multicolumn{3}{|c|}{ Liquid Fraction } & \multicolumn{2}{|c|}{ Leached Solids Fraction } \\
\hline & $\mu g / m l$ & [M] & $\mathbf{g}$ & $\mu g / g$ & g \\
\hline $\mathbf{F}$ & $2.0 \mathrm{E}+01$ & $1.1 \mathrm{E}-03$ & $3.9 \mathrm{E}-02$ & $3.8 \mathrm{E}+02$ & $1.1 \mathrm{E}-01$ \\
\hline $\mathbf{C l}$ & $1.1 \mathrm{E}+02$ & 3.0E-03 & 2.1E-01 & $1.9 \mathrm{E}+03$ & 5.7E-01 \\
\hline $\mathrm{C}_{2} \mathrm{O}_{4}$ & $5.3 \mathrm{E}+01$ & $6.0 \mathrm{E}-04$ & $1.0 \mathrm{E}-01$ & $1.6 \mathrm{E}+03$ & 4.7E-01 \\
\hline $\mathrm{NO}_{2}$ & $4.1 \mathrm{E}+02$ & $9.0 \mathrm{E}-03$ & 8.1E-01 & $1.3 \mathrm{E}+04$ & $3.9 \mathrm{E}+00$ \\
\hline $\mathrm{NO}_{3}$ & $3.5 \mathrm{E}+03$ & 5.7E-02 & $6.9 \mathrm{E}+00$ & $7.0 \mathrm{E}+04$ & $2.1 \mathrm{E}+01$ \\
\hline $\mathrm{SO}_{4}$ & $3.6 \mathrm{E}+02$ & 3.8E-03 & 7.1E-01 & 7.7E+03 & $2.3 \mathrm{E}+00$ \\
\hline
\end{tabular}


WTP-RPT-169, Rev 0

Table 5.31 (Contd)

\begin{tabular}{|c|c|c|c|c|c|}
\hline & Slurry $^{(a)}$ & \multicolumn{2}{|c|}{ Liquid Fraction $^{(b)}$} & \multicolumn{2}{|c|}{ Solids Fraction ${ }^{(c)}$} \\
\hline Mass (kg) & 2.34 & \multicolumn{2}{|c|}{2.04} & \multicolumn{2}{|c|}{0.30} \\
\hline Wt\% of Slurry & $100 \%$ & \multicolumn{2}{|c|}{$87.2 \%$} & \multicolumn{2}{|c|}{$12.8 \%$} \\
\hline Metal & g & g & $\mu \mathrm{g} / \mathrm{ml}$ & g & $\mu \mathrm{g} / \mathrm{g}$ \\
\hline $\mathrm{PO}_{4}$ & $2.2 \mathrm{E}+03$ & $2.4 \mathrm{E}-02$ & $4.3 \mathrm{E}+00$ & $3.5 \mathrm{E}+04$ & $1.0 \mathrm{E}+01$ \\
\hline OH & $3.1 \mathrm{E}+03$ & $1.8 \mathrm{E}-01$ & $6.2 \mathrm{E}+00$ & & \\
\hline $\begin{array}{ll}\text { (a) } & \text { Slurry Mas } \\
& \text { mass from } \\
\text { (b) } & \text { Liquid Fra } \\
& \text { G7-H (AS } \\
\text { (c) } & \text { Solids Fra } \\
& \text { and liquid } \\
\text { (d) } & \text { Values (ba }\end{array}$ & $\begin{array}{l}\text { mponents were } \\
\text { pling was incor } \\
\text { mass compon } \\
\text { 08-02062) anc } \\
\text { mass compone } \\
\text { ponent mass fr } \\
\text { on supernate) w }\end{array}$ & $\begin{array}{l}\text { llated from cha } \\
\text { ed. } \\
\text { vere calculated } \\
\text { predicted mass } \\
\text { ere calculated } \\
\text { alculated to be }\end{array}$ & $\begin{array}{l}\text { rization data } \\
\text { g analytical re } \\
\text { pernate in the } \\
\text { the differenc } \\
\text { han zero. }\end{array}$ & $\begin{array}{l}\text { RPT-169, Sec } \\
\text { om supernate } \\
\text { n. } \\
\text { een the slurry }\end{array}$ & $\begin{array}{l}\text { Loss of } \\
\text { le TI624- }\end{array}$ \\
\hline
\end{tabular}


Table 5.32. Caustic Wash Solutions Radionuclide and Opportunistic Compositions

\begin{tabular}{|c|c|c|c|c|c|}
\hline & Wash 1 & Wash 2 & Wash 3 & Wash 4 & $\begin{array}{c}\text { Composite } \\
\text { Wash } \\
\end{array}$ \\
\hline ASO Sample ID & 08-02069 & 08-01370 & 08-01371 & 08-02062 & 08-02063 \\
\hline Density $^{(a)}, g / m L>$ & 1.17 & 1.11 & 1.07 & 1.04 & NA \\
\hline \multicolumn{6}{|l|}{ Analyte } \\
\hline free $\mathrm{OH}, \mathrm{M}$ & $1.48 \mathrm{M}$ & $0.77 \mathrm{M}$ & $0.39 \mathrm{M}$ & $0.19 \mathrm{M}$ & $0.72 \mathrm{M}$ \\
\hline \multicolumn{6}{|c|}{ Opportunistic Analytes } \\
\hline Analyte & $\mu \mathrm{g} / \mathrm{mL}$ & $\mu \mathrm{g} / \mathrm{mL}$ & $\mu \mathrm{g} / \mathrm{mL}$ & & $\mu \mathrm{g} / \mathrm{mL}$ \\
\hline $\mathrm{Ag}$ & 2.92 & [1.3] & 0.685 & {$[0.32]$} & 1.45 \\
\hline As & $<6.4 \mathrm{E}+0$ & $<6.4 \mathrm{E}+0$ & $<1.3 \mathrm{E}+0$ & $<1.3 \mathrm{E}+0$ & $<1.3 \mathrm{E}+0$ \\
\hline $\mathrm{Ba}$ & {$[0.094]$} & [0.053] & {$[0.032]$} & {$[0.024]$} & {$[0.071]$} \\
\hline $\mathrm{Be}$ & [0.012] & $<6.4 \mathrm{E}-3$ & {$[0.0016]$} & $<1.3 \mathrm{E}-3$ & [0.0029] \\
\hline $\mathrm{Ca}$ & {$[2.7]$} & {$[2.4]$} & [0.95] & {$[1.1]$} & {$[0.87]$} \\
\hline $\mathrm{Ce}$ & $<1.2 \mathrm{E}+0$ & $<1.2 \mathrm{E}+0$ & $<2.5 \mathrm{E}-1$ & $<2.5 \mathrm{E}-1$ & $<2.5 \mathrm{E}-1$ \\
\hline Co & $<2.9 \mathrm{E}-1$ & $<3.0 \mathrm{E}-1$ & $<5.9 \mathrm{E}-2$ & $<5.9 \mathrm{E}-2$ & $<6.0 \mathrm{E}-2$ \\
\hline $\mathrm{Cu}$ & {$[0.59]$} & $<1.7 \mathrm{E}-1$ & [0.039] & $<3.5 \mathrm{E}-2$ & {$[0.15]$} \\
\hline Dy & $<3.5 \mathrm{E}-1$ & $<3.6 \mathrm{E}-1$ & $<7.2 \mathrm{E}-2$ & $<7.2 \mathrm{E}-2$ & $<7.3 \mathrm{E}-2$ \\
\hline Eu & $<1.3 \mathrm{E}-1$ & $<1.4 \mathrm{E}-1$ & $<2.7 \mathrm{E}-2$ & $<2.7 \mathrm{E}-2$ & $<2.8 \mathrm{E}-2$ \\
\hline La & $<3.4 \mathrm{E}-1$ & $<3.5 \mathrm{E}-1$ & $<6.9 \mathrm{E}-2$ & $<6.9 \mathrm{E}-2$ & $<7.0 \mathrm{E}-2$ \\
\hline Li & [1.4] & [1.2] & 0.733 & 0.571 & 0.959 \\
\hline Mg & $<2.8 \mathrm{E}-1$ & $<2.8 \mathrm{E}-1$ & $<5.7 \mathrm{E}-2$ & $<5.7 \mathrm{E}-2$ & $<5.8 \mathrm{E}-2$ \\
\hline Mo & [1.4] & [1.1] & {$[0.30]$} & {$[0.17]$} & {$[0.71]$} \\
\hline $\mathrm{Nd}$ & $<2.1 \mathrm{E}+0$ & $<2.1 \mathrm{E}+0$ & $<4.2 \mathrm{E}-1$ & $<4.2 \mathrm{E}-1$ & $<4.3 \mathrm{E}-1$ \\
\hline $\mathrm{Pb}$ & $<3.9 \mathrm{E}+0$ & $<4.0 \mathrm{E}+0$ & {$[0.98]$} & [1.5] & [2.0] \\
\hline Pd & $<7.7 \mathrm{E}-1$ & $<7.8 \mathrm{E}-1$ & $<1.6 \mathrm{E}-1$ & $<1.6 \mathrm{E}-1$ & $<1.6 \mathrm{E}-1$ \\
\hline $\mathbf{R h}$ & $<1.5 \mathrm{E}+0$ & $<1.5 \mathrm{E}+0$ & $<3.0 \mathrm{E}-1$ & $<3.0 \mathrm{E}-1$ & {$[0.37]$} \\
\hline $\mathrm{Ru}$ & [2.9] & [1.9] & [0.67] & {$[0.34]$} & [1.4] \\
\hline $\mathrm{Sb}$ & $<2.4 \mathrm{E}+0$ & $<2.5 \mathrm{E}+0$ & {$[0.50]$} & $<4.9 \mathrm{E}-1$ & $<5.0 \mathrm{E}-1$ \\
\hline $\mathrm{Se}$ & [15] & $<8.7 \mathrm{E}+0$ & [2.5] & $<1.7 \mathrm{E}+0$ & [2.6] \\
\hline Sn & $<3.3 \mathrm{E}+0$ & [5.6] & [2.3] & [1.2] & [2.7] \\
\hline $\mathrm{Ta}$ & $<2.1 \mathrm{E}+0$ & $<2.1 \mathrm{E}+0$ & $<4.2 \mathrm{E}-1$ & $<4.2 \mathrm{E}-1$ & $<4.3 \mathrm{E}-1$ \\
\hline $\mathrm{Te}$ & $<3.2 \mathrm{E}+0$ & $<3.2 \mathrm{E}+0$ & $<6.4 \mathrm{E}-1$ & $<6.4 \mathrm{E}-1$ & $<6.5 \mathrm{E}-1$ \\
\hline Th & $<1.2 \mathrm{E}+0$ & $<1.2 \mathrm{E}+0$ & $<2.4 \mathrm{E}-1$ & $<2.4 \mathrm{E}-1$ & $<2.5 \mathrm{E}-1$ \\
\hline $\mathrm{Ti}$ & $<5.3 \mathrm{E}-2$ & $<5.3 \mathrm{E}-2$ & $<1.1 \mathrm{E}-2$ & [0.013] & $<1.1 \mathrm{E}-2$ \\
\hline $\mathrm{TI}$ & $<4.7 \mathrm{E}+0$ & $<4.7 \mathrm{E}+0$ & $<9.4 \mathrm{E}-1$ & $<9.4 \mathrm{E}-1$ & $<9.6 \mathrm{E}-1$ \\
\hline v & 0.953 & {$[0.71]$} & 0.274 & 0.189 & 0.496 \\
\hline $\mathbf{w}$ & [9.4] & [4.5] & [1.8] & [1.2] & 4.02 \\
\hline$Y$ & $<5.4 \mathrm{E}-2$ & $<5.4 \mathrm{E}-2$ & $<1.1 \mathrm{E}-2$ & $<1.1 \mathrm{E}-2$ & $<1.1 \mathrm{E}-2$ \\
\hline Analyte & $\mu \mathrm{Ci} / \mathrm{mL}$ & $\mu \mathrm{Ci} / \mathrm{mL}$ & $\mu \mathrm{Ci} / \mathrm{mL}$ & $\mu \mathrm{Ci} / \mathrm{mL}$ & $\mu \mathrm{Ci} / \mathrm{mL}$ \\
\hline${ }^{137} \mathrm{Cs}$ & & & & $6.81 \mathrm{E}-1$ & $3.02 \mathrm{E}+0$ \\
\hline${ }^{60} \mathrm{Co}$ & & & & $<7$. E-5 & $<8 . \mathrm{E}-5$ \\
\hline${ }^{241} \mathrm{Am}$ & & & & $<2$. E-3 & $<3$. E-3 \\
\hline
\end{tabular}


Table 5.32 (Contd)

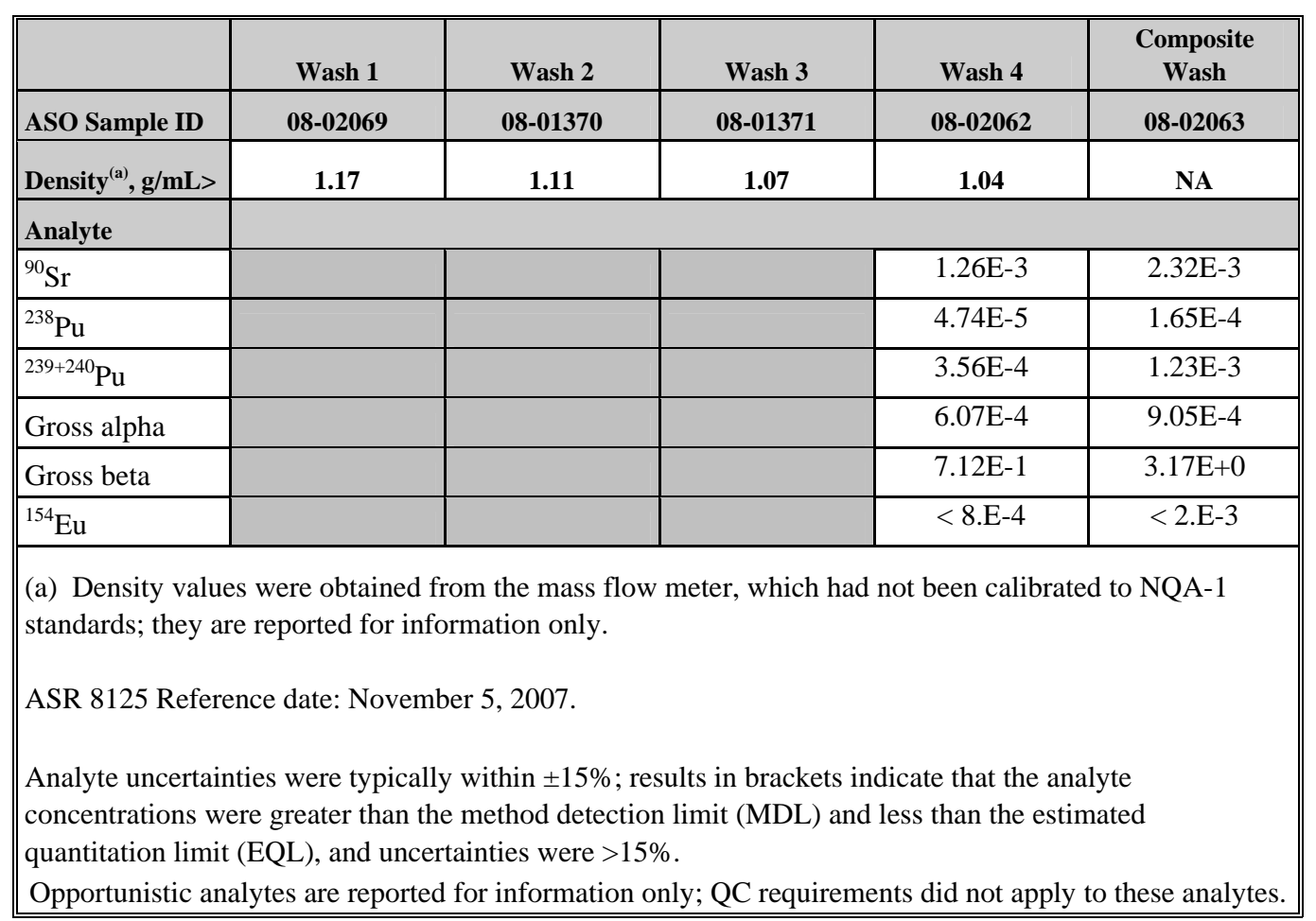

Adding the AY-102 sample to the Group 7 sample considerably increased the Al inventory, with virtually all $\mathrm{Al}$ in the solids (Figure 5.34). The caustic leach removed $57 \mathrm{wt} \%$ of the $\mathrm{Al}$ from the insoluble solids. The addition of AY-102 also increased the quantity of insoluble $\mathrm{Cr}$ in the waste slurry (Figure 5.35). Caustic leaching dissolved $16 \mathrm{wt} \%$ of the $\mathrm{Cr}$ in the insoluble solids present in the composite waste.

Soluble phosphorus accounts for $38 \mathrm{wt} \%$ of the original Group 7 slurry P content (Figure 5.36) and can be directly attributed to phosphates. It is believed that the portion of the $\mathrm{P}$ that appears as solid in the slurry is either a result of gelling (WTP-RPT-173 [Lumetta 2008]) or $\mathrm{PO}_{4}$ entrainment in solids. The phosphorus content of the AY102 slurry was relatively low (Coleman 2003), so the addition was not expected to contribute to the total inventory of the blended slurry. After adding the AY-102 sample, 41\% of the insoluble P present in the blended slurry dissolved into the slurry supernate. Since the phosphate concentration in the AY-102 supernate was lower that that of the Group 7 supernate, a portion of the phosphate present in the Group 7 insoluble solids dissolved until the phosphate concentration in the supernate was in equilibrium with the solid phase. Interestingly, a significant increase in the $U$ concentration in the supernate occurred at the same time of this event.

Washing the solids removes a large portion of the remaining $\mathrm{P}$ as phosphate after caustic leaching. The high caustic during the leaching and the washing precipitates the phosphate, leading to the irregular behavior noted in Figure 5.36. At the start of the leach, it appeared that some phosphorus precipitated after adding caustic. Once the slurry was heated, it re-dissolved, but precipitated back during the leach cool down and stayed as a solid during the leach dewatering step. It would take additional washing to remove this portion of the phosphate out of the slurry. By the end of the test, $43 \mathrm{wt} \%$ of the original insoluble P had been dissolved by the AY-102 addition and by caustic leaching and washing. When looking at the caustic-leached slurry, washing removed $46 \mathrm{wt} \%$ of the remaining inventory at that point (Figure 5.37). Dewatering and washing of the leach slurry removed the $\mathrm{Al}$ and $\mathrm{Cr}$ in the aqueous phase of 
the slurry after caustic leaching. By the end of the fourth wash, $50 \mathrm{wt} \%$ of $\mathrm{Al}$ and $15 \mathrm{wt} \%$ of the $\mathrm{Cr}$ present in the leached slurry was removed.

The concentration of phosphorus in the supernate tracks inversely with the sodium concentration, suggesting the precipitation of $\mathrm{Na}_{3} \mathrm{PO}_{4} \cdot 12 \mathrm{H}_{2} \mathrm{O}$ at high sodium concentrations. As the concentration of all species drops with the washes, the phosphate initially rises as the precipitate is re-dissolved and then drops as almost all of the soluble $\mathrm{P}$ is removed by the washes (Figure 5.38). The aluminum concentration in the supernate mimics that of the $\mathrm{Na}$ and free-hydroxide concentrations, reflecting dissolution at high hydroxide, which is removed by the washes. This is consistent with gibbsite behavior. 


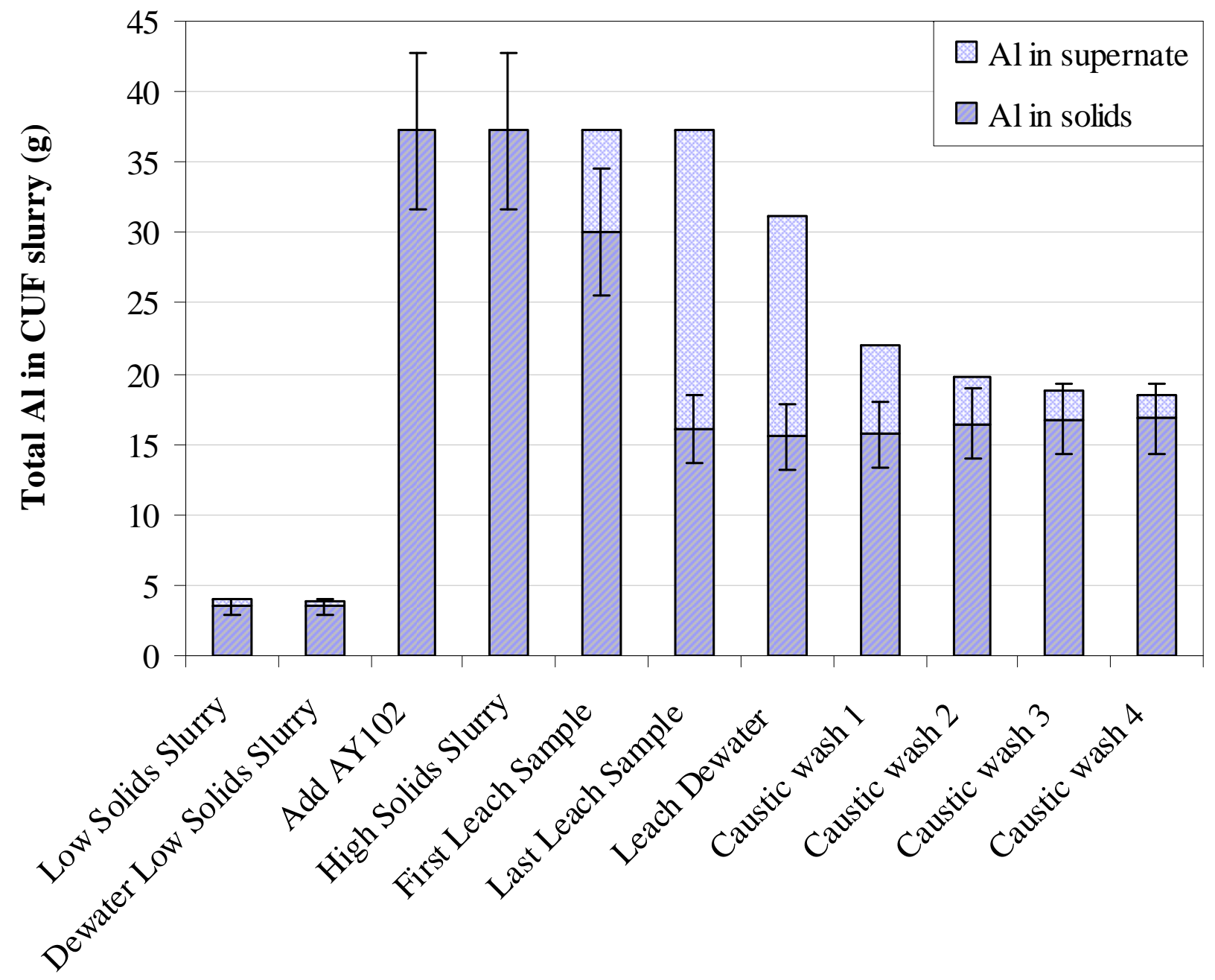

Figure 5.34. Total Aluminum in Group 7/AY-102 CUF Slurry 


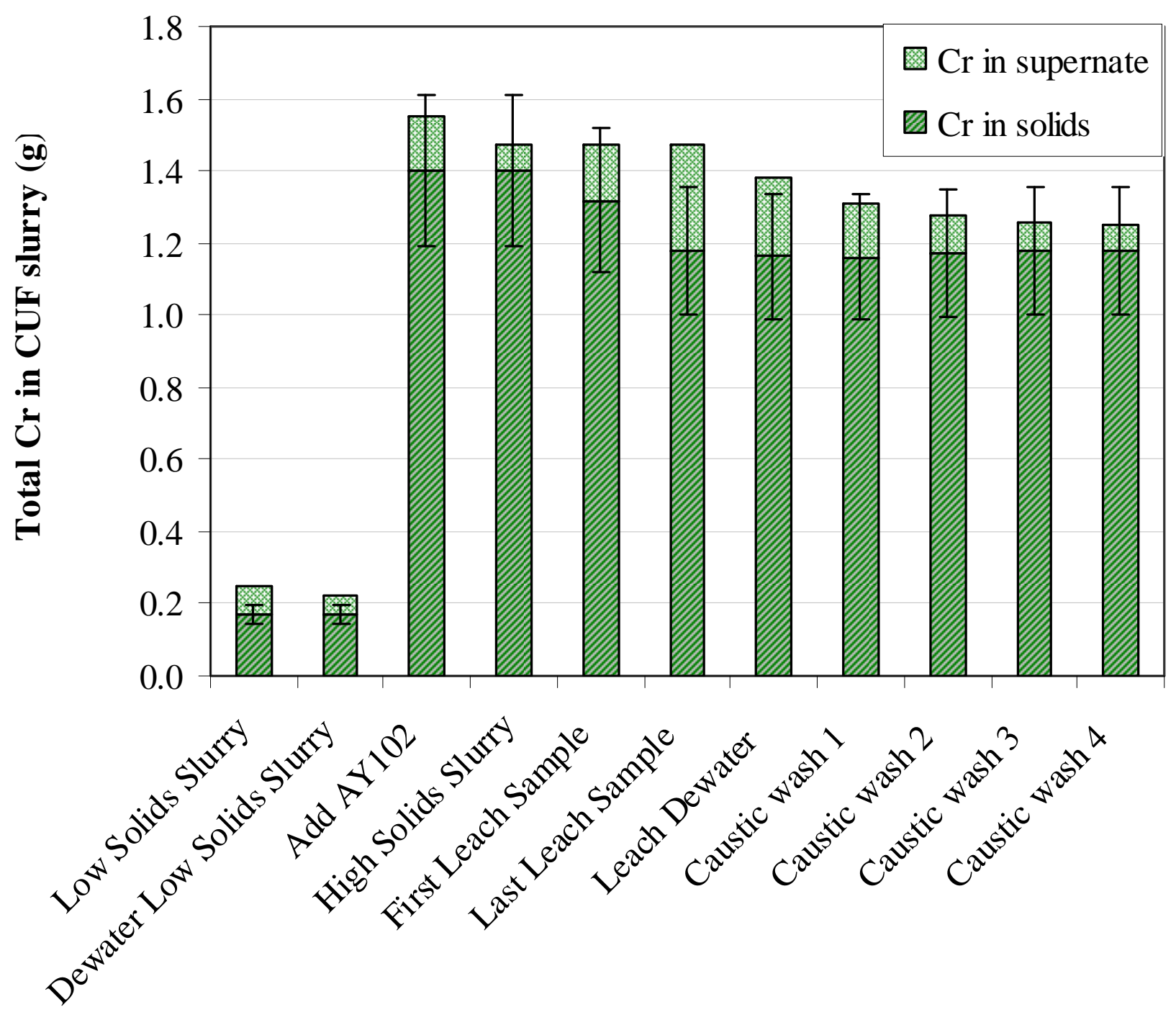

Figure 5.35. Total Chromium in Group 7/AY-102 CUF Slurry 


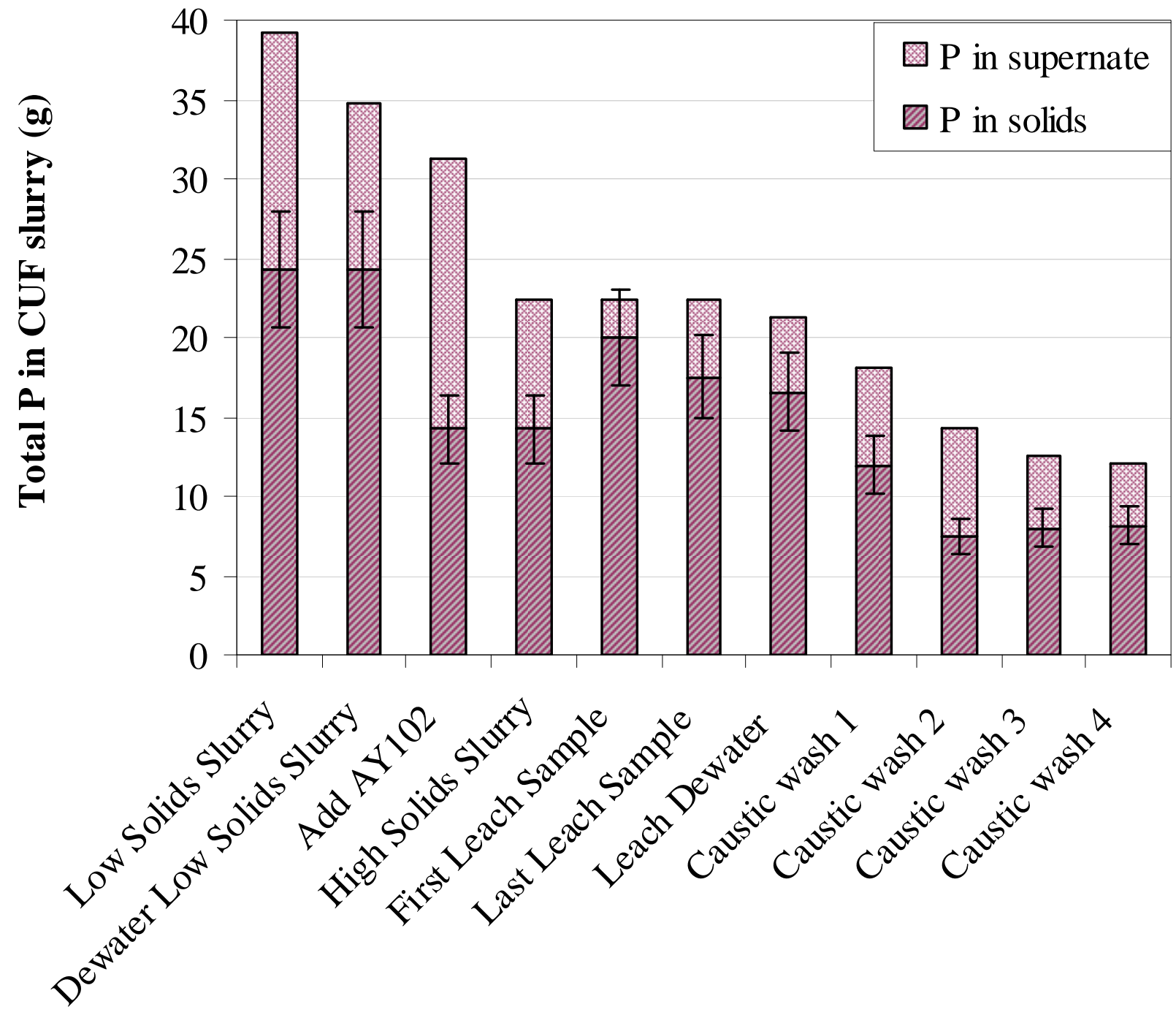

Figure 5.36. Total Phosphorus in Group 7/AY-102 CUF Slurry 


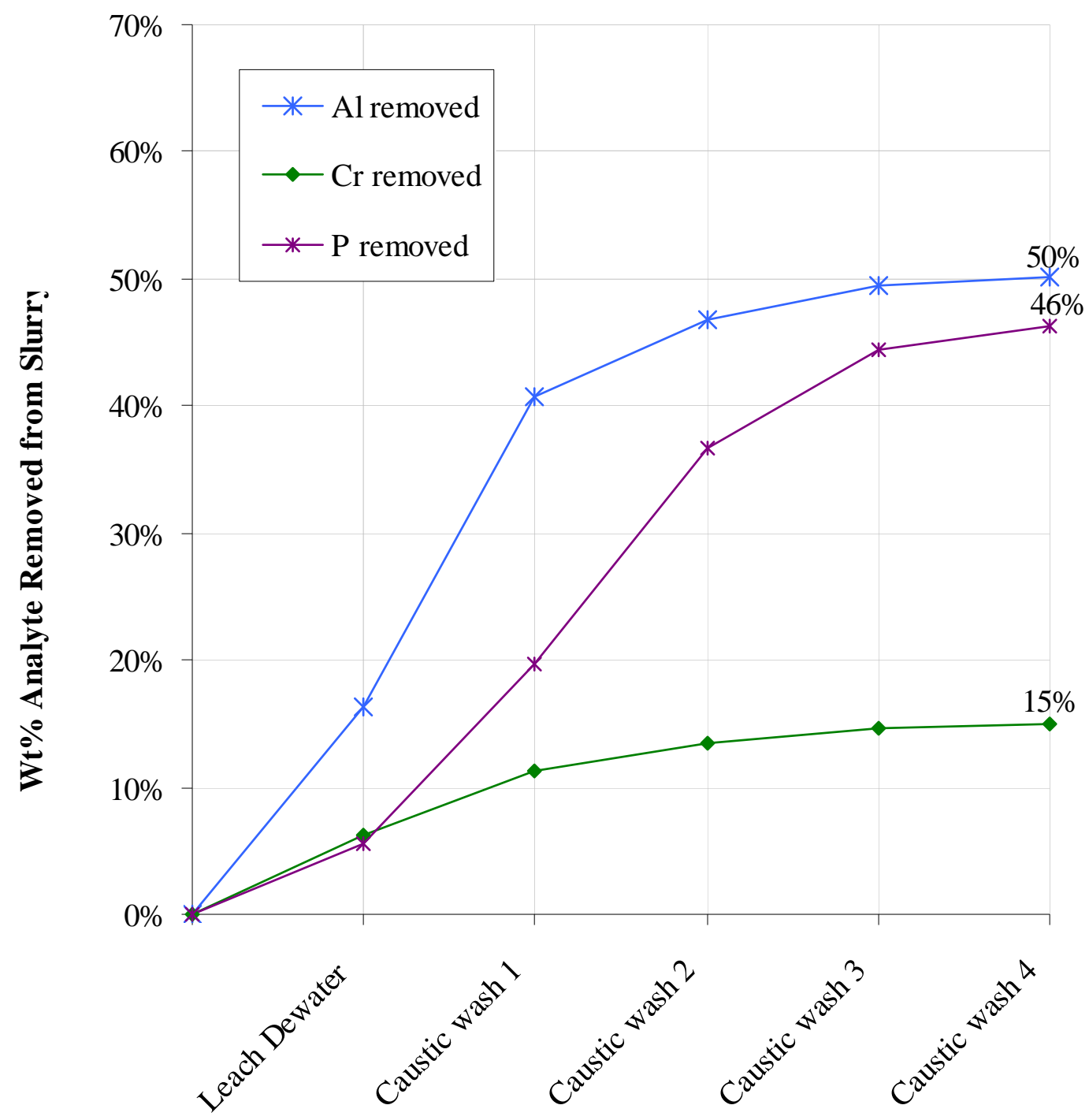

Figure 5.37. Al, Cr and P removed from Dewatering and Washing the Group 7/AY-102 CUF Slurry After Caustic Leaching 


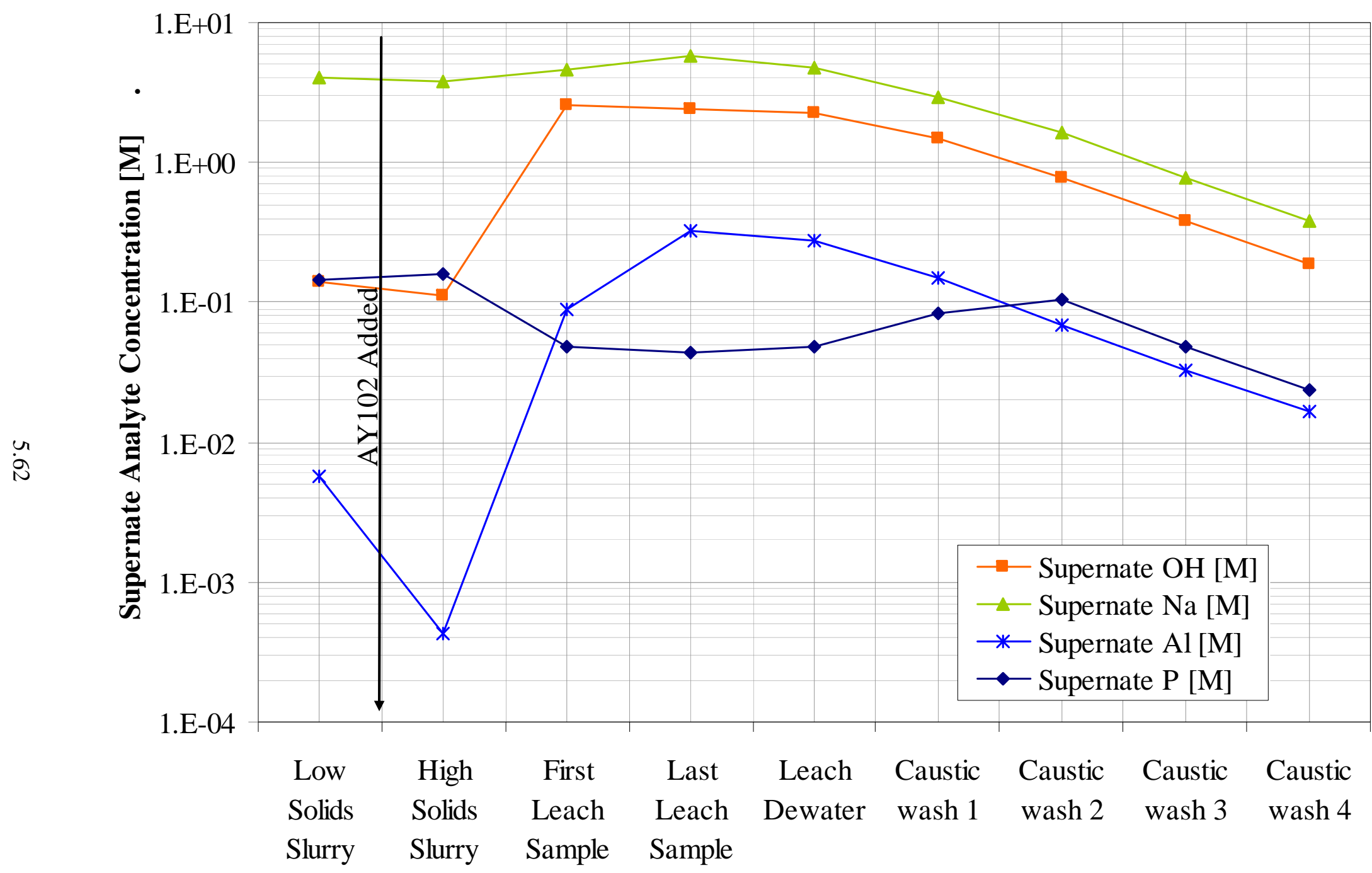

Figure 5.38. Free $\mathrm{OH}, \mathrm{Na}, \mathrm{Al}$, and $\mathrm{P}$ Molarity in Group 7/AY-102 CUF Slurry 


\subsubsection{Dewatering Caustic-Wash Solutions}

The filter flux results from dewatering the slurry after each wash solution are shown in Figure 5.39 and Table 5.33. Each wash volume was filtered from the slurry in 103, 69, 57, and 48 minutes sequentially. Comparing the average filter flux from each dewatering operation to the ionic composition of the supernate shows how diluting the supernate improves filter flux by reducing supernate viscosity.

Decreases in the flux for the last two washes resulted from decreases in TMP and axial velocity during the dewatering step. As the slurry volume was reduced, pump cavitation increased, also resulting in more scatter in the permeate flow data presented in Figure 5.39. The final TMP for the last two washes decreased from 40 psid to 30 psid, while the axial velocity decreased from $13 \mathrm{ft} / \mathrm{s}$ to $11 \mathrm{ft} / \mathrm{s}$.

Table 5.33. Comparison of Washed Slurry Supernate Attributes to Filter Flux

\begin{tabular}{|c|c|c|c|c|c|c|}
\hline \multirow[b]{2}{*}{ Process Step } & \multirow{2}{*}{$\begin{array}{c}\text { Wash } \\
\text { Volume } \\
\text { (L) }\end{array}$} & \multirow{2}{*}{$\begin{array}{c}\text { Wash addition } \\
\text { [NaOH }] \\
\mathrm{M}\end{array}$} & \multicolumn{3}{|c|}{ Dewatered Supernate } & \multirow{2}{*}{$\begin{array}{l}\text { Average } \\
\text { Filter Flux } \\
\left(\mathbf{G P M} / \mathbf{f t}^{2}\right)\end{array}$} \\
\hline & & & $\begin{array}{c}{[\mathrm{Na}]} \\
\mathrm{M}\end{array}$ & $\begin{array}{c}{[\mathrm{OH}]} \\
\mathbf{M}\end{array}$ & $\begin{array}{c}\text { [Al] } \\
\mathbf{M}\end{array}$ & \\
\hline Wash 1 Dewater & 1.20 & 0.50 & 2.9 & 1.5 & 0.15 & 0.012 \\
\hline Wash 2 Dewater & 1.20 & 0.10 & 1.6 & 0.77 & 0.069 & 0.018 \\
\hline Wash 3 Dewater & 1.20 & 0.05 & 0.77 & 0.39 & 0.032 & 0.023 \\
\hline Wash 4 Dewater & 1.20 & 0.01 & 0.38 & 0.18 & 0.016 & 0.024 \\
\hline $\begin{array}{l}\text { Blended Slurry } \\
\text { Dewater }\end{array}$ & & & 3.7 & 0.11 & 4.6E-4 & 0.014 \\
\hline $\begin{array}{l}\text { Leached Slurry } \\
\text { Dewater }\end{array}$ & & & 4.7 & 2.3 & 0.27 & 0.006 \\
\hline
\end{tabular}




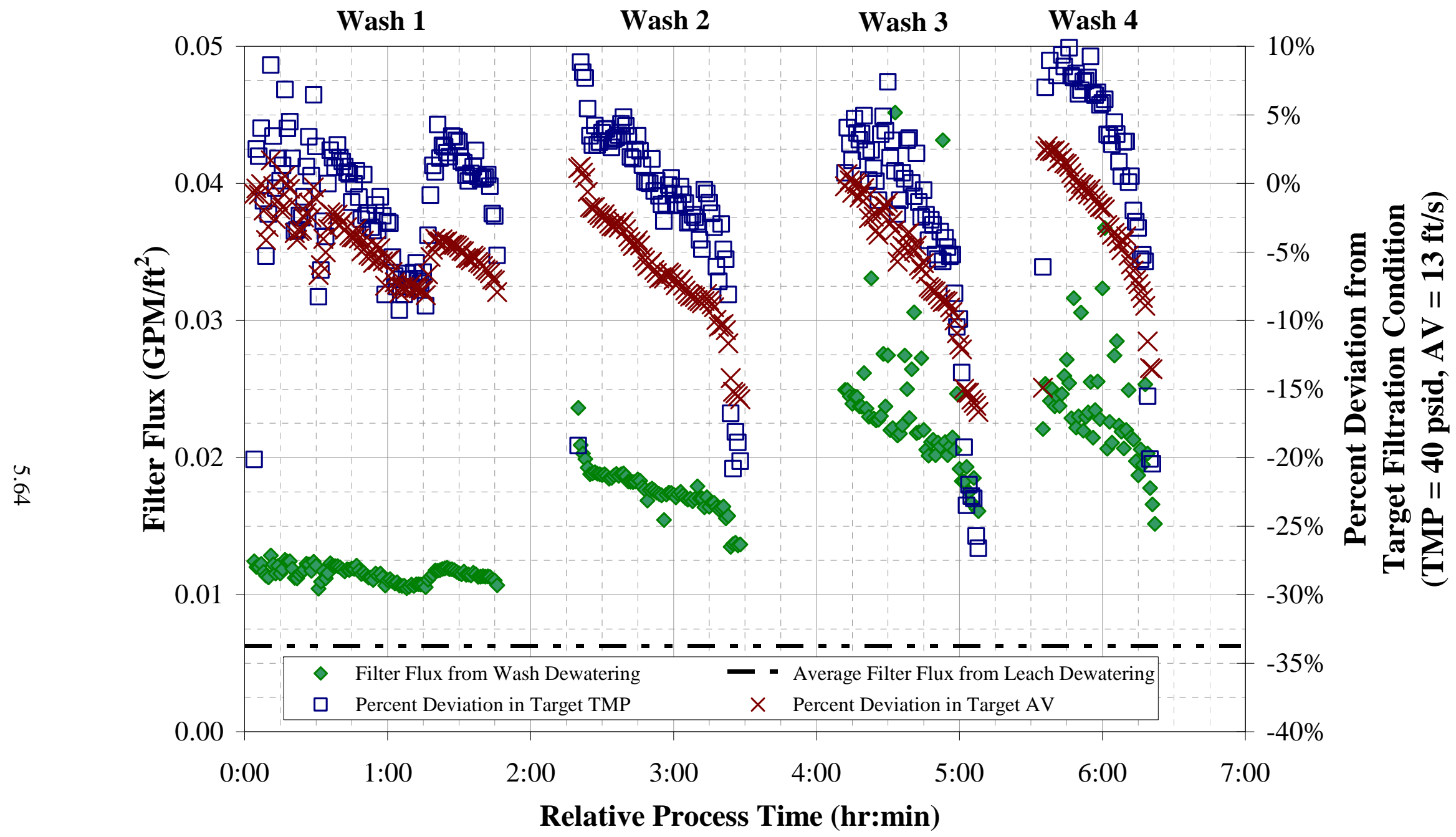

Figure 5.39. Filter Flux During Caustic Wash Steps and Comparison to Leach Dewatering Average Flux 


\subsection{Final Filter Flux Test Matrix}

As discussed earlier (Section 5.5.5), dewatering the final wash solution from the slurry decreased the volume of the slurry to a point where the pump began to cavitate and entrain air into the slurry. This resulted in a loss of pumping efficiency, making it impossible to reach the desired velocities and pressures needed for the test matrix. It was decided that the best course of action was to return permeate from the last dewatering step back to the slurry. Once $\sim 0.4 \mathrm{~L}$ of the filtered supernate was returned, the cavitation stopped, and the pumping efficiency improved (Figure 5.40).

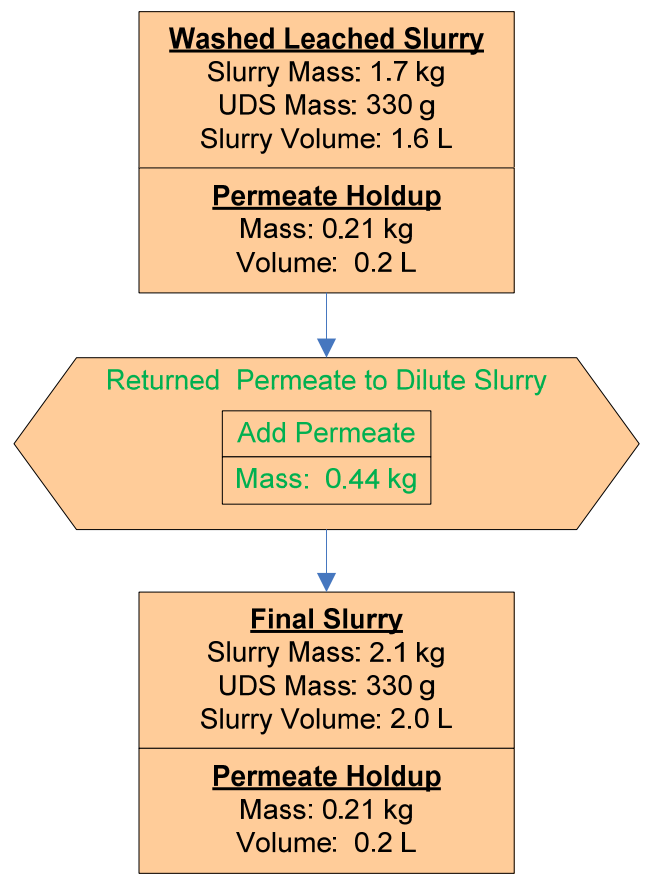

Figure 5.40. Process Flow for Final Filter Slurry

The filter-flux results from the test matrix are shown in Figure 5.41. Cavitation was still an issue, even after adding the permeate. This caused variations in the measured permeate flow rate. Also, the target axial velocity could not be met for test conditions 4 and 8, as shown in Table 5.34 and Figure 5.42. The average filter flux and process conditions achieved during the matrix test ranged from 0.014 to 0.036 $\mathrm{GPM} / \mathrm{ft}^{2}$. The average filter flux at the standard condition (TMP $=40 \mathrm{psid}$ and $\mathrm{AV}=13 \mathrm{ft} / \mathrm{s}$ ) stayed relatively constant, varying between 0.024 and $0.025 \mathrm{GPM} / \mathrm{ft}^{2}$.

The average filter flux from each test condition (Table 5.34) was plotted against TMP, AV, and the median operational time of the test condition to qualitatively gauge their impact, as shown in Figure 5.43 through Figure 5.45. As with the low-solids slurry, filter flux was found to be directly proportional to the TMP (Figure 5.43), while AV showed little impact (Figure 5.44). As in the high-solids slurry, no impact from the processing time (Figure 5.45) was found either.

Modeling the data using a least-squares-fit method was then used to quantify the effects of TMP, AV, and processing time on filter flux. Process time reflects the average time for the given process conditions since the start of testing. This variable is intended to assess the fouling of the filter that occurs through 
the duration of testing. A linear-fit equation with an $\mathrm{R}^{2}$ correlation of 0.97 was developed using only TMP (Figure 5.46). The modeling confirmed the results shown in Figure 5.44 and Figure 5.45, which showed no relationship between AV and process time with filter flux for the slurry at this concentration (measured at $14 \mathrm{wt} \%$ in Section 5.7). As Figure 5.43 demonstrated, the TMP significantly impacted filter flux and was proportional to filter flux as predicted by the Darcy equation. Centrifuge UDS measurements of this slurry were taken afterwards (Section 5.7), which is considered a good estimate of the gel concentration of the slurry. The value measured was $52 \mathrm{wt} \%$, which indicates that the slurry UDS concentration needed to be much higher before the axial velocity began to have any impacts. Diluting the slurry to perform the test could have impacted these results.

The use of this model was limited to comparing TMP and AV impacts on filter flux during this test and how the filter behavior changed after caustic leaching and washing. During development of the linear model, a negative offset was created. Therefore, the model does not predict a zero filter flux when the TMP is zero, demonstrating that the input to these models must be bound by the range of TMP used in this filter test, shown in Table 5.34. The use of the model should also be limited to when the test matrix occurred because the filter resistance was not at steady state, and the parameters developed in these models would be expected to change past the 16-hour period that this model predicts.

Table 5.34. Average Flux Values for Rinsed Leached Group 7 Solids

\begin{tabular}{|c|c|c|c|c|c|c|c|}
\hline $\begin{array}{c}\text { Design } \\
\text { Test } \\
\text { Condition } \\
\end{array}$ & $\begin{array}{c}\text { Median } \\
\text { Operation } \\
\text { Time of } \\
\text { Test }^{\text {(a) }} \\
\text { (hr:mm) } \\
\end{array}$ & $\begin{array}{c}\text { Slurry } \\
\text { Temp }^{(b)} \\
\left({ }^{\circ} \mathrm{C}\right)\end{array}$ & $\begin{array}{l}\mathrm{TMP}^{(\mathrm{c})} \\
\text { (psid) }\end{array}$ & $\begin{array}{c}\text { Axial } \\
\text { Velocity } \\
(\mathbf{f t} / \mathrm{s}) \\
\end{array}$ & $\begin{array}{l}\text { Permeate } \\
\text { Flowrate } \\
\text { (mL/min) }\end{array}$ & $\begin{array}{c}\text { Corrected } \\
\text { Permeate } \\
\text { Flux } \\
\left(\mathrm{GPM} / \mathrm{ft}^{2}\right)\end{array}$ & $\begin{array}{c}\text { Axial } \\
\text { Pressure } \\
\text { Drop } \\
\text { (psid/ft) }\end{array}$ \\
\hline 1 & $1: 31$ & 25.3 & 40.5 & 13.1 & 24.8 & 0.025 & 1.5 \\
\hline 2 & $3: 37$ & 25.1 & 31.6 & 10.9 & 17.9 & 0.018 & 1.2 \\
\hline 3 & $4: 40$ & 25.1 & 31.7 & 15.0 & 17.8 & 0.018 & 1.5 \\
\hline 4 & $6: 32$ & 25.2 & 47.9 & 13.9 & 27.8 & 0.028 & 1.5 \\
\hline 5 & $7: 48$ & 25.1 & 51.7 & 11.3 & 29.1 & 0.029 & 1.2 \\
\hline 6 & 9:08 & 25.1 & 40.2 & 13.1 & 24.0 & 0.024 & 1.3 \\
\hline 7 & $10: 26$ & 25.0 & 41.1 & 9.1 & 25.8 & 0.026 & 1.0 \\
\hline 8 & $11: 42$ & 25.2 & 41.0 & 14.2 & 24.3 & 0.024 & 1.5 \\
\hline 9 & $12: 50$ & 25.2 & 20.1 & 13.0 & 13.6 & 0.014 & 1.3 \\
\hline 10 & $14: 01$ & 26.6 & 60.1 & 12.8 & 37.4 & 0.036 & 1.6 \\
\hline 11 & $15: 12$ & 25.2 & 40.5 & 13.3 & 23.6 & 0.024 & 1.4 \\
\hline \multicolumn{8}{|c|}{$\begin{array}{l}\text { (a) Median operation time refers to the midpoint in processing time of the specific filtration test condition } \\
\text { relative to the start time of the test }(\mathrm{T}=0) \text {. Time periods between test conditions were excluded. } \\
\text { (b) Thermocouple accuracy } \pm 2^{\circ} \mathrm{C} \text {. }\end{array}$} \\
\hline
\end{tabular}




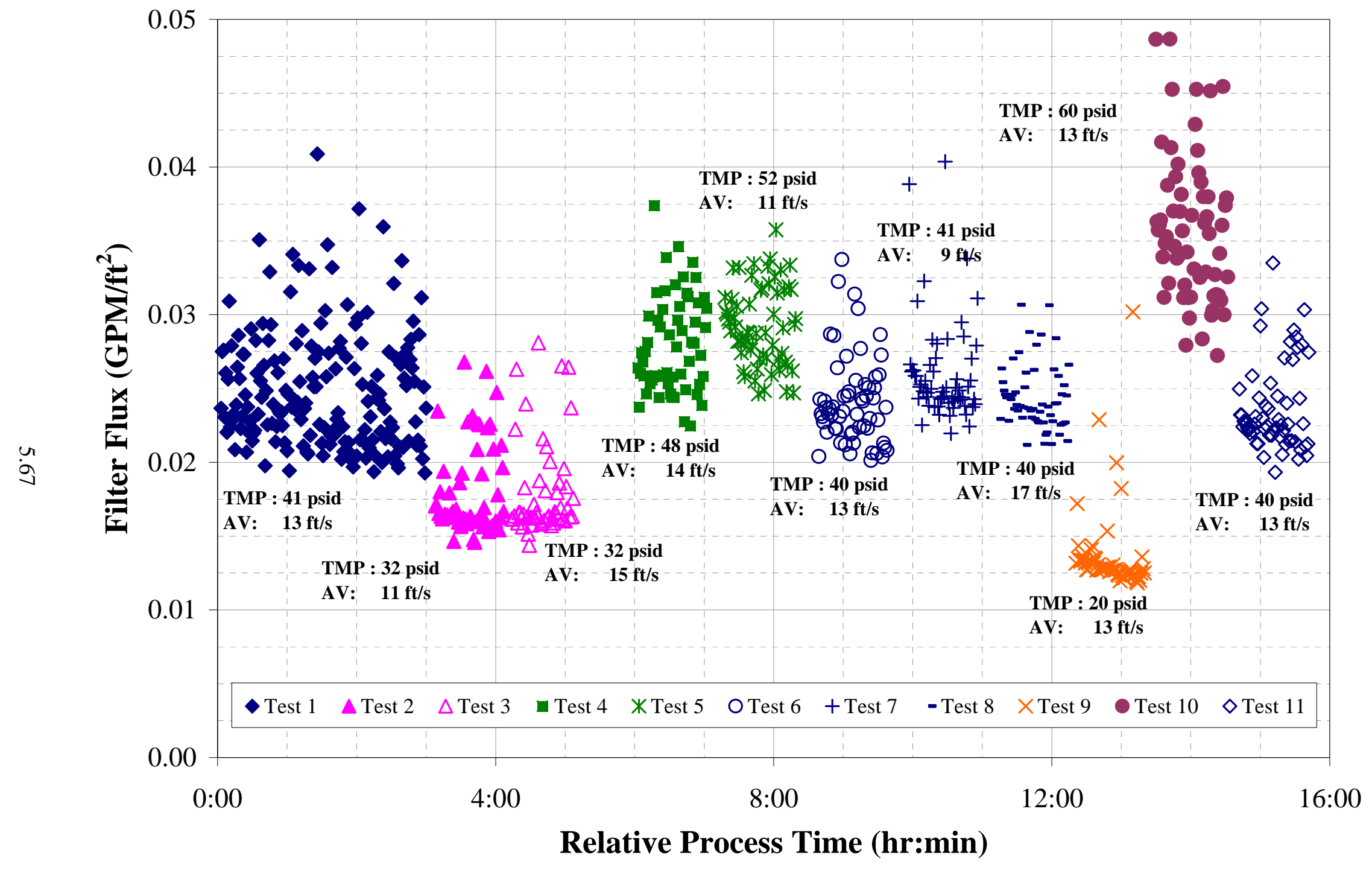

Figure 5.41. Filter Flux for the Washed Leached Filter Test Matrix (Measured UDS of $14 \mathrm{wt} \%$ ) 


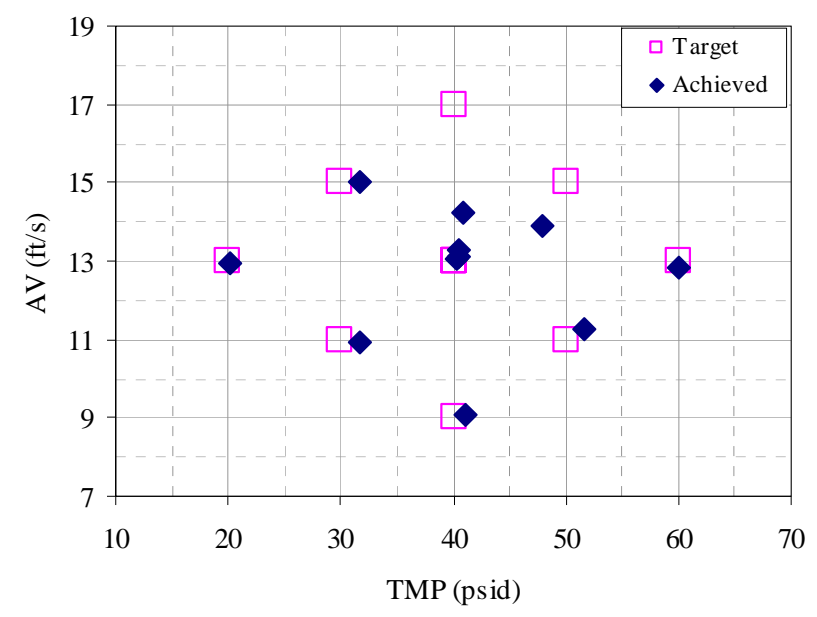

Figure 5.42. Filter Test Matrix for Group 7-AY102 Leached-Solids

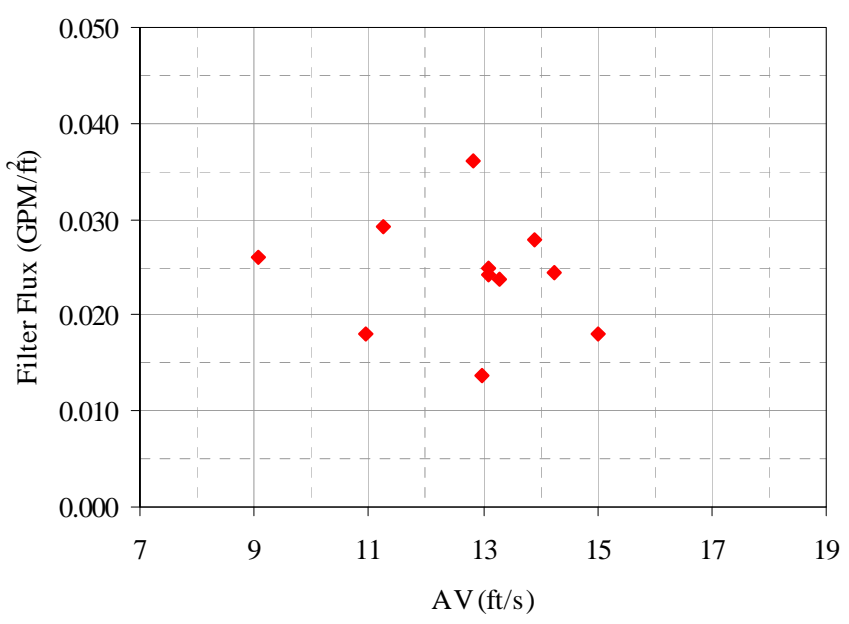

Figure 5.44. Flux vs. AV for Group 7-AY102 Leached-Solids

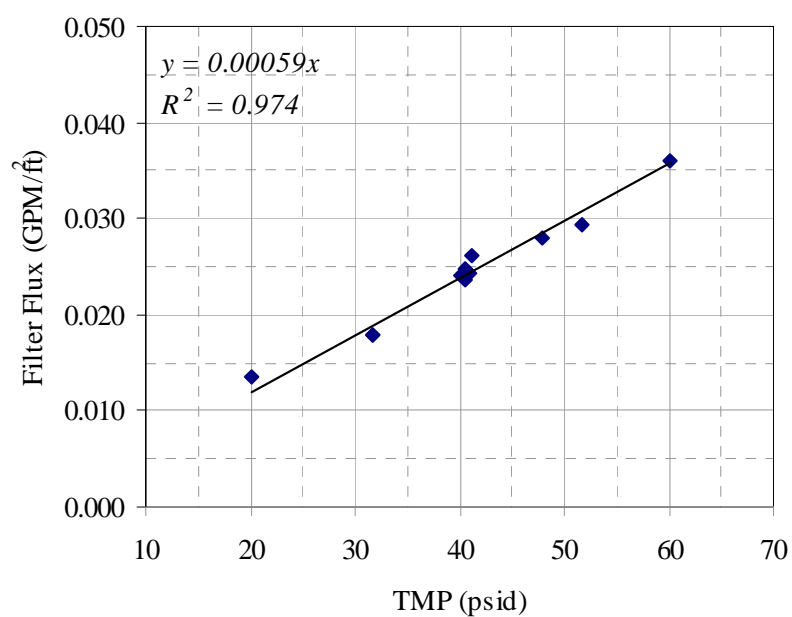

Figure 5.43. Flux vs. TMP for Group 7-AY102 Leached-Solids

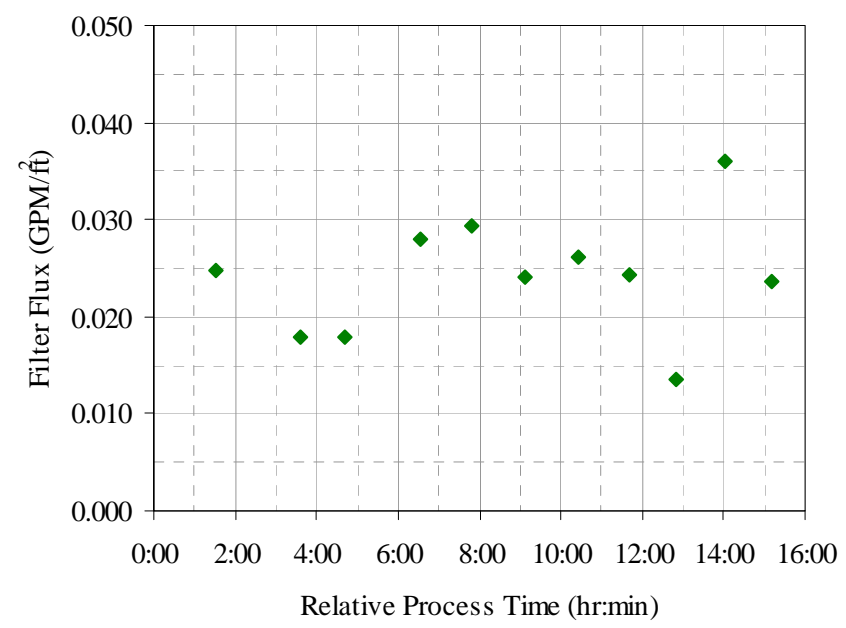

Figure 5.45. Flux vs. Median Process Time of Test for Group 7-AY102 Leached-Solids 


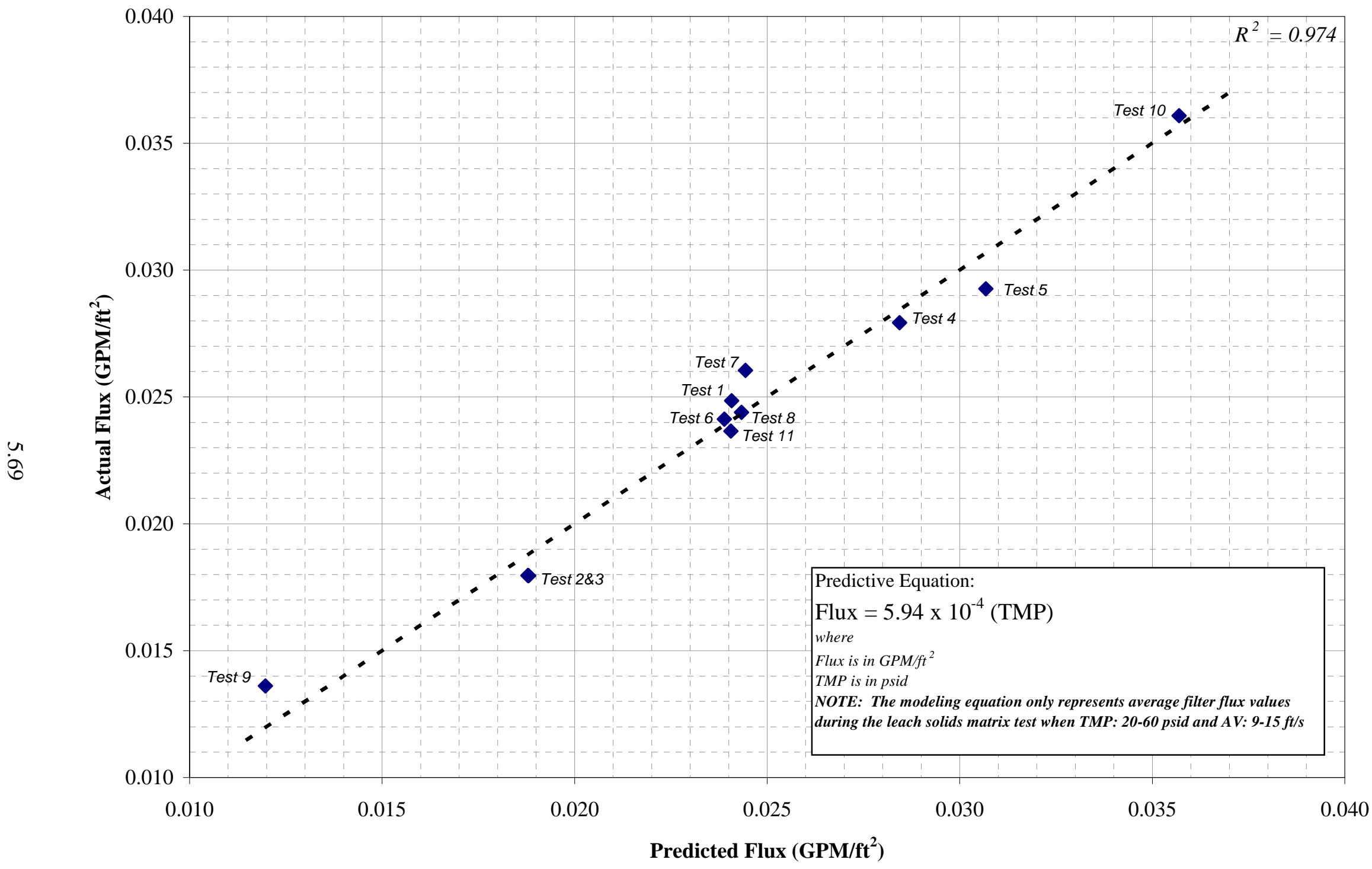

Figure 5.46. Least-Squares-Fit of Leached Solid Test Matrix Results with Linear Model (Measured UDS of 14 wt\%) 


\subsection{Leached-Material Characterization}

After leaching and washing operations, the slurry was sampled and drained from the CUF. Physical and chemical analyses were performed on the samples collected, and the remaining slurry was saved as an archive sample to be used later. Physical-property measurements shown in Table 5.35 found the UDS concentration to be $14 \mathrm{wt} \%$, which compared well to the predicted concentrations of $16 \mathrm{wt} \%$ $(0.33 \mathrm{~kg} / 2.1 \mathrm{~kg})$. The final predicted composition of the slurry is shown in Table 5.36. The data in this table are the result of mass-balance calculations performed on the slurry using supernate ICP-OES/IC/radionuclides data and measured mass changes to the slurry. The measured composition of the slurry by ICP-OES/radionuclide analysis is found in Table 5.37. The slurry composition is broken down to supernate and solid concentrations. The solids compositions were then used to calculate solids leach factors for the analytes listed using data generated in Table 5.17.

Overall, leach factors calculated after the caustic leach (Table 5.25) compared well with those calculated for those after washing (Table 5.37). The radiochemical isotopes measured in the slurry all have calculated negative leach factors, indicating that they do not leave the HLW stream. Mass-balance calculations showed no significant quantities of the measured isotopes in the permeate removed, with the exception of cesium, which was already partially present in a soluble phase. Figure 5.47 shows the remaining fraction of each isotope measured in the slurry by mass-balance calculations. After correcting for sample losses, the chart showed that almost all of the material stayed in the slurry. Some cesium was removed during dewatering operations, but $88 \%$ still remained in the slurry. After caustic leaching was performed, the majority uranium present remained in the solid phase.

The biggest discrepancy in the leach-factor data was with phosphorus, which now showed a calculated leach factor of 0.63 instead of -0.24 . As discussed early, the caustic leach was expected to suppress the release of phosphorus as soluble phosphate because of increases in the sodium concentration. As discussed in Section 5.5.4, phosphorus does not dissolve until slurry washing decreases the $\mathrm{Na}$ concentration (Figure 5.38). Figure 5.48 shows the quantity of anions released at different parts of the test. While the mass of released nitrate and nitrite concentrations decreased after washing, significant quantities of phosphate were still being released. This supports the ICP data, which indicates that phosphorus removal occurs later in the process and not during the caustic-leach dewatering.

Table 5.35. Final Leached and Washed Slurry Physical-Property Measurements

\begin{tabular}{|r|c||}
\hline Slurry Density (g/mL) & 1.19 \\
\hline Supernate Density (g/mL) & 1.05 \\
Settled Solids (Vol \%) & $81 \%$ \\
\hline Centrifuged UDS (Wt \%) & $52 \%$ \\
\hline Total Solids (Wt \%) & $19 \%$ \\
\hline Dissolved Solids (Wt \%) & $10 \%$ \\
\hline UDS (Wt \%) & $14 \%$ \\
\hline \hline
\end{tabular}


Table 5.36. Final Leached, Washed Dewatered Slurry Composition (Including Permeate Hold-up)

\begin{tabular}{|c|c|c|c|c|c|}
\hline & Slurry $^{(\mathbf{a})}$ & \multicolumn{2}{|c|}{ "Liquid Fraction ${ }^{(b)}$} & \multicolumn{2}{|c|}{ Solids Fraction $^{(c)}$} \\
\hline Mass (kg) & 2.32 & \multicolumn{2}{|c|}{2.02} & \multicolumn{2}{|c|}{0.30} \\
\hline Wt\% of Slurry & $100 \%$ & \multicolumn{2}{|c|}{$87.2 \%$} & \multicolumn{2}{|c|}{$12.8 \%$} \\
\hline Metal & g & g & $\mu \mathrm{g} / \mathrm{ml}$ & g & $\mu g / g$ \\
\hline Al & $1.3 \mathrm{E}+01$ & $8.4 \mathrm{E}-01$ & $4.4 \mathrm{E}+02$ & $1.2 \mathrm{E}+01$ & $4.2 \mathrm{E}+04$ \\
\hline B & $2.9 \mathrm{E}-03$ & $2.9 \mathrm{E}-03$ & $1.5 \mathrm{E}+00$ & $\mathrm{n} / \mathrm{a}^{(\mathrm{d})}$ & $\mathrm{n} / \mathrm{a}^{(\mathrm{d})}$ \\
\hline $\mathbf{B i}$ & 6.7E-01 & 5.2E-03 & $2.7 \mathrm{E}+00$ & 6.7E-01 & $2.2 \mathrm{E}+03$ \\
\hline $\mathrm{Ca}$ & $3.8 \mathrm{E}+00$ & $2.1 \mathrm{E}-03$ & $1.1 \mathrm{E}+00$ & $3.8 \mathrm{E}+00$ & $1.3 \mathrm{E}+04$ \\
\hline Cd & 7.6E-02 & 5.0E-04 & 2.6E-01 & 7.5E-02 & $2.5 \mathrm{E}+02$ \\
\hline $\mathrm{Cr}$ & 8.5E-01 & 1.3E-02 & $7.0 \mathrm{E}+00$ & 8.3E-01 & $2.8 \mathrm{E}+03$ \\
\hline $\mathbf{F e}$ & $5.9 \mathrm{E}+01$ & $7.1 \mathrm{E}-04$ & 3.7E-01 & $5.9 \mathrm{E}+01$ & $2.0 \mathrm{E}+05$ \\
\hline $\mathbf{K}$ & 6.3E-02 & $6.3 \mathrm{E}-02$ & $3.3 \mathrm{E}+01$ & $\mathrm{n} / \mathrm{a}^{(\mathrm{d})}$ & $\mathrm{n} / \mathrm{a}^{(\mathrm{d})}$ \\
\hline Mn & $8.6 \mathrm{E}+00$ & 5.9E-05 & $3.1 \mathrm{E}-02$ & $8.6 \mathrm{E}+00$ & $2.9 \mathrm{E}+04$ \\
\hline $\mathrm{Na}$ & $4.8 \mathrm{E}+01$ & $1.7 \mathrm{E}+01$ & $8.8 \mathrm{E}+03$ & $3.1 \mathrm{E}+01$ & $1.0 \mathrm{E}+05$ \\
\hline $\mathrm{Ni}$ & $1.5 \mathrm{E}+00$ & $<1 . \mathrm{E}-4$ & $<6 . \mathrm{E}-2$ & $1.5 \mathrm{E}+00$ & $4.9 \mathrm{E}+03$ \\
\hline $\mathbf{P}$ & $5.3 \mathrm{E}+00$ & $1.4 \mathrm{E}+00$ & $7.3 \mathrm{E}+02$ & $3.9 \mathrm{E}+00$ & $1.3 \mathrm{E}+04$ \\
\hline $\mathrm{S}$ & $1.1 \mathrm{E}-01$ & 2.5E-01 & $1.3 \mathrm{E}+02$ & $\mathrm{n} / \mathrm{a}^{(\mathrm{d})}$ & $\mathrm{n} / \mathrm{a}^{(\mathrm{d})}$ \\
\hline $\mathrm{Si}$ & $1.5 \mathrm{E}+01$ & 1.6E-02 & $8.4 \mathrm{E}+00$ & $1.5 \mathrm{E}+01$ & $4.9 \mathrm{E}+04$ \\
\hline $\mathrm{Sr}$ & $5.8 \mathrm{E}-01$ & $8.1 \mathrm{E}-06$ & $4.2 \mathrm{E}-03$ & 5.8E-01 & $1.9 \mathrm{E}+03$ \\
\hline Zn & $1.4 \mathrm{E}-01$ & $1.5 \mathrm{E}-03$ & 7.9E-01 & 1.4E-01 & $4.8 \mathrm{E}+02$ \\
\hline $\mathrm{Zr}$ & $1.4 \mathrm{E}+00$ & $<5$. E-5 & $<3 . \mathrm{E}-2$ & $1.4 \mathrm{E}+00$ & $4.6 \mathrm{E}+03$ \\
\hline $\mathbf{U}$ & $8.5 \mathrm{E}+00$ & $2.1 \mathrm{E}-02$ & $1.1 \mathrm{E}+01$ & $8.5 \mathrm{E}+00$ & $2.9 \mathrm{E}+04$ \\
\hline \multirow{2}{*}{$\begin{array}{c}\text { Radiochemical } \\
\text { Isotopes }\end{array}$} & Slurry & \multicolumn{2}{|c|}{ Liquid Fraction } & \multicolumn{2}{|c|}{ Solid Fraction } \\
\hline & $\mu \mathrm{Ci}$ & $\mu \mathrm{Ci}$ & $\mu \mathrm{Ci} / \mathrm{ml}$ & $\mu \mathrm{Ci}$ & $\mu \mathrm{Ci} / \mathrm{g}$ \\
\hline Co-60 & $6.4 \mathrm{E}+01$ & $<1 . \mathrm{E}-1$ & $<7$. E-5 & $6.4 \mathrm{E}+01$ & 2.2E-01 \\
\hline Cs-137 & $1.2 \mathrm{E}+05$ & $1.3 \mathrm{E}+03$ & $6.8 \mathrm{E}-01$ & $1.2 \mathrm{E}+05$ & $4.0 \mathrm{E}+02$ \\
\hline Eu-152 & $8.7 \mathrm{E}+01$ & $<5 . \mathrm{E}-1$ & $<3$. -E -4 & $8.7 \mathrm{E}+01$ & 2.9E-01 \\
\hline Eu-154 & $2.1 \mathrm{E}+03$ & $<3$. E-1 & $<2$.E-4 & $2.1 \mathrm{E}+03$ & $7.1 \mathrm{E}+00$ \\
\hline Eu-155 & $9.6 \mathrm{E}+02$ & $<2 . \mathrm{E}+0$ & $<8$. -E -4 & $9.6 \mathrm{E}+02$ & $3.2 \mathrm{E}+00$ \\
\hline Am-241 & $3.5 E+03$ & $<3 . \mathrm{E}+0$ & $<2$.E-3 & $3.5 E+03$ & $1.2 \mathrm{E}+01$ \\
\hline Gross Alpha & $5.1 \mathrm{E}+03$ & $1.2 \mathrm{E}+00$ & $6.1 \mathrm{E}-04$ & $5.1 \mathrm{E}+03$ & $1.7 \mathrm{E}+01$ \\
\hline Gross Beta & $5.9 \mathrm{E}+06$ & $1.4 \mathrm{E}+03$ & 7.1E-01 & $5.9 \mathrm{E}+06$ & $2.0 \mathrm{E}+04$ \\
\hline Sr-90 & $3.1 \mathrm{E}+06$ & $2.4 \mathrm{E}+00$ & 1.3E-03 & $3.1 \mathrm{E}+06$ & $1.0 \mathrm{E}+04$ \\
\hline $\mathrm{Pu}-239+240$ & $1.3 \mathrm{E}+03$ & $6.8 \mathrm{E}-01$ & $3.6 \mathrm{E}-04$ & $1.3 \mathrm{E}+03$ & $4.4 \mathrm{E}+00$ \\
\hline Pu-238 & $2.0 \mathrm{E}+02$ & 9.1E-02 & 4.7E-05 & $2.0 \mathrm{E}+02$ & 6.8E-01 \\
\hline \multirow[t]{2}{*}{ Anions } & \multicolumn{3}{|c|}{ Liquid Fraction } & \multicolumn{2}{|c|}{ Leached Solids Fraction } \\
\hline & $\mu \mathrm{g} / \mathrm{ml}$ & [M] & g & $\mu g / g$ & g \\
\hline $\mathbf{F}$ & $2.0 \mathrm{E}+01$ & $1.1 \mathrm{E}-03$ & 3.9E-02 & $3.8 \mathrm{E}+02$ & 1.1E-01 \\
\hline $\mathrm{Cl}$ & $1.1 \mathrm{E}+02$ & 3.0E-03 & $2.1 \mathrm{E}-01$ & $1.9 \mathrm{E}+03$ & 5.7E-01 \\
\hline $\mathrm{C}_{2} \mathrm{O}_{4}$ & $5.3 \mathrm{E}+01$ & $6.0 \mathrm{E}-04$ & $1.0 \mathrm{E}-01$ & $1.6 \mathrm{E}+03$ & 4.6E-01 \\
\hline $\mathrm{NO}_{2}$ & $4.1 \mathrm{E}+02$ & $9.0 \mathrm{E}-03$ & $8.0 \mathrm{E}-01$ & $1.3 \mathrm{E}+04$ & $3.9 \mathrm{E}+00$ \\
\hline $\mathrm{NO}_{3}$ & $3.5 E+03$ & 5.7E-02 & $6.9 \mathrm{E}+00$ & $7.0 \mathrm{E}+04$ & $2.1 \mathrm{E}+01$ \\
\hline $\mathrm{SO}_{4}$ & $3.6 \mathrm{E}+02$ & 3.8E-03 & 7.1E-01 & $7.7 E+03$ & $2.3 \mathrm{E}+00$ \\
\hline
\end{tabular}


WTP-RPT-169, Rev 0

Table 5.36 (Contd)

\begin{tabular}{||c|c|c|c|c|c|}
\hline & Slurry $^{(\mathbf{a})}$ & \multicolumn{2}{|c|}{ Liquid Fraction $^{(\mathbf{b})}$} & \multicolumn{2}{c|}{ Solids Fraction $^{(\mathbf{c})}$} \\
\hline Mass (kg) & 2.32 & \multicolumn{2}{|c|}{2.02} & \multicolumn{2}{|c|}{0.30} \\
\hline $\mathbf{W t \%}$ of Slurry & $100 \%$ & \multicolumn{2}{|c|}{$87.2 \%$} & \multicolumn{2}{|c|}{$12.8 \%$} \\
\hline $\mathbf{P O}_{\mathbf{4}}$ & $2.2 \mathrm{E}+03$ & $2.4 \mathrm{E}-02$ & $4.3 \mathrm{E}+00$ & $3.5 \mathrm{E}+04$ & $1.0 \mathrm{E}+01$ \\
\hline $\mathbf{O H}$ & $3.1 \mathrm{E}+03$ & $1.8 \mathrm{E}-01$ & $6.1 \mathrm{E}+00$ & & \\
\hline
\end{tabular}

(a) Slurry Mass components were calculated from characterization data (WTP-RPT-169, Section 3). Loss of mass from sampling was incorporated.

(b) Liquid Fraction mass components were calculated using analytical results from supernate sample TI624G7-H (ASO ID 08-02062) and the predicted mass of supernate in the system.

(c) Solids Fraction mass components were calculated from the difference between the slurry component mass and liquid component mass fraction.

(d) Values (based on supernate) were calculated to be less than zero. 
WTP-RPT-169, Rev 0

Table 5.37. Washed Caustic-Leached Slurry Composition and Solid-Leach-Factor Calculations

\begin{tabular}{|c|c|c|c|c|c|c|}
\hline \multirow{4}{*}{$\begin{array}{c}\text { Slurry Prep } \\
\text { Method }\end{array}$} & \multirow[b]{2}{*}{ Analyte } & \multirow[b]{2}{*}{$\begin{array}{c}\text { Dry Slurry }^{(a)} \\
(\mu \mathrm{g} / \mathrm{g})\end{array}$} & \multirow[b]{2}{*}{$\begin{array}{c}\text { Supernate }^{(b)} \\
(\mu \mathrm{g} / \mathrm{mL})\end{array}$} & \multirow[b]{2}{*}{$\begin{array}{c}\text { Dry Solids }^{(c)} \\
(\mu \mathrm{g} / \mathrm{g})\end{array}$} & \multicolumn{2}{|c|}{ Solid Leach Factor $^{(\mathrm{d})}$} \\
\hline & & & & & $\begin{array}{c}\text { Before } \\
\text { washing }\end{array}$ & $\begin{array}{c}\text { After } \\
\text { washing }\end{array}$ \\
\hline & $\mathrm{Al}$ & 41,900 & 440 & 53,000 & 0.51 & 0.48 \\
\hline & $\mathrm{B}$ & [22] & {$[1.5]$} & [21] & -0.14 & 2.64 \\
\hline \multirow{31}{*}{ 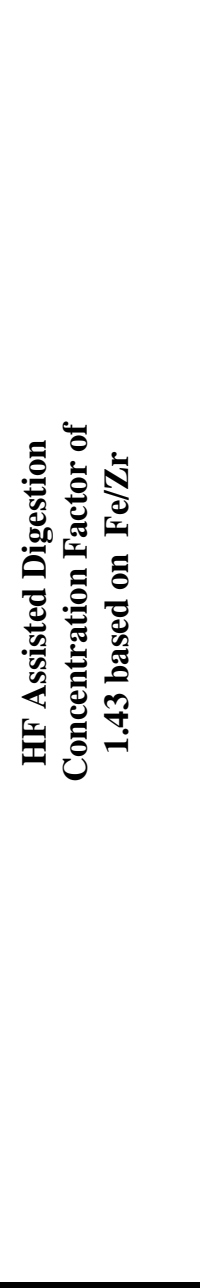 } & $\mathrm{Bi}$ & 1,910 & {$[2.7]$} & 2,500 & -0.02 & 0.00 \\
\hline & $\mathrm{Cd}$ & 213 & {$[0.26]$} & 2300 & 0.01 & -0.04 \\
\hline & $\mathrm{Cr}$ & 2,500 & 7.00 & 3,300 & 0.15 & 0.14 \\
\hline & $\mathrm{Fe}$ & 168,000 & {$[0.37]$} & 220,000 & & \\
\hline & $\mathrm{Mn}$ & 24,700 & [0.031] & 33,000 & 0.00 & 0.00 \\
\hline & $\mathrm{Na}$ & 110,000 & 8,800 & 96,000 & -0.58 & -0.12 \\
\hline & $\mathrm{Ni}$ & 4,450 & -- & 5,900 & -0.01 & 0.00 \\
\hline & $\mathrm{P}$ & 13,700 & 726 & 14,000 & -0.24 & 0.63 \\
\hline & $\mathrm{S}$ & {$[1,600]$} & 129 & {$[1,400]$} & 1.64 & {$[1.80]$} \\
\hline & $\mathrm{Sr}$ & 1,610 & {$[0.0042]$} & 2,200 & 0.00 & 0.01 \\
\hline & $\mathrm{U}$ & 22,900 & 11.1 & 31,000 & -0.80 & -0.75 \\
\hline & $\mathrm{Zn}$ & 456 & {$[0.79]$} & 6600 & 0.07 & 0.08 \\
\hline & $\mathrm{Zr}$ & 4,140 & -- & 5,500 & & \\
\hline & $A g$ & 183 & [.32] & 240 & 0.39 & -0.89 \\
\hline & $B a$ & 1,050 & 0.02 & 1,400 & 0.00 & 0.01 \\
\hline & $B e$ & 1.5 & -- & 2.0 & 0.01 & -0.05 \\
\hline & Ca & 11,400 & [1.1] & 15,000 & 0.00 & 0.01 \\
\hline & $\mathrm{Ce}$ & 1,150 & -- & 1,500 & -0.01 & 0.01 \\
\hline & $\mathrm{Cu}$ & 383 & -- & 510 & 0.00 & 0.00 \\
\hline & $L a$ & 1320 & -- & 1,800 & -0.01 & 0.00 \\
\hline & $\mathrm{Li}$ & 149 & 0.571 & 200 & 0.01 & 0.02 \\
\hline & Mg & 3,060 & -- & 4,100 & 0.00 & 0.01 \\
\hline & Mo & [22] & {$[0.17]$} & [28] & -0.21 & -0.15 \\
\hline & $N d$ & 1,990 & -- & 2,700 & -0.03 & -0.03 \\
\hline & $P b$ & 7,150 & [1.5] & 9,500 & 0.00 & 0.00 \\
\hline & $R u$ & 234 & {$[0.34]$} & 310 & 0.03 & 0.38 \\
\hline & $T h$ & 875 & -- & 1,200 & -0.02 & 0.02 \\
\hline & $\mathrm{Ti}$ & 370 & [0.013] & 490 & 0.00 & -0.02 \\
\hline & $V$ & 25.1 & 0.189 & 30 & 0.07 & 0.18 \\
\hline & $W$ & 365 & [1.2] & 480 & 0.02 & 0.09 \\
\hline & $Y$ & 169 & -- & 230 & -0.01 & 0.02 \\
\hline \multirow{11}{*}{ 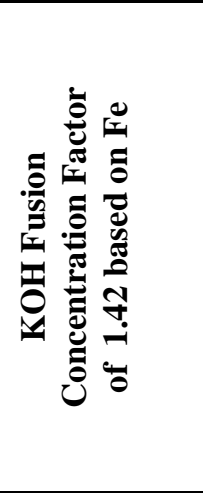 } & $\mathrm{Fe}$ & 178,000 & {$[0.37]$} & 240,000 & & \\
\hline & $\mathrm{Si}$ & 39,900 & 8.35 & 53,000 & 0.05 & -0.06 \\
\hline & Radionuclide & $\begin{array}{l}\text { Dry Slurry } \\
(\mu \mathrm{Ci} / \mathrm{g})\end{array}$ & Supernate $(\mu \mathrm{Ci} / \mathrm{mL})$ & $\begin{array}{l}\text { Dry Solids } \\
(\mu \mathrm{Ci} / \mathrm{g})\end{array}$ & & \\
\hline & ${ }^{60} \mathrm{Co}$ & $2.05 \mathrm{E}-1$ & $<7 . \mathrm{E}-5$ & $2.7 \mathrm{E}-1$ & -0.24 & -0.12 \\
\hline & ${ }^{137} \mathrm{Cs}$ & $3.85 \mathrm{E}+2$ & $6.81 \mathrm{E}-1$ & $5.1 \mathrm{E}+2$ & -0.15 & 0.01 \\
\hline & ${ }^{154} \mathrm{Eu}$ & $6.63 \mathrm{E}+0$ & $<2$.E-4 & $8.8 \mathrm{E}+0$ & -0.22 & -0.08 \\
\hline & ${ }^{155} \mathrm{Eu}$ & $3.25 \mathrm{E}+0$ & $<8$.E-4 & $4.3 \mathrm{E}+0$ & -0.14 & -0.20 \\
\hline & ${ }^{241} \mathrm{Am}$ & $1.03 \mathrm{E}+1$ & $<2$. E-3 & $1.4 \mathrm{E}+1$ & -0.34 & -0.03 \\
\hline & ${ }^{90} \mathrm{Sr}$ & $8.75 \mathrm{E}+3$ & $1.26 \mathrm{E}-3$ & $1.2 \mathrm{E}+4$ & 0.06 & 0.00 \\
\hline & ${ }^{239+240} \mathrm{Pu}$ & $3.93 \mathrm{E}+0$ & $3.56 \mathrm{E}-4$ & $5.2 \mathrm{E}+0$ & -0.09 & -0.11 \\
\hline & ${ }^{238} \mathrm{Pu}$ & $6.73 \mathrm{E}-1$ & $4.74 \mathrm{E}-5$ & $9.0 \mathrm{E}-1$ & -0.34 & -0.13 \\
\hline \multicolumn{7}{|c|}{$\begin{array}{l}\text { (c) Calculated using results in from TI624-G7-12 and TI624-G7-H. } \\
\text { (d) Calculated using the concentration factor in the first column and }\end{array}$} \\
\hline
\end{tabular}




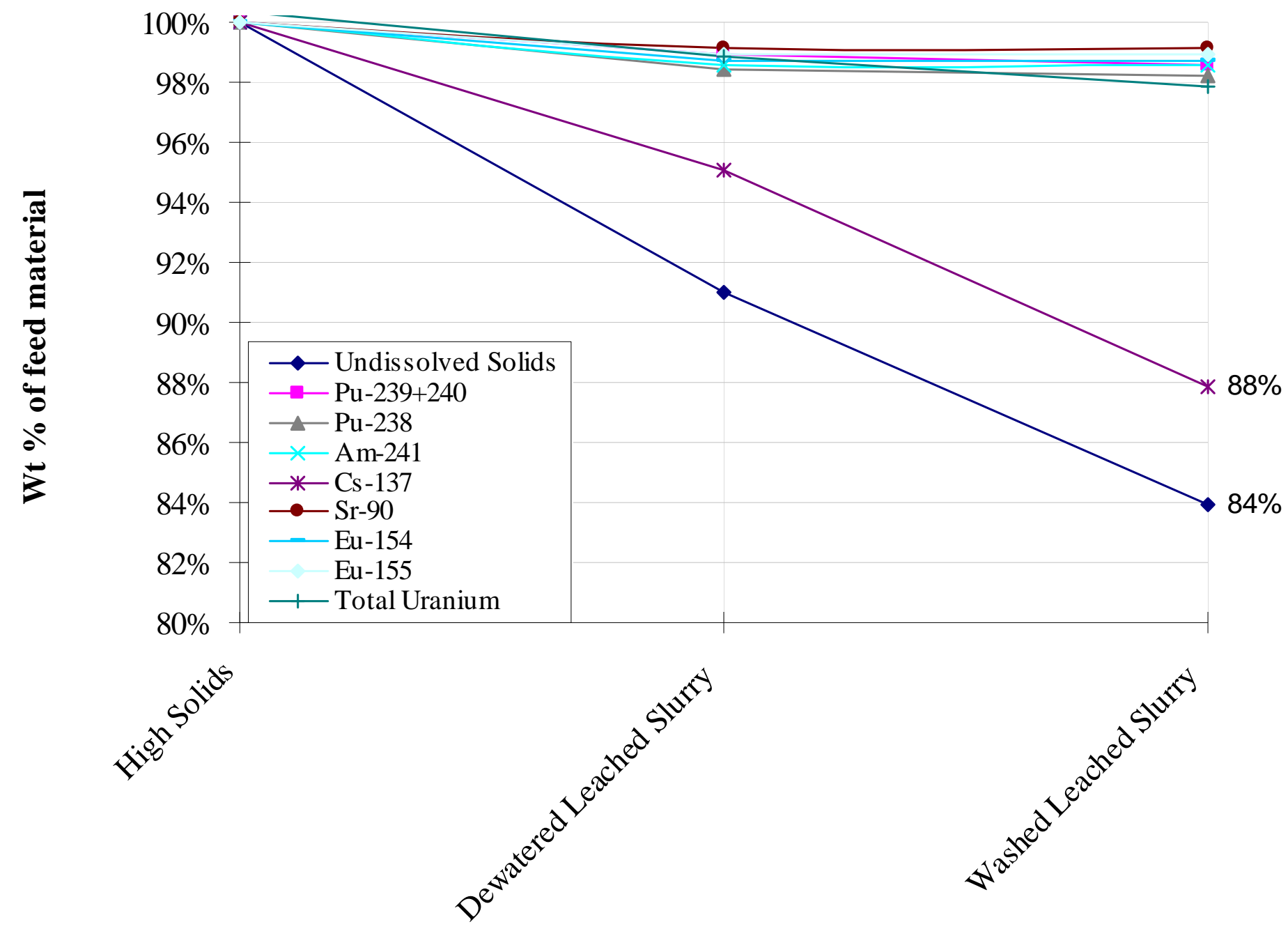

Figure 5.47. Radionuclides/Total Solids in Group 7/AY-102 CUF Slurry, Adjusted for Sampling 


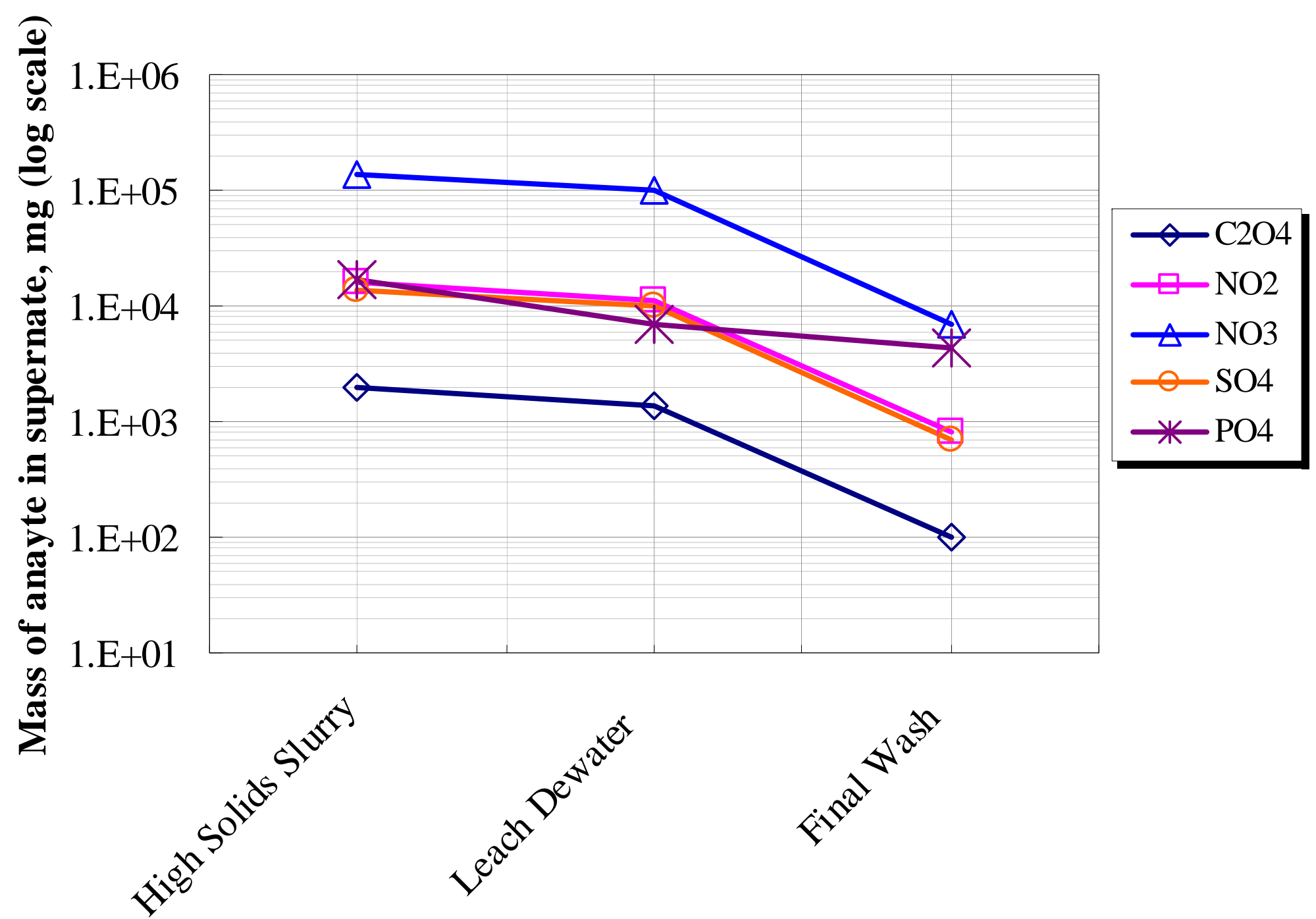

Figure 5.48. Anions in the Group 7/AY-102 Slurry Supernate 
The leached and washed solids were examined by XRD analysis. The identified phases, ranked by relative peak intensities, are given below (Figure 5.49). All of the phases identified in the sample are at very low concentration, which in general equates to less certainty of the identified phases. It is possible that there are additional phases present in the sample, but due to the small amount of sample that could be used (driven by the high radioactivity), minor phases are not visible in the scan. Gibbsite was observed as a significant phase of aluminum in the AY-102 waste sample [Krupka 2004]. The absence of gibbsite in the XRD scans from the leached slurry sample indicated that aluminum in this phase was completely dissolved..

- Hematite, $\mathrm{Fe}_{2} \mathrm{O}_{3}$

- Cancrinite, $\mathrm{Na}_{6} \mathrm{Ca}_{2} \mathrm{Al}_{6} \mathrm{Si}_{6} \mathrm{O}_{24}\left(\mathrm{CO}_{3}\right)_{2} \cdot 2 \mathrm{H} 2 \mathrm{O}$

- Collinsite, Fairfieldite group, $\mathrm{MgCa}_{2}\left(\mathrm{PO}_{4}\right)_{2}\left(\mathrm{H}_{2} \mathrm{O}\right)_{2}$

- Hydroxyapatite, $\mathrm{Ca}_{5}\left(\mathrm{PO}_{4}\right)_{3}(\mathrm{OH})$

SEM images and subsequent EDS analysis (Figure 5.50 and Figure 5.51) are consistent with the XRD results because phases rich in $\mathrm{Fe}, \mathrm{Si}, \mathrm{Ca}, \mathrm{Al}, \mathrm{Mg}$ were all identified. 


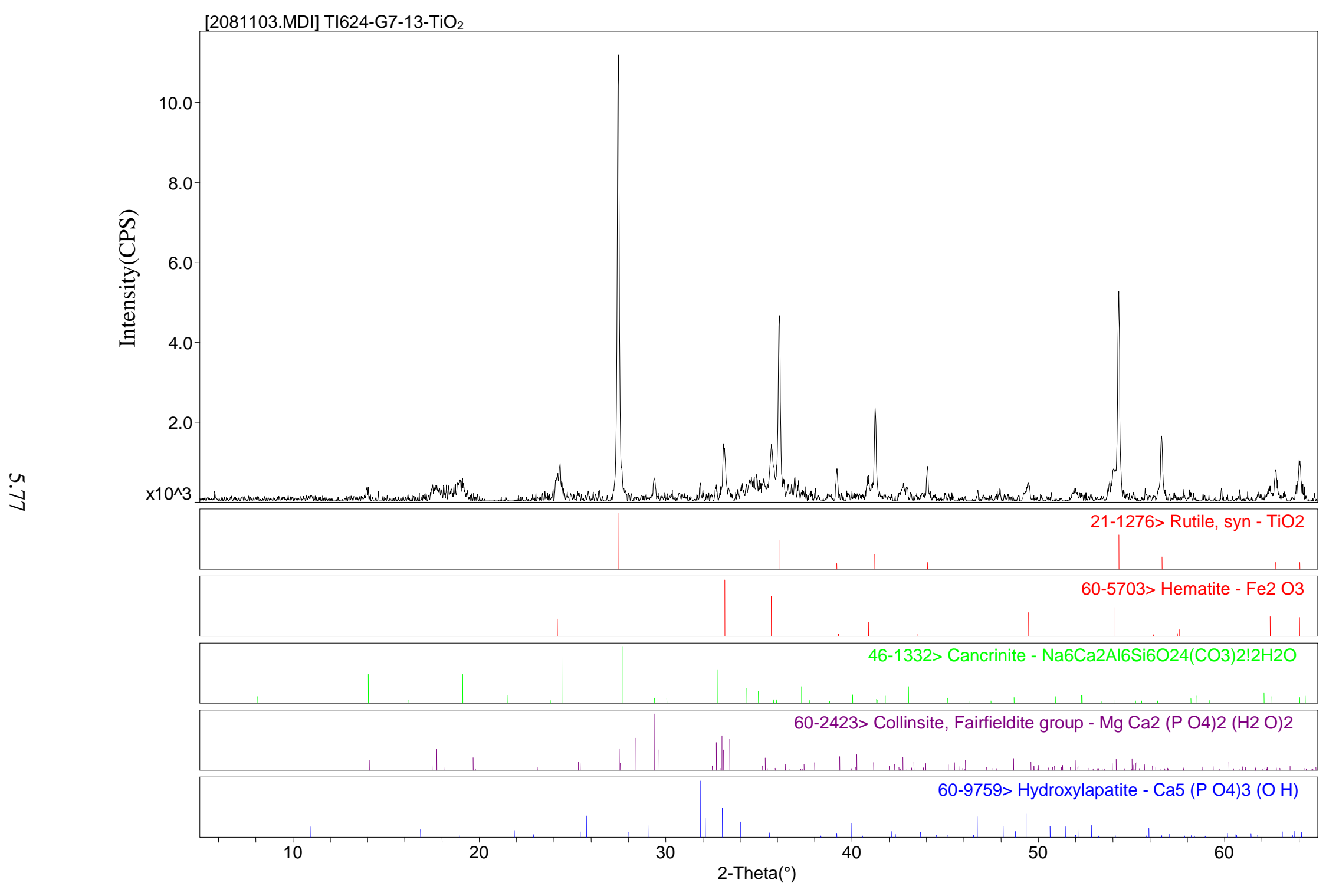

Figure 5.49. XRD Scan Result for the Leached and Washed Solids from the CUF Experiments 


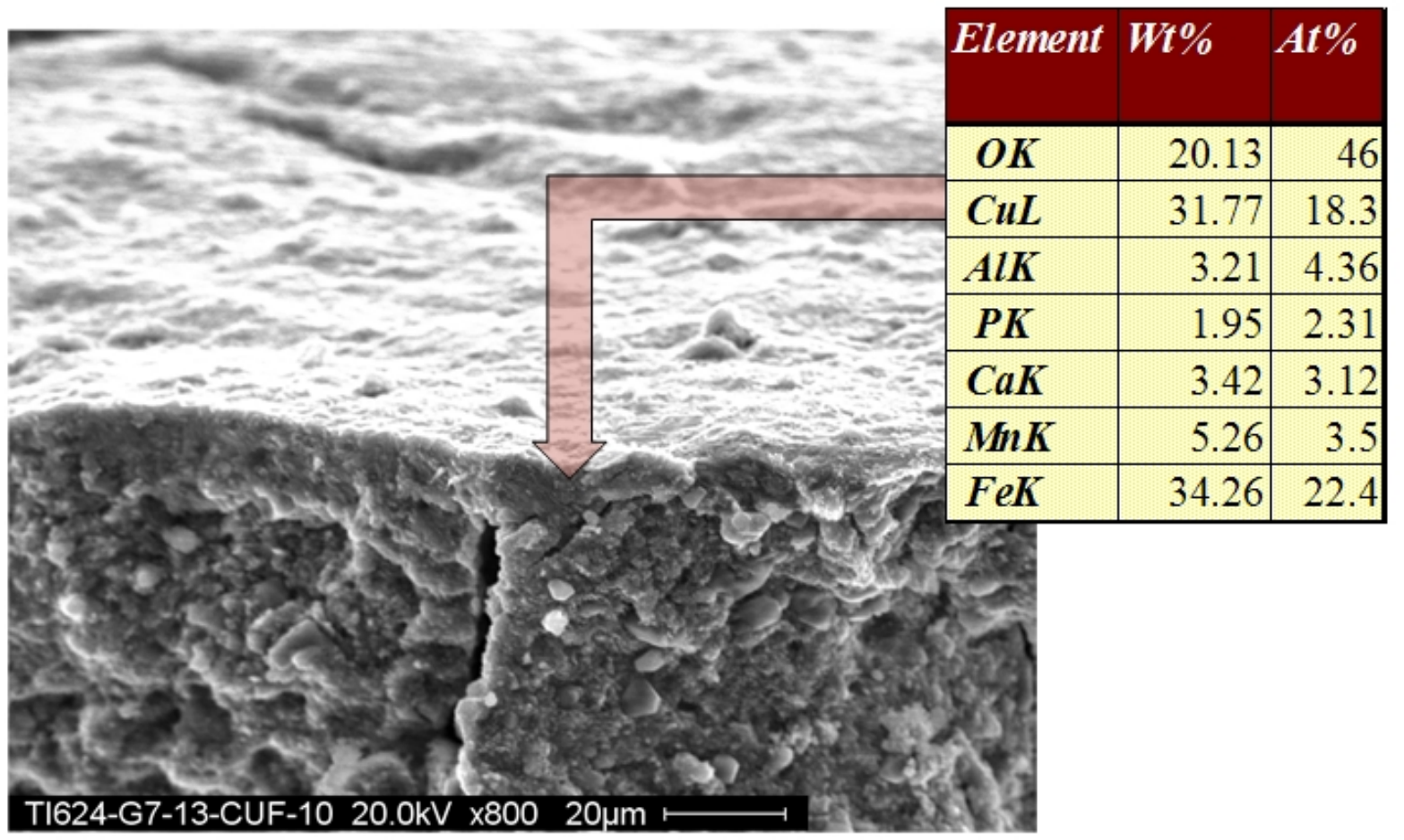

Figure 5.50. SEM of Leached and Washed Particle

\begin{tabular}{|l|r|r|}
\hline Element & \multicolumn{1}{l|}{ Wt $\%$ It\% } \\
\hline $\boldsymbol{C K}$ & 18.38 & 25.49 \\
\hline $\boldsymbol{O K}$ & 51.72 & 53.84 \\
\hline $\boldsymbol{N a K}$ & 25.13 & 18.21 \\
\hline $\boldsymbol{M g K}$ & 0.06 & 0.04 \\
\hline $\boldsymbol{A l K}$ & 2.02 & 1.24 \\
\hline $\boldsymbol{S i K}$ & 1.15 & 0.68 \\
\hline $\boldsymbol{P K}$ & 0.43 & 0.23 \\
\hline $\boldsymbol{P b M}$ & 0.32 & 0.03 \\
\hline $\boldsymbol{U M}$ & 0.06 & 0.00 \\
\hline $\boldsymbol{C a K}$ & 0.09 & 0.04 \\
\hline $\boldsymbol{M n K}$ & 0.08 & 0.03 \\
\hline $\boldsymbol{F e K}$ & 0.52 & 0.15 \\
\hline $\boldsymbol{N i K}$ & 0.03 & 0.01 \\
\hline & &
\end{tabular}

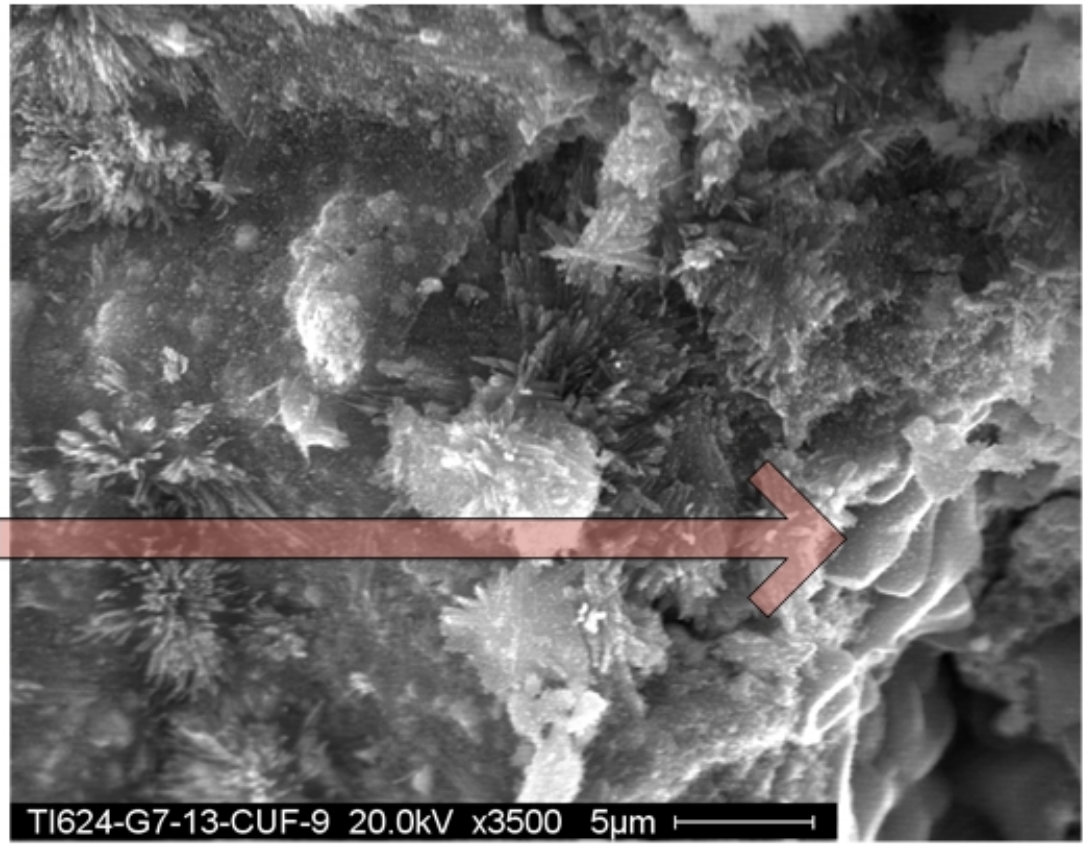

Figure 5.51. SEM 2 of Leached and Washed Particle 
Rheology measurements were performed on the leached and washed slurry. Figure 5.52 shows the results of flow-curve testing. The results of the measurement indicate that the flow behavior is weakly nonNewtonian. The yield stress is low $(\sim 0.5 \mathrm{~Pa})$ and near or at the instrument limit of detection. After the yield stress is exceeded, the flow-curve data show a linear stress response over shear rates from zero up to $500 \mathrm{~s}^{-1}$. At higher shear rates (generally $500 \mathrm{~s}^{-1}$ and above), flow-curve data show an increase in the slope of the stress response curve. This increase is likely a result of Taylor vortex formation onset (i.e., unstable/turbulent flow), which renders the affected data unusable.

Flow-curve data at $25^{\circ} \mathrm{C}, 40^{\circ} \mathrm{C}$, and $60^{\circ} \mathrm{C}$ were fit to both Bingham-Plastic and Casson models. The instrument uncertainty matched the nominal value measured, and establishing the Bingham-plastic nature of the specimen is questionable. Table 5.38 summarizes the best-fit model parameters for the leached washed slurry. Since the data were influenced by Taylor vortex formation, only the range of shear rates, 0 to $500 \mathrm{~s}^{-1}$, is employed in the Casson fitting analysis. Bingham-Plastic analysis cannot account for slurry shear thinning, and as a result, its fitting analysis is limited to 100 to $500 \mathrm{~s}^{-1}$ to avoid bias introduced by slurry shear thinning at low shear rates. Both models provide reasonable fits of the data up to the limit of fitting analysis (i.e., $500 \mathrm{~s}^{-1}$ ). Beyond $500 \mathrm{~s}^{-1}$, the model and data diverge as a result of Taylor vortex formation.

Apparent viscosities at 33, 100, 500, and $1000 \mathrm{~s}^{-1}$ were derived from each measurement. For each temperature, the 33, 100, and $500 \mathrm{~s}^{-1}$ reference viscosities were determined from the average of both upramp and down-ramp flow-curve data. The apparent viscosity at $1000 \mathrm{~s}^{-1}$ is derived from the averaging of all apparent viscosity measurements during constant rotation at $1000 \mathrm{~s}^{-1}$. As a point of comparison, apparent viscosities were also calculated using the Bingham-Plastic and Casson fitting parameters in Table 5.38. The results of these analyses are provided in Table 5.39. 


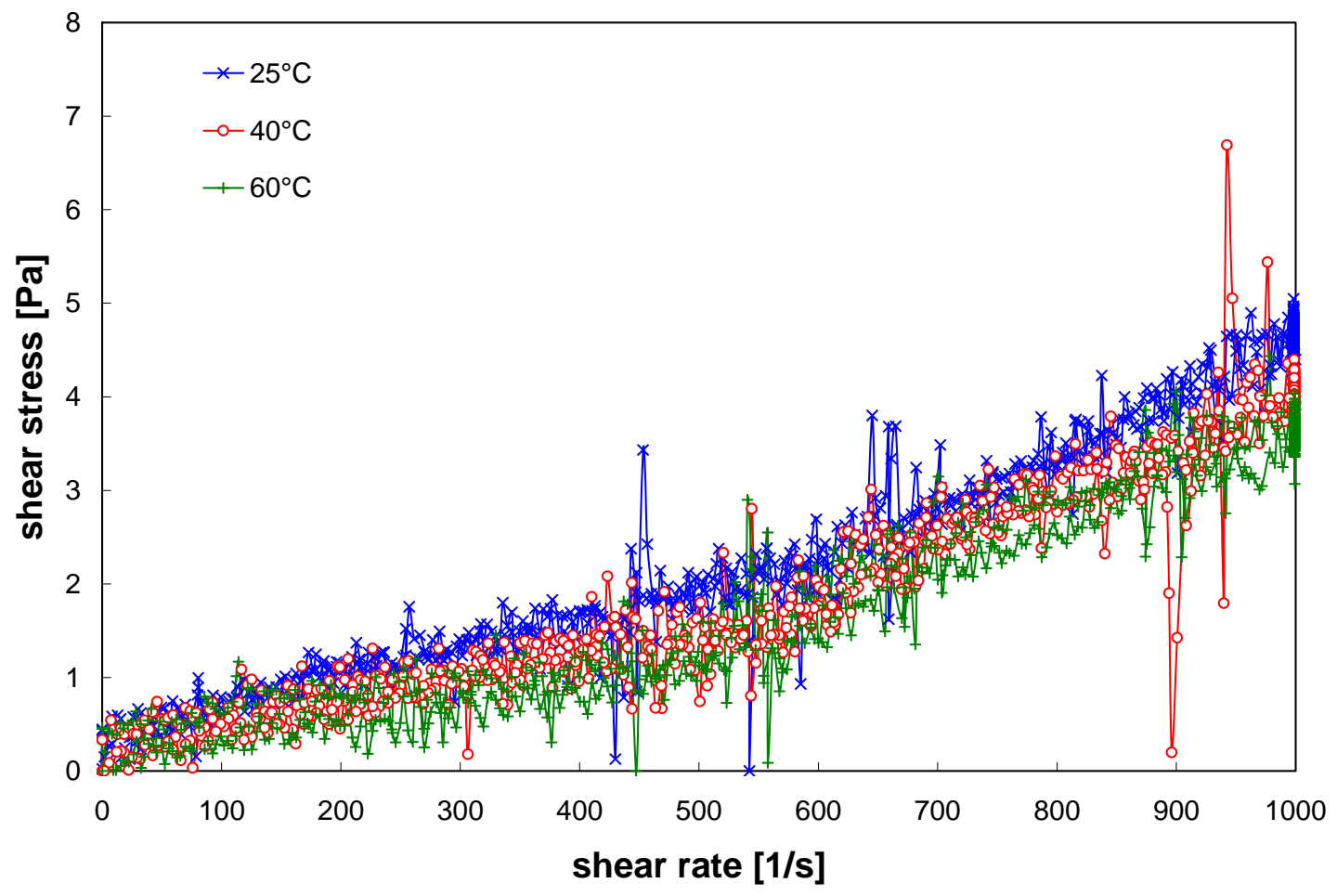

Figure 5.52. Flow Curves for the Group 7 Leached, Washed Slurry

Table 5.38. Results of Fitting Analysis for the Group 7 Leached, Washed Slurry

\begin{tabular}{||c|c|c|c|c|c||}
\hline \multirow{3}{*}{ Model } & $\begin{array}{c}\text { Temperature } \\
{\left[{ }^{\circ} \mathbf{C}\right]}\end{array}$ & Range & $\begin{array}{c}\text { Yield Stress } \\
{[\mathbf{P a}]}\end{array}$ & $\begin{array}{c}\text { Consistency } \\
{[\mathbf{m P a} \cdot \mathbf{s}]}\end{array}$ & $\mathbf{R}$ \\
\hline \multirow{3}{*}{ Bingham-Plastic } & $25(1$ of 2$)$ & $100-400 \mathrm{~s}^{-1}$ & 0.5 & 3.1 & 0.85 \\
\cline { 2 - 6 } & $25(2$ of 2$)$ & $100-400 \mathrm{~s}^{-1}$ & 0.5 & 2.8 & 0.84 \\
\cline { 2 - 6 } & 40 & $100-400 \mathrm{~s}^{-1}$ & 0.3 & 2.3 & 0.73 \\
\cline { 2 - 6 } & 60 & $100-400 \mathrm{~s}^{-1}$ & 0.4 & 1.4 & 0.46 \\
\hline \multirow{5}{*}{ Casson } & $25(1$ of 2$)$ & $0-400 \mathrm{~s}^{-1}$ & 0.1 & 2.1 & 0.93 \\
\cline { 2 - 6 } & $25(2$ of 2$)$ & $0-400 \mathrm{~s}^{-1}$ & 0.2 & 1.7 & 0.92 \\
\cline { 2 - 6 } & 40 & $0-400 \mathrm{~s}^{-1}$ & 0.1 & 1.4 & 0.84 \\
\cline { 2 - 6 } & 60 & $0-400 \mathrm{~s}^{-1}$ & 0.2 & 0.7 & 0.67 \\
\hline
\end{tabular}


Table 5.39. Select Apparent Viscosities for the Leached Washed Slurry

\begin{tabular}{|c|c|c|c|c|c|}
\hline \multirow[b]{2}{*}{ Source } & \multirow{2}{*}{$\begin{array}{c}\text { Temperature } \\
{\left[{ }^{\circ} \mathrm{C}\right]} \\
\end{array}$} & \multicolumn{4}{|c|}{ Apparent Viscosity [mPa·s] } \\
\hline & & @ $33 \mathrm{~s}^{-1}$ & @ $100 \mathrm{~s}^{-1}$ & @ $500 \mathrm{~s}^{-1}$ & @ $1000 \mathrm{~s}^{-1}$ \\
\hline \multirow[t]{4}{*}{ Measured } & 25 (1 of 2$)$ & 12 & 5.1 & $\mathrm{n} / \mathrm{a}^{(\mathrm{a})}$ & $\mathrm{n} / \mathrm{a}^{(\mathrm{a})}$ \\
\hline & 25 (2 of 2$)$ & 13 & 7.2 & 3.8 & 4.7 \\
\hline & 40 & 10 & 5.0 & 2.5 & 4.1 \\
\hline & 60 & 7.6 & 4.8 & 2.4 & 3.6 \\
\hline \multirow[t]{4}{*}{ Bingham-Plastic } & 25 (1 of 2$)$ & 17 & 7.7 & 4.0 & 3.5 \\
\hline & 25 (2 of 2$)$ & 18 & 7.7 & 3.8 & 3.3 \\
\hline & 40 & 12 & 5.5 & 3.0 & 2.6 \\
\hline & 60 & 13 & 5.2 & 2.1 & 1.7 \\
\hline \multirow[t]{4}{*}{ Casson } & 25 (1 of 2$)$ & 13 & 7.0 & 4.0 & 3.4 \\
\hline & 25 (2 of 2$)$ & 14 & 7.3 & 3.7 & 3.0 \\
\hline & 40 & 9.9 & 5.4 & 2.9 & 2.4 \\
\hline & 60 & 10 & 4.9 & 2.1 & 1.6 \\
\hline
\end{tabular}

Table 5.40 compares the rheology at different points during the test. The Group 7 source material is nonNewtonian with a yield stress of $3.3 \mathrm{~Pa}$ and a consistency of $12 \mathrm{mPa} \cdot \mathrm{s}$ at $25^{\circ} \mathrm{C}$ and has an UDS concentration of $\sim 10 \mathrm{wt} \%$. In comparison, the Group 7 slurry low-solids matrix is also non-Newtonian with a yield stress of $1.2 \mathrm{~Pa}$ and a consistency of $3.1 \mathrm{mPa} \cdot \mathrm{s}$ at $25^{\circ} \mathrm{C}$. The lower mixture viscosity relative to the source material is consistent with the lower UDS concentration of the dilute CUF slurry ( 5 wt\%). As expected, the solids concentration appears to have a significant influence on both Group 7 slurry yield stress and consistency.

The concentrated Group 7/AY-102 mixed slurry shows significant non-Newtonian rheology. It has a yield stress of 4.6 Pa and a consistency of $10 \mathrm{mPa} \cdot \mathrm{s}$. The source materials for this mixed Group 7/AY102 slurry include the low solids Group 7 CUF slurry and the archive AY-102 slurry. The concentrated mixed slurry shows increased yield stress and consistency relative to both of these materials. Part of this increase is a result of increased UDS concentration in the mixed slurry. Dewatering and solids addition increases the slurry solids concentration from $\sim 5 \mathrm{wt} \%$ to $\sim 26 \mathrm{wt} \%$. An increased solids concentration will likely yield increased slurry yield stress and consistency. However, because of adding AY-102 solids, the increase in slurry rheology that occurs solely as a result of increased solids concentration cannot be quantified.

Relative to the source Group 7 material, the mixed Group 7/AY-102 shows similar rheology. Despite having almost twice the UDS concentration of the source material, the mixed CUF slurry has a lower consistency (10 mPa·s for the mixed slurry versus $12 \mathrm{mPa} \cdot \mathrm{s}$ for the source slurry) and a somewhat higher yield stress (4.6 Pa for the mixed slurry versus 3.3 Pa for the source slurry). It can be speculated that the similarity of the mixed and source slurry rheologies, despite their dissimilar concentrations, derives from weakening the mixed slurry yield stress and consistency either as a result of mixing with AY-102 slurry (which is Newtonian) or as a result of prolonged shear in the CUF. Unfortunately, without additional information on how quickly Group 7 slurry rheology changes with respect to solids concentration, it is difficult to make conclusions about the slurry behavior with certainty. 
Before leaching, the slurry shows non-Newtonian behavior with a yield stress of $4.6 \mathrm{~Pa}$ and a consistency of $10 \mathrm{mPa} \cdot \mathrm{s}$. After leaching, the slurry is also non-Newtonian and exhibits a lowered yield stress of 2.6 $\mathrm{Pa}$ and a similar viscosity of $11 \mathrm{mPa} \cdot \mathrm{s}$, relative to the pre-leach slurry. The lowered yield stress can be attributed in part to the lowered UDS concentration of the leached slurry (20 wt $\%$ for the post-leach slurry versus $26 \mathrm{wt} \%$ for the pre-leach slurry). Changes in particle chemistry as a result of leaching may also contribute to the lower yield stress. With regard to consistency, the similarity between the pre- and postleach samples is unexpected given the difference in both dissolved solids and UDS concentrations. The leached slurry shows significantly lower dissolved solids and UDS concentrations, and on this basis, would be expected to show lower consistency. The fact that the post-leach slurry shows similar consistency suggests that changes in particle surface chemistry and interactions are influencing slurry rheology.

The results indicate that washing effects a significant reduction in viscosity. Before washing, the slurry is non-Newtonian with a yield stress of $2.6 \mathrm{~Pa}$ and a consistency of $11 \mathrm{mPa} \cdot \mathrm{s}$ at $25^{\circ} \mathrm{C}$. After washing, the slurry is borderline Newtonian (i.e., has a yield stress near $\sim 0.5 \mathrm{~Pa}$ ) with a consistency of $2.8 \mathrm{mPa} \cdot \mathrm{s}$ at $25^{\circ} \mathrm{C}$. The reduction in UDS from $\sim 20 \mathrm{wt} \%$ to $\sim 14 \mathrm{wt} \%$ likely contributed to the reduction. Another factor is a reduction in the dissolved-solids content of the slurry. Washing of the Group 7 slurry employed dilute sodium hydroxide solutions and reduced dissolved solids from $\sim 19 \mathrm{wt} \%$ to $\sim 6 \mathrm{wt} \%$. It is certain that this reduction in dissolved solids content also contributes to the observed reduction in viscosity. 
WTP-RPT-169, Rev 0

Table 5.40. Rheology at Different Points During the CUF Testing

\begin{tabular}{|c|c|c|c|c|c|c|}
\hline Description & Total Solids & $\begin{array}{l}\text { Dissolved } \\
\text { Solids }\end{array}$ & $\begin{array}{c}\text { Undissolved } \\
\text { Solids }\end{array}$ & Rheology & $\begin{array}{c}\text { Yield } \\
\text { Stress } \\
\text { [Pa] }\end{array}$ & $\begin{array}{c}\text { Consistency } \\
\text { [mPa·s] }\end{array}$ \\
\hline Group 7 Source & 36-wt\% & 29-wt\% & 10-wt\% & $\begin{array}{c}\text { Non- } \\
\text { Newtonian }^{(a)}\end{array}$ & 3.3 & 12 \\
\hline AY-102 Sample & $\mathrm{n} / \mathrm{a}$ & $\mathrm{n} / \mathrm{a}$ & 20-wt\% & Newtonian & $\mathrm{n} / \mathrm{a}$ & 4.1 \\
\hline $\begin{array}{c}\text { Group } 7 \text { CUF } \\
\text { Low-Solids Matrix }\end{array}$ & $\mathrm{n} / \mathrm{a}$ & $\mathrm{n} / \mathrm{a}$ & $\sim 5-\mathrm{wt} \%$ & $\begin{array}{c}\text { Non- } \\
\text { Newtonian }^{(a)}\end{array}$ & 1.2 & 3.1 \\
\hline $\begin{array}{c}\text { Concentrated Group } \\
7 \text { Mixture }\end{array}$ & 44-wt\% & 24-wt\% & 26-wt\% & $\begin{array}{c}\text { Non- } \\
\text { Newtonian }^{(a)}\end{array}$ & 4.6 & 10 \\
\hline $\begin{array}{l}\text { Caustic-Leached / } \\
\text { Dewatered }\end{array}$ & 35-wt\% & 19-wt\% & 20-wt\% & $\begin{array}{c}\text { Non- } \\
\text { Newtonian }^{(a)}\end{array}$ & 2.6 & 11 \\
\hline $\begin{array}{c}\text { Caustic-Leached / } \\
\text { Dewatered / Washed }\end{array}$ & 19-wt\% & 6-wt\% & 14-wt\% & $\begin{array}{c}\text { Non- } \\
\text { Newtonian }^{(a)}\end{array}$ & 0.5 & 2.8 \\
\hline
\end{tabular}

(a) Non-Newtonian properties reported are Bingham-Plastic model parameters. 


\subsection{Summary and Conclusions}

A scope of work ${ }^{(a)}$ was developed to perform caustic and oxidative leaching bench-scale tests of actual Hanford tank waste samples to address Task 4 of the M-12 External Flowsheet Review Team (EFRT) response plan. ${ }^{\text {(b) }}$ Supporting this response, eight groupings of actual waste had been developed encompassing a large fraction of the high-level waste (HLW) types present at the Hanford Site. Each waste grouping was developed to specifically address a Waste Treatment and Immobilization Plant (WTP) processing challenge. Together, the eight waste groupings represented $\sim 75 \%$ of the HLW mass expected to be processed through the WTP.

The waste group tested and discussed in this report is Tributyl Phosphate (Group 7, TBP). This waste type was of interest because of its high phosphate content. Aluminum in the form of gibbsite $\left[\mathrm{Al}(\mathrm{OH})_{3}\right]$ was also expected in lesser quantities. The work focused on understanding the behavior of these elements during caustic leaching. Because of its relatively low chromium content, no oxidative leaching tests were performed on the Group 7 sample.

Materials representative of Group 7 were retrieved from archived samples of Tanks BX-109 and B-106 at the 222S Laboratory, although the sample composite used was dominated by the BX-109 waste. Samples were shipped to the hot cells at the Radiochemical Processing Laboratory (RPL), transferred to a compositing vessel with water, homogenized, and then subdivided. The composited material was characterized for physical properties, chemical composition, and crystal habit of the insoluble solids. The Group 7 sludge was subjected to parametric caustic-leach testing to evaluate phosphate and aluminum leaching kinetics for this waste type. The remaining composite material was tested in a bench top filtration/leaching apparatus, commonly called the CUF, in the hot cells where ultrafiltration and caustic leaching conditions that were expected to be conducted at the WTP pre-treatment facility were simulated. The filtration testing was conducted in a parametric test sequence to understand filter-flux dependency on axial velocity and trans-membrane pressure both before caustic leaching (low and high solids content) and after leaching and washing (high solids content.). The CUF system was capable of filtering HLW slurry using a cross-flow ultrafilter ( $2 \mathrm{ft}$ long with a 0.5 inch ID) rated for $0.1-\mu \mathrm{m}$-diameter particles. Caustic leaching and solids washing in conjunction with filtration were performed in the apparatus; the effectiveness of maintaining transuranic material in the HLW process stream (slurry side of the CUF) was evaluated.

The following objectives of the test plan were accomplished:

- Physical and chemical characterization (settling rate, particle-size distribution [PSD], rheology, concentrations of metal, anions, and radionuclides, and crystal habit and morphology using X-ray Diffraction [XRD], scanning electron microscopy [SEM], and transmission electron microscopy [TEM]).

(a) SK Fiskum, TP-RPP-WTP-467, Rev. 0, 2/2/07 and Rev. 1 7/31/07, Characterization and Small Scale Testing of Hanford Wastes to Support the Development and Demonstration of Leaching and Ultrafiltration Pretreatment Processes.

(b) WTP Doc. No. 24590-WTP-PL-ENG-06-0008, Rev 0, "Hanford Waste Treatment and Immobilization Plant (WTP) Project Response Plan for Resolution of Issues Identified by the Comprehensive Review of the WTP Flowsheet and Throughput.” L Lucas, March 2006. 
- Parametric filtration testing at $4 \mathrm{wt} \%$ UDS and $26 \mathrm{wt} \%$ UDS before caustic leaching was performed and at $14 \mathrm{wt} \%$ UDS after caustic leaching and washing.

- Caustic leaching at $60^{\circ} \mathrm{C}$ for $8 \mathrm{~h}$ in a 2.6-M free-hydroxide matrix while periodically sampling the aqueous fraction to evaluate $\mathrm{Al}$ and $\mathrm{P}$ dissolution as a function of time.

- Final characterization of the caustic leached and washed solids including PSD, concentrations of metal, anions, and radionuclides, and crystal habit and morphology.

\subsection{Characterization}

The major analyte concentrations of the Group 7 supernatant before processing are shown in Table 6.1 and Table 6.2.

Table 6.1. Initial Radionuclide Content in Group 7

\begin{tabular}{|c|c|c|c|c|}
\hline \multirow{3}{*}{$\begin{array}{l}\text { Process } \\
\text { Phase }> \\
\text { Analyte }\end{array}$} & \multicolumn{3}{|c|}{ Initial Composition } & \\
\hline & \multicolumn{2}{|c|}{ Supernatant } & \multicolumn{2}{|l|}{ Washed solids } \\
\hline & $\mu \mathrm{Ci} / \mathrm{mL}$ & RPD & $\mu \mathrm{Ci} / \mathrm{g}$ & RPD \\
\hline${ }^{137} \mathrm{Cs}$ & $4.56 \mathrm{E}+0$ & 1.3 & $3.64 \mathrm{E}+1$ & 7.7 \\
\hline${ }^{60} \mathrm{Co}$ & $<8 . E-5$ & na & $2.11 \mathrm{E}-2$ & 0.95 \\
\hline${ }^{241} \mathrm{Am}$ & $<4 . \mathrm{E}-3$ & na & [8.7E-2] & na \\
\hline${ }^{238} \mathrm{Pu}$ & [3.9E-6] & [59] & $5.63 \mathrm{E}-3$ & 3.7 \\
\hline${ }^{239+240} \mathrm{Pu}$ & $1.21 \mathrm{E}-4$ & 0.83 & $1.95 \mathrm{E}-1$ & 7.2 \\
\hline Gross alpha & $<3 . \mathrm{E}-4$ & na & $3.00 \mathrm{E}-1$ & 8.0 \\
\hline Gross beta & $4.59 \mathrm{E}+0$ & 1.3 & $1.57 \mathrm{E}+3$ & 7.0 \\
\hline${ }^{90} \mathrm{Sr}$ & $1.00 \mathrm{E}-2$ & 5.5 & $7.41 \mathrm{E}+2$ & 7.6 \\
\hline${ }^{154} \mathrm{Eu}$ & $<2$.E-4 & na & $5.90 \mathrm{E}-2$ & 19 \\
\hline${ }^{155} \mathrm{Eu}$ & $<2$.E-3 & na & $<5 \mathrm{E}-2$ & na \\
\hline
\end{tabular}


Table 6.2. Initial ICP Metals Content in Group 7

\begin{tabular}{|c|c|c|c|c|c|c|}
\hline \multirow{3}{*}{$\begin{array}{l}\text { Process } \\
\text { Phase }> \\
\text { Analyte }\end{array}$} & \multirow{2}{*}{\multicolumn{2}{|c|}{$\frac{\text { Initial Composition }}{\text { Supernatant }}$}} & \multicolumn{4}{|c|}{ Washed Solids } \\
\hline & & & Fusion & & acid digest & \\
\hline & $\mu \mathrm{g} / \mathrm{mL}$ & RPD & $\mu \mathrm{g} / \mathrm{g}$ & RPD & $\mu \mathrm{g} / \mathrm{g}$ & RPD \\
\hline $\mathrm{Al}$ & $<0.73$ & na & 16,000 & 7.5 & 18,550 & 0.54 \\
\hline $\mathrm{B}$ & 30.0 & 5.3 & [115] & [9] & $<13$ & na \\
\hline $\mathrm{Bi}$ & $<3.65$ & na & 5,710 & 6.0 & 6,475 & 1.7 \\
\hline $\mathrm{Cd}$ & $<0.41$ & na & $<7.7$ & na & $<9.2$ & na \\
\hline $\mathrm{Cr}$ & 57.8 & 1.7 & 718 & 7.5 & 826 & 0.48 \\
\hline $\mathrm{Fe}$ & {$[1.15]$} & [8.7] & 140,000 & 7.1 & 156,000 & 2.6 \\
\hline $\mathrm{K}$ & {$[86]$} & [1.9] & na & na & [315] & [54] \\
\hline $\mathrm{Mn}$ & {$[0.16]$} & [13] & 884 & 7 & 926 & 0.3 \\
\hline $\mathrm{Na}$ & 92,300 & 0.22 & 130,500 & 6.9 & 151,500 & 2.0 \\
\hline $\mathrm{Ni}$ & $<0.42$ & na & na & na & 517 & 0.19 \\
\hline $\mathrm{P}$ & 3,760 & 1.6 & 107,500 & 6.5 & 123,000 & 0.0 \\
\hline$S$ & 6,260 & 1.9 & [875] & [74] & [940] & [77] \\
\hline $\mathrm{Si}$ & $<0.68$ & na & 7,285 & 7.0 & na & na \\
\hline $\mathrm{Sr}$ & {$[0.050]$} & [2.0] & 3,905 & 6.9 & 4,460 & 2.2 \\
\hline $\mathrm{U}$ & 162 & 1.9 & 113,000 & 7.1 & 125,000 & 0.0 \\
\hline $\mathrm{Zn}$ & [0.99] & {$[2.0]$} & 687 & 8.3 & 856 & 1.3 \\
\hline $\mathrm{Zr}$ & $<0.13$ & na & $<9.3$ & na & [23] & [17] \\
\hline U KPA & $\mathrm{Na}$ & na & 114,500 & 4.4 & & \\
\hline
\end{tabular}

XRD analysis was done on the initial washed solids. In general, the patterns contain a very large number of peaks along with significant peak overlapping in areas. Phases identified were:

- Zeolite, $\mathrm{NaAlSiO}_{4}\left(\mathrm{H}_{2} \mathrm{O}\right)_{1.1}$

- Threadgoldite, $\mathrm{Al}\left(\mathrm{UO}_{2}\right)_{2}\left(\mathrm{PO}_{4}\right)_{2}(\mathrm{OH})\left(\mathrm{H}_{2} \mathrm{O}\right)_{8}$

- Sodium Iron Phosphate, $\mathrm{Na}_{7}\left(\mathrm{FeP}_{2} \mathrm{O}_{7}\right)_{4} \mathrm{PO}_{4}$

- Lepidocrocite, $\mathrm{FeO}(\mathrm{OH})$

- Humboldtine, $\mathrm{C}_{2} \mathrm{FeO}_{4} \cdot 2 \mathrm{H}_{2} \mathrm{O}$

- Iron (III) phosphate oxide, $\mathrm{Fe}_{2} \mathrm{PO}_{5}$

- Dioxouranium(VI) bis(dihydrogenphosphate(I)) hydrate, $\left(\mathrm{UO}_{2}\right)\left(\mathrm{H}_{2} \mathrm{PO}_{2}\right)_{2}\left(\mathrm{H}_{2} \mathrm{O}\right)$

- Sodium Uranyl Phosphate, $\mathrm{Na}_{6}\left(\mathrm{UO}_{2}\right)_{2}\left(\mathrm{PO}_{4}\right)_{4}$

- Gibbsite, $\mathrm{Al}(\mathrm{OH})_{3}$.

Washing data from the initial characterization shows $96 \mathrm{wt} \%$ of the aluminum, $68 \mathrm{wt} \%$ of the chromium, and $82 \mathrm{wt} \%$ of the phosphorus are water insoluble. Particle size and rheology measurements were also done on the washed solids, and results are summarized in Table 6.3 with the filtration results. 
Table 6.3. Summary of Group 7 Filtration Results

\begin{tabular}{|c|c|c|}
\hline Filtration Step & Property & Results \\
\hline \multirow{4}{*}{$\begin{array}{l}\text { Initial Characterization of } \\
\text { Group } 7 \\
\text { (Section } 3.0 \text { ) }\end{array}$} & Material Description & TBP tank waste sludge \\
\hline & UDS & $10.0 \mathrm{wt} \%$ \\
\hline & $\begin{array}{l}\text { Slurry Rheology } \\
\text { @ } 25^{\circ} \mathrm{C} \\
\text { @ } 40^{\circ} \mathrm{C} \\
\text { @ } 60^{\circ} \mathrm{C}\end{array}$ & $\begin{array}{ll}\text { Newtonian } & \\
\text { Viscosity: } & 6.3-12 \mathrm{mPa} \cdot \mathrm{s} @ 25^{\circ} \mathrm{C} \\
& 6.0-11 \mathrm{mPa} \cdot \mathrm{s} @ 40^{\circ} \mathrm{C} \\
& 4.4-8.9 \mathrm{mPa} \cdot \mathrm{s} @ 60^{\circ} \mathrm{C}\end{array}$ \\
\hline & $\begin{array}{l}\text { PSD } \\
\text { (3000 RPM pump speed) }\end{array}$ & $\begin{array}{l}\mathrm{d}(10): 1.0-1.1 \mu \mathrm{m} \\
\mathrm{d}(50): 5.5-19 \mu \mathrm{m} \\
\mathrm{d}(90): 17-130 \mu \mathrm{m}\end{array}$ \\
\hline \multirow{2}{*}{$\begin{array}{l}\text { Low Solids } \\
\text { Filtration Testing } \\
\text { (Section 5.2) }\end{array}$} & Material Description & $\begin{array}{l}\text { Group } 7 \text { diluted w/ simulant } \\
\text { supernatant and circulated in CUF }\end{array}$ \\
\hline & UDS & Predicted to be $4 \mathrm{wt} \%$ \\
\hline \multirow[t]{4}{*}{$\begin{array}{l}\text { Baseline Conditions } \\
\text { TMP: } 40 \text { psid } \\
A V: 13 \mathrm{ft} / \mathrm{s}\end{array}$} & $\begin{array}{l}\text { Slurry Rheology } \\
\text { @ } 25^{\circ} \mathrm{C} \\
\text { @ } 40^{\circ} \mathrm{C} \\
\text { @ } 60^{\circ} \mathrm{C}\end{array}$ & $\begin{array}{ll}\text { Newtonian } & \\
\text { Viscosity: } & 1.3-3.1 \mathrm{mPa} \cdot \mathrm{s} @ 25^{\circ} \mathrm{C} \\
& 1.0-2.4 \mathrm{mPa} \cdot \mathrm{s} @ 40^{\circ} \mathrm{C} \\
& 0.7-1.9 \mathrm{mPa} \cdot \mathrm{s} @ 60^{\circ} \mathrm{C}\end{array}$ \\
\hline & $\begin{array}{l}\text { PSD } \\
\text { (3000 RPM pump speed) }\end{array}$ & $\begin{array}{l}\mathrm{d}(10): 28 \mu \mathrm{m} \\
\mathrm{d}(50): 81 \mu \mathrm{m} \\
\mathrm{d}(90): 150 \mu \mathrm{m}\end{array}$ \\
\hline & Baseline Filter Flux & $0.028 \mathrm{GPM} / \mathrm{ft}^{2}$ \\
\hline & Controlling Parameter & $\begin{array}{l}\text { Proportional to TMP } \\
\text { Secondary negative effects from Time }\end{array}$ \\
\hline \multirow{3}{*}{$\begin{array}{l}\text { Dewatering of Group } 7 \\
\text { Waste Prior to Leaching } \\
\text { (Section 5.3) }\end{array}$} & Initial Flux & $0.018 \mathrm{GPM} / \mathrm{ft}^{2}$ \\
\hline & Final Flux & $0.016 \mathrm{GPM} / \mathrm{ft}^{2}$ \\
\hline & Final UDS & Predicted at $12 \mathrm{wt} \%$ \\
\hline \multirow{2}{*}{$\begin{array}{l}\text { Filtration Conditions } \\
T M P: 40 \mathrm{psid} \\
A V: 13 \mathrm{ft} / \mathrm{s}\end{array}$} & Behavior & TMP controlling \\
\hline & Supernate Composition & $\begin{array}{ll}{[\mathrm{Na}]:} & 4.0 \\
{[\mathrm{OH}]:} & 0.14 \\
{[\mathrm{Al}]:} & 0.006\end{array}$ \\
\hline \multirow{4}{*}{$\begin{array}{l}\text { Dewatering of Blend Slurry } \\
\text { (Group } 7 \text { /AY102) } \\
\text { Prior to Leaching } \\
\text { (Section 5.3) }\end{array}$} & Initial Flux & $0.016 \mathrm{GPM} / \mathrm{ft}^{2}$ \\
\hline & Final Flux & $0.012 \mathrm{GPM} / \mathrm{ft}^{2}$ \\
\hline & Final UDS & Measured at $26 \mathrm{wt} \%$ \\
\hline & Behavior & TMP controlling \\
\hline $\begin{array}{l}\text { Filtration Conditions } \\
\text { TMP: } 40 \text { psid } \\
A V: 13 \mathrm{ft} / \mathrm{s}\end{array}$ & Supernate Composition & $\begin{array}{lc}{[\mathrm{Na}]:} & 3.7 \mathrm{M} \\
{[\mathrm{OH}]:} & 0.12 \mathrm{M} \\
{[\mathrm{Al}]:} & 11 \mu \mathrm{g} / \mathrm{mL}\end{array}$ \\
\hline
\end{tabular}


Table 6.3 (Contd)

\begin{tabular}{|c|c|c|}
\hline Filtration Step & Property & Results \\
\hline \multirow{6}{*}{$\begin{array}{l}\text { High Solids } \\
\text { Filtration Testing } \\
\text { (Section 5.3) } \\
\text { Baseline Conditions } \\
T M P: 40 \mathrm{psid} \\
A V: 13 \mathrm{ft} / \mathrm{s}\end{array}$} & Material Description & $\begin{array}{l}\text { Added AY102 to Group } 7 \text { slurry, } \\
\text { dewatered and circulated in CUF }\end{array}$ \\
\hline & UDS & Measured at $26 \mathrm{wt} \%$ \\
\hline & $\begin{array}{l}\text { Slurry Rheology } \\
\text { @ } 25^{\circ} \mathrm{C} \text { to } 60^{\circ} \mathrm{C}\end{array}$ & $\begin{array}{lr}\text { non-Newtonian } & \\
\text { Shear Stress range: } & 0.1 \text { to } 0.5 \mathrm{~Pa} \\
\text { Consistency range: } & 3.4 \text { to } 10 \mathrm{mPa} \cdot \mathrm{s}\end{array}$ \\
\hline & $\begin{array}{l}\text { PSD } \\
\text { (3000 RPM pump speed) }\end{array}$ & $\begin{array}{l}\text { Could not be run because of dose } \\
\text { concerns }\end{array}$ \\
\hline & Baseline Filter Flux & $0.012 \mathrm{GPM} / \mathrm{ft}^{2}$ \\
\hline & Controlling Parameter & Proportional to TMP and AV \\
\hline \multirow{5}{*}{$\begin{array}{l}\text { Caustic Leach Dewater } \\
\text { (Section 5.5) }\end{array}$} & Initial Flux & $0.007 \mathrm{GPM} / \mathrm{ft}^{2}$ \\
\hline & Final Filter Flux & $0.006 \mathrm{GPM} / \mathrm{ft}^{2}$ \\
\hline & Final UDS & Measured at $20 \mathrm{wt} \%$ \\
\hline & Behavior & TMP controlling \\
\hline & Supernate Composition & $\begin{array}{ll}{[\mathrm{Na}]:} & 4.7 \mathrm{M} \\
{[\mathrm{OH}]:} & 2.3 \mathrm{M} \\
{[\mathrm{Al}]:} & 0.27 \mathrm{M}\end{array}$ \\
\hline \multirow{3}{*}{$\begin{array}{l}\text { Caustic Wash } 1 \text { (Section 5.5) } \\
\text { Filtration Conditions } \\
T M P: 40 \text { psid } \\
A V: 13 f t / s\end{array}$} & Wash Solution & $0.5 \mathrm{M} \mathrm{NaOH}$ \\
\hline & Supernate Composition & $\begin{array}{ll}{[\mathrm{Na}]:} & 2.9 \mathrm{M} \\
{[\mathrm{OH}]:} & 1.5 \mathrm{M} \\
{[\mathrm{Al}]:} & 0.15 \mathrm{M} \\
\end{array}$ \\
\hline & Filter Flux & $0.012-0.011 \mathrm{GPM} / \mathrm{ft}^{2}$ \\
\hline \multirow{3}{*}{$\begin{array}{l}\text { Caustic Wash } 2 \text { (Section 5.5) } \\
\text { Filtration Conditions } \\
T M P: 40 \text { psid } \\
A V: 13 f t / s\end{array}$} & Wash Solution & $0.1 \mathrm{M} \mathrm{NaOH}$ \\
\hline & Supernate Composition & $\begin{array}{ll}{[\mathrm{Na}]:} & 1.6 \mathrm{M} \\
{[\mathrm{OH}]:} & 0.77 \mathrm{M} \\
{[\mathrm{Al}]:} & 0.069 \mathrm{M} \\
\end{array}$ \\
\hline & Filter Flux & $0.024-0.014 \mathrm{GPM} / \mathrm{ft}^{2}$ \\
\hline \multirow{3}{*}{$\begin{array}{l}\text { Caustic Wash } 3 \text { (Section 5.5) } \\
\text { Filtration Conditions } \\
T M P: 40 \text { psid } \\
A V: 13 f t / s\end{array}$} & Wash Solution & $0.05 \mathrm{M} \mathrm{NaOH}$ \\
\hline & Supernate Composition & $\begin{array}{ll}{[\mathrm{Na}]:} & 0.77 \mathrm{M} \\
{[\mathrm{OH}]:} & 0.39 \mathrm{M} \\
{[\mathrm{Al}]:} & 0.032 \mathrm{M} \\
\end{array}$ \\
\hline & Filter Flux & $0.025-0.016 \mathrm{GPM} / \mathrm{ft}^{2}$ \\
\hline \multirow{3}{*}{$\begin{array}{l}\text { Caustic Wash } 4 \text { (Section } 5.5) \\
\text { Filtration Conditions } \\
\text { TMP: } 40 \text { psid } \\
A V: 13 \mathrm{ft} / \mathrm{s}\end{array}$} & Wash Solution & $0.01 \mathrm{M} \mathrm{NaOH}$ \\
\hline & Supernate Composition & $\begin{array}{ll}{[\mathrm{Na}]:} & 0.38 \mathrm{M} \\
{[\mathrm{OH}]:} & 0.18 \mathrm{M} \\
{[\mathrm{Al}]:} & 0.0016 \mathrm{M} \\
\end{array}$ \\
\hline & Filter Flux & $0.022-0.015 \mathrm{GPM} / \mathrm{ft}^{2}$ \\
\hline \multirow{3}{*}{$\begin{array}{l}\text { Washed Caustic Leached } \\
\text { Slurry (Section 5.6-5.7) }\end{array}$} & UDS & $14 \mathrm{wt} \%$ \\
\hline & $\begin{array}{l}\text { PSD } \\
\text { (3000 RPM pump speed) }\end{array}$ & $\begin{array}{l}\text { Could not be run because of dose } \\
\text { concerns }\end{array}$ \\
\hline & $\begin{array}{l}\text { Rheology } \\
\text { @ } 25^{\circ} \mathrm{C} \text { to } 60^{\circ} \mathrm{C}\end{array}$ & $\begin{array}{l}\text { Weakly non-Newtonian } \\
\text { Yield Stress range: } \quad 0.1 \text { to } 0.5 \mathrm{~Pa} \\
\text { Consistency range: }\end{array}$ \\
\hline
\end{tabular}




\subsection{Parametric Leaching Results}

The Group 7 TBP sludge was subjected to parametric caustic-leach testing to understand phosphorus and aluminum dissolution characteristics and to support the development of a suitable simulant material for this type of waste (although simulant development was outside the scope of the work reported here). Leaching was conducted in a 1:100 solids-mass to solution-volume ratio under varying hydroxide concentrations $(0.25,1$, and $3 \mathrm{M})$ and varying temperature $(40,60$, and $80^{\circ} \mathrm{C}$ ). Periodic sampling ( 0 to $24 \mathrm{~h}$ ) and analysis was conducted to determine the reaction behavior at each leaching condition. The composition of the caustic-leached solids and the leach factors for select analytes are given in Table 6.4. The following are the key conclusions from this work.

- Under all caustic-leaching conditions examined, phosphorus removal from the Group 7 solids was rapid and nearly complete (85 to $95 \%$ dissolution was obtained). Even before the application of heat, $\sim 50$ to $80 \%$ of the $\mathrm{P}$ was removed from the solid phase. The removal of $\mathrm{P}$ before the application of heat was dependent on the hydroxide concentration, with $\sim 52 \%, 61$ to $69 \%$, and 71 to $82 \%$ of the $\mathrm{P}$ removed in 0.25 , 1 , and $3 \mathrm{M} \mathrm{NaOH}$, respectively. This is in contrast to the results seen in the CUF, where the leach factor for phosphorus after causticleaching was calculated to be a negative value. The difference is because in the CUF, the leachate solutions were likely near the phosphate solubility, whereas in the parametric tests, the greater dilution volume resulted in lower phosphate concentrations.

- For all temperatures and all hydroxide concentrations, a steady-state value of P dissolution was reached in the first hour. Hydroxide concentration and temperature had little effect on the $\mathrm{P}$ dissolution.

- A steady-state value of Al dissolution was obtained for the higher temperatures (60 and $80^{\circ} \mathrm{C}$ ), but at $40^{\circ} \mathrm{C}$, the amount of $\mathrm{Al}$ dissolved continued increasing throughout the entire sampling period.

- Dissolution of $\mathrm{Al}$ at lower temperatures and hydroxide concentrations $\left(40^{\circ} \mathrm{C}\right.$ in and $1 \mathrm{M}$ $\mathrm{NaOH}$ and $60^{\circ} \mathrm{C}$ in $0.25 \mathrm{M} \mathrm{NaOH}$ ) was lower than for other conditions, reaching only 59 to $65 \%$ dissolution.

- Between 80 and $90 \%$ of the $\mathrm{Al}$ was dissolved at the higher temperatures, suggesting that a small amount of a caustic-insoluble $\mathrm{Al}$ compound was present, perhaps zeolite, as identified by XRD.

- Both temperature and hydroxide concentration had a large effect on the gibbsite dissolution rate at the lower temperatures and lower hydroxide concentrations.

- Under all conditions, there was a rapid dissolution of uranium. Before heating was applied, 50 to $100 \%$ of the $U$ was removed from the solid phase. The amount of $U$ removed before the application of heat was dependent on the hydroxide concentration, with much more $\mathrm{U}$ dissolution seen in $3 \mathrm{M} \mathrm{NaOH}$ than in $0.25 \mathrm{M} \mathrm{NaOH}$. As heat was applied, the uranium reprecipitated, leaving 12 to $20 \%$ in solution. Examination by TEM suggests that crystals of a uranyl phosphate phase were present in the initial solids. These appeared to have dissolved and then re-precipitated as smaller uranyl phosphate phases during the caustic-leaching process.

- 59 to $93 \%$ of the $\mathrm{Al}$ present in the washed Group 7 solids is readily dissolved in caustic media (during a 24-hour caustic-leach). 
- 86 to $95 \%$ of the P present in the washed Group 7 solids is readily dissolved in caustic media (during a 24-hour caustic-leach).

- Iron would likely be the component constraining waste loading in the HLW glass for the Group 7 solids remaining after leaching in $3 \mathrm{M} \mathrm{NaOH}$ at $40^{\circ} \mathrm{C}$ for 24 hours.

- The PSD for the leached Group 7 solids shows that both the initial solids and the causticleached and washed solids have tri-modal particle sizes, with peak maxima located around similar particle diameters. With caustic leaching and washing, there is a shift of these populations of particles to lower particle diameters, from $\sim 75$ and $7.5 \mu \mathrm{m}$ before leaching to $\sim 8.5$ and $1.3 \mu \mathrm{m}$ after caustic-leaching.

- The reduction in particle size is likely a result of either dissolution of material from the particle surface or agglomerate breakage, but it is not entirely clear which is the case.

Table 6.4. Composition of Caustic-Leached Group 7 Solids with Leach Factors of Selected Analytes (3 $\left.\mathrm{M} \mathrm{NaOH}, 40^{\circ} \mathrm{C}, 24 \mathrm{~h}\right)$

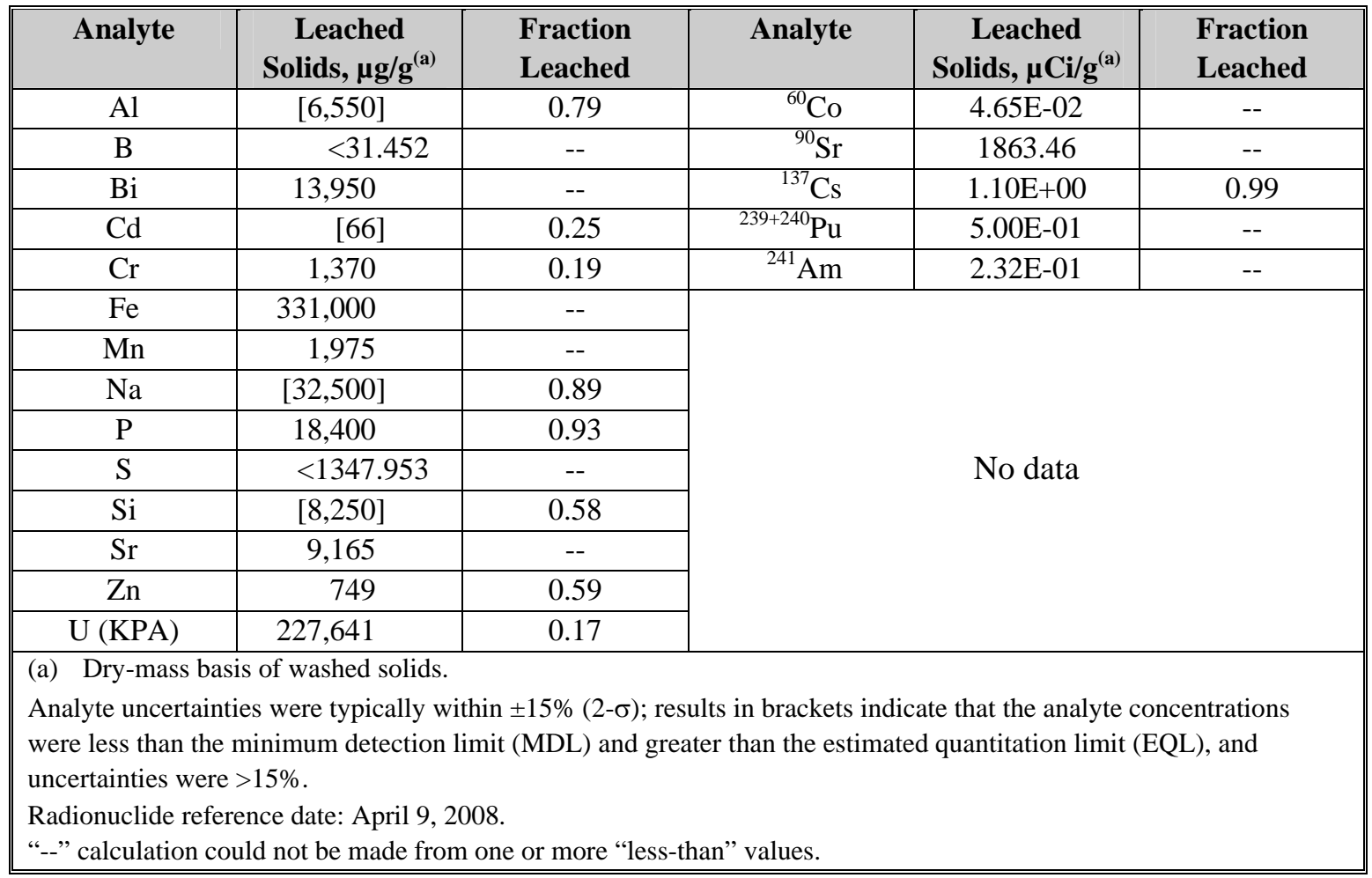

\subsection{Filtration Behavior}

The parametric filtration test evaluated Group 7 with $4.3 \mathrm{wt} \%$ UDS before caustic leaching. This slurry was blended with archived tank samples from AY-102 and dewatered to 26 wt $\%$ UDS, and another parametric filtration test was performed. Filtration tests were conducted on $20 \mathrm{wt} \%$ UDS after caustic leaching and $14 \mathrm{wt} \%$ UDS blended after washing the slurry. The filtration results are summarized in Table 6.3 along with relevant slurry parameters such as rheology and PSD. The following general observations were made: 
- Despite the slurry supernate viscosity being relatively low (1 to $2 \mathrm{cP}$ ), the filter flux for the blended cladding waste slurry was relatively low $\left(0.012\right.$ to $\left.0.018 \mathrm{GPM} / \mathrm{ft}^{2}\right)$. The supernate viscosity of the REDOX sludge was similar, but had high filter flux $\left(0.06 \mathrm{GPM} / \mathrm{ft}^{2}\right)$.

- Increases in transmembrane pressure (TMP) correlated to proportional increases in the filter flux throughout the test.

- Axial velocity appeared to have an impact on filtration at the concentrations tested when the slurry UDS concentration exceeded $20 \mathrm{wt} \%$.

- The filter flux showed some decay over time on the onset of testing. However, after 2 days of operations, this effect became less pronounced.

- Changes to the permeate viscosity from caustic leaching to washing operations significantly changed the filter flux more than changes in the UDS concentration of the slurry up to $20 \mathrm{wt} \%$. The estimated gel concentration of the slurry was $>50 \mathrm{wt} \%$ based on centrifugal UDS measurements, indicating that the slurry could be concentrated a great deal before the UDS concentration impacted filtration.

\subsection{Leaching Behavior During CUF Testing}

The Group 7 material was caustic leached during the CUF test. The leaching of the slurry was performed at $60^{\circ} \mathrm{C}$ for 8 hours at a free-hydroxide concentration of 2.4 to $2.6 \mathrm{M}$ (sodium concentration was 4.6 to $4.8 \mathrm{M}$ ) at an initial UDS concentration of $12 \mathrm{wt} \%$. The caustic leaching results of the Group 7 CUF test are summarized in Table 6.5. The following general observations were made:

- Overall kinetic dissolution of $\mathrm{Al}$ appeared very fast, completing before the temperature of the leach slurry reached $50^{\circ} \mathrm{C}$. Previous XRD scans of AY102 [Krupka 2004] found aluminum phases of gibbsite, and cancrinite present. While gibbsite was expected to be dissolved by caustic leach, cancrinite was not. .XRD results of the leached material showed the absence of gibbsite with the major crystalline phase present being:

o Hematite, $\mathrm{Fe}_{2} \mathrm{O}_{3}$

o Cancrinite, $\mathrm{Na}_{6} \mathrm{Ca}_{2} \mathrm{Al}_{6} \mathrm{Si}_{6} \mathrm{O}_{24}\left(\mathrm{CO}_{3}\right)_{2} \cdot 2 \mathrm{H}_{2} \mathrm{O}$

o Collinsite, Fairfieldite group, $\mathrm{MgCa}_{2}\left(\mathrm{PO}_{4}\right)_{2}\left(\mathrm{H}_{2} \mathrm{O}\right)_{2}$

o Hydroxyapatite, $\mathrm{Ca}_{5}\left(\mathrm{PO}_{4}\right)_{3}(\mathrm{OH})$

Therefore, all of gibbsite present in the waste slurry was dissolved during caustic leaching as expected.

- Leach factors for solid aluminum were found to be between 56 and $58 \mathrm{wt} \%$ from supernate and slurry ICP measurements. The extent of reaction here for aluminum indicates that 42-44 $\mathrm{wt} \%$ of the aluminum present in the slurry solids was present in an insoluble form, such as cancrinite.

- A significant fraction (42 wt\%) of phosphate in the Group 7 insoluble solids dissolved into the liquid phase of the slurry after the addition of the AY-102 waste sample. Previous studies of the composition of the AY-102 [Coleman 2003] found the supernate have a significantly lower phosphate concentration. It is likely that phosphate salts present in the Group 7 solids became soluble after the supernate was diluted from the AY-102 addition. The mechanism 
causing this increase in phosphate (and uranium, see below) concentration is not known at this time.

- A significant fraction of the uranium present in the solids became soluble in the blended slurry supernate as well after the AY-102 addition at the same time that a fraction of the phosphate dissolved. As seen in the parametric testing, soluble uranium in the supernate precipitated out during caustic leaching. However, dewatering of the slurry prior to caustic leach removed $39 \mathrm{wt} \%$ of the uranium present in the slurry.

- Phosphate in the supernate appeared to have precipitated during the caustic leach because of the high sodium concentration in the slurry supernate after the caustic addition. This slowed the release of phosphorus from the slurry, where a majority of it was removed during the washing steps instead of the caustic dewatering step.

- Caustic leaching did not dissolve measureable quantities of transuranic isotopes from the slurry solids.

- The concentration of chromium was low $(6.5 \mathrm{E}-1 \mathrm{mg} / \mathrm{g})$ in the initial slurry. Of that, however, a solid leach factor between 25 and 27 wt\% was found.

- After four volumetric washes, $9 \mathrm{mg}$ sodium/g slurry was present in the interstitial liquid of the slurry (Figure 6.1). Additional rinses would likely further reduce the quantities present.

Table 6.5. Caustic Leaching Summary of Group 7 Slurry

\begin{tabular}{||cccc|}
\hline & $\begin{array}{c}\text { Solid Leach } \\
\text { Factor from Total } \\
\text { Mass Balance } \\
\text { (Supernate } \\
\text { Analysis), } \\
\text { (wt\%) }\end{array}$ & $\begin{array}{c}\text { Solid Leach } \\
\text { Factor } \\
\text { Using } \\
\text { (Slurry/Supernate } \\
\text { Analysis), }\end{array}$ & $\begin{array}{c}\text { Total Removal } \\
\text { from Slurry } \\
\text { (Four Equal } \\
\text { Volume Washes) } \\
\text { (wt\%) }\end{array}$ \\
$\mathrm{Al}$ & 55 & $48-51$ & 53 \\
$\mathrm{P}$ & 69 & 63 & 58 \\
$\mathrm{Cr}$ & 18 & $14-15$ & 21 \\
\hline
\end{tabular}




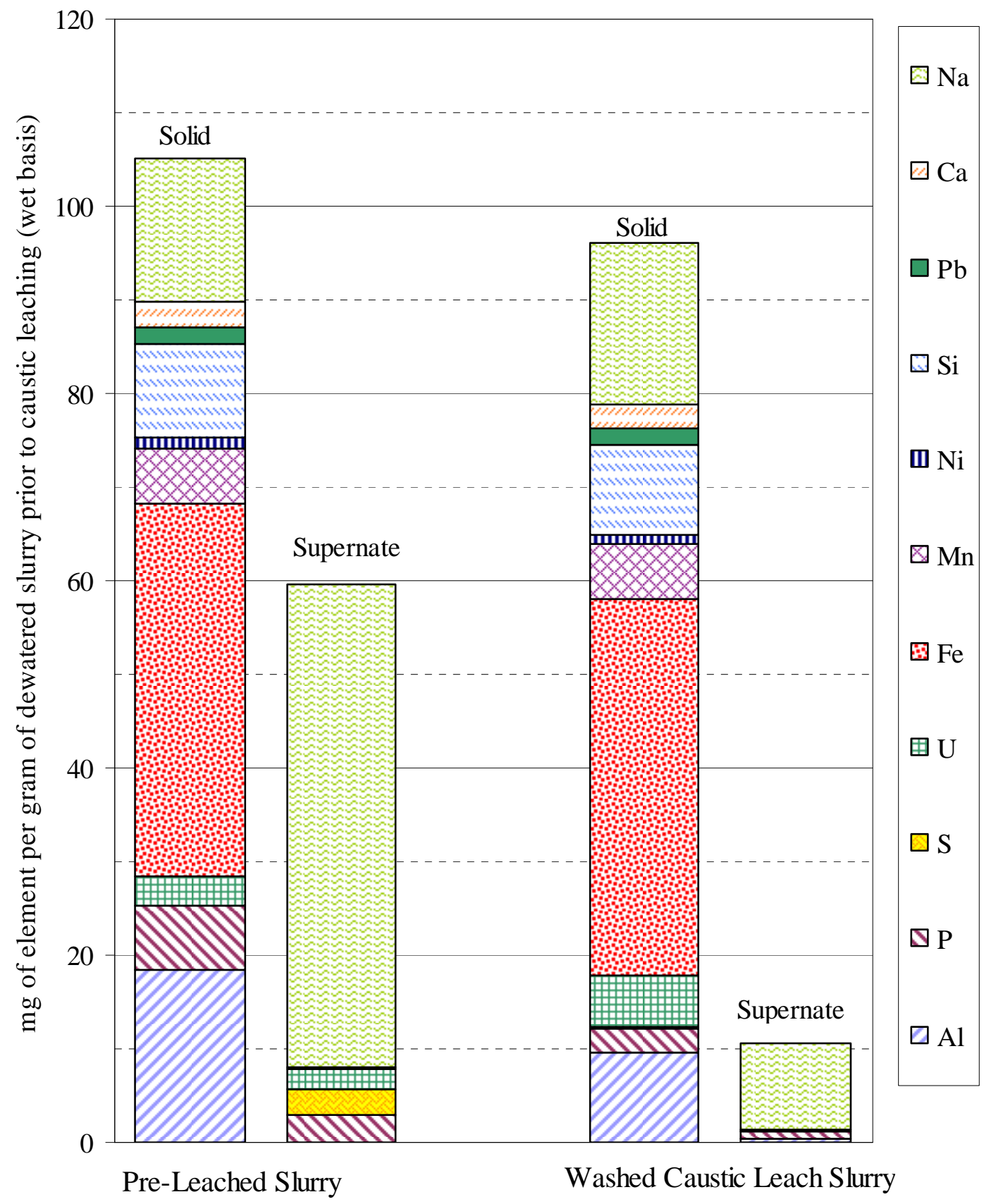

Figure 6.1. Comparison of Slurry Composition Before and After Caustic Leaching and Washing (Basis 1 gram of dewatered slurry) 
Appendix A

\section{Analytical Methods}




\section{Appendix A: Analytical Methods}

This section describes the analytical methods used to determine the chemical and radiochemical composition of the Group 7 samples.

\section{A.1 Sample Preparation for Chemical Characterization}

The samples taken for chemical characterization were centrifuged at $1000 \mathrm{G}$ for 1 hour, and then the supernatant liquids were decanted. The solids were washed with three successive additions of $0.01 \mathrm{M}$ $\mathrm{NaOH} .{ }^{(a)}$ After adding each washing solution, the sample was agitated for $15 \mathrm{~min}$ and centrifuged $30 \mathrm{~min}$ at $1000 \mathrm{G}$, and then the liquid phase was removed. The three wash solutions were combined into a composite and passed through a 0.45 -micron pore size nylon filter. The supernatant and wash-solution densities were determined by measuring the masses of 1-mL volume deliveries four times per sample.

More $0.01 \mathrm{M} \mathrm{NaOH}$ was added to the washed solids so that the slurry could be easily mixed with a Teflon ${ }^{\circledR}$-coated stirbar, and the solids were suspended. Aliquots of the suspended-solids slurries were taken for chemical and radiochemical analysis, particle-size distribution (PSD), the Brunauer, Emmett, and Teller (BET) method for determining surface area, scanning electron microscopy (SEM), transmission electron microscopy (TEM), and X-ray diffraction (XRD) analyses. The washed solids slurry sample aliquots taken for chemical analysis were dried to constant mass at $105^{\circ} \mathrm{C}$; the solids chemical analysis was based on the dry sample mass. The supernatant liquid and the filtered solids washing solution were provided directly to the Analytical Services Operation (ASO) for chemical characterization.

\section{A.2 Chemical and Radioisotope Characterization}

The following sections describe the procedures used to support the chemical and radiochemical characterization of the solids and aqueous samples. Aqueous samples were distributed directly to the free hydroxide, ion chromatrography (IC), and total inorganic carbon/total organic carbon (TIC/TOC) analytical workstations. The solids and liquids required a digestion step before distribution to the inductively coupled plasma-optical emission spectroscopy (ICP-OES) and radiochemistry workstations.

\section{A.2.1 Free Hydroxide}

The free-hydroxide concentration was determined by potentiometric titration with standardized $\mathrm{HCl}$ according to procedure RPG-CMC-228, Determination of Hydroxyl $(\mathrm{OH})$ and Alkalinity of Aqueous Solutions, Leachates, and Supernates and Operation of Brinkman 636 Auto-Titrator. The free hydroxide was defined as the first inflection point on the titration curve. Quality control (QC) samples were generated at the analytical workstation and included a sample replicate determination, process blank, blank spike (BS), and matrix spike (MS).

\section{A.2.2 Anions}

Anions were determined by IC using a Dionix ICS-2500 IC system equipped with a conductivity detector according to procedure RPG-CMC-212, Determination of Common Anions by Ion Chromatography.

(a) Specific wash volumes are provided in the context of the results discussion. 
WTP-RPT-169, Rev 0

Additional sample dilutions from $100 \times$ to $25,000 \times$ were required to accurately measure the analytes. QC samples were generated at the analytical workstation and included a sample replicate determination, process blank, BS, and MS.

\section{A.2.3 TIC/TOC}

The TIC was determined by using silver-catalyzed hot persulfate (HP) oxidation according to procedure RPG-CMC-385, Carbon Measured in Solids, Sludge, and Liquid Matrices. The HP wet-oxidation method was used. This method takes advantage of acid decomposition of the carbonate (TIC measure) followed by oxidation of organic carbon (TOC measure) using acidic potassium persulfate at 92 to $95^{\circ} \mathrm{C}$. QC samples were generated at the analytical workstation and included a sample replicate determination, process blank, BS, and MS.

\section{A.2.4 Acid Digestion}

Aqueous samples were digested with acid according to procedure PNL-ALO-128, $\mathrm{HNO}_{3}-\mathrm{HCl}$ Acid Extraction of Liquids for Metals Analysis Using a Dry-Block Heater. The acid-digested solutions were brought to a nominal $25-\mathrm{mL}$ volume (resulting in a nominal $25 \times$ dilution where the initial sample size was 1-mL); absolute volumes were determined based on final solution weights and densities. As part of the analytical preparation batch, the ASO processed a digestion preparation blank (PB), a BS, and an MS. The spike solution contained a broad suite of stable elements; radionuclides were not included in the digestion preparation. Aliquots of the BS, MS, and PB, along with the sample aliquots, were delivered to the ICP-OES workstation for analysis; sample and PB aliquots were delivered to the radiochemical workstations for separations supporting specific radioisotope analysis.

\section{A.2.5 KOH Fusion}

The potassium hydroxide (KOH) fusion was conducted in the shielded analytical facility (hot cells) according to PNL-ALO-115, Solubilization of Metals from Solids using $\mathrm{KOH}-\mathrm{KNO}_{3}$ Fusion. A nominal sample size of 0.1 to $0.2 \mathrm{~g}$ dry solids was combined with a $\mathrm{KOH} / \mathrm{KNO}_{3}$ flux mixture and fused at $550^{\circ} \mathrm{C}$ for 1 hour in a nickel crucible. The fused material was acidified with $\mathrm{HNO}_{3}$, taken to a 100 -mL volume with DI water, and then split for metals and radionuclide analysis. Samples were typically prepared in duplicate along with a fusion blank and a laboratory control sample (LCS) (SRM-2710, Montana Soil, purchased from the National Institute for Science and Technology [NIST]).

\section{A.2.6 $\mathrm{NaOH} / \mathrm{Na}_{2} \mathrm{O}_{2}$ Fusion}

The $\mathrm{NaOH} / \mathrm{Na}_{2} \mathrm{O}_{2}$ fusion was conducted in the shielded analytical facility (hot cells) according to PNL-ALO-114, Solubilization of Metals from Solids using a $\mathrm{Na}_{2} \mathrm{O}_{2}-\mathrm{NaOH}$ Fusion. A nominal sample size of 0.1 to $0.2 \mathrm{~g}$ dry solids was combined with a $\mathrm{NaOH} / \mathrm{Na}_{2} \mathrm{O}_{2}$ flux mixture and fused at $550^{\circ} \mathrm{C}$ for 1 hour in a zirconium crucible. The fused material was acidified with $\mathrm{HNO}_{3}$, taken to a 100 -mL volume with DI water, and then split for metals analysis. The sample was prepared in duplicate along with a fusion blank and an LCS (SRM-2710, Montana Soil).

\section{A.2.7 HF-Assisted Acid Digestion}

The HF-assisted acid digestion was conducted in the Sample Receiving and Preparation Laboratory according to PNL-ALO-138, $\mathrm{HNO}_{3}-\mathrm{HF}-\mathrm{HCl}$ Acid Digestion of Solids for Metals Analyses Using a Dry Block Heater. A nominal sample size of 0.1 to $0.2 \mathrm{~g}$ dry solids was contacted with a mixture of 
concentrated $\mathrm{HF}$ and $\mathrm{HNO}_{3}$ and evaporated to dryness in a Teflon ${ }^{\circledR}$ reaction tube. Concentrated $\mathrm{HCl}$ was then added, and the sample was evaporated to dryness a second time. Additional concentrated $\mathrm{HNO}_{3}$ and $\mathrm{HCl}$ were added, the reaction tube was capped tightly, and the mixture was heated in a dry-block heater at $95^{\circ} \mathrm{C}$ for $6.5 \mathrm{~h}$. The digestate was cooled, brought to a $50-\mathrm{mL}$ volume, and then split for metals analysis. The sample was prepared in duplicate along with a fusion blank and an LCS (SRM-2710, Montana Soil).

\section{A.2.8 Metals Analysis by ICP-OES}

Metals were measured by ICP-OES according to procedure RPG-CMC-211, Determination of Elemental Composition by Inductively Coupled Argon Plasma Optical Emission Spectrometry (ICPOES). The preparative QC samples (duplicate, PB, BS, MS) were processed along with analytical workstation QC (post digestion spike and serial dilution).

\section{A.2.9 U (KPA)}

Uranium was determined directly from samples prepared by $\mathrm{KOH}$ fusion with a Chem Chek Instruments KPA according to procedure RPG-CMC-4014, Rev. 1, Uranium by Kinetic Phosphorescence Analysis. The LCS did not contain U, so preparative QC was limited to the duplicate and PB. A post-digestion spike was conducted at the analytical workstation.

\section{A.2.10 Gamma Energy Analysis}

Gamma energy analysis was performed with direct or diluted samples that were prepared from acid digestion, fusion, or neat (see Figure 4.1). Sample counting was conducted according to procedure RPG-CMC-450, Gamma Energy Analysis (GEA) and Low-Energy Photon Spectroscopy (LEPS), using high-purity germanium detectors. Extended count times (up to 20 hours) were employed as needed to achieve low detection limits. In many cases, the Compton background from the high ${ }^{137} \mathrm{Cs}$ activity $(661 \mathrm{keV})$ limited the achievable detection limit of lower energy gamma emitters (e.g., ${ }^{241} \mathrm{Am}$ at $\left.59 \mathrm{keV}\right)$. The QC associated with the GEA analysis was composed of the sample duplicate and PB; because this is a direct analysis, no additional QC samples were required.

\section{A.2.11 Gross Alpha and Gross Beta}

Aqueous samples were prepared for gross alpha and beta determinations by acid-digestion, and the washed-solids samples were prepared by $\mathrm{KOH} / \mathrm{KNO}_{3}$ fusion. Prepared sample aliquots were plated directly onto stainless steel planchets according to procedure RPG-CMC-4001, Source Preparation for Gross Alpha and Gross Beta Analysis. The mounts prepared for gross alpha analysis were counted with Ludlum alpha scintillation counters. The gross alpha analysis tends to be confounded by the dissolved solids in the sample matrix. The solids can absorb the alpha particles, decreasing the intensity relative to the detector, which biases the results low. The sources prepared for gross beta analysis were counted with an LB4100 gas-proportional counter. In both cases, counting operations were conducted according to procedure RPG-CMC-408, Rev.1, Total Alpha and Total Beta Analysis. The preparative QC included the sample duplicates and the preparation blank. The BS and MS were prepared at the analytical workstation on sample dilutions.

\section{A.2.12 Pu Isotopes: ${ }^{238} \mathrm{Pu}$ and ${ }^{239+240} \mathrm{Pu}$}

The ${ }^{238} \mathrm{Pu}$ and ${ }^{239+240} \mathrm{Pu}$ activities were measured from aqueous samples prepared by acid-digestion, and washed-solids samples prepared by $\mathrm{KOH} / \mathrm{KNO}_{3}$ fusion. Radiochemical separations were conducted 
according to procedure RPG-CMC-4017, Analysis of Environmental Water Samples for Actinides and Strontium-90 (analyte purification using ion exchange); source preparation was conducted according to RPG-CMC-496, Coprecipitation Mounting of Actinides for Alpha Spectroscopy (co-precipitation of PuF 3 with $\mathrm{LaF}_{3}$ ); and alpha counting was conducted according to RPG-CMC-422, Rev.1, Solutions Analysis: Alpha Spectrometry. The preparative QC included the sample duplicates and the preparation blank. The BS and MS were prepared at the analytical workstation on sample dilutions.

\section{A.2.13 Strontium-90}

The ${ }^{90} \mathrm{Sr}$ activities were measured from aqueous samples prepared by acid-digestion, and washed-solids samples were prepared by $\mathrm{KOH} / \mathrm{KNO}_{3}$ fusion. Radiochemical separation was conducted according to procedure RPG-CMC-476, Strontium-90 Separation Using Eichrom Strontium Resin; source preparation and beta counting were conducted according RPG-CMC-474, Measurement of Alpha and Beta Activity by Liquid Scintillation Spectrometry. 
Appendix B

\section{Physical Properties Determination and BET Methods}




\section{Appendix B: Physical Properties Determination and BET Methods}

This appendix describes the experimental methods used to determine physical properties and surface area measurements.

\section{B.1 Physical Properties}

The physical-property characterization was conducted according to procedure RPL-COLLOID-02, Rev. 1, Measurement of Physical and Rheological Properties of Solutions, Slurries and Sludges, which is consistent with the Waste Treatment and Immobilization Plant (WTP) guidelines document. ${ }^{\text {(a) }}$ Samples for physical-properties characterization were taken in triplicate near the beginning (S1), middle (S2), and end (S3) of the aliquoting activity following slurry homogenization. Samples sizes were generally between 10 and $15 \mathrm{~mL}$. The samples were collected in volume-graduated, glass centrifuge tubes.

Settling studies were conducted by thoroughly agitating the samples and then allowing the solids to settle by gravity with periodic measurement of the settled-solids volume. The sample tubes were undisturbed over the 3-day settling period. Following the settling measurements, the samples were centrifuged at $\sim 1000 \mathrm{G}$ for 1 hour. The total sample volume and solids volume were recorded to assess the vol\% wet centrifuged solids (WCSs). The centrifuged supernatants were decanted and transferred to tared graduated cylinders; the net solution masses and volumes were determined. The remaining WCSs were weighed in the centrifuge tubes to assess gross densities. The supernatant samples were transferred to tared glass vials. Both the supernatant fractions and the residual solids fractions (containing interstitial supernatant) were air-dried and then transferred to a $105^{\circ} \mathrm{C}$ oven for continued drying until constant mass was attained. The data collected were processed as described by Smith and Prindiville ${ }^{(a)}$ to determine the volume and weight percent of wet solids (total, settled, and centrifuged), densities, total undissolved solids, and dissolved solids content.

\section{B.2 Surface Area (BET)}

Samples were prepared for surface-area measurements in an effort to minimize solidification into a monolith upon drying. To this end, the solids were rinsed twice with ethanol and twice again with diethyl ether according to procedure TPR-RPP-WTP-486, Procedure for BET Sample Preparation Using Ethanol and Ethyl Ether as Drying Agents. Each rinse was conducted in a centrifuge tube. The solids were well suspended in the rinse solution, and then the phases were separated by centrifuging and decanting. The final ethyl ether rinse was used to transfer the solids slurry to the sample cell. The diethyl ether was then evaporated at room temperature directly from the sample cell.

The sample was further dried and out-gassed using the Quantachrome Instruments Monosorb Model MS-21 (Boynton Beach, FL) outgassing station. This entailed pre-flushing nitrogen through the sample cell for $\sim 10 \mathrm{~min}$ and then heating and flushing for overnight $(>10 \mathrm{~h})$ at $110^{\circ} \mathrm{C}$.

(a) 24590-WTP-GPG-RTD-001, Rev 0, "Guidelines for Performing Chemical, Physical, and Rheological Properties Measurements,” GL Smith and K Prindiville, May 2002. 
The surface-area measurements were conducted according to OCRWM-BET-01, Surface Area Measurement with a Monosorb Gas Analyzer, which is consistent with American Society for Testing and Materials (ASTM) method D5604-96, “Test Method B” (Single-Point Surface Area by Flowing Gas Apparatus). The flow gas used in the measurement mode was composed of $30 \%$ nitrogen in helium. The system was calibrated per manufacturer instructions. The system performance was assessed using a 29.9 $\pm 0.75 \mathrm{~m}^{2} / \mathrm{g}$ carbon surface area standard Lot D-6 obtained from Micromeritics (Norcross, GA). 


\section{Appendix C}

\section{Crystal Form and Habit}




\section{Appendix C: Crystal Form and Habit}

This section describes the methods used to determine the crystal forms and habits of the tank-solids samples. The solids crystal characteristics were determined on small aliquots of the solids. In all cases, the solids sample fractions were allowed to air dry at room temperature in preparation for analysis. This effort was intended to minimize morphological changes that might occur upon heating. The methods applied for X-ray diffraction (XRD), scanning electron microscopy (SEM), and transmission electron microscopy (TEM) evaluations are discussed in the following sections.

\section{C.1 X-Ray Diffraction}

The sample mounts for XRD examination were prepared from the dried solids according to procedure RPL-PIP-4, Preparing Sealed Radioactive Samples for XRD and Other Purposes. Specimens were pulverized to a powder with a boron carbide mortar and pestle, mixed with an internal standard (rutile, $\mathrm{TiO}_{2}$, or alumina, $\mathrm{Al}_{2} \mathrm{O}_{3}$ ), and mounted on a glass slide. In some cases, the internal standard was omitted to provide better clarity of the sample diffraction pattern free from potential interference from the internal standard diffraction pattern. The XRD examination was conducted according to procedure PNNL-RPG268, Solids Analysis, X-Ray Diffraction Using RGD \#34. Process parameters included examining the $\mathrm{X}$-ray 2-theta range from 5 to 65 degrees with a step size of 0.02 degrees and a dwell time of 20 seconds.

Phase identification was performed with JADE, Version 8.0 (Materials Data Inc., Livermore, CA) software search and peak match routines with comparison to the International Centre for Diffraction Data (ICDD) database PDF-2, Version 2.0602 (2006). The ICDD database included the Inorganic Crystal Structure Database (ICSD) maintained by Fachinformationszentrum, Karlsruhe, Germany. Phase identification incorporated chemistry restrictions based on the elements determined from chemical analysis.

\section{C.2 Scanning Electron Microscopy}

A small sample was transferred with a wooden Q-tip stem onto carbon tape supported by an aluminum pedestal mount. The sample was analyzed using the radiation-shielded Amray Model 1610T SEM according to RPL-611A-SEM, Scanning Electron Microscope Examinations. In selected cases, the mount was carbon-coated. Selected sample areas were evaluated by energy dispersive X-ray spectroscopy (EDS) for qualitative elemental composition.

\section{C.3 Transmission Electron Microscopy}

The TEM samples were prepared in a two-step methanol rinsing process. A small amount of the sludge slurry was mixed and transferred into methanol; a drop of the methanol slurry was transferred into a second vial containing methanol; then a drop of this second solution was deposited onto a lacey carbon TEM grid. The particles were air-dried on the lacey grid. Note that the sample drying process may induce changes in the morphology of the particle agglomerates. However, the objective of the TEM investigation was to look at the fundamental characteristics and sizes of individual particle crystallites that are not dependent on drying effects. 
The TEM examinations were performed on an FEI Tecnai G2-30 (FEI Inc., Hillsboro, OR) with a field emission filament operating at $300 \mathrm{keV}$ equipped with a Scanning Transmission Unit and High Angle Annular Dark-Field Detector (HAADF), EDS detector, and a Gatan Imaging Filter (GIF), model GIF2000 (Gatan Inc., Pleasanton, CA). Particle or area analysis was performed by identifying the composition with EDS and electron energy-loss spectroscopy (EELS). Images were obtained with either the scanning transmission electron microscopy (STEM) system or normal bright-field imaging. Energy-filtered images were also obtained with the image filter to produce element-specific area maps.

\section{C.4 Electron Energy-Loss Spectroscopy}

The EELS spectra were obtained with a 0.6-mm entrance aperture and an energy dispersion of $0.1 \mathrm{eV} / \mathrm{channel}$. Low-loss spectra (including the zero loss peak) were acquired with an integration time of $<0.2 \mathrm{~s}$ and core-loss spectra between 2 and $5 \mathrm{~s}$. To reduce potential beam reduction, the acquisition time was kept as small as possible. The spectra were collected in the imaging mode of the transmission electron microscope and were corrected for dark current and channel-to-channel gain variation of the charge coupled device (CCD) detector.

The core-loss regime was energy calibrated, and the energy drift was measured while data were being acquired by collecting zero-loss spectra before or after core-loss spectra were collected. The position of the C-K (1 s) peak at $284 \mathrm{eV}$ (arising from transitions to the $\pi^{*}$ molecular orbital) from the TEM lacy carbon support film was used to evaluate the energy calibration and roughly check that the energy resolution was sufficient for collecting data.

Two methods were adopted for determining the chemical state of chromium in the sludge samples. In the first method, we obtained the following ratio defined as:

$$
\mathrm{I}-\text { ratio }=\frac{\mathrm{I}\left(\mathrm{L}_{3}\right)}{\mathrm{I}\left(\mathrm{L}_{2}\right)}
$$

$\mathrm{L}_{2}$ and $\mathrm{L}_{3}$ are the intensities of background-corrected Cr-absorption edges. The second method was to look at the O:Cr ratio as an indication of oxygen content. Oxygen detection with EELS is more accurate that with X-rays because the loss in energy of the primary beam is measured instead of an emitted X-ray, as in the case of EDS analyses, which can be subjected to significant attenuation. 
Appendix D

\section{Quality Assurance and Quality Control}


WTP-RPT-169, Rev 0

\section{Appendix D: Quality Assurance and Quality Control}

This appendix describes the quality assurance (QA) program and quality control (QC) measures applied to the conduct of work.

\section{D.1 Application of Waste Treatment Plant Support Program Quality Assurance Requirements}

Pacific Northwest National Laboratory's (PNNL's) QA program is based on requirements defined in DOE Order 414.1C, “Quality Assurance,' and 10 CFR 830, “Energy/Nuclear Safety Management,” Subpart A-Quality Assurance Requirements (a.k.a., the Quality Rule). PNNL has chosen to implement the requirements of DOE Order 414.1C and 10 CFR 830, Subpart A by integrating them into the laboratory's management systems and daily operating processes. The procedures necessary to implement the requirements are documented through PNNL’s Standards-Based Management System.

PNNL implemented the River Protection Project-Waste Treatment Plant (RPP-WTP) quality requirements by performing work in accordance with the River Protection Project - Waste Treatment Plant Support Program (RPP-WTP) Quality Assurance Plan (RPP-WTP-QA-001, QAP). Work was performed to the quality requirements of NQA-1-1989 Part I, "Basic and Supplementary Requirements," NQA-2a-1990, Part 2.7, and DOE/RW-0333P, Rev 13, Quality Assurance Requirements and Descriptions (QARD). These quality requirements are implemented through the River Protection Project - Waste Treatment Plant Support Program (RPP-WTP) Quality Assurance Manual (RPP-WTP-QA-003, QAM).

A matrix that cross-references the NQA-1, NQA-2a, and QARD requirements with PNNL's procedures for this work was given in the test plan, TP-RPP-WTP-467. ${ }^{(a)}$ It included justification for those requirements not implemented. The QA requirements of DOE/RW-0333P, Rev 13, QARD and DOE Order 414.1C were not identified as a requirement for this work in the test specification.

\section{D.2 Conduct of Experimental and Analytical Work}

Experiments that were not method-specific were performed in accordance with PNNL's procedures QA-RPP-WTP-1101 “Scientific Investigations” and QA-RPP-WTP-1201 "Calibration and Control of Measuring and Testing Equipment,” verifying that sufficient data were taken with properly calibrated measuring and test equipment to obtain quality results.

As specified in the supporting Test Specification, 24590-PTF-TSP-RT-06-0001, Rev. 0, BNI's Quality Assurance Project Plan (QAPjP), PL-24590-QA00001, was not applicable because the work was not performed in support of environmental/regulatory testing, and the data will not be used as such.

Balances are calibrated annually by a certified contractor, QC Services, Portland, Oregon. A balance performance check was conducted each day the balance was used.

(a) SK Fiskum, TP-RPP-WTP-467, Rev. 0, 2/2/07 and Rev. 1 7/31/07, Characterization and Small Scale Testing of Hanford Wastes to Support the Development and Demonstration of Leaching and Ultrafiltration Pretreatment Processes, Pacific Northwest National Laboratory, Richland, WA. 
ASO conducted analytical testing according to the Statement of Work RPP-WTP-QA-005, Rev. 2, Analytical Support by the PNNL RPL Analytical Support Operation. The analytical results and raw data are traceable through the project files according to the Analytical Services Request number and Radiochemical Processing Laboratory number.

\section{D.3 Internal Data Verification and Validation}

PNNL addressed internal verification and validation activities by conducting an independent technical review of the final data report in accordance with PNNL's procedure QA-RPP-WTP-604. This review verified that the reported results were traceable, that inferences and conclusions were soundly based, and the reported work satisfied the Test Plan objectives. This review procedure is part of PNNL's RPP-WTP QAM. 


\section{Appendix E}

Group 7 Particle-Size Methods and Analysis (TDP-WTP-273) 


\title{
Appendix E: Group 7 Particle-Size Methods and Analysis (TDP-WTP-273)
}

\section{Battelle}

The Business of Innovation

Date $\quad$ November 10, 2008

To $\quad$ Sandy Fiskum

Rick Shimskey

Lanée Snow

From Amanda Casella

Subject $\quad$ Particle Size Distribution for Group 7 [Tributyl Phosphate (TBP) Sludge] Initial Characteristic, Parametric Testing and CUF Testing Samples
TDP-WTP-273

Internal Distribution

Sandy Fiskum

Rick Shimskey

Lanée Snow

Amanda Casella

File/LB

\section{Acronyms and Abbreviations}

\author{
AV Axial Velocity \\ CA Contamination Area \\ CUF Cells Unit Filter \\ DI Deionized (water) \\ CCP Computational Computer Program (application) \\ LRB Laboratory Record Book \\ NIST National Institute of Standards and Technology \\ PSD Particle Size Distribution \\ RI Refractive Index \\ RMA Radioactive Material Area \\ RPL Radiochemical Processing Laboratory \\ RPP River Protection Project \\ SAL Shielded Analytical Laboratory \\ TBP Tributyl Phosphate \\ TMP Transmembrane Pressure \\ UDS Undissolved Solids \\ WTP Waste Treatment Plant (Support Program)
}


WTP-RPT-169, Rev 0

\section{Introduction}

In fulfillment of the requirements of Test Plan TP-RPP-WTP-467 [1], the particle size distribution (PSD) of select Hanford tank waste water insoluble solids was characterized at the Radiochemical Processing Laboratory (RPL). This interim characterization report presents PSD results for Group 7 [Tributyl Phosphate (TBP) Sludge] wastes derived during initial characterization and parametric testing and processed in the Cells Unit Filter (CUF) located at the RPL's Shielded Analytical Laboratory (SAL).

\section{Background}

Particle size distribution (PSD) describes the size fractionation of solid species in a given powder, dispersion, or slurry sample. PSD is typically described by either cumulative or differential population fraction versus a given particle size indicator. For example, the size distribution of particles in a slurry are often described using a histogram expressing the differential volume of particles falling between two equivalent sphere diameters over a large array of equivalent sphere diameters. PSD measurements can be accomplished using a number of approaches, such as settling experiments, microscopic imaging, and light obscuration and scattering.

The particle size measurements discussed herein are carried out on a Malvern Mastersizer 2000 particle size analyzer (Malvern Instruments, Inc., Southborough, MA). This instrument operates using the principle of laser diffraction (see Figure 1). Here, a monochromatic laser (red and/or blue) is directed through a transparent cell containing a dilute dispersion of the solid particles being analyzed. On the opposite side of the flow cell is a series of ring detectors capable of detecting the intensity of laser light at various scattering angles. If the laser does not strike a particle in the flow cell, it simply passes through the cell undisturbed and strikes the central detector. When the laser interacts with a particle, it is scattered at various angles. The scattered light is picked up across a number of rings of the detector, creating a unique "scattering pattern" that can be mapped as a function of scattered light intensity versus ring detector position. Prolonged observation of the light scattered from the dispersion allows complete sampling of the particle species contained therein. Comparison of the time-averaged scattering signal against a reference "clean” cell signal generates a scattering pattern unique to that dispersion. Given the optical properties of the particulate and dispersing phases, mathematical analysis of the averaged "scattering pattern" allows determination of size fractionation species contained in the dispersion. 
WTP-RPT-169, Rev 0

flow cell filled with dilute

particle dispersion

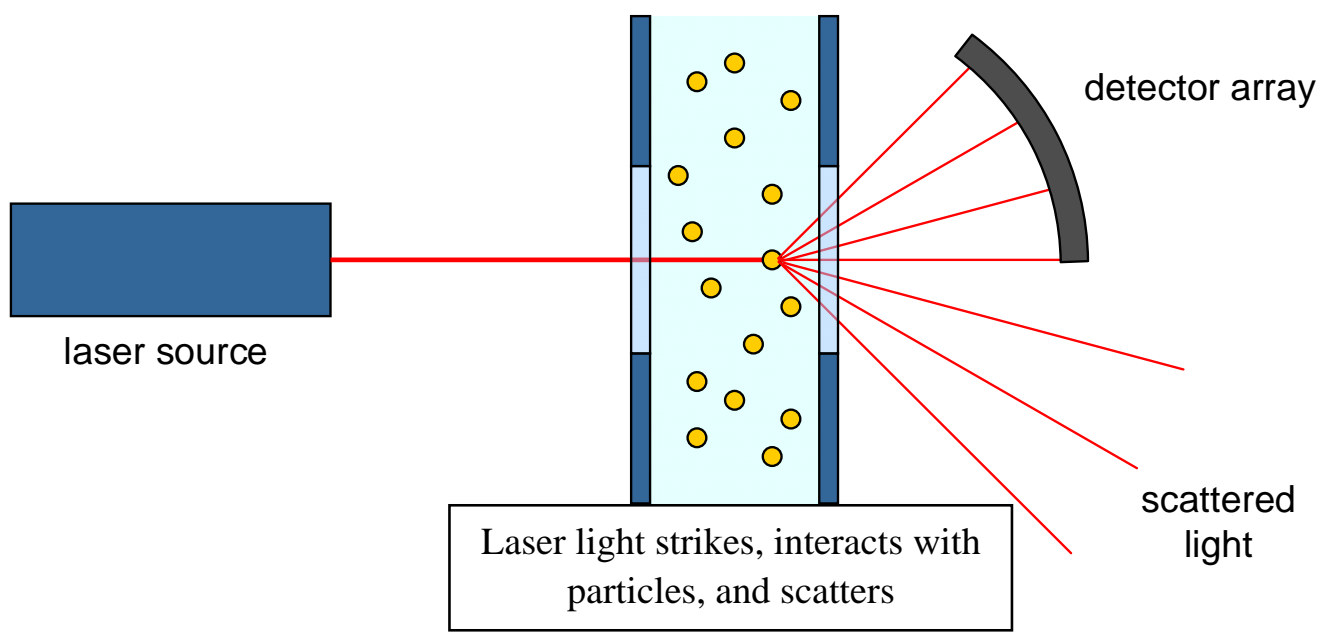

Figure 1. Schematic of a typical laser diffraction particle size analyzer.

It is important to recognize that particle size measurements by laser diffraction are intended to capture the size of a single, well-dispersed particle species. This "true” PSD captures all particles in the solid dispersion in an un-agglomerated primary particle state. Full dispersion at the primary particle level requires the correct selection of suspending phase chemistry, which is often further modified through the use of dispersing agents or surfactants, and sufficient flow to suspend all particles during analysis.

When dealing with complex dispersions such as Hanford tank waste, which contain multiple particle species and a broad distribution of sizes, finding the correct dispersing medium and measurement conditions is difficult (if not impossible), as individual particle species in the solids mixture may have contradictory suspending phase chemistry requirements. As such, particle size analysis of complex solids dispersions is generally performed to determine the "apparent” PSD as a function of processing conditions such as flow rate and sonication and suspending phase chemistry such as $\mathrm{pH}$. The apparent PSD differs from the true PSD in two ways: 1) particle agglomerates exist and are treated as single particle species and 2) not all particles may be suspended at the flow conditions selected. Despite these short comings, apparent PSDs provide useful information about how the PSD of the test dispersion exists in the process from which it is derived and can highlight potential difficulties in suspending large/dense particles.

\section{Samples}

Group 7 particle size measurement samples were derived as part of bench-scale homogenization and leaching studies using actual tank waste. Source material for the studies included initial characterization, parametric testing, and CUF testing of Group 7 [TBP Sludge] solids. Four samples were submitted for analysis, including a primary and duplicate of the initial characterization (TI576-G7-S-WL-PSD-1 and TI576-G7-S-WL-PSD-2), a caustic-leached (i.e. parametric testing) sample (TI623-G7-CL-PSD) and a low-solids matrix sample (TI624-G7-3-PSD) before the caustic-leach in the CUF. 
Group 7 CUF particle size measurement samples were derived as part of bench-scale crossflow ultrafiltration and leaching studies using actual tank waste. The Group 7 sludge samples were added to the slurry reservoir tank with simulant supernate. The combination was initially mixed in the tank then allowed to circulate through the CUF at a high flow rate for approximately an hour. Sample TI623-G7-3PSD was taken after the initial slurry had been circulated in the CUF, although before any dewatering or leaching took place. Various transmembrane pressures (TMP) and axial velocities (AV) were examined. This slurry was then dewatered and sample AY-102 added to obtain a high-solids slurry. This mixture resulted in a break-down of the pump due to an unnoticed stir bar remaining in the slurry. The mixture in the CUF was drained from the system while the pump was repaired. After the system became operational and the slurry mixture added back to the CUF the slurry was subjected to the following operations:

1. dewatering of the waste slurry to transform the low-concentration Group 7 slurry to a highconcentration Group 7 slurry

2. full-recycle ultrafiltration of the high-concentration waste slurry at various AV and TMP

3. caustic-leaching of the waste slurry with $\sim 5 \mathrm{M}$ sodium hydroxide for 8 hours at $60^{\circ} \mathrm{C}$ (not including time for slurry heat-up and cool-down)

4. dewatering of the caustic-leached slurry

5. full-recycle ultrafiltration of the high-concentration caustic-leached slurry at various AV and TMP

6. washing of the caustic-leached slurry with relatively dilute sodium hydroxide solutions (includes four successive washes with increasingly dilute $\mathrm{NaOH}$ solutions)

For CUF particle size testing, samples were derived from various points in the ultrafiltration process outlined above. With regard to slurry samples, waste aliquots for particle size were sampled after:

- after loading and circulating the sample in the CUF (before pump break-down),

- after caustic-leaching and dewatering (i.e. after step 4)

- dewatering the initial slurry (i.e. after step 1),

- after washing the caustic-leached slurry (i.e., after step 6),

For sampling, approximately $0.5 \mathrm{~mL}$ of source slurry was taken. These slurry samples were subsequently diluted to $\sim 5 \mathrm{~mL}$ total volume with a solution of $0.01 \mathrm{M} \mathrm{NaOH}$ in water. It should be noted that this dilution step may alter both the apparent and primary particle size distributions of solids in the sample submitted for size analysis (by either particle dissolution or change in the state of particle agglomeration). As such, the PSDs measured during analysis may not correspond directly to the size distribution that exists in the CUF at a given processing step. Due to dose concerns the only CUF sample able to be analyzed for PSD was TI624-G7-3-PSD. Table 1 provides a summary of the samples analyzed and their given sample identification number.

Table 1. Samples associated with Group 7 particle size testing.

\begin{tabular}{||c|l||}
\hline \hline Sample Jar ID & Description \\
\hline TI576-G7-S-WL-PSD-1 & Primary Group 7 Initial Characterization Sample \\
\hline TI576-G7-S-WL-PSD-2 & Duplicate Group 7 Initial Characterization Sample \\
\hline TI623-G7-CL-PSD & Group 7 Parametric Testing Sample \\
\hline TI624-G7-3-PSD & Slurry - Low-solids matrix Group 7 slurry before caustic leaching \\
\hline
\end{tabular}




\section{Analysis}

Particle size distributions for Group 7 samples were measured on the dates shown in Table 2. The analyses produced the following reportable data:

- particle diameters corresponding to the $10 \%, 50 \%$, and $90 \%$ cumulative weight/volume undersize percentiles

- volume differential distributions (mass population percentage versus diameter)

Alternate analyses of the data, such as number/surface area distributions, are available on request.

Table 2. Sample analysis dates for Groups 7

\begin{tabular}{|c|c|}
\hline Sample & Date \\
\hline TI576-G7-S-WL-PSD-1 & October 7, 2008 \\
\hline TI576-G7-S-WL-PSD-2 & October 7, 2008 \\
\hline TI623-G7-CL-PSD & October 7, 2008 \\
\hline TI624-G7-3-PSD & October 16, 2008 \\
\hline
\end{tabular}

\section{Instrument}

Particle size characterization was accomplished using a Mastersizer 2000 (Malvern Instruments, Inc., Southborough, MA 01772 USA) with a Hydro $\mu$ P wet dispersion accessory. The Mastersizer has a nominal size measurement range of $0.02-2000 \mu \mathrm{m}$. The actual range is dependent on the accessory used as well as the properties of the solids being analyzed. When coupled with the Hydro $\mu \mathrm{P}$ wet dispersion accessory, the nominal measuring range is reduced to 0.02-150 $\mu \mathrm{m}$. Although particle sizes above 150 $\mu \mathrm{m}$ can be observed with the Hydro $\mu \mathrm{P}$, their volume/number contribution cannot be determined reliably.

The Hydro $\mu \mathrm{P}$ wet dispersion accessory consists of a $20 \mathrm{~mL}$ sample flow cell with a continuously variable and independent pump and ultrasound. Both flow and sonication can be controlled and changed during measurement. As such, PSD measurements can be made before, during, and after sonication, allowing determination of the influence of each on the sample's PSD. The primary measurement functions of the Malvern analyzer are controlled through computer software. For the current measurements, Mastersizer 2000 software, Version 5.40 [Malvern Instruments, Ltd. Copyright (C) 19982007] was employed.

Table 3 provides a summary of basic information regarding the analyzer and accessory. The Malvern Mastersizer 2000 is located in the northwest contamination area (CA) fume hood in RPL Room 302. It should be noted that the dispersion unit's sonication capability was not functioning at the time the standard or sample measurements were taken. As such, only "before sonication" data are available. 
WTP-RPT-169, Rev 0

Table 3. Summary of Malvern Mastersizer 2000 instrument information.

\begin{tabular}{||l|l||}
\hline Analyzer: & Mastersizer 2000 \\
\hline Measurement principle: & Laser Diffraction (Mie Scattering) \\
\hline Analyzer Accessory: & Hydro $\mu \mathrm{P}$ \\
\hline Serial Number: & MAL100406 \\
\hline Measurement Range: & $0.02-2000 \mu \mathrm{m}$ nominal $(0.02-150 \mu \mathrm{m}$ with accessory) \\
\hline Type: & $\begin{array}{l}\text { Flow cell system with continuously variable and } \\
\text { independent pump and ultrasound. }\end{array}$ \\
\hline Capacity: & $20 \mathrm{~mL}$ \\
\hline Pump Speed Range: & $0-5000$ RPM (variable) \\
\hline Ultrasound Power & $0-20 \mathrm{~W}$ (variable) \\
\hline Software Version & 5.40 \\
\hline
\end{tabular}

\section{Governing Test Plan, Procedure, and Test Instructions}

The test plan governing the physical characterizations for these samples is River Protection Project - Waste Treatment Plant Support Program (RPP-WTP) document number TP-RPP-WTP-467, Revision 0 [1]. Operation of the Malvern Mastersizer 2000 is governed by RPL-COLLOID-01, Revision $1[2]$.

\section{Instrument Performance Check}

As required by RPL-COLLOID-01, the performance of the Malvern analyzer must be verified at the beginning of each series of analyses (with the period between performance checks not to exceed 90 days during use). Checks are performed using particle size standards traceable to the National Institute of Standards and Technology (NIST). Checks verify that the particle size analyzer can measure a PSD standard's $d(50)$, the $50 \%$ volume/weight fractile and mean particle size, to within $10 \%$ of the value specified on the manufacturer's certificate of analysis.

For the measurements described in this report, the performance check employed a NIST traceable polydisperse particle size standard purchased from Whitehouse Scientific (Waverton, Chester, CH3 7PB, UK). Table 4 provides a summary of the standard properties. The standard is traceable back to its certificate of analysis through a unique bottle number identifier.

Table 4. Properties of the NIST standard used to verify performance of the Malvern Mastersizer 2000 and performance check results.

\begin{tabular}{|c|c|c|c|}
\hline Size Range: & \multicolumn{3}{|l|}{$1-10 \mu \mathrm{m}$} \\
\hline Catalogue \#: & \multicolumn{3}{|l|}{ PS-192 } \\
\hline Bottle \# & \multicolumn{3}{|l|}{2103} \\
\hline Weight: & \multicolumn{3}{|l|}{$0.10 \mathrm{~g}$} \\
\hline PSD Percentiles & List & Measured $(\mu \mathrm{m}) *$ & Absolute Error** \\
\hline $\mathrm{d}(10):$ & $2.88 \pm 0.24 \mu \mathrm{m}$ & 2.60 & $\mathrm{n} / \mathrm{a}$ \\
\hline $\mathrm{d}(50):$ & $4.18 \pm 0.34 \mu \mathrm{m}$ & 4.16 & $0.43 \%$ \\
\hline d(90): & $6.23 \pm 0.56 \mu \mathrm{m}$ & 6.74 & $\mathrm{n} / \mathrm{a}$ \\
\hline
\end{tabular}

*As measured for the period of performance applicable for this report.

**Calculated before rounding of significant figures in List and Measured 
The instrument performance check covering size analysis of samples TI576-G7-S-WL-PSD-1, TI576-G7-S-WL-PSD-2, TI623-G7-CL-PSD, and TI624-G7-3-PSD was run on October 2, 2008. Performance check results for this period were recorded to the Malvern file "2008-10Oct02-G2 Para PSD.mea”.

The particle size standard was supplied as $0.10 \mathrm{~g}$ single shot of dry powder that was dispersed in $\sim 0.5 \%$ sodium hexametaphosphate in water. This dispersion was subsequently sonicated for 5 minutes in a bath sonicator. Addition of sodium hexametaphosphate and subsequent sonication helps eliminate any particle agglomerates in the initial dispersion. Before measuring the performance check standard, the Hydro $\mu \mathrm{P}$ dispersion unit was filled with $\sim 0.5 \%$ sodium hexametaphosphate in water. Next, an aliquot of the particle size standard dispersion was then sampled and loaded into the Malvern using a $5 \mathrm{~mL}$ plastic transfer pipette. A continuous pump speed of 2000 RPM was set to mix the flow cell contents and the PSD was measured.

The performance check size analysis employed a particle refractive index and absorption of 1.544 and 0 , respectively, and a suspending phase particle refractive index of 1.33 (for water). An average of three 2000 RPM measurements of the PSD indicated a d(50) of $4.16 \mu \mathrm{m}$. This deviates less than $1 \%$ from the $\mathrm{d}(50)$ listed on the standard's certificate of analysis from Whitehouse Scientific and is also within the range provided on the certificate. As such, acceptable instrument performance was verified for the period of performance covering samples TI576-G7-S-WL-PSD-1, TI576-G7-S-WL-PSD-2, TI623-G7-CL-PSD, and TI624-G7-3-PSD.

\section{Sample Handling}

Group 7 samples were analyzed "as-is”. No additional treatment was performed except for the mechanical agitation and re-suspension of any settled solids at the time of analysis.

\section{Experimental}

Particle size measurements of waste samples TI576-G7-S-WL-PSD-1, TI576-G7-S-WL-PSD-2, TI623-G7-CL-PSD, and TI624-G7-3-PSD were performed using the Malvern analyzer in RPL Room 302. All measurements were performed in $0.01 \mathrm{M}$ sodium hydroxide. Before each analysis, the analyzer was drained, flushed with $20 \mathrm{~mL}$ of deionized (DI) water at least three times, filled with $20 \mathrm{~mL} 0.01 \mathrm{M}$ sodium hydroxide solution, and brought into a measurement ready state. PSD characterization for each sample was accomplished as follows:

1. The analyzer flow cell pump was set to 3000 RPM with no sonication.

2. The material (sample) and suspending phase optical properties were set in the analyzer software (see Table 5).

3. The sample was prepared for analysis by re-suspending the settled solids. This was accomplished by repeatedly pulsing the samples with a $10 \mathrm{~mL}$ disposable plastic pipette until the contents were uniformly dispersed. Each pulse involved drawing off a fraction of the sample into the pipette and immediately jetting the drawn liquid back into the sample vial.

4. Immediately after re-suspension, the sample dispersion was added drop-wise to the instrument (while the pump was active) until the appropriate laser obscuration was achieved. Obscurations 
ranging from 3.5 to $35 \%$ were considered acceptable. For the current analyses, an obscuration of $10-20 \%$ was targeted.

5. The sample PSD was measured under the conditions outlined in the sample test matrix (see Table $6)$.

Table 5. Material and suspending optical properties used for analysis of Group 7 particle size distributions.

\begin{tabular}{||c|c|c|c||}
\hline Sample Name & $\begin{array}{c}\text { Material Selected for } \\
\text { Optical Properties }\end{array}$ & $\begin{array}{c}\text { Refractive } \\
\text { Index (RI) }\end{array}$ & Absorption \\
\hline TI576-G7-S-WL-PSD-1 & Boehmite & 1.655 & 1.0 \\
\hline TI576-G7-S-WL-PSD-2 & Boehmite & 1.655 & 1.0 \\
\hline TI623-G7-CL-PSD & Boehmite & 1.655 & 1.0 \\
\hline TI624-G7-3-PSD & Boehmite & 1.655 & 1.0 \\
\hline Suspending Phase & Water & 1.33 & $\mathrm{n} / \mathrm{a}$ \\
\hline
\end{tabular}

Table 6. Particle size analysis test matrix used for samples TI576-G7-S-WL-PSD-1, TI576-G7-S-WL-PSD-2, TI623-G7-CL-PSD, and TI624-G7-3-PSD.

\begin{tabular}{||c|c|c|c||}
\hline \hline Condition No. & $\begin{array}{c}\text { Pump Speed } \\
\text { (RPM) }\end{array}$ & Sonic Power & Comment \\
\hline 1 & 3000 & n/a & no sonication \\
\hline 2 & 4000 & n/a & no sonication \\
\hline 3 & 2000 & n/a & no sonication \\
\hline 4 & 2000 & n/a & no sonication \\
\hline
\end{tabular}

As indicated in the analysis outline above, the optical properties, such as the refractive index (RI) of the sample and suspending phase must be entered into analyzer at the time of measurement. Because the exact optical properties of the tank waste solids are unknown, the optical properties selected were those of most abundant species. Analytical results indicate $\mathrm{Al}$ as the major species, so optical properties for boehmite $[\mathrm{AlO}(\mathrm{OH})]$ were employed in the measurement and analysis of Group 7 samples. Use of the correct optical properties (in particular the RI) only serves to refine measured PSD (see Appendix A of TDP-WTP-271). As such, the boehmite optical properties can be used while still allowing the analysis to provide a reasonable representation of the actual waste PSD.

The size distribution of particles was measured under flow conditions without sonication. Table 6 outlines the test matrix performed for all sample measurements. For each condition, three successive 20-second measurements of PSD were taken. An average of these measurements was then generated by the analyzer software. Both individual and averaged PSDs were saved to the analyzer data file. Once measurements were complete, the flow rate for the next condition was set, the sample was given approximately 30 seconds to equilibrate, and the next set of measurements was taken. Measurements for TI576-G7-S-WL-PSD-1, TI576-G7-S-WL-PSD-2, and TI623-G7-CL-PSD were logged to the Mastersizer 2000 file "2008-10Oct07-initial char PSD.mea”. Measurements for TI624-G7-3-PSD were logged to the Mastersizer 2000 file "2008-10Oct16-G8 CUF PSD.mea”.

Analysis of the raw particle size data is performed automatically by the Mastersizer software immediately after each measurement. Analysis calculates the particle size distribution based on 1) the scattered light intensity as a function of detection angle, the particle size model selected [single narrow, multiple narrow, or broad peaks] and 2) the optical properties entered into the software at the time of 
measurement. For the current measurements, appropriate optical properties were selected at the time of measurement for all samples.

The particle size results for Group 7 initial characterization and parametric testing samples appear largely free of defects or data artifacts caused by air/bubble entrapment in the instrument. In the Group 7 CUF testing (TI624-G7-3-PSD) a peak is observed around $1300 \mu \mathrm{m}$. As particles of this size exceed the instrument's upper measuring range boundary of $150 \mu \mathrm{m}$, the $\sim 1300 \mu \mathrm{m}$ particle population may not have been properly suspended and/or reliably sampled due to their size. Likewise, size determinations between 1000-2000 $\mu \mathrm{m}$ appear to be strongly influenced by instrument electronic background, and determination of particles in this size range can sometimes result from measurement artifacts (such as a poor background reading). For these reasons, the distribution range was limited to less than $1000 \mu \mathrm{m}$ to remove these peaks from the analysis.

\section{Results and Discussion}

\subsection{Group 7 Initial Characterization PSD Results}

\section{Results for TI576-G7-S-WL-PSD (Group 7 Initial Characterization)}

Figures 2-3 and Tables 7 and 8 present the results of Group 7 initial characterization particle size analysis as a function of test condition. Figures 2-3 show the differential volume population distribution for the Group 7 initial characterization sample and allow a qualitative examination of the PSD behavior with respect to pump speed. Table 7 is a summary of the measured oversize diameter percentiles (by volume/weight) for the primary sample, TI576-G7-S-WL-PSD-1. Table 8 presents the same results for the duplicate sample, TI576-G7-S-WL-PSD-2. Both tables present cumulative oversize diameters corresponding to the $10^{\text {th }}, 50^{\text {th }}$, and $90^{\text {th }}$ volume/weight percentiles, hereafter referred to as $\mathrm{d}(10), \mathrm{d}(50)$, and d(90), respectively. More extensive percentile results are provided in section 12 of this interim report. These tables will be used to quantitatively examine reproducibility and changes in particle size.

Figure 2 shows the PSD for the primary Group 7 initial characterization sample as a function of pump speed. The sample displayed a multi-modal distribution at all pump speeds. At 2000 RPM the distribution ranges from 0.2-750 $\mu \mathrm{m}$ with peak maxima around 0.7, 7.5, 84 and $475 \mu \mathrm{m}$. At $3000 \mathrm{RPM}$, the distribution ranges from $0.2-500 \mu \mathrm{m}$ and displays peak maxima around $0.7,7.5$, and $75 \mu \mathrm{m}$. At 4000 RPM, the distribution ranges from 0.2-200 $\mu \mathrm{m}$ and contains peak maxima around $60,7.5$, and $0.7 \mu \mathrm{m}$. Overall, the higher pump speeds show an increasing population of particles or agglomerates $>20 \mu \mathrm{m}$. The $475 \mu \mathrm{m}$ peak seen at 2000 RPM may be an artifact of scattering signal interpretation by the Malvern software or possible flocculates in the solution which are sheared apart at higher pump speeds. The sample appears to have numerous large particles, agglomerates, or flocculates, which may result in poor sampling due to settling and/or insufficient solids. 
WTP-RPT-169, Rev 0

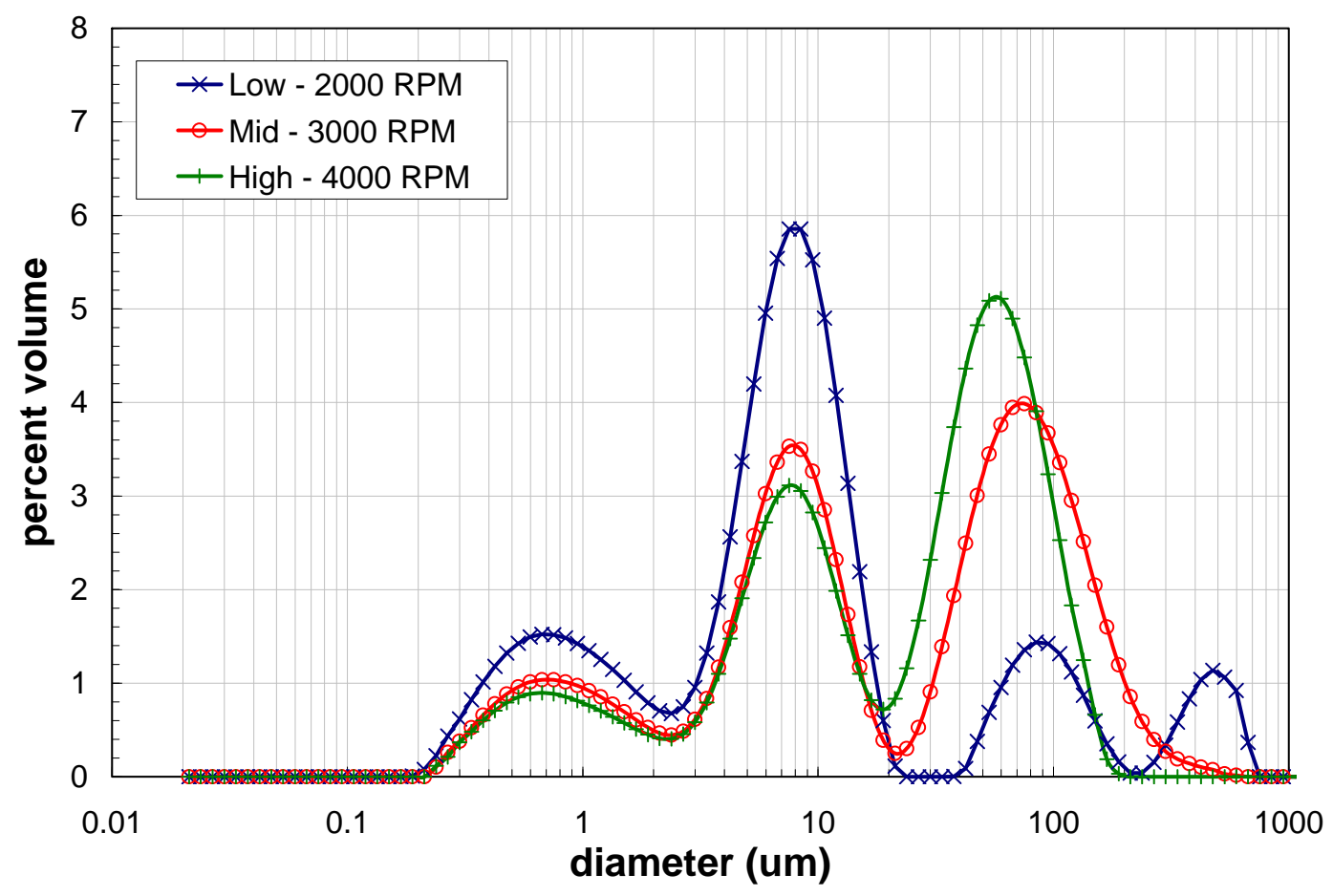

Figure 2. Volume distribution result for the primary Group 7 initial characterization sample as a function of pump speed.

Figure 3 shows the PSD for the duplicate Group 7 initial characterization sample as a function of pump speed. This distribution shows a range of 0.2-150 $\mu \mathrm{m}$ with the exception of a $475 \mu \mathrm{m}$ peak at 2000 RPM. As this $475 \mu \mathrm{m}$ peak is observed in both the primary and duplicate sample only at $2000 \mathrm{RPM}$ it is probable that it corresponds to flocculates which are sheared apart at higher pump speeds. In the duplicate sample a primary peak is present around $6 \mu \mathrm{m}$ and a shoulder exists around $0.75 \mu \mathrm{m}$ at all pump speeds. At 4000 RPM an additional small peak is seen around $60 \mu \mathrm{m}$ and at 3000 and 2000 RPM either a small peak or a shoulder is present around $75 \mu \mathrm{m}$. 


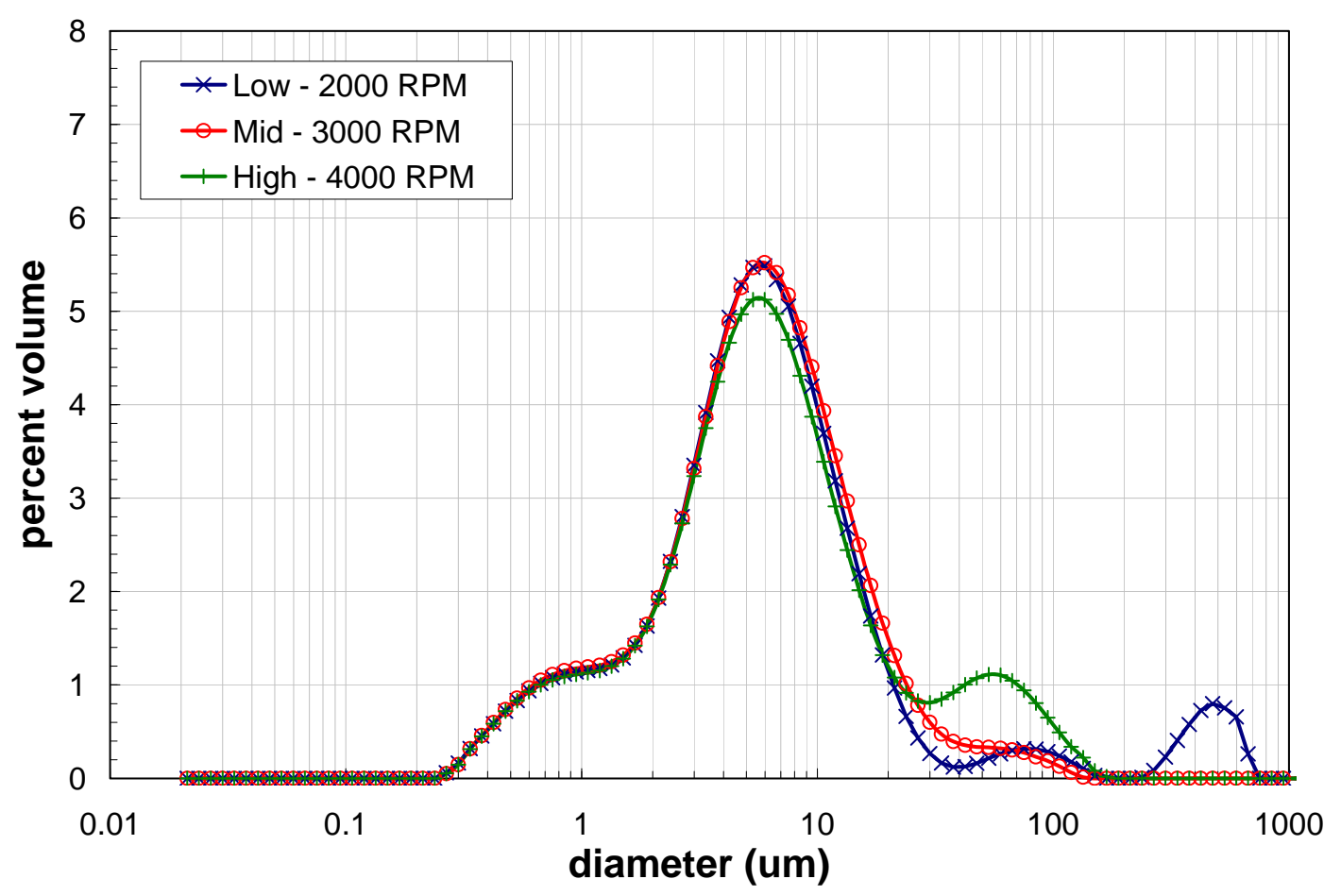

Figure 3. Volume distribution result for the duplicate Group 7 initial characterization sample as a function of pump speed.

Tables 7 and 8 show select cumulative oversize percentiles for the primary and duplicate Group 7 particle dispersions. Using the primary results as a reference, the behavior of Group 7 initial characterization particle size as a function of pump speed can be quantitatively evaluated. Specifically, the following observations can be made:

- In general, the $\mathrm{d}(10)$ falls between 0.70 and $1.3 \mu \mathrm{m}$, the $\mathrm{d}(50)$ between 7.4 and $31 \mu \mathrm{m}$, and the d(90) between 89 and $130 \mu \mathrm{m}$

- The listed diameter percentiles appear to be highly sensitive to changes in pump speed. Increases in pump speed appear to result in increases in the d(50). For example, a decrease between 4000 and 2000 RPM decreases the particle diameter from 31 to $9.8 \mu \mathrm{m}$. This is a decrease of $68 \%$, which is above the instrument limit of accuracy (10\%) and is significant and not merely random noise or measurement error.

Table 7. Particle size analysis percentile results from primary Group 7 initial characterization sample, TI576-G7-S-WL-PSD-1.

\begin{tabular}{||c|c|c|c|c|c||}
\hline $\begin{array}{c}\text { Measurement } \\
\text { Condition }\end{array}$ & Pump Speed & Sonication & $\begin{array}{c}\mathbf{d}(\mathbf{1 0}) \\
{[\boldsymbol{\mu m}]}\end{array}$ & $\begin{array}{c}\mathbf{d}(\mathbf{5 0}) \\
{[\boldsymbol{\mu m}]}\end{array}$ & $\begin{array}{c}\mathbf{d}(\mathbf{9 0}) \\
{[\boldsymbol{\mu m}]}\end{array}$ \\
\hline 1 & 3000 & $\mathrm{n} / \mathrm{a}$ & 1.0 & 19 & 130 \\
\hline 2 & 4000 & $\mathrm{n} / \mathrm{a}$ & 1.3 & 31 & 89 \\
\hline 3 & 2000 & $\mathrm{n} / \mathrm{a}$ & 0.87 & 9.8 & 120 \\
\hline 4 & 2000 & $\mathrm{n} / \mathrm{a}$ & 0.70 & 7.4 & 110 \\
\hline
\end{tabular}


WTP-RPT-169, Rev 0

Table 8. Particle size analysis percentile results from duplicate Group 7 initial characterization sample, TI576-G7-S-WL-PSD-2.

\begin{tabular}{||c|c|c|c|c|c||}
\hline $\begin{array}{c}\text { Measurement } \\
\text { Condition }\end{array}$ & Pump Speed & Sonication & $\begin{array}{c}\mathbf{d}(\mathbf{1 0}) \\
{[\boldsymbol{\mu m}]}\end{array}$ & $\begin{array}{c}\mathbf{d}(\mathbf{5 0}) \\
{[\boldsymbol{\mu m}]}\end{array}$ & $\begin{array}{c}\mathbf{d}(\mathbf{9 0}) \\
{[\boldsymbol{\mu m}]}\end{array}$ \\
\hline 1 & 3000 & $\mathrm{n} / \mathrm{a}$ & 1.1 & 5.5 & 17 \\
\hline 2 & 4000 & $\mathrm{n} / \mathrm{a}$ & 1.2 & 5.8 & 35 \\
\hline 3 & 2000 & $\mathrm{n} / \mathrm{a}$ & 1.2 & 5.9 & 66 \\
\hline 4 & 2000 & $\mathrm{n} / \mathrm{a}$ & 1.2 & 5.5 & 19 \\
\hline
\end{tabular}

Behavior of the duplicate sample PSD with respect to pump speed shows it favors smaller diameters for the $d(50)$ and $d(90)$ than that of the primary at equivalent measurement conditions. Table 9 shows the absolute relative percent difference between the $d(10), d(50)$, and $d(90)$ values determined for the primary and duplicate Group 7 initial characterization samples. Here, absolute relative percent difference is determined using the following equation:

$$
R P D=\left|\frac{d_{d}(n)-d_{p}(n)}{d_{p}(n)}\right|
$$

where $d_{p}(n)$ and $d_{d}(n)$ are the primary and duplicate cumulative oversize diameters corresponding to the $n^{\text {th }}$ percentile. The listed RPDs indicate that there is a significant difference between samples.

Table 9. Absolute relative percent difference between primary and duplicate Group 7 initial characterization samples.

\begin{tabular}{||c|c|c|c|c|c||}
\hline \multirow{2}{*}{$\begin{array}{c}\text { Measurement } \\
\text { Condition }\end{array}$} & \multirow{2}{*}{ Pump Speed } & \multirow{2}{*}{ Sonication } & \multicolumn{3}{|c|}{ Absolute RPD } \\
\cline { 4 - 6 } & & & $\mathbf{d ( 1 0 )}$ & $\mathbf{d ( 5 0 )}$ & $\mathbf{d ( 9 0 )}$ \\
\hline 1 & 3000 & $\mathrm{n} / \mathrm{a}$ & $9.1 \%$ & $71 \%$ & $87 \%$ \\
\hline 2 & 4000 & $\mathrm{n} / \mathrm{a}$ & $6.5 \%$ & $81 \%$ & $61 \%$ \\
\hline 3 & 2000 & $\mathrm{n} / \mathrm{a}$ & $44 \%$ & $40 \%$ & $45 \%$ \\
\hline 4 & 2000 & $\mathrm{n} / \mathrm{a}$ & $67 \%$ & $25 \%$ & $82 \%$ \\
\hline
\end{tabular}

For particle size measurements on the Malvern Mastersizer 2000, RPDs of up to $10 \%$ are generally expected given the accuracy of the instrument. The results for Group 7 initial characterization samples show RPDs that range from 9.1 to $87 \%$ depending on the measurement condition and percentile examined. Based on the large number of RPDs greater than $10 \%$ in Table 9 , it is likely that there is a significant size difference in the solids species in the primary and duplicate samples.

Figure 4 shows how the differences in the primary and duplicate PSDs described in the preceding paragraphs manifest in the differential volume distributions. The peak maxima for the two samples are around similar diameters, although the population distribution between the samples is dissimilar. The increased number of $>20 \mu \mathrm{m}$ particles in the primary sample may be a result of flocculates or aggregates. Therefore, this may indicate poor sampling due to the settling of these larger difficult-to-suspend particles, flocculates, and/or agglomerates. 


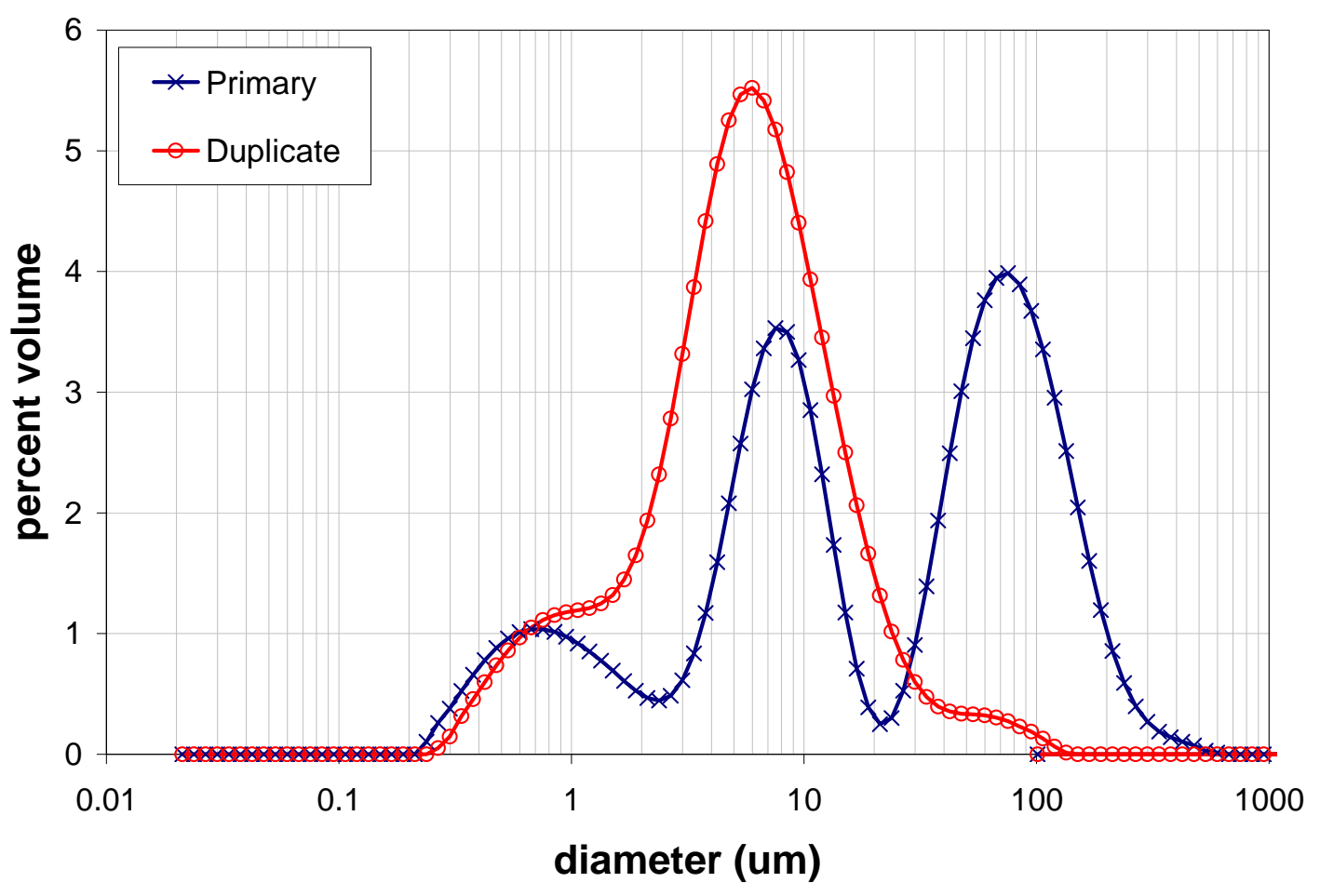

Figure 4. Comparison of primary and duplicate sample differential volume PSD of Group 7 initial characterization at 3000 RPM.

The Group 7 initial characterization particle size distribution ranged from 0.2-800 $\mu \mathrm{m}$ and was multi-modal. The primary and duplicate samples show similar peak maxima although the population distribution shows a preference to larger particle diameters, agglomerates, or flocculates in the primary sample. The varying distribution may indicate poor sampling due to settling of larger particles that are difficult-to-suspend. At the low pump speed (2000 RPM) an additional peak appears around $475 \mu \mathrm{m}$ in both the primary and duplicate samples and is most likely due to flocculates, which are sheared at the higher pump speeds.

\subsection{Group 7 Parametric Testing PSD Results}

Results for TI623-G7-CL-PSD (Group 7 Parametric Testing)

Figure 5 and Table 10 present the results of Group 7 parametric testing particle size analysis as a function of test condition. Figure 5 shows the differential volume population distribution for the Group 7 parametric testing sample and allows a qualitative examination of the PSD behavior with respect to pump speed. Table 10 is a summary of the measured oversize diameter percentiles (by volume/weight) for TI623-G7-CL-PSD which presents the $d(10), d(50)$, and d(90) results. More extensive percentile results are provided in section 12 of this interim report.

Figure 5 shows the PSD for the Group 7 parametric testing sample as a function of pump speed. All of the pump speeds show a multi-modal distribution with peak maxima around 1.2 and $8 \mu \mathrm{m}$. At 
2000 RPM the range is $0.24-20 \mu \mathrm{m}$, although at higher pump speeds a broader range exists. At 3000 RPM the range is $0.24-300 \mu \mathrm{m}$ and an additional peak is seen around $135 \mu \mathrm{m}$. At $4000 \mathrm{RPM}$ the range is 0.24-200 $\mu \mathrm{m}$ and again an additional peak is observed, although its maximum is around $70 \mu \mathrm{m}$. This larger diameter peak most likely indicates the presence of larger particles or agglomerates, which are suspended by faster pump speeds. As this peak shifts to smaller particle diameters at 4000 RPM this may also indicate shear induced breakage of agglomerates, which would account for the relative increase in the 4-10 $\mu$ m peak observed.

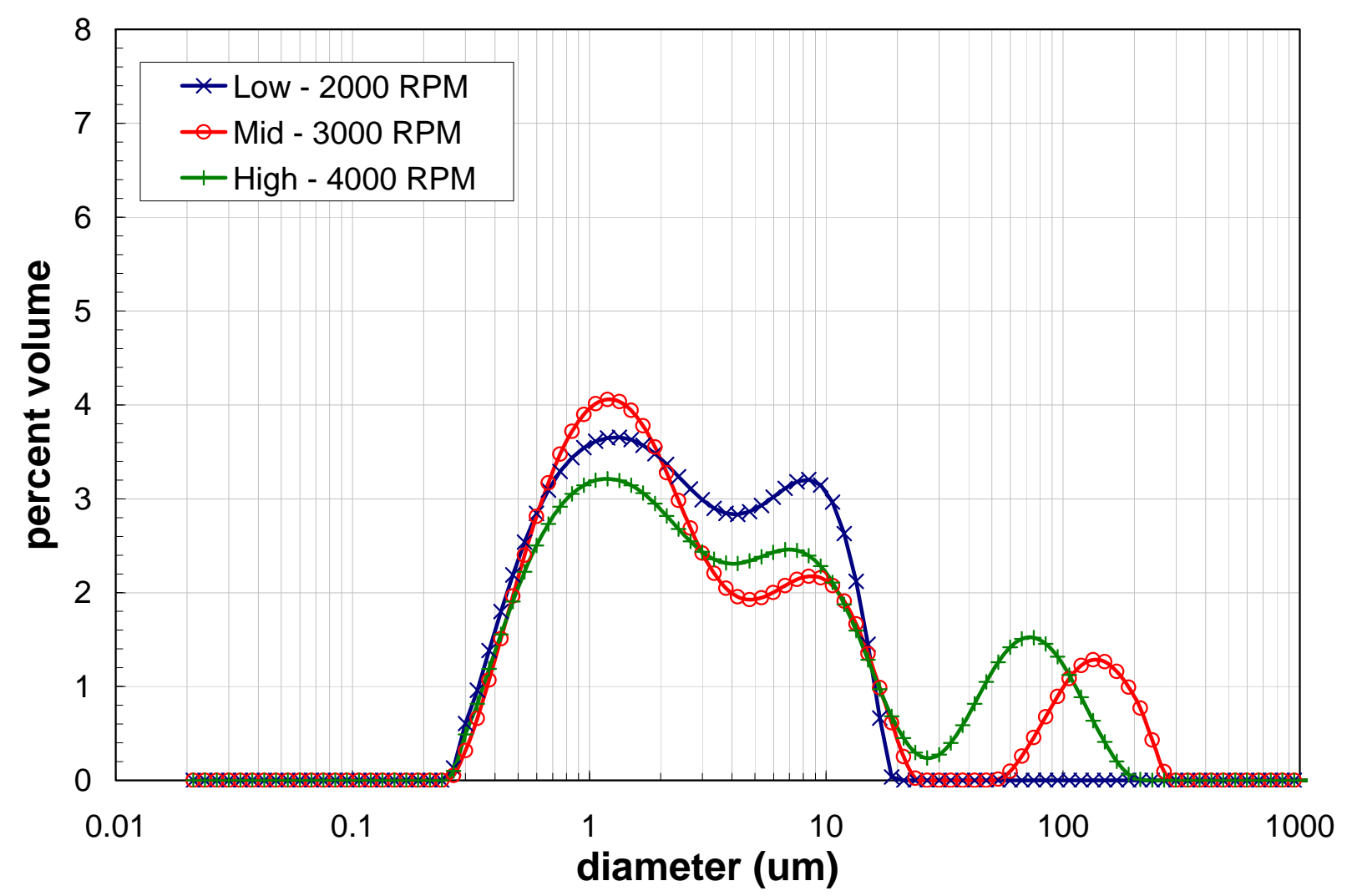

Figure 5. Volume distribution result for the Group 7 parametric testing sample as a function of pump speed.

Table 10 shows select cumulative oversize percentiles for the Group 7 parametric testing particle dispersion (TI623-G7-CL-PSD). Using these results as a reference, the behavior of Group 7 particle size as a function of pump speed can be quantitatively evaluated. Specifically, the following observations can be made:

- In general, the $\mathrm{d}(10)$ falls between 0.57 and $0.72 \mu \mathrm{m}$, the $\mathrm{d}(50)$ between 2.1 and $2.9 \mu \mathrm{m}$, and the $\mathrm{d}(90)$ between 10 and $93 \mu \mathrm{m}$

- The listed diameter percentiles appear to be sensitive to changes in pump speeds. Increases in flow rate appear to result in increases in the mean diameter [i.e., the d(50)]. For an increase from 3000 to 4000 RPM the mean particle diameter increases from 2.1 to $2.9 \mu \mathrm{m}$. This is an increase of $\sim 38 \%$ and is significant relative to the accuracy of the instrument. 
Table 10. Particle size analysis percentile results from Group 7 parametric testing sample, TI623-G7-CL-PSD.

\begin{tabular}{||c|c|c|c|c|c||}
\hline $\begin{array}{c}\text { Measurement } \\
\text { Condition }\end{array}$ & Pump Speed & Sonication & $\begin{array}{c}\mathbf{d}(\mathbf{1 0}) \\
{[\boldsymbol{\mu m}]}\end{array}$ & $\begin{array}{c}\mathbf{d}(\mathbf{5 0}) \\
{[\mathbf{\mu m}]}\end{array}$ & $\begin{array}{c}\mathbf{d}(\mathbf{9 0}) \\
{[\mathbf{\mu m}]}\end{array}$ \\
\hline 1 & 3000 & $\mathrm{n} / \mathrm{a}$ & 0.61 & 2.1 & 78 \\
\hline 2 & 4000 & $\mathrm{n} / \mathrm{a}$ & 0.61 & 2.9 & 59 \\
\hline 3 & 2000 & $\mathrm{n} / \mathrm{a}$ & 0.72 & 2.7 & 93 \\
\hline 4 & 2000 & $\mathrm{n} / \mathrm{a}$ & 0.57 & 2.2 & 10 \\
\hline
\end{tabular}

The particle size analysis of parametric testing of Group 7 displays multi-modal particle size distributions ranging from 0.24-300 $\mu \mathrm{m}$. Higher pump speeds result in an additional peak consisting of particles $>20 \mu \mathrm{m}$. This may indicate the presence of larger difficult-to-suspend particles, which may result in poor sampling due to settling.

\subsection{Influence of Chemical Treatment on Group 7}

Comparison of the percentiles and distributions presented in Sections 10.1 and 10.2 of this report can highlight the effects of chemical treatment on Group 7 waste PSD. Caution must be used when directly comparing PSDs, as these PSDs include both primary particles and particle agglomerates. The structure of the agglomerates fractions depends on 1) physical conditions such as the analyzer pump speed and 2) chemical conditions such as particle interaction potentials and sample history.

One expected outcome of caustic leaching is a decrease in particle size as a result of solid dissolution. However, removal of leachable solid species may reveal the size distribution of particles only minimally represented in the initial sample. In addition, changes in the dominant particle surface chemistry can yield increased particle agglomeration, which in turn results in increases in the apparent particle size. In addition to chemical effects, the mechanical force needed to pump the dispersion can also shear particle agglomerates (as well as influence the volume of agglomerates suspended). As such, the apparent PSD of a material may also vary with pump speed. Comparisons will be made at measurement condition 1 (Table 6: 3000 RPM).

\section{Caustic-Leaching and Washing of Group 7 Waste Solids}

The influence of caustic-leaching and washing of Group 7 (Tributyl Phosphate Sludge) solids can be evaluated by comparing PSDs for the source material (i.e., for initial characterization sample TI576G7-S-WL-PSD) to the caustic-leached and washed Group 7 parametric testing PSD sample (TI623-G7CL-PSD). The PSD measurement for the primary initial characterization sample is used for this comparison.

Table 11 and Figure 6 show changes that occur to the Group 7 solids PSD as a result of causticleaching and washing operations. Figure 6 shows both the initial characterization and parametric testing samples are tri-modal with peak maxima located around similar particle diameters. The most noticeable difference is the shift to lower particles diameters after caustic-leaching and washing. The reduction in particle size is likely a result of either dissolution of material off of the particle surface or agglomerate breakage. As the peak maxima are similar this may indicate the particle size is $0.3-4 \mu \mathrm{m}$ and those particles greater than this range, particularly $>20 \mu \mathrm{m}$ may be mostly agglomerates. 
Table 11. Cumulative undersize percentiles showing the influence of caustic-leaching and washing on the PSD of Group 7 (Tributyl Phosphate Sludge) solids at measurement condition 1 -3000 RPM (see Table 6).

\begin{tabular}{||l|c|c|c||}
\hline \multicolumn{1}{|c|}{ Sample } & $\begin{array}{c}\mathbf{d}(\mathbf{1 0}) \\
{[\mathbf{\mu m}]}\end{array}$ & $\begin{array}{c}\mathbf{d}(\mathbf{5 0}) \\
{[\boldsymbol{\mu m}]}\end{array}$ & $\begin{array}{c}\mathbf{d}(\mathbf{9 0}) \\
{[\boldsymbol{\mu m}]}\end{array}$ \\
\hline Group 7 Initial Characterization (TI576-G7-S-WL-PSD-1) & 1.0 & 19 & 130 \\
\hline Group 7 Parametric Testing (TI623-G7-CL-PSD) & 0.61 & 2.1 & 78 \\
\hline \hline
\end{tabular}

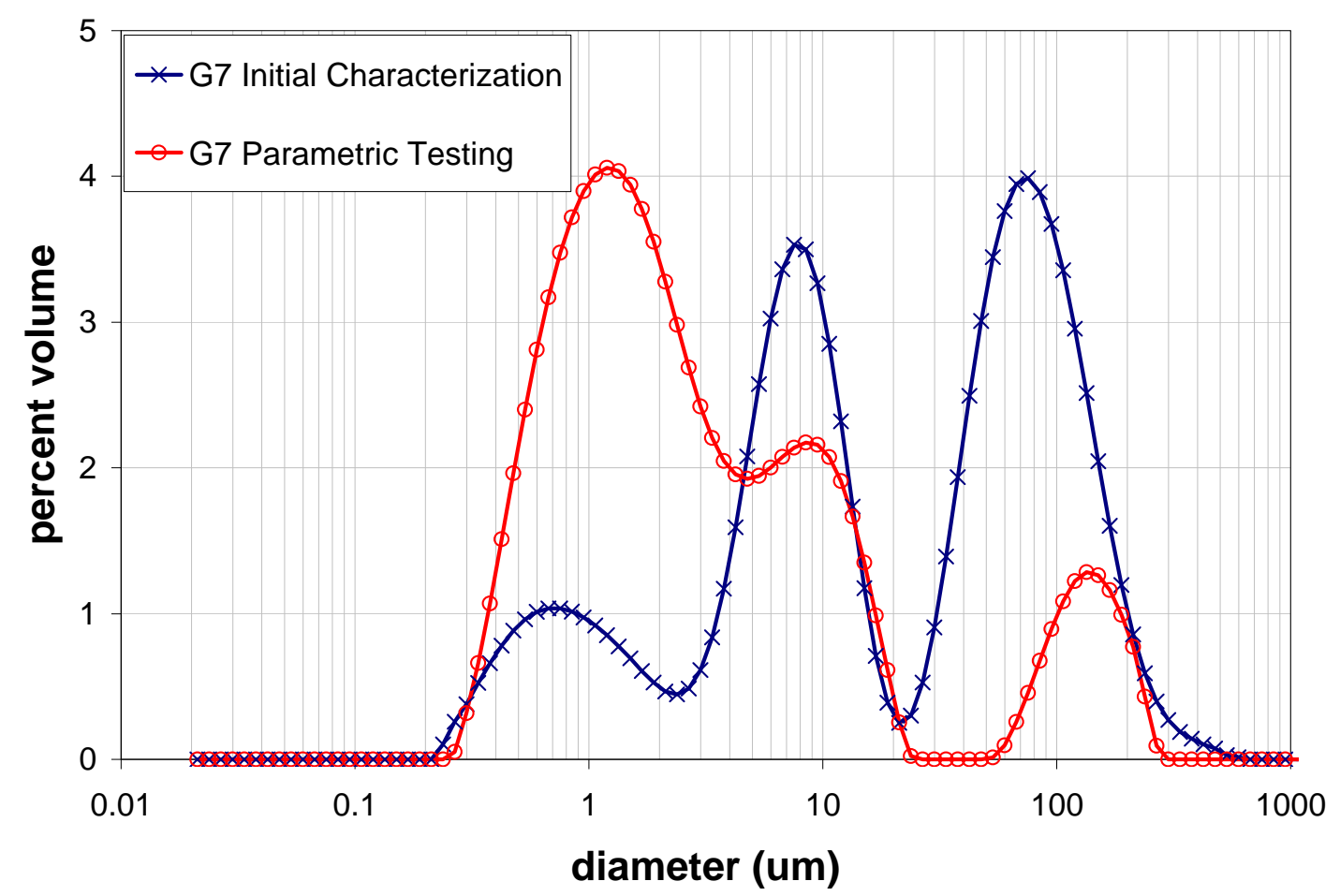

Figure 6. Influence of caustic-leaching and washing on Group 7 (Tributyl Phosphate Sludge) waste solids PSD. PSDs were taken at measurement condition 1 - 3000 RPM (see Table 6).

\section{$\underline{10.4 \text { Group } 7 \text { CUF Testing PSD Results }}$}

The following sub-section discusses the PSD results for Group 7 CUF testing sample. A brief outline of how select cumulative oversize diameter percentiles behave as a function of test condition is given, and a graph of particle size distributions is given as a function of flow rate without sonication. The reproducibility of PSD for each sample in not assessed. In addition, the current section focuses on changes in the PSD with measurement condition. Comparison of PSDs to one another to highlight effects of CUF processing shall be examined in Section 10.5. 


\section{$\underline{\text { Results for TI624-G7-3-PSD (Low-Solids Matrix) }}$}

Sample TI624-G7-3-PSD is representative of the low-solids matrix (dilute) slurry that was initially run in the CUF system. Table 12 shows select cumulative undersize percentiles for sample TI624-G7-3PSD, more extensive percentile results are shown in section 12. Here the $\mathrm{d}(10)$ ranges between 28 and 38 $\mu \mathrm{m}$, the $\mathrm{d}(50)$ between 81 and $240 \mu \mathrm{m}$, and the d(90) between 150 and $510 \mu \mathrm{m}$. With regards to pump speed effects, the d(50) and d(90) percentiles show a significant increase in size at $4000 \mathrm{RPM}$, indicating the presence of large, difficult-to-suspend particles.

Table 12. Particle size analysis percentile results the Group 7 low-solids matrix sample (TI624-G7-3-PSD).

\begin{tabular}{||c|c|c|c|c|c||}
\hline $\begin{array}{c}\text { Measurement } \\
\text { Condition }\end{array}$ & Pump Speed & Sonication & $\begin{array}{c}\mathbf{d}(\mathbf{1 0}) \\
{[\boldsymbol{\mu m}]}\end{array}$ & $\begin{array}{c}\mathbf{d}(\mathbf{5 0}) \\
{[\boldsymbol{\mu m}]}\end{array}$ & $\begin{array}{c}\mathbf{d}(\mathbf{9 0}) \\
{[\mathbf{\mu m}]}\end{array}$ \\
\hline 1 & 3000 & $\mathrm{n} / \mathrm{a}$ & 28 & 81 & 150 \\
\hline 2 & 4000 & $\mathrm{n} / \mathrm{a}$ & 38 & 240 & 510 \\
\hline 3 & 2000 & $\mathrm{n} / \mathrm{a}$ & 38 & 190 & 350 \\
\hline 4 & 2000 & $\mathrm{n} / \mathrm{a}$ & 31 & 170 & 290 \\
\hline
\end{tabular}

Figure 7 shows the PSD for Group 7 low-solids matrix (TI624-G7-3-PSD) sample as a function of pump speed. The sample shows a broad bi-modal distribution. At 2000 RPM the distribution ranges from 1-500 $\mu \mathrm{m}$ with peak maxima at 190 and $30 \mu \mathrm{m}$. At $3000 \mathrm{RPM}$ the range is from 0.3-300 $\mu \mathrm{m}$ with peak maxima at 90 and $12 \mu \mathrm{m}$. At 4000 RPM the distribution ranges from 0.6-750 $\mu \mathrm{m}$ with peak maxima at 330 and $50 \mu \mathrm{m}$. As the pump speed increases, from 3000 to $4000 \mathrm{RPM}$, there are more large particles or agglomerates that may be difficult-to-suspend, this may account for the extended range at $4000 \mathrm{RPM}$. These particles suspended at 4000 RPM may be slow settling relative to the measurement time and may contribute to the larger particle diameters at 2000 RPM in comparison with the distribution at 3000 RPM. Overall, the distribution shows the majority of particles and/or agglomerates are $>20 \mu \mathrm{m}$ and their distribution is dependent upon pump speed. 


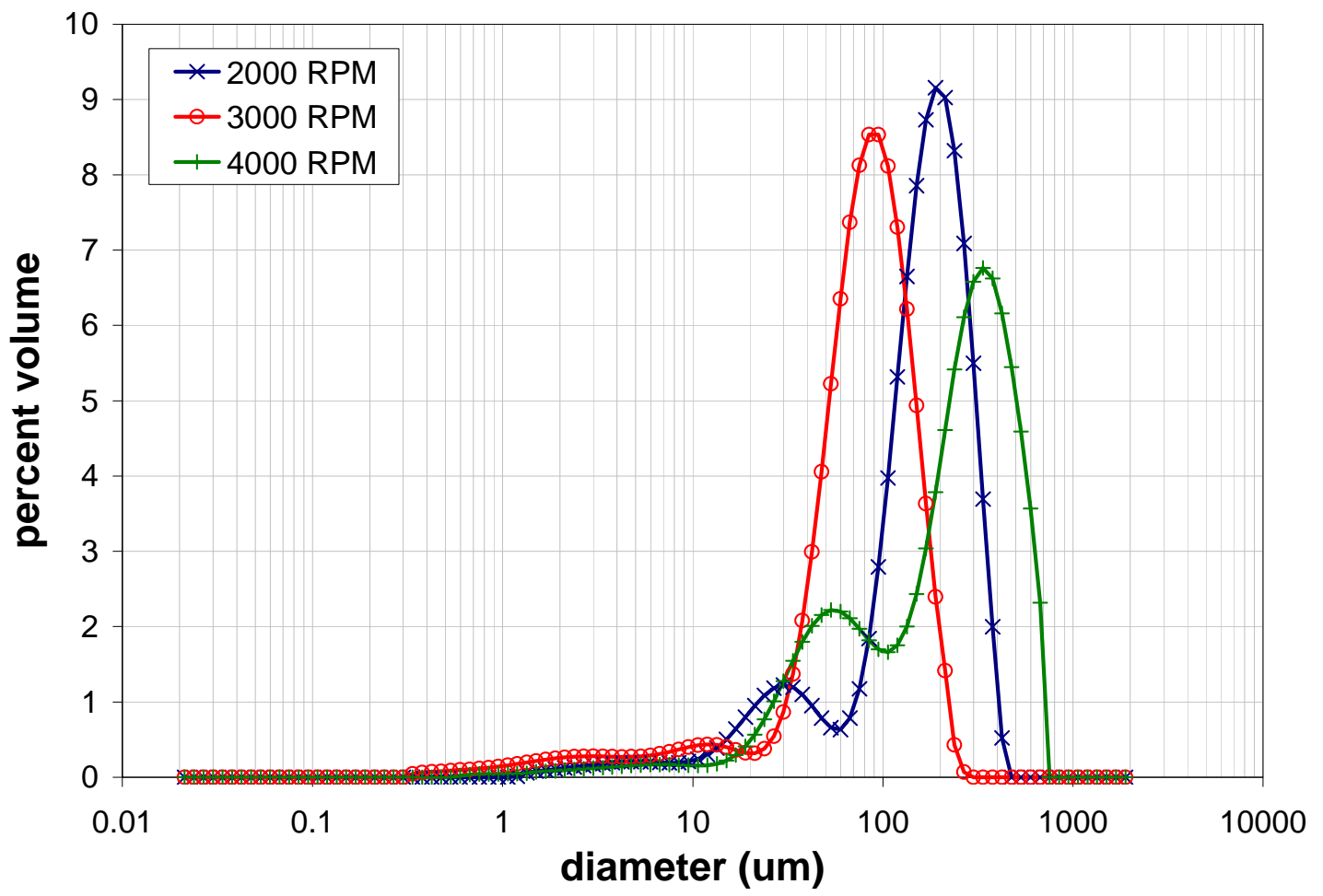

Figure 7. Volume distribution result for the Group 7 low-solids matrix (TI624-G7-3-PSD) sample as a function of pump speed.

\subsection{CUF Processing Effects on Group 7 Solids}

\section{Shearing Effect on Group 7 (Low-solids matrix)}

Table 13 and Figure 8 show the influence of circulation in the CUF on the PSD of Group 7 waste solids. Here, select cumulative undersize percentiles and PSD for the initial characterization (TI576-G7S-WL-PSD-1) are compared to low-solids matrix slurry (TI624-G7-3-PSD). Both samples show a similar particle size distribution range of 0.2-400 $\mu \mathrm{m}$ with a primary peak maximum between $70-90 \mu \mathrm{m}$. The major difference observed in the low-solids matrix slurry is a large shift in the population to the primary peak diameter. This shift may likely be due to transient effects, such as shear induced agglomeration or flocculation resulting in a significant relative increase in 20-300 $\mu \mathrm{m}$ particles. This shift may also indicate a variation in composition as a result of sampling difficulties due to large difficult-to-suspend particles. These larger particles also present a complication, since they are near the upper limit of the instrument detection, and may not be as accurately measured.

Table 13. Cumulative undersize percentiles showing the influence of circulation in the CUF on Group 7 PSD at measurement condition 1 - 3000 RPM (see Table 6).

\begin{tabular}{||l|c|c|c||}
\hline \hline Sample & $\begin{array}{c}\mathbf{d}(\mathbf{1 0}) \\
{[\boldsymbol{\mu m}]}\end{array}$ & $\begin{array}{c}\mathbf{d}(\mathbf{5 0 )} \\
{[\boldsymbol{\mu m}]}\end{array}$ & $\begin{array}{c}\mathbf{d}(\mathbf{9 0}) \\
{[\boldsymbol{\mu m}]}\end{array}$ \\
\hline Group 7 Initial Characterization (TI576-G7-S-WL-PSD-1) & 1.0 & 19 & 130 \\
\hline Group 7 Low Solids Matrix Slurry (TI624-G7-3-PSD) & 28 & 81 & 150 \\
\hline
\end{tabular}




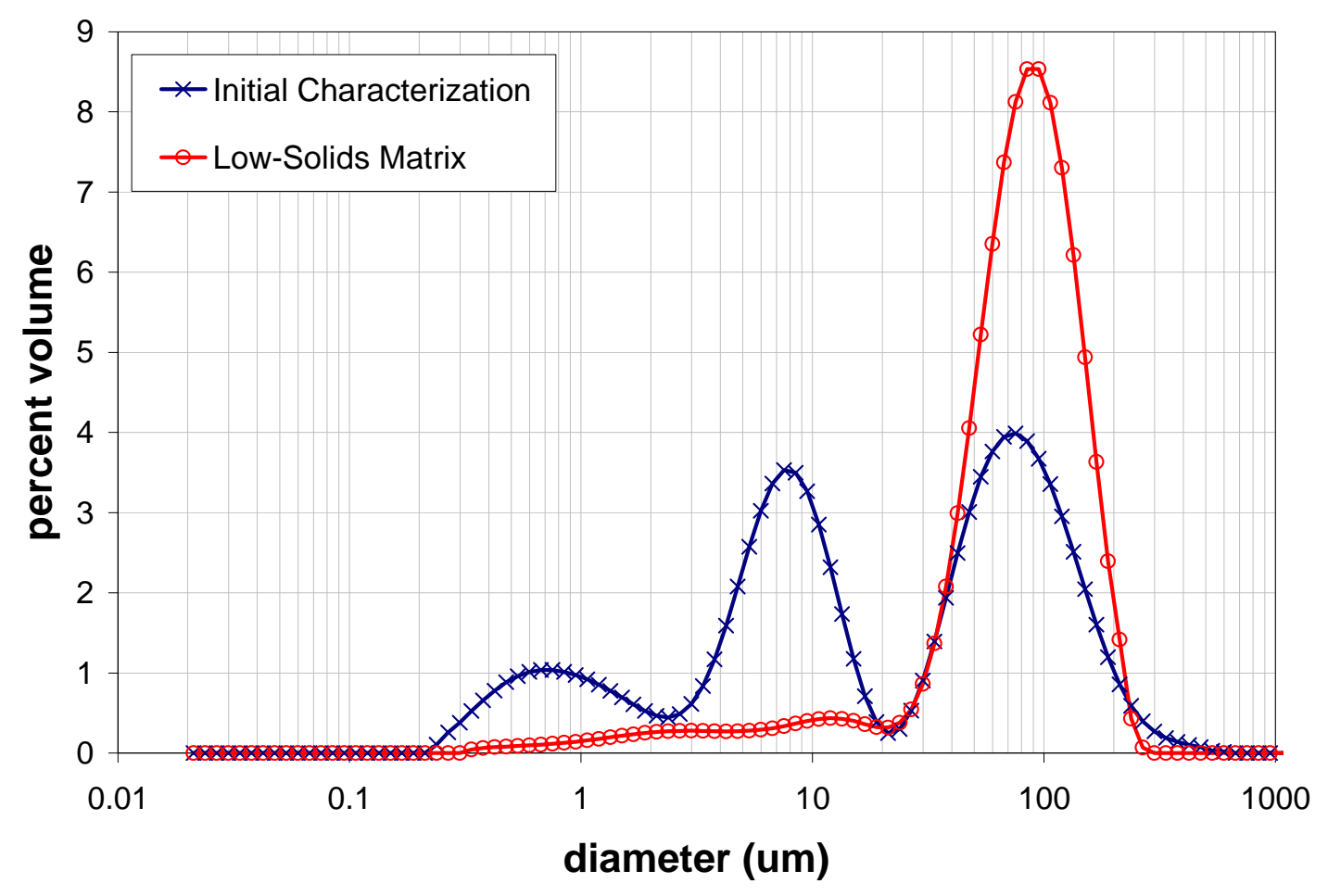

Figure 8. Influence of circulation in the CUF for Group 7. All PSDs taken at measurement condition 1 - 3000 RPM (see Table 6).

\section{Records}

Data records relating to Group 7 particle size distribution measurements and post-measurement analysis exist in original Malvern Mastersizer 2000 data files and Laboratory Record Books (LRBs):

- Malvern Mastersizer Files: "2008-10Oct16-G8 CUF PSD.mea", "2008-10Oct02-G2 Para PSD.mea", "2008-100ct07-G7 initial char PSD.mea"

- $\quad$ LRB BNW 56933: Pages 134, 138, 139, 144, and 145

- Test Data Package: TDP-WTP-273, TDP-WTP-271, CCP-WTPSP-573, CCP-WTPSP-641, and CCP-WTPSP-651

\section{References}

1. Doc. No. TP-RPP-WTP-567, Revision 0, "Characterization and Small Scale Testing of Hanford Wastes to Support the Development and Demonstration of Leaching and Ultrafiltration Pretreatment Processes," SK Fiskum, Battelle - Pacific Northwest Division, February 2007.

2. Doc. No. RPL-COLLOID-01, Revision 1, "Particle Size Analysis Using Malvern MS2000,” AP Poloski, Pacific Northwest National Laboratory, May 2007. 


\section{Detailed Cumulative PSD}

\section{Results: TI576-G7-S-WL-PSD (Group 7 Initial Characterization)}

Table 12-1 and 12-2 present detailed cumulative oversize distributions (by volume/weight) for Group 7 initial characterization samples TI576-G7-S-WL-PSD-1 and -2, respectively. Results are reported as a function of test condition (see Table 6). This section does not provide discussion of the detailed distributions; however, a portion of these results (specifically, the $10^{\text {th }}, 50^{\text {th }}$, and $90^{\text {th }}$ diameter percentiles) are presented and discussed in other sections of this interim report.

Table 12-1. Cumulative oversize diameter distributions for the primary Group 7 initial characterization sample, TI576-G7-S-WL-PSD-1.

\begin{tabular}{||l|c|r|r|r|r|r|r|r|r|r|r|r|r|r|r||}
\hline \multirow{2}{*}{ Test Condition } & \multicolumn{10}{|c||}{ Volume / Weight Cumulative Oversize Diameter $(\boldsymbol{\mu m})$} \\
\cline { 2 - 21 } & $\mathbf{1 \%}$ & $\mathbf{5 \%}$ & $\mathbf{1 0 \%}$ & $\mathbf{2 0 \%}$ & $\mathbf{2 5 \%}$ & $\mathbf{3 0 \%}$ & $\mathbf{4 0 \%}$ & $\mathbf{5 0 \%}$ & $\mathbf{6 0 \%}$ & $\mathbf{7 0 \%}$ & $\mathbf{7 5 \%}$ & $\mathbf{8 0 \%}$ & $\mathbf{9 0 \%}$ & $\mathbf{9 5 \%}$ & $\mathbf{9 9 \%}$ \\
\hline $\mathbf{1}-3000$ & 0.34 & 0.59 & 1.0 & 4.6 & 5.8 & 6.9 & 9.7 & 19 & 49 & 67 & 77 & 89 & 130 & 160 & 270 \\
\hline $\mathbf{2}-4000$ & 0.34 & 0.63 & 1.3 & 5.2 & 6.5 & 7.8 & 12 & 31 & 43 & 54 & 60 & 68 & 89 & 110 & 140 \\
\hline $\mathbf{3}-2000$ & 0.31 & 0.53 & 0.87 & 3.6 & 4.8 & 5.8 & 7.6 & 9.8 & 14 & 60 & 71 & 83 & 120 & 170 & 550 \\
\hline $\mathbf{4}-2000$ & 0.30 & 0.47 & 0.70 & 1.7 & 3.4 & 4.5 & 6.0 & 7.4 & 9.0 & 11 & 13 & 16 & 110 & 380 & 580 \\
\hline
\end{tabular}

Table 12-2. Cumulative oversize diameter distributions for the duplicate Group 7 initial characterization sample, TI576-G7-S-WL-PSD-2.

\begin{tabular}{|c|c|c|c|c|c|c|c|c|c|c|c|c|c|c|c|}
\hline \multirow[t]{2}{*}{ Test Condition } & \multicolumn{15}{|c|}{ 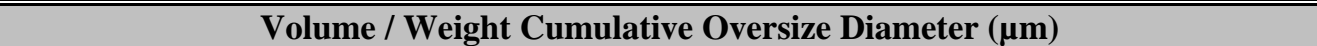 } \\
\hline & $1 \%$ & $5 \%$ & $10 \%$ & $20 \%$ & $25 \%$ & \begin{tabular}{|l|}
$30 \%$ \\
\end{tabular} & \begin{tabular}{|l|l|}
$40 \%$ \\
\end{tabular} & \begin{tabular}{|l|l|}
$50 \%$ \\
\end{tabular} & $60 \%$ & $70 \%$ & \begin{tabular}{|l|}
$75 \%$ \\
\end{tabular} & \begin{tabular}{|l|l|}
$80 \%$ \\
\end{tabular} & $90 \%$ & $95 \%$ & $99 \%$ \\
\hline $1-3000$ & 0.40 & 0.70 & 1.1 & 2.4 & 3.0 & 3.5 & 4.5 & 5.5 & 6.8 & 8.5 & 9.7 & 11 & 17 & 25 & 68 \\
\hline $2-4000$ & 0.40 & 0.71 & 1.2 & 2.5 & 3.0 & 3.6 & 4.6 & 5.8 & 7.2 & 9.4 & 11 & 14 & 35 & 61 & 100 \\
\hline $3-2000$ & 0.40 & 0.73 & 1.2 & 2.6 & 3.1 & 3.7 & 4.7 & 5.9 & 7.4 & 9.6 & 11 & 14 & 66 & 130 & 560 \\
\hline $4-2000$ & 0.40 & 0.70 & 1.2 & 2.5 & 3.0 & 3.5 & 4.5 & 5.5 & 6.8 & 8.6 & 9.9 & 12 & $\overline{19}$ & 100 & 56 \\
\hline
\end{tabular}

Table 12-3 shows the absolute relative percent difference (RPD) between primary and duplicate results, which is calculated as:

$$
R P D=\left|\frac{d_{d}(n)-d_{p}(n)}{d_{p}(n)}\right|
$$

where $d_{p}(n)$ and $d_{d}(n)$ are the primary and duplicate cumulative oversize diameters corresponding to the $n^{\text {th }}$ percentile. As before, this section does not provide discussion of the RPD results; however, the RPD for the $10^{\text {th }}, 50^{\text {th }}$, and $90^{\text {th }}$ diameter percentiles are presented and discussed in other sections of this interim report. 
WTP-RPT-169, Rev 0

Table 12-3. Relative percent difference between primary and duplicate Group 7 initial characterization samples (TI576-G7-S-WL-PSD -1 and -2, respectively) as a function of test condition.

\begin{tabular}{|l|c|c|c|c|c|c|c|c|c|c|c|c|c|c|c||}
\hline \multirow{2}{*}{ Test Condition } & \multicolumn{10}{|c|}{ Absolute RPD (\%) } \\
\cline { 2 - 14 } & $\mathbf{1 \%}$ & $\mathbf{5 \%}$ & $\mathbf{1 0 \%}$ & $\mathbf{2 0 \%}$ & $\mathbf{2 5 \%}$ & $\mathbf{3 0 \%}$ & $\mathbf{4 0 \%}$ & $\mathbf{5 0 \%}$ & $\mathbf{6 0 \%}$ & $\mathbf{7 0 \%}$ & $\mathbf{7 5 \%}$ & $\mathbf{8 0 \%}$ & $\mathbf{9 0 \%}$ & $\mathbf{9 5 \%}$ & $\mathbf{9 9 \%}$ \\
\hline $\mathbf{1}-3000$ & $19 \%$ & $17 \%$ & $9.1 \%$ & $47 \%$ & $49 \%$ & $50 \%$ & $54 \%$ & $71 \%$ & $86 \%$ & $87 \%$ & $87 \%$ & $87 \%$ & $87 \%$ & $85 \%$ & $75 \%$ \\
\hline $\mathbf{2}-4000$ & $18 \%$ & $12 \%$ & $6.5 \%$ & $52 \%$ & $53 \%$ & $55 \%$ & $62 \%$ & $81 \%$ & $83 \%$ & $83 \%$ & $82 \%$ & $80 \%$ & $61 \%$ & $45 \%$ & $29 \%$ \\
\hline $\mathbf{3}-2000$ & $30 \%$ & $37 \%$ & $44 \%$ & $28 \%$ & $35 \%$ & $37 \%$ & $38 \%$ & $40 \%$ & $47 \%$ & $84 \%$ & $84 \%$ & $83 \%$ & $45 \%$ & $24 \%$ & $1.8 \%$ \\
\hline $\mathbf{4}-2000$ & $34 \%$ & $49 \%$ & $67 \%$ & $42 \%$ & $13 \%$ & $22 \%$ & $25 \%$ & $25 \%$ & $24 \%$ & $23 \%$ & $24 \%$ & $30 \%$ & $82 \%$ & $74 \%$ & $3.4 \%$ \\
\hline
\end{tabular}

\section{Results: TI623-G7-CL-PSD (Group 7 Parametric Testing)}

Table 12-4 presents detailed cumulative oversize distributions (by volume/weight) for Group 7 parametric testing samples TI623-G7-CL-PSD. Results are reported as a function of test condition (see Table 6). This section does not provide discussion of the detailed distributions; however, a portion of these results (specifically, the $10^{\text {th }}, 50^{\text {th }}$, and $90^{\text {th }}$ diameter percentiles) are presented and discussed in other sections of this interim report.

Table 12-4. Cumulative oversize diameter distributions for the primary Group 7 parametric testing sample, TI623-G7-CL-PSD.

\begin{tabular}{|c|c|c|c|c|c|c|c|c|c|c|c|c|c|c|c|}
\hline \multirow[t]{2}{*}{ Test Condition } & \multicolumn{15}{|c|}{ Volume / Weight Cumulative Oversize Diameter $(\mu \mathrm{m})$} \\
\hline & $1 \%$ & $5 \%$ & $10 \%$ & $20 \%$ & $25 \%$ & $30 \%$ & $40 \%$ & $50 \%$ & $60 \%$ & $70 \%$ & $75 \%$ & $\mathbf{8 0} \%$ & $90 \%$ & $95 \%$ & $99 \%$ \\
\hline $1-3000$ & 0.35 & 0.49 & 0.61 & 0.86 & 1.0 & 1.2 & 1.5 & 2.1 & 3.2 & 5.7 & 7.5 & 9.8 & 78 & 140 & 210 \\
\hline $2-4000$ & 0.34 & 0.47 & 0.61 & 0.91 & 1.1 & 1.3 & 1.9 & 2.9 & 4.7 & 7.6 & 9.7 & 13 & 59 & 87 & 130 \\
\hline $3-2000$ & 0.40 & 0.57 & 0.72 & 1.0 & 1.2 & 1.4 & 1.9 & 2.7 & 4.3 & 6.5 & 7.9 & 9.8 & 93 & 140 & 530 \\
\hline $4-2000$ & 0.33 & 0.45 & 0.57 & 0.83 & 0.98 & 1.1 & \begin{tabular}{l|}
1.6 \\
\end{tabular} & 2.2 & 3.2 & 4.7 & 5.8 & 6.9 & 10 & 12 & \\
\hline
\end{tabular}

Results: TI624-G7-3-PSD (Low-solids matrix Group 7)

Table 12-5 present detailed cumulative oversize distributions (by volume/weight) for Group 7 CUF testing sample TI624-G7-3-PSD. Results are reported as a function of test condition (see Table 6). This section does not provide discussion of the detailed distributions; however, a portion of these results (specifically, the $10^{\text {th }}, 50^{\text {th }}$, and $90^{\text {th }}$ diameter percentiles) are presented and discussed in other sections of this interim report.

Table 12-5. Cumulative oversize diameter distributions for the Group 7 CUF testing sample, TI624-G7-3-PSD.

\begin{tabular}{|c|c|c|c|c|c|c|c|c|c|c|c|c|c|c|c|}
\hline \multirow[t]{2}{*}{ Test Condition } & \multicolumn{15}{|c|}{ Volume / Weight Cumulative Oversize Diameter $(\mu \mathrm{m})$} \\
\hline & $1 \%$ & $5 \%$ & $10 \%$ & $20 \%$ & $25 \%$ & $30 \%$ & $40 \%$ & $50 \%$ & $60 \%$ & $70 \%$ & $75 \%$ & $80 \%$ & $90 \%$ & $95 \%$ & $99 \%$ \\
\hline $1-3000$ & 1.0 & 6.5 & 28 & 49 & 55 & 60 & 71 & 81 & 93 & 110 & 110 & 120 & 150 & 170 & 210 \\
\hline $2-4000$ & 3.2 & 24 & 38 & 65 & 87 & 120 & 190 & 240 & 290 & 350 & 380 & 410 & 510 & 580 & 67 \\
\hline $3-2000$ & 3.1 & 19 & 38 & 110 & 130 & 140 & 170 & 190 & 220 & 250 & 270 & 290 & 350 & 410 & 570 \\
\hline $4-2000$ & 3.3 & 18 & 31 & 92 & 110 & 120 & 150 & 170 & 190 & 220 & 230 & 250 & 290 & 330 & 38 \\
\hline
\end{tabular}




\section{Appendix $\mathrm{F}$}

\section{Group 7 Rheology Methods and Analysis}




\section{Appendix F: Group 7 Rheology Methods and Analysis}

$\begin{array}{llll}\text { Date: } & \text { November 6, 2008 } & \text { Project No.: } & \mathbf{5 3 0 1 9} \\ \text { To: } & \text { Sandy Fiskum } & \text { Internal Distribution: } & \begin{array}{l}\text { Sandy Fiskum } \\ \text { Richard Daniel }\end{array} \\ \text { From: } & \text { Richard Daniel } & & \text { File/LB } \\ \text { Subject: } & \begin{array}{l}\text { Rheology of TBP Waste Sludge (Group } \\ \text { 7): Initial Characterization }\end{array} & \end{array}$

\section{Acronyms and Abbreviations}

$\begin{array}{ll}\begin{array}{ll}\text { Acronym } \\ \text { CCP }\end{array} & \text { Definition } \\ \text { CUF } & \text { Computational Computer Program } \\ \text { DI } & \text { Cells Unit Filter } \\ \text { LRB } & \text { Deionized (Water) } \\ \text { NIST } & \text { Laboratory Record Book } \\ \text { RPL } & \text { National Institute of Technology } \\ \text { RPP } & \text { Radiochemical Processing Laboratory } \\ \text { SAL } & \text { Shielded Analytical Laboratory } \\ \text { TBP } & \text { Tributyl Phosphate } \\ \text { TDP } & \text { Test Data Package } \\ \text { UDS } & \text { Undissolved Solids (Concentration) } \\ \text { WTP } & \text { Waste Treatment Plant (Support Program) }\end{array}$

\section{Introduction}

In fulfillment of the requirements of Test Plan TP-RPP-WTP-467 [1], the rheology of select Hanford tank waste samples was characterized at the Radiochemical Processing Laboratory (RPL). This interim characterization report presents rheology test results for a single initial characterization sample for waste processing Group 7, tributyl phosphate (TBP) waste sludge. The studies described herein will be limited to flow-curve and shear strength testing of this single waste group.

\section{Background}

Rheology is the science of material flow and deformation. For fluid systems, including pure liquids, mixtures of liquids, and suspensions of solids in liquids, the rheological properties of that system describe how it responds to an applied force or stress. When applied to solids, stress (below that required yield the solid material) induces a strain or finite deformation in the material. When applied to pure liquids, stress causes a continuous deformation of the substance or, in simpler terms, fluid flow. Suspensions of solids in liquids or liquid mixtures with internal structure can show a combination of both solid- and liquid-like behavior. In addition, the response of materials to force and deformation may not be constant. Changes in internal structure of materials that occur as a result of mechanical and chemical 
processes, such as breakage, precipitation of solids, and gelation, may alter the macroscopic flow and deformation properties. For the current study, two regions of tank waste flow behavior are considered: 1) incipient motion in settled tank waste solids and 2) non-elastic flow of tank waste slurries and supernates. Both are discussed in more detail in the following sub-sections.

\section{Characterization of Incipient Motion - Shear Strength Testing}

For settled tank waste slurry solids, a finite stress must be applied before the material will begin to flow. The stress required to transition the settled solids from elastic deformation to viscous flow is referred to as the shear strength, and its origin can be attributed to static and kinetic friction between individual particles and/or aggregates, strength of the matrix supporting the coarse fraction (i.e., the interstitial fluid), and sludge cohesion arising from interparticle adhesive forces such as van der Waals forces. The resistance of settled solids to motion can be quantified through shear strength testing.

In the current study, measurement of shear strength will be accomplished using the vane method. For the vane technique, the stress required to begin motion is determined by slowly rotating a vane immersed in the test sample's settled solids while continuously monitoring the resisting torque as a function of time. A material's static shear strength is then associated with the maximum torque measured during the transition from initial to steady-state vane rotation. A typical experimental setup for measuring shear strength with a vane is shown in Figure 1. An example torque versus time curve is shown in Figure 2.
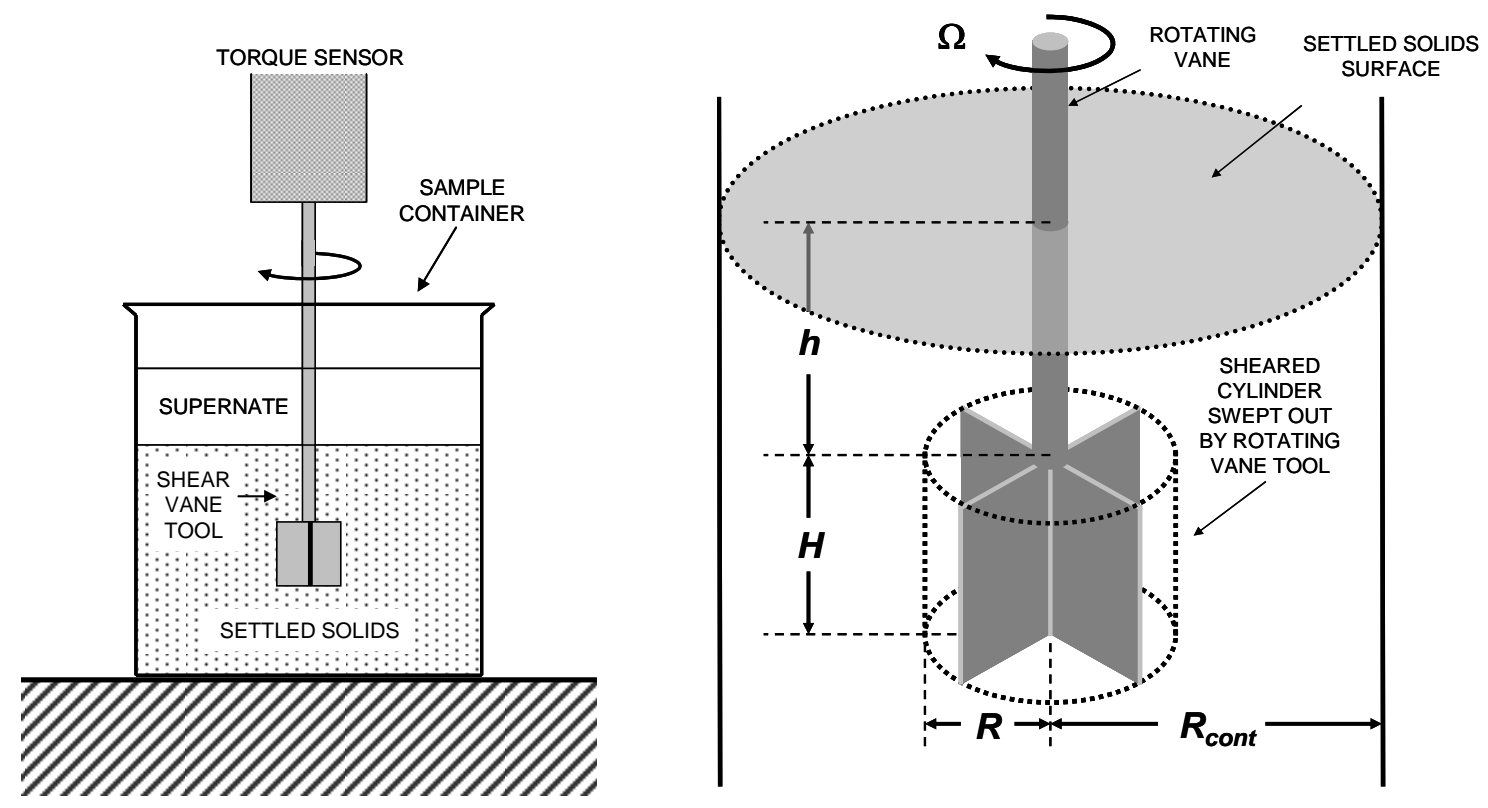

Figure 1. Typical shear strength experimental setup. A sludge / slurry sample in a container of radius $R_{\text {cont }}$ is allowed to settle over a given period of time. A vane tool attached to a viscometer (i.e., a torque sensor) is immersed into the settled solids portion of a sludge or slurry to a depth $h$ (relative to the top of the vane blades). The vane blades have a radius $R$ and a height $H$. The vane is then slowly rotated at a constant rotational speed, $\Omega$. The torque versus time profile is recorded and the maximum torque required to initiate rotation determined. The shear strength is then calculated from this maximum torque based on the assumption of a uniform stress distribution on the known vane tool geometry. 
The maximum torque required for incipient motion is dependent on vane geometry. To account for vane geometry effects, shear strength is expressed in terms of a uniform and isotropic stress acting over the surface area of the cylinder of rotation swept out by the vane. This uniform stress (i.e., the shear strength of the material) is related to the maximal torque during incipient motion by the equation [2]:

$$
\tau_{S S}=\frac{M_{\max }}{4 \pi R^{3}\left(\frac{H}{2 R}+\frac{1}{3}\right)}
$$

Here, $\tau_{s s}$ is the shear strength $\left[\mathrm{N} / \mathrm{m}^{2}\right], M_{\max }$ is the maximum torque [N·m], and $R$ and $H$ are the radius and height of the cylinder of rotation swept out by the vane $[\mathrm{m}]$. Because the shear band observed upon slow rotation of the vane does not extend appreciably beyond the vane paddles, $R$ and $H$ are taken to be the dimensions of the vane itself.

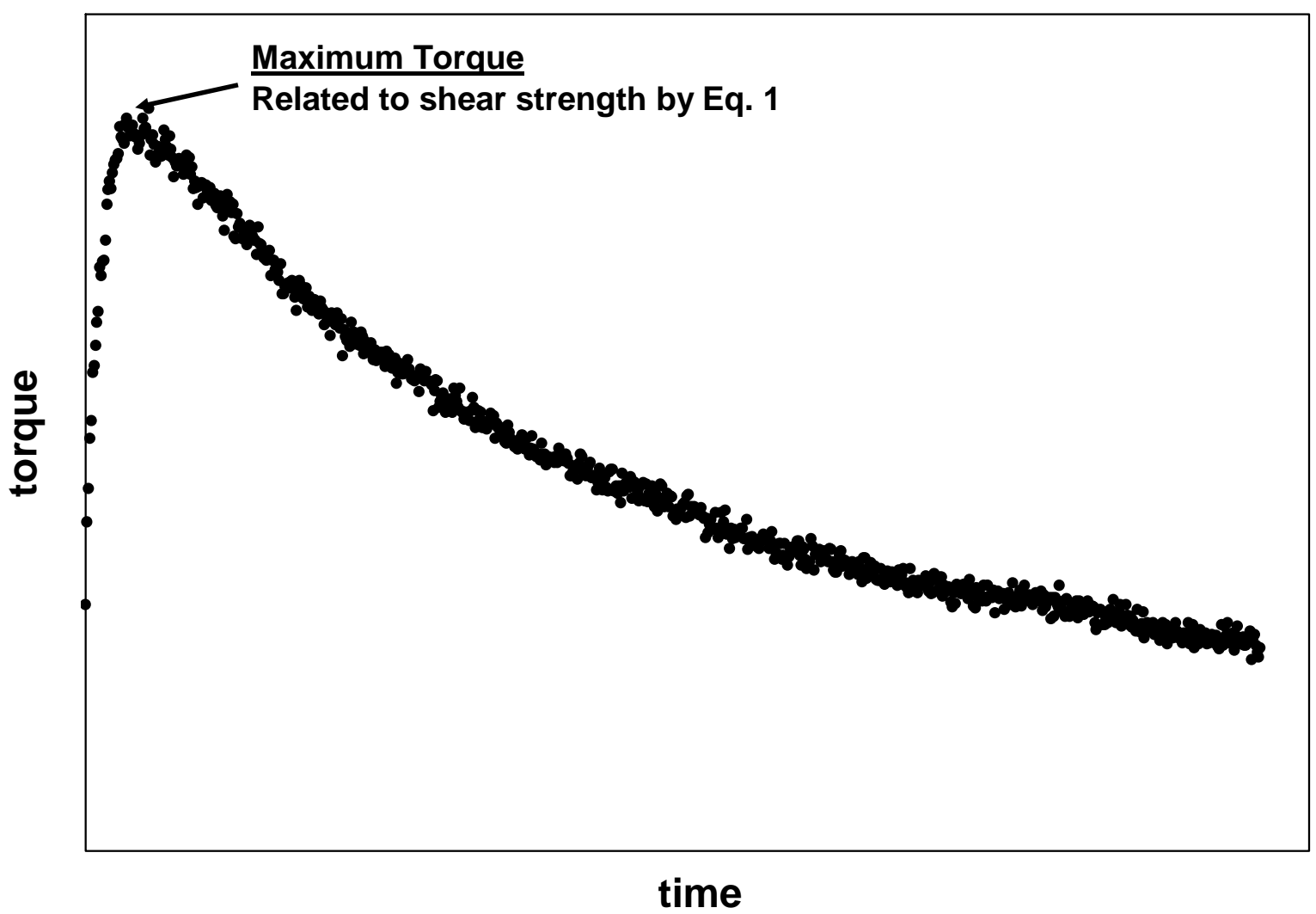

Figure 2. Example shear strength torque versus time curve. The maximum torque corresponds to the onset of motion. Here, the stress applied by vane rotation is finally sufficient to overcome frictional, cohesive, and other structural forces stabilizing the settled solids. 
Proximity of the vane to the sample container inner surfaces as well as the free surface of the settled solids can impact shear strength results. As such, certain geometric constraints must be satisfied for the test to be considered independent of container geometry. These constraints are outlined in Table 1.

Table 1. Vane immersion depth and container geometry constraints for shear strength tests using the vane technique.

\begin{tabular}{||l|l|l||}
\hline Constraint & Criterion & For $\mathbf{8} \times \mathbf{1 6} \mathbf{~ m m}(\mathbf{R} \times \mathbf{H})$ Vane \\
\hline Vane height to radius & $\mathrm{H}<7 \mathrm{R}$ & $\mathrm{H}<56 \mathrm{~mm}$ (Satisfied) \\
\hline Container radius to vane radius & $\mathrm{R}_{\text {cont }}>2 \mathrm{R}$ & $\mathrm{R}_{\text {cont }}>16 \mathrm{~mm}$ \\
\hline Immersion depth to vane height & $\mathrm{h}>\mathrm{H}$ & $\mathrm{h}>16 \mathrm{~mm}$ \\
\hline $\begin{array}{l}\text { Separation between bottom of vane and } \\
\text { container floor }\left(\mathrm{h}_{\text {floor }}\right)\end{array}$ & $\mathrm{h}_{\text {floor }}>0.5 \mathrm{H}$ & $\mathrm{h}_{\text {floor }}>8 \mathrm{~mm}$ \\
\hline \hline
\end{tabular}

\section{Characterization of Fluid Flow - Flow Curve Testing}

Non-elastic flow of tank waste slurries and supernatants is characterized with rotational viscometry. The goal of rotational viscometry is measurement of a material's flow curve, which describes the shear stress response, $\tau$, as a function of applied shear rate, $\dot{\gamma}$ (also called the rate-ofstrain). The result of a flow curve measurement is a set of $\tau$ versus $\dot{\gamma}$ measurements, which are called flow curve data. Flow curve data can be interpreted with several constitutive equations that relate viscous stress to shear-rate. Such analysis allows the flow behavior over a broad range of conditions to be described with just a few rheological descriptors such as viscosity, yield stress, consistency, and flow index.

A concentric cylinder rotational viscometer operated in controlled-rate mode will be used for flow curve testing of tank waste slurries and supernatants. These viscometers operate by placing a given volume of test sample into a measurement cup of known geometry. A cylindrical rotor attached to a torque sensor is then lowered into the sample until the slurry is even with, but does not cover, the top of the rotor. Both the radius and height of the rotor are known such that the gap distance between cup and rotor and surface area of fluid contact can be determined. In addition, the top and bottom of the rotor have recessed surfaces such that the fluid only contacts the radial surfaces of the rotor. A filled rotor-incup test geometry is shown in Figure 3. Determination of the fluid flow properties of the sample is made by spinning the rotor at a known rotational speed, $\Omega$, and measuring the resisting torque, $M$, acting on the rotor. Because fluid only contacts the rotor on the radial surfaces of rotation, all of the force resisting steady-state rotation can be ascribed to shearing of the fluid in the cup-rotor gap. Assuming an isotropic fluid and cup and rotor dimensions as shown in Figure 3, the torque acting on the rotor can be directly related to the shear stress at the rotor using the equation,

$$
\tau=\frac{M}{2 \pi H R_{I}^{2}}
$$

Shear stress has units of force per area $\left[\mathrm{N} / \mathrm{m}^{2}\right]$. Calculation of the fluid shear rate at the rotor is complicated by the fact that shear rate depends on both on the measurement system geometry and the fluid rheological properties. For the simplest fluids (i.e., Newtonian fluids) the shear rate of the fluid at the rotor can be calculated given the geometry of the cup rotor shear (see Figure 3) by using the equation, 


$$
\dot{\gamma}=\left(\frac{2 R_{O}^{2}}{R_{O}^{2}-R_{I}^{2}}\right) \Omega
$$

Eq. 3

Here, shear rate has units of inverse seconds $\left[\mathrm{s}^{-1}\right]$. Calculation of shear rate for materials showing more complex shear stress versus shear rate behavior (i.e., non-Newtonian fluids) requires input of flow curve parameters such as yield stress and degree of shear-thinning or shear-thickening. Because the required input parameters are typically not known prior to measurement, this requirement is typically circumvented by using a cup and rotor system with a small gap $(\sim 1 \mathrm{~mm})$ such that shear rate effects introduced by fluid properties are minimized. For these systems, Eq. 3 provides an accurate determination of shear rate for non-Newtonian materials.

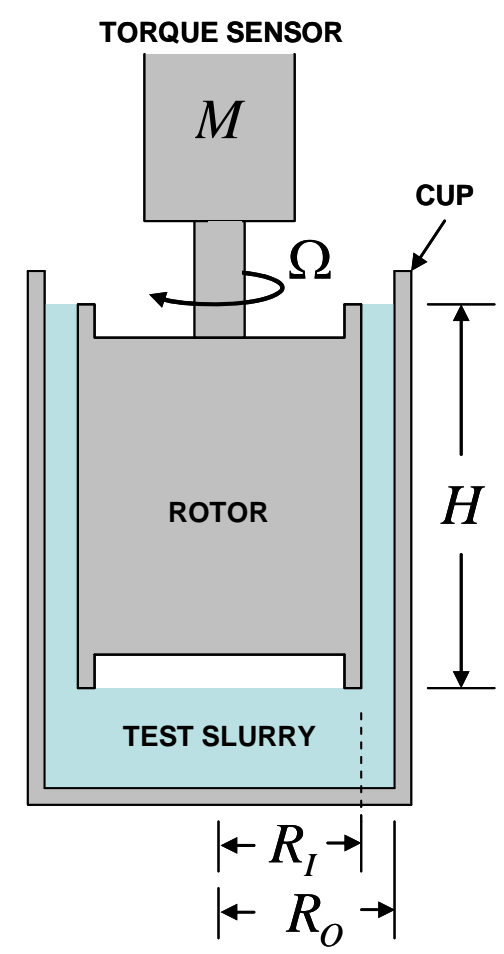

Figure 3. Rotor and cup geometry used in rotational viscometry testing.

Shear rates examined in this study will span approximately 1 to $1000 \mathrm{~s}^{-1}$ and are typical of the order of magnitude of shear rates experienced in pipeline flow [3]. Pipeline flows encountered in the Waste Treatment Plant may exceed the range studied herein. As such, mechanistic models of waste rheology shall be employed to fit shear stress versus shear rate data, allowing extension to shear rates beyond those studied herein.

The resistance of a fluid to flow can be described in terms of the fluid's apparent viscosity, $\eta_{a p p}$, which is defined as the ratio of the shear stress to shear rate: 


$$
\eta_{a p p}=\frac{\tau}{\dot{\gamma}}
$$

Often the shear stress and viscosity vary as a function of shear rate. Since the viscosity is defined as the ratio of shear stress to shear rate, the units of the variable are Pa·s. Typically, viscosity is reported in units of centipoise (cP; where $1 \mathrm{cP}=1 \mathrm{mPa} \cdot \mathrm{s})$.

Flow curve data are usually combined plots of $\tau$ and $\eta_{\text {app }}$ as a function of $\dot{\gamma}$. As stated above, flow curve data can be interpreted with several constitutive equations (i.e., flow curves), allowing characterization of that data with just a few rheological descriptors. The behavior of tank waste sludges, slurries, and supernates can be described by five common flow curve equations. These are:

- Newtonian - Newtonian fluids flow as a result of any applied stress and show constant viscosity over all shear conditions. The flow curve for Newtonian fluids is,

$$
\tau=\eta \dot{\gamma}
$$

where $\eta$ is the Newtonian viscosity.

- Power-Law (Ostwald) - Power law fluids flow as a result of any applied stress and have viscosities that either increase or decrease with increasing shear rate. The are described by,

$$
\tau=m \dot{\gamma}^{n}
$$

where $m$ is the power law consistency index and $n$ is the power law index. Power law fluids with $n<1$ are referred to as psuedoplastic (shear-thinning), whereas power law fluids with $n>1$ are referred to as dilatant (shear-thickening).

- Bingham Plastic - Bingham plastics are fluids that show finite yield points. This stress (i.e., the yield stress) must be exceeded before these types of materials flow. Once flow is initiated, the stress response of the material is Newtonian over the rest of the shear rate range. Bingham plastics are described by,

$$
\tau=\tau_{o}^{B}+k_{B} \dot{\gamma}
$$

where $\tau_{o}^{B}$ is the Bingham yield index and $k_{B}$ is the Bingham consistency index.

- Herschel-Bulkley - Fluids that behave in accordance with a Herschel-Bulkley model show a finite yield followed by power-law behavior over the rest of the shear rate range. They are described by,

$$
\tau=\tau_{o}^{H}+k_{H} \dot{\gamma}^{b}
$$


where $\tau_{o}^{H}$ is the Herschel-Bulkley yield index, $k_{H}$ is the Herschel-Bulkley consistency index, and $b$ is the Herschel-Bulkley power law index.

- $\quad$ Casson - Fluids that behave in accordance with a Casson model show a finite yield followed by psuedoplastic behavior. They are described by,

$$
(\tau)^{0.5}=\left(\tau_{o}^{C}\right)^{0.5}+\left(k_{C} \dot{\gamma}\right)^{0.5} \quad \text { Eq. } 9
$$

where $\tau_{o}^{C}$ is the Casson yield index and $k_{C}$ is the Casson consistency index. Although more limited in the types of flow behavior it can describe relative to the Herschel-Bulkley equation, the Casson model is popular because it is capable of accurately describing many shear-thinning fluids and because units on the parameters are more physically meaningful (e.g., the consistency is in $\mathrm{Pa} \cdot \mathrm{s}$ versus Pa$\cdot \mathrm{s}^{\mathrm{n}}$ for the Herschel-Bulkley model).

Power-law fluids, Bingham plastics, Herschel-Bulkley, and Casson fluids are referred to as nonNewtonian fluids. In generally, liquids without internal and/or interconnected structures (such as tank waste supernatants) are Newtonian. Sludges and slurries are typically non-Newtonian, but their exact behavior depends on the concentration of solids and suspending phase chemistry. Sufficiently dilute slurries may show Newtonian behavior.

\section{Sample and Analysis}

A single waste sample, Jar TI515-G7-AR-RH1, was employed for shear strength and flow curve testing of waste Group 7. This sample was derived from homogenization of tank wastes associated with processing Group 7. Flow curve testing was performed on July 31, 2008; shear strength testing was performed on October 16, 2008. Flow curve and shear strength analyses produced the following reportable data for the Group 7 initial characterization sample:

- a single measurement of settled solids shear strength after 48 to 72 hours

- flow curve data for Group 7 slurries at $25^{\circ} \mathrm{C}, 40^{\circ} \mathrm{C}$, and $60^{\circ} \mathrm{C}$

- best-fit Bingham-Plastic and Casson parameters at $25^{\circ} \mathrm{C}, 40^{\circ} \mathrm{C}$, and $60^{\circ} \mathrm{C}$

\section{Instrumentation}

Rheological characterization was accomplished using a Rotovisco® RV20 Measuring System equipped with an M5 measuring head and RC20 controller. These components were purchased from HAAKE Mess-Technik GmbH u. Co. (now the Thermo Electron Corporation, Madison, WI 53711). This system is installed in Cell 4 of the Shielded Analytical Laboratory (SAL) at the Radiochemical Processing Laboratory (RPL). The M5 measuring head (SN\# 902398) is a "Searle" type viscometer capable of producing rotational speeds up to $500 \mathrm{RPM}$ and measuring torques up to $0.049 \mathrm{~N} \cdot \mathrm{m}$. The

minimum rotational speed and torque resolution achievable by this measuring head are 0.05 RPM and $0.49 \mathrm{mN} \cdot \mathrm{m}$, respectively. Table 2 summarizes the M5 measuring system information. 
Table 2. Summary of Haake RV20 system with M5 measuring head.

\begin{tabular}{||l|l||}
\hline \hline Analyzer: & $\begin{array}{l}\text { Rotorvisco }{ }^{\circledR} \text { RV20 Measuring System M with M5 } \\
\text { Measuring Head. }\end{array}$ \\
\hline Measurement principle: & Controlled Rate \\
\hline Serial Number: & 902398 \\
\hline Torque Sensor Range & 0.49 to $49 \mathrm{mN} \cdot \mathrm{s}$ \\
\hline Rotational Rate Range & 0.05 to $500 \mathrm{RPM}$ \\
\hline
\end{tabular}

Specific measurement tools such as cup and rotor assemblies and shear vanes are attached to measure selected rheological properties. Shear strength measurements employ $8 \mathrm{~mm} \times 16 \mathrm{~mm}(\mathrm{R} \times \mathrm{H})$ shear vane tool. Flow curve measurements employed an MV1 stainless steel measuring cup and rotor. The dimensions of the MV1 and vane measuring systems are listed in Table 3.

Table 3. Vane and Cup and Rotor Measuring System Dimensions.

\begin{tabular}{||l|c|c|c|c||}
\hline \hline Measuring System & $\begin{array}{c}\text { Vane/Rotor } \\
\text { Radius }\end{array}$ & $\begin{array}{c}\text { Vane/Rotor } \\
\text { Height }\end{array}$ & Cup Radius & Gap Width \\
\hline Vane Tool & $8 \mathrm{~mm}$ & $16 \mathrm{~mm}$ & $>16 \mathrm{~mm}(\mathrm{a})$ & $>8 \mathrm{~mm} \mathrm{(a)}$ \\
\hline MV1 & $20.04 \mathrm{~mm}$ & $60 \mathrm{~mm}$ & $21 \mathrm{~mm}$ & $0.96 \mathrm{~mm}$ \\
\hline (a) Vane tests must satisfy the requirements outlined in Table 1. \\
\hline
\end{tabular}

Temperature control is achieved using a combination of the standard measuring system temperature jacket and a Cole-Parmer ${ }^{\circledR}$ Polystat ${ }^{\circledR}$ Temperature-Controlled Recirculator, Model Number C-12920-00. This recirculator allows heating and cooling of recirculation fluid to the rheometer over $-5^{\circ}$ to $80^{\circ} \mathrm{C}$ with a stability of $\pm 0.5^{\circ} \mathrm{C}$. The temperature jacket is used only for flow curve measurements. It connects the measuring head to the measuring system, centers the cup, and provides heat transfer area between cup and recirculating fluid. The recirculating unit is located next to, but outside, the SAL Cell 4. The recirculator is connected to the water jacket through a combination of stainless steel piping (outside of cell) and flexible fiber reinforced plastic hose (inside cell). The desired temperature is set using the digital control interface on the recirculating unit. Fluid is circulated between the recirculator and jacket until the desired temperature is achieved at the jacket. Jacket temperature is monitored using a Type-K thermocouple (Omega Model TJ36-CASS-116-G-6-CC) calibrated over $0^{\circ}$ to $100^{\circ} \mathrm{C}$ connected to a multichannel display unit located in the SAL Gallery. Temperature control is employed only for flow curve measurements. Shear strength measurements are carried out at ambient temperature. Details of the temperature measurement and display calibration are given in Table 4. It should be noted that only the first two channels of the temperature display were calibrated. All measurements taken herein employ channel 1.

Temperature control and measurement employed thermocouple 22887 and display 22890. For shear strength measurement of Group 7 settled solids, the ambient in-cell temperature was measured using the thermocouple attached to the Cells Unit Filter (CUF) slurry reservoir installed in SAL Cell 5 (Calibration Barcode 24072). 
WTP-RPT-169, Rev 0

Table 4. Calibration information for temperature measurement and display systems.

\begin{tabular}{||l|c|c|c|c|c||}
\hline \hline System & Serial \# & $\begin{array}{c}\text { Calibration } \\
\text { Barcode }\end{array}$ & Range Calibrated & $\begin{array}{c}\text { Date } \\
\text { Calibrated }\end{array}$ & Date Due \\
\hline $\begin{array}{l}\text { Type-K } \\
\text { Thermocouple }\end{array}$ & $\mathrm{n} / \mathrm{a}$ & 22887 & $0^{\circ}$ to $100^{\circ} \mathrm{C}\left( \pm 2^{\circ} \mathrm{C}\right)$ & $4 / 4 / 2008$ & $4 / 4 / 2009$ \\
\hline $\begin{array}{l}\text { Temperature } \\
\text { Display }\end{array}$ & 6220071 & 22890 & $0^{\circ}$ to $100^{\circ} \mathrm{C}\left( \pm 2^{\circ} \mathrm{C}\right)$ & $4 / 2 / 2008$ & $4 / 2 / 2009$ \\
\hline $\begin{array}{l}\text { Type-K } \\
\text { Thermocouple }\end{array}$ & $\mathrm{n} / \mathrm{a}$ & 24072 & $0^{\circ}$ to $110^{\circ} \mathrm{C}\left( \pm 2^{\circ} \mathrm{C}\right)$ & $5 / 28 / 2008$ & $5 / 28 / 2009$ \\
\hline
\end{tabular}

Rheometer control and data acquisition are accomplished through remote computer connection using the RheoWin Pro Job Manager Software, Version 2.96. The RheoWin software serves as a central program for obtaining, processing, and recording to disk data from the RV20-M5 Measuring System. During measurement, the software automatically converted rotor torque readings into shear stresses based on the appropriate A-factor conversion, such that

$$
\tau=A M
$$

For the cup and rotor system, the A-factor is defined by

$$
A=\frac{1}{2 \pi H R_{I}^{2}}
$$

The vane tool, the A-factor is defined as:

$$
A=\frac{1}{4 \pi R^{3}\left(\frac{H}{2 R}+\frac{1}{3}\right)}
$$

A-factors for MV1 and $8 \mathrm{~mm} \times 16 \mathrm{~mm}$ vane sensor systems are $6570 \mathrm{~m}^{-3}$ and $\sim 117,000 \mathrm{~m}^{-3}$, respectively. For flow curve testing, the RheoWin software also automatically converted the rotational rate readings into shear rates based on a factory-set "M-factor”, such that:

$$
\dot{\gamma}=M_{R} \Omega
$$

where $\Omega$ is the rotational rate in radians per second, and $M_{R}$ is the "M-factor". The M-factor is defined as

$$
M=\left(\frac{2 R_{O}^{2}}{R_{O}^{2}-R_{I}^{2}}\right)
$$

For the MV1 sensor system, the M-factor is 22.350. The RheoWin software also allows postmeasurement processing and interpretation of data. Specifically, it can be used to determine maxima points in shear strength testing and fit flow curve data to any flow curve model (i.e., Eqs. 5-9). 


\section{Governing Test Plan, Procedure, and Test Instructions}

The test plan governing the physical characterizations for these samples is River Protection Project - Waste Treatment Plant Support Program (RPP-WTP) document number TP-RPP-WTP-467, Revision 0 [1]. Operation of the HAAKE RV20-M5 Measurement System is governed by RPLCOLLOID-02, Revision 1 [4].

\section{Experimental}

The waste slurry and settled solids were tested "as-is"; that is, no sample treatment was performed prior to analysis with exception of the mechanical agitation required to disperse the waste solids in sample jar TI515-G7-AR-RH1. The sample slurry jars had been stored undisturbed, and the sludge solids had settled to the bottom of the sample jars. Immediately before flow curve testing, the solids in jar TI515-G7-AR-RH1 were dispersed uniformly by vigorously shaking the jar by remote manipulator. After shaking, the sample jar was moved to Cell 4, and a sub-sample of the slurry quickly transferred to the rheometer measuring cup to minimize the potential for settling and evaporation. Visual inspection of the slurry during and after transfer found no immediately observable solids settling. Shear strength testing was done at a later date. Before shear strength testing, settled slurry solids were again dispersed uniformly by vigorously shaking the jar by remote manipulator. The dispersion was then transferred to Cell 4 and allowed to settle for 72 hours. After this period of time, the shear strength of the settled solids was measured.

\section{Instrument Performance Check}

As required by RPL-COLLOID-02, the performance of the Haake M5 rheometer must be verified at the beginning of each series of analyses (with the period between performance checks not to exceed 30 days during use). Checks are performed using Newtonian viscosity standards certified by methods traceable to the United States National Institute of Standards and Technology (NIST). Checks verify that the Haake M5 rheometer can measure the standard's viscosity to within $10 \%$ for fluids of $10 \mathrm{cP}$ or greater and to within $15 \%$ for fluids less than $10 \mathrm{cP}$ at the temperature listed on the certificate of analysis.

For the measurements described in this report, the performance check employed General Purpose Silicone Fluids purchased from Brookfield Engineering Laboratories, Inc. (Middleboro, Massachusetts, USA, 02346). Silicone oils are single phase liquids and have no suspended solids. For testing, two standards were used: Brookfield Fluid 10 and Brookfield Fluid 100. Tables 5 to 6 provide a summary of each viscosity standard's properties. Standards are traceable back to their certificate of analysis through a unique lot number. 
WTP-RPT-169, Rev 0

Table 5. Properties of Brookfield Fluid 10.

\begin{tabular}{||l|l||}
\hline Fluid & 10 \\
\hline Viscosity & $9.1 \mathrm{cP}$ \\
\hline Temperature & 25 \\
\hline Lot Number & 021308 \\
\hline Expires & April 2009 \\
\hline
\end{tabular}

Table 6. Properties of Brookfield Fluid 100.

\begin{tabular}{||l|l||}
\hline \hline Fluid & 100 \\
\hline Viscosity & $98.2 \mathrm{cP}$ \\
\hline Temperature & 25 \\
\hline Lot Number & 020108 \\
\hline Expires & April 2009 \\
\hline
\end{tabular}

Performance checks consisted of temperature controlled flow curve measurements that employed the MV1 measuring cup and rotor. The instrument performance check covering the period of testing for Group 7 slurry flow curve measurement was run on July $16^{\text {th }}$, 2008; the performance check covering Group 7 settled solids shear strength measurements took place on October $7^{\text {th }}$, 2008. In both cases, execution of performance verifications was as follows:

1. The MVI rotor was installed on the M5 measuring head.

2. The temperature jacket was installed and the recirculator turned on and set to $25^{\circ} \mathrm{C}$. The jacket was allowed to achieve temperature equilibrium before continuing.

3. Approximately 40 to $50 \mathrm{~mL}$ of viscosity fluid was added to the MV1 cup.

4. The measuring cup was installed into the water jacket by slowly raising it on a laboratory jack stand. During installation, the cup slides into the base of the water jacket where it slides over the rotor. The rotor volume displaces the test material, forcing it to fill the gap between cup and rotor. While the cup was being raised, the liquid level relative to the top of the rotor was monitored through an opening in the top of the water jacket using a small digital video camera installed in-cell. The cup was raised until the test material was observed to spill over the top of the rotor. Before continuing, an attempt was made to remove the excess viscosity standard from the top of the rotor using a plastic transfer pipette. However, 1 to $3 \mathrm{~mL}$ of excess test liquid could not be retrieved and remained in the upper rotor recess during flow curve measurement.

5. The viscosity standard was left undisturbed in the measuring system for 5 minutes to allow temperature equilibration.

6. The material flow curve data were measured. Rheological analysis was performed over a 15minute period, split into three 5-minute intervals. Over the first 5 minutes, the shear rate was smoothly increased from zero to $1000 \mathrm{~s}^{-1}$. For the second 5 minutes, the shear rate is held constant at $1000 \mathrm{~s}^{-1}$. For the final 5-minutes, the shear rate was smoothly reduced back to zero. During this time, the resisting torque and rotational rate is continuously monitored and recorded.

After the measurement, flow curve data were automatically fit to a Newtonian model (Eq. 5) by the RheoWin software. The regressed value was saved to the measurement file and was also transcribed into the LRB. The absolute percent error, $E$, between the measured viscosity, $\eta_{\text {meas }}$, and that listed on the certificate of analysis, $\eta_{\text {list }}$, was calculated as:

$$
E=\left|\frac{\eta_{\text {meas }}-\eta_{\text {list }}}{\eta_{\text {list }}}\right| \times 100 \%
$$

The performance check is considered acceptable if $E$ is less than $10 \%$ for fluids with list viscosities greater than or equal to $10 \mathrm{cP}$ or is less than $15 \%$ for fluids with list viscosities less than $10 \mathrm{cP}$. Before the start of any quality affecting measurements of Group 7 rheology, the RV20-M5 was verified to be in acceptable performance. Table 7 lists the results of each performance verification/check carried out in 
association with Group 7 Initial Characterization efforts. As indicated in the table, the RV20-M5 measuring system showed acceptable performance for all tests.

Table 7. Results of rheometer performance checks.

\begin{tabular}{||l|c|c|c|c|c||}
\hline Fluid & $\begin{array}{c}\text { Period of } \\
\text { Performance }\end{array}$ & $\begin{array}{c}\text { List } \\
\text { Viscosity } \\
\text { (cP) }\end{array}$ & $\begin{array}{c}\text { Measured } \\
\text { Viscosity } \\
\text { (cP) }\end{array}$ & $E$ & Acceptable \\
\hline Brookfield Fluid 10 & July ‘08 & 9.1 & 9.9 & $8.7 \%$ & Yes \\
\hline Brookfield Fluid 100 & July '08 & 98.2 & 100.9 & $2.7 \%$ & Yes \\
\hline Brookfield Fluid 100 & October '08 & 98.2 & 99.1 & $0.9 \%$ & Yes \\
\hline
\end{tabular}

\section{Shear Strength Testing}

A single measurement of shear strength was made on settled solids in sample jar TI515-G7-ARRH1. Because the volume of settled solids in the test jar as it was provided for shear strength measurement was limited, it was not possible to satisfy the insertion depth and floor clearance constraints outlined in Table 1. After 72 hours of settling, the settled solids provided approximately $20 \mathrm{~mm}$ of height of settled solids for testing. To avoid contact with the floor of the sample jar, the vane was immersed until the top of the blades were just beneath the surface of the solids. Because the constraints in Table 1 were not satisfied during testing, the shear strength result reported herein is not independent of container geometry.

The settled solids in test jar TI515-G7-AR-RH1 were dispersed 72 hours before testing and allowed to settle undisturbed for the entire period between dispersion and testing. The shear strength test was performed directly in the $120 \mathrm{~mL}$ Qorpak sample jar in which the slurry was provided. Shear strength testing was conducted as follows:

1. A $8 \times 16 \mathrm{~mm}$ (radius by height) shear vane tool was installed on the measuring head.

2. The sample jar being tested was opened and positioned on a laboratory jack stand directly beneath the measuring head/vane.

3. The lab jack was slowly raised until the maximum vane insertion depth was achieved.

4. The vane was slowly rotated at 0.3 RPM for 240 seconds. For the entire duration of rotation, the time, rotational rate, and vane torque were continuously monitored and recorded.

5. At the completion of testing, the vane was removed from the settled solids and rinsed clean of residual solids with deionzied (DI) water. The sample jar was closed and set aside.

At the end of the measurement, the software parsed the shear stress versus time data and determined and reported the maximum measured shear stress (i.e., the material's shear strength). The curve of shear stress versus time was visually inspected using the RheoWin software to verify that the appropriate stress maximum was selected. All information relevant to the measurement, including raw and calculated measurement results and sample information, are saved to disk using the RheoWin file format and a unique filename identifier. The shear strength and filename associated with that measurement, along with a basic sample identifier, are recorded in a Laboratory Record Book (LRB). A separate data file is used for each shear strength measurement. It should be noted that shear strength measurements were conducted at ambient cell temperature $\left(27.6^{\circ} \mathrm{C}\right)$. 
WTP-RPT-169, Rev 0

\section{Flow Curve Testing}

Flow curve testing for slurry sample TI515-G7-AR-RH1 employed an MV1 cup and rotor. Each flow curve measurement was accomplished as follows:

1. The MV1 rotor was installed on the measuring head.

2. The temperature jacket was installed and the recirculator turned on and set to $25^{\circ} \mathrm{C}$. The jacket was allowed to achieve temperature equilibrium.

3. The test sample was transferred from its source jar into the MV1 measurement cup. Sample was added to the cup until the fluid level was above the first (i.e., lowest) cup level marker but still below the second level marker. This typically required 40 to $50 \mathrm{~mL}$ of sample. Gross material transfer was accomplished by pouring the sample into the test container until a rough estimate of the required sample volume was obtained. Fine level adjustments were made by adding and removing material to and from the measuring cup using a plastic transfer pipette.

4. The measuring cup was installed into the water jacket by slowly raising it on a laboratory jack stand. The cup was raised until the test material was observed to spill over the top of the rotor. Before continuing, excess material was removed from the top of the rotor (to the extent possible) using a plastic transfer pipette. In most cases, there was approximately 1-3 $\mathrm{mL}$ of excess material that could not be removed from the upper rotor recess.

5. A moisture barrier was wetted and installed over the opening at the top of the temperature jacket. This barrier is a stainless steel clamshell collar lined with a sponge. It serves to minimize sample evaporation by blocking openings at the top of the water jacket (where the sample is exposed to air) and by humidifying the air space above the sample.

6. The sample was left undisturbed in the measuring system for 5 minutes to allow temperature equilibration.

7. The sample was sheared for 3 minutes to break sample structure, to attempt re-suspension any settled slurry particles, and to verify that the rotor was properly centered.

8. The material flow curve data were measured. Rheological analysis was performed over a 15minute period, split into three 5-minute intervals. Over the first 5 minutes, the shear rate was smoothly increased from zero to $1000 \mathrm{~s}^{-1}$. For the second 5 minutes, the shear rate was held constant at $1000 \mathrm{~s}^{-1}$. For the final 5-minutes, the shear rate was smoothly reduced back to zero. During this time, the resisting torque and rotational rate were continuously monitored and recorded.

9. The flow curve data for $25^{\circ} \mathrm{C}$ were saved using the RheoWin file format and a unique filename identifier. Sample information and the associated RheoWin filename were entered into the LRB.

10. The cup was raised so that fresh sludge/slurry filled the gap. Excess sludge was pipetted from the top. The moisture guard was, removed, re-wetted, and then re-installed.

11. The flow curve measurement at $25^{\circ} \mathrm{C}$ was repeated as per steps 7 through 9 .

12. The temperature set point was set to $40^{\circ} \mathrm{C}$. Once, the jacket had reached the temperature set point, the sample was allowed an additional 5 minutes to reach temperature equilibrium. The cup was raised so that fresh sludge/slurry filled the gap. Excess sludge was pipetted from the top. The moisture guard was, removed, re-wetted, and then re-installed.

13. The flow curve at $40^{\circ} \mathrm{C}$ was measured as per steps 7 through 9 .

14. The temperature set point was set to $60^{\circ} \mathrm{C}$. Once, the jacket had reached the temperature set point, the sample was allowed an additional 5 minutes to reach temperature equilibrium. The cup was raised so that fresh sludge/slurry filled the gap. Excess sludge was pipetted from the top. The moisture guard was, removed, re-wetted, and then re-installed.

15. The flow curve at $60^{\circ} \mathrm{C}$ was measured as per steps 7 through 9 .

16. At the end of testing, the measuring cup was removed from the system. The test material was returned to its original container. The measuring system was disassembled. Any slurry or 
precipitated salt solids remaining in the cup or rotor were cleaned-off using by rinsing with copious amounts of water and by wiping down the instrument with a damp cloth.

At the end of each flow curve or constant rotation measurement, all information relevant to the measurement, including raw and calculated measurement results and sample information, were saved to disk using the RheoWin file format and a unique filename identifier. The filename, temperature, start and end of temperature equilibration, and a basic sample identifier were recorded in a Laboratory Record Book (LRB). A separate data file was used for each flow curve measurement.

Post-measurement analysis and review of flow curve data were accomplished using the RheoWin Pro Data Manager software, Version 2.96. For each set of measurement data, the flow curve data was characterized by determining the best-fit parameters for the constitutive equation outlined in Section 2.0 of this report (i.e., the Newtonian, Power-Law, Bingham-Plastic, Herschel-Bulkley, and Casson flow models). This analysis utilized the least-squares data regression routine native to the RheoWin 2.96 software. Regressions typically included both up- and down-ramp portions of the flow curve, resulting in an "average" set of model parameters for the total flow curve. Model fits were often limited to specific shear rate ranges to avoid flow curve anomalies such as Taylor Vortex formation.

\section{Results and Discussion}

\section{Results of Shear Strength Testing}

The result for Group 7 initial characterization shear strength testing is shown in Table 8. The single measurement for sample TI515-G7-AR-RH1 settled solids at 72 hours of settling time indicates shear strength of $23 \mathrm{~Pa}$. Because the vane immersion requirements could not be met, the shear strength reported for Group 7 settled solids is likely influenced by proximity of the vane to the surface of the solids and the floor of the test jar.

Table 8. Shear strength of Group 7 Initial Characterization settled solids at ambient hot-cell temperature $\left(27.6^{\circ} \mathrm{C}\right)$

\begin{tabular}{||l|c|c||}
\hline Test Sample & Settling Time & $\begin{array}{c}\text { Shear Strength } \\
{[\mathrm{Pa}]}\end{array}$ \\
\hline TI515-G7-AR-RH1 & 72 hours & $23 \mathrm{~Pa}$ \\
\hline
\end{tabular}

The degree to which the measured shear strength for Group 7 settled solids is affected by limited immersion is difficult to ascertain. It can be speculated that proximity of the top of the vane to the surface of the settled solids lowers the measured shear strength as the vane no longer has to shear settled solids above the top of the blades (i.e., the upper rotational surface). In contrast, proximity of the vane and floor of the test container likely increases the measured value of shear strength through frictional contact and stress chain formation between vane, solid slurry particles, and the container floor. Such coupling effects were observed during the measurement of Group 4 settled shear strength solids strength [5], where shear strength was made at both central and radial test locations. Because of limited space for Group 4 settled solids testing, radial test locations were run with wall-vane clearances of 1-vane radius or less. Two repeat tests at radial locations exhibited shear strengths $\sim 3$ times greater than that at the central location.

Because of the limitations of the current test for shear strength, the strength of $23 \mathrm{~Pa}$ measured for Group 7 settled solids should be approached with caution. The measurement is likely affected by 
competing effects of proximity of the vane to the surface of the settled solids and to the floor of the container and, as such, it should be treated as an order of magnitude estimate.

\section{Results of Flow Curve Testing - Group 7 Slurry}

Figure 4 shows the results of flow curve testing for the Group 7 initial characterization slurry sample, TI515-G7-AR-RH1. The measured flow curves indicate non-Newtonian slurry behavior, with the slurry showing finite yield stress, shear-thinning, and significant hysteresis.

Flow curve hysteresis is illustrated more clearly in Figure 5, which shows flow curve data for the initial measurement at $25^{\circ} \mathrm{C}$. As indicated by the figure, the up-ramp stress response is significantly higher than the down-ramp stress response and shows a higher degree of shear thinning behavior. The nature of hysteresis is similar during the repeat measurement at $25^{\circ} \mathrm{C}$ and during the single measurement at $40^{\circ} \mathrm{C}$. Although the flow curve data at $60^{\circ} \mathrm{C}$ show hysteresis, the difference between the up- and downramp curves is significantly smaller than at the lower temperatures. The exact cause of hysteresis in the current measurements is difficult to ascertain from flow curve data alone. However, because the hysteresis is characterized by a transient decrease in stress response over the course of the measurement, it can be speculated that hysteresis results from either shear-induced solids structure changes (i.e., sample thixotropy) or as a result of solids settling out of the measurement gap.

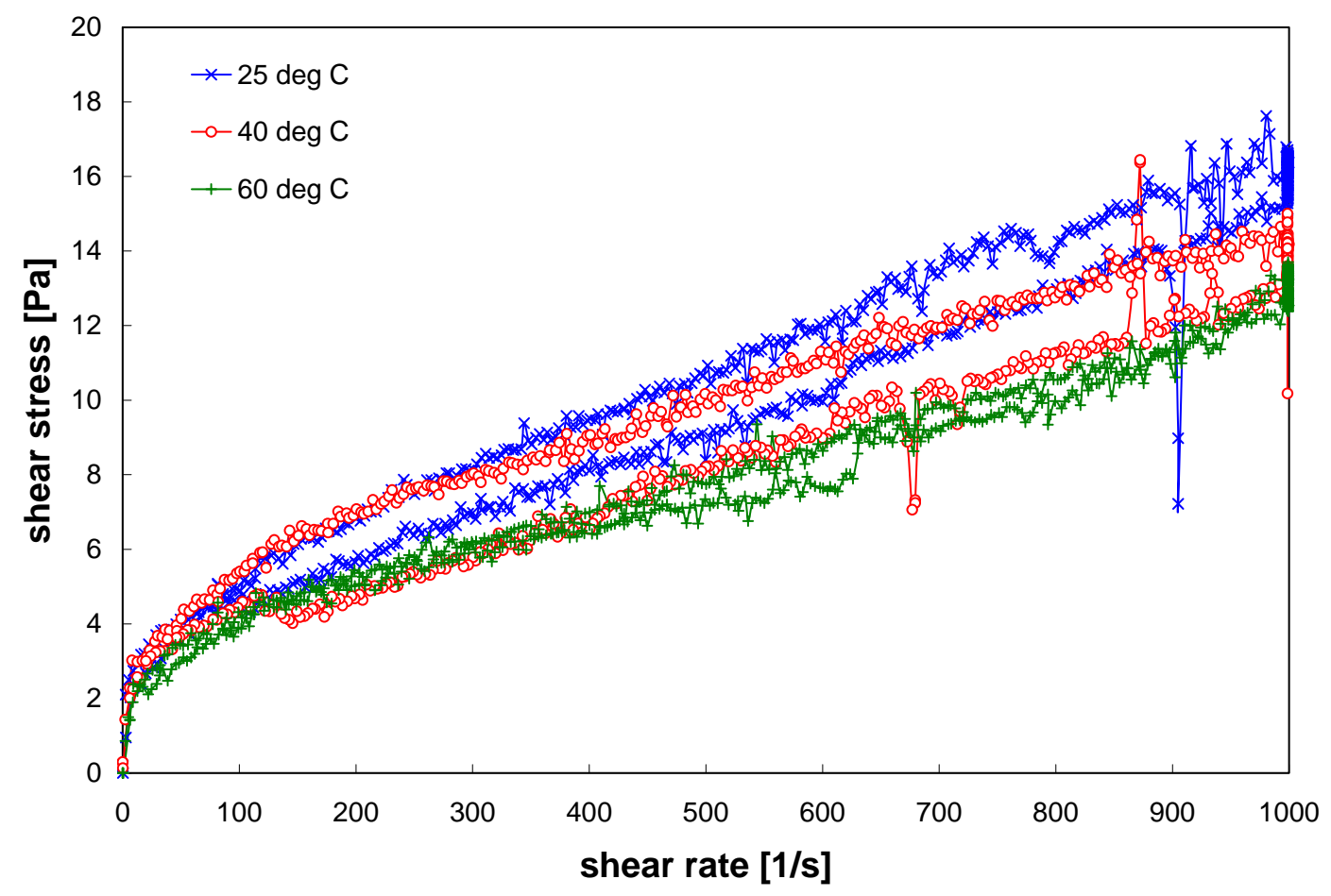

Figure 4. Flow curve (shear stress versus shear rate) for the Group 7 initial characterization slurry sample TI515-G7-AR-RH1 at $25^{\circ} \mathrm{C}, 40^{\circ} \mathrm{C}$, and $60^{\circ} \mathrm{C}$. The second repeat measurement for $25^{\circ} \mathrm{C}$ is shown. 


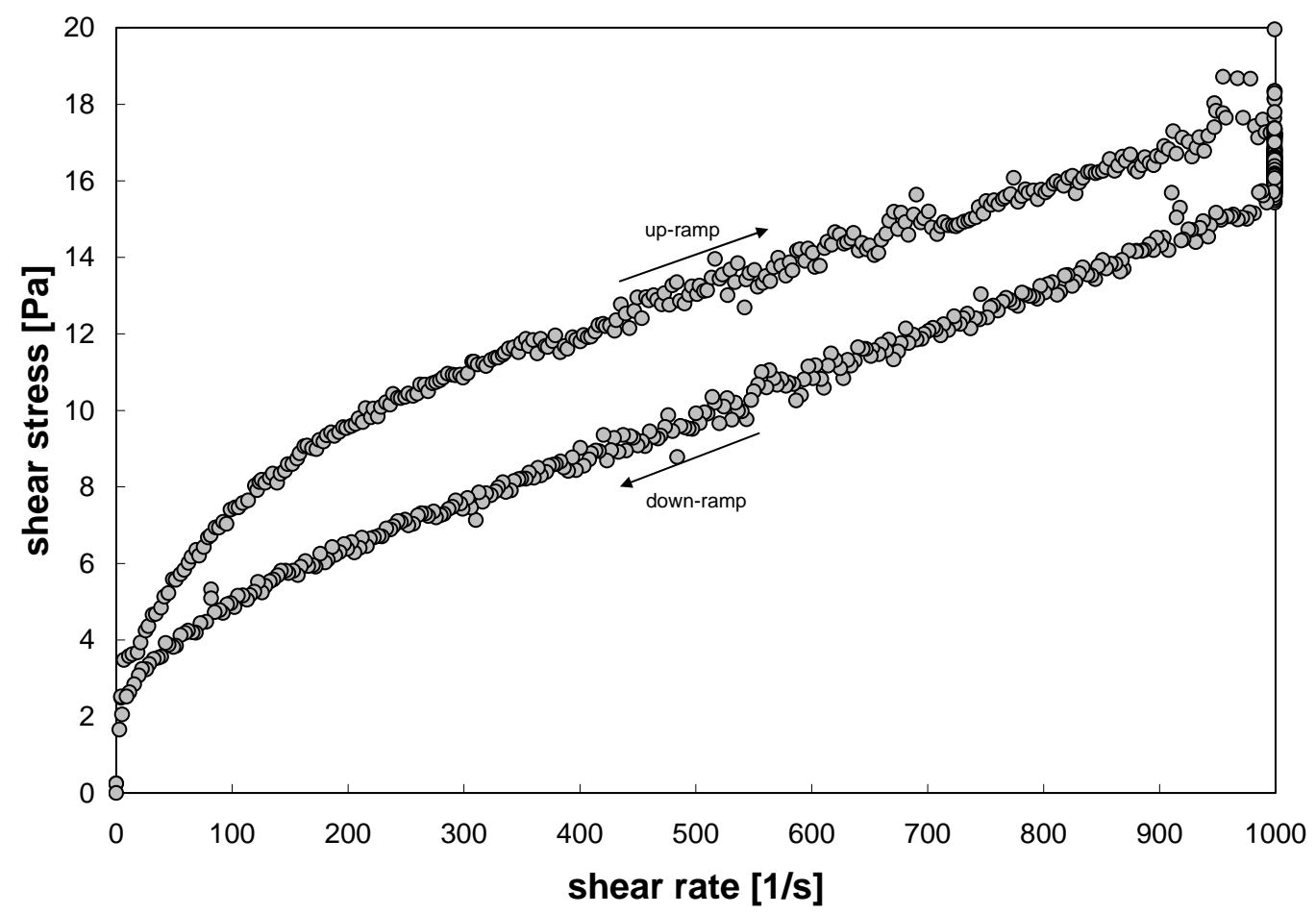

Figure 5. Initial flow curve measurement of sample TI515-G7-AR-RH1 at $25^{\circ} \mathrm{C}$ highlighting significant flow curve hysteresis.

Significant data overlap between the different temperature results from measurement hysteresis. As such, it is difficult to clearly determine how temperature influences the flow curve data. Despite this difficultly, some trends can be based on rough visual inspection of the data. First, all flow curve data indicate a slurry yield stress that falls between 2 and $4 \mathrm{~Pa}$. Based on a rough average of upper and lower data bounds at each temperature, it appears that the stress response of the fluid (i.e., the slurry consistency) decreases with increasing temperature.

The flow curve data measured for sample TI515-G7-AR-RH1 are fit to both Bingham-Plastic and Casson constitutive equations to obtain a quantitative description of flow behavior. Because of the significant hysteresis, it is not feasible to derive an averaged set of flow curve parameters by fitting both up- and down-ramp flow curve data simultaneously. Instead, flow curve fits are limited to down-ramp data alone (shown in Figure 6). Exclusion of up-ramp data is based on the assumption that hysteresis likely results from transient break down of slurry structure, and that the well-mixed flow behavior is most closely represented by the down-ramp flow curve data. For Bingham-Plastic fitting analysis, data fits are restricted to a shear rate range of $100-1000 \mathrm{~s}^{-1}$ at $25^{\circ} \mathrm{C}$ and $40^{\circ} \mathrm{C}$ and of $100-800 \mathrm{~s}^{-1}$ at $60^{\circ} \mathrm{C}$. The lower bound excludes the non-linear region that occurs over 0-100 $\mathrm{s}^{-1}$ from the Bingham fitting analysis as this model cannot account for curvature. The $800 \mathrm{~s}^{-1}$ upper bound excludes $60^{\circ} \mathrm{C}$ down-ramp data that exhibit a sharp and unexpected increase in slope. 


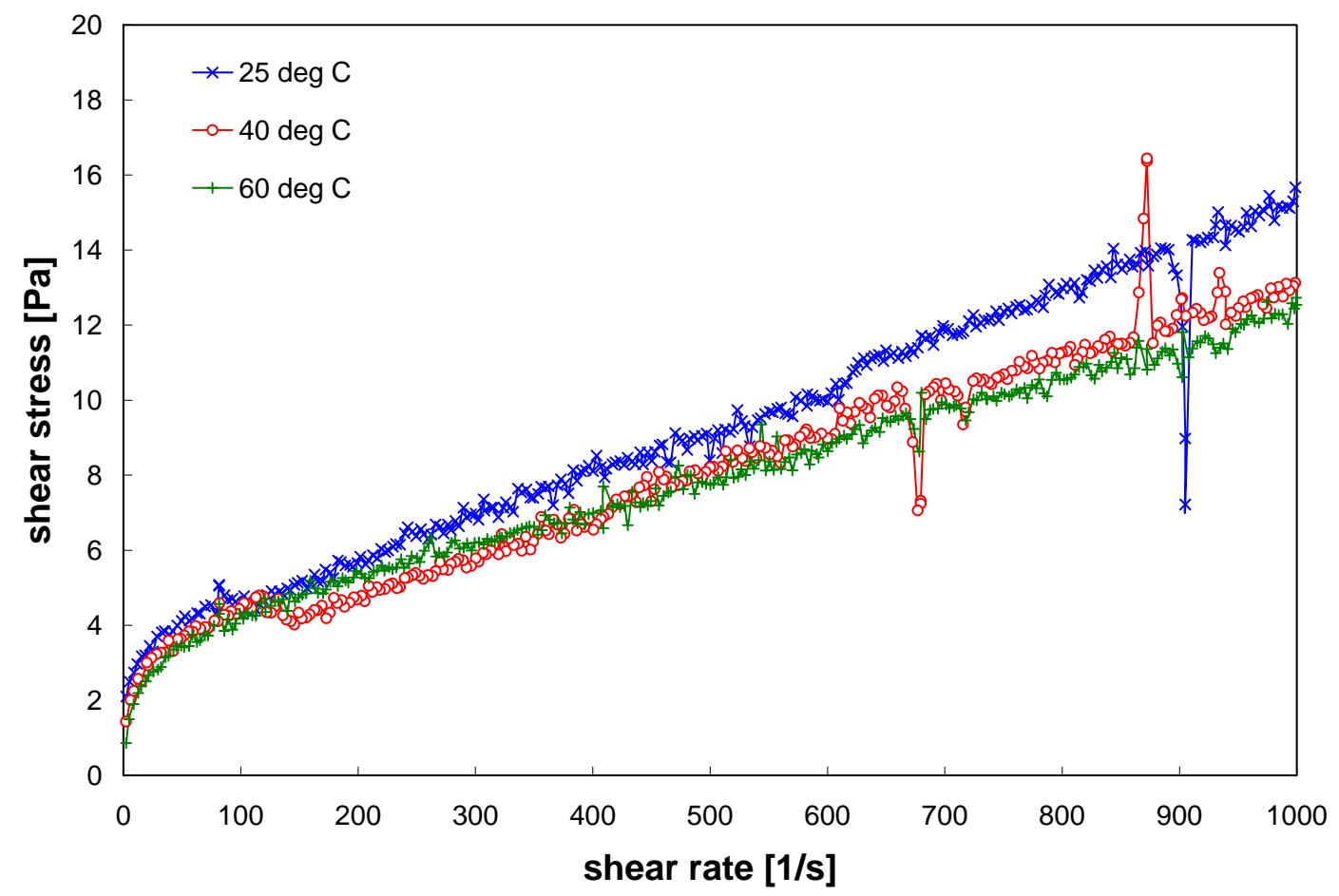

Figure 6. Down-ramp flow curve data for the Group 7 initial characterization slurry sample TI515G7-AR-RH1 at $25^{\circ} \mathrm{C}, 40^{\circ} \mathrm{C}$, and $60^{\circ} \mathrm{C}$. The second repeat measurement for $25^{\circ} \mathrm{C}$ is shown.

Table 9 summarizes the best-fit Bingham-Plastic and Casson parameters for sample TI515-G7AR-RH1. The Bingham-Plastic parameters indicate a slurry yield stress and consistency that range from 2.8 to $4.1 \mathrm{~Pa}$ and a 8.9 to $12 \mathrm{mPa} \cdot \mathrm{s}$, respectively. Likewise, the Casson model indicates a yield stress and consistency that range from 1.3-1.9 Pa and 4.4 to $6.6 \mathrm{mPa} \cdot \mathrm{s}$. As shown in Figure 7 (and also by the similarity of their correlation coefficients - R), the Casson and Bingham-Plastic models provide roughly the same fit of the data. The lower consistency and yield stress provided by the Casson fits is simply a result of model curvature.

The fitting results in Table 9 indicate do not provide much insight into how slurry yield stress and consistency behave as a function of temperature. Although Bingham-Plastic yield stress varies over a significant range 2.8-4.1 Pa, its variation does not track with temperature. Yield stress reproducibility is poor, as indicated by the significant difference of $0.8 \mathrm{~Pa}$ in initial and repeat measurements at $25^{\circ} \mathrm{C}(4.1$ and 3.3 Pa, respectively). Similar yield stress issues are observed with the Casson fits.

Slurry consistency does not vary significantly for the repeat measurements at $25^{\circ} \mathrm{C}$ and the measurement $40^{\circ} \mathrm{C}$. Bingham-Plastic and Casson consistencies range from 11-12 and 6.0-6.6 mPa.s, respectively. Because both ranges cover less than the expected limit of instrument accuracy of $10 \%$, it is unlikely that the variation between slurry consistency at $25^{\circ} \mathrm{C}$ and $40^{\circ} \mathrm{C}$ is significant. On the other hand, Bingham-Plastic consistency drops from 11 to $8.9 \mathrm{mPa} \cdot \mathrm{s}$ as slurry temperature is raised from $40^{\circ} \mathrm{C}$ to $60^{\circ} \mathrm{C}$. Although this is a significant decrease, it is difficult to state that this decrease would continue at higher temperatures with confidence given the variation in the yield stress results. Overall, the fitting results do not indicate strong temperature trends, as it is difficult to distinguish measurement-to- 
measurement variation from changes induced by increased temperature. It is speculated that the significant flow curve hysteresis is the source of measurement-to-measurement variation.

Table 9. Results of fitting analysis for rheology sample TI515-G7-AR-RH1. All model parameters are based on down-ramp data only.

\begin{tabular}{||c|c|c|c|c|c||}
\hline MODEL & $\begin{array}{c}\text { TEMPERATURE } \\
{\left[{ }^{\circ} \mathbf{C}\right]}\end{array}$ & RANGE & $\begin{array}{c}\text { YIELD } \\
\text { STRESS } \\
\text { [PA] }\end{array}$ & $\begin{array}{c}\text { VISCOSITY } \\
\text { [MPA·S }]\end{array}$ & $\mathbf{R}$ \\
\hline \multirow{3}{*}{$\begin{array}{c}\text { Bingham-Plastic } \\
\text { (Flow Curve) }\end{array}$} & $25(1$ of 2$)$ & $100-1000 \mathrm{~s}^{-1}$ & 4.1 & 11 & 1.00 \\
\cline { 2 - 6 } & $25(2$ of 2$)$ & $100-1000 \mathrm{~s}^{-1}$ & 3.3 & 12 & 0.98 \\
\cline { 2 - 6 } & 40 & $100-1000 \mathrm{~s}^{-1}$ & 2.8 & 11 & 0.98 \\
\cline { 2 - 6 } & 60 & $100-800 \mathrm{~s}^{-1}$ & 3.5 & 8.9 & 0.99 \\
\hline \multirow{4}{*}{$\begin{array}{c}\text { Casson } \\
\text { (Flow Curve) }\end{array}$} & $25(1$ of 2$)$ & $0-1000 \mathrm{~s}^{-1}$ & 1.9 & 6.3 & 1.00 \\
\cline { 2 - 6 } & $25(2$ of 2$)$ & $0-1000 \mathrm{~s}^{-1}$ & 1.6 & 6.6 & 0.98 \\
\cline { 2 - 6 } & 40 & $0-1000 \mathrm{~s}^{-1}$ & 1.3 & 6.0 & 0.98 \\
\cline { 2 - 6 } & 60 & $0-800 \mathrm{~s}^{-1}$ & 1.8 & 4.4 & 0.99 \\
\hline
\end{tabular}

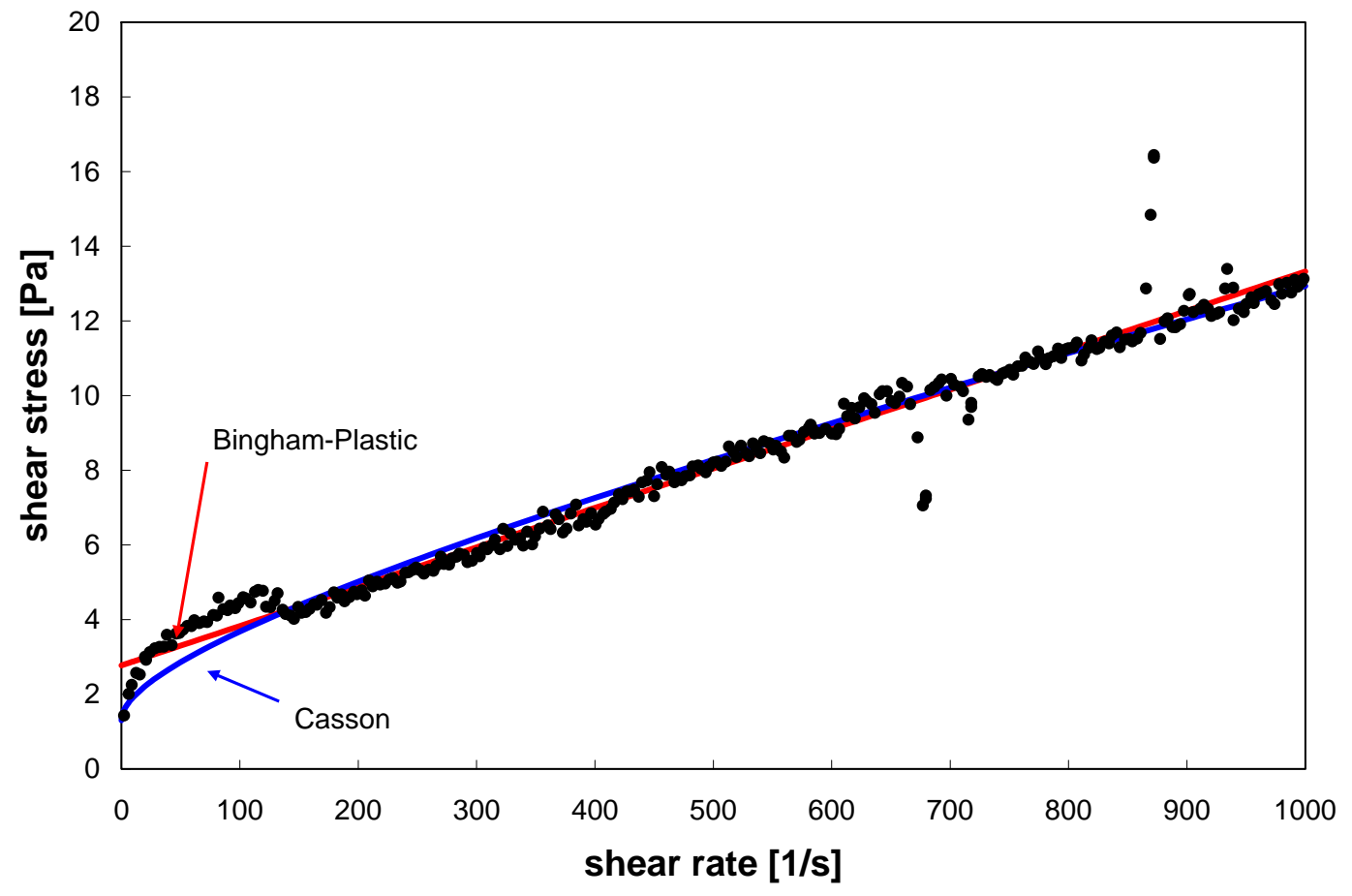

Figure 7. Example result for the fitting analysis of Group 7 initial characterization sample TI515-G7AR-RH1. Data points (solid circles) correspond to the measurement at $40^{\circ} \mathrm{C}$. The solid lines correspond to the best-fit Bingham-Plastic and Casson model calculations.

To supplement flow curve measurement and analysis, apparent viscosities for slurry sample TI515-G7-AR-RH1 were determined at 33, 100, 500, and $1000 \mathrm{~s}^{-1}$. Two separate approaches were employed to determine apparent viscosity at these shear rates: 1) from actual measurement data and 2) from the flow curve fitting parameters listed in Table 9. Table 10 lists apparent viscosities determined from the actual shear versus shear rate measurement data. Here, apparent viscosities for both up- and 
down-ramp data, as well as an average of the two, are given for shear rates of 33, 100, $500 \mathrm{~s}^{-1}$. The apparent viscosity for $1000 \mathrm{~s}^{-1}$ listed in Table 10 is determined by average all apparent viscosity observations made during the period of constant rotation at $1000 \mathrm{~s}^{-1}$. Table 11 lists the apparent viscosities calculated using the Bingham-Plastic and Casson constitutive equations (i.e., Eqs. 7 and 9) with the apparent viscosity relationship Eq. 4. The results in Table 11 are based on fits of down-ramp data, and should match most closely with the down-ramp viscosities listed in Table 10.

Table 10. Apparent viscosities at select shear rates for sample TI515-G7-AR-RH1. Reported values are determined from flow curve measurement data.

\begin{tabular}{|c|c|c|c|c|c|}
\hline \multirow[t]{2}{*}{ Temperature $\left[{ }^{\circ} \mathrm{C}\right]$} & \multirow[t]{2}{*}{ Section } & \multicolumn{4}{|c|}{ Apparent Viscosity [mPa·s] } \\
\hline & & @ $33 \mathrm{~s}^{-1}$ & @ $100 \mathrm{~s}^{-1}$ & @ $500 \mathrm{~s}^{-1}$ & @ $1000 \mathrm{~s}^{-1}$ \\
\hline \multirow[t]{3}{*}{25 (1 of 2$)$} & up-ramp & 142 & 74 & 26 & $\mathrm{n} / \mathrm{a}$ \\
\hline & down-ramp & 106 & 49 & 20 & $\mathrm{n} / \mathrm{a}$ \\
\hline & average & 124 & 62 & 23 & 16 \\
\hline \multirow[t]{3}{*}{25 (2 of 2$)$} & up-ramp & 94 & 49 & 22 & $\mathrm{n} / \mathrm{a}$ \\
\hline & down-ramp & 116 & 45 & 17 & $\mathrm{n} / \mathrm{a}$ \\
\hline & average & 105 & 47 & 19 & 16 \\
\hline \multirow[t]{3}{*}{40} & up-ramp & 111 & 54 & 20 & $\mathrm{n} / \mathrm{a}$ \\
\hline & down-ramp & 99 & 45 & 16 & $\mathrm{n} / \mathrm{a}$ \\
\hline & average & 105 & 49 & 18 & 14 \\
\hline \multirow[t]{3}{*}{60} & up-ramp & 82 & 39 & 15 & $\mathrm{n} / \mathrm{a}$ \\
\hline & down-ramp & 90 & 43 & 15 & $\mathrm{n} / \mathrm{a}$ \\
\hline & average & 86 & 41 & 15 & 13 \\
\hline
\end{tabular}

Table 11. Apparent viscosities at select shear rates for sample TI515-G7-AR-RH1. Reported values are calculated from the flow curve fitting parameters listed in Table 9.

\begin{tabular}{|c|c|c|c|c|c|}
\hline \multirow[t]{2}{*}{ Source } & \multirow{2}{*}{$\begin{array}{c}\text { Temperature } \\
{\left[{ }^{\circ} \mathrm{C}\right]} \\
\end{array}$} & \multicolumn{4}{|c|}{ Apparent Viscosity [mPa·s] } \\
\hline & & @ $33 \mathrm{~s}^{-1}$ & @ $100 \mathrm{~s}^{-1}$ & @ $500 \mathrm{~s}^{-1}$ & @ $1000 \mathrm{~s}^{-1}$ \\
\hline \multirow[t]{4}{*}{ Bingham-Plastic } & 25 ( 1 of 2$)$ & 140 & 52 & 20 & 15 \\
\hline & 25 (2 of 2$)$ & 110 & 45 & 18 & 15 \\
\hline & 40 & 95 & 38 & 16 & 13 \\
\hline & 60 & 110 & 44 & 16 & 12 \\
\hline \multirow[t]{4}{*}{ Casson } & 25 (1 of 2$)$ & 100 & 47 & 20 & 15 \\
\hline & 25 (2 of 2$)$ & 90 & 43 & 19 & 15 \\
\hline & 40 & 76 & 37 & 17 & 13 \\
\hline & 60 & 90 & 40 & 16 & 12 \\
\hline
\end{tabular}

The results in Table 10 and 11 indicate apparent viscosities that range from $\sim 80$ to $140 \mathrm{mPa} \cdot \mathrm{s}$ at low shear $\left(33 \mathrm{~s}^{-1}\right)$ but that quickly decay down to $\sim 12$ to $16 \mathrm{mPa} \cdot \mathrm{s}$ at high shear rates $\left(1000 \mathrm{~s}^{-1}\right)$. High apparent slurry viscosity at low shear is not surprising given the $\sim 2$ to 4 Pa yield stress of the slurry. In addition, up- and down-ramp data in Table 10 show significant difference; however, this difference is indicative of flow curve hysteresis.

In summary, flow curve analysis for Group 7 Initial Characterization slurry sample TI515-G7AR-RH1 indicates non-Newtonian rheology. Fits of the data to a Bingham-Plastic parameters indicate a slurry yield stress and consistency that range from 2.8 to $4.1 \mathrm{~Pa}$ and a 8.9 to $12 \mathrm{mPa} \cdot \mathrm{s}$, respectively. 
Similar fits using the Casson model indicate a yield stress and consistency that range from 1.3-1.9 Pa and 4.4 to $6.6 \mathrm{mPa} \cdot \mathrm{s}$ Overall, experimental and fitting results do not indicate strong temperature trends, as it is difficult to distinguish measurement-to-measurement variation from changes induced by increased temperature. One cause for this difficulty is that the flow curve measurements are subject to significant hysteresis. Specifically, the slurry shows a transient decrease in stress response throughout the course of the measurement such that the down-ramp stress response falls below that observed during the up-ramp. This behavior is consistent slurry thixotropy or could indicate solids settling during flow curve testing.

\section{Records}

Data records relating to rheological characterization of Group 7 Initial Characterization samples include original Computational Computer Package (CCPs) and LRB entries. These include:

- $\quad$ LRB BNW 59633 - Pages 132 and 146-147

- $\quad$ CCP-WTPSP-616 - Group 7 initial characterization shear strength

- $\quad$ CCP-WTPSP-642 - Group 7 initial characterization slurry flow curves

\section{References}

1. Doc. No. TP-RPP-WTP-467, Revision 0, “Characterization and Small Scale Testing of Hanford Wastes to Support the Development and Demonstration of Leaching and Ultrafiltration Pretreatment Processes,” SK Fiskum, Battelle - Pacific Northwest Division, February 2007.

2. Barnes HA, and NQ Dzuy, "Rotating vane rheometry - a review,” J. Non-Newtonian Fluid Mech., 1-14 (2001).

3. Steffe JF, Rheological Methods in Food Process Engineering, Freeman Press, East Lansing (1996).

4. Doc. No. RPL-COLLOID-02, Revision 1, "Measurement of Physical and Rheological Properties of Solutions, Slurries and Sludges,” RC Daniel, Pacific Northwest National Laboratory, May 2007.

5. Doc. No. TDP-WTP-286, Revision 0, "Rheology of Waste Processing Group 4 (REDOX Cladding Waste Sludge): Initial Characterization,” RC Daniel, Pacific Northwest National Laboratory, October 2008. 


\section{Rheograms}

This section contains detailed rheograms (shear stress and apparent viscosity as a function of shear) for Group 7 Initial Characterization slurry sample TI515-G7-AR-RH1. No discussion of these results is provided. They are provided for reference only.

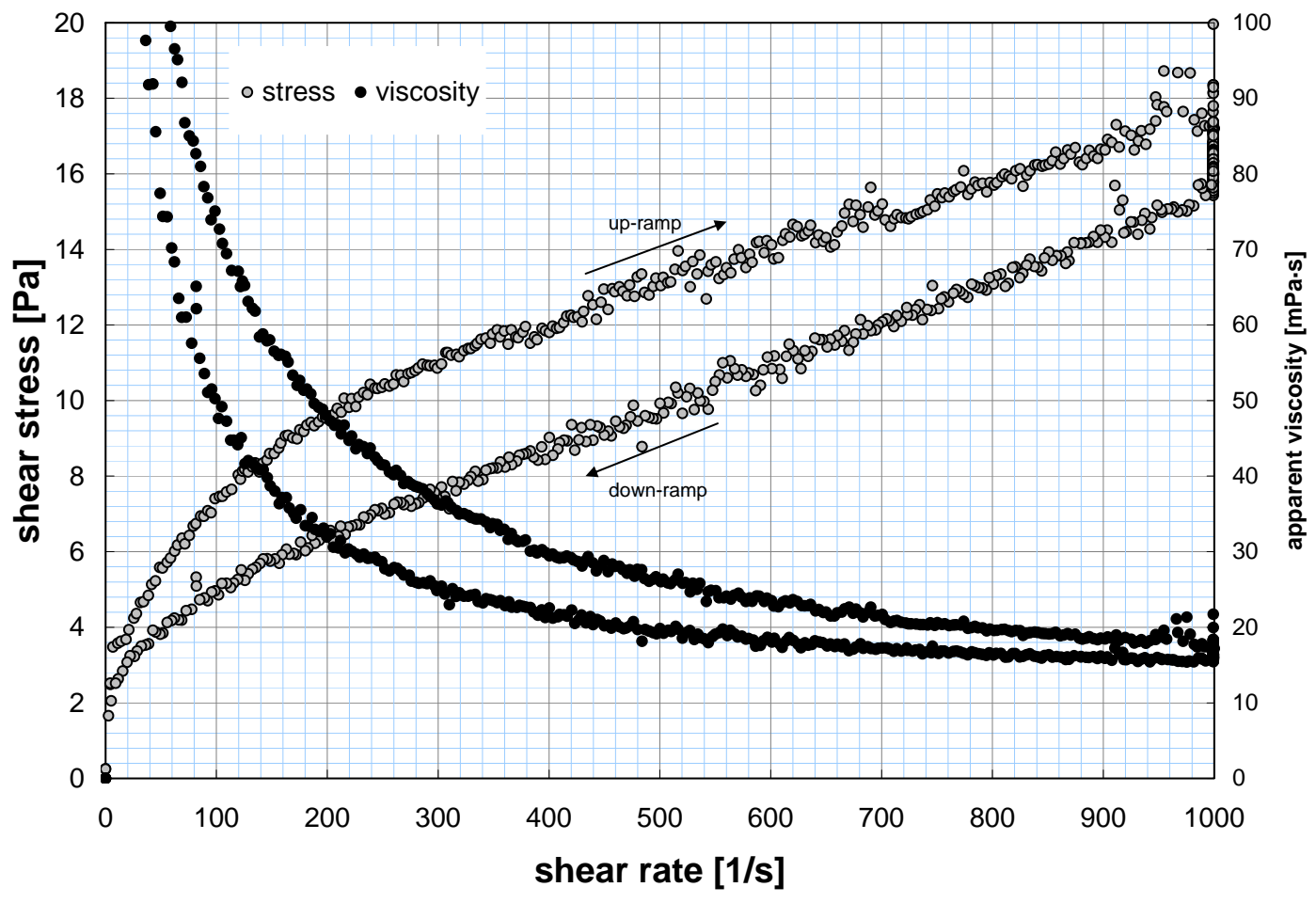

Figure 10-1. Rheogram for TI515-G7-AR-RH1 at $25^{\circ} \mathrm{C}$. 
WTP-RPT-169, Rev 0

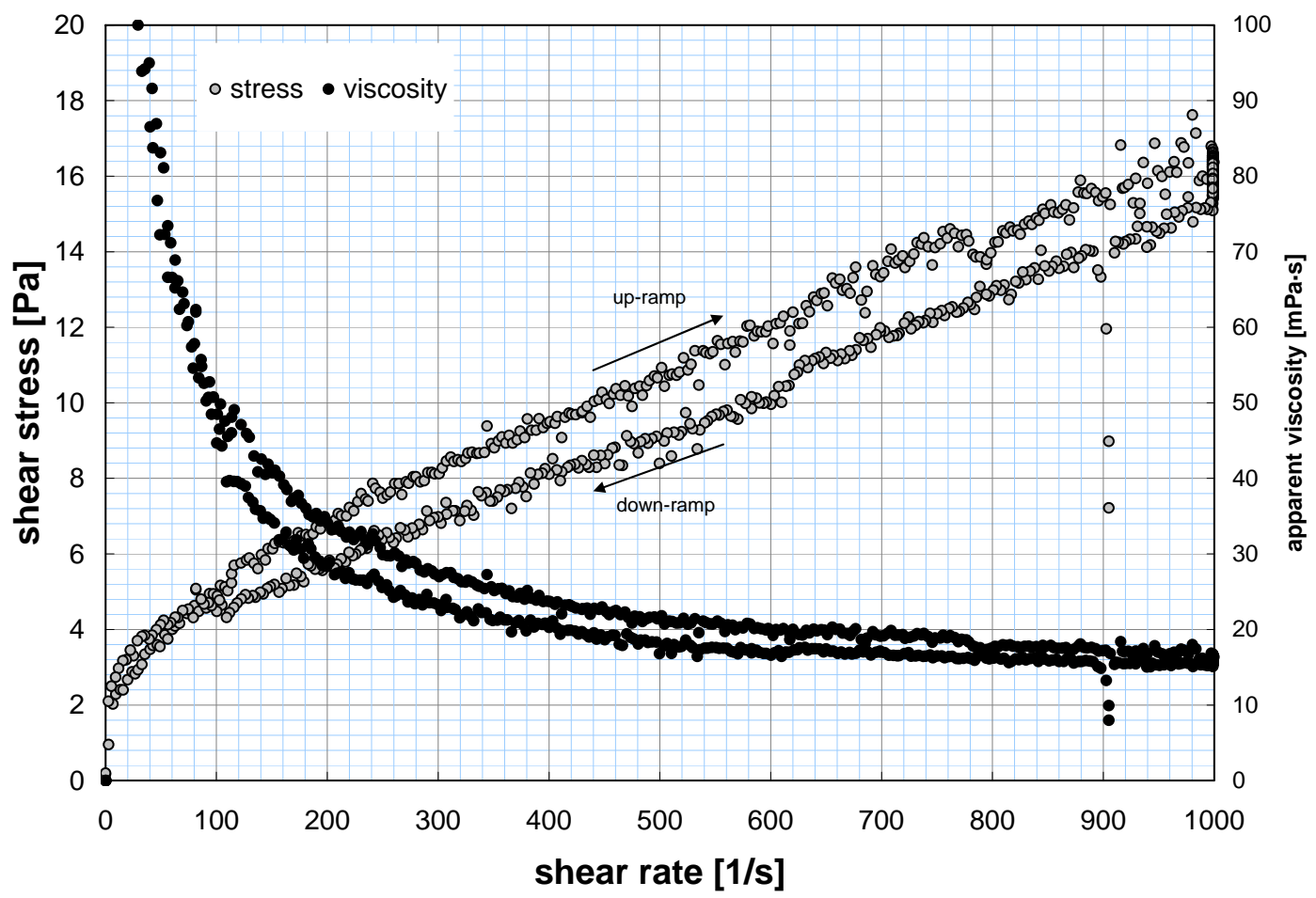

Figure 10-2. Replicate rheogram for TI515-G7-AR-RH1 at $25^{\circ} \mathrm{C}$.

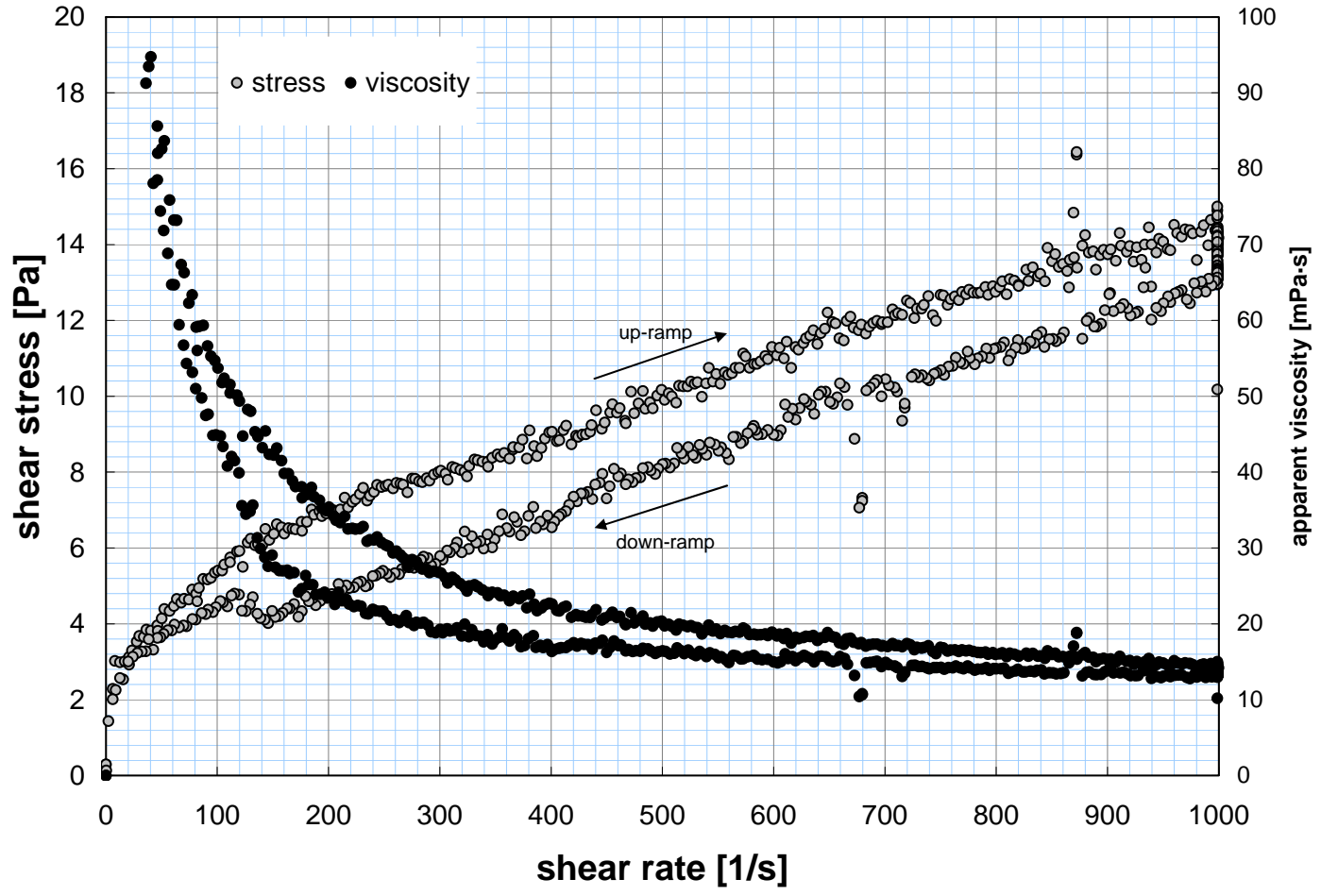

Figure 10-3. Rheogram for TI515-G7-AR-RH1 at $40^{\circ} \mathrm{C}$. 
WTP-RPT-169, Rev 0

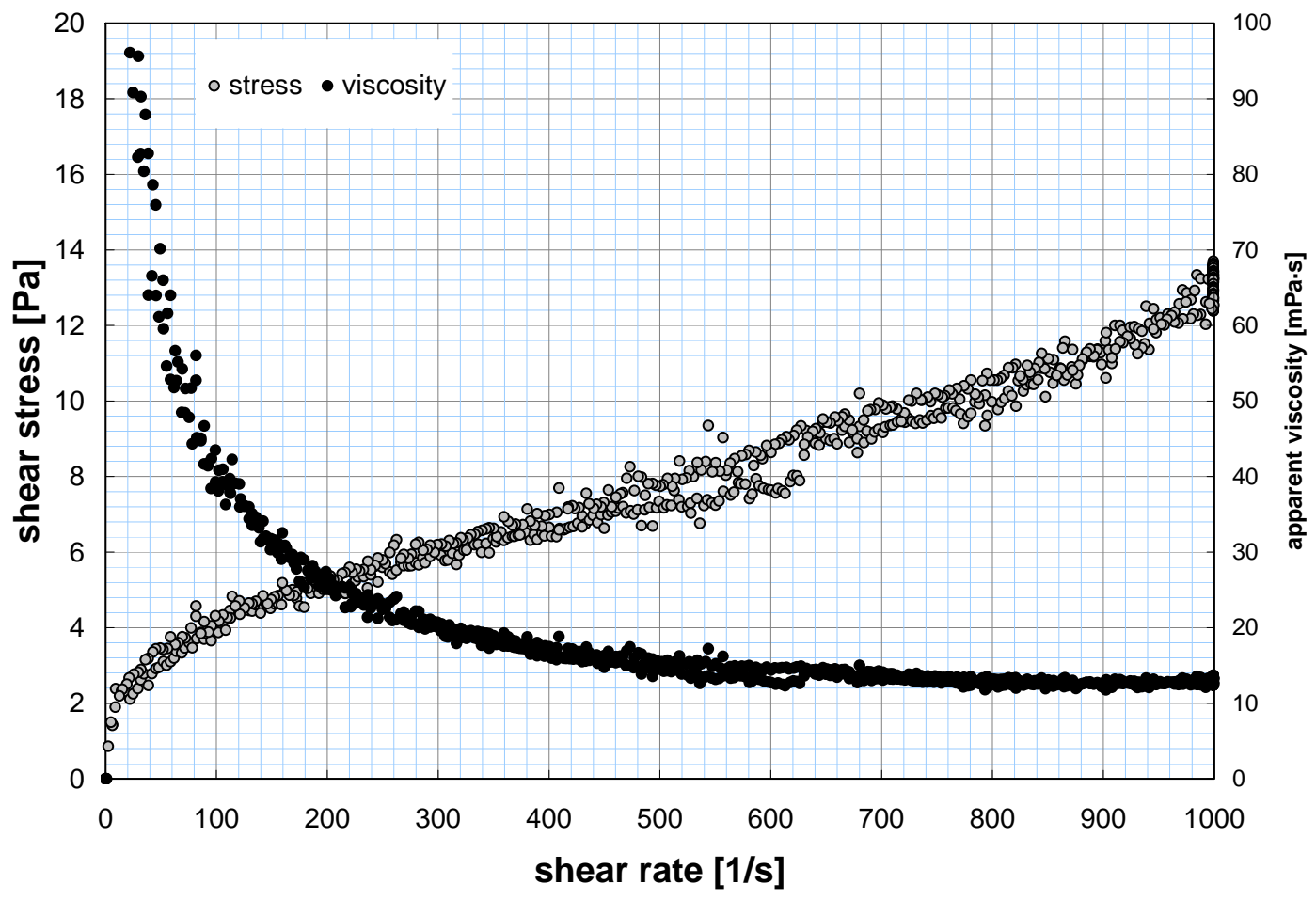

Figure 10-4. Rheogram for TI515-G7-AR-RH1 at $60^{\circ} \mathrm{C}$. 
Appendix G

Group 7 Analytical Results from Parametric Leaching 


\section{Appendix G: Group 7 Analytical Results from Parametric Leaching}

Table G.1 provides information about analyte concentrations during leaching at various time increments at $40^{\circ} \mathrm{C}$ in units of $\mu \mathrm{g} / \mathrm{mL}$, Table G.2 at $40^{\circ} \mathrm{C}$ in units of M, Tables $\mathrm{G} .3$ and $\mathrm{G} .4$ at $60^{\circ} \mathrm{C}$ in units of $\mu \mathrm{g} / \mathrm{mL}$ and M, respectively, and Tables G.5 and G.6 at $80^{\circ} \mathrm{C}$ in units of $\mu \mathrm{g} / \mathrm{mL}$ and $\mathrm{M}$, respectively. All data in the following tables are from CCP-WTPSP-689, Group 7 parametric leaching liquid results.

Table G.1. Analyte Concentrations as a Function of Time for Leaching at $40^{\circ} \mathrm{C}$, in $\mu \mathrm{g} / \mathrm{mL}$

\begin{tabular}{|c|c|c|c|c|c|c|}
\hline \multirow[b]{2}{*}{ Analyte } & \multicolumn{6}{|c|}{$\begin{array}{l}\text { Analyte Concentration and Density at Given Time After Cooling to Ambient }\left(\sim 21^{\circ} \mathrm{C}\right) \\
\text { Temperature; } \mathrm{g} / \mathrm{mL} \text { for Density; } \mu \mathrm{g} / \mathrm{mL} \text { for Metals and Anions; } \mu \mathrm{Ci} / \mathrm{mL} \text { for } \\
\text { Radionuclides }\end{array}$} \\
\hline & $0 \mathrm{hr}$ & $1 \mathrm{hr}$ & $2 \mathrm{hr}$ & $4 \mathrm{hr}$ & $8 \mathrm{hr}$ & $24 \mathrm{hr}$ \\
\hline \multicolumn{7}{|l|}{$1 \mathrm{M} \mathrm{NaOH}$} \\
\hline Density & 1.04 & 1.05 & 1.06 & 1.05 & 1.05 & 1.05 \\
\hline $\mathrm{Al}$ & 29.2 & 55.1 & 57.7 & 59.9 & 59.2 & 71.0 \\
\hline B & [0.411] & {$[0.405]$} & {$[0.376]$} & [0.449] & [0.355] & [1.85] \\
\hline $\mathrm{Bi}$ & $<0.948$ & $<0.935$ & $<0.941$ & $<0.962$ & $<0.711$ & $<4.63$ \\
\hline $\mathrm{Cd}$ & $<0.107$ & $<0.106$ & $<0.107$ & $<0.109$ & $<0.081$ & $<0.525$ \\
\hline $\mathrm{Cr}$ & {$[0.272]$} & {$[0.374]$} & {$[0.408]$} & {$[0.417]$} & 0.512 & [0.679] \\
\hline $\mathrm{Fe}$ & 3.82 & 2.55 & 2.30 & 2.28 & 1.99 & {$[2.44]$} \\
\hline $\mathrm{Mn}$ & 0.245 & 0.223 & 0.219 & 0.217 & 0.165 & [0.210] \\
\hline $\mathrm{Na}$ & 24,045 & 24,454 & 24,426 & 24,552 & 25,120 & 25,219 \\
\hline $\mathrm{Ni}$ & $<0.076$ & $<0.075$ & $<0.075$ & $<0.077$ & $<0.057$ & $<0.370$ \\
\hline $\mathrm{P}$ & 423 & 607 & 611 & 619 & 604 & 611 \\
\hline$S$ & $<5.06$ & $<4.98$ & $<5.02$ & $<5.13$ & $<<3.79$ & 24.7 \\
\hline $\mathrm{Si}$ & 5.78 & 21.0 & 23.1 & 24.0 & 23.4 & 21.1 \\
\hline $\mathrm{Sr}$ & 0.088 & [0.047] & {$[0.038]$} & {$[0.030]$} & {$[0.024]$} & {$[0.034]$} \\
\hline $\bar{U}$ & 239 & 163 & 137 & 109 & 80.1 & 59.3 \\
\hline Zn & 2.60 & 3.03 & 2.86 & 2.80 & 2.63 & [3.70] \\
\hline $\mathrm{Zr}$ & $<0.035$ & $<0.034$ & $<0.034$ & $<0.035$ & $<0.026$ & $<0.170$ \\
\hline Fluoride & {$[6.60]$} & {$[8.00]$} & [7.90] & {$[8.00]$} & {$[7.80]$} & {$[8.10]$} \\
\hline Nitrite & [7.60] & [7.90] & [7.60] & [7.60] & [7.60] & [7.70] \\
\hline Nitrate & [80.7] & 84.4 & 81.7 & 83.2 & 82.7 & 83.8 \\
\hline Phosphate & 1,370 & 1,950 & 1,870 & 1,890 & 1,880 & 2,020 \\
\hline Sulfate & 9.50 & {$[11.0]$} & {$[10.0]$} & {$[10.0]$} & {$[10.0]$} & {$[10.0]$} \\
\hline${ }^{60} \mathrm{Co}$ & \multirow{5}{*}{\multicolumn{5}{|c|}{ Not Measured }} & $<4 . \mathrm{E}-6$ \\
\hline${ }^{137} \mathrm{Cs}$ & & & & & & 0.245 \\
\hline${ }^{154} \mathrm{Eu}$ & & & & & & $<1 . \mathrm{E}-5$ \\
\hline${ }^{155} \mathrm{Eu}$ & & & & & & $<1$.E-4 \\
\hline${ }^{241} \mathrm{Am}$ & & & & & & $<1 . \mathrm{E}-4$ \\
\hline \multicolumn{7}{|c|}{ Opportunistic Analytes } \\
\hline $\mathrm{Ag}$ & $<0.066$ & $<0.065$ & [0.09] & $<0.067$ & [0.05] & $<0.324$ \\
\hline As & $<1.359$ & $<1.340$ & $<1.348$ & $<1.378$ & $<1.019$ & $<6.637$ \\
\hline $\mathrm{Ba}$ & {$[0.07]$} & {$[0.09]$} & {$[0.10]$} & {$[0.08]$} & 0.14 & {$[0.05]$} \\
\hline $\mathrm{Be}$ & {$[0.00]$} & {$[0.00]$} & {$[0.00]$} & {$[0.00]$} & {$[0.00]$} & $<0.008$ \\
\hline
\end{tabular}


Table G.1 (Contd)

\begin{tabular}{|c|c|c|c|c|c|c|}
\hline \multirow[b]{2}{*}{ Analyte } & \multicolumn{6}{|c|}{$\begin{array}{l}\text { Analyte Concentration and Density at Given Time After Cooling to Ambient }\left(\sim 21^{\circ} \mathrm{C}\right) \\
\text { Temperature; } \mathrm{g} / \mathrm{mL} \text { for Density; } \mu \mathrm{g} / \mathrm{mL} \text { for Metals and Anions; } \mu \mathrm{Ci} / \mathrm{mL} \text { for } \\
\text { Radionuclides }\end{array}$} \\
\hline & $0 \mathrm{hr}$ & $1 \mathrm{hr}$ & $2 \mathrm{hr}$ & $4 \mathrm{hr}$ & 8 hr & $24 \mathrm{hr}$ \\
\hline $\mathrm{Ca}$ & 2.38 & 2.23 & 2.24 & 2.10 & 1.50 & [5.86] \\
\hline $\mathrm{Ce}$ & $<0.316$ & $<0.312$ & $<0.314$ & $<0.321$ & $<0.237$ & $<1.543$ \\
\hline Co & $<0.076$ & $<0.075$ & $<0.075$ & $<0.077$ & $<0.057$ & $<0.370$ \\
\hline $\mathrm{Cu}$ & 0.55 & 0.69 & 0.52 & 0.56 & 0.43 & {$[0.59]$} \\
\hline Dy & $<0.092$ & $<0.090$ & $<0.091$ & $<0.093$ & $<0.069$ & $<0.448$ \\
\hline $\mathrm{Eu}$ & $<0.035$ & $<0.034$ & $<0.034$ & $<0.035$ & $<0.026$ & $<0.170$ \\
\hline $\mathrm{K}$ & [11.06] & [18.07] & [21.32] & [21.80] & 24.41 & $<11.112$ \\
\hline $\mathrm{La}$ & $<0.088$ & $<0.087$ & $<0.088$ & $<0.090$ & $<0.066$ & $<0.432$ \\
\hline $\mathrm{Li}$ & {$[0.30]$} & 0.40 & {$[0.38]$} & 0.49 & 0.39 & {$[0.77]$} \\
\hline $\mathrm{Mg}$ & $<0.073$ & $<0.072$ & $<0.072$ & $<0.074$ & $<0.055$ & $<0.355$ \\
\hline Mo & $<0.164$ & $<0.162$ & $<0.163$ & $<0.167$ & $<0.123$ & $<0.803$ \\
\hline $\mathrm{Nd}$ & $<0.171$ & $<0.168$ & $<0.169$ & $<0.173$ & $<0.128$ & $<0.833$ \\
\hline $\mathrm{Pb}$ & $<1.011$ & [1.25] & $<1.003$ & $<1.026$ & $<0.758$ & $<4.939$ \\
\hline $\mathrm{Pd}$ & $<0.199$ & $<0.196$ & $<0.198$ & $<0.202$ & $<0.149$ & $<0.972$ \\
\hline $\mathrm{Rh}$ & $<0.379$ & $<0.374$ & $<0.376$ & $<0.385$ & $<0.284$ & $<1.852$ \\
\hline $\mathrm{Ru}$ & $<0.269$ & $<0.265$ & $<0.267$ & $<0.272$ & $<0.201$ & [1.73] \\
\hline $\mathrm{Sb}$ & $<0.632$ & {$[0.78]$} & $<0.627$ & $<0.641$ & $<0.474$ & $<3.087$ \\
\hline Se & $<2.212$ & $<2.181$ & $<2.195$ & $<2.244$ & $<1.659$ & $<10.804$ \\
\hline Sn & $<0.853$ & $<0.841$ & $<0.847$ & $<0.865$ & $<0.640$ & $<<4.167$ \\
\hline $\mathrm{Ta}$ & $<0.537$ & $<0.530$ & $<0.533$ & $<0.545$ & $<0.403$ & $<2.624$ \\
\hline $\mathrm{Te}$ & $<0.822$ & $<0.810$ & $<0.815$ & $<0.833$ & $<0.616$ & $<4.013$ \\
\hline Th & $<0.310$ & $<0.305$ & $<0.307$ & $<0.314$ & $<0.232$ & $<1.513$ \\
\hline $\mathrm{Ti}$ & {$[0.05]$} & {$[0.03]$} & {$[0.03]$} & {$[0.02]$} & {$[0.02]$} & $<0.066$ \\
\hline $\mathrm{Tl}$ & $<1.201$ & $<1.184$ & $<1.192$ & $<1.218$ & $<0.901$ & $<5.865$ \\
\hline $\mathrm{V}$ & $<0.023$ & {$[0.04]$} & {$[0.05]$} & {$[0.08]$} & {$[0.09]$} & {$[0.17]$} \\
\hline $\mathrm{W}$ & $<0.600$ & $<0.592$ & $<0.596$ & $<0.609$ & $<0.450$ & $<2.932$ \\
\hline $\mathrm{Y}$ & $<0.014$ & $<0.014$ & $<0.014$ & $<0.014$ & $<0.010$ & $<0.068$ \\
\hline \multicolumn{7}{|c|}{3 M NaOH, Trial a } \\
\hline Density & 1.13 & 1.13 & 1.13 & 1.13 & 1.13 & 1.14 \\
\hline $\mathrm{Al}$ & 42.5 & 62.2 & 62.9 & 66.6 & 70.0 & 88.1 \\
\hline $\mathrm{B}$ & [1.61] & [1.47] & {$[0.762]$} & [1.02] & $<0.740$ & $<0.747$ \\
\hline $\mathrm{Bi}$ & $<4.83$ & $<4.89$ & $<4.76$ & $<4.78$ & $<4.62$ & $<4.67$ \\
\hline $\mathrm{Cd}$ & $<0.547$ & $<0.554$ & $<0.540$ & $<0.542$ & $<0.524$ & $<0.529$ \\
\hline $\mathrm{Cr}$ & {$[0.483]$} & {$[0.554]$} & [0.699] & {$[0.605]$} & {$[0.863]$} & {$[1.28]$} \\
\hline $\mathrm{Fe}$ & 16.4 & 11.8 & 11.4 & 10.5 & 10.1 & 9.21 \\
\hline $\mathrm{Mn}$ & [0.483] & {$[0.391]$} & 0.314 & [0.284] & {$[0.253]$} & {$[0.246]$} \\
\hline $\mathrm{Na}$ & 74,374 & 73,282 & 72,709 & 73,933 & 72,732 & 73,782 \\
\hline $\mathrm{Ni}$ & $<0.386$ & $<0.391$ & $<0.381$ & $<0.382$ & $<0.370$ & $<0.374$ \\
\hline $\mathrm{P}$ & 547 & 651 & 651 & 644 & 656 & 654 \\
\hline$S$ & $<25.8$ & $<26.1$ & $<25.4$ & $<25.5$ & $<24.7$ & $<24.9$ \\
\hline $\mathrm{Si}$ & 9.11 & 24.9 & 25.5 & 25.7 & 26.7 & 26.9 \\
\hline $\mathrm{Sr}$ & {$[0.225]$} & {$[0.121]$} & {$[0.092]$} & {$[0.080]$} & {$[0.065]$} & {$[0.056]$} \\
\hline $\mathrm{U}$ & 200 & 111 & 94.0 & 70.1 & 61.3 & {$[43.6]$} \\
\hline
\end{tabular}


Table G.1 (Contd)

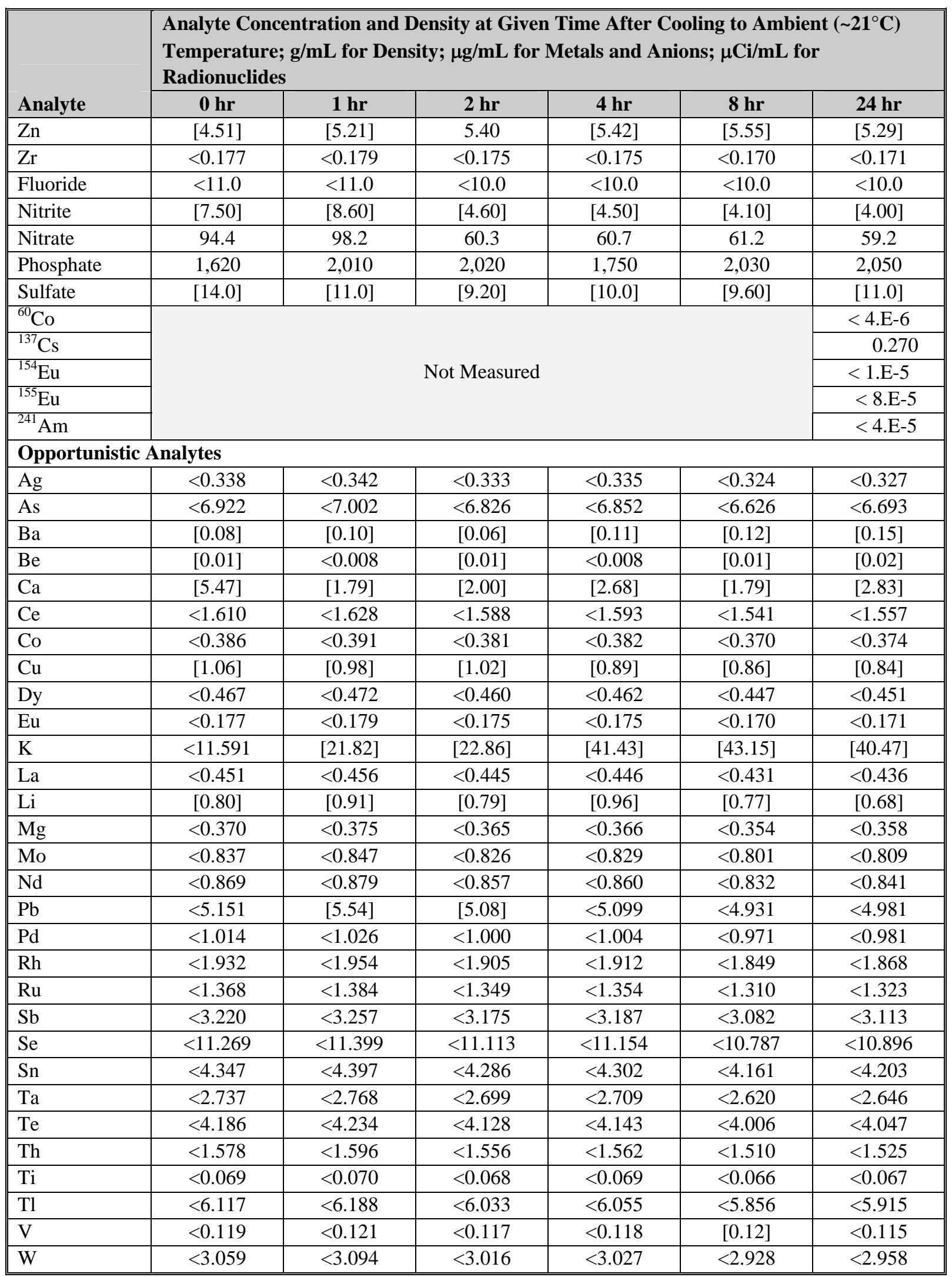


Table G.1 (Contd)

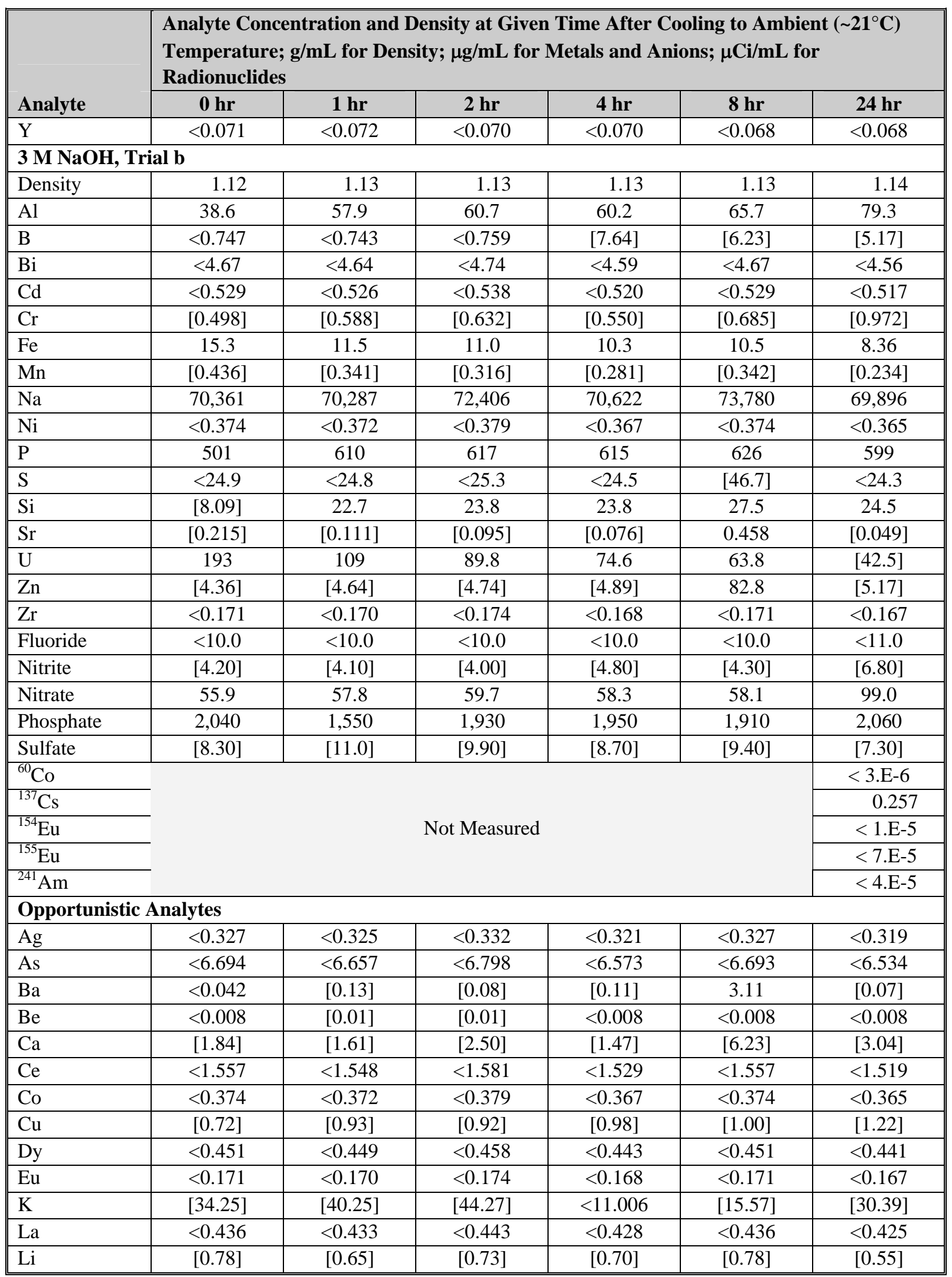


Table G.1 (Contd)

\begin{tabular}{|c|c|c|c|c|c|c|}
\hline \multirow[b]{2}{*}{ Analyte } & \multicolumn{6}{|c|}{$\begin{array}{l}\text { Analyte Concentration and Density at Given Time After Cooling to Ambient }\left(\sim 21^{\circ} \mathrm{C}\right) \\
\text { Temperature; } \mathrm{g} / \mathrm{mL} \text { for Density; } \mu \mathrm{g} / \mathrm{mL} \text { for Metals and Anions; } \mu \mathrm{Ci} / \mathrm{mL} \text { for } \\
\text { Radionuclides }\end{array}$} \\
\hline & $0 \mathrm{hr}$ & $1 \mathrm{hr}$ & $2 \mathrm{hr}$ & $4 \mathrm{hr}$ & 8 hr & $24 \mathrm{hr}$ \\
\hline $\mathrm{Mg}$ & $<0.358$ & $<0.356$ & $<0.364$ & $<0.352$ & [3.11] & $<0.349$ \\
\hline Mo & $<0.809$ & $<0.805$ & $<0.822$ & $<0.795$ & $<0.809$ & $<0.790$ \\
\hline $\mathrm{Nd}$ & $<0.841$ & $<0.836$ & $<0.854$ & $<0.825$ & $<0.841$ & $<0.821$ \\
\hline $\mathrm{Pb}$ & $<4.981$ & $<4.954$ & $<5.059$ & $<4.892$ & $<4.981$ & $<4.862$ \\
\hline $\mathrm{Pd}$ & $<0.981$ & $<0.975$ & $<0.996$ & [1.31] & $<0.981$ & $<0.957$ \\
\hline $\mathrm{Rh}$ & $<1.868$ & $<1.858$ & $<1.897$ & $<1.834$ & $<1.868$ & $<1.823$ \\
\hline $\mathrm{Ru}$ & $<1.323$ & $<1.316$ & $<1.344$ & $<1.299$ & {$[1.68]$} & $<1.292$ \\
\hline $\mathrm{Sb}$ & $<3.113$ & $<3.096$ & $<3.162$ & [3.97] & $<3.113$ & $<3.039$ \\
\hline Se & $<10.897$ & $<10.837$ & $<11.066$ & $<10.700$ & $<10.896$ & $<10.636$ \\
\hline Sn & $<4.203$ & $<4.180$ & $<4.268$ & $<4.127$ & $<<.203$ & $<4.103$ \\
\hline $\mathrm{Ta}$ & $<2.646$ & $<2.632$ & $<2.688$ & $<2.599$ & $<2.646$ & $<2.583$ \\
\hline $\mathrm{Te}$ & $<4.047$ & $<4.025$ & $<4.110$ & $<3.974$ & $<4.047$ & $<3.951$ \\
\hline Th & $<1.526$ & $<1.517$ & $<1.549$ & $<1.498$ & $<1.525$ & $<1.489$ \\
\hline $\mathrm{Ti}$ & $<0.067$ & $<0.067$ & $<0.068$ & $<0.066$ & {$[0.12]$} & $<0.065$ \\
\hline $\mathrm{Tl}$ & $<5.915$ & $<5.883$ & $<6.007$ & [6.42] & $<5.915$ & $<5.774$ \\
\hline $\mathrm{V}$ & $<0.115$ & $<0.115$ & $<0.117$ & $<0.113$ & $<0.115$ & $<0.112$ \\
\hline $\mathrm{W}$ & $<2.958$ & $<2.942$ & $<3.004$ & $<2.904$ & $\begin{array}{l}<2.957 \\
\end{array}$ & $<2.887$ \\
\hline $\mathrm{Y}$ & $<0.068$ & $<0.068$ & $<0.070$ & $<0.067$ & $<0.068$ & $<0.067$ \\
\hline \multicolumn{7}{|c|}{$3 \mathrm{M} \mathrm{NaOH}$, Trial c } \\
\hline Density & 1.12 & 1.13 & 1.13 & 1.13 & 1.14 & 1.14 \\
\hline $\mathrm{Al}$ & 36.9 & 59.8 & 60.8 & 63.5 & 65.7 & 87.1 \\
\hline $\mathrm{B}$ & {$[4.35]$} & {$[3.48]$} & {$[2.60]$} & {$[2.73]$} & {$[2.61]$} & {$[1.80]$} \\
\hline $\mathrm{Bi}$ & $<4.66$ & $<4.74$ & $<4.82$ & $<4.88$ & $<4.67$ & $<4.65$ \\
\hline $\mathrm{Cd}$ & $<0.528$ & $<0.537$ & $<0.547$ & $<0.553$ & $<0.529$ & $<0.527$ \\
\hline $\mathrm{Cr}$ & {$[0.466]$} & {$[0.294]$} & [0.547] & [0.553] & {$[0.840]$} & [1.209] \\
\hline $\mathrm{Fe}$ & 15.2 & 12.2 & 11.4 & 11.3 & 9.99 & 8.86 \\
\hline $\mathrm{Mn}$ & {$[0.466]$} & {$[0.348]$} & {$[0.318]$} & {$[0.303]$} & {$[0.277]$} & {$[0.245]$} \\
\hline $\mathrm{Na}$ & 72,641 & 73,668 & 72,680 & 73,232 & 72,820 & 72,836 \\
\hline $\mathrm{Ni}$ & $<0.373$ & $<0.379$ & $<0.386$ & $<0.391$ & $<0.373$ & $<0.372$ \\
\hline $\mathrm{P}$ & 484 & 645 & 640 & 631 & 629 & 638 \\
\hline $\mathrm{S}$ & $<24.8$ & $<25.3$ & $<25.7$ & $<26.0$ & $<24.9$ & $<24.8$ \\
\hline $\mathrm{Si}$ & [8.69] & 25.3 & 25.0 & 25.3 & 26.0 & 26.4 \\
\hline $\mathrm{Sr}$ & {$[0.220]$} & [0.117] & {$[0.103]$} & [0.081] & {$[0.078]$} & [0.053] \\
\hline $\mathrm{U}$ & 201 & 116 & 97.1 & 78.4 & 60.1 & [46.5] \\
\hline $\mathrm{Zn}$ & {$[4.35]$} & {$[5.06]$} & [5.15] & [5.53] & [5.29] & [5.27] \\
\hline $\mathrm{Zr}$ & $<0.171$ & $<0.174$ & $<0.177$ & $<0.179$ & $<0.171$ & $<0.170$ \\
\hline Fluoride & $<7.50$ & {$[7.50]$} & {$[7.50]$} & {$[8.20]$} & {$[7.50]$} & {$[7.60]$} \\
\hline Nitrite & [7.20] & [7.40] & [7.70] & [8.90] & [7.10] & [7.20] \\
\hline Nitrate & 79.0 & 82.2 & 84.3 & 87.8 & 82.1 & 84.9 \\
\hline Phosphate & 1,580 & 2,000 & 1,990 & 2,110 & 1,940 & 2,000 \\
\hline Sulfate & [16.0] & [10.0] & [11.0] & [11.0] & [9.90] & {$[10.0]$} \\
\hline
\end{tabular}


Table G.1 (Contd)

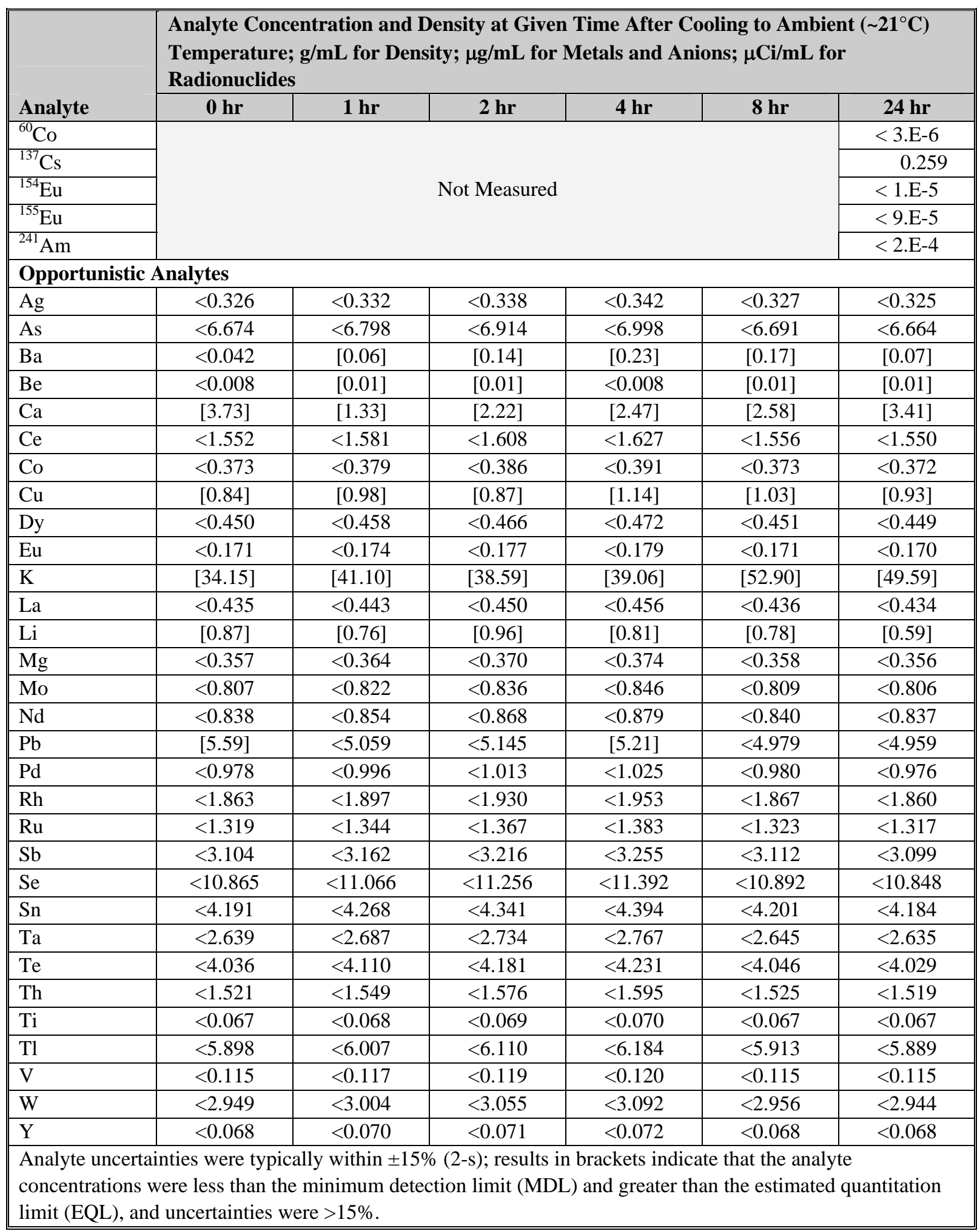


Table G.2. Analyte Concentrations as a Function of Time for Leaching at $40^{\circ} \mathrm{C}$, in $\mathrm{M}$

\begin{tabular}{|c|c|c|c|c|c|c|}
\hline \multirow[b]{2}{*}{ Analyte } & \multicolumn{6}{|c|}{$\begin{array}{l}\text { Analyte Concentration and Density at Given Time After Cooling to Ambient }\left(\sim 21^{\circ} \mathrm{C}\right) \\
\text { Temperature; } \mathrm{g} / \mathrm{mL} \text { for Density; } \mathrm{M} \text { for Metals and Anions }\end{array}$} \\
\hline & $0 \mathrm{hr}$ & $1 \mathrm{hr}$ & $2 \mathrm{hr}$ & $4 \mathrm{hr}$ & $8 \mathrm{hr}$ & $24 \mathrm{hr}$ \\
\hline \multicolumn{7}{|l|}{$1 \mathrm{M} \mathrm{NaOH}$} \\
\hline Density & 1.04 & 1.05 & 1.06 & 1.05 & 1.05 & 1.05 \\
\hline $\mathrm{Al}$ & $1.08 \mathrm{E}-03$ & 2.04E-03 & $2.14 \mathrm{E}-03$ & 2.22E-03 & $2.20 \mathrm{E}-03$ & 2.63E-03 \\
\hline B & [3.80E-05] & [3.75E-05] & [3.48E-05] & [4.15E-05] & [3.29E-05] & [1.71E-04] \\
\hline$\overline{\mathrm{Bi}}$ & $<4.54 \mathrm{E}-06$ & $<4.47 \mathrm{E}-06$ & $<4.50 \mathrm{E}-06$ & $<4.60 \mathrm{E}-06$ & $<3.40 \mathrm{E}-06$ & $<2.22 \mathrm{E}-05$ \\
\hline $\mathrm{Cd}$ & $<9.56 \mathrm{E}-07$ & $<9.42 \mathrm{E}-07$ & $<9.48 \mathrm{E}-07$ & $<$ <9.69E-07 & $<7.17 \mathrm{E}-07$ & $<4.67 \mathrm{E}-06$ \\
\hline $\mathrm{Cr}$ & [5.23E-06] & [7.19E-06] & [7.84E-06] & [8.01E-06] & 9.84E-06 & [1.31E-05] \\
\hline $\mathrm{Fe}$ & 6.85E-05 & 4.56E-05 & 4.12E-05 & $4.08 \mathrm{E}-05$ & 3.56E-05 & [4.37E-05] \\
\hline $\mathrm{Mn}$ & $4.45 \mathrm{E}-06$ & $4.05 \mathrm{E}-06$ & $3.98 \mathrm{E}-06$ & $3.94 \mathrm{E}-06$ & $3.00 \mathrm{E}-06$ & [3.82E-06] \\
\hline $\mathrm{Na}$ & 1.05 & 1.06 & 1.06 & 1.07 & 1.09 & 1.10 \\
\hline $\mathrm{Ni}$ & $<1.29 \mathrm{E}-06$ & $<1.27 \mathrm{E}-06$ & $<1.28 \mathrm{E}-06$ & $<1.31 \mathrm{E}-06$ & $<9.69 \mathrm{E}-07$ & $<6.31 \mathrm{E}-06$ \\
\hline $\mathrm{P}$ & 1.37E-02 & 1.96E-02 & 1.97E-02 & $2.00 \mathrm{E}-02$ & 1.95E-02 & 1.97E-02 \\
\hline$S$ & $<1.58 \mathrm{E}-04$ & $<1.55 \mathrm{E}-04$ & $<1.56 \mathrm{E}-04$ & $<1.60 \mathrm{E}-04$ & $<4.99 \mathrm{E}-06$ & $<7.70 \mathrm{E}-04$ \\
\hline $\mathrm{Si}$ & $2.06 \mathrm{E}-04$ & 7.48E-04 & 8.23E-04 & 8.56E-04 & 8.34E-04 & 7.53E-04 \\
\hline $\mathrm{Sr}$ & 9.99E-07 & [5.33E-07] & [4.29E-07] & [3.48E-07] & [2.70E-07] & [3.88E-07] \\
\hline $\mathrm{U}$ & $1.00 \mathrm{E}-03$ & $6.83 \mathrm{E}-04$ & $5.76 \mathrm{E}-04$ & $4.57 \mathrm{E}-04$ & $3.37 \mathrm{E}-04$ & $2.49 \mathrm{E}-04$ \\
\hline $\mathrm{Zn}$ & 3.98E-05 & 4.64E-05 & 4.37E-05 & $4.29 \mathrm{E}-05$ & $4.02 \mathrm{E}-05$ & [5.67E-05] \\
\hline $\mathrm{Zr}$ & $<3.81 \mathrm{E}-07$ & $<3.76 \mathrm{E}-07$ & $<3.78 \mathrm{E}-07$ & $<<3.87 \mathrm{E}-07$ & $<2.86 \mathrm{E}-07$ & $<1.86 \mathrm{E}-06$ \\
\hline Fluoride & [3.47E-04] & [4.21E-04] & [4.16E-04] & [4.21E-04] & [4.11E-04] & [4.26E-04] \\
\hline Nitrite & [1.65E-04] & [1.72E-04] & [1.65E-04] & [1.65E-04] & [1.65E-04] & [1.67E-04] \\
\hline Nitrate & [1.30E-03] & [1.36E-03] & $1.32 \mathrm{E}-03$ & $1.34 \mathrm{E}-03$ & $1.33 \mathrm{E}-03$ & $1.35 \mathrm{E}-03$ \\
\hline Phosphate & $1.44 \mathrm{E}-02$ & 2.05E-02 & 1.97E-02 & 1.99E-02 & 1.98E-02 & 2.13E-02 \\
\hline Sulfate & 9.89E-05 & [1.15E-04] & [1.04E-04] & [1.04E-04] & [1.04E-04] & [1.04E-04] \\
\hline \multicolumn{7}{|c|}{$3 \mathrm{M} \mathrm{NaOH}$, Trial a } \\
\hline Density & 1.13 & 1.13 & 1.13 & 1.13 & 1.13 & 1.14 \\
\hline $\mathrm{Al}$ & $1.58 \mathrm{E}-03$ & 2.31E-03 & 2.33E-03 & $2.47 \mathrm{E}-03$ & 2.59E-03 & $3.27 \mathrm{E}-03$ \\
\hline $\mathrm{B}$ & [1.49E-04] & [1.36E-04] & [7.05E-05] & [9.43E-05] & $<6.84 \mathrm{E}-05$ & $<6.91 \mathrm{E}-05$ \\
\hline $\mathrm{Bi}$ & $<2.31 \mathrm{E}-05$ & $<2.34 \mathrm{E}-05$ & $<2.28 \mathrm{E}-05$ & $<2.29 \mathrm{E}-05$ & $<2.21 \mathrm{E}-05$ & $<2.23 \mathrm{E}-05$ \\
\hline $\mathrm{Cd}$ & $<4.87 \mathrm{E}-06$ & $<4.93 \mathrm{E}-06$ & $<4.80 \mathrm{E}-06$ & $<4.82 \mathrm{E}-06$ & $<4.66 \mathrm{E}-06$ & $<4.71 \mathrm{E}-06$ \\
\hline $\mathrm{Cr}$ & [9.29E-06] & [1.06E-05] & [1.34E-05] & [1.16E-05] & [1.66E-05] & [2.45E-05] \\
\hline $\mathrm{Fe}$ & $2.94 \mathrm{E}-04$ & $2.11 \mathrm{E}-04$ & $2.04 \mathrm{E}-04$ & $1.88 \mathrm{E}-04$ & $1.81 \mathrm{E}-04$ & $1.65 \mathrm{E}-04$ \\
\hline $\mathrm{Mn}$ & [8.79E-06] & [7.11E-06] & $5.72 \mathrm{E}-06$ & [5.16E-06] & {$[4.60 \mathrm{E}-06]$} & [4.48E-06] \\
\hline $\mathrm{Na}$ & 3.24 & 3.19 & 3.16 & 3.22 & 3.16 & 3.21 \\
\hline $\mathrm{Ni}$ & $<6.58 \mathrm{E}-06$ & $<6.66 \mathrm{E}-06$ & $<6.49 \mathrm{E}-06$ & $<6.52 \mathrm{E}-06$ & $<6.30 \mathrm{E}-06$ & $<6.36 \mathrm{E}-06$ \\
\hline $\mathrm{P}$ & $1.77 \mathrm{E}-02$ & $2.10 \mathrm{E}-02$ & $2.10 \mathrm{E}-02$ & $2.08 \mathrm{E}-02$ & $2.12 \mathrm{E}-02$ & $2.11 \mathrm{E}-02$ \\
\hline$S$ & $<8.03 \mathrm{E}-04$ & $<8.13 \mathrm{E}-04$ & $<7.92 \mathrm{E}-04$ & $<7.95 \mathrm{E}-04$ & $<2.50 \mathrm{E}-05$ & $<7.77 \mathrm{E}-04$ \\
\hline $\mathrm{Si}$ & $3.24 \mathrm{E}-04$ & 8.88E-04 & 9.07E-04 & 9.15E-04 & 9.51E-04 & $9.59 \mathrm{E}-04$ \\
\hline Sr & [2.57E-06] & [1.38E-06] & [1.05E-06] & [9.09E-07] & [7.39E-07] & [6.40E-07] \\
\hline $\mathrm{U}$ & $8.40 \mathrm{E}-04$ & $4.67 \mathrm{E}-04$ & $3.95 \mathrm{E}-04$ & $2.95 \mathrm{E}-04$ & $2.58 \mathrm{E}-04$ & [1.83E-04] \\
\hline $\mathrm{Zn}$ & [6.89E-05] & [7.97E-05] & 8.26E-05 & [8.29E-05] & [8.48E-05] & [8.09E-05] \\
\hline $\mathrm{Zr}$ & $<1.94 \mathrm{E}-06$ & $<1.96 \mathrm{E}-06$ & $<1.91 \mathrm{E}-06$ & $<1.92 \mathrm{E}-06$ & $<1.86 \mathrm{E}-06$ & $<1.88 \mathrm{E}-06$ \\
\hline Fluoride & $<5.79 \mathrm{E}-04$ & $<5.79 \mathrm{E}-04$ & $<5.26 \mathrm{E}-04$ & $<5.26 \mathrm{E}-04$ & $<5.26 \mathrm{E}-04$ & $<5.26 \mathrm{E}-04$ \\
\hline Nitrite & [1.63E-04] & [1.87E-04] & [1.00E-04] & [9.78E-05] & [8.91E-05] & [8.70E-05] \\
\hline Nitrate & $1.52 \mathrm{E}-03$ & $1.58 \mathrm{E}-03$ & 9.73E-04 & 9.79E-04 & 9.87E-04 & 9.55E-04 \\
\hline
\end{tabular}


Table G.2 (Contd)

\begin{tabular}{|c|c|c|c|c|c|c|}
\hline \multirow[b]{2}{*}{ Analyte } & \multicolumn{6}{|c|}{$\begin{array}{l}\text { Analyte Concentration and Density at Given Time After Cooling to Ambient }\left(\sim 21^{\circ} \mathrm{C}\right) \\
\text { Temperature; } \mathrm{g} / \mathrm{mL} \text { for Density; } \mathrm{M} \text { for Metals and Anions }\end{array}$} \\
\hline & $0 \mathrm{hr}$ & $1 \mathrm{hr}$ & $2 \mathrm{hr}$ & $4 \mathrm{hr}$ & $8 \mathrm{hr}$ & $24 \mathrm{hr}$ \\
\hline Phosphate & $1.71 \mathrm{E}-02$ & 2.12E-02 & 2.13E-02 & $1.84 \mathrm{E}-02$ & $2.14 \mathrm{E}-02$ & $2.16 \mathrm{E}-02$ \\
\hline Sulfate & [1.46E-04] & [1.15E-04] & [9.58E-05] & [1.04E-04] & [9.99E-05] & [1.15E-04] \\
\hline \multicolumn{7}{|c|}{3 M NaOH, Trial b } \\
\hline Density & 1.12 & 1.13 & 1.13 & 1.13 & 1.13 & 1.14 \\
\hline $\mathrm{Al}$ & 1.43E-03 & 2.15E-03 & $2.25 \mathrm{E}-03$ & 2.23E-03 & 2.43E-03 & 2.94E-03 \\
\hline B & $<6.91 \mathrm{E}-05$ & $<6.87 \mathrm{E}-05$ & $<7.02 \mathrm{E}-05$ & [7.07E-04] & [5.76E-04] & [4.78E-04] \\
\hline $\mathrm{Bi}$ & $<2.23 \mathrm{E}-05$ & $<2.22 \mathrm{E}-05$ & $<2.27 \mathrm{E}-05$ & $<2.19 \mathrm{E}-05$ & $<2.23 \mathrm{E}-05$ & $<2.18 \mathrm{E}-05$ \\
\hline$\overline{\mathrm{Cd}}$ & $<4.71 \mathrm{E}-06$ & $<4.68 \mathrm{E}-06$ & $<4.78 \mathrm{E}-06$ & $<4.62 \mathrm{E}-06$ & $<4.71 \mathrm{E}-06$ & $<4.60 \mathrm{E}-06$ \\
\hline $\mathrm{Cr}$ & [9.58E-06] & [1.13E-05] & [1.22E-05] & [1.06E-05] & [1.32E-05] & [1.87E-05] \\
\hline $\mathrm{Fe}$ & $2.74 \mathrm{E}-04$ & $2.06 \mathrm{E}-04$ & $1.96 \mathrm{E}-04$ & $1.84 \mathrm{E}-04$ & $1.88 \mathrm{E}-04$ & $1.50 \mathrm{E}-04$ \\
\hline Mn & [7.93E-06] & [6.20E-06] & [5.76E-06] & [5.12E-06] & [6.23E-06] & {$[4.26 \mathrm{E}-06]$} \\
\hline $\mathrm{Na}$ & 3.06 & 3.06 & 3.15 & 3.07 & 3.21 & 3.04 \\
\hline $\mathrm{Ni}$ & $<6.37 \mathrm{E}-06$ & $<6.33 \mathrm{E}-06$ & $<6.46 \mathrm{E}-06$ & $<6.25 \mathrm{E}-06$ & $<6.36 \mathrm{E}-06$ & $<6.21 \mathrm{E}-06$ \\
\hline $\mathrm{P}$ & 1.62E-02 & 1.97E-02 & 1.99E-02 & $1.98 \mathrm{E}-02$ & 2.02E-02 & 1.93E-02 \\
\hline$S$ & $<$ <7.77E-04 & $<7.73 \mathrm{E}-04$ & $<7.89 \mathrm{E}-04$ & $<7.63 \mathrm{E}-04$ & [1.46E-03] & $<7.58 \mathrm{E}-04$ \\
\hline Si & [2.88E-04] & 8.08E-04 & 8.48E-04 & 8.47E-04 & 9.79E-04 & 8.72E-04 \\
\hline $\mathrm{Sr}$ & [2.45E-06] & [1.27E-06] & [1.08E-06] & [8.72E-07] & $5.22 \mathrm{E}-06$ & [5.55E-07] \\
\hline $\mathrm{U}$ & $8.12 \mathrm{E}-04$ & $4.58 \mathrm{E}-04$ & 3.77E-04 & 3.13E-04 & $2.68 \mathrm{E}-04$ & [1.79E-04] \\
\hline $\mathrm{Zn}$ & [6.67E-05] & [7.10E-05] & [7.25E-05] & [7.48E-05] & $1.27 \mathrm{E}-03$ & [7.90E-05] \\
\hline $\mathrm{Zr}$ & $<1.88 \mathrm{E}-06$ & $<1.87 \mathrm{E}-06$ & $<1.91 \mathrm{E}-06$ & $<1.84 \mathrm{E}-06$ & $<1.88 \mathrm{E}-06$ & $<1.83 \mathrm{E}-06$ \\
\hline Fluoride & $<5.26 \mathrm{E}-04$ & $<5.26 \mathrm{E}-04$ & $<5.26 \mathrm{E}-04$ & $<5.26 \mathrm{E}-04$ & $<5.26 \mathrm{E}-04$ & $<5.79 \mathrm{E}-04$ \\
\hline Nitrite & [9.13E-05] & [8.91E-05] & [8.70E-05] & [1.04E-04] & [9.35E-05] & [1.48E-04] \\
\hline Nitrate & 9.02E-04 & 9.32E-04 & 9.63E-04 & $9.40 \mathrm{E}-04$ & 9.37E-04 & $1.60 \mathrm{E}-03$ \\
\hline Phosphate & $2.15 \mathrm{E}-02$ & $1.63 \mathrm{E}-02$ & 2.03E-02 & $2.05 \mathrm{E}-02$ & $2.01 \mathrm{E}-02$ & $2.17 \mathrm{E}-02$ \\
\hline Sulfate & [8.64E-05] & [1.15E-04] & [1.03E-04] & [9.06E-05] & [9.79E-05] & [7.60E-05] \\
\hline \multicolumn{7}{|c|}{3 M NaOH, Trial c } \\
\hline Density & 1.12 & 1.13 & 1.13 & 1.13 & 1.14 & 1.14 \\
\hline $\mathrm{Al}$ & 1.37E-03 & $2.21 \mathrm{E}-03$ & $2.25 \mathrm{E}-03$ & 2.35E-03 & 2.43E-03 & 3.23E-03 \\
\hline B & [4.02E-04] & [3.22E-04] & [2.41E-04] & [2.53E-04] & [2.42E-04] & [1.66E-04] \\
\hline $\mathrm{Bi}$ & $<2.23 \mathrm{E}-05$ & $<2.27 \mathrm{E}-05$ & $<2.31 \mathrm{E}-05$ & $<2.34 \mathrm{E}-05$ & $<2.23 \mathrm{E}-05$ & $<2.22 \mathrm{E}-05$ \\
\hline $\mathrm{Cd}$ & $<4.69 \mathrm{E}-06$ & $<4.78 \mathrm{E}-06$ & $<4.86 \mathrm{E}-06$ & $<4.92 \mathrm{E}-06$ & $<4.71 \mathrm{E}-06$ & $<4.69 \mathrm{E}-06$ \\
\hline $\mathrm{Cr}$ & [8.96E-06] & [5.66E-06] & [1.05E-05] & [1.06E-05] & [1.62E-05] & [2.32E-05] \\
\hline $\mathrm{Fe}$ & $2.73 \mathrm{E}-04$ & $2.19 \mathrm{E}-04$ & $2.05 \mathrm{E}-04$ & $2.02 \mathrm{E}-04$ & $1.79 \mathrm{E}-04$ & $1.59 \mathrm{E}-04$ \\
\hline $\mathrm{Mn}$ & [8.48E-06] & [6.33E-06] & [5.80E-06] & [5.51E-06] & [5.04E-06] & [4.46E-06] \\
\hline $\mathrm{Na}$ & 3.16 & 3.20 & 3.16 & 3.19 & 3.17 & 3.17 \\
\hline $\mathrm{Ni}$ & $<6.35 \mathrm{E}-06$ & $<6.46 \mathrm{E}-06$ & $<6.58 \mathrm{E}-06$ & $<6.65 \mathrm{E}-06$ & $<6.36 \mathrm{E}-06$ & $<6.34 \mathrm{E}-06$ \\
\hline $\mathrm{P}$ & $1.56 \mathrm{E}-02$ & 2.08E-02 & 2.07E-02 & $2.04 \mathrm{E}-02$ & 2.03E-02 & $2.06 \mathrm{E}-02$ \\
\hline$S$ & $<7.75 \mathrm{E}-04$ & $<7.89 \mathrm{E}-04$ & $<8.02 \mathrm{E}-04$ & $<8.12 \mathrm{E}-04$ & $<2.50 \mathrm{E}-05$ & $<7.73 \mathrm{E}-04$ \\
\hline Si & [3.09E-04] & 9.01E-04 & 8.89E-04 & 9.02E-04 & 9.25E-04 & $9.40 \mathrm{E}-04$ \\
\hline $\mathrm{Sr}$ & [2.52E-06] & [1.34E-06] & [1.17E-06] & [9.29E-07] & [8.88E-07] & [6.01E-07] \\
\hline $\mathrm{U}$ & 8.45E-04 & 4.89E-04 & 4.08E-04 & 3.30E-04 & 2.52E-04 & [1.95E-04] \\
\hline $\mathrm{Zn}$ & [6.65E-05] & [7.74E-05] & [7.87E-05] & [8.46E-05] & [8.09E-05] & [8.06E-05] \\
\hline $\mathrm{Zr}$ & $<1.87 \mathrm{E}-06$ & $<1.91 \mathrm{E}-06$ & $<1.94 \mathrm{E}-06$ & $<1.96 \mathrm{E}-06$ & $<1.88 \mathrm{E}-06$ & $<1.87 \mathrm{E}-06$ \\
\hline Fluoride & $<3.95 \mathrm{E}-04$ & [3.95E-04] & [3.95E-04] & [4.32E-04] & [3.95E-04] & [4.00E-04] \\
\hline
\end{tabular}


Table G.2 (Contd)

\begin{tabular}{|c|c|c|c|c|c|c|}
\hline \multirow[b]{2}{*}{ Analyte } & \multicolumn{6}{|c|}{$\begin{array}{l}\text { Analyte Concentration and Density at Given Time After Cooling to Ambient }\left(\sim 21^{\circ} \mathrm{C}\right) \\
\text { Temperature; } \mathrm{g} / \mathrm{mL} \text { for Density; } \mathrm{M} \text { for Metals and Anions }\end{array}$} \\
\hline & $0 \mathrm{hr}$ & $1 \mathrm{hr}$ & $2 \mathrm{hr}$ & $4 \mathrm{hr}$ & $8 \mathrm{hr}$ & $24 \mathrm{hr}$ \\
\hline Nitrite & [1.57E-04] & [1.61E-04] & [1.67E-04] & [1.93E-04] & [1.54E-04] & [1.57E-04] \\
\hline Nitrate & 1.27E-03 & $1.33 \mathrm{E}-03$ & $1.36 \mathrm{E}-03$ & 1.42E-03 & 1.32E-03 & $1.37 \mathrm{E}-03$ \\
\hline Phosphate & $1.66 \mathrm{E}-02$ & $2.11 \mathrm{E}-02$ & $2.10 \mathrm{E}-02$ & $2.22 \mathrm{E}-02$ & $2.04 \mathrm{E}-02$ & $2.11 \mathrm{E}-02$ \\
\hline Sulfate & [1.67E-04] & [1.04E-04] & [1.15E-04] & [1.15E-04] & [1.03E-04] & [1.04E-04] \\
\hline
\end{tabular}


Table G.3. Analyte Concentrations as a Function of Time for Leaching at $60^{\circ} \mathrm{C}$, in $\mu \mathrm{g} / \mathrm{mL}$

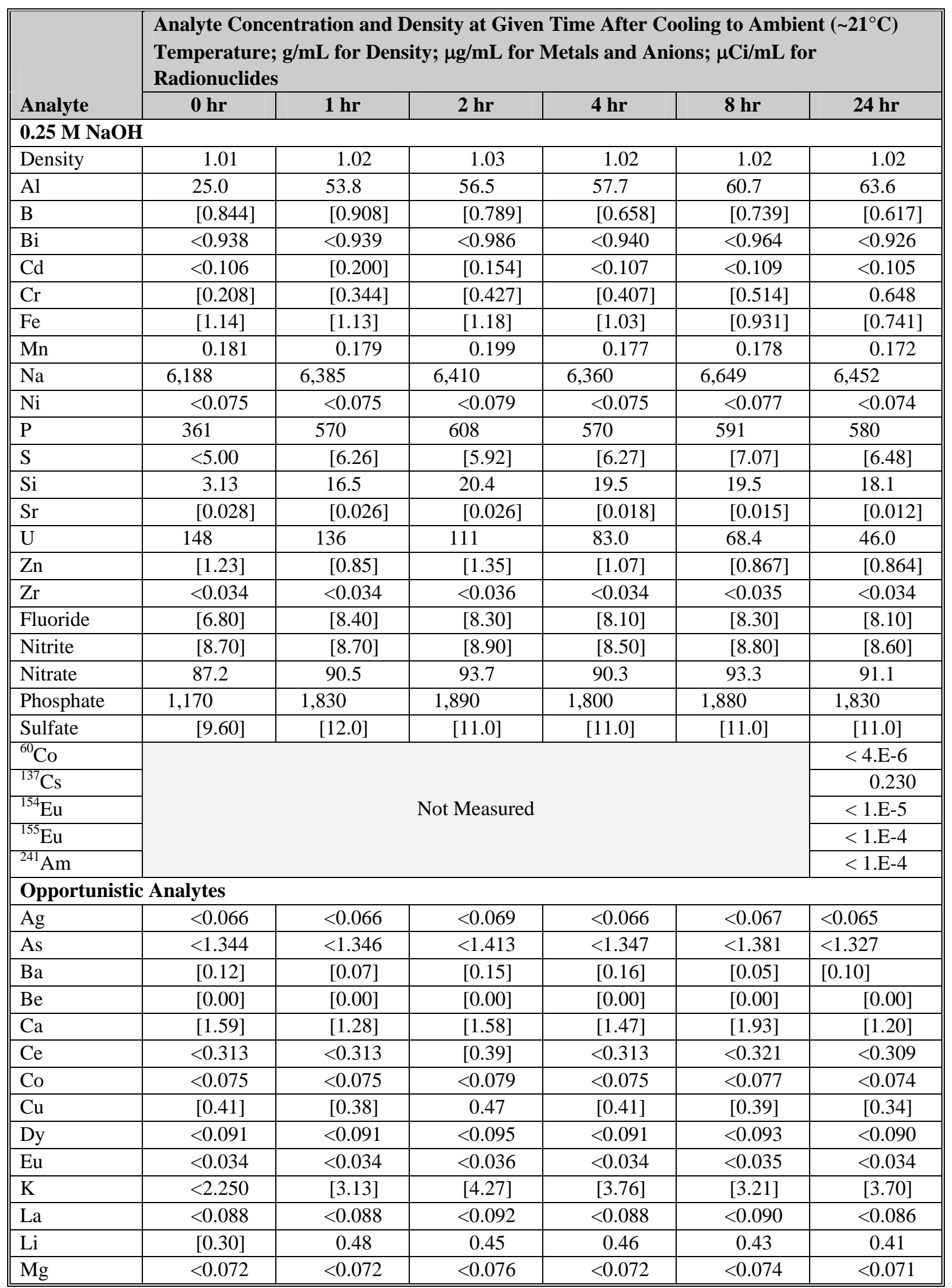


Table G.3 (Contd)

\begin{tabular}{|c|c|c|c|c|c|c|}
\hline \multirow[b]{2}{*}{ Analyte } & \multicolumn{6}{|c|}{$\begin{array}{l}\text { Analyte Concentration and Density at Given Time After Cooling to Ambient }\left(\sim 21^{\circ} \mathrm{C}\right) \\
\text { Temperature; } \mathrm{g} / \mathrm{mL} \text { for Density; } \mu \mathrm{g} / \mathrm{mL} \text { for Metals and Anions; } \mu \mathrm{Ci} / \mathrm{mL} \text { for } \\
\text { Radionuclides }\end{array}$} \\
\hline & o hr & $1 \mathrm{hr}$ & 2 hr & $4 \mathrm{hr}$ & $8 \mathrm{hr}$ & $24 \mathrm{hr}$ \\
\hline Mo & $<0.163$ & $<0.163$ & $<0.171$ & $<0.163$ & $<0.167$ & $<0.161$ \\
\hline $\mathrm{Nd}$ & $<0.169$ & $<0.169$ & $<0.178$ & $<0.169$ & $<0.173$ & $<0.167$ \\
\hline $\mathrm{Pb}$ & $<1.000$ & $<1.002$ & $<1.052$ & $<1.003$ & $<1.028$ & $<0.988$ \\
\hline $\mathrm{Pd}$ & $<0.197$ & $<0.197$ & $<0.207$ & $<0.197$ & $<0.202$ & $<0.194$ \\
\hline $\mathrm{Rh}$ & $<0.375$ & $<0.376$ & $<0.394$ & $<0.376$ & $<0.385$ & $<0.370$ \\
\hline $\mathrm{Ru}$ & $<0.266$ & $<0.266$ & [0.29] & $<0.266$ & $<0.273$ & $<0.262$ \\
\hline $\mathrm{Sb}$ & $<0.625$ & {$[0.72]$} & {$[0.72]$} & $<0.627$ & {$[0.87]$} & {$[0.62]$} \\
\hline Se & $<2.188$ & $<2.191$ & $<2.301$ & $<2.193$ & $<2.248$ & $<2.161$ \\
\hline Sn & $<0.844$ & $<0.845$ & $<0.888$ & $<0.846$ & $<0.867$ & $<0.833$ \\
\hline $\mathrm{Ta}$ & $<0.531$ & $<0.532$ & $<0.559$ & $<0.533$ & $<0.546$ & $<0.525$ \\
\hline $\mathrm{Te}$ & $<0.813$ & $<0.814$ & $<0.855$ & $<0.815$ & $<0.835$ & $<0.803$ \\
\hline Th & $<0.306$ & $<0.307$ & $<0.322$ & $<0.307$ & $<0.315$ & $<0.303$ \\
\hline $\mathrm{Ti}$ & {$[0.04]$} & {$[0.04]$} & {$[0.04]$} & {$[0.03]$} & {$[0.02]$} & {$[0.02]$} \\
\hline $\mathrm{Tl}$ & $<1.188$ & $<1.189$ & $<1.249$ & $<1.191$ & $<1.221$ & $<1.173$ \\
\hline $\mathrm{V}$ & $<0.023$ & {$[0.03]$} & $<0.024$ & {$[0.04]$} & {$[0.07]$} & {$[0.05]$} \\
\hline $\mathrm{W}$ & $<0.594$ & $<0.595$ & $<0.625$ & $<0.595$ & $<0.610$ & $<0.587$ \\
\hline $\bar{Y}$ & $<0.014$ & $<0.014$ & $<0.014$ & $<0.014$ & $<0.014$ & $<0.014$ \\
\hline \multicolumn{7}{|l|}{$1 \mathrm{M} \mathrm{NaOH}$} \\
\hline Density & 1.03 & 1.06 & 1.05 & 1.05 & 1.05 & 1.05 \\
\hline $\mathrm{Al}$ & 32.4 & 57.8 & 60.9 & 68.9 & 84.9 & 90.5 \\
\hline B & {$[0.472]$} & {$[0.601]$} & {$[0.377]$} & [0.475] & [0.511] & {$[0.404]$} \\
\hline $\mathrm{Bi}$ & $<0.944$ & $<0.948$ & $<0.942$ & $<0.891$ & $<1.023$ & $<0.933$ \\
\hline $\mathrm{Cd}$ & $<0.107$ & $<0.107$ & $<0.107$ & $<0.101$ & $<0.116$ & $<0.106$ \\
\hline $\mathrm{Cr}$ & [0.315] & [0.474] & 0.578 & 0.686 & 0.839 & 1.18 \\
\hline $\mathrm{Fe}$ & 3.21 & 3.64 & 3.24 & 2.92 & 2.43 & 1.91 \\
\hline $\mathrm{Mn}$ & 0.227 & 0.200 & 0.193 & 0.182 & 0.205 & 0.190 \\
\hline $\mathrm{Na}$ & 22,206 & 23,076 & 22,742 & 23,242 & 24,273 & 23,260 \\
\hline $\mathrm{Ni}$ & $<0.075$ & $<0.076$ & $<0.075$ & $<0.071$ & $<0.082$ & $<0.075$ \\
\hline $\mathrm{P}$ & 472 & 591 & 578 & 594 & 617 & 600 \\
\hline$S$ & [5.66] & [5.37] & [5.03] & [5.64] & {$[5.80]$} & [5.29] \\
\hline Si & 5.98 & 24.3 & 23.4 & 25.2 & 24.4 & 23.8 \\
\hline Sr & 0.077 & {$[0.027]$} & {$[0.027]$} & {$[0.033]$} & {$[0.026]$} & {$[0.021]$} \\
\hline $\mathrm{U}$ & 199 & 121 & 92.0 & 72.7 & 60.0 & 42.0 \\
\hline $\mathrm{Zn}$ & 2.99 & 2.70 & 2.86 & 2.65 & 2.54 & 2.23 \\
\hline $\mathrm{Zr}$ & $<0.035$ & $<0.035$ & $<0.035$ & $<0.033$ & $<0.038$ & $<0.034$ \\
\hline Fluoride & {$[8.10]$} & {$[7.20]$} & {$[7.10]$} & {$[7.20]$} & {$[7.20]$} & {$[7.40]$} \\
\hline Nitrite & 8.55 & 8.75 & 9.24 & 8.84 & 8.78 & 8.77 \\
\hline Nitrate & 93.7 & 97.3 & 99.0 & 98.2 & 98.9 & 99.1 \\
\hline Phosphate & 1,590 & 1,920 & 1,910 & 1,900 & 1,970 & 1,930 \\
\hline Sulfate & {$[10.0]$} & [11.0] & [11.0] & [12.0] & [11.0] & [11.0] \\
\hline
\end{tabular}


Table G.3 (Contd)

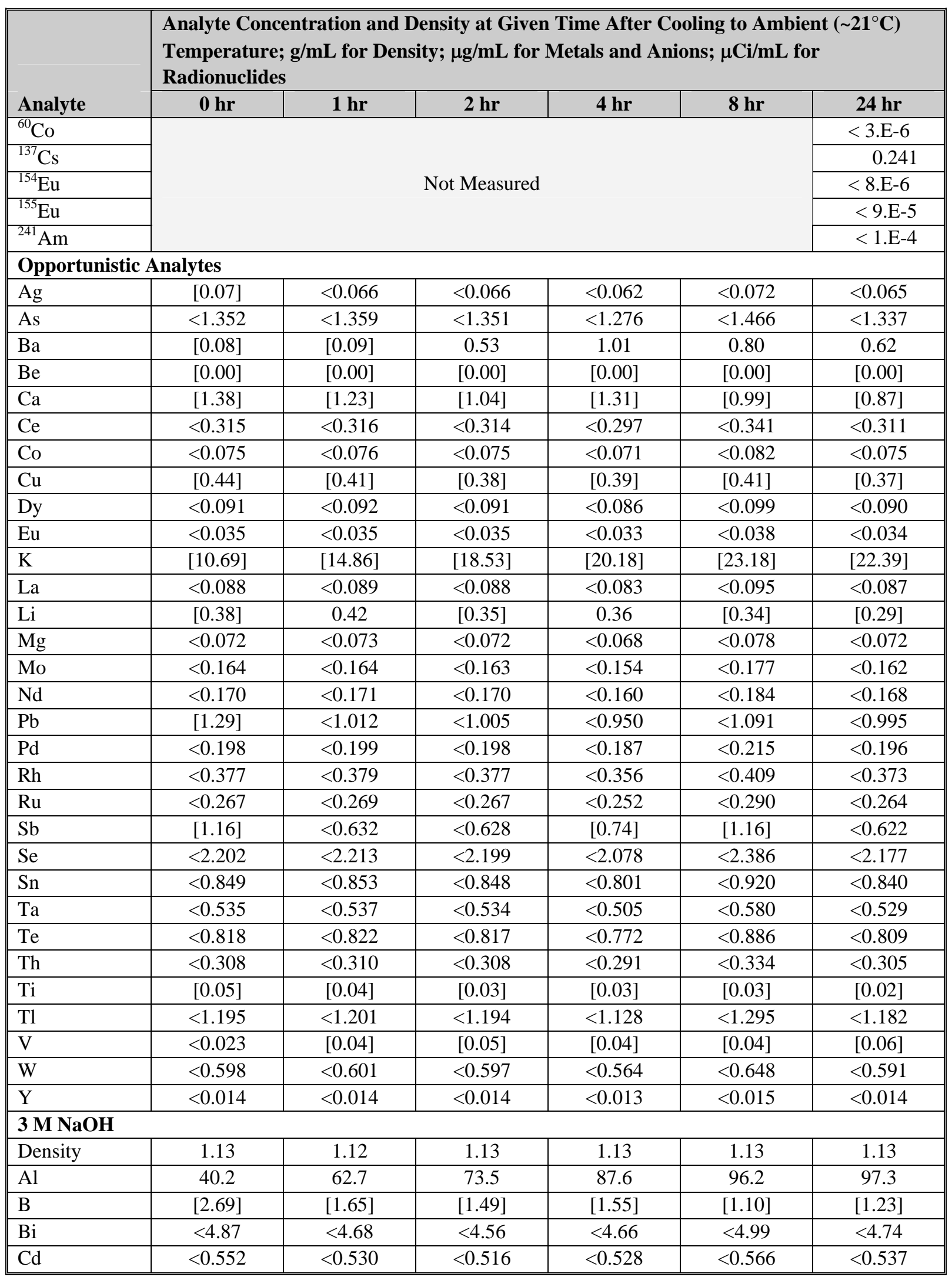


Table G.3 (Contd)

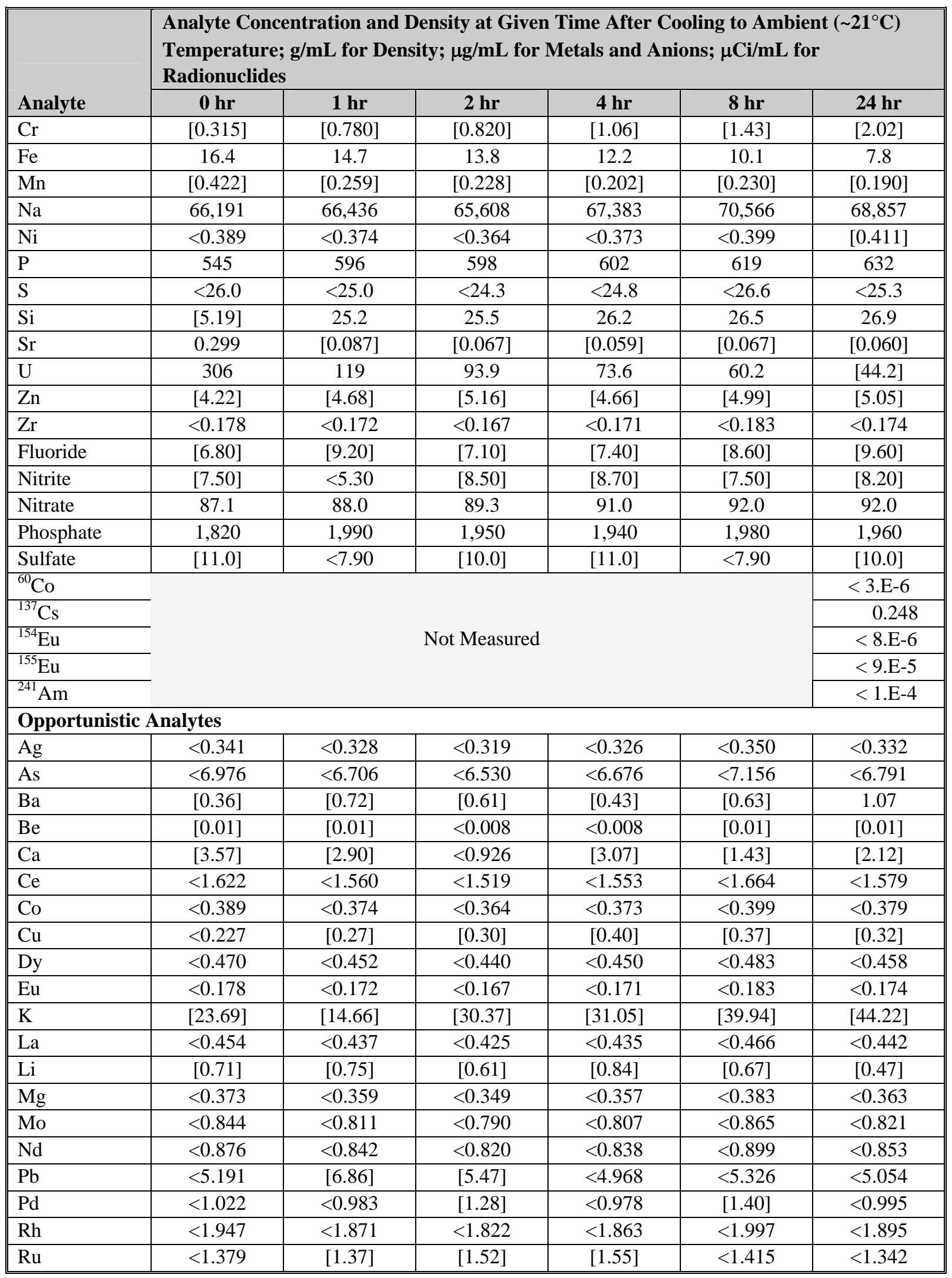


Table G.3 (Contd)

\begin{tabular}{|c|c|c|c|c|c|c|}
\hline \multirow[b]{2}{*}{ Analyte } & \multicolumn{6}{|c|}{$\begin{array}{l}\text { Analyte Concentration and Density at Given Time After Cooling to Ambient }\left(\sim 21^{\circ} \mathrm{C}\right) \\
\text { Temperature; } \mathrm{g} / \mathrm{mL} \text { for Density; } \mu \mathrm{g} / \mathrm{mL} \text { for Metals and Anions; } \mu \mathrm{Ci} / \mathrm{mL} \text { for } \\
\text { Radionuclides }\end{array}$} \\
\hline & $0 \mathrm{hr}$ & $1 \mathrm{hr}$ & $2 \mathrm{hr}$ & $4 \mathrm{hr}$ & $8 \mathrm{hr}$ & $24 \mathrm{hr}$ \\
\hline $\mathrm{Sb}$ & [4.54] & $<3.119$ & $<3.037$ & [3.42] & [5.99] & $<3.159$ \\
\hline Se & $<11.356$ & $<10.917$ & $<10.631$ & $<10.868$ & $<11.650$ & $<11.055$ \\
\hline Sn & $<4.380$ & $<4.211$ & $<4.101$ & $<4.192$ & $<4.494$ & $<4.264$ \\
\hline $\mathrm{Ta}$ & $<2.758$ & $<2.651$ & $<2.582$ & $<2.639$ & $<2.829$ & $<2.685$ \\
\hline $\mathrm{Te}$ & $<4.218$ & $<4.055$ & $<3.949$ & $<4.037$ & $<4.327$ & $<4.106$ \\
\hline Th & $<1.590$ & $<1.528$ & $<1.488$ & $<1.522$ & $<1.631$ & $<1.548$ \\
\hline $\mathrm{Ti}$ & {$[0.11]$} & {$[0.10]$} & $<0.065$ & $<0.067$ & $<0.072$ & $<0.068$ \\
\hline $\mathrm{Tl}$ & $<6.165$ & $<5.926$ & $<5.771$ & $<5.900$ & $<6.324$ & $<6.001$ \\
\hline $\mathrm{V}$ & $<0.120$ & $<0.115$ & $<0.112$ & $<0.115$ & $<0.123$ & $<0.117$ \\
\hline $\mathrm{W}$ & $<3.082$ & $<2.963$ & $<2.886$ & $<2.950$ & $<3.162$ & $<3.001$ \\
\hline $\mathrm{Y}$ & $<0.071$ & $<0.069$ & $<0.067$ & $<0.068$ & $<0.073$ & $<0.069$ \\
\hline
\end{tabular}


Table G.4. Analyte Concentrations as a Function of Time for Leaching at $60^{\circ} \mathrm{C}$, in $\mathrm{M}$

\begin{tabular}{|c|c|c|c|c|c|c|}
\hline \multirow[b]{2}{*}{ Analyte } & \multicolumn{6}{|c|}{$\begin{array}{l}\text { Analyte Concentration and Density at Given Time After Cooling to Ambient }\left(\sim 21^{\circ} \mathrm{C}\right) \\
\text { Temperature; } \mathrm{g} / \mathrm{mL} \text { for Density; } \mathrm{M} \text { for Metals and Anions }\end{array}$} \\
\hline & $0 \mathrm{hr}$ & $1 \mathrm{hr}$ & $2 \mathrm{hr}$ & $4 \mathrm{hr}$ & $8 \mathrm{hr}$ & $24 \mathrm{hr}$ \\
\hline \multicolumn{7}{|c|}{$0.25 \mathrm{M} \mathrm{NaOH}$} \\
\hline Density & 1.01 & 1.02 & 1.03 & 1.02 & 1.02 & 1.02 \\
\hline $\mathrm{Al}$ & $9.27 \mathrm{E}-04$ & $2.00 \mathrm{E}-03$ & $2.10 \mathrm{E}-03$ & $2.14 \mathrm{E}-03$ & $2.25 \mathrm{E}-03$ & $2.36 \mathrm{E}-03$ \\
\hline $\mathrm{B}$ & [7.81E-05] & [8.40E-05] & [7.30E-05] & [6.09E-05] & [6.83E-05] & [5.71E-05] \\
\hline $\mathrm{Bi}$ & $<4.49 \mathrm{E}-06$ & $<4.49 \mathrm{E}-06$ & $<4.72 \mathrm{E}-06$ & $<4.50 \mathrm{E}-06$ & $<4.61 \mathrm{E}-06$ & $<4.43 \mathrm{E}-06$ \\
\hline $\mathrm{Cd}$ & $<9.45 \mathrm{E}-07$ & [1.78E-06] & [1.37E-06] & $<9.48 \mathrm{E}-07$ & $<9.72 \mathrm{E}-07$ & $<9.34 \mathrm{E}-07$ \\
\hline $\mathrm{Cr}$ & [4.00E-06] & [6.62E-06] & [8.22E-06] & [7.83E-06] & [9.88E-06] & $1.25 \mathrm{E}-05$ \\
\hline $\mathrm{Fe}$ & [2.04E-05] & [2.02E-05] & [2.12E-05] & [1.85E-05] & [1.67E-05] & [1.33E-05] \\
\hline $\mathrm{Mn}$ & 3.30E-06 & 3.26E-06 & 3.61E-06 & 3.23E-06 & 3.23E-06 & 3.14E-06 \\
\hline $\mathrm{Na}$ & 0.27 & 0.28 & 0.28 & 0.28 & 0.29 & 0.28 \\
\hline $\mathrm{Ni}$ & $<1.28 \mathrm{E}-06$ & $<1.28 \mathrm{E}-06$ & $<1.34 \mathrm{E}-06$ & $<1.28 \mathrm{E}-06$ & $<1.31 \mathrm{E}-06$ & $<1.26 \mathrm{E}-06$ \\
\hline $\mathrm{P}$ & 1.17E-02 & $1.84 \mathrm{E}-02$ & $1.96 \mathrm{E}-02$ & $1.84 \mathrm{E}-02$ & $1.91 \mathrm{E}-02$ & $1.87 \mathrm{E}-02$ \\
\hline$S$ & $<1.56 \mathrm{E}-04$ & [1.95E-04] & [1.85E-04] & [1.95E-04] & [2.20E-04] & [2.02E-04] \\
\hline Si & $1.11 \mathrm{E}-04$ & $5.86 \mathrm{E}-04$ & $7.26 \mathrm{E}-04$ & $6.94 \mathrm{E}-04$ & 6.94E-04 & $6.45 \mathrm{E}-04$ \\
\hline $\mathrm{Sr}$ & [3.16E-07] & [2.96E-07] & [2.96E-07] & [2.04E-07] & [1.76E-07] & [1.34E-07] \\
\hline $\mathrm{U}$ & $6.22 \mathrm{E}-04$ & 5.72E-04 & 4.68E-04 & 3.49E-04 & 2.87E-04 & 1.93E-04 \\
\hline Zn & [1.89E-05] & [1.29E-05] & [2.06E-05] & [1.63E-05] & [1.33E-05] & [1.32E-05] \\
\hline $\mathrm{Zr}$ & $<3.77 \mathrm{E}-07$ & $<3.77 \mathrm{E}-07$ & $<3.96 \mathrm{E}-07$ & $<3.78 \mathrm{E}-07$ & $<3.87 \mathrm{E}-07$ & $<3.72 \mathrm{E}-07$ \\
\hline Fluoride & [3.58E-04] & [4.42E-04] & [4.37E-04] & [4.26E-04] & [4.37E-04] & [4.26E-04] \\
\hline Nitrite & [1.89E-04] & [1.89E-04] & [1.93E-04] & [1.85E-04] & [1.91E-04] & [1.87E-04] \\
\hline Nitrate & $1.41 \mathrm{E}-03$ & $1.46 \mathrm{E}-03$ & $1.51 \mathrm{E}-03$ & $1.46 \mathrm{E}-03$ & $1.50 \mathrm{E}-03$ & $1.47 \mathrm{E}-03$ \\
\hline Phosphate & 1.23E-02 & $1.93 \mathrm{E}-02$ & 1.99E-02 & $1.90 \mathrm{E}-02$ & 1.98E-02 & $1.93 \mathrm{E}-02$ \\
\hline Sulfate & [9.99E-05] & [1.25E-04] & [1.15E-04] & [1.15E-04] & [1.15E-04] & [1.15E-04] \\
\hline \multicolumn{7}{|l|}{$1 \mathrm{M} \mathrm{NaOH}$} \\
\hline Density & 1.03 & 1.06 & 1.05 & 1.05 & 1.05 & 1.05 \\
\hline $\mathrm{Al}$ & $1.20 \mathrm{E}-03$ & $2.14 \mathrm{E}-03$ & $2.26 \mathrm{E}-03$ & $2.55 \mathrm{E}-03$ & 3.15E-03 & 3.35E-03 \\
\hline $\mathrm{B}$ & [4.36E-05] & [5.56E-05] & [3.49E-05] & [4.39E-05] & [4.73E-05] & [3.74E-05] \\
\hline $\mathrm{Bi}$ & $<4.52 \mathrm{E}-06$ & $<4.54 \mathrm{E}-06$ & $<4.51 \mathrm{E}-06$ & $<4.26 \mathrm{E}-06$ & $<4.89 \mathrm{E}-06$ & $<4.46 \mathrm{E}-06$ \\
\hline $\mathrm{Cd}$ & $<<9.51 \mathrm{E}-07$ & $<9.56 \mathrm{E}-07$ & $<9.50 \mathrm{E}-07$ & $<8.98 \mathrm{E}-07$ & $<1.03 \mathrm{E}-06$ & $<9.41 \mathrm{E}-07$ \\
\hline $\mathrm{Cr}$ & [6.05E-06] & [9.12E-06] & $1.11 \mathrm{E}-05$ & $1.32 \mathrm{E}-05$ & $1.61 \mathrm{E}-05$ & $2.26 \mathrm{E}-05$ \\
\hline $\mathrm{Fe}$ & $5.74 \mathrm{E}-05$ & $6.51 \mathrm{E}-05$ & 5.79E-05 & 5.22E-05 & 4.36E-05 & $3.42 \mathrm{E}-05$ \\
\hline $\mathrm{Mn}$ & 4.14E-06 & 3.65E-06 & 3.50E-06 & 3.32E-06 & 3.73E-06 & 3.45E-06 \\
\hline $\mathrm{Na}$ & 0.97 & 1.00 & 0.99 & 1.01 & 1.06 & 1.01 \\
\hline $\mathrm{Ni}$ & $<1.29 \mathrm{E}-06$ & $<1.29 \mathrm{E}-06$ & $<1.28 \mathrm{E}-06$ & $<1.21 \mathrm{E}-06$ & $<1.39 \mathrm{E}-06$ & $<1.27 \mathrm{E}-06$ \\
\hline $\mathrm{P}$ & $1.52 \mathrm{E}-02$ & 1.91E-02 & $1.87 \mathrm{E}-02$ & $1.92 \mathrm{E}-02$ & $1.99 \mathrm{E}-02$ & $1.94 \mathrm{E}-02$ \\
\hline$S$ & [1.77E-04] & [1.68E-04] & [1.57E-04] & [1.76E-04] & [1.81E-04] & [1.65E-04] \\
\hline Si & 2.13E-04 & 8.67E-04 & 8.32E-04 & 8.96E-04 & $8.70 \mathrm{E}-04$ & $8.46 \mathrm{E}-04$ \\
\hline $\mathrm{Sr}$ & 8.79E-07 & [3.10E-07] & [3.05E-07] & [3.73E-07] & [2.92E-07] & [2.38E-07] \\
\hline $\mathrm{U}$ & 8.37E-04 & 5.09E-04 & 3.87E-04 & $3.06 \mathrm{E}-04$ & 2.52E-04 & $1.76 \mathrm{E}-04$ \\
\hline $\mathrm{Zn}$ & 4.57E-05 & 4.12E-05 & 4.37E-05 & $4.06 \mathrm{E}-05$ & 3.89E-05 & $3.41 \mathrm{E}-05$ \\
\hline $\mathrm{Zr}$ & $<3.79 \mathrm{E}-07$ & $<3.81 \mathrm{E}-07$ & $<3.79 \mathrm{E}-07$ & $<3.58 \mathrm{E}-07$ & $<4.11 \mathrm{E}-07$ & $<3.75 \mathrm{E}-07$ \\
\hline Fluoride & [4.26E-04] & [3.79E-04] & [3.74E-04] & [3.79E-04] & [3.79E-04] & [3.90E-04] \\
\hline Nitrite & $1.86 \mathrm{E}-04$ & 1.90E-04 & 2.01E-04 & 1.92E-04 & $1.91 \mathrm{E}-04$ & $1.91 \mathrm{E}-04$ \\
\hline Nitrate & $1.51 \mathrm{E}-03$ & $1.57 \mathrm{E}-03$ & $1.60 \mathrm{E}-03$ & $1.58 \mathrm{E}-03$ & $1.60 \mathrm{E}-03$ & 1.60E-03 \\
\hline
\end{tabular}


WTP-RPT-169, Rev 0

Table G.4 (Contd)

\begin{tabular}{|c|c|c|c|c|c|c|}
\hline \multirow[b]{2}{*}{ Analyte } & \multicolumn{6}{|c|}{$\begin{array}{l}\text { Analyte Concentration and Density at Given Time After Cooling to Ambient }\left(\sim 21^{\circ} \mathrm{C}\right) \\
\text { Temperature; } \mathrm{g} / \mathrm{mL} \text { for Density; } \mathrm{M} \text { for Metals and Anions }\end{array}$} \\
\hline & o hr & $1 \mathrm{hr}$ & $2 \mathrm{hr}$ & $4 \mathrm{hr}$ & $8 \mathrm{hr}$ & $24 \mathrm{hr}$ \\
\hline Phosphate & 1.67E-02 & 2.02E-02 & 2.01E-02 & 2.00E-02 & 2.07E-02 & 2.03E-02 \\
\hline Sulfate & [1.04E-04] & [1.15E-04] & [1.15E-04] & [1.25E-04] & [1.15E-04] & [1.15E-04] \\
\hline \multicolumn{7}{|l|}{$3 \mathrm{M}$ NaOH } \\
\hline Density & $\begin{array}{l}1.13 \\
\end{array}$ & 1.12 & $\begin{array}{l}1.13 \\
\end{array}$ & 1.13 & 1.13 & $\begin{array}{l}1.13 \\
\end{array}$ \\
\hline $\mathrm{Al}$ & $1.49 \mathrm{E}-03$ & 2.32E-03 & $2.72 \mathrm{E}-03$ & 3.25E-03 & 3.57E-03 & 3.61E-03 \\
\hline $\mathrm{B}$ & [2.49E-04] & [1.53E-04] & [1.38E-04] & [1.44E-04] & [1.02E-04] & [1.14E-04] \\
\hline $\mathrm{Bi}$ & $<2.33 \mathrm{E}-05$ & $<2.24 \mathrm{E}-05$ & $<2.18 \mathrm{E}-05$ & $<2.23 \mathrm{E}-05$ & $<2.39 \mathrm{E}-05$ & $<2.27 \mathrm{E}-05$ \\
\hline $\mathrm{Cd}$ & $<4.91 \mathrm{E}-06$ & $<4.72 \mathrm{E}-06$ & $<4.59 \mathrm{E}-06$ & $<4.70 \mathrm{E}-06$ & $<5.03 \mathrm{E}-06$ & $<4.78 \mathrm{E}-06$ \\
\hline $\mathrm{Cr}$ & [6.05E-06] & [1.50E-05] & [1.58E-05] & [2.03E-05] & [2.75E-05] & [3.89E-05] \\
\hline $\mathrm{Fe}$ & 2.93E-04 & 2.63E-04 & 2.47E-04 & 2.19E-04 & $1.81 \mathrm{E}-04$ & $1.40 \mathrm{E}-04$ \\
\hline $\mathrm{Mn}$ & [7.68E-06] & [4.71E-06] & [4.15E-06] & [3.67E-06] & [4.18E-06] & [3.45E-06] \\
\hline $\mathrm{Na}$ & 2.88 & 2.89 & 2.85 & 2.93 & 3.07 & 3.00 \\
\hline $\mathrm{Ni}$ & $<6.63 \mathrm{E}-06$ & $<6.38 \mathrm{E}-06$ & $<6.21 \mathrm{E}-06$ & $<6.35 \mathrm{E}-06$ & $<6.81 \mathrm{E}-06$ & [7.00E-06] \\
\hline $\mathrm{P}$ & $1.76 \mathrm{E}-02$ & 1.92E-02 & 1.93E-02 & 1.94E-02 & $2.00 \mathrm{E}-02$ & $2.04 \mathrm{E}-02$ \\
\hline$S$ & $<8.10 \mathrm{E}-04$ & $<7.78 \mathrm{E}-04$ & $<7.58 \mathrm{E}-04$ & $<7.75 \mathrm{E}-04$ & $<8.31 \mathrm{E}-04$ & $<7.88 \mathrm{E}-04$ \\
\hline $\mathrm{Si}$ & [1.85E-04] & 8.97E-04 & $9.10 \mathrm{E}-04$ & 9.34E-04 & 9.45E-04 & $9.57 \mathrm{E}-04$ \\
\hline $\mathrm{Sr}$ & 0.0000 & [9.97E-07] & [7.63E-07] & [6.73E-07] & [7.60E-07] & [6.85E-07] \\
\hline $\mathrm{U}$ & $1.28 \mathrm{E}-03$ & $5.01 \mathrm{E}-04$ & $3.94 \mathrm{E}-04$ & $3.09 \mathrm{E}-04$ & $2.53 \mathrm{E}-04$ & [1.86E-04] \\
\hline $\mathrm{Zn}$ & [6.45E-05] & [7.16E-05] & [7.90E-05] & [7.12E-05] & [7.64E-05] & [7.73E-05] \\
\hline $\mathrm{Zr}$ & $<1.96 \mathrm{E}-06$ & $<1.88 \mathrm{E}-06$ & $<1.83 \mathrm{E}-06$ & $<1.87 \mathrm{E}-06$ & $<2.01 \mathrm{E}-06$ & $<1.90 \mathrm{E}-06$ \\
\hline Fluoride & [3.58E-04] & [4.84E-04] & [3.74E-04] & [3.90E-04] & [4.53E-04] & [5.05E-04] \\
\hline Nitrite & [1.63E-04] & $<1.15 \mathrm{E}-04$ & [1.85E-04] & [1.89E-04] & [1.63E-04] & [1.78E-04] \\
\hline Nitrate & $1.40 \mathrm{E}-03$ & [1.42E-03] & $1.44 \mathrm{E}-03$ & $1.47 \mathrm{E}-03$ & [1.48E-03] & $1.48 \mathrm{E}-03$ \\
\hline Phosphate & 1.92E-02 & 2.10E-02 & 2.05E-02 & 2.04E-02 & 2.08E-02 & $2.06 \mathrm{E}-02$ \\
\hline Sulfate & [1.15E-04] & $<8.22 \mathrm{E}-05$ & [1.04E-04] & [1.15E-04] & $<8.22 \mathrm{E}-05$ & [1.04E-04] \\
\hline
\end{tabular}


Table G.5. Analyte Concentrations as a Function of Time for Leaching at $80^{\circ} \mathrm{C}$, in $\mu \mathrm{g} / \mathrm{mL}$

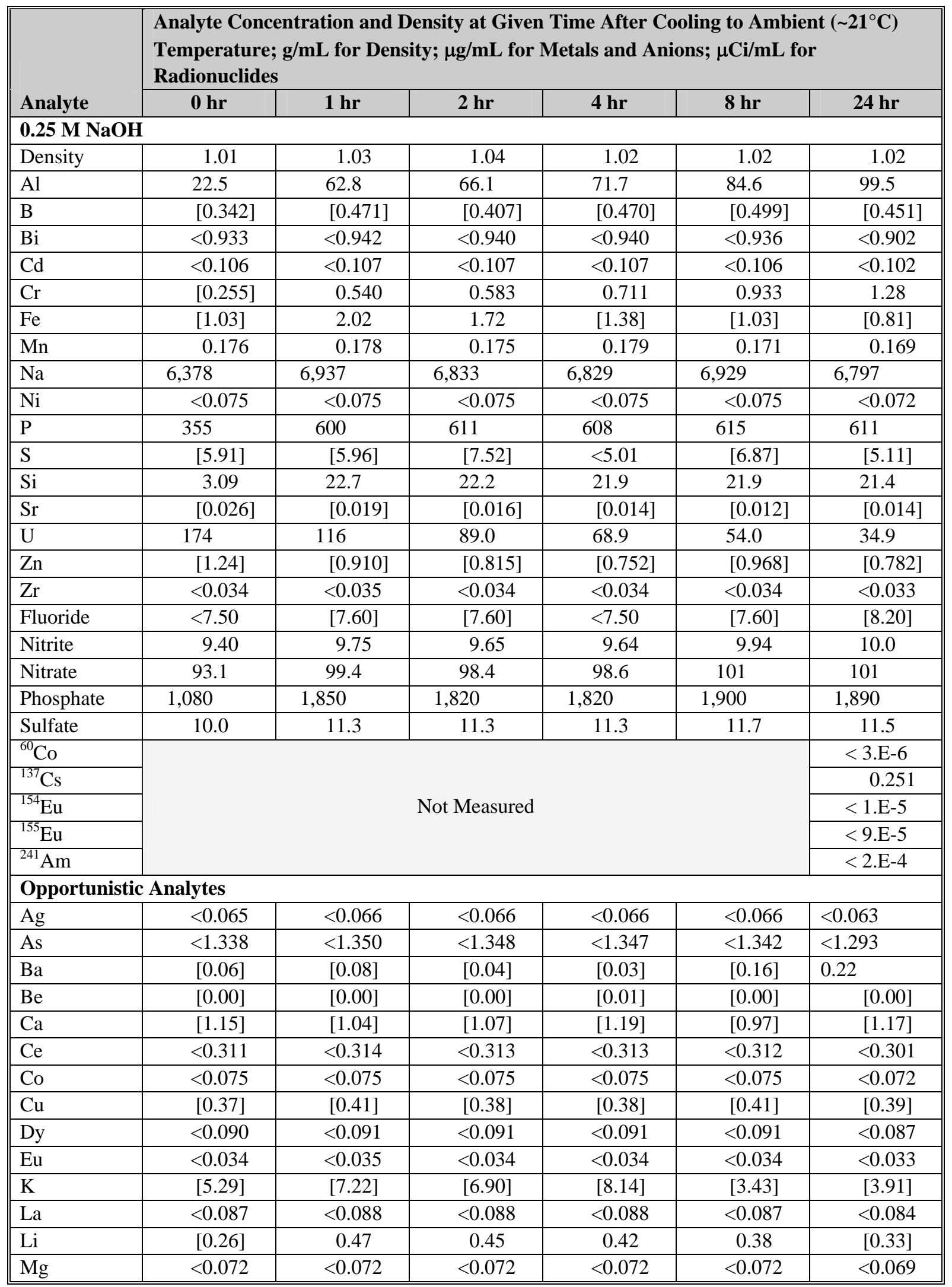


Table G.5 (Contd)

\begin{tabular}{|c|c|c|c|c|c|c|}
\hline \multirow[b]{2}{*}{ Analyte } & \multicolumn{6}{|c|}{$\begin{array}{l}\text { Analyte Concentration and Density at Given Time After Cooling to Ambient }\left(\sim 21^{\circ} \mathrm{C}\right) \\
\text { Temperature; } \mathrm{g} / \mathrm{mL} \text { for Density; } \mu \mathrm{g} / \mathrm{mL} \text { for Metals and Anions; } \mu \mathrm{Ci} / \mathrm{mL} \text { for } \\
\text { Radionuclides }\end{array}$} \\
\hline & o hr & $1 \mathrm{hr}$ & 2 hr & $4 \mathrm{hr}$ & $8 \mathrm{hr}$ & $24 \mathrm{hr}$ \\
\hline Mo & $<0.162$ & $<0.163$ & $<0.163$ & $<0.163$ & $<0.162$ & $<0.156$ \\
\hline $\mathrm{Nd}$ & $<0.168$ & $<0.170$ & $<0.169$ & $<0.169$ & $<0.169$ & $<0.162$ \\
\hline $\mathrm{Pb}$ & $<0.996$ & $<1.004$ & $<1.003$ & $<1.002$ & $<0.999$ & $<0.962$ \\
\hline $\mathrm{Pd}$ & $<0.196$ & $<0.198$ & $<0.197$ & $<0.197$ & $<0.197$ & $<0.189$ \\
\hline $\mathrm{Rh}$ & $<0.373$ & $<0.377$ & $<0.376$ & $<0.376$ & $<0.375$ & $<0.361$ \\
\hline $\mathrm{Ru}$ & $<0.264$ & $<0.267$ & $<0.266$ & $<0.266$ & $<0.265$ & $<0.256$ \\
\hline $\mathrm{Sb}$ & $<0.622$ & {$[0.66]$} & {$[0.75]$} & $<0.626$ & $<0.624$ & $<0.601$ \\
\hline Se & $<2.178$ & $<2.197$ & $<2.194$ & $<2.193$ & $<2.185$ & $<2.105$ \\
\hline Sn & $<0.840$ & $<0.848$ & $<0.846$ & $<0.846$ & $<0.843$ & $<0.812$ \\
\hline Тa & $<0.529$ & $<0.534$ & $<0.533$ & $<0.533$ & $<0.531$ & $<0.511$ \\
\hline $\mathrm{Te}$ & $<0.809$ & $<0.816$ & $<0.815$ & $<0.814$ & $<0.811$ & $<0.782$ \\
\hline Th & $<0.305$ & $<0.308$ & $<0.307$ & $<0.307$ & $<0.306$ & $<0.295$ \\
\hline $\mathrm{Ti}$ & {$[0.05]$} & {$[0.03]$} & {$[0.03]$} & {$[0.03]$} & {$[0.03]$} & {$[0.02]$} \\
\hline $\mathrm{Tl}$ & $<1.182$ & $<1.193$ & $<1.191$ & $<1.190$ & $<1.186$ & $<1.143$ \\
\hline $\mathrm{V}$ & $<0.023$ & {$[0.08]$} & {$[0.08]$} & {$[0.07]$} & {$[0.07]$} & {$[0.08]$} \\
\hline $\mathrm{W}$ & $<0.591$ & $<0.596$ & $<0.596$ & $<0.595$ & $<0.593$ & $<0.571$ \\
\hline $\mathrm{Y}$ & $<0.014$ & $<0.014$ & $<0.014$ & $<0.014$ & $<0.014$ & $<0.013$ \\
\hline \multicolumn{7}{|l|}{$1 \mathrm{M} \mathrm{NaOH}$} \\
\hline Density & 1.05 & 1.06 & 1.06 & 1.06 & 1.06 & 1.05 \\
\hline $\mathrm{Al}$ & 30.8 & 74.7 & 85.5 & 90.6 & 89.8 & 90.3 \\
\hline B & {$[0.325]$} & [0.413] & [0.369] & {$[0.346]$} & {$[0.316]$} & {$[0.367]$} \\
\hline $\mathrm{Bi}$ & $<0.996$ & $<0.954$ & $<0.923$ & $<0.944$ & $<0.949$ & $<0.919$ \\
\hline $\mathrm{Cd}$ & $<0.113$ & $<0.108$ & $<0.105$ & $<0.107$ & $<0.108$ & $<0.104$ \\
\hline $\mathrm{Cr}$ & [0.249] & $\begin{array}{l}0.770 \\
\end{array}$ & 1.03 & 1.29 & 1.55 & 2.10 \\
\hline $\mathrm{Fe}$ & 2.78 & 4.80 & 3.66 & 3.13 & 2.66 & 2.32 \\
\hline $\mathrm{Mn}$ & 0.226 & 0.194 & 0.191 & 0.189 & 0.197 & 0.182 \\
\hline $\mathrm{Na}$ & 21,745 & 23,792 & 23,663 & 24,077 & 24,002 & 23,882 \\
\hline $\mathrm{Ni}$ & $<0.080$ & $<0.076$ & $<0.074$ & $<0.076$ & $<0.076$ & $<0.073$ \\
\hline $\mathrm{P}$ & 471 & 620 & 615 & 633 & 629 & 634 \\
\hline$S$ & [6.64] & [7.95] & [6.15] & [5.67] & [7.91] & [6.74] \\
\hline Si & 5.94 & 25.7 & 25.4 & 26.2 & 26.0 & 26.4 \\
\hline $\mathrm{Sr}$ & 0.073 & {$[0.019]$} & {$[0.016]$} & {$[0.016]$} & {$[0.015]$} & {$[0.012]$} \\
\hline $\mathrm{U}$ & 157 & 90.0 & 67.1 & 55.4 & 44.9 & 34.6 \\
\hline $\mathrm{Zn}$ & 3.10 & 2.66 & 2.54 & 2.44 & 2.39 & 2.12 \\
\hline $\mathrm{Zr}$ & $<0.037$ & $<0.035$ & $<0.034$ & $<0.035$ & $<0.035$ & $<0.034$ \\
\hline Fluoride & {$[6.80]$} & {$[8.40]$} & {$[8.60]$} & {$[8.60]$} & {$[8.60]$} & {$[8.80]$} \\
\hline Nitrite & 8.5 & 9.4 & 9.7 & 9.6 & 9.6 & 9.6 \\
\hline Nitrate & 92.8 & 103 & 107 & 106 & 105 & 106 \\
\hline Phosphate & 1,500 & 1,980 & 2,020 & 2,000 & 1,970 & 2,000 \\
\hline Sulfate & [10.0] & 12.0 & 12.0 & [12.0] & 12.0 & 12.0 \\
\hline
\end{tabular}


Table G.5 (Contd)

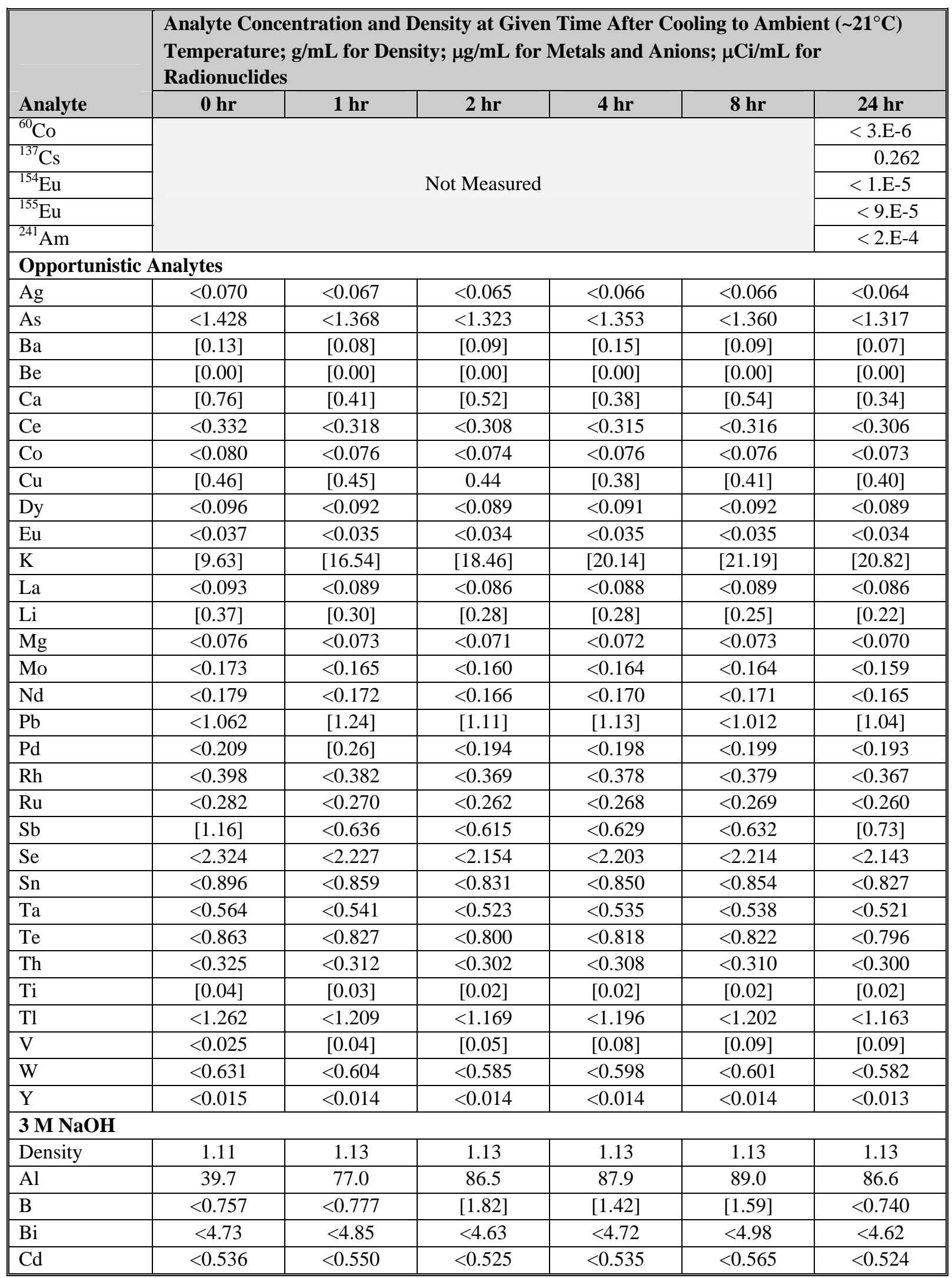


Table G.5 (Contd)

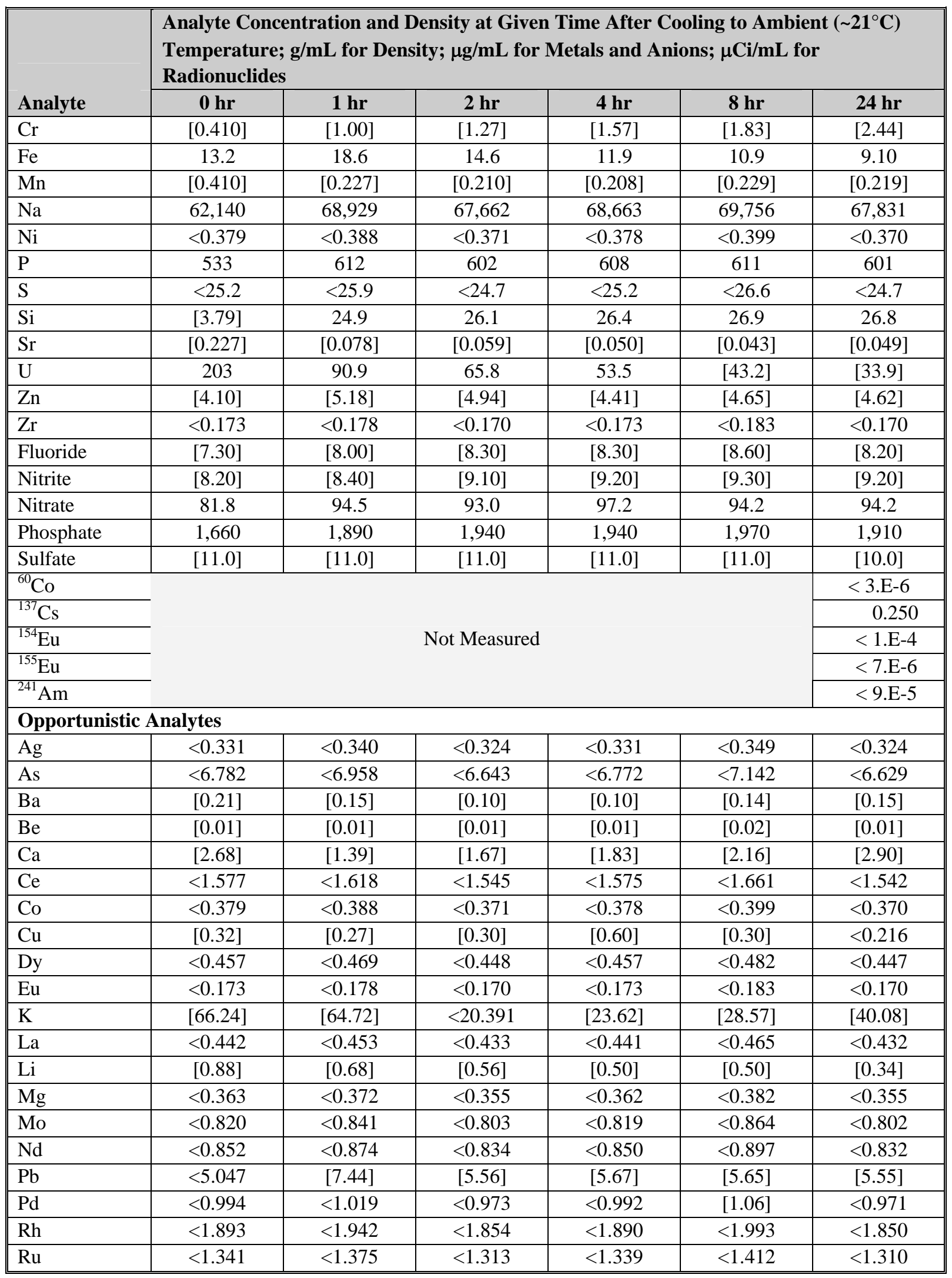


Table G.5 (Contd)

\begin{tabular}{|c|c|c|c|c|c|c|}
\hline \multirow[b]{2}{*}{ Analyte } & \multicolumn{6}{|c|}{$\begin{array}{l}\text { Analyte Concentration and Density at Given Time After Cooling to Ambient }\left(\sim 21^{\circ} \mathrm{C}\right) \\
\text { Temperature; } \mathrm{g} / \mathrm{mL} \text { for Density; } \mu \mathrm{g} / \mathrm{mL} \text { for Metals and Anions; } \mu \mathrm{Ci} / \mathrm{mL} \text { for } \\
\text { Radionuclides }\end{array}$} \\
\hline & $0 \mathrm{hr}$ & $1 \mathrm{hr}$ & $2 \mathrm{hr}$ & $4 \mathrm{hr}$ & $8 \mathrm{hr}$ & $24 \mathrm{hr}$ \\
\hline $\mathrm{Sb}$ & [3.47] & $<3.236$ & [3.09] & $<3.150$ & [5.65] & $<3.083$ \\
\hline Se & $<11.040$ & $<11.326$ & $<10.814$ & $<11.024$ & $<11.626$ & $<10.791$ \\
\hline Sn & $<4.258$ & $<4.369$ & $<4.171$ & $<4.252$ & $<4.484$ & $<4.162$ \\
\hline $\mathrm{Ta}$ & $<2.681$ & $<2.751$ & $<2.626$ & $<2.677$ & $<2.823$ & $<2.621$ \\
\hline $\mathrm{Te}$ & $<4.101$ & $<4.207$ & $<4.016$ & $<4.095$ & $<4.318$ & $<4.008$ \\
\hline Th & $<1.546$ & $<1.586$ & $<1.514$ & $<1.543$ & $<1.628$ & $<1.511$ \\
\hline $\mathrm{Ti}$ & $<0.068$ & $<0.070$ & $<0.066$ & $<0.068$ & $<0.071$ & $<0.066$ \\
\hline $\mathrm{Tl}$ & $<5.993$ & $<6.149$ & $<5.870$ & $<5.984$ & $<6.311$ & $<5.858$ \\
\hline $\mathrm{V}$ & $<0.117$ & $<0.120$ & $<0.114$ & $<0.117$ & $<0.123$ & $<0.114$ \\
\hline $\mathrm{W}$ & $<2.997$ & $<3.074$ & $<2.935$ & $<2.992$ & $<3.156$ & $<2.929$ \\
\hline $\mathrm{Y}$ & $<0.069$ & $<0.071$ & $<0.068$ & $<0.069$ & $<0.073$ & $<0.068$ \\
\hline
\end{tabular}


Table G.6. Analyte Concentrations as a Function of Time for Leaching at $80^{\circ} \mathrm{C}$, in $\mathrm{M}$

\begin{tabular}{|c|c|c|c|c|c|c|}
\hline \multirow[b]{2}{*}{ Analyte } & \multicolumn{6}{|c|}{$\begin{array}{l}\text { Analyte Concentration and Density at Given Time After Cooling to Ambient }\left(\sim 21^{\circ} \mathrm{C}\right) \\
\text { Temperature; } \mathrm{g} / \mathrm{mL} \text { for Density; } \mathrm{M} \text { for Metals and Anions }\end{array}$} \\
\hline & $0 \mathrm{hr}$ & $1 \mathrm{hr}$ & $2 \mathrm{hr}$ & $4 \mathrm{hr}$ & $8 \mathrm{hr}$ & $24 \mathrm{hr}$ \\
\hline \multicolumn{7}{|c|}{$0.25 \mathrm{M} \mathrm{NaOH}$} \\
\hline Density & 1.01 & 1.03 & 1.04 & 1.02 & 1.02 & 1.02 \\
\hline $\mathrm{Al}$ & 8.35E-04 & 2.33E-03 & $2.45 \mathrm{E}-03$ & 2.66E-03 & 3.13E-03 & 3.69E-03 \\
\hline $\mathrm{B}$ & [3.17E-05] & [4.36E-05] & [3.77E-05] & [4.35E-05] & [4.62E-05] & [4.17E-05] \\
\hline$\overline{\mathrm{Bi}}$ & $<4.47 \mathrm{E}-06$ & $<4.51 \mathrm{E}-06$ & $<4.50 \mathrm{E}-06$ & $<4.50 \mathrm{E}-06$ & $<4.48 \mathrm{E}-06$ & $<4.32 \mathrm{E}-06$ \\
\hline $\mathrm{Cd}$ & $<9.41 \mathrm{E}-07$ & $<9.49 \mathrm{E}-07$ & $<9.48 \mathrm{E}-07$ & $<9.47 \mathrm{E}-07$ & $<9.44 \mathrm{E}-07$ & $<9.10 \mathrm{E}-07$ \\
\hline $\mathrm{Cr}$ & [4.91E-06] & $1.04 \mathrm{E}-05$ & $1.12 \mathrm{E}-05$ & $1.37 \mathrm{E}-05$ & 1.79E-05 & $2.45 \mathrm{E}-05$ \\
\hline $\mathrm{Fe}$ & [1.84E-05] & 3.63E-05 & 3.09E-05 & [2.47E-05] & [1.84E-05] & [1.45E-05] \\
\hline $\mathrm{Mn}$ & $3.20 \mathrm{E}-06$ & $3.25 \mathrm{E}-06$ & $3.19 \mathrm{E}-06$ & $3.26 \mathrm{E}-06$ & $3.11 \mathrm{E}-06$ & $3.08 \mathrm{E}-06$ \\
\hline $\mathrm{Na}$ & 0.28 & 0.30 & 0.30 & 0.30 & 0.30 & 0.30 \\
\hline $\mathrm{Ni}$ & $<1.27 \mathrm{E}-06$ & $<1.28 \mathrm{E}-06$ & $<1.28 \mathrm{E}-06$ & $<1.28 \mathrm{E}-06$ & $<1.28 \mathrm{E}-06$ & $<1.23 \mathrm{E}-06$ \\
\hline $\mathrm{P}$ & 1.15E-02 & 1.94E-02 & 1.97E-02 & $1.96 \mathrm{E}-02$ & 1.99E-02 & $1.97 \mathrm{E}-02$ \\
\hline$S$ & [1.84E-04] & [1.86E-04] & [2.35E-04] & $<1.56 \mathrm{E}-04$ & [2.14E-04] & [1.59E-04] \\
\hline $\mathrm{Si}$ & $1.10 \mathrm{E}-04$ & 8.09E-04 & $7.90 \mathrm{E}-04$ & 7.78E-04 & 7.79E-04 & 7.63E-04 \\
\hline $\mathrm{Sr}$ & [3.02E-07] & [2.11E-07] & [1.79E-07] & [1.61E-07] & [1.35E-07] & [1.58E-07] \\
\hline $\mathrm{U}$ & $7.32 \mathrm{E}-04$ & $4.89 \mathrm{E}-04$ & $3.74 \mathrm{E}-04$ & $2.90 \mathrm{E}-04$ & $2.27 \mathrm{E}-04$ & $1.47 \mathrm{E}-04$ \\
\hline $\mathrm{Zn}$ & [1.90E-05] & [1.39E-05] & [1.25E-05] & [1.15E-05] & [1.48E-05] & [1.20E-05] \\
\hline $\mathrm{Zr}$ & $<3.75 \mathrm{E}-07$ & $<3.79 \mathrm{E}-07$ & $<3.78 \mathrm{E}-07$ & $<<3.78 \mathrm{E}-07$ & $<3.76 \mathrm{E}-07$ & $<3.63 \mathrm{E}-07$ \\
\hline Fluoride & $<3.95 \mathrm{E}-04$ & [4.00E-04] & [4.00E-04] & $<3.95 \mathrm{E}-04$ & [4.00E-04] & [4.32E-04] \\
\hline Nitrite & 2.04E-04 & $2.12 \mathrm{E}-04$ & $2.10 \mathrm{E}-04$ & $2.10 \mathrm{E}-04$ & $2.16 \mathrm{E}-04$ & $2.16 \mathrm{E}-04$ \\
\hline Nitrate & $1.50 \mathrm{E}-03$ & $1.60 \mathrm{E}-03$ & $1.59 \mathrm{E}-03$ & $1.59 \mathrm{E}-03$ & $1.63 \mathrm{E}-03$ & $1.63 \mathrm{E}-03$ \\
\hline Phosphate & $1.14 \mathrm{E}-02$ & 1.95E-02 & 1.92E-02 & $1.92 \mathrm{E}-02$ & $2.00 \mathrm{E}-02$ & 1.99E-02 \\
\hline Sulfate & $1.04 \mathrm{E}-04$ & $1.18 \mathrm{E}-04$ & $1.18 \mathrm{E}-04$ & $1.18 \mathrm{E}-04$ & $1.22 \mathrm{E}-04$ & $1.20 \mathrm{E}-04$ \\
\hline \multicolumn{7}{|l|}{$1 \mathrm{M} \mathrm{NaOH}$} \\
\hline Density & 1.05 & 1.06 & 1.06 & 1.06 & 1.06 & 1.05 \\
\hline $\mathrm{Al}$ & $1.14 \mathrm{E}-03$ & 2.77E-03 & 3.17E-03 & 3.36E-03 & 3.33E-03 & 3.35E-03 \\
\hline B & [3.01E-05] & [3.83E-05] & [3.42E-05] & [3.20E-05] & [2.93E-05] & [3.40E-05] \\
\hline $\mathrm{Bi}$ & $<4.77 \mathrm{E}-06$ & $<4.57 \mathrm{E}-06$ & $<4.42 \mathrm{E}-06$ & $<4.52 \mathrm{E}-06$ & $<4.54 \mathrm{E}-06$ & $<4.40 \mathrm{E}-06$ \\
\hline $\mathrm{Cd}$ & $<1.00 \mathrm{E}-06$ & $<9.62 \mathrm{E}-07$ & $<9.31 \mathrm{E}-07$ & $<9.52 \mathrm{E}-07$ & $<9.56 \mathrm{E}-07$ & $<9.26 \mathrm{E}-07$ \\
\hline $\mathrm{Cr}$ & [4.79E-06] & $1.48 \mathrm{E}-05$ & $1.98 \mathrm{E}-05$ & $2.48 \mathrm{E}-05$ & 2.99E-05 & $4.05 \mathrm{E}-05$ \\
\hline $\mathrm{Fe}$ & $4.98 \mathrm{E}-05$ & $8.60 \mathrm{E}-05$ & 6.56E-05 & 5.60E-05 & 4.76E-05 & $4.16 \mathrm{E}-05$ \\
\hline $\mathrm{Mn}$ & 4.11E-06 & 3.53E-06 & 3.48E-06 & $3.45 \mathrm{E}-06$ & 3.59E-06 & 3.32E-06 \\
\hline $\mathrm{Na}$ & 0.95 & 1.03 & 1.03 & 1.05 & 1.04 & 1.04 \\
\hline $\mathrm{Ni}$ & $<1.36 \mathrm{E}-06$ & $<1.30 \mathrm{E}-06$ & $<1.26 \mathrm{E}-06$ & $<1.29 \mathrm{E}-06$ & $<1.29 \mathrm{E}-06$ & $<1.25 \mathrm{E}-06$ \\
\hline $\mathrm{P}$ & 1.52E-02 & $2.00 \mathrm{E}-02$ & 1.99E-02 & 2.04E-02 & 2.03E-02 & 2.05E-02 \\
\hline$S$ & [2.07E-04] & [2.48E-04] & [1.92E-04] & [1.77E-04] & [2.47E-04] & [2.10E-04] \\
\hline $\mathrm{Si}$ & $2.12 \mathrm{E}-04$ & $9.14 \mathrm{E}-04$ & $9.06 \mathrm{E}-04$ & $9.35 \mathrm{E}-04$ & $9.27 \mathrm{E}-04$ & $9.41 \mathrm{E}-04$ \\
\hline Sr & 8.37E-07 & [2.18E-07] & [1.83E-07] & [1.80E-07] & [1.66E-07] & [1.40E-07] \\
\hline $\mathrm{U}$ & $6.58 \mathrm{E}-04$ & $3.78 \mathrm{E}-04$ & $2.82 \mathrm{E}-04$ & $2.33 \mathrm{E}-04$ & $1.89 \mathrm{E}-04$ & $1.45 \mathrm{E}-04$ \\
\hline $\mathrm{Zn}$ & 4.75E-05 & 4.07E-05 & 3.89E-05 & 3.73E-05 & 3.66E-05 & 3.25E-05 \\
\hline $\mathrm{Zr}$ & $<4.00 \mathrm{E}-07$ & $<3.84 \mathrm{E}-07$ & $<3.71 \mathrm{E}-07$ & $<3.80 \mathrm{E}-07$ & $<3.81 \mathrm{E}-07$ & $<3.69 \mathrm{E}-07$ \\
\hline Fluoride & [3.58E-04] & [4.42E-04] & [4.53E-04] & [4.53E-04] & [4.53E-04] & [4.63E-04] \\
\hline Nitrite & 1.85E-04 & 2.05E-04 & 2.11E-04 & $2.08 \mathrm{E}-04$ & 2.08E-04 & 2.08E-04 \\
\hline Nitrate & $1.50 \mathrm{E}-03$ & $1.66 \mathrm{E}-03$ & 1.73E-03 & $1.71 \mathrm{E}-03$ & $1.69 \mathrm{E}-03$ & $1.71 \mathrm{E}-03$ \\
\hline
\end{tabular}


WTP-RPT-169, Rev 0

Table G.6 (Contd)

\begin{tabular}{|c|c|c|c|c|c|c|}
\hline \multirow[b]{2}{*}{ Analyte } & \multicolumn{6}{|c|}{$\begin{array}{l}\text { Analyte Concentration and Density at Given Time After Cooling to Ambient }\left(\sim 21^{\circ} \mathrm{C}\right) \\
\text { Temperature; } \mathrm{g} / \mathrm{mL} \text { for Density; } \mathrm{M} \text { for Metals and Anions }\end{array}$} \\
\hline & o hr & $1 \mathrm{hr}$ & $2 \mathrm{hr}$ & $4 \mathrm{hr}$ & $8 \mathrm{hr}$ & $24 \mathrm{hr}$ \\
\hline Phosphate & $1.58 \mathrm{E}-02$ & 2.08E-02 & 2.13E-02 & 2.11E-02 & 2.07E-02 & 2.11E-02 \\
\hline Sulfate & [1.04E-04] & $1.25 \mathrm{E}-04$ & $1.25 \mathrm{E}-04$ & [1.25E-04] & $1.25 \mathrm{E}-04$ & $1.25 \mathrm{E}-04$ \\
\hline \multicolumn{7}{|l|}{$3 \mathrm{M}$ NaOH } \\
\hline Density & 1.11 & 1.13 & 1.13 & 1.13 & 1.13 & 1.13 \\
\hline $\mathrm{Al}$ & $1.47 \mathrm{E}-03$ & $2.85 \mathrm{E}-03$ & $3.21 \mathrm{E}-03$ & $3.26 \mathrm{E}-03$ & $3.30 \mathrm{E}-03$ & $3.21 \mathrm{E}-03$ \\
\hline $\mathrm{B}$ & $<7.00 \mathrm{E}-05$ & $<7.18 \mathrm{E}-05$ & [1.69E-04] & [1.31E-04] & [1.47E-04] & $<6.85 \mathrm{E}-05$ \\
\hline $\mathrm{Bi}$ & $<2.26 \mathrm{E}-05$ & $<2.32 \mathrm{E}-05$ & $<2.22 \mathrm{E}-05$ & $<2.26 \mathrm{E}-05$ & $<2.38 \mathrm{E}-05$ & $<2.21 \mathrm{E}-05$ \\
\hline $\mathrm{Cd}$ & $<4.77 \mathrm{E}-06$ & $<4.89 \mathrm{E}-06$ & $<4.67 \mathrm{E}-06$ & $<4.76 \mathrm{E}-06$ & $<5.02 \mathrm{E}-06$ & $<4.66 \mathrm{E}-06$ \\
\hline $\mathrm{Cr}$ & [7.89E-06] & [1.93E-05] & [2.44E-05] & [3.03E-05] & [3.51E-05] & [4.68E-05] \\
\hline $\mathrm{Fe}$ & 2.37E-04 & 3.34E-04 & 2.62E-04 & 2.14E-04 & 1.95E-04 & 1.63E-04 \\
\hline $\mathrm{Mn}$ & [7.46E-06] & [4.12E-06] & [3.82E-06] & [3.78E-06] & [4.17E-06] & [3.98E-06] \\
\hline $\mathrm{Na}$ & 2.70 & 3.00 & 2.94 & 2.99 & 3.03 & 2.95 \\
\hline $\mathrm{Ni}$ & $<6.45 \mathrm{E}-06$ & $<6.62 \mathrm{E}-06$ & $<6.32 \mathrm{E}-06$ & $<6.44 \mathrm{E}-06$ & $<6.79 \mathrm{E}-06$ & $<6.30 \mathrm{E}-06$ \\
\hline $\mathrm{P}$ & $1.72 \mathrm{E}-02$ & 1.97E-02 & 1.95E-02 & 1.96E-02 & 1.97E-02 & $1.94 \mathrm{E}-02$ \\
\hline$S$ & $<7.87 \mathrm{E}-04$ & $<8.08 \mathrm{E}-04$ & $<7.71 \mathrm{E}-04$ & $<7.86 \mathrm{E}-04$ & $<8.29 \mathrm{E}-04$ & $<7.69 \mathrm{E}-04$ \\
\hline $\mathrm{Si}$ & [1.35E-04] & 8.87E-04 & 9.30E-04 & $9.40 \mathrm{E}-04$ & 9.58E-04 & $9.55 \mathrm{E}-04$ \\
\hline $\mathrm{Sr}$ & [2.59E-06] & [8.86E-07] & [6.70E-07] & [5.75E-07] & [4.93E-07] & [5.63E-07] \\
\hline $\mathrm{U}$ & $8.52 \mathrm{E}-04$ & $3.82 \mathrm{E}-04$ & $2.77 \mathrm{E}-04$ & $2.25 \mathrm{E}-04$ & [1.81E-04] & [1.43E-04] \\
\hline $\mathrm{Zn}$ & [6.27E-05] & [7.92E-05] & [7.56E-05] & [6.74E-05] & [7.11E-05] & [7.07E-05] \\
\hline $\mathrm{Zr}$ & $<1.90 \mathrm{E}-06$ & $<1.95 \mathrm{E}-06$ & $<1.86 \mathrm{E}-06$ & $<1.90 \mathrm{E}-06$ & $<2.00 \mathrm{E}-06$ & $<1.86 \mathrm{E}-06$ \\
\hline Fluoride & [3.84E-04] & [4.21E-04] & [4.37E-04] & [4.37E-04] & [4.53E-04] & [4.32E-04] \\
\hline Nitrite & [1.78E-04] & [1.83E-04] & [1.98E-04] & [2.00E-04] & [2.02E-04] & [2.00E-04] \\
\hline Nitrate & 1.32E-03 & $1.52 \mathrm{E}-03$ & $1.50 \mathrm{E}-03$ & $1.57 \mathrm{E}-03$ & $1.52 \mathrm{E}-03$ & $1.52 \mathrm{E}-03$ \\
\hline Phosphate & $1.75 \mathrm{E}-02$ & 1.99E-02 & $2.04 \mathrm{E}-02$ & 2.04E-02 & 2.07E-02 & $2.01 \mathrm{E}-02$ \\
\hline Sulfate & [1.15E-04] & [1.15E-04] & [1.15E-04] & [1.15E-04] & [1.15E-04] & [1.04E-04] \\
\hline
\end{tabular}




\section{Appendix $\mathrm{H}$}

\section{CUF Filtration/Leaching Experimental Methods and Analyses}




\section{Appendix H: CUF Filtration/Leaching Experimental Methods and Analyses}

This appendix describes the experimental equipment and analyses used to perform the bench top filtration and leaching tests of the Group 7 composite waste sample using the crossflow ultrafiltration testing apparatus (commonly called the CUF) described in Section 5 of this report.

\section{H.1 Filtration/Leaching Apparatus}

The testing apparatus is a bench top skid that allows up to 4-liters of a waste solution to be circulated through a tubular filter. The apparatus can simultaneously measure the filter feed flow rates, filtrate flow rates, system pressures, and temperatures. The testing skid uses a heat exchanger on the main flow loop to cool the feed solution during filtration operations, and it has a heater on the main holding tank to perform leaching at elevated temperatures.

\section{H.1.1 Cell Unit Filter}

The Waste Treatment and Immobilization Plant (WTP) Pre-Treatment Facility (PTF) plans to use cross flow ultrafiltration to separate the low-activity waste (LAW) liquid streams from the high-level waste (HLW) slurry streams through the process. The filter elements, called cell unit filters, are porous, sintered metal tubes. The filter feed flows through the inside of the filter element axially while the feed permeate passes through the tube walls radially. Filtration occurs when the pressure differential between the inside and outside walls of the filter element (known as the transmembrane pressure) is high enough to drive the slurry permeate through the tubular walls. The axial flow across the filter walls minimizes solid buildup and allows filtration to occur continuously with minimal downtime for back pulsing.

The filters purchased for this testing work were supplied by the Mott Corporation, ${ }^{(a)}$ using the same specifications $^{(\mathrm{b})}$ for the filters being purchased for the WTP PTF. The filters are made of 316 stainless steel and have an effective filtration rating of $0.1 \mu \mathrm{m}$. The dimensions of the filter element used in this test are shown in Figure H.1.

(a) Mott Corporation, 84 Spring Lane, Farmington, CT 06032.

(b) Specification WTP-070110, written by JGH Geeting, for PNNL Purchase Order 38825, February 2, 2007. 


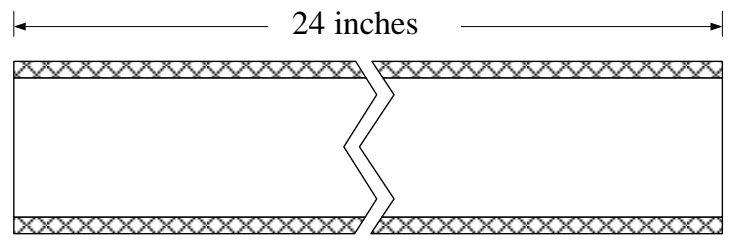

$\varnothing 5 / 8$ inch

$\varnothing 1 / 2$ inch
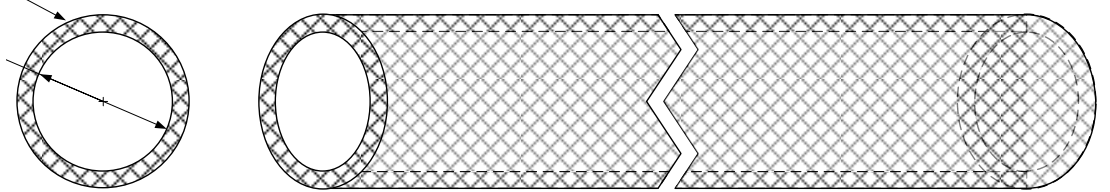

Figure H.1. Illustration of the Filter Element

The filter element was received installed in a shell-in-tube configuration with an outer tube surrounding the filter element to capture the filtrate while the inlet and the outlet of the filter (which extend past the shell and provide access to the inside diameter of the filter) were welded to steel tubing of a matching outer/inner diameter. The shell side had two $3 / 8$-inch stainless steel tubes exiting from the filter assembly, one in the center to collect filtrate from the filter, and the other near the inlet of the filter to function as a drain. Pressure ports ( $1 / 4$-inch stainless steel tubing) were installed on the inlet and outlet connections of the assembly to measure the pressure inside the filter. O-ring face seal fittings (Swagelok ${ }^{(a)} \mathrm{VCO}^{\circledR}$ ) were also placed on the inlet and outlet filter feed tube connections for easy installation on the filtration/leaching skid. Figure H.2 and Figure H.3show the filter assembly.

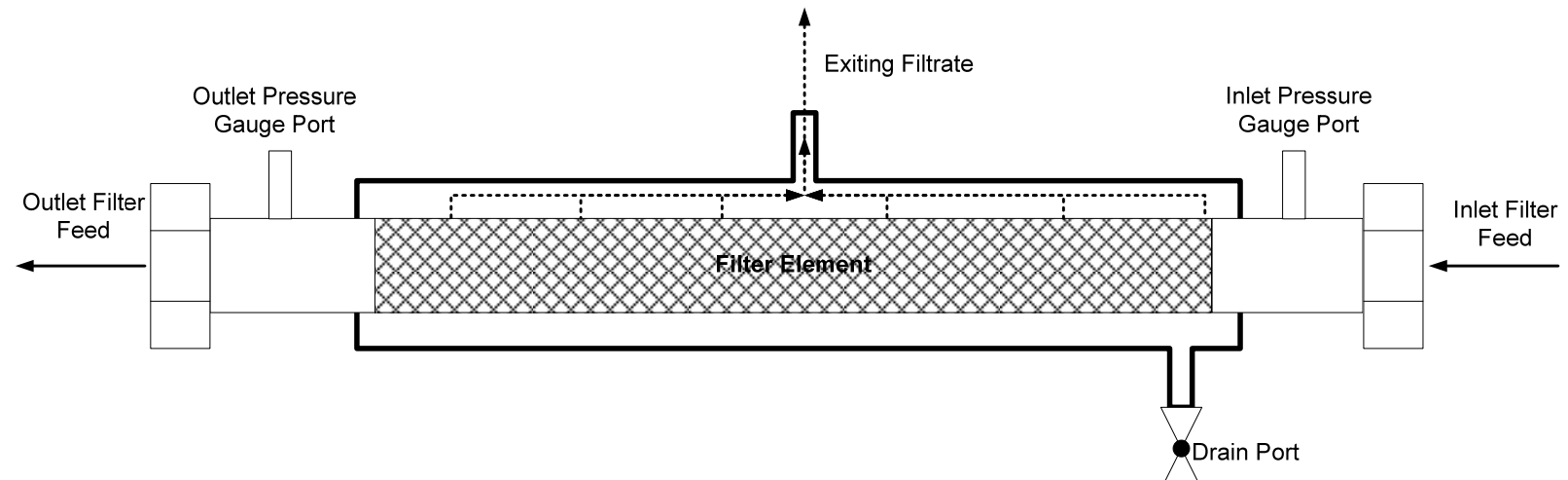

Figure H.2. Illustration of the Filter Assembly Sketch (Not to Scale)

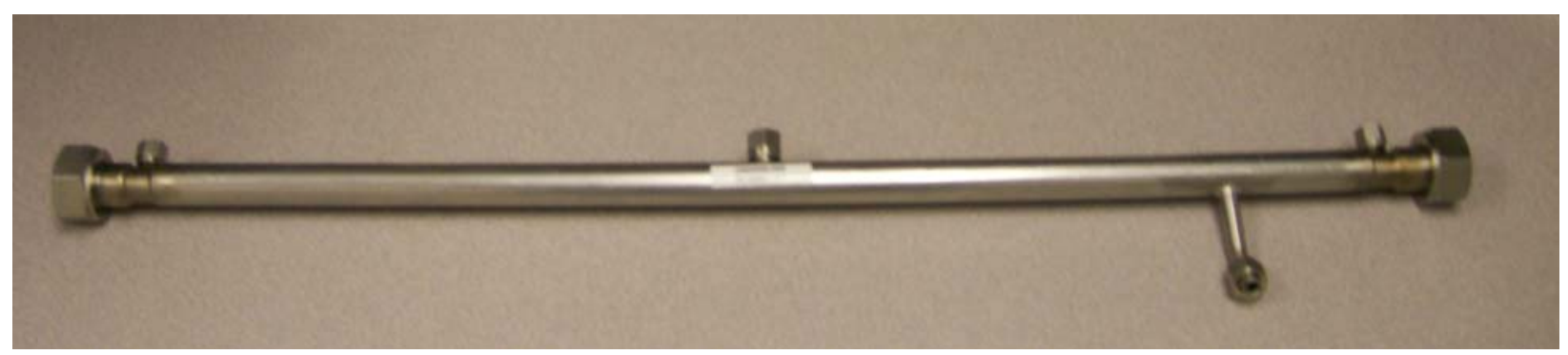

Figure H.3. Photograph of the Filter Assembly

(a) Swagelok Company, 31400 Aurora Road, Solon, Ohio 44139 


\section{H.1.1.1 Filtration/Leaching Skid}

The filter described in the section above is installed in a bench top skid that circulates the test waste slurries through the inside of the filter and diverts the filter permeate to a collection bottle or recycles it back into the slurry. Figure H.4 shows a piping diagram of the testing skid. Figure H.5 and Figure H.6 are electronic photographs of the assembled system before and after installation into a hot cell in the Shielded Analytical Laboratory where the testing was performed.

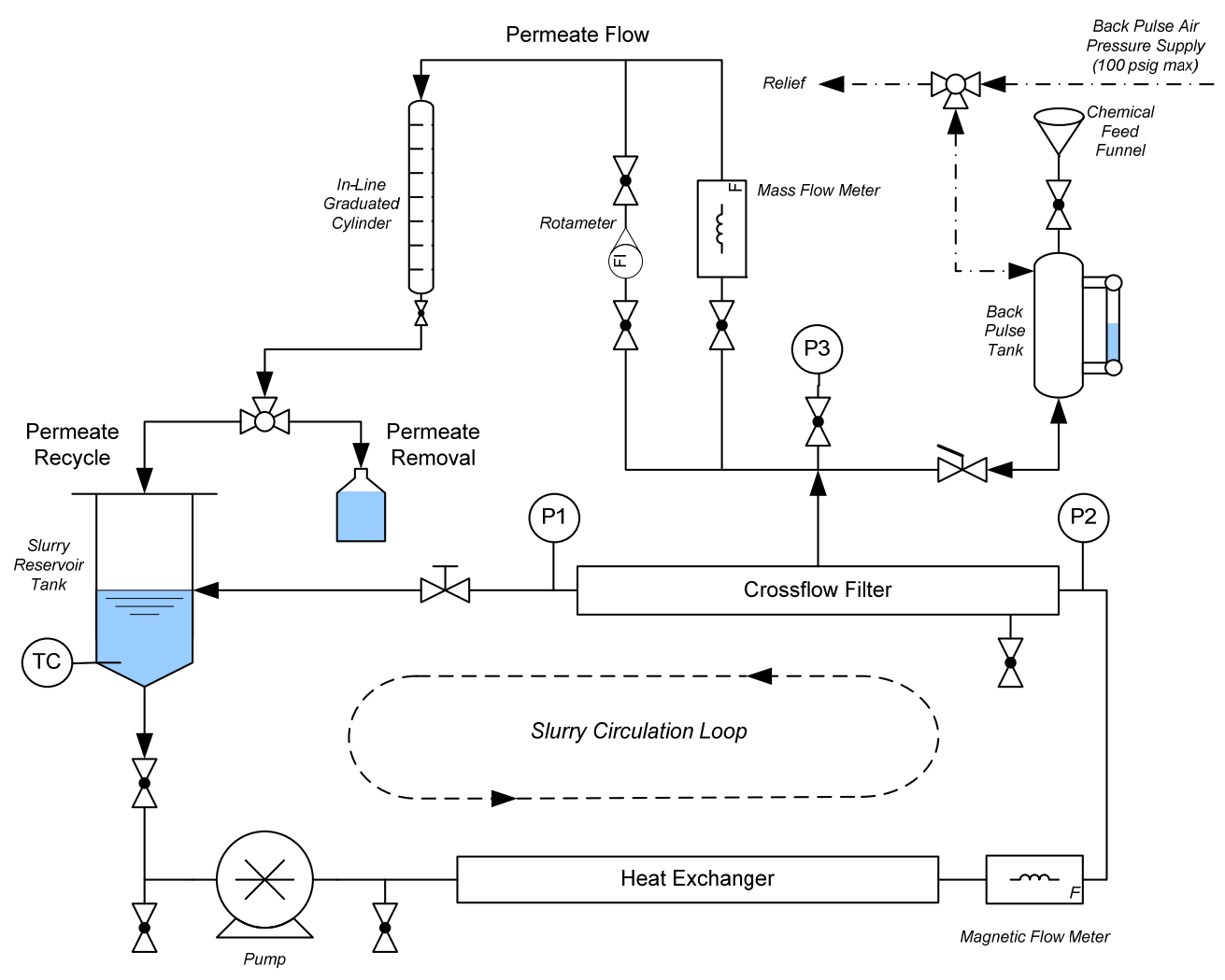

Figure H.4. Piping Diagram of CUF Skid 


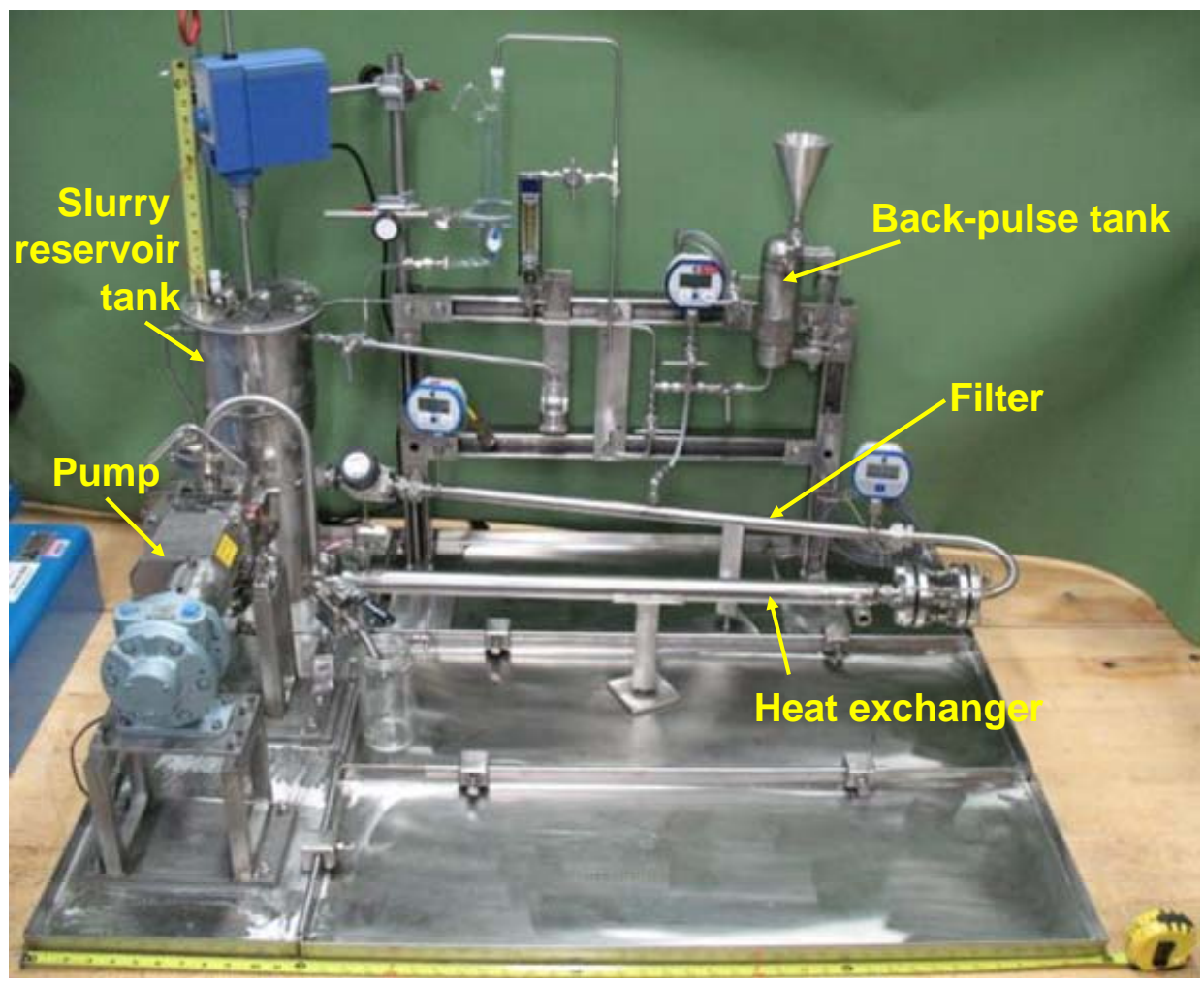

Figure H.5. Photograph of the CUF Prior to Hot Cell Installation

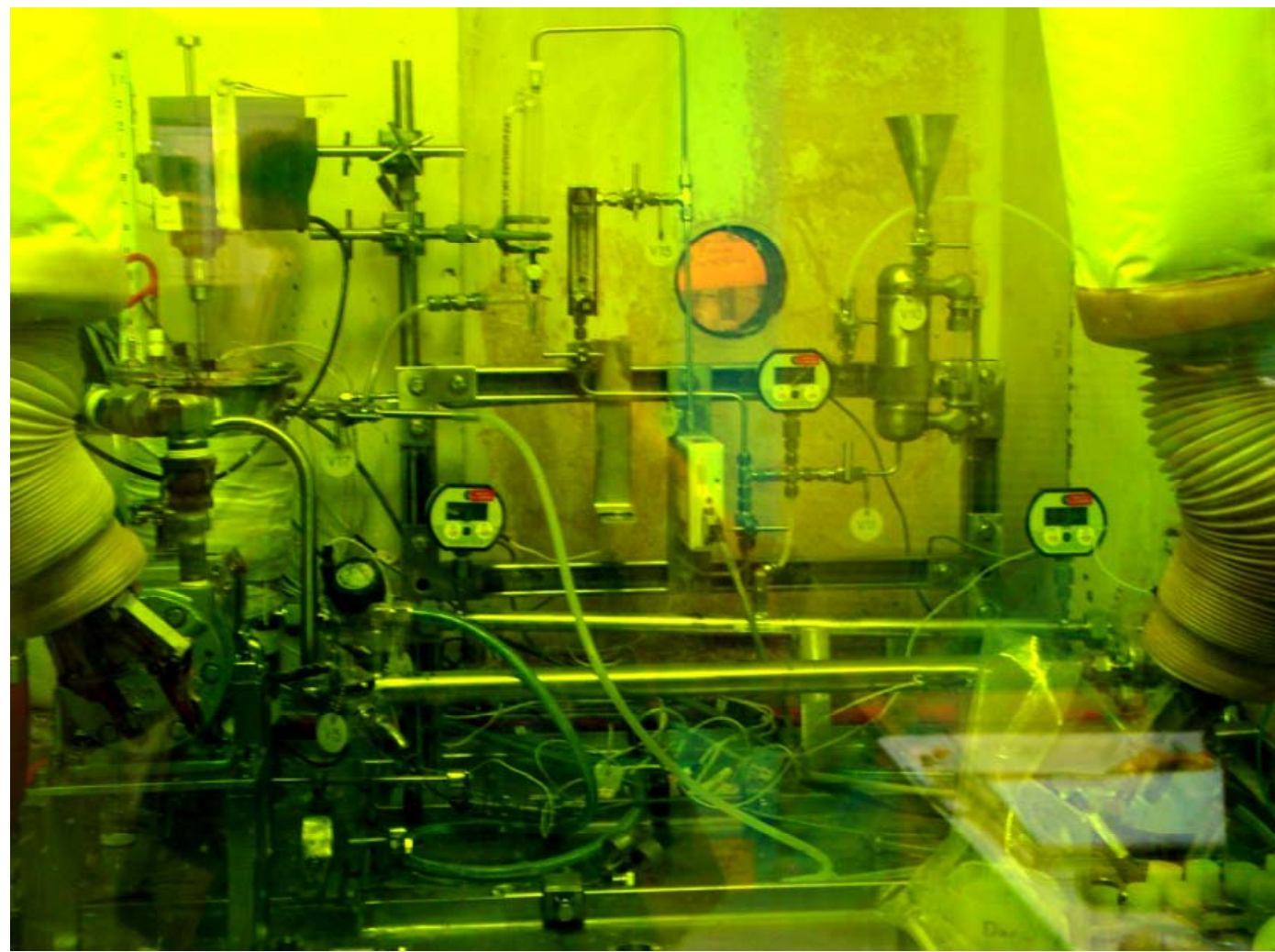

Figure H.6. Picture of the CUF Installed in Cell 5 of the Shielded Analytical Laboratory 
The CUF skid has four main parts:

- Slurry reservoir tank

- Slurry recirculation loop

- Permeate flow loop

- Permeate back-pulse chamber.

The slurry reservoir was a cylindrical, stainless steel tank with a four-liter capacity. Agitation in the tank was provided with an overhead mixer using a 2-inch-diameter, three-blade, marine propeller. The bottom of the vessel was sloped at a $15^{\circ}$ angle to allow the system to be easily drained,. Baffles were also installed on the tank wall to improve slurry mixing. Heat tape was installed around the walls of the tank for leaching at elevated temperatures. The heat tape was connected to a temperature controller that adjusted the electrical load to the heat tape based on a thermocouple input. A dual, Type-K thermocouple was installed inside the reservoir tank (extending just below the overhead mixing impeller) to measure the temperature of the slurry inside the reservoir. One of the thermocouple elements was connected to the heat tape's temperature controller and the other to a data collection system.

The slurry recirculation loop routed slurry flow from the slurry reservoir, through the filter, and back into the reservoir for filtration operations. The bottom of the slurry reservoir was connected to the suction side of the slurry recirculation pump, a positive displacement, rotary lobe pump. The pump was driven by an air motor supplied with compressed air from an external air compressor. The speed of the pump was controlled by an external air regulator controlling the pressure supplied to the air motor. An optical tachometer measured the speed of the pump by measuring the rotation speed of the connection coupling between the air motor and the pump, which had a piece of reflective tape placed on it. The pump discharge flowed through a single pass shell and tube heat exchanger used to remove excess heat from the system caused by the mechanical energy input from the mixer and pump, as well as heat generated from frictional flow.

An exterior chiller circulated chiller fluid (water/anti-freeze mixture) through the exterior shell of the heat exchanger to remove heat away from the circulating slurry on the tube side of the heat exchanger. The chiller controlled the chilling fluid temperature by monitoring the temperature of the slurry exiting the heat exchanger via a resistance temperature detector installed in the discharge line.

The slurry then flowed through a magnetic flow sensor that monitored the volumetric flow of the slurry inside the slurry recirculation loop. The sensor's output was displayed on an external panel meter that generated an analog output signal monitored by a data collection system. The data from this device was used to calculate the axial velocity (AV) inside the filter element.

The flowing slurry then entered the filter. Digital pressure gauges were installed on the inlet and outlet ports of the filter, which displayed the pressure at both locations in pounds per square inch, gauge (psig). The gauges also transmit analog output signals monitored by a data collection system. The data from these devices were used to calculate the average pressure inside the filter and the axial pressure drop across the element. 
A manual pinch valve was placed on the filter's discharge. The valve was used to adjust the pressure inside the filter to drive permeate flow through the filter membrane wall. It was also connected to the slurry reservoir tank and was closed completely when the tank was isolated for leaching.

The permeate flow loop started at the center of the filter assembly where a poly-line connected the filter to a $1 / 4$-inch stainless steel pipe manifold that directed the filter permeate through a series of measurement devices. A digital pressure gauge was installed at this point to measure the pressure, in psig, on the permeate side of the filter. Like the other two digital gauges, this instrument transmitted an analog output signal to a data collection system. The transmembrane pressure (TMP) across the filter was then calculated by subtracting the pressure on the permeate side of the filter from the average pressure of the slurry inside the filter.

Flow from the filter was either diverted through a mass flow meter calibrated up to $180 \mathrm{~mL} / \mathrm{min}$ or to a user calibrated rotometer that could measure flow up to $30 \mathrm{~mL} / \mathrm{s}$. The mass flow meter also measured density of the permeate flow and transmitted two analog output signals to the data collection system for the volumetric flow rate and the density. An in-line glass cylinder was installed on the discharge of both meters to take manual measurements of the permeate flow rate. Measurements were taken by closing a valve at the bottom of the cylinder, allowing permeate to fill the vessel. Liquid volume in the glass vessel was measured by markings on the outside. The permeate flow rate was calculated from observed changes in permeate volume in the cylinder over a measured time interval.

Permeate exited through a three-way valve connected to the slurry reservoir tank. This valve directed permeate either back to the slurry reservoir tank to be mixed back into the slurry or to a sampling hose used to collect permeate into sample containers.

The permeate back-pulse chamber was to the right of the permeate flow loop and connected to the filter at the same location as the permeate pressure gauge. The chamber was an approximately $500-\mathrm{mL}$ steel vessel with a sight glass to track the volume inside the chamber. The vessel had three entry ports:

- $1 / 4$ inch line with a two-way toggle valve on the bottom connecting the vessel to the permeate side of the filter

- $1 / 4$ inch line with a two-way valve connecting the top of the vessel to a funnel

- $1 / 4$ inch line with a three-way valve connecting the top of the vessel to a compressed air line and vent line connected to the top of the slurry reservoir tank

The bottom line was used to direct permeate flow from the chamber to the filter. The funnel on the top of the chamber was used to introduce cleaning and rinse solutions directly to the vessel. The compressed gas line was used to pressurize the fluid in the chamber with compressed gas and to vent the chamber to atmospheric pressure.

To back-pulse the filter, the vessel was first vented to atmospheric pressure. Next, permeate was allowed to fill the chamber by opening the toggle valve. Once the chamber was half full of permeate (as seen through the sight glass), the toggle valve was closed. The three-way valve was then positioned to allow compressed gas at 80 psig to fill to the chamber and pressurize the fluid. The three-way valve was then positioned to isolate the now pressurized chamber. The slurry pressure inside the filter was then dropped below the pressure of the compressed gas line $(<20 \mathrm{psig})$. The toggle valve at the bottom of the tank was opened, allowing the pressurized permeate inside the chamber to flow backwards through the filter 
element. The toggle valve was closed when the permeate level was below the visible portion of the sight glass. After the back-pulse was completed, the three-way valve was positioned to vent the chamber back to atmospheric pressure.

Flow from the glass cylinder goes through a 3-way valve. This valve directs flow either back to the slurry reservoir tank to be mixed back to the slurry or to a sampling hose that is used to transfer the permeate into a sample container.

\section{H.1.1.2 Instrumentation and Data-Acquisition System}

Because the system was to be operated in a hot cell, one of the design goals of the skid was to minimize the number of manual measurements during testing and record the data in an electronic format that could be analyzed readily with other approved software. Most of the sensors on the testing apparatus transmitted analog data to an external data acquisition collection system (DACS), manufactured by National Instruments. ${ }^{(a)}$ This system relayed the analog data to a LabView data-collection program operating on a desktop computer system using Windows XP (Professional), service pack 2. The software program scaled the analog data and simultaneously recorded the data electronically and displayed it on the computer's monitor. The performance of the software was verified by test plan RPP-WTP-QA-010, and all reportable data were measured on calibrated instrumentation, including the external DACS board. Figure H.7 shows a diagram of the electronic sensors attached to the DACS, and Figure H.8 displays the screen windows from the data-collection program.

(a) National Instruments Corporation, 11500 N Mopac Expwy, Austin, TX 78759-3504 
WTP-RPT-169, Rev 0

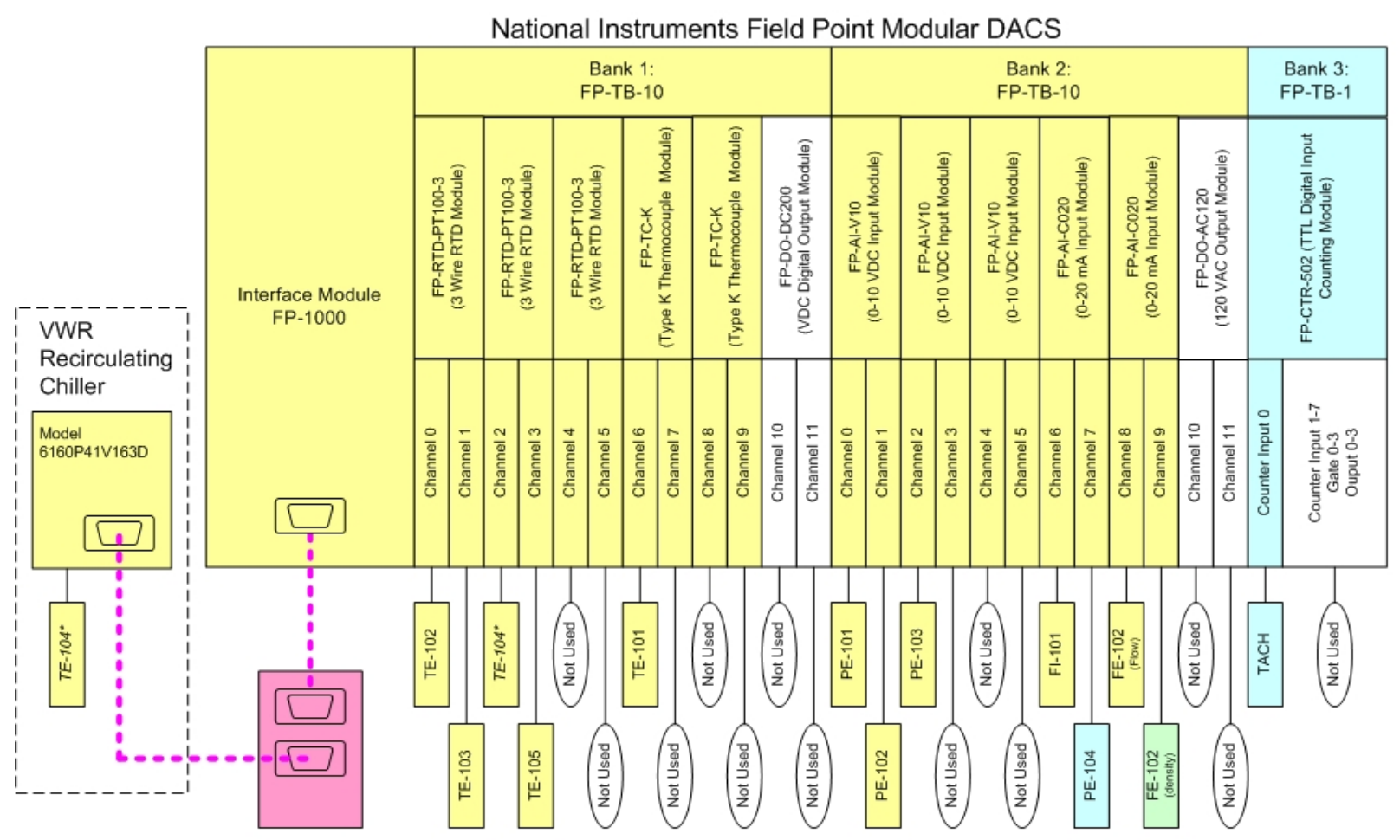

\begin{tabular}{|lll|}
\hline $\begin{array}{l}\square \text { Windows XP PC } \\
\text {-- RS-232 Communication }\end{array}$ & $\square$ M\&TE Data \\
\hline User Calibration & $\square$ Not Used & $\begin{array}{l}\text { Indication Only } \\
\text { * Note: TE-104 can only be wired to } \\
\text { either the chiller or the Field } \\
\text { Point system - not both. }\end{array}$ \\
\hline
\end{tabular}

Figure H.7. Diagram of DACS System 


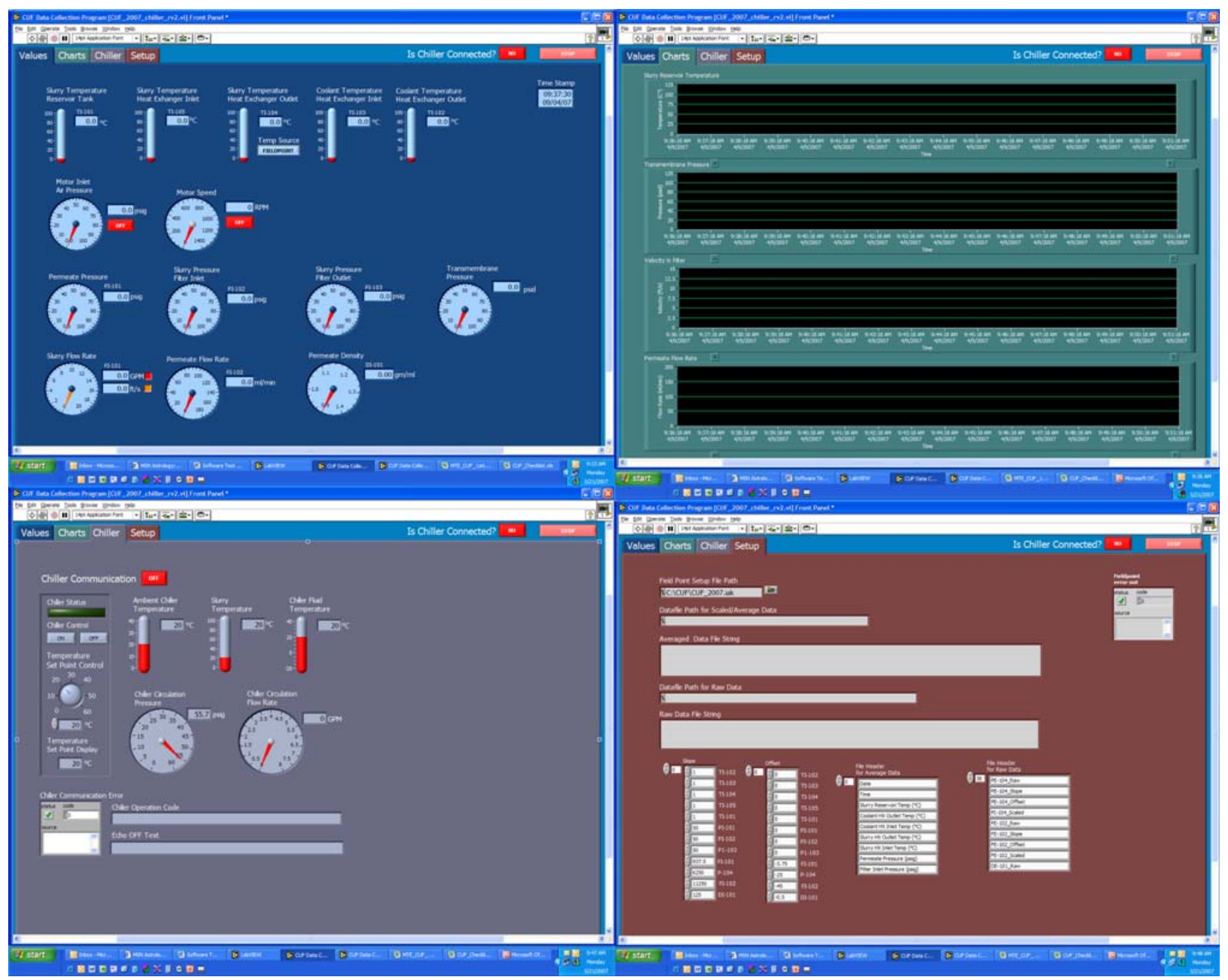

Figure H.8. Digital Images of DACS Display Windows

\section{H.1.1.3 CUF Operation and Sampling}

The CUF was developed to operate in several different operational modes to simulate filtration and leaching processes of the WTP pretreatment system. The filtration operation occurred in a recycling or dewatering mode. During recycling operations, permeate was returned to the slurry reservoir tank. By returning permeate back into the slurry, the undissolved solids (UDS) concentration in the slurry was maintained in a steady-state condition. The CUF was operated in this mode to understand how the effects of time, pressure, and axial velocity impact the filtration of slurry while maintaining the physical properties of the slurry. During dewatering operations, permeate from the filter was diverted to a collection vessel, operating the system at a constant transmembrane pressure and axial flow rate and allowing the UDS concentration of the slurry to change. The CUF was operated in this mode to understand how the slurry's rheological and filtration properties changed as its UDS concentration changed.

Chemical leaching occurred in the slurry reservoir tank when isolated from the slurry circulation loop. Isolating the slurry reservoir tank for leaching operations required draining the slurry and permeate inside the CUF filtration piping first. Once the tank was isolated from the slurry circulation loop, the slurry and 
permeate were returned to the slurry reservoir tank along with the leaching agent. When the leaching operations occurred at elevated temperatures, heat tape surrounding the slurry reservoir was used to heat the vessel.

Samples were collected throughout testing to measure the physical and chemical properties of the waste slurry or permeate. Slurry samples were collected from two separate locations on the system. Small slurry samples $(20 \mathrm{~mL})$ were collected from the top of the slurry reservoir with the mixer operating using 18-in.-long pipettes. The tips of the pipettes were cut at an angle to allow slurry to flow into the pipette without being plugged. Larger samples $(100 \mathrm{~mL})$, such as for rheology measurement, were collected using the drain valve on the pump discharge while the pump is running. Permeate samples were collected during dewatering operations directly from the dewatering sample hose. However, permeate collected during leaching operations required manual filtration. A slurry sample was initially collected from the slurry reservoir using a pipette described earlier. The sample was filtered through a $0.45-\mu \mathrm{m}$ syringe filter.

\section{H.1.1.4 Baseline Testing of Filter}

Before testing with HLW composite, the skid and the filter were initially cleaned with a laboratory cleaning solution (Alconox ${ }^{(a)}$ at 1:100 dilution) and rinsed with DI water to remove cutting oils and soils from the skid fabrication process and shipping from the manufacturer. After cleaning, the filter flux was measured with a solution of $0.01 \mathrm{M} \mathrm{NaOH}$-this is referred to as the clean water flux. Testing was performed at 10, 15, and 20 transmembrane pressure (TMP) at an axial velocity of $11 \mathrm{ft} / \mathrm{s}$. Each pressure condition was held for 20 minutes with a single back-pulse performed before changing the pressure. Next, a strontium carbonate $\left(\mathrm{SrCO}_{3}\right)$ slurry was prepared to test the filter flux with a slurry solution. As before, the $\mathrm{SrCO}_{3}$ slurry was placed in the filtration skid and was operated with the permeate recycling back into the slurry reservoir. Testing was performed at 10, 20, and $30 \mathrm{TMP}$ at an axial velocity of $11 \mathrm{ft} / \mathrm{s}$. A single back-pulse was performed between each test condition. Afterwards, the slurry was removed and rinsed out with DI water (approximately $10 \mathrm{~L}$ ). The clean water flux was again tested with a solution of $0.01 \mathrm{M} \mathrm{NaOH}$ to verify that the filter was clean before testing with HLW slurries.

The results of the baseline filter flux testing are shown in Figure H.9. Overall, the baseline flux for the filter was demonstrated to be considerably higher than the predicted flux for the waste slurries to be tested (e.g., $0.04 \mathrm{gpm} / \mathrm{ft}^{2}$ for dewatering operations). No solids were evident in the permeate during filtration of the strontium carbonate slurry, and the density of the permeate was measured at $1.12 \mathrm{~g} / \mathrm{mL}$ by the mass flow meter. A sample of the permeate was taken, and its density was measured as $1.11 \mathrm{~g} / \mathrm{mL}$ with a calibrated balance and a 50-mL volumetric flask. While the density could be measured, the volumetric flow of the permeate was beyond the range of the mass flow meter for all three tests. After a density check, permeate flow was diverted through the skid's rotometer. For the $\mathrm{SrCO}_{3}$ flux measurements, the flow was slow enough to verify the flow rate using the in-line volumetric cylinder to measure the permeate flow.

(a) Alconox, Inc., 30 Glenn Street, Suite 309, White Plains, NY 10603 USA. 
WTP-RPT-169, Rev 0

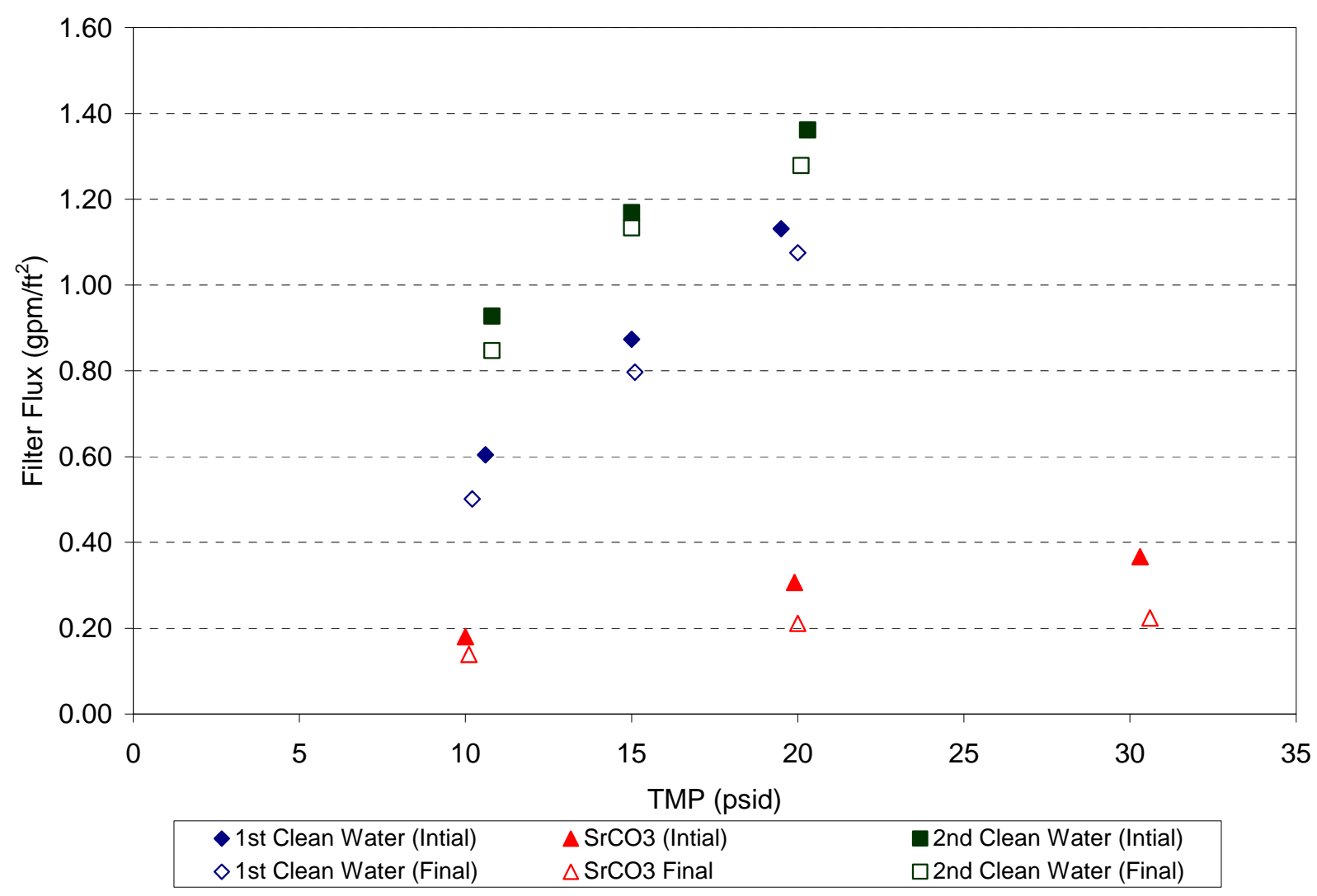

Figure H.9. Initial Clean Water/SrCO 3 Flux Measurements of Filter

\section{H.1.2 Filtration Data Analysis}

\section{H.1.2.1 Filtration Terms and Equations}

Filtration is examined in this report as a filter flux defined as:

$$
J=\frac{Q_{\text {permeate }}}{A_{\text {filter }}}
$$

where $J$ is the filter flux (gpm/ $\mathrm{ft}^{2}$ ), $Q_{\text {permeate }}$ is the volumetric permeate flow, and $A_{\text {filter }}$ is the filtration surface area.

In this study, the filter area is assumed as the inside area of the filter element, which is defined as:

$$
A_{\text {filter }}=\pi D i_{\text {filter }} L_{\text {filter }}
$$

where $D i_{\text {filter }}$ is the filter element inside diameter, and $L_{\text {filter }}$ is the filter element length. 
The permeate volumetric flow rate is also corrected for viscosity and surface tension effects because the permeate temperature deviated from $25^{\circ} \mathrm{C}$. For a temperature T, the corrected permeate flow rate and filter flux are given as:

$$
\begin{aligned}
& Q_{25^{\circ} \mathrm{C}}=Q_{T} e^{2500\left[\frac{1}{T+273}-\frac{1}{298}\right]} \\
& J_{25^{\circ} \mathrm{C}}=J_{T} e^{2500\left[\frac{1}{T+273}-\frac{1}{298}\right]}
\end{aligned}
$$

The pressure drop across the filter (i.e., the TMP) was calculated in this test as:

$$
T M P=\Delta P_{m}=\frac{\left(P_{\text {inlet }}+P_{\text {outlet }}\right)}{2}-P_{\text {permeate }}
$$

where $P_{\text {inlet }}$ is the pressure at the filter inlet, $P_{\text {outlet }}$ is the pressure at the filter outlet, and $P_{\text {permeate }}$ is the pressure at the permeate side of the filter. A common unit for measuring TMP is psid, which is pounds per square inch, differential.

The axial velocity inside the filter is calculated by dividing the volumetric slurry flow of the filter by the cross-section area of the inside diameter of filter:

$$
A V=\frac{Q_{\text {slurry }}}{S_{a}}=\frac{Q_{\text {slurry }}}{\frac{\pi}{4} D i_{\text {filter }}^{2}}
$$

where $S_{a}$ is the cross sectional area of axial flow, and $Q_{\text {slurry }}$ is the volumetric slurry flowrate in the axial direction.

The Darcy equation describes filter flux as:

$$
J=\frac{\Delta P_{m}}{\mu_{\text {permeate }} R_{m}}
$$

where $\Delta P_{m}$ is the pressure drop across the filter membrane, $\mu_{\text {permeate }}$ is the viscosity of the permeate, and $R_{m}$ is the overall resistance of the filter membrane.

The filter-resistance term is considered a more complicated term, which is a sum of the resistance of the actual filter, the resistance of the filter cake that forms on the surface of the filter surface, and the resistance due to fouling of the filter. For cross-flow filtration, the overall resistance of the filter membrane for low concentrated slurries is usually constant, and turbulent flow conditions exist inside the filter. The transmembrane pressure and permeate viscosity are the controlling operational parameters. During dewatering, the slurry's flow properties change, and the filter resistance becomes more significant. When the slurry's UDS concentration begins to approach a maximum limit, known as the gel concentration, the filter flux can be described as 


$$
J=k \cdot \ln \left[\frac{C_{s}}{C_{g}}\right]
$$

where $C_{s}$ is the slurry UDS concentration, and $C_{g}$ is the slurry gel concentration.

When the flux is impacted by the UDS concentration, the impact of axial velocity becomes significant as well. This is due to how the axial velocity affects the thickness of the filter cake inside the filter.

\section{H.1.2.2 Filtration Test Matrix}

To understand the impact of the transmembrane pressure and axial velocity on the filter flux of the waste slurry, a filtration test matrix was developed to understand their individual effects. Like the clean water and $\mathrm{SrCO}_{3}$ slurry flux testing described in section H.1.1.4, the waste slurry is circulated through the filtration skid while the slurry permeate leaving the filter is recycled back to the slurry reservoir. By recycling permeate in this way, the UDS concentration of the slurry stays constant. Using a TMP of $40 \mathrm{psid}$ and an AV of $13 \mathrm{ft} / \mathrm{s}$ as the baseline condition, the testing conditions are varied to demonstrate how the flux varies as TMP and AV change from the center condition. Table H.1 and Figure H.9 outline the conditions for the testing performed.

Each filtration condition is maintained for at least an hour while permeate is recycled back to the slurry reservoir tank. Before the test condition is changed, a back-pulse on the filter is performed to provide the same starting conditions for each test. The initial test performed at the baseline condition is performed for a minimum of 3 hours to track how the filter flux varies with time to track possible fouling due to the waste.

Table H.1. Filtration Test Matrix Operating Conditions

\begin{tabular}{|c|c|c|c||}
\hline $\begin{array}{c}\text { Test } \\
\text { number }\end{array}$ & $\begin{array}{c}\text { Minimum } \\
\text { Duration } \\
\text { (hours) }\end{array}$ & $\begin{array}{c}\text { Target TMP } \\
\text { (psid) }\end{array}$ & $\begin{array}{c}\text { Target AV* } \\
\text { (fps) }\end{array}$ \\
\hline 1 & 3 & 40 & 13 \\
\hline 2 & 1 & 30 & 11 \\
\hline 3 & 1 & 30 & 15 \\
\hline 4 & 1 & 50 & 15 \\
\hline 5 & 1 & 50 & 11 \\
\hline 6 & 1 & 40 & 13 \\
\hline 7 & 1 & 40 & 9 \\
\hline 8 & 1 & 40 & 17 \\
\hline 9 & 1 & 20 & 13 \\
\hline 10 & 1 & 60 & 13 \\
\hline 11 & 1 & 40 & 13 \\
\hline (a) Actual conditions may vary based upon slurry \\
volume and rheology. All conditions may not \\
be obtainable.
\end{tabular}


WTP-RPT-169, Rev 0

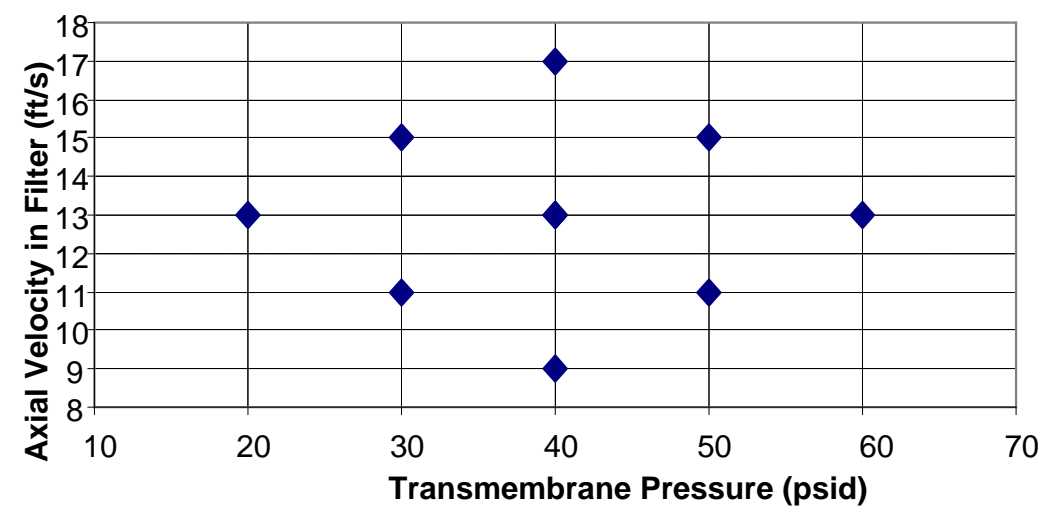

Figure H.9. Filtration Test Matrix Chart

When the slurry is at low solids concentrations, the system is expected to be controlled by the transmembrane pressure (Equation H.6), with little impact from the axial velocity. However, once the slurry is concentrated and the flow properties change, it is expected that the axial velocity will have some effect on the filtration of the system.

\section{H.1.2.3 Dewatering Operation Analysis}

During dewatering operations of the waste slurries, the transmembrane pressure and axial velocity are maintained at the baseline condition of 40 psid and $13 \mathrm{fps}$. By maintaining the operating conditions of the filtration, the only effect on filtration should be the slurry concentration. As the slurry's UDS changes, the filter flux can be monitored and graphically charted, as shown in Figure H.10. As discussed earlier, the filter flux is initially expected to follow Equation H-6 for low-solids concentrations, which will appear as a horizontal line on the chart when the TMP is held constant. However, as the slurry begins to concentrate, the filtration behavior of the slurry is expected to change and begin to follow Equation H.7. With graphic analysis, the transition in filtration behavior can be understood. 


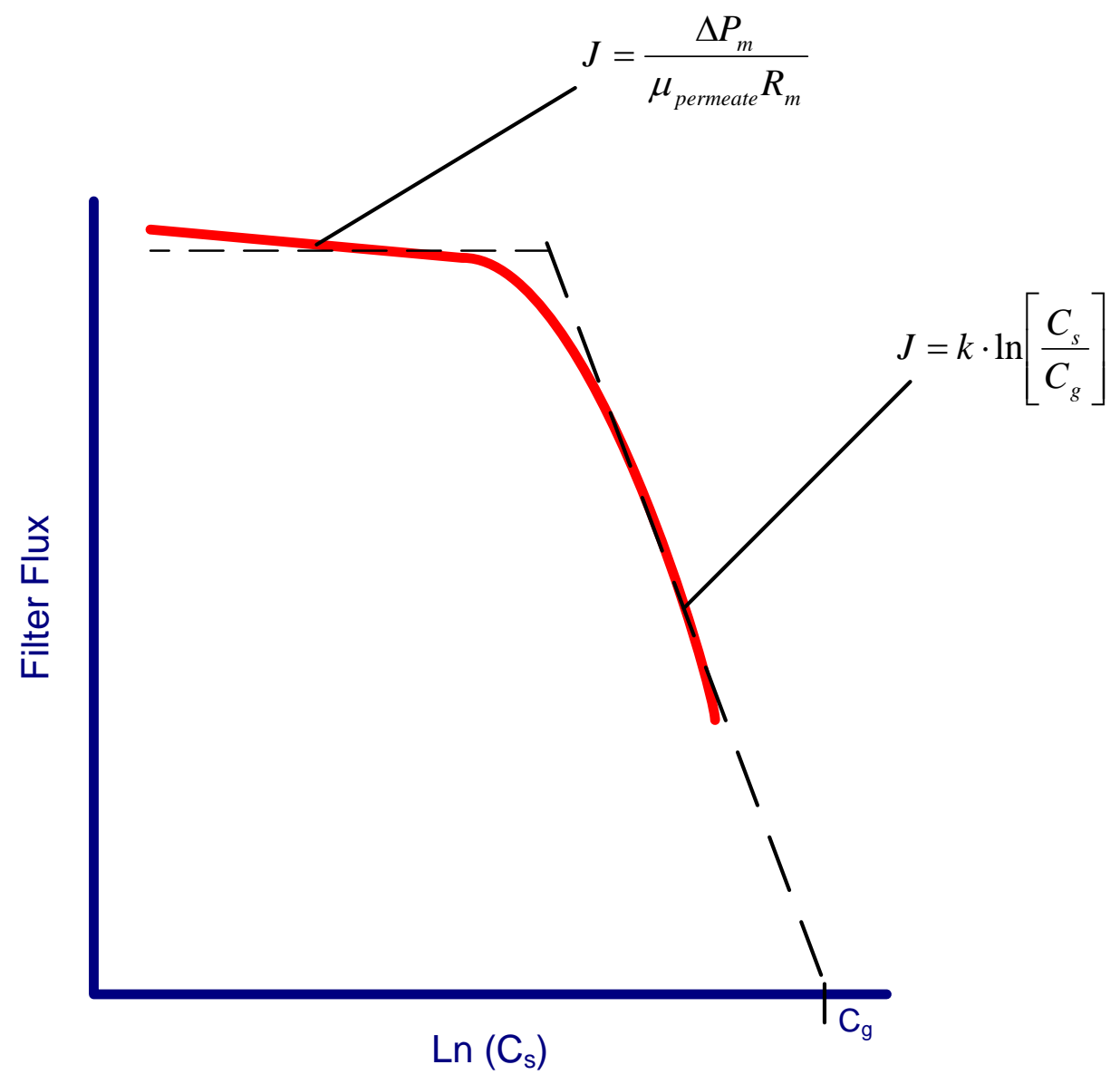

Figure H.10. Example of a Dewatering Curve

\section{H.1.2.4 Effects of Rheology and Particle Size}

During testing operations, rheology and particle-size samples are collected to characterize the solids in the slurry and their impact on flow and filtration behavior. As slurries concentrate, their flow behavior changes and becomes more viscous and less Newtonian. This directly impacts the cross-flow behavior of the filter and the formation of filter cake. The particle size also can have an impact by affecting the gel concentration of the slurry and possibly impact fouling. Because the slurries are sheared during filtration, the particle size of the slurry can change-especially if the initial solids are agglomerated. Chemical leaching has a similar impact as well.

\section{H.1.3 Chemical Data Analysis}

During the test, the mass of material placed inside the skid and removed is constantly measured to perform an overall mass balance of the slurry during the test. Two main goals are to be achieved from this analysis: 1) verification that transuranic (TRU) material stays in the HLW stream and 2) calculation of the chemical leach factors of glass-limiting compounds of interest. 


\section{H.1.3.1 Validation of Filtration Separation of TRU Material}

The main goal of the chemical and physical separation processes tested in this report is to demonstrate the effectiveness of removing the glass load-limiting glass components (e.g., phosphorus) from the HLW stream while not introducing TRU material into the LAW waste stream. This is examined during filtration and leaching processes. During filtration, it is important to verify that TRU materials present in the waste slurry do not pass through the filtration media as a colloid or as a particle $<0.1 \mathrm{~mm}$. During leaching, it is also important to verify that TRU compounds are not chemically dissolved during operations designed only to remove glass-limiting compounds for the LAW stream. This was achieved by performing radiochemical analysis on permeate and slurry samples throughout the test to verify that the permeate streams contain minimal TRU elements and that a mass balance on the system shows that almost all the TRU stays in the HLW slurry stream.

\section{H.1.3.2 Chemical Leach Factors for Caustic and Oxidative Leaching}

In this report, the chemical leach factor is defined as the percentage difference in mass of a solid component in the waste after chemical leaching.

$$
f_{i}=1-\frac{m_{i}^{\text {final }}}{m_{i}^{\text {initial }}}
$$

where $f_{i}$ is the leach factor for component $\mathrm{i}, m_{i}^{\text {initial }}$ is the initial solid mass of component $\mathrm{i}$, and $m_{i}^{\text {final }}$ is the final solid mass of component $i$.

The following methods are used to calculate solid leach factors:

- Perform an overall elemental mass balance of the system along with a physical-property measurement of the solids fraction of the slurry. Using chemical analytical data and mass measurements of additions and removals of waste slurry, samples, and dewatered permeate, the elemental changes to the solids and liquid fractions of the slurry can be calculated at each stage of the test as well as the leach factor.

- Perform a mass balance of the slurry before and after leaching using insoluble components, such as iron and uranium, to trace the fractional change in mass. Substituting dry mass compositions for leach component $i$ and inert $j$ in Equation 2.8, the leach factor becomes:

$$
f_{i}=1-\left(\frac{x_{i}^{\text {final }}}{x_{i}^{\text {initial }}}\right)\left(\frac{x_{j}^{\text {initial }}}{x_{j}^{\text {final }}}\right)
$$

- Perform a mass balance of the liquid supernate before and after leaching to measure the change of mass in the solids to calculate the leach factor.

\section{H.1.3.3 Physical Examination of Final Leach Material}

The chemical characterization and physical morphology are examined after leaching. While most of the analyses used are qualitative, they can show:

- If particles are crystal, agglomerates, or amorphous 
- Whether TRU and glass-limiting compounds (like aluminum or chromium) are blends of different phases or single compounds

- What is the crystal phase of the remaining glass-limiting compound (e.g., boehmite for aluminum). 


\section{Appendix I}

\section{Homogenization Methods}




\section{Appendix I: Homogenization Methods}

The homogenization vessel and mixing system used to homogenize the Group 7 TBP sludge sample was designed and fabricated for use at Pacific Northwest National Laboratory (PNNL) in the High-Level Radiochemistry Facility (HLRF). This stainless steel equipment was specifically designed to composite tank wastes and divide them into homogeneous sub-samples. The homogenization vessel was designed to hold and effectively mix a variable volume of 1 to $5 \mathrm{~L}$ of waste. A set of removable baffles was designed and added to enhance mixing. Industry experience shows that the best mixing is achieved when a tank height-to-diameter ratio is 1:1. For a fixed volume batch tank, this is easy to achieve. For a variable volume tank, this presents a challenge usually solved by making the tank conical. Height restrictions and volume requirements made it unfeasible to make the entire homogenization vessel conical, so to optimize mixing, a compromise tank design was devised. The bottom of the tank with a volume capacity of $\sim 1.5$ to 2.0 L was conical. At low volumes, the mixing assistance from the baffles was less than at larger volumes. Therefore, the need to rigorously maintain the 1:1 ratio was achieved in this section of the tank. When the volumes are above $2 \mathrm{~L}$, the baffles combined with a down-sweeping mixer blade were shown to be sufficient to maintain a good mixing profile in the non-conical portion of the tank. The bottom of the conical section slopes toward the side to facilitate good subdivision of the samples.

Figure I.1shows photographs of the homogenization vessel along with a schematic representation of its design. The Group 7 sample material was loaded into the vessel through a Tyler sieve mounted to the top of the vessel (see right side of Figure I.1). This was done so that no chunks of material greater than $3.2 \mathrm{~mm}$ in diameter were included in the composite, which was necessary for forming a uniform composite and protecting the CUF equipment during later testing. This vessel was used to composite several groups of tank samples. Extensive cleaning was done between each group with water, $0.01 \mathrm{M}$ $\mathrm{NaOH}$, and $0.01 \mathrm{M} \mathrm{HNO}_{3}$.

Before the actual tank waste samples were homogenized, non-radioactive testing of this system with various simulants was performed to establish the best operating conditions and procedures and to verify the uniformity of the sub-samples obtained with this tank. Simulants with high yield stress values (Figure I.2) and simulants with the capability to settle rapidly (Figure I.3) were tested to verify that good mixing could be maintained and uniform sub-samples removed. Operating conditions and guidelines that resulted in a composite with homogeneous sub-samples of the most challenging simulants were then incorporated into the test instructions for the actual waste testing.

Clay simulants were prepared with high Bingham yield stresses and cohesive properties that would make them sticky. These consisted primarily of kaolin and bentonite clay mixtures. These simulants mixed well and delivered uniform samples while the homogenization vessel was tested (Figure I.2, left and center). However, they did leave a thick film of material coating the tank, mixer, and baffle surfaces (Figure I.2, right). In compositing the actual tank waste samples, solids materials with these characteristics would need to be recovered for CUF testing with extra rinses of de-ionized (DI) water after completing homogenization and sub-sampling of the bulk material. 

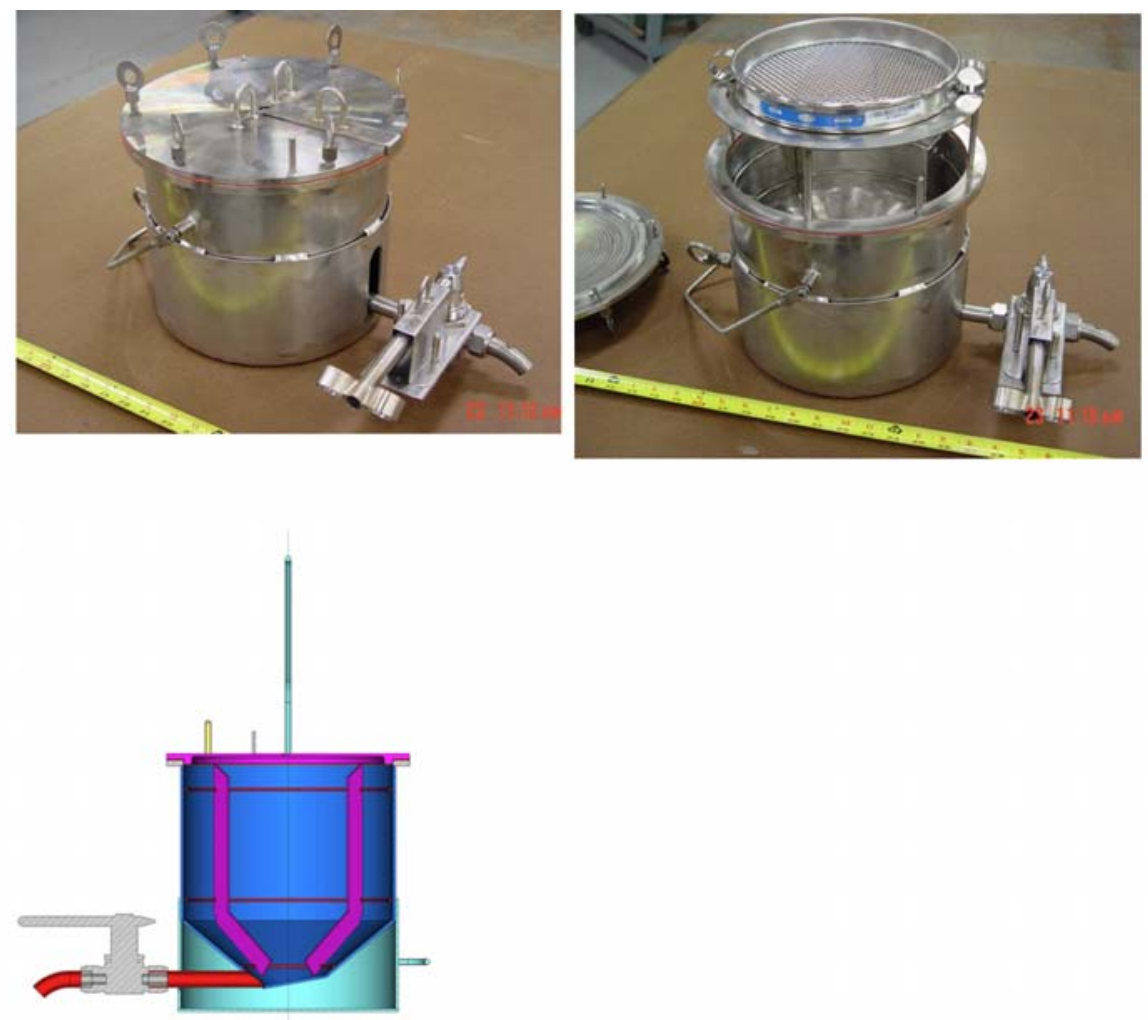

Figure I.1. Homogenization Vessel Used to Prepare and Sub-Sample the Group 7 Composite Slurry
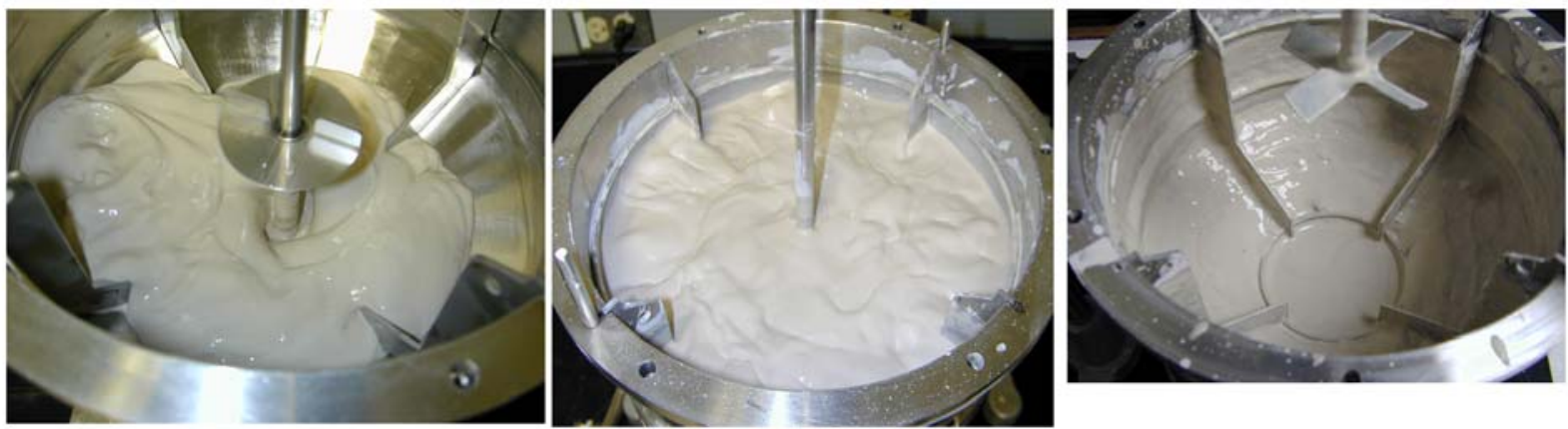

Figure I.2. Photographs of a High Yield Stress Clay Simulant in the Homogenization Vessel Used for Group 7

Min-u-sil ${ }^{\circledR}$-based simulants were used to test variable mixing speeds and propeller placement because of their tendency to settle swiftly when mixing is not sufficient. Figure I.3 shows that these simulant types could usually be cleanly and completely recovered from the tanks. However, the sub-samples were often non-uniform with the Min-u-sil ${ }^{\circledR}$ simulants. Figure I.4 shows an example of non-uniform settling results for sub-samples taken when the mixer speed was too low. Based on these results, a hold point was inserted into the compositing test instructions such that after 3 days of settling, the settled solids of all the composite samples would be compared and statistically analyzed to verify that good homogenization of the composite had been achieved and maintained during the sub-sampling process. 


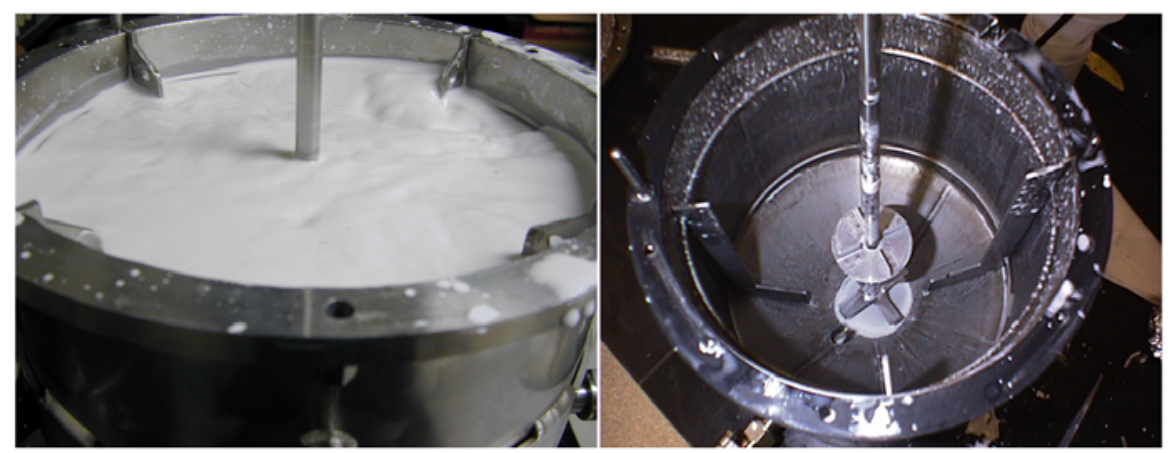

Figure I.3. Photographs of the Mixing of a Min-u-sil ${ }^{\circledR}$ Simulant that Settles Rapidly in the Homogenization Vessel Used for Group 7 (left) and the Vessel After Draining of the Material (right)
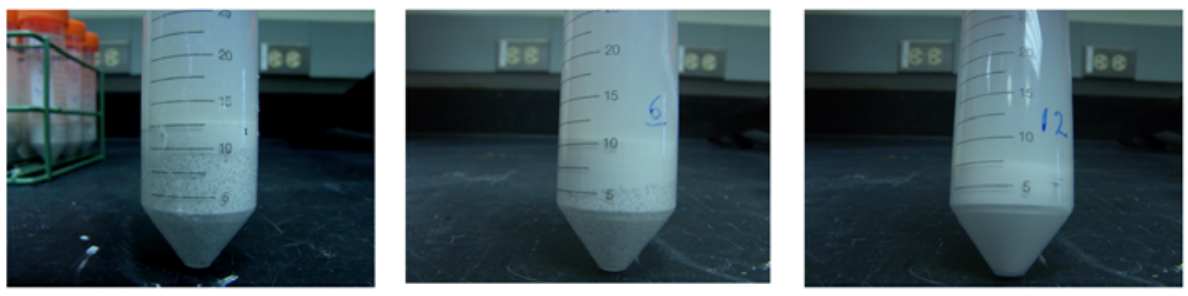

Figure I.4. Photographs of Three Different Sub-Samples Taken from the Homogenization Vessel During Non-Radioactive Testing with a Min-u-sil ${ }^{\circledR}$ Simulant. Note the different degrees of settling, which indicates in-homogeneity in the slurry. 
Appendix $\mathbf{J}$

\section{Group 7IAY-102 CUF Analytical Results}




\title{
Appendix J: Group 7IAY-102 CUF Analytical Results
}

\author{
Special Instructions for the \\ CUF Group 7 (TBP Sludge)/241-AY-102 Treatability Study \\ Analysis Requirements
}

A blend of two HLW samples containing liquid and sludge from Hanford waste tanks was subjected to CUF process as per TI-RPP-WTP-624. The first sample is a composite blend from tanks 241-B-106 and 241-BX, representing waste described as TBP Sludge waste (Group 7). The second waste sample was an archive tanks 241-AY101, which was similar in composition. The start date for this treatability study is April 27th, 2008. Color code: Pastel Pink

The processing and analysis schematic is shown by Figure 1 and Table 1 . The aqueous samples are ready to directly sub-sample for analysis and acid digestion. The solid slurry samples have yet to be split into aliquots and prepped for fusion or HF-assisted acid digestion.

Two samples from ASR 8113, Group 2 CUF, will be re-sampled in cell and added to this ASR. These samples are an attempt to identify a source of contamination and will require only ICP metals. Color code: Fluorescent Pink

\section{SAL Preparation/Analysis}

Please record observations associated with the dissolution preparations, and record the test sample being aliquotted before and after sampling to document changes in weight since the treatability study occurred. If any residual solids remain after any of the fusion and acid digestions, note on the bench sheet (include estimated quantity, color, texture, etc.) and contact RW Shimskey or MK Edwards for further instruction prior to distribution.

\section{Archive of SAL Fusion Preparation Samples}

The fusion preparations will result in a $100-\mathrm{mL}$ volume. This solution will be apportioned to the laboratory as needed to conduct work-station-specific analyses. Please prepare a 15-mL aliquot from each preparation as an archive sample. The vials need to be labeled with the following: date, ASO-ID, matrix, treatablility study, hazard, fusion prep (if applicable) and their tare, gross masses, and IDs provided to RW Shimskey or MK Edwards. The vials may be removed from the hot cells for storage. The remaining portions of the fusion preparations may be disposed of.

\section{Quality Control}

All work is to be conducted according to RPP-WTP-QA-005, Rev. 2.

Preparative or sample analysis QC includes a preparation blank, sample, sample duplicate, matrix spike, and a LCS or BS. The samples submitted for fusion are sub-aliquoted into fusion vessels in duplicate (sample, sample duplicate). If possible, the matrix spike and LCS/BS need to include all the analytes of interest to be reported for the specific analysis. 
The duplicate, LCS/BS, and MS QC acceptance criteria for the aqueous phases and solid phases are provided in Table 4 . The preparation blank (PB) analyte concentration shall be less than the estimated quantitation limit (EQL) or the minimum detectable activity (MDA) of the associated sample. When the PB concentration is equal to or exceeds the EQL, then the PB concentration shall not exceed 5\% of the measured concentration present in the sample. Failure of the PB, and/or duplicates, and/or LCS/BS to meet the acceptance criteria requires that affected samples in the processing batch be re-prepared and re-analyzed for the failed analytes, availability of samples permitting, at ASO expense.

In the case of multi-elemental methods (IC and ICP-OES), isolated QC failure(s) may be communicated to RW Shimskey or MK Edwards for an assessment of the impact on data interpretation. If the data are acceptable, RW Shimskey or MK Edwards will indicate, in writing, that the data may be reported, and the resulting limitations on the data from the QC sample failure(s) shall be included in the final report.

When the MS fails to meet the acceptance criteria, the results shall be investigated for potential sources of error. When the sources of error cannot be identified, the failure of the MS and any resulting limitations on the data shall be included in the report.

Note that in some cases BS and MS are requested for U/KPA as well as ICP metals in solution analysis. Because the broad suite of ICP BS metals will interfere with the U KPA analysis, two MS and BS samples (one supporting each technique) will need to be prepared as part of the acid digestion.

\section{Reporting Units}

Report aqueous sample results in units of $\mathrm{ug} / \mathrm{mL}$ or $\mathrm{uCi} / \mathrm{mL}$. Report solids sample results as ug/g or $\mathrm{uCi} / \mathrm{g}$; the initial dry mass of solids (as measured in each fusion crucible, preferably in the form of SAL drying bench sheets) will be provided with the ICP results. For radiochemistry, the reference date shall be February 17, 2008 for samples from TI-RPP-WTP-624.

\section{Reporting}

Please prepare the analytical data report in accordance with PNL-ASO-058, Rev. 0, Section 5.3, Comprehensive Data Report. Please be sure to include action taken with respect to any identified unexpected results and discrepancies.

The following elements may be included in the final report or be traceable to the test results (usually by entry in the LRB, Test Instruction, or data sheet) and be maintained as lifetime records:

- identification of standards used

- identification of M\&TE used

- reference to the Test Plan (identified on page 1 of the ASR)

- $\quad$ signature and date of person who performed the test and recorded the data

- hand calculation review documentation.

Analytical results shall be reported both in hard copy and electronically. Preliminary data reports and electronic files shall be provided as soon as practical after completion of analysis. The final ASR data report shall be provided no later than the commitment date on the ASR. 


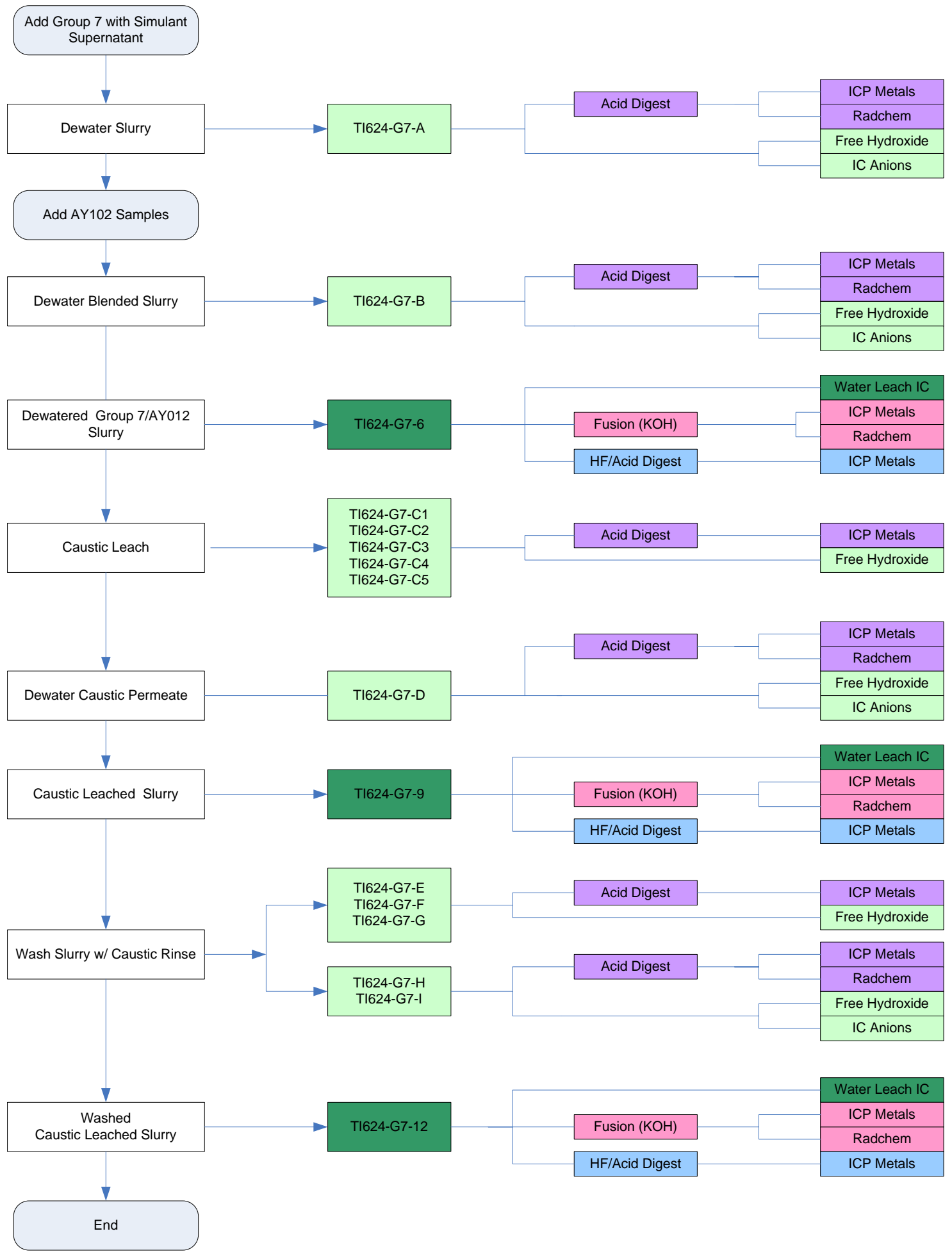

Figure 1: TI-RPP-WTP-624 Process Sampling Plan 
Table 1. Cross-Reference of Process component, Sample ID, and RPL ID

\begin{tabular}{|l|l|c|}
\hline \multicolumn{1}{|c|}{ Component } & \multicolumn{1}{c|}{ Sample ID } & ASO ID \\
\hline Group 7 Dewater filtrate & TI624-G7-A & $08-02059$ \\
\hline Group 7/AY102 Dewater filtrate & TI624-G7-B & $08-02060$ \\
\hline Dewatered Caustic Leach & TI624-G7-D & $08-02061$ \\
\hline Wash 4 Permeate & TI624-G7-H & $08-02062$ \\
\hline Composite Wash Sample & TI624-G7-I & $08-02063$ \\
\hline Caustic leach filtrate, 1 hour heat up & TI624-G7-C1 & $08-02064$ \\
\hline Caustic leach filtrate, 0 hour heat up & TI624-G7-C2 & $08-02065$ \\
\hline Caustic leach filtrate, 2 hour leach & TI624-G7-C3 & $08-02066$ \\
\hline Caustic leach filtrate, 4 hour leach & TI624-G7-C4 & $08-02067$ \\
\hline Caustic leach filtrate, 8 hour leach & TI624-G7-C5 & $08-02068$ \\
\hline Wash 1 Permeate & TI624-G7-E & $08-02069$ \\
\hline Wash 2 Permeate & TI624-G7-F & $08-02070$ \\
\hline Wash 3 Permeate & TI624-G7-G & $08-02071$ \\
\hline Group 2, 3 & TI572-G2-OxWash 3-1 & $08-02072$ \\
\hline Group 2, 3 ${ }^{\text {rd }}$ Oxidative wash permeate & TI572-G2-O-1 & $08-02073$ \\
\hline Dewatered Slurry & TI624-G7-6 & $08-02074$ \\
\hline Caustic Leached Slurry & TI624-G7-9 & $08-02075$ \\
\hline Washed Caustic Leached Slurry & TI624-G7-12 & $08-02076$ \\
\hline
\end{tabular}




\section{Laboratory Analysis}

The required sample analyses are shown below in Table 2.

Table 2. Filtration and Leach Testing Characterization Plan

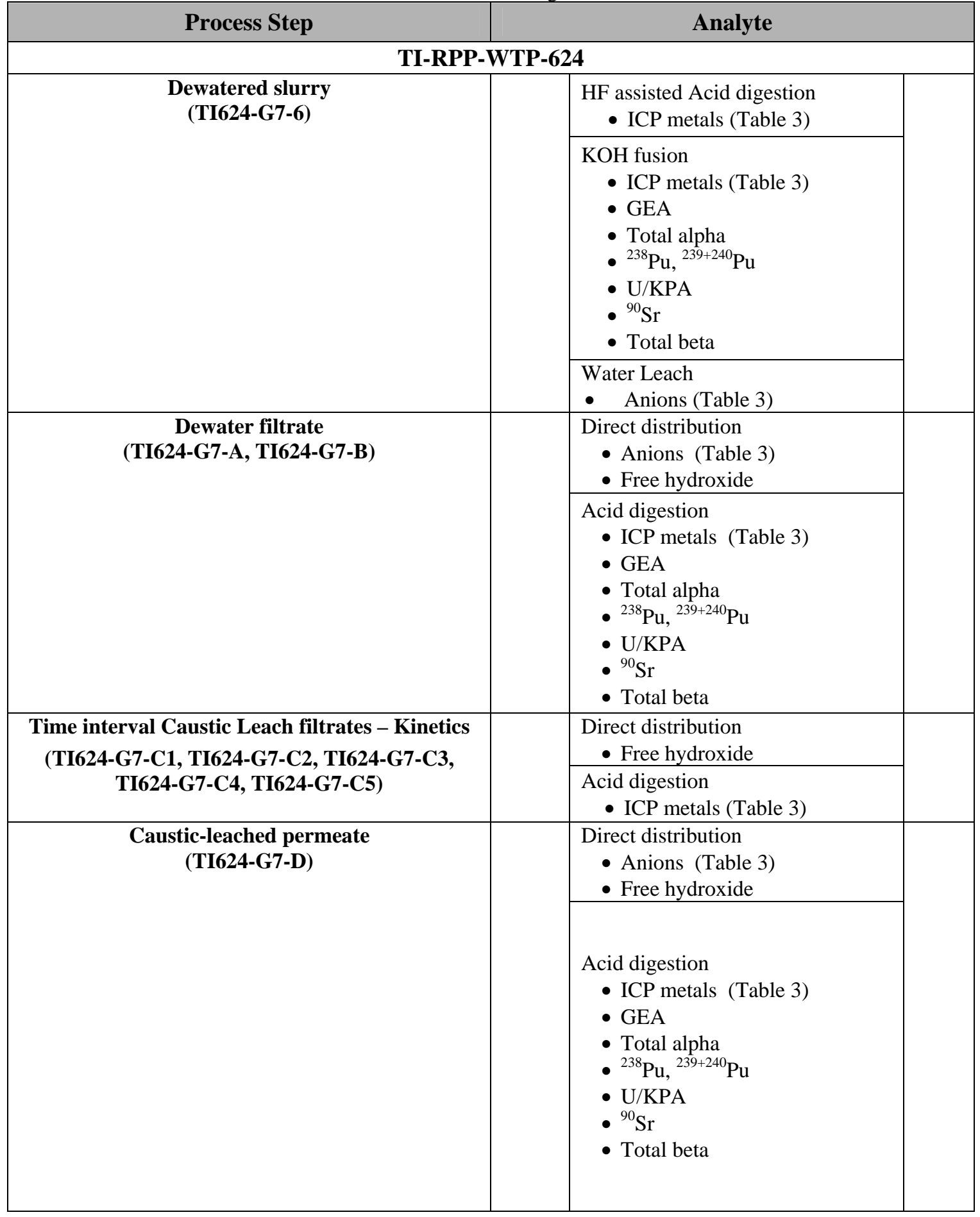




\begin{tabular}{|c|c|}
\hline Process Step & Analyte \\
\hline \multirow[t]{3}{*}{$\begin{array}{l}\text { Caustic-leached slurry } \\
\text { (TI624-G7-9) }\end{array}$} & $\begin{array}{l}\text { HF assisted Acid digestion } \\
\text { • ICP metals (Table 3) }\end{array}$ \\
\hline & $\begin{array}{l}\text { KOH fusion } \\
\text { - ICP metals (Table 3) } \\
\text { - GEA } \\
\text { - Total alpha } \\
\text { - }{ }^{238} \mathrm{Pu},{ }^{239+240} \mathrm{Pu} \\
\text { - U/KPA } \\
\text { - }{ }^{90} \mathrm{Sr} \\
\text { - Total beta }\end{array}$ \\
\hline & $\begin{array}{l}\text { Water Leach } \\
\bullet \quad \text { Anions (Table 3) } \\
\end{array}$ \\
\hline \multirow{2}{*}{$\begin{array}{c}\text { First and Second washes } \\
\text { following caustic leach } \\
\text { (TI624-G7-E, TI624-G7-F, TI624-G7-G) }\end{array}$} & $\begin{array}{l}\text { Direct distribution } \\
\text { • Free hydroxide } \\
\end{array}$ \\
\hline & $\begin{array}{l}\text { Acid digestion } \\
\text { • ICP metals (Table 3) }\end{array}$ \\
\hline \multirow[t]{2}{*}{$\begin{array}{c}\text { Third wash and combined wash composite } \\
\text { following caustic leach } \\
\text { (TI624-G7-H, TI624-G7-I) }\end{array}$} & $\begin{array}{l}\text { Direct distribution } \\
\text { - Anions (Table 3) } \\
\text { - Free hydroxide } \\
\end{array}$ \\
\hline & $\begin{array}{l}\text { Acid digestion } \\
\text { - ICP metals (Table 3) } \\
\text { - GEA } \\
\text { - Total alpha } \\
\text { - }{ }^{238} \mathrm{Pu},{ }^{239+240} \mathrm{Pu} \\
\text { - U/KPA } \\
\text { - }{ }^{90} \mathrm{Sr} \\
\text { - Total beta }\end{array}$ \\
\hline \multirow[t]{3}{*}{$\begin{array}{l}\text { Caustic-leached and washed slurry } \\
\text { (TI624-G7-12) }\end{array}$} & $\begin{array}{l}\text { HF assisted Acid digestion } \\
\text { • ICP metals (Table 3) }\end{array}$ \\
\hline & $\begin{array}{l}\text { KOH fusion } \\
\text { - ICP metals (Table 3) } \\
\text { - GEA } \\
\text { - Total alpha } \\
\text { - }{ }^{238} \mathrm{Pu},{ }^{239+240} \mathrm{Pu} \\
\text { - } \mathrm{U} / \mathrm{KPA} \\
\text { - }{ }^{90} \mathrm{Sr} \\
\text { - Total beta }\end{array}$ \\
\hline & $\begin{array}{l}\text { Water Leach } \\
-\quad \text { Anions (Table 3) }\end{array}$ \\
\hline $\begin{array}{c}\text { Group 2, } 3^{\text {rd }} \text { Oxidative wash permeate } \\
\text { (TI572-G2-OxWash 3-1) }\end{array}$ & $\begin{array}{l}\text { Acid digestion } \\
\qquad \quad \text { ICP metals (Table 3) }\end{array}$ \\
\hline $\begin{array}{l}\text { Group 2, } 3^{\text {rd }} \text { Oxidative wash permeate } \\
\text { (TI572-G2-O-1) }\end{array}$ & $\begin{array}{l}\text { Acid digestion } \\
\bullet \quad \text { ICP metals (Table 3) }\end{array}$ \\
\hline
\end{tabular}

All analyses are to be conducted per approved PNNL procedures or test plans with the QC defined in the QC information Section. Table 3 defines the analytes of interest, the required detection limits, and analysis methods. 
Table 3. Method Detection Limits for Solids and Supernatants

\begin{tabular}{|c|c|c|c|}
\hline Analyte & Solids & Solutions & Analysis Method \\
\hline & $\mu \mathrm{Ci} / \mathrm{g}^{(\mathrm{a})}$ & $\mu \mathrm{Ci} / \mathrm{ml}$ & \\
\hline${ }^{137} \mathrm{Cs}$ & 6.0E-02 & $1.0 \mathrm{E}-02$ & \multirow{5}{*}{ GEA } \\
\hline${ }^{60} \mathrm{Co}$ & $3.0 \mathrm{E}-02$ & $1.0 \mathrm{E}-02$ & \\
\hline${ }^{154} \mathrm{Eu}$ & $5.0 \mathrm{E}-03$ & $4.0 \mathrm{E}-04$ & \\
\hline${ }^{155} \mathrm{Eu}$ & 8.0E-03 & $4.0 \mathrm{E}-04$ & \\
\hline${ }^{241} \mathrm{Am}$ & $3.0 \mathrm{E}-03$ & 2.0E-03 & \\
\hline $\mathrm{Pu}$ & $1.0 \mathrm{E}-03$ & $1.0 \mathrm{E}-04$ & ${ }^{239+240} \mathrm{Pu}$ and ${ }^{238} \mathrm{Pu}$ by AEA \\
\hline Total alpha & $1.0 \mathrm{E}-02$ & 4.0E-03 & Proportional counting \\
\hline Total beta & $1.0 \mathrm{E}-02$ & 1.0E-03 & Proportional counting \\
\hline \multirow[t]{2}{*}{${ }^{90} \mathrm{Sr}$} & $1.0 \mathrm{E}-02$ & $1.0 \mathrm{E}-03$ & Separation and proportional counting \\
\hline & $\mu \mathrm{g} / \mathrm{g}$ & $\mu \mathrm{g} / \mathrm{ml}$ & \\
\hline $\mathrm{Al}$ & $3.0 \mathrm{E}+02$ & $7.5 \mathrm{E}+01$ & \multirow{17}{*}{ ICP-OES } \\
\hline B & $2.0 \mathrm{E}+02$ & $7.5 \mathrm{E}+01$ & \\
\hline $\mathrm{Bi}$ & $4.0 \mathrm{E}+02$ & $3.0 \mathrm{E}+01$ & \\
\hline $\mathrm{Cd}$ & $7.5 \mathrm{E}+01$ & $7.5 \mathrm{E}+01$ & \\
\hline $\mathrm{Cr}$ & $1.2 \mathrm{E}+02$ & $1.5 \mathrm{E}+01$ & \\
\hline $\mathrm{Fe}$ & $3.0 \mathrm{E}+02$ & $7.5 \mathrm{E}+01$ & \\
\hline $\mathrm{K}$ & $1.0 \mathrm{E}+03^{(\mathrm{b})}$ & $5.0 \mathrm{E}+01$ & \\
\hline $\mathrm{Mn}$ & $3.0 \mathrm{E}+02$ & $1.5 \mathrm{E}+01$ & \\
\hline $\mathrm{Na}$ & $3.0 \mathrm{E}+03$ & $7.5 \mathrm{E}+01$ & \\
\hline $\mathrm{Ni}$ & $1.6 \mathrm{E}+02^{(\mathrm{b})}$ & $3.0 \mathrm{E}+01$ & \\
\hline $\mathrm{P}$ & $2.0 \mathrm{E}+02$ & $1.0 \mathrm{E}+01$ & \\
\hline$S$ & $1.5 \mathrm{E}+03$ & $2.0 \mathrm{E}+2$ & \\
\hline $\mathrm{Si}$ & $3.0 \mathrm{E}+03$ & $7.5 \mathrm{E}+01$ & \\
\hline $\mathrm{Sr}$ & $3.0 \mathrm{E}+02$ & $7.5 \mathrm{E}+01$ & \\
\hline $\mathrm{Zn}$ & $3.0 \mathrm{E}+02$ & $7.5 \mathrm{E}+01$ & \\
\hline $\mathrm{Zr}$ & $3.0 \mathrm{E}+02$ & $7.5 \mathrm{E}+01$ & \\
\hline $\mathrm{U}$ & $2.5 \mathrm{E}+03$ & $7.5 \mathrm{E}+01$ & \\
\hline $\mathrm{U}$ & $6.0 \mathrm{E}+01$ & $6.0 \mathrm{E}+01$ & Kinetic Phosphorescence \\
\hline Fluoride & $2.5 \mathrm{E}+02$ & $1.2 \mathrm{E}+02$ & \multirow{6}{*}{$\begin{array}{l}\text { Ion Chromatography } \\
\text { (water-soluble species) }\end{array}$} \\
\hline Nitrite & $2.5 \mathrm{E}+02$ & $1.2 \mathrm{E}+02$ & \\
\hline Nitrate & $2.5 \mathrm{E}+02$ & $1.2 \mathrm{E}+02$ & \\
\hline Phosphate & $2.5 \mathrm{E}+02$ & $1.2 \mathrm{E}+02$ & \\
\hline Sulfate & $2.5 \mathrm{E}+02$ & $1.2 \mathrm{E}+02$ & \\
\hline Oxalate & $8.0 \mathrm{E}+02$ & $4.0 \mathrm{E}+02$ & \\
\hline Hydroxide & NA & $1 \mathrm{E}-01 \mathrm{M}$ & Titration \\
\hline
\end{tabular}




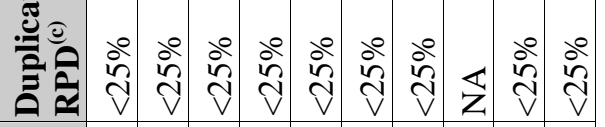

荾

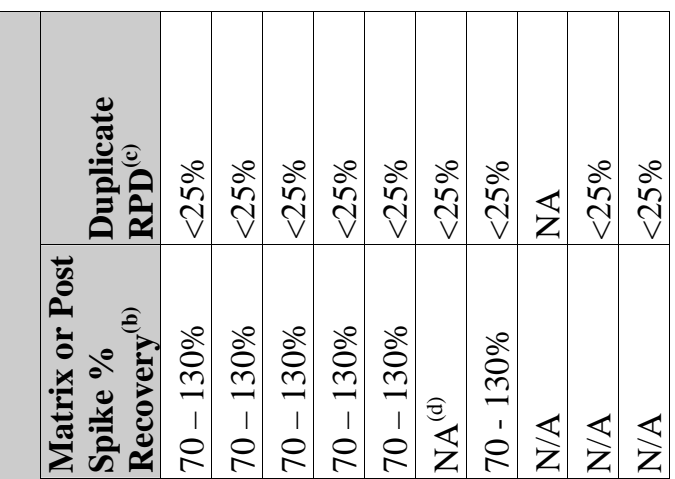

$\frac{n}{2}$
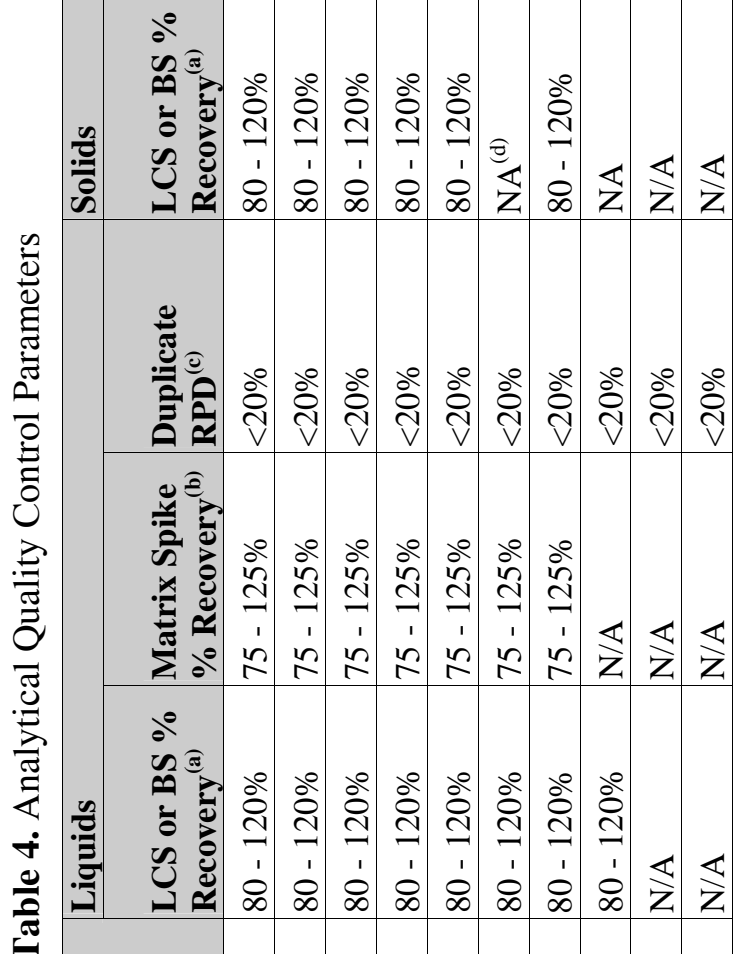

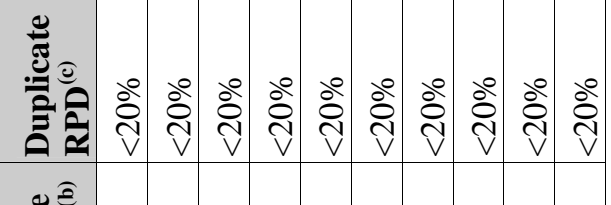

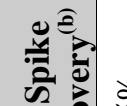

•

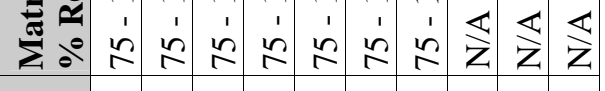

बe

की

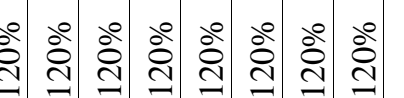

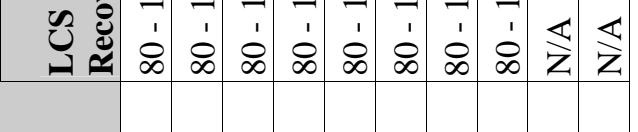

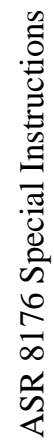

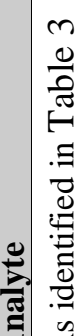

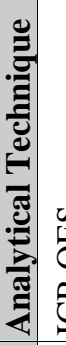

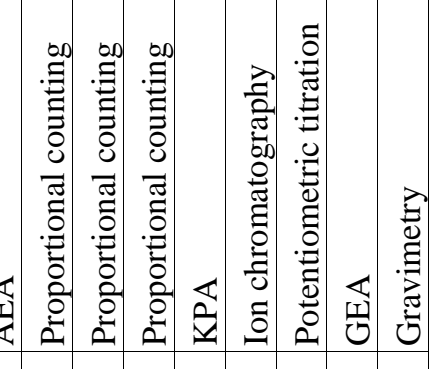

윤

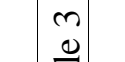

啇

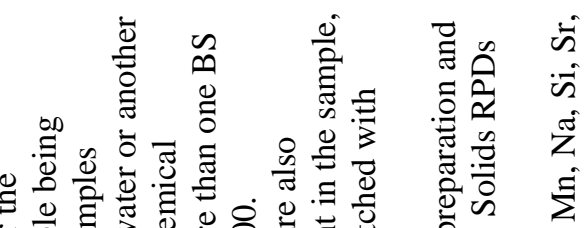

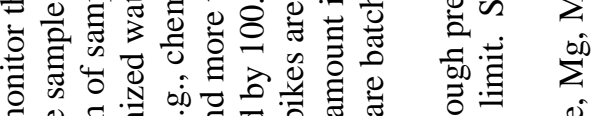

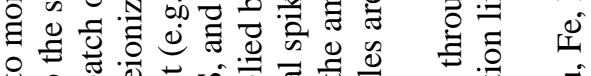

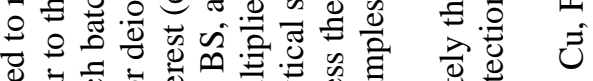

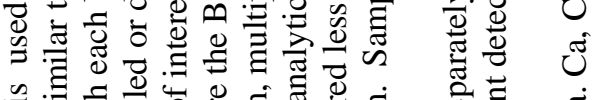

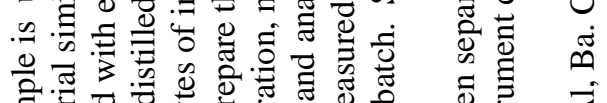

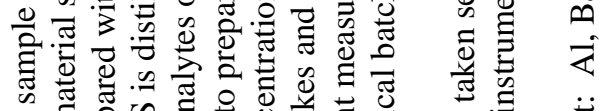

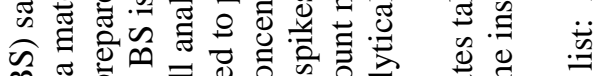
صీ.

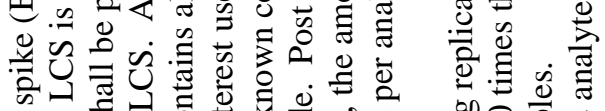

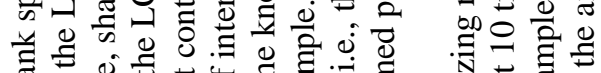

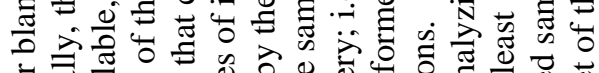

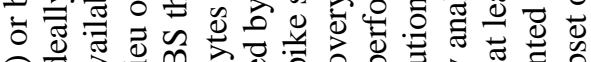

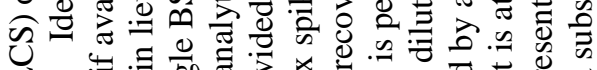

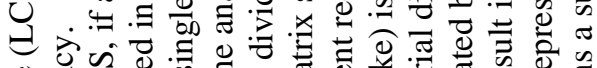

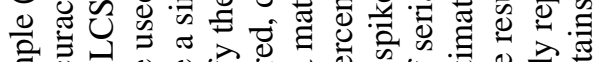

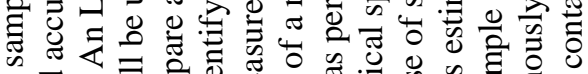

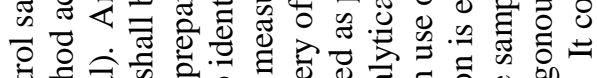

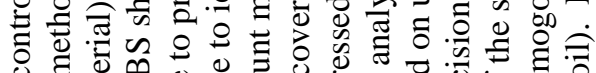

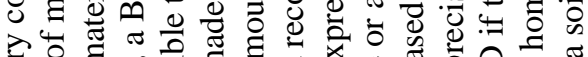

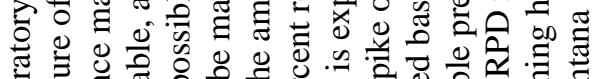

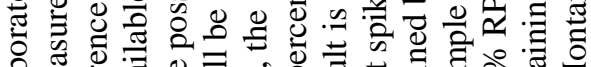

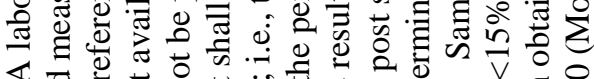

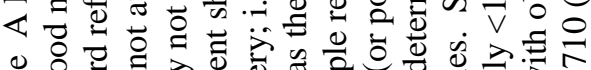

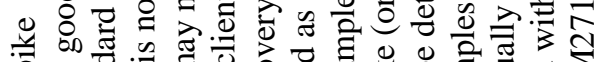
की

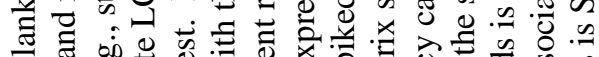

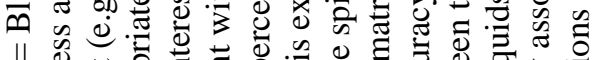

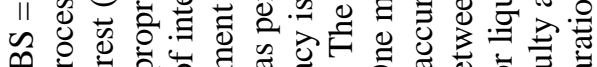

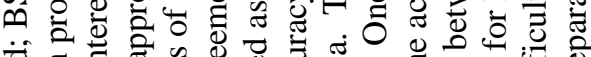

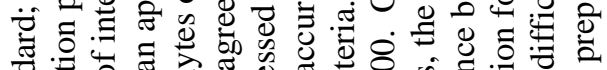
卷

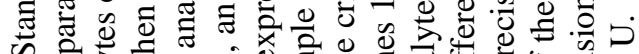

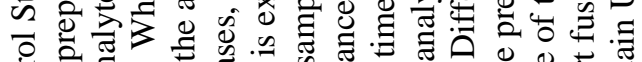

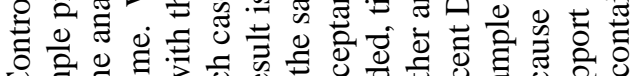

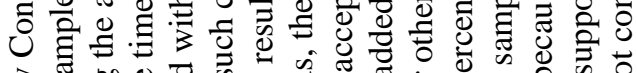
त्र

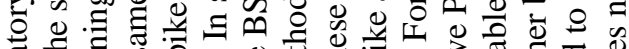

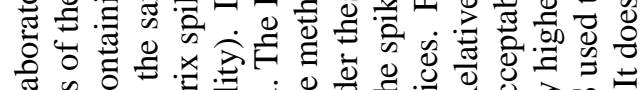

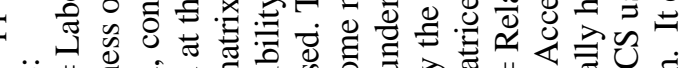

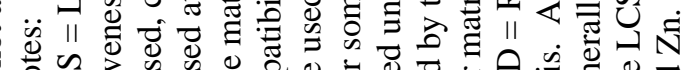

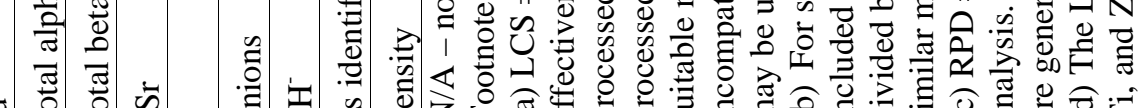

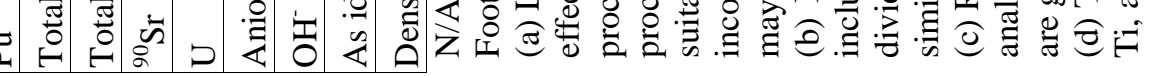


Requestor --- Complete all fiełds on this COVER PAGE, unless specified as optional or ASR is a revision

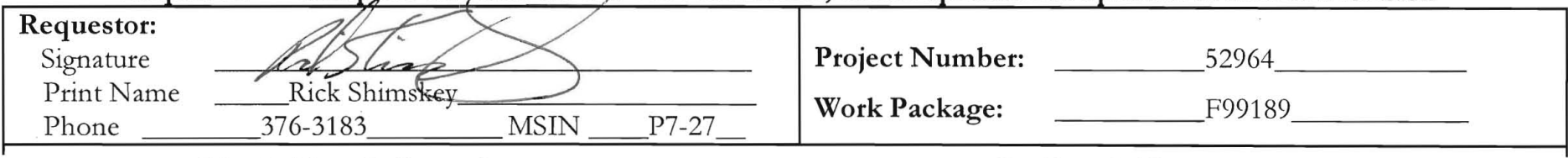

Matrix Type Information

- Liquids: X Aqueous $\square$ Organic $\square$ Multi-phase

- Solids: $\square$ Soil X Sludge $\square$ Sediment

$\square$ Glass $\quad \square$ Filter $\quad \square$ Metal

$\square$ Smear $\quad \square$ Organic $\quad \square$ Other

- Other: $\quad \square$ Solid/Liquid Mixture, Slurry

$\square$ Gas $\quad \square$ Biological Specimen

(If sample matrices vary, specify on Request Page)

\section{Disposal Information}

- Disposition of Virgin Samples:

Virgin samples are returned to requestor unless archiving provisions are made with receiving group!

If archiving, provide:

Archiving Reference Doc:

- Disposition of Treated Samples:

$\mathrm{X}$ Dispose $\square$ Return

Data Reporting Information

- Is Work Associated with a Fee-Based

Milestone? X No $\square$ Yes

If yes, milestone due date:

- Preliminary Results Requested, As Available? $\square$ No X Yes
- Data Reporting Level

X ASO-QAP-001 (Equivalent to HASQARD).

Minimum data report.

$\square$ Project Specific Requirements:

Contact ASO Lead or List Reference

Document:
QA/Special Requirements

- QA Plan:

X ASO-QAP-001, Rev. 6 (Equivalent to HASQARD)

$\mathrm{X}$ Additional QA Requirements, List Document Below:

Reference Doc Number:_RPP_WTP-QA-005, Rev. 2_

- Field COC Submitted? X No $\square$ Yes

- Lab COC Required? X No $\square$ Yes

- Sample/Container Inspection Documentation Required? $\mathrm{X}$ No $\square$ Yes

- Hold Time: X No $\square$ Yes

If $Y e s$,

Contact ASO

Lead before

submitting

Samples

- Special Storage Requirements:

X None $\square$ Refrigerate $\square$ Other, Specify:

- Data Requires ASO Quality Engineer Review? X No $\square$ Yes

\section{Waste Designation Information $M J S, B M O, P K R$}

- Sample Information Check List Attached? X No $\square$ Yes If no, Reference Doc Attached:

or, Previous ASR Number: 8035 and 8078
Does the Waste Designation Documentation Indicate Presence of PCBs? $\mathrm{X}$ No $\square$ Yes

or, Previous RPL Number:

Send Report To:

Rick Shimskey

MSIN

P7-27

Matt Edwards

MSIN

P7-25

Additional or Special Instructions_The requirements of Statement of Work, RPP-WTP-QA-005, Rev. 2, apply to this work. Task-specific Quality Control criteria are attached. Reference Document (i.e., TP-RPP-WTP____

Receiving and Login Information (to be completed by ASO staff)

Date Delivered:

Delivered By (optional)

Time Delivered (optional)

Group ID (optional)

CMC Waste Sample?

$\frac{6 / 19108}{\text { Nicole Green }}$

$\overline{\text { RPP-WTP/Task No: [ ] }}$

X No $\square$ Yes
Received By:

ASR Number:

8176

Rev:

00

RPL Numbers:

08-02059 to 08-02076 

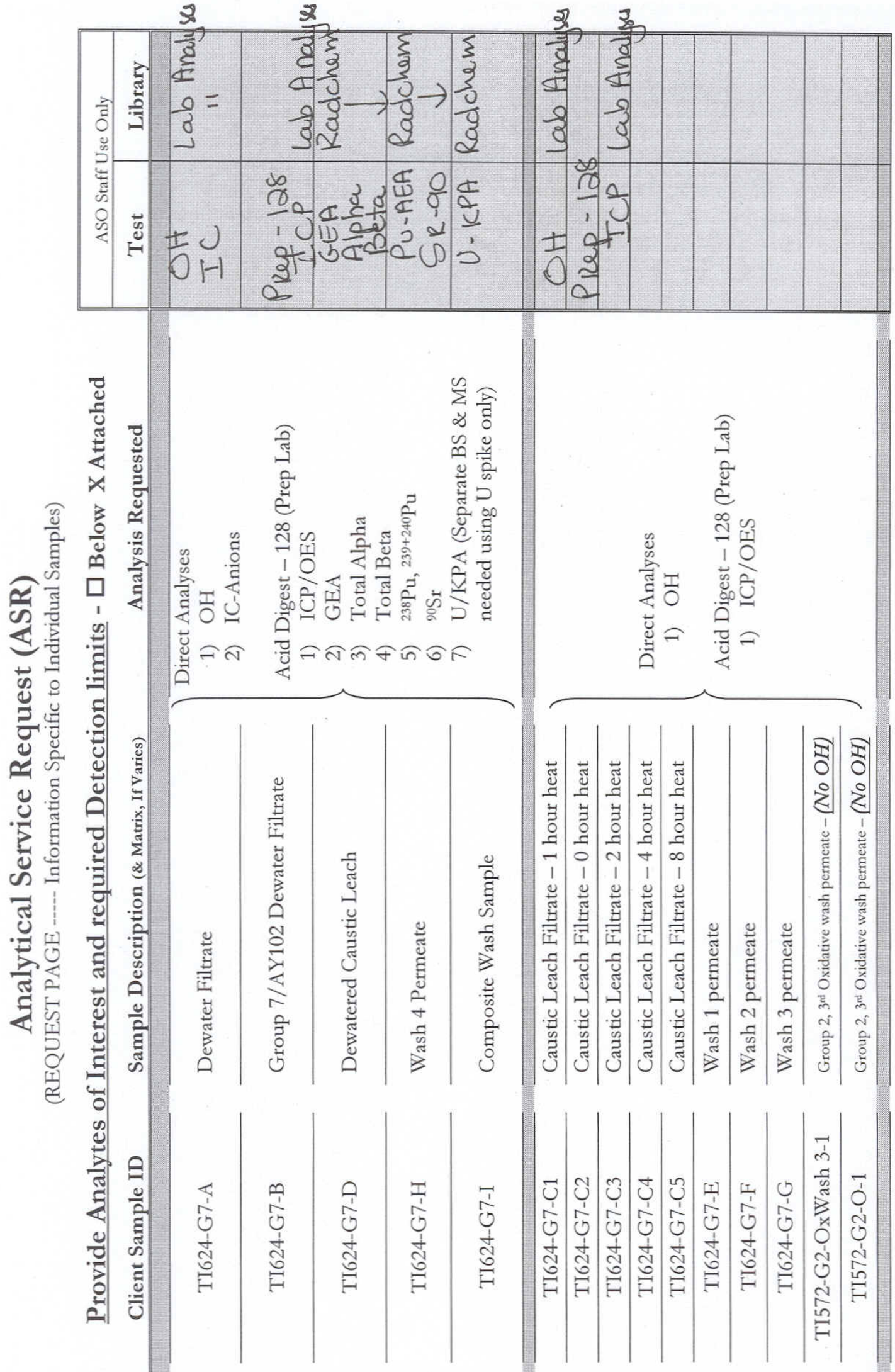

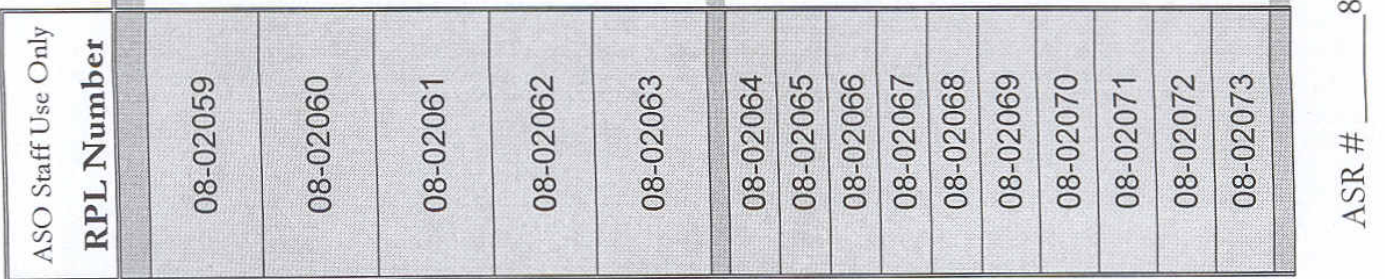




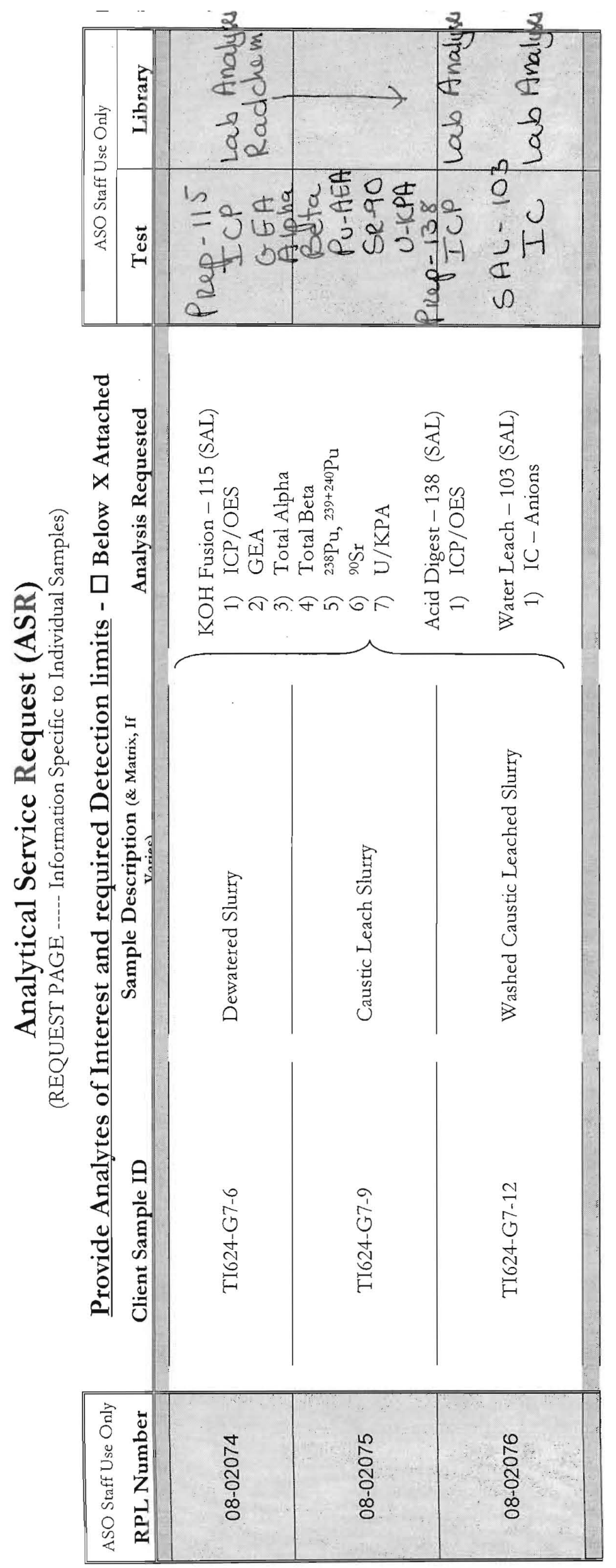

WTP-RPT-169

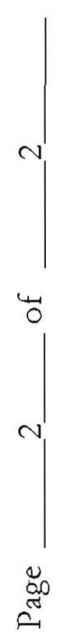


Battelle PNNL/RS\&E/Inorganic Analysis ... ICP-OES Analysis Report PO Box 999, Richland, Washington 99352

Project / WP\#: 52964 / F99189

ASR\#: $\quad 8176$

Client: $\quad$ R. Shimskey

Total Samples: $\quad 3$ (solid)

\begin{tabular}{|c|c|c|}
\hline & First & Last \\
\hline RPL\#: & 08-02074 & $08-02076$ \\
\hline Client ID: & TI624-G7-6 & TI624-G7-12 \\
\hline
\end{tabular}

Procedure: $\quad$ RPG-CMC-211, "Determination of Elemental Composition by Inductively Coupled Argon Plasma Optical Emission Spectrometry (ICP-OES)", Rev 2.

Analyst: $\quad \underline{\text { J. Deschane }}$

Analysis Date (File): $\quad \underline{07-18-2008}$ (C0148)

See Chemical Measurement Center 98620 file: $\underline{\text { ICP-325-405-3 }}$

(Calibration and Maintenance Records)

M\&TE Number: $\quad \underline{\text { N827583 }}$ (ICP-OES instrument) $\underline{\text { M19445 }}$ (Mettler AT400 Balance)
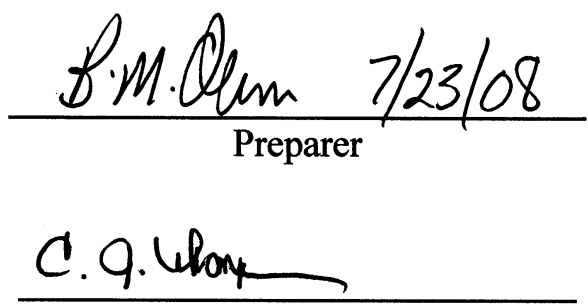

Review and Concur 


\section{Battelle PNNL/RS\&E/Inorganic Analysis ... ICP-OES Analysis Report}

Three samples submitted under Analytical Service Request (ASR) 8176 were analyzed by ICPOES. The samples were prepared in the Shielded Analytical Laboratory (SAL) following RPL fusion procedure PNL-ALO- 115 using a nominal 0.2 grams of sample. The samples were dried to constant mass prior to undergoing fusion and then diluted to a final volume of $100 \mathrm{~mL}$.

Analytes of interest (AOIs) were specified in the ASR, and are listed in the upper section of the attached ICP-OES Data Report. The quality control (QC) results for these AOIs have been evaluated and are presented below. Analytes other than AOIs are reported in the bottom section of the report, but have not been fully evaluated for QC performance. The results are given as $\mu \mathrm{g} / \mathrm{g}$ for each detected analyte, and have been adjusted for all laboratory processing factors and instrument dilutions.

Calibration of the ICP-OES was done following the manufacturer's recommended calibration procedure and using multi-analyte custom standard solutions traceable to the National Institute of Standards and Technology (NIST). Midrange calibration verification standards (MCVA and MCVB) were used to verify acceptance of the two-point calibration curves obtained for each analyte, and also used for continuing calibration verification.

Minimum Method Detection Limit (MDL) values were specified in the ASR. Except for Al, Fe, and $\mathrm{Na}, \mathrm{MDL}$ levels were met for all AOIs. Because of known impurities of these analytes in the 115 fusion flux, the MDL values for these analytes have been set artificially high to account for these impurity levels. It should be noted, however, that measured levels of these analytes in the samples exceeded the requested MDL levels.

The controlling documents were ASO-QAP-001, and the client supplied RPP-WTP-QA-005, Rev. 2, and ASR 8176 Special Instructions. Instrument calibrations, QC checks and blanks (e.g., ICV/ICB, CCV/CCB, LLS, ICS), post-spike, laboratory control standard (LCS), duplicate, and serial dilution were conducted during the analysis run. The LCS was prepared using a nominal 0.2 grams of SRM-2710 (Montana Soil).

\section{Preparation Blank (PB):}

A preparation blank (reagents only) was prepared for the fusion process. The concentrations of all AOIs were within the acceptance criteria of $\leq \mathrm{EQL}$ (estimated quantitation level) or less than $\leq 5 \%$ of the concentration in the sample.

Blank Spike (BS)/Laboratory Control Sample (LCS):

An LCS (Montana Soil) was prepared for the fusion process. Recovery values are listed for all analytes included in the spike that were measured at or above the EQL. The recovery values were within the acceptance criterion of $80 \%$ to $120 \%$ for all AOIs meeting the above requirement.

Matrix-Spiked Sample:

No matrix spike sample was provided for analysis. 


\section{Battelle PNNL/RS\&E/Inorganic Analysis ... ICP-OES Analysis Report}

\section{Duplicate Relative Percent Difference (RPD):}

A duplicate was prepared for the sample batch. RPDs are listed for all analytes that were measured at or above the EQL. Except for zirconium ( 56\%), the RPDs were within the client acceptance criterion of $\leq 25 \%$ for all AOIs meeting the above requirement. The reason for the high RPD for zirconium is suspected to be from precipitation of zirconiumphosphate resulting from the high phosphorous levels in the samples. As a result, the zirconium values for the present samples should be considered as suspect low.

\section{Post-Spike/Analytical Spike Sample (A component):}

An analytical spike (A component) was conducted for the sample batch. Recovery values are listed for all analytes in the spike that were measured at or above the EQL, and that had a spike concentration $\geq 25 \%$ of that in the sample. The recovery values were within the client acceptance criterion of $70 \%$ to $130 \%$ for all AOIs meeting the above requirements.

\section{Post Spike/Analytical Spike Sample (B component):}

An analytical spike (B component) was conducted for the sample batch. Recovery values are listed for all analytes in the spike that were measured at or above the EQL, and that had a spike concentration $\geq 25 \%$ of that in the sample. The recovery values were within the client acceptance criterion of $70 \%$ to $130 \%$ for all AOIs meeting the above requirements.

\section{Serial dilution:}

Five-fold serial dilution was conducted for the sample batch. Percent differences (\%Ds) are listed for all analytes that had a concentration at or above the EQL in the diluted sample. Except for zirconium ( $14 \%)$, the $\%$ Ds were within the acceptance criterion of $\leq 10 \%$ for all AOIs meeting the above requirement. The reason for the high $\% \mathrm{D}$ for zirconium is not clear. A serial dilution test on Sample 08-02075, which had a lower zirconium content, was within the $10 \%$ criterion.

\section{Other QC:}

All other instrument-related QC tests for the AOIs passed within the appropriate acceptance criteria.

\section{Comments:}

1) The "Final Results" have been corrected for all laboratory dilutions performed on the samples during processing and analysis, unless specifically noted.

2) Instrument detection limits (IDL) and estimated quantitation limits (EQL) shown are for acidified water. Detection limits for other matrices may be determined if requested. Method detection limits (MDL) can be estimated by multiplying the IDL by the "Multiplier". The estimated quantitation limit (EQL) for each concentration value can be obtained by multiplying the EQL by the "Multiplier".

3) Routine precision and bias is typically $\pm 15 \%$ or better for samples in dilute, acidified water (e.g. $2 \% \mathrm{v} / \mathrm{v}$ $\mathrm{HNO}_{3}$ or less) at analyte concentrations $>\mathrm{EQL}$ up to the upper calibration level. This also presumes that the total dissolved solids concentration in the sample is less than $5000 \mu \mathrm{g} / \mathrm{mL}(0.5$ per cent by weight). Note that bracketed values listed in the data report are within the MDL and the EQL, and have potential uncertainties greater than $15 \%$. Concentration values $<$ MDL are listed as "- -". Note, that calibration and QC standards are validated to a precision of $\pm 10 \%$.

4) Absolute precision, bias and detection limits may be determined on each sample if required by the client. The maximum number of significant figures for all ICP measurements is two. 


\section{Battelle PNNL/RS\&E/Inorganic Analysis ... ICP-OES Analysis Report}

5) Analytes included in the spike A component (for the AS/PS) are; $\mathrm{Ag}, \mathrm{Al}, \mathrm{As}, \mathrm{B}, \mathrm{Ba}, \mathrm{Be}, \mathrm{Bi}, \mathrm{Ca}, \mathrm{Cd}, \mathrm{Co}, \mathrm{Cr}$, $\mathrm{Cu}, \mathrm{Fe}, \mathrm{K}, \mathrm{Li}, \mathrm{Mg}, \mathrm{Mn}, \mathrm{Mo}, \mathrm{Na}, \mathrm{Ni}, \mathrm{P}, \mathrm{Pb}, \mathrm{Sb}, \mathrm{Se}, \mathrm{Si}, \mathrm{Sn}, \mathrm{Sr}, \mathrm{Ta}, \mathrm{Ti}, \mathrm{Tl}, \mathrm{V}, \mathrm{W}, \mathrm{Y}, \mathrm{Zn}$, and Zr. Analytes included in the spike B component are; Ce, Dy, Eu, La, Nd, Pd, Rh, Ru, S, Te, Th, and U. 


\begin{tabular}{|c|c|c|c|c|c|c|c|}
\hline & & Run Date > & $7 / 18 / 2008$ & $7 / 18 / 2008$ & $7 / 18 / 2008$ & $7 / 18 / 2008$ & $7 / 18 / 2008$ \\
\hline & & Multiplier > & 1895.2 & 1689.2 & 1912.8 & 1785.1 & 2295.7 \\
\hline & & & 08-02074- & 08-02074- & 08-02074- & 08-02075- & 08-02076- \\
\hline & & RPL/LAB > & 115-B @5 & 115-S@5 & 115-D @5 & 115-S@5 & 115-S@5 \\
\hline Instr. Det. & Est. Quant. & & & \multirow{2}{*}{\multicolumn{2}{|c|}{ TI624-G7-6 }} & & \\
\hline Limit (IDL) & Limit (EQL) & Client ID > & Prep Blank & & & T1624-G7-9 & II624-G7-12 \\
\hline$(\mu \mathrm{g} / \mathrm{mL})$ & $(\mu \mathrm{g} / \mathrm{mL})$ & (Analyte) & $(\mu \mathrm{g} / \mathrm{g})$ & $(\mu \mathrm{g} / \mathrm{g})$ & $(\mu \mathrm{g} / \mathrm{g})$ & $(\mu \mathrm{g} / \mathrm{g})$ & $(\mu \mathrm{g} / \mathrm{g})$ \\
\hline 0.2900 & 2.900 & Al & $=$ & 45,000 & 46,600 & 23,400 & 46,100 \\
\hline 0.0077 & 0.077 & $B$ & {$[17]$} & {$[36]$} & {$[44]$} & {$[36]$} & {$[35]$} \\
\hline 0.0240 & 0.240 & $B i$ & -. & 1,150 & 1,160 & 852 & 2,100 \\
\hline 0.0029 & 0.029 & $\mathrm{Cd}$ & [21] & 136 & 151 & 108 & 244 \\
\hline 0.0024 & 0.024 & $\mathrm{Cr}$ & {$[7.2]$} & 1,770 & 1,820 & 1,280 & 2,820 \\
\hline 0.1800 & 1.800 & $\mathrm{Fe}$ & - & 98,000 & 101,000 & 64,600 & 178,000 \\
\hline 4.0000 & 40.000 & $\mathrm{~K}$ & na & na & na & na & na \\
\hline 0.0011 & 0.011 & $M n$ & {$[6.9]$} & 14,500 & 14,800 & 11,200 & 27,100 \\
\hline 1.9000 & 19.000 & $\mathrm{Na}$ & -- & 168,000 & 165,000 & 174,000 & 111,000 \\
\hline 0.0400 & 0.400 & $\mathrm{Ni}$ & na & na & na & na & na \\
\hline 0.0540 & 0.540 & $P$ & - & 25,000 & 25,100 & 17,900 & 12,500 \\
\hline 0.3300 & 3.300 & $\mathrm{~s}$ & -- & 6,250 & 6,400 & {$[3,100]$} & {$[1,800]$} \\
\hline 0.2300 & 2.300 & $\mathrm{Si}$ & -- & 23,200 & 23,600 & 16,300 & 39,900 \\
\hline 0.0003 & 0.005 & $\mathrm{Sr}$ & {$[0.69]$} & 978 & 987 & 747 & 1,800 \\
\hline 0.0410 & 0.820 & $\mathrm{u}$ & -- & 13,500 & 13,500 & 9,830 & 24,900 \\
\hline 0.0032 & 0.064 & $\mathrm{Zn}$ & .. & 267 & 255 & 211 & 469 \\
\hline 0.0035 & 0.035 & $\operatorname{Zr}(a)$ & .- & 1,550 & 869 & 86.5 & 258 \\
\hline
\end{tabular}

\section{Other Analytes}

\begin{tabular}{|c|c|c|c|c|c|c|c|}
\hline 0.0015 & 0.015 & Ag &.- & 298 & 495 & 257 & 351 \\
\hline 0.0390 & 0.390 & As & - & - & - & - & - \\
\hline
\end{tabular}

\begin{tabular}{|c|c|c|c|c|c|c|c|}
\hline 0.0015 & 0.015 & $\mathrm{Ag}$ & 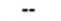 & 298 & 490 & $20 \%$ & \\
\hline 0.0390 & 0.390 & As & -- & - & -- & .. & -- \\
\hline 0.0005 & 0.010 & $\mathrm{Ba}$ & [1.2] & 626 & 628 & 465 & 1,180 \\
\hline 0.0000 & 0.000 & $\mathrm{Be}$ & - & 1.02 & 0.977 & {$[0.75]$} & 1.60 \\
\hline 1.1000 & 11.000 & $\mathrm{Ca}$ & - & {$[7,000]$} & {$[7,000]$} & {$[5,300]$} & {$[13,000]$} \\
\hline 0.0083 & 0.083 & $\mathrm{Ce}$ & - & 666 & 661 & 467 & 1,210 \\
\hline 0.0027 & 0.027 & Co & - & [38] & [42] & [23] & 65.6 \\
\hline 0.0020 & 0.020 & $\mathrm{Cu}$ & -- & 250 & 229 & 183 & 418 \\
\hline 0.0029 & 0.029 & Dy & - & -. &.- & - & -- \\
\hline 0.0004 & 0.004 & Eu & - & 14.3 & 15.8 & 10.6 & 27.2 \\
\hline 0.0027 & 0.027 & La & - & 758 & 735 & 612 & 1,450 \\
\hline 0.0019 & 0.019 & $\mathrm{Li}$ & {$[7.0]$} & 91.0 & 94.3 & 71.9 & 154 \\
\hline 0.0052 & 0.052 & $\mathrm{Mg}$ & - & 1,720 & 1,720 & 1,350 & 3,260 \\
\hline 0.0072 & 0.072 & Mo & - & [21] & [21] & - & [31] \\
\hline 0.0062 & 0.062 & $\mathrm{Nd}$ & -- & 1,080 & 1,070 & 889 & 2,070 \\
\hline 0.0320 & 0.320 & $\mathrm{~Pb}$ & - & 4,000 & 3,890 & 3,500 & 7,710 \\
\hline 0.0064 & 0.064 & $\mathrm{Pd}$ & -- & -- & -- & -- & .. \\
\hline 0.0130 & 0.130 & $\mathrm{Rh}$ & -- & [29] & [30] & -- &. \\
\hline 0.0067 & 0.067 & $\mathrm{Ru}$ & .- & 267 & 251 & 174 & 453 \\
\hline 0.0310 & 0.310 & $\mathrm{Sb}$ &.- & $=$ & -- &.. & - \\
\hline 0.1100 & 1.100 & Se & $*$ & - & - & .. & -- \\
\hline 0.0250 & 0.250 & Sn & - & [59] & - & 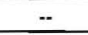 & [89] \\
\hline 0.0200 & 0.200 & $\mathrm{Ta}$ & -- & - & - & - & -- \\
\hline 0.0260 & 0.260 & $\mathrm{Te}$ & - & [140] & [180] & [120] & [320] \\
\hline 0.0084 & 0.084 & Th & .- & 490 & 504 & 262 & 886 \\
\hline 0.0005 & 0.005 & $\mathrm{Ti}$ & - & 214 & 209 & 156 & 412 \\
\hline 0.0300 & 0.300 & $\mathrm{TI}$ & - & - &.. & - & - \\
\hline 0.0032 & 0.032 & v & -- & {$[18]$} & [19] & [15] & [29] \\
\hline 0.0210 & 0.210 & w & - & {$[250]$} & {$[260]$} & [170] & [380] \\
\hline 0.0003 & 0.003 & $\mathrm{Y}$ & - & 102 & 103 & 77.3 & 187 \\
\hline
\end{tabular}

1) "--" indicates the value is $<M D L$. The method detection limit (MDL) $=I D L$ times the "multiplier"

near the top of each column. The estimated sample quantitation limit $=E Q L$ (in Column 2)

times the "multiplier". Overall error for values $\geq E Q L$ is estimated to be within $\pm 15 \%$.

2) Values in brackets [ ] are $2 M D L$ but $<E Q L$, with errors likely to exceed $15 \%$.

$n a=$ not applicable; $\mathrm{KOH}$ flux and $\mathrm{Ni}$ crucible or $\mathrm{Na}_{2} \mathrm{O}_{2}$ flux and $\mathrm{Zr}$ crucible for fusion preparations, or Si for $\mathrm{HF}$ assisted digests.

a) Zr values are suspect low from possible precipitation of zirconium phosphate during the fusion process. 


\begin{tabular}{|c|c|c|c|c|c|c|}
\hline Criteria > & $\leq 25 \%$ & $80 \%-120 \%$ & $70 \%-130 \%$ & $70 \%-130 \%$ & $70 \%-130 \%$ & $\leq 10 \%$ \\
\hline QC ID > & $\begin{array}{c}08-02074 \\
\text { Dup }\end{array}$ & LCS/BS & MS (none) & $\begin{array}{c}08-02074+ \\
\text { AS-A }\end{array}$ & $\begin{array}{c}08-02074+ \\
\text { AS-B }\end{array}$ & $\begin{array}{c}\text { 08-02074 } \\
5 \text {-fold } \\
\text { Serial Dil }\end{array}$ \\
\hline Analytes & RPD $(\%)$ & $\%$ Rec & \%Rec & $\% \operatorname{Rec}$ & \%Rec & $\%$ Diff \\
\hline Al & 3.4 & 93 & & 101 & & 5.6 \\
\hline B & & & & 101 & & \\
\hline $\mathrm{Bi}$ & 0.6 & & & 92 & & \\
\hline Cd & 10.4 & & & 99 & & \\
\hline $\mathrm{Cr}$ & 3.1 & & & 99 & & 6.3 \\
\hline $\mathrm{Fe}$ & 2.7 & 94 & & 104 & & 6.4 \\
\hline$K$ & na & na & na & na & na & na \\
\hline Mn & 2.1 & 98 & & $\mathrm{nr}$ & & 5.9 \\
\hline $\mathrm{Na}$ & 2.1 & & & 94 & & 5.6 \\
\hline $\mathrm{Ni}$ & na & na & na & na & na & na \\
\hline $\mathbf{P}$ & 0.5 & & & 108 & & 2.5 \\
\hline $\mathrm{S}$ & 2.5 & & & & 98 & \\
\hline $\mathbf{S i}$ & 1.8 & 94 & & 94 & & 3.3 \\
\hline $\mathrm{Sr}$ & 0.9 & & & 101 & & 5.1 \\
\hline $\mathbf{U}$ & 0.3 & & & & 95 & 7.5 \\
\hline $\mathrm{Zn}$ & 4.4 & 97 & & 102 & & \\
\hline $\operatorname{Zr}(\mathrm{a})$ & 56.5 & & & 119 & & 14.1 \\
\hline
\end{tabular}

Other Analytes

\begin{tabular}{|c|c|c|c|c|c|}
\hline $\mathrm{Ag}$ & 49.7 & & 86 & & 9.9 \\
\hline As & & & 98 & & \\
\hline $\mathbf{B a}$ & 0.3 & 90 & 95 & & 5.1 \\
\hline Be & 4.3 & & 98 & & \\
\hline $\mathrm{Ca}$ & & & 96 & & \\
\hline $\mathrm{Ce}$ & 0.8 & & & 93 & \\
\hline Co & & & 99 & & \\
\hline $\mathrm{Cu}$ & 8.9 & 94 & 101 & & 0.3 \\
\hline Dy & & & & 95 & \\
\hline Eu & 9.5 & & & 97 & \\
\hline La & 3.0 & & & 94 & 7.4 \\
\hline $\mathrm{Li}$ & 3.5 & & 95 & & \\
\hline $\mathrm{Mg}$ & 0.2 & 91 & 95 & & 3.2 \\
\hline Mo & & & 99 & & \\
\hline Nd & 1.6 & & & 97 & 22.2 \\
\hline $\mathrm{Pb}$ & 2.7 & 93 & 100 & & 4.7 \\
\hline $\mathrm{Pd}$ & & & & 89 & \\
\hline $\mathbf{R h}$ & & & & 92 & \\
\hline $\mathbf{R u}$ & 6.3 & & & 94 & \\
\hline $\mathrm{Sb}$ & & & 99 & & \\
\hline $\mathrm{Se}$ & & & 99 & & \\
\hline Sn & & & 97 & & \\
\hline $\mathrm{Ta}$ & & & 99 & & \\
\hline $\mathrm{Te}$ & & & & 94 & \\
\hline Th & 2.9 & & & 96 & \\
\hline $\mathrm{Ti}$ & 2.3 & 87 & 96 & & 3.7 \\
\hline $\mathrm{TI}$ & & & 92 & & \\
\hline $\mathbf{V}$ & & & 93 & & \\
\hline$w$ & & & 98 & & \\
\hline $\mathbf{Y}$ & 1.1 & & 95 & & 1.2 \\
\hline
\end{tabular}

Shaded results are outside the acceptance criteria.

$n r=$ spike concentration less than $25 \%$ of sample concentration. Matnix effects can be assessed from the serial dilution.

$\mathrm{na}=$ not applicable; $\mathrm{KOH}$ flux and $\mathrm{Ni}$ crucible or $\mathrm{Na}_{2} \mathrm{O}_{2}$ fiux and $\mathrm{Zr}$ crucible for fusion preparations, or Si for HF assisted digests.

a) Zr values are suspect low from possible precipitation of zirconium phosphate during the kision process. 
Battelle PNNL/RS\&E/Inorganic Analysis ... ICP-OES Analysis Report PO Box 999, Richland, Washington 99352

$\begin{array}{ll}\text { Project / WP\#: } & 52964 \text { / F99189 } \\ \text { ASR\#: } & 8176 \\ \text { Client: } & \text { R. Shimskey } \\ \text { Total Samples: } & \text { 15 (liquid) }\end{array}$

\begin{tabular}{|c|c|c|}
\hline & First & Last \\
\hline RPL\#: & $08-02059$ & $08-02073$ \\
\hline Client ID: & TI624-G7-A & TI572-G2-O-1 \\
\hline
\end{tabular}

Procedure: RPG-CMC-211, "Determination of Elemental Composition by Inductively Coupled Argon Plasma Optical Emission Spectrometry (ICP-OES)", Rev 2.

Analyst: $\quad \underline{J}$. Deschane

Analysis Date (File): $\quad \underline{\text { 07-09-2008 (C0146) }}$

See Chemical Measurement Center 98620 file: $\quad \underline{\text { ICP-325-405-3 }}$

(Calibration and Maintenance Records)

M\&TE Number: $\quad \underline{\text { N827583 }}$ (ICP-OES instrument) M19445 (Mettler AT400 Balance)

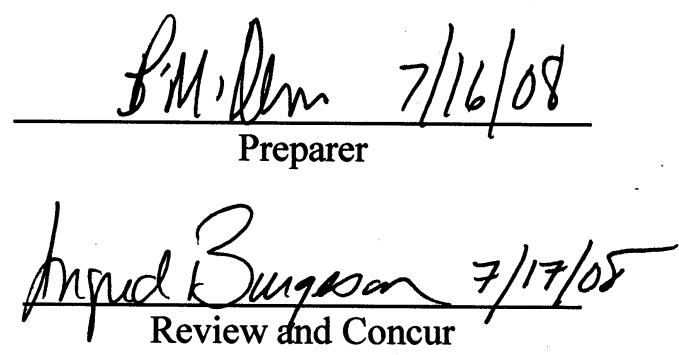


Battelle PNNL/RS\&E/Inorganic Analysis ... ICP-OES Analysis Report

Fifteen samples submitted under Analytical Service Request (ASR) 8176 were analyzed by ICPOES. The samples were prepared in the RPL Sample Receiving and Preparation Laboratory (SRPL) following Procedure RPG-CMC-128 using $1 \mathrm{~mL}$ of sample and diluting to a final volume of approximately $25 \mathrm{~mL}$.

Analytes of interest (AOIs) were specified in the ASR, and are listed in the upper section of the attached ICP-OES Data Report. The quality control (QC) results for these AOIs have been evaluated and are presented below. Analytes other than AOIs are reported in the bottom section of the report, but have not been fully evaluated for QC performance. The results are given as $\mu \mathrm{g} / \mathrm{mL}$ for each detected analyte, and have been adjusted for all laboratory processing factors and instrument dilutions.

Calibration of the ICP-OES was done following the manufacturer's recommended calibration procedure and using multi-analyte custom standard solutions traceable to the National Institute of Standards and Technology (NIST). Midrange calibration verification standards (MCVA and $\mathrm{MCVB}$ ) were used to verify acceptance of the two-point calibration curves obtained for each analyte, and also used for continuing calibration verification.

Minimum Method Detection Limit (MDL) values were specified in the ASR. MDL levels were met for all AOIs.

The controlling documents were ASO-QAP-001, and the client supplied RPP-WTP-QA-005, Rev. 2 and ASR 8176 Special Instructions. Instrument calibrations, QC checks and blanks (e.g., ICV/ICB, CCV/CCB, LLS, ICS), post-spike, blank spike, matrix spike, duplicate, and serial dilution were conducted during the analysis run. The blank spike and matrix spike were prepared using $1 \mathrm{~mL}$ each of BPNL-QC-1A and -2B solutions.

\section{Preparation Blank (PB):}

A preparation blank (reagents only) was prepared for the extraction process. The concentrations of all AOIs were within the acceptance criteria of $\leq \mathrm{EQL}$ (estimated quantitation level) or less than $\leq 5 \%$ of the concentration in the sample.

\section{Blank Spike (BS)/Laboratory Control Sample (LCS):}

A blank spike was prepared for the extraction process. Recovery values are listed for all analytes included in the spike that were measured at or above the EQL. The recovery values were within the acceptance criterion of $80 \%$ to $120 \%$ for all AOIs meeting the above requirement.

\section{Matrix-Spiked Sample:}

A matrix spike was prepared for the extraction process. Recovery values are listed for all analytes included in the spike that were measured at or above the EQL. The recovery values were within the acceptance criterion of $75 \%$ to $125 \%$ for all AOIs meeting the above requirement. 


\section{Battelle PNNL/RS\&E/Inorganic Analysis ... ICP-OES Analysis Report}

\section{Duplicate Relative Percent Difference (RPD):}

A duplicate was prepared for the extraction process. RPDs are listed for all analytes that were measured at or above the EQL. The RPDs were within the acceptance criterion of $\leq 20 \%$ for all AOIs meeting the above requirement.

\section{Post-Spike/Analytical Spike Sample (A component):}

A post spike (A component) was conducted on one sample from the analysis batch. Recovery values are listed for all analytes in the spike that were measured at or above the EQL, and that had a spike concentration $\geq 25 \%$ of that in the sample. The recovery values were within the acceptance criterion of $75 \%$ to $125 \%$ for all AOIs meeting the above requirements.

\section{Post Spike/Analytical Spike Sample (B component):}

A post spike (B component) was conducted on one sample from the analysis batch.

Recovery values are listed for all analytes in the spike that were measured at or above the $\mathrm{EQL}$, and that had a spike concentration $\geq 25 \%$ of that in the sample. The recovery values were within the acceptance criterion of $75 \%$ to $125 \%$ for all AOIs meeting the above requirements.

\section{Serial dilution:}

Five-fold serial dilution was conducted on one sample from the analysis batch. Percent differences (\%Ds) are listed for all analytes that had a concentration at or above the EQL in the diluted sample. The \%Ds were within the acceptance criterion of $\leq 10 \%$ for all AOIs meeting the above requirement.

\section{Other QC:}

All other instrument-related QC tests for the AOIs passed within the appropriate acceptance criteria.

\section{Comments:}

1) The "Final Results" have been corrected for all laboratory dilutions performed on the samples during processing and analysis, unless specifically noted.

2) Instrument detection limits (IDL) and estimated quantitation limits (EQL) shown are for acidified water. Detection limits for other matrices may be determined if requested. Method detection limits (MDL) can be estimated by multiplying the IDL by the "Multiplier". The estimated quantitation limit (EQL) for each concentration value can be obtained by multiplying the EQL by the "Multiplier".

3) Routine precision and bias is typically $\pm 15 \%$ or better for samples in dilute, acidified water (e.g. $2 \% \mathrm{v} / \mathrm{v}$ $\mathrm{HNO}_{3}$ or less) at analyte concentrations $>\mathrm{EQL}$ up to the upper calibration level. This also presumes that the total dissolved solids concentration in the sample is less than $5000 \mu \mathrm{g} / \mathrm{mL}$ ( 0.5 per cent by weight). Note that bracketed values listed in the data report are within the MDL and the EQL, and have potential uncertainties greater than $15 \%$. Concentration values $<$ MDL are listed as "- .". Note, that calibration and QC standards are validated to a precision of $\pm 10 \%$.

4) Absolute precision, bias and detection limits may be determined on each sample if required by the client. The maximum number of significant figures for all ICP measurements is two.

5) Analytes included in the spike $\mathrm{A}$ component (for the $\mathrm{AS} / \mathrm{PS}$ ) are; $\mathrm{Ag}, \mathrm{Al}, \mathrm{As}, \mathrm{B}, \mathrm{Ba}, \mathrm{Be}, \mathrm{Bi}, \mathrm{Ca}, \mathrm{Cd}, \mathrm{Co}, \mathrm{Cr}$, $\mathrm{Cu}, \mathrm{Fe}, \mathrm{K}, \mathrm{Li}, \mathrm{Mg}, \mathrm{Mn}, \mathrm{Mo}, \mathrm{Na}, \mathrm{Ni}, \mathrm{P}, \mathrm{Pb}, \mathrm{Sb}, \mathrm{Se}, \mathrm{Si}, \mathrm{Sn}, \mathrm{Sr}, \mathrm{Ta}, \mathrm{Ti}, \mathrm{Tl}, \mathrm{V}, \mathrm{W}, \mathrm{Y}, \mathrm{Zn}$, and $\mathrm{Zr}$. Analytes included in the spike B component are; Ce, Dy, Eu, La, Nd, Pd, Rh, Ru, S, Te, Th, and U. 


\begin{tabular}{|c|c|c|c|c|c|c|c|c|c|c|}
\hline & & & & & & & & & & \\
\hline & & \multirow{2}{*}{\begin{tabular}{l|} 
Run Date > \\
Multiplier $>$ \\
\end{tabular}} & \multirow{2}{*}{$\begin{array}{c}7 / 9 / 2008 \\
24.7\end{array}$} & \multirow{2}{*}{$\begin{array}{c}7 / 9 / 2008 \\
120.4\end{array}$} & \multirow{2}{*}{$\begin{array}{c}7 / 9 / 2008 \\
122.8\end{array}$} & \multirow{2}{*}{$\begin{array}{c}7 / 9 / 2008 \\
122.3\end{array}$} & \multirow{2}{*}{$\begin{array}{c}7 / 9 / 2008 \\
124.3\end{array}$} & \multirow{2}{*}{$\begin{array}{c}7 / 9 / 2008 \\
24.7\end{array}$} & \multirow{2}{*}{$\begin{array}{c}7 / 9 / 2008 \\
25.2\end{array}$} & 7/9/2008 \\
\hline & & & & & & & & & & 125.8 \\
\hline & & RPL/LAB > & BLK-02059 & $\begin{array}{c}08-02059 \\
\text { @5 }\end{array}$ & $\begin{array}{c}\text { DUP-02059 } \\
\text { @5 }\end{array}$ & $\begin{array}{c}08-02060 \\
\text { @5 }\end{array}$ & $\begin{array}{c}\text { 08-02061 } \\
\text { @5 }\end{array}$ & 08-02062 & $08-02063$ & $\begin{array}{c}08-02063 \\
@ 5\end{array}$ \\
\hline $\begin{array}{l}\text { Instr. Det. } \\
\text { Limit (IDL) }\end{array}$ & $\begin{array}{l}\text { Est. Quant. } \\
\text { Limit (EQL) }\end{array}$ & Client ID > & Prep Blank & \multicolumn{2}{|c|}{ TI624-G7-A } & TI624-G7-B & II624-G7-D & TI624-G7-H & \multicolumn{2}{|c|}{ TI624-G7-I } \\
\hline$(\mu \mathrm{g} / \mathrm{mL})$ & $(\mu \mathrm{g} / \mathrm{mL})$ & (Analyte) & $(\mu \mathrm{g} / \mathrm{mL})$ & $(\mu \mathrm{g} / \mathrm{mL})$ & $(\mu \mathrm{g} / \mathrm{mL})$ & $(\mu \mathrm{g} / \mathrm{mL})$ & $(\mu \mathrm{g} / \mathrm{mL})$ & $(\mu \mathrm{g} / \mathrm{mL})$ & $(\mu \mathrm{g} / \mathrm{mL})$ & $(\mu \mathrm{g} / \mathrm{mL})$ \\
\hline 0.0060 & 0.060 & Al & -- & 157 & 154 & 11.4 & 7,370 & 440 & 1,870 & \\
\hline 0.0048 & 0.096 & $B$ & {$[1.4]$} & 21.1 & 19.7 & 20.5 & 17.5 & {$[1.5]$} & 3.25 & \\
\hline 0.0300 & 0.300 & $\mathrm{Bi}$ & {$[3.5]$} & -- & -- & .. & -- & {$[2.7]$} & {$[2.9]$} & \\
\hline 0.0037 & 0.037 & $\mathrm{Cd}$ & {$[0.30]$} & {$[1.5]$} & {$[1.4]$} & {$[1.3]$} & {$[1.4]$} & {$[0.26]$} & {$[0.26]$} & \\
\hline 0.0017 & 0.017 & $\mathrm{Cr}$ & -- & 23.5 & 23.2 & 44.7 & 110 & 7.00 & 28.8 & \\
\hline 0.0019 & 0.038 & $\mathrm{Fe}$ & {$[0.66]$} & {$[0.62]$} & {$[0.69]$} & {$[1.8]$} & 6.24 & {$[0.37]$} & 1.13 & \\
\hline 0.0720 & 0.720 & $\mathrm{~K}$ & [5.1] & 130 & 144 & 303 & 287 & 32.6 & 154 & \\
\hline 0.0002 & 0.005 & $\mathrm{Mn}$ & {$[0.014]$} & {$[0.17]$} & {$[0.16]$} & [0.22] & {$[0.15]$} & {$[0.031]$} & {$[0.057]$} & \\
\hline 0.0160 & 0.320 & $\mathrm{Na}$ & $-\cdot$ & 91,700 & 91,900 & 86,000 & 108,000 & 8,800 & over-range & 37,000 \\
\hline 0.0024 & 0.024 & $\mathrm{Ni}$ &.. & -- & -. & .- & $*$ & -- & -. & \\
\hline 0.0500 & 0.500 & $\mathbf{P}$ & {$[1.5]$} & 4,550 & $\mathbf{4 , 4 9 0}$ & 4,960 & 1,500 & 726 & 2,520 & \\
\hline 0.1600 & 1.600 & $\mathbf{s}$ & $-\cdot$ & 5,980 & 5,840 & 4,390 & 2,310 & 129 & 578 & \\
\hline 0.0056 & 0.056 & Si & -- & -- & -- & {$[1.7]$} & 50.0 & 8.35 & 20.1 & \\
\hline 0.0001 & 0.002 & $\mathrm{Sr}$ & {$[0.024]$} & {$[0.12]$} & {$[0.096]$} & 0.205 & {$[0.011]$} & {$[0.0042]$} & {$[0.0037]$} & \\
\hline 0.0320 & 0.320 & u &.- & 135 & 137 & 3,840 & 51.7 & 11.1 & 24.0 & \\
\hline 0.0028 & 0.056 & $\mathrm{Zn}$ & {$[0.86]$} & {$[1.0]$} & [0.99] & {$[0.88]$} & 12.3 & {$[0.79]$} & 2.09 & \\
\hline 0.0011 & 0.011 & $\mathrm{Zr}$ &.- & {$[0.16]$} &.- & {$[1.3]$} & {$[0.31]$} & 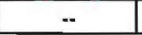 & {$[0.15]$} & \\
\hline \multicolumn{11}{|c|}{ Other Analytes } \\
\hline 0.0021 & 0.021 & $\mathrm{Ag}$ & -- & -- & -- & 10.9 & 5.34 & [0.32] & 1.45 & \\
\hline 0.0520 & 0.520 & As &.. &.- & -- &.- & .- &.- & -- & \\
\hline 0.0003 & 0.005 & $\mathrm{Ba}$ & [0.021] & [0.19] & {$[0.15]$} & [0.19] & {$[0.16]$} & {$[0.024]$} & {$[0.071]$} & \\
\hline 0.0001 & 0.001 & $\mathrm{Be}$ & $-\cdot$ & -- &.- & {$[0.0064]$} & {$[0.022]$} & -. & {$[0.0029]$} & \\
\hline 0.0130 & 0.130 & $\mathrm{Ca}$ & 5.46 & [16] & {$[4.0]$} & 16.1 & {$[2.9]$} & [1.1] & {$[0.87]$} & \\
\hline 0.0100 & 0.100 & $\mathrm{Ce}$ & -- & -- & -- & -- & -- & -- & -- & \\
\hline 0.0024 & 0.024 & Co & -- & -- & -- & -- & -- & -- & $-\cdot$ & \\
\hline 0.0014 & 0.014 & $\mathrm{Cu}$ & .- & -- & -- &.- & [1.1] & -- & {$[0.15]$} & \\
\hline 0.0029 & 0.029 & Dy & .- & .- & -. & -. & .. & $\ldots$ &.- & \\
\hline 0.0011 & 0.011 & $\mathrm{Eu}$ & -. & -. & -. & -- & -- & .. & -- & \\
\hline 0.0028 & 0.028 & La & -- & ..- & -- & $\overline{--}$ & .- & .- & -. & \\
\hline 0.0006 & 0.012 & $\mathrm{Li}$ & {$[0.063]$} & 3.75 & 3.76 & 3.65 & 1.84 & 0.571 & 0.959 & \\
\hline 0.0023 & 0.023 & $\mathrm{Mg}$ & - & -- & -- & -- & -- & -- & .. & \\
\hline 0.0052 & 0.052 & Mo & {$[0.14]$} & [2.9] & [2.9] & {$[5.0]$} & {$[2.7]$} & {$[0.17]$} & [0.71] & \\
\hline 0.0170 & 0.170 & $\mathrm{Nd}$ & -- & -. & -- & -- & -- & -- &.- & \\
\hline 0.0320 & 0.320 & $\mathrm{~Pb}$ & {$[1.8]$} & - & -- & [5.2] & {$[5.7]$} & [1.5] & {$[2.0]$} & \\
\hline 0.0063 & 0.063 & $P d$ & -- & -- & $-\cdot$ & -- & -- & -- & -- & \\
\hline 0.0120 & 0.120 & $\mathrm{Rh}$ & -- & [1.9] & {$[1.7]$} & -- & -- & -- & {$[0.37]$} & \\
\hline 0.0085 & 0.085 & $\mathrm{Ru}$ & -- & [1.1] & [1.1] & [9.6] & [6.0] & {$[0.34]$} & {$[1.4]$} & \\
\hline 0.0200 & 0.200 & $\mathrm{Sb}$ & {$[0.57]$} & -- &.- & -- & $-\cdot$ & -- & $\cdots$ & \\
\hline 0.0700 & 0.700 & Se & {$[2.4]$} & [11] & [16] & -- & [11] & -- & [2.6] & \\
\hline 0.0270 & 0.270 & Sn & -- & -- & -- & -- & -- & [1.2] & [2.7] & \\
\hline 0.0170 & 0.170 & $\mathrm{Ta}$ & -- & -- &.. & -- & -- & -- & -- & \\
\hline 0.0260 & 0.260 & $\mathrm{Te}$ & -- & -- & -- & -- & $\because$ & -- & -- & \\
\hline 0.0098 & 0.098 & Th & -- & -- &.. & -- & -- & -- & -- & \\
\hline 0.0004 & 0.004 & $\mathrm{Ti}$ & -- & -- &.- & -- & -- & {$[0.013]$} & -- & \\
\hline 0.0380 & 0.380 & $\mathrm{TI}$ & -. & -- & -. & -- & -- &.- & -- & \\
\hline 0.0007 & 0.007 & $\mathrm{~V}$ & {$[0.039]$} & {$[0.33]$} & {$[0.36]$} & {$[0.59]$} & 0.980 & 0.189 & 0.496 & \\
\hline 0.0140 & 0.140 & $w$ & -- & [3.4] & {$[2.9]$} & [12] & [15] & [1.2] & 4.02 & \\
\hline 0.0004 & 0.004 & $Y$ & -.. & -- & .- & {$[0.069]$} & -- & -- & -- & \\
\hline
\end{tabular}

1) "-" indicates the value is $<M D L$. The method detection limit (MDL) $=I D L$ times the "multiplier"

near the top of each column. The estimated sample quantitation limit $=E Q L$ (in Column 2)

times the "multiplier". Overall error for values $\geq E Q L$ is estimated to be within $\pm 15 \%$.

2) Values in brackets [ / are $\geq$ MDL but $<E Q L$, with errors likely to exceed $15 \%$. 


\begin{tabular}{|c|c|c|c|c|c|c|c|c|}
\hline Run Date > & 7/9/2008 & 7/9/2008 & 7/9/2008 & $7 / 9 / 2008$ & 7/9/2008 & 7/9/2008 & 7/9/2008 & $7 / 9 / 2008$ \\
\hline Multiplier > & 125.3 & 122.5 & 122.8 & 122.6 & 125.1 & 625.7 & 122.4 & 123.7 \\
\hline RPLLAB > & $\begin{array}{c}08-02064 \\
\text { @5 }\end{array}$ & $\begin{array}{c}08-02065 \\
@ 5\end{array}$ & $\begin{array}{c}08-02066 \\
@ 5\end{array}$ & $\begin{array}{c}08-02067 \\
@ 5\end{array}$ & $\begin{array}{c}08-02068 \\
\text { @5 }\end{array}$ & $\begin{array}{c}08-02068 \\
@ 25\end{array}$ & $\begin{array}{c}08-02069 \\
@ 5\end{array}$ & $\begin{array}{c}08-02070 \\
\text { @5 }\end{array}$ \\
\hline Client ID > & T1624-G7-C1 & TI624-G7-C2 & T1624-G7-C3 & T1624-G7-C4 & \multicolumn{2}{|c|}{ T1624-G7-C5 } & II624-G7-E & II624-G7-F \\
\hline (Analyte) & $(\mu \mathrm{g} / \mathrm{mL})$ & $(\mu \mathrm{g} / \mathrm{mL})$ & $(\mu \mathrm{g} / \mathrm{mL})$ & \begin{tabular}{|l|}
$(\mu \mathrm{g} / \mathrm{mL})$ \\
\end{tabular} & $(\mu \mathrm{g} / \mathrm{mL})$ & $(\mu \mathrm{g} / \mathrm{mL})$ & $(\mu \mathrm{g} / \mathrm{mL})$ & $(\mu \mathrm{g} / \mathrm{mL})$ \\
\hline $\mathrm{Al}$ & 2,430 & 5,100 & 7,220 & 7,580 & 8,820 & & 3,990 & 1,860 \\
\hline$B$ & [10] & [11] & [12] & [11] & 13.3 & & {$[6.4]$} & [3.3] \\
\hline $\mathrm{Bi}$ & -- & -- & -- &.- & [3.9] & & 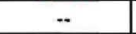 & -- \\
\hline $\mathrm{Cd}$ & [1.4] & [1.4] & {$[1.4]$} & [1.5] & {$[1.4]$} & & {$[1.2]$} & [1.2] \\
\hline $\mathrm{Cr}$ & 55.7 & 80.6 & 101 & 109 & 128 & & 61.1 & 28.5 \\
\hline $\mathrm{Fe}$ & 24.7 & 36.1 & 32.2 & 83.4 & 7.13 & & [2.1] & {$[1.3]$} \\
\hline $\mathrm{K}$ & 263 & 281 & 259 & 276 & 345 & & 142 & [74] \\
\hline $\mathrm{Mn}$ & 2.76 & 4.50 & 4.32 & 12.7 & {$[0.37]$} & & {$[0.12]$} & {$[0.071]$} \\
\hline $\mathrm{Na}$ & 106,000 & 105,000 & 109,000 & 111,000 & over-range & 131,000 & 67,500 & 37,100 \\
\hline $\mathrm{Ni}$ & {$[0.48]$} & {$[0.61]$} & {$[0.52]$} & {$[2.1]$} & .. & & -- & -. \\
\hline$P$ & 1,480 & 1,640 & 1,550 & 1,520 & 1,370 & & 2,610 & 3,200 \\
\hline $\mathrm{s}$ & 2,290 & 2,240 & 2,290 & 2,380 & 2,710 & & 1,230 & 567 \\
\hline $\mathrm{Si}$ & 129 & 105 & 72.7 & 74.7 & 72.8 & & 29.4 & 14.6 \\
\hline $\mathrm{Sr}$ & 0.234 & 0.344 & 0.327 & 0.787 & {$[0.078]$} & & -. & {$[0.011]$} \\
\hline$u$ & 143 & 78.6 & 48.3 & 47.8 & {$[34]$} & & 40.7 & {$[27]$} \\
\hline $\mathrm{Zn}$ & 17.2 & 18.1 & 16.5 & 16.2 & 16.1 & & [4.9] & {$[1.9]$} \\
\hline $\mathrm{Zr}$ & {$[0.43]$} & {$[0.75]$} & {$[0.55]$} & 1.42 & .- & & {$[0.32]$} & {$[0.16]$} \\
\hline
\end{tabular}

\begin{tabular}{|c|c|c|c|c|c|c|c|}
\hline $\mathrm{Ag}$ & 6.35 & 6.20 & 6.26 & 6.85 & 6.81 & 2.92 & {$[1.3]$} \\
\hline As & -. & -- & -- & -- & .. & -- & -. \\
\hline $\mathrm{Ba}$ & {$[0.27]$} & [0.33] & {$[0.35]$} & 0.839 & {$[0.31]$} & {$[0.094]$} & {$[0.053]$} \\
\hline $\mathrm{Be}$ & {$[0.028]$} & {$[0.042]$} & {$[0.036]$} & {$[0.034]$} & {$[0.043]$} & {$[0.012]$} & -- \\
\hline $\mathrm{Ca}$ & [4.3] & {$[4.6]$} & [4.9] & [14] & {$[2.3]$} & {$[2.7]$} & {$[2.4]$} \\
\hline $\mathrm{Ce}$ & .. & -- & -- & -. & -- & -- & -- \\
\hline Co & -- & .- & 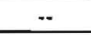 & -. & -- & -- & .- \\
\hline $\mathrm{Cu}$ & [1.1] & 2.04 & 1.83 & 1.94 & 1.84 & [0.59] & -- \\
\hline Dy & -. & -- & -- &.. & -- & -. & -- \\
\hline $\mathrm{Eu}$ & -- &.. & -- & .. & -- & -- & -- \\
\hline La & {$[0.37]$} & {$[0.38]$} & -- & {$[0.79]$} & -- &.- & -- \\
\hline $\mathrm{Li}$ & 2.05 & 3.11 & 2.85 & 2.60 & 2.37 & {$[1.4]$} & {$[1.2]$} \\
\hline $\mathrm{Mg}$ & -- & -. & -- &.- & -- & -- & -- \\
\hline Mo & [2.5] & {$[2.8]$} & [2.8] & {$[2.7]$} & [2.9] & [1.4] & [1.1] \\
\hline $\mathrm{Nd}$ & -- & -. & -- & -. & - & -. & -- \\
\hline $\mathrm{Pb}$ & [12] & [12] & [9.5] & [15] & [7.3] & -- & -- \\
\hline$P d$ & -- & -- & 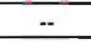 & -- & $-\cdot$ & -- & -- \\
\hline$R h$ & -- & -- & {$[1.6]$} & -- & {$[1.5]$} & -- & -- \\
\hline $\mathrm{Ru}$ & [5.3] & [5.3] & {$[5.7]$} & [6.5] & [6.8] & [2.9] & [1.9] \\
\hline $\mathrm{Sb}$ & -- & $-\cdot$ &.- & -- & -- & -- & -- \\
\hline Se & [13] & [12] & [12] & [11] & {$[9.4]$} & [15] & -- \\
\hline Sn & -- &.- & -- & -- & -- & -- & [5.6] \\
\hline $\mathrm{Ta}$ & -- & -- & -. & -- & -- & -- &.- \\
\hline $\mathrm{Te}$ & -- & -- & -- & -- & -- & -- & -- \\
\hline Th & -- & -- & -- & -- & -- &.. & -- \\
\hline $\mathrm{Ti}$ & -- & {$[0.069]$} & -. & {$[0.15]$} & -- & -- & -- \\
\hline TI & {$[6.6]$} & -- & $-\cdot$ & -- & -- & -- & -- \\
\hline $\mathrm{v}$ & {$[0.76]$} & {$[0.85]$} & 0.922 & 0.933 & [0.92] & 0.953 & [0.71] \\
\hline$w$ & {$[9.5]$} & [13] & [15] & [16] & [16] & {$[9.4]$} & [4.5] \\
\hline$Y$ & -- & -- &.-- & {$[0.11]$} & -- & -- & -- \\
\hline
\end{tabular}




\begin{tabular}{|c|c|c|c|}
\hline Run Date > & $7 / 9 / 2008$ & $7 / 9 / 2008$ & 7/9/2008 \\
\hline Multiplier > & 24.7 & 24.6 & 24.8 \\
\hline RPL/LAB > & 08-02071 & $08-02072$ & $08-02073$ \\
\hline Client ID > & T1624-G7-G & $\frac{\text { TI572-G2- }}{\text { OxWash 3-1 }}$ & $\frac{\text { TI572-G2-O- }}{1}$ \\
\hline (Analyte) & $(\mu \mathrm{g} / \mathrm{mL})$ & $(\mu \mathrm{g} / \mathrm{mL})$ & $(\mu \mathrm{g} / \mathrm{mL})$ \\
\hline Al & 871 & 83.5 & 89.7 \\
\hline B & {$[1.5]$} & {$[0.77]$} & [0.83] \\
\hline$B i$ & [2.4] & {$[2.9]$} & [2.6] \\
\hline Cd & {$[0.26]$} & {$[0.25]$} & [0.19] \\
\hline $\mathrm{Cr}$ & 13.9 & 122 & 131 \\
\hline $\mathrm{Fe}$ & {$[0.37]$} & 0.947 & {$[0.60]$} \\
\hline $\mathrm{K}$ & 48.9 & [11] & {$[9.6]$} \\
\hline$M n$ & {$[0.040]$} & {$[0.015]$} & {$[0.010]$} \\
\hline $\mathrm{Na}$ & 17,700 & 2,870 & 3,100 \\
\hline $\mathrm{Ni}$ & -- & -- & -- \\
\hline$P$ & 1,480 & 447 & 493 \\
\hline $\mathrm{s}$ & 266 & [27] & [31] \\
\hline $\mathrm{Si}$ & 12.0 & 11.5 & 11.8 \\
\hline $\mathrm{Sr}$ & {$[0.0049]$} & {$[0.0086]$} & {$[0.0052]$} \\
\hline$u$ & 16.5 & -- & - \\
\hline $\mathrm{Zn}$ & {$[0.65]$} & {$[0.54]$} & {$[0.57]$} \\
\hline $\mathrm{Zr}$ & {$[0.034]$} & -- & -- \\
\hline
\end{tabular}

\begin{tabular}{|c|c|c|c|}
\hline Ag & 0.685 & .. & -- \\
\hline As & -- & -- &.- \\
\hline $\mathrm{Ba}$ & {$[0.032]$} & 0.308 & {$[0.012]$} \\
\hline $\mathrm{Be}$ & {$[0.0016]$} & $\cdots$ & -- \\
\hline $\mathrm{Ca}$ & {$[0.96]$} & {$[0.64]$} & {$[0.93]$} \\
\hline $\mathrm{Ce}$ & -- & -- & -. \\
\hline Co & 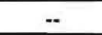 & $\ldots$ & $\ldots$ \\
\hline $\mathrm{Cu}$ & [0.039] & .- & -- \\
\hline Dy & -- & -- & -- \\
\hline Eu &.- & -- & -- \\
\hline La & $-\cdot$ & -- &.- \\
\hline $\mathrm{Li}$ & 0.733 & {$[0.15]$} & {$[0.15]$} \\
\hline $\mathrm{Mg}$ & .. & -- & -. \\
\hline Mo & {$[0.30]$} & -- & -. \\
\hline Nd & .- & -- & -- \\
\hline $\mathrm{Pb}$ & {$[0.98]$} & {$[1.5]$} & {$[1.5]$} \\
\hline Pd & .. & -- & -- \\
\hline Rh & -. & -- & -- \\
\hline $\mathbf{R u}$ & {$[0.67]$} & -- & -- \\
\hline $\mathrm{Sb}$ & {$[0.50]$} & $=$ & -- \\
\hline $\mathrm{Se}$ & [2.5] & {$[2.0]$} & [3.1] \\
\hline Sn & [2.3] & -- & -- \\
\hline $\mathrm{Ta}$ & $=$ &.- & -- \\
\hline $\mathrm{Te}$ & -- & -- & -- \\
\hline Th & -- & -- & -- \\
\hline $\mathrm{Ti}$ & -- & $-\cdot$ & -- \\
\hline $\mathrm{TI}$ & -- & -- & -- \\
\hline $\mathrm{v}$ & 0.274 & [0.099] & {$[0.12]$} \\
\hline $\mathbf{w}$ & {$[1.8]$} & .. &.- \\
\hline $\mathrm{Y}$ & -- & -- & -. \\
\hline
\end{tabular}




\begin{tabular}{|c|c|c|c|c|c|c|}
\hline Criteria > & $\leq 20 \%$ & $80 \%-120 \%$ & $75 \%-125 \%$ & $75 \%-125 \%$ & $75 \%-125 \%$ & $\leq 10 \%$ \\
\hline QC ID > & $\begin{array}{c}\text { 08-02059 } \\
\text { Dup }\end{array}$ & LCSIBS & $\begin{array}{c}\text { 08-02059 } \\
\text { MS }\end{array}$ & $\begin{array}{c}\text { 08-02059 + } \\
\text { PS-A }\end{array}$ & $\begin{array}{l}08.02059+ \\
\text { PS-B }\end{array}$ & $\begin{array}{c}08-02059 \\
5 \text {-fold } \\
\text { Serial Dil }\end{array}$ \\
\hline Analytes & RPD (\%) & $\% \operatorname{Rec}$ & $\%$ Rec & $\%$ Rec & $\%$ Rec & $\%$ Diff \\
\hline Al & 1.9 & 101 & 99 & 102 & & 2.6 \\
\hline B & 6.7 & 106 & 103 & 105 & & \\
\hline $\mathrm{Bi}$ & & 88 & 99 & 94 & & \\
\hline Cd & & 99 & 99 & 99 & & \\
\hline $\mathrm{Cr}$ & 1.3 & 99 & 99 & 100 & & 3.3 \\
\hline $\mathrm{Fe}$ & & 98 & 99 & 100 & & \\
\hline $\mathbf{K}$ & 10.5 & 103 & 101 & 99 & & \\
\hline $\mathrm{Mn}$ & & 101 & 100 & 101 & & \\
\hline $\mathrm{Na}$ & 0.3 & 98 & $\mathrm{nr}$ & $\mathrm{nr}$ & & 2.8 \\
\hline $\mathrm{Ni}$ & & 100 & 102 & 102 & & \\
\hline $\mathbf{P}$ & 1.3 & 100 & $\mathrm{nr}$ & 100 & & 0.9 \\
\hline $\mathrm{s}$ & 2.3 & 99 & $\mathrm{nr}$ & & 95 & 0.1 \\
\hline Si & & 97 & 100 & 97 & & \\
\hline $\mathrm{Sr}$ & & 102 & 100 & 101 & & \\
\hline $\mathbf{U}$ & 1.5 & 99 & 98 & & 95 & \\
\hline $\mathrm{Zn}$ & & 99 & 103 & 105 & & \\
\hline $\mathrm{Zr}$ & & 103 & 101 & 101 & & \\
\hline \multicolumn{7}{|c|}{ Other Analytes } \\
\hline $\mathrm{Ag}$ & & & & 92 & & \\
\hline As & & & & 96 & & \\
\hline $\mathrm{Ba}$ & & 99 & 98 & 99 & & \\
\hline $\mathrm{Be}$ & & 101 & 101 & 101 & & \\
\hline $\mathrm{Ca}$ & & 104 & 101 & 99 & & \\
\hline $\mathrm{Ce}$ & & 96 & 97 & & 93 & \\
\hline Co & & & & 103 & & \\
\hline $\mathrm{Cu}$ & & 101 & 104 & 105 & & \\
\hline Dy & & & & & 95 & \\
\hline Eu & & & & & 97 & \\
\hline La & & 95 & 95 & & 93 & \\
\hline $\mathrm{Li}$ & 0.4 & 104 & 99 & 100 & & \\
\hline $\mathrm{Mg}$ & & 100 & 99 & 100 & & \\
\hline Mo & & 101 & 100 & 102 & & \\
\hline $\mathrm{Nd}$ & & 98 & 97 & & 97 & \\
\hline $\mathrm{Pb}$ & & 100 & 100 & 100 & & \\
\hline $\mathrm{Pd}$ & & & & & 92 & \\
\hline Rh & & & & & 91 & \\
\hline Ru & & & & & 96 & \\
\hline Sb & & & & 100 & & \\
\hline Se & & & & 99 & & \\
\hline Sn & & & & 97 & & \\
\hline $\mathrm{Ta}$ & & & & 102 & & \\
\hline $\mathrm{Te}$ & & & & & 98 & \\
\hline Th & & 97 & 96 & & 95 & \\
\hline $\mathbf{T i}$ & & 101 & 99 & 99 & & \\
\hline TI & & & & 93 & & \\
\hline V & & 95 & 94 & 96 & & \\
\hline $\mathbf{W}$ & & 99 & 96 & 98 & & \\
\hline$Y$ & & & & 96 & & \\
\hline
\end{tabular}

Shaded results are outside the acceptance criteria.

$n r=$ spike concentration less than $25 \%$ of sample concentration. Matrix effects can be assessed from the serial dilution. 
Battelle PNNL/RS\&E/Inorganic Analysis ... ICP-OES Analysis Report PO Box 999, Richland, Washington 99352

Project / WP\#: $\quad 52964$ / F99189

ASR\#: $\quad 8176$

Client: $\quad$ R. Shimskey

Total Samples: $\quad 3$ (solid)

\begin{tabular}{|l|c|c|}
\hline \multicolumn{3}{c}{ First } \\
\hline RPL\#: & 08-02074 & Last \\
\hline Client ID: & TI624-G7-6 & TI624-G7-12 \\
\hline
\end{tabular}

Sample Preparation: RPG-CMC-138, " $\mathrm{HNO}_{3}-\mathrm{HF}-\mathrm{HCl}$ Acid Digestion of Solids for Metals Analysis Using a Dry-Block Heater", 7/11/08 (SAL/ng).

Procedure: $\quad$ RPG-CMC-211, "Determination of Elemental Composition by Inductively Coupled Argon Plasma Optical Emission Spectrometry (ICP-OES)", Rev 2.

Analyst: $\quad \underline{\text { J. Deschane }}$

Analysis Date (File): $\quad \underline{7-18-2008}$ (C0148)

See Chemical Measurement Center 98620 file: $\quad \underline{\text { ICP-325-405-3 }}$

(Calibration and Maintenance Records)

M\&TE Number: $\quad \underline{\text { N827583 }}$ (ICP-OES instrument) $\underline{\text { M19445 }}$ (Mettler AT400 Balance)

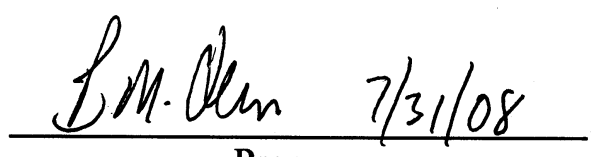

Preparer

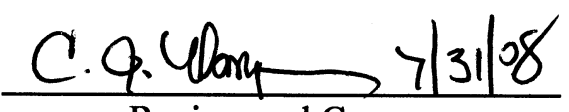

Review and Concur 
Battelle PNNL/RS\&E/Inorganic Analysis ... ICP-OES Analysis Report

Three samples submitted under Analytical Service Request (ASR) 8125 were analyzed by ICPOES. The samples were prepared following RPL procedure RPG-CMC-138 using a nominal 0.2 grams of sample and diluting to a final volume of $100 \mathrm{~mL}$.

Analytes of interest (AOIs) were specified in the ASR, and are listed in the upper section of the attached ICP-OES Data Report. The quality control (QC) results for these AOIs have been evaluated and are presented below. Analytes other than AOIs are reported in the bottom section of the report, but have not been fully evaluated for QC performance. The results are given as $\mu \mathrm{g} / \mathrm{g}$ for each detected analyte, and have been adjusted for all laboratory processing factors and instrument dilutions.

Calibration of the ICP-OES was done following the manufacturer's recommended calibration procedure and using multi-analyte custom standard solutions traceable to the National Institute of Standards and Technology (NIST). Midrange calibration verification standards (MCVA and MCVB) were used to verify acceptance of the two-point calibration curves obtained for each analyte, and also used for continuing calibration verification.

Minimum Method Detection Limit (MDL) values were specified in the ASR. MDL levels were met for all AOIs.

The controlling documents were ASO-QAP-001, and the client supplied RPP-WTP-QA-005, Rev. 2, and ASR-8176 Special Instructions. Instrument calibrations, QC checks and blanks (e.g., ICV/ICB, CCV/CCB, LLS, ICS), post-spike, laboratory control standard (LCS), duplicate, and serial dilution were conducted during the analysis run. The LCS was prepared using a nominal 0.1 grams of SRM-2710 (Montana Soil).

\section{Preparation Blank (PB):}

A preparation blank (reagents only) was prepared for the digestion process. The concentrations of all AOIs were within the acceptance criteria of $\leq \mathrm{EQL}$ (estimated quantitation level) or less than $\leq 5 \%$ of the concentration in the sample.

\section{Blank Spike (BS)/Laboratory Control Sample (LCS):}

An LCS (Montana Soil) was prepared for the digestion process. Recovery values are listed for all analytes included in the spike that were measured at or above the EQL. The recovery values were within the acceptance criterion of $80 \%$ to $120 \%$ for all AOIs meeting the above requirement.

\section{Matrix-Spiked Sample:}

No matrix spike sample was provided for analysis.

\section{Duplicate Relative Percent Difference (RPD):}

A duplicate was prepared for the digestion process. RPDs are listed for all analytes that were measured at or above the EQL. The RPDs were within the client acceptance criterion of $\leq 25 \%$ for all AOIs meeting the above requirement. 
Battelle PNNL/RS\&E/Inorganic Analysis ... ICP-OES Analysis Report

Post-Spike/Analytical Spike Sample (A component):

An analytical spike (A component) was conducted for the sample batch. Recovery values are listed for all analytes in the spike that were measured at or above the EQL, and that had a spike concentration $\geq 25 \%$ of that in the sample. The recovery values were within the client acceptance criterion of $70 \%$ to $130 \%$ for all AOIs meeting the above requirements.

Post Spike/Analytical Spike Sample (B component):

An analytical spike (B component) was conducted for the sample batch. Recovery values are listed for all analytes in the spike that were measured at or above the EQL, and that had a spike concentration $\geq 25 \%$ of that in the sample. The recovery values were within the client acceptance criterion of $70 \%$ to $130 \%$ for all AOIs meeting the above requirements.

\section{Serial dilution:}

Five-fold serial dilution was conducted for the sample batch. Percent differences (\%Ds) are listed for all analytes that had a concentration at or above the EQL in the diluted sample. The $\%$ Ds were within the acceptance criterion of $\leq 10 \%$ for all AOIs meeting the above requirement.

\section{Other QC:}

All other instrument-related QC tests for the AOIs passed within the appropriate acceptance criteria.

\section{Comments:}

1) The "Final Results" have been corrected for all laboratory dilutions performed on the samples during processing and analysis, unless specifically noted.

2) Instrument detection limits (IDL) and estimated quantitation limits (EQL) shown are for acidified water. Detection limits for other matrices may be determined if requested. Method detection limits (MDL) can be estimated by multiplying the IDL by the "Multiplier". The estimated quantitation limit (EQL) for each concentration value can be obtained by multiplying the EQL by the "Multiplier".

3) Routine precision and bias is typically $\pm 15 \%$ or better for samples in dilute, acidified water (e.g. $2 \% \mathrm{v} / \mathrm{v}$ $\mathrm{HNO}_{3}$ or less) at analyte concentrations $>\mathrm{EQL}$ up to the upper calibration level. This also presumes that the total dissolved solids concentration in the sample is less than $5000 \mu \mathrm{g} / \mathrm{mL}(0.5$ per cent by weight). Note that bracketed values listed in the data report are within the MDL and the EQL, and have potential uncertainties greater than $15 \%$. Concentration values < MDL are listed as "- .". Note, that calibration and QC standards are validated to a precision of $\pm 10 \%$.

4) Absolute precision, bias and detection limits may be determined on each sample if required by the client. The maximum number of significant figures for all ICP measurements is two.

5) Analytes included in the spike $\mathrm{A}$ component (for the $\mathrm{AS} / \mathrm{PS}$ ) are; $\mathrm{Ag}, \mathrm{Al}, \mathrm{As}, \mathrm{B}, \mathrm{Ba}, \mathrm{Be}, \mathrm{Bi}, \mathrm{Ca}, \mathrm{Cd}, \mathrm{Co}, \mathrm{Cr}$, $\mathrm{Cu}, \mathrm{Fe}, \mathrm{K}, \mathrm{Li}, \mathrm{Mg}, \mathrm{Mn}, \mathrm{Mo}, \mathrm{Na}, \mathrm{Ni}, \mathrm{P}, \mathrm{Pb}, \mathrm{Sb}, \mathrm{Se}, \mathrm{Si}, \mathrm{Sn}, \mathrm{Sr}, \mathrm{Ta}, \mathrm{Ti}, \mathrm{Tl}, \mathrm{V}, \mathrm{W}, \mathrm{Y}, \mathrm{Zn}$, and $\mathrm{Zr}$. Analytes included in the spike B component are; Ce, Dy, Eu, La, Nd, Pd, Rh, Ru, S, Te, Th, and U. 


\begin{tabular}{|c|c|c|c|c|c|c|c|}
\hline & Run Date > & $7 / 18 / 2008$ & $7 / 18 / 2008$ & $7 / 18 / 2008$ & $7 / 18 / 2008$ & $7 / 18 / 2008$ \\
\hline & & Multiplier > & 1679.5 & 1377.8 & 1436.8 & 1830.8 & 2417.8 \\
\hline & & RPL/LAB > & $\begin{array}{l}\text { 08-02074- } \\
\text { 138-B @5 }\end{array}$ & $\begin{array}{l}\text { 08-02074- } \\
\text { 138-S @5 }\end{array}$ & $\begin{array}{l}08-02074- \\
138-D @ 5\end{array}$ & $\begin{array}{l}08-02075- \\
138-S @ 55\end{array}$ & $\begin{array}{l}\text { 08-02076- } \\
138-S \text { @5 }\end{array}$ \\
\hline $\begin{array}{l}\text { Instr. Det. } \\
\text { Limit (IDL) } \\
\end{array}$ & $\begin{array}{l}\text { Est. Quant. } \\
\text { Limit (EQL) }\end{array}$ & Client ID > & Prep Blank & \multicolumn{2}{|c|}{ II624-G7-6 } & II624-G7-9 & I|624-G7-12 \\
\hline$(\mu \mathrm{g} / \mathrm{mL})$ & $(\mu \mathrm{g} / \mathrm{mL})$ & (Analyte) & $(\mu \mathrm{g} / \mathrm{g})$ & $(\mu \mathrm{g} / \mathrm{g})$ & $(\mu \mathrm{g} / \mathrm{g})$ & $(\mu \mathrm{g} / \mathrm{g})$ & $(\mu \mathrm{g} / \mathrm{g})$ \\
\hline 0.0060 & 0.060 & Al & -. & 42,000 & 41,300 & 36,800 & 41,900 \\
\hline 0.0048 & 0.096 & B &.. & {$[23]$} & {$[28]$} & {$[23]$} & {$[22]$} \\
\hline 0.0300 & 0.300 & $\mathrm{Bi}$ & -- & 1,040 & 1,030 & 1,240 & 1,910 \\
\hline 0.0037 & 0.037 & $\mathrm{Cd}$ &.- & 113 & 118 & 132 & 213 \\
\hline 0.0017 & 0.017 & $\mathrm{Cr}$ & .- & 1,630 & 1,600 & 1,750 & 2,500 \\
\hline 0.0019 & 0.038 & $\mathrm{Fe}$ & {$[5.0]$} & 91,200 & 89,900 & 107,000 & 168,000 \\
\hline 0.0720 & 0.720 & $K$ & -- & [550] & {$[430]$} & {$[550]$} & {$[260]$} \\
\hline 0.0002 & 0.005 & $\mathrm{Mn}$ & {$[0.41]$} & 13,500 & 13,300 & 15,800 & 24,700 \\
\hline 0.0160 & 0.320 & $\mathrm{Na}$ & [170] & 153,000 & 151,000 & 249,000 & 110,000 \\
\hline 0.0024 & 0.024 & $\mathrm{Ni}$ & [7.4] & 2,440 & 2,410 & 2,900 & 4,450 \\
\hline 0.0500 & 0.500 & $P$ & -- & 22,500 & 22,100 & 25,300 & 13,700 \\
\hline 0.1600 & 1.600 & $\mathrm{~s}$ & -- & 5,320 & 5,420 & 4,480 & {$[1,600]$} \\
\hline 0.0056 & 0.056 & $\mathrm{Si}$ & -- & na & na & na & na \\
\hline 0.0001 & 0.002 & $\mathrm{Sr}$ & -. & 892 & 877 & 1,050 & 1,610 \\
\hline 0.0320 & 0.320 & $u$ & -- & 12,400 & 12,100 & 15,100 & 22,900 \\
\hline 0.0028 & 0.056 & $\mathrm{Zn}$ & [19] & 270 & 273 & 313 & 456 \\
\hline 0.0011 & 0.011 & $\mathrm{Zr}$ & -- & 2,280 & 2,240 & 2,670 & 4,140 \\
\hline
\end{tabular}

\section{Other Analytes}

\begin{tabular}{|c|c|c|c|c|c|c|c|}
\hline 0.0021 & 0.021 & $\mathrm{Ag}$ & -- & 67.6 & 30.6 & 47.0 & 183 \\
\hline 0.0520 & 0.520 & As & - & .- & -- & .. &.- \\
\hline 0.0003 & 0.005 & $\mathrm{Ba}$ & {$[0.85]$} & 580 & 572 & 680 & 1,050 \\
\hline 0.0001 & 0.001 & $\mathrm{Be}$ & -- & 0.787 & 0.860 & {$[0.94]$} & 1.50 \\
\hline 0.0130 & 0.130 & $\mathrm{Ca}$ & [22] & 6,330 & 6,180 & 7,390 & 11,400 \\
\hline 0.0100 & 0.100 & $\mathrm{Ce}$ & -- & 633 & 632 & 751 & 1,150 \\
\hline 0.0024 & 0.024 & Co & -- & [28] & [29] & [36] & {$[56]$} \\
\hline 0.0014 & 0.014 & $\mathrm{Cu}$ & -- & 209 & 209 & 247 & 383 \\
\hline 0.0029 & 0.029 & Dy & -- & -- & -- & -- &.- \\
\hline 0.0011 & 0.011 & Eu & -- & [14] & [13] & [17] & [24] \\
\hline 0.0028 & 0.028 & La & .. & 725 & 703 & 862 & 1,320 \\
\hline 0.0006 & 0.012 & $\mathrm{Li}$ & -- & 87.1 & 85.6 & 98.9 & 149 \\
\hline 0.0023 & 0.023 & $\mathrm{Mg}$ & -- & 1,690 & 1,660 & 1,990 & 3,060 \\
\hline 0.0052 & 0.052 & Mo & -- & {$[17]$} & {$[14]$} & [19] & [22] \\
\hline 0.0170 & 0.170 & Nd & -- & 1,060 & 1,040 & 1,280 & 1,990 \\
\hline 0.0320 & 0.320 & $\mathrm{~Pb}$ & -- & 3,930 & 3,840 & 4,590 & 7,150 \\
\hline 0.0063 & 0.063 & Pd & $\because$ & $\cdots$ & -- & -- & -- \\
\hline 0.0120 & 0.120 & $\mathrm{Rh}$ & -- & -- & [25] & -- & [36] \\
\hline 0.0085 & 0.085 & Ru & -- & 217 & 220 & 243 & 234 \\
\hline 0.0200 & 0.200 & Sb & -- & -- & - &.$\cdot$ & - \\
\hline 0.0700 & 0.700 & Se & - &.$\cdot$ & -- & -- & -- \\
\hline 0.0270 & 0.270 & Sn & -- & [39] & [56] & 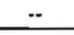 & -- \\
\hline 0.0170 & 0.170 & Ta & - &.. & -- &.. & [53] \\
\hline 0.0260 & 0.260 & Te & -- & {$[180]$} & [170] & [190] & [250] \\
\hline 0.0098 & 0.098 & Th & -- & 486 & 473 & 579 & 875 \\
\hline 0.0004 & 0.004 & $\mathrm{Ti}$ & -- & 199 & 197 & 234 & 370 \\
\hline 0.0380 & 0.380 & $\mathrm{TI}$ & -- &.. & -- & .. & -- \\
\hline 0.0007 & 0.007 & $v$ & {$[1.3]$} & 16.9 & 17.0 & 19.3 & 25.1 \\
\hline 0.0140 & 0.140 & $w$ & -- & 232 & 253 & 273 & 365 \\
\hline 0.0004 & 0.004 & $\mathrm{Y}$ & -- & 94.0 & 91.7 & 111 & 169 \\
\hline
\end{tabular}

1) "-" indicates the value is $<M D L$. The method detection limit $(M D L)=I D L$ times the "multiplier"

near the fop of each column. The estimated sample quantitation limit $=E Q L$ (in Column 2)

times the "multiplier". Overall error for values $\geq E Q L$ is estimated to be within $\pm 15 \%$.

2) Values in brackets (] are $\geq M D L$ but $<E Q L$, with errors likely to exceed $15 \%$.

na = not applicable; $\mathrm{KOH}$ flux and Ni crucible or $\mathrm{Na}_{2} \mathrm{O}_{2}$ flux and $\mathrm{Zr}$ crucible for fusion preparations, or Si for HF assisted digests. 


\begin{tabular}{|c|c|c|c|c|c|c|}
\hline Criteria > & $\leq 25 \%$ & $80 \%-120 \%$ & $70 \%-130 \%$ & $70 \%-130 \%$ & $70 \%-130 \%$ & $\leq 10 \%$ \\
\hline QC ID > & $\begin{array}{c}\text { 08-02074 } \\
\text { Dup }\end{array}$ & LCS/BS & MS (none) & $\begin{array}{c}08-02074+ \\
\text { AS-A }\end{array}$ & $\begin{array}{c}08-02074+ \\
\text { AS-B }\end{array}$ & $\begin{array}{c}08-02074 \\
5 \text {-fold } \\
\text { Serial Dil }\end{array}$ \\
\hline Analytes & RPD (\%) & $\%$ Rec & $\% \operatorname{Rec}$ & $\% \operatorname{Rec}$ & \%Rec & $\%$ Diff \\
\hline Al & 1.8 & 96 & & 101 & & 0.5 \\
\hline $\mathrm{B}$ & & & & 104 & & \\
\hline $\mathrm{Bi}$ & 1.0 & & & 96 & & \\
\hline $\mathrm{Cd}$ & 4.4 & & & 102 & & \\
\hline $\mathrm{Cr}$ & 2.0 & & & 102 & & 1.2 \\
\hline $\mathrm{Fe}$ & 1.4 & 96 & & 102 & & 1.0 \\
\hline $\mathbf{K}$ & & & & 99 & & \\
\hline Mn & 1.4 & 100 & & $\mathrm{nr}$ & 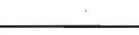 & 0.7 \\
\hline $\mathrm{Na}$ & 1.6 & 87 & & 98 & & 1.4 \\
\hline $\mathrm{Ni}$ & 1.5 & & & 101 & & 1.0 \\
\hline $\mathbf{P}$ & 1.9 & & & 102 & & 0.7 \\
\hline 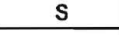 & 1.8 & & & & 99 & \\
\hline Si & na & na & na & na & na & na \\
\hline Sr & 1.7 & & & 104 & & 0.4 \\
\hline U & 2.0 & & & & 98 & 0.5 \\
\hline $\mathrm{Zn}$ & 1.3 & 99 & & 104 & & \\
\hline $\mathrm{Zr}$ & 1.6 & & & 99 & & 0.8 \\
\hline \multicolumn{7}{|c|}{ Other Analytes } \\
\hline $\mathrm{Ag}$ & 75.5 & & & 92 & & \\
\hline As & & & & 98 & & \\
\hline $\mathrm{Ba}$ & 1.4 & 93 & & 98 & & 0.0 \\
\hline $\mathrm{Be}$ & 8.8 & & & 101 & & \\
\hline $\mathrm{Ca}$ & 2.4 & 94 & & 98 & & 0.0 \\
\hline $\mathrm{Ce}$ & 0.1 & & & & 96 & \\
\hline Co & & & & 102 & & \\
\hline $\mathrm{Cu}$ & 0.2 & 97 & & 100 & & 0.1 \\
\hline Dy & & & & & 98 & \\
\hline Eu & & & & & 99 & \\
\hline La & 3.0 & & & & 97 & 1.8 \\
\hline Li & 1.8 & & & 102 & & 13.1 \\
\hline Mg & 2.1 & 95 & & 99 & & 2.4 \\
\hline Mo & & & & 101 & & \\
\hline Nd & 2.3 & & & & 99 & \\
\hline $\mathrm{Pb}$ & 2.5 & 100 & & 100 & & 2.3 \\
\hline $\mathbf{P d}$ & & & & & 92 & \\
\hline $\mathbf{R h}$ & & & & & 96 & \\
\hline Ru & 1.2 & & & & 98 & \\
\hline Sb & & & & 101 & & \\
\hline Se & & & & 104 & & \\
\hline Sn & & & & 100 & & \\
\hline $\mathrm{Ta}$ & & & & 101 & & \\
\hline $\mathrm{Te}$ & $\cdot$ & & & & 97 & \\
\hline Th & 2.7 & & & & 98 & \\
\hline $\mathrm{Ti}$ & 1.2 & 91 & & 98 & & 0.4 \\
\hline $\mathrm{TI}$ & & & & 95 & & \\
\hline V & 1.0 & 96 & & 96 & & \\
\hline$w$ & 8.9 & & & 102 & & \\
\hline$Y$ & 2.4 & & & 98 & & 0.2 \\
\hline
\end{tabular}




\section{Battelle - Pacific Northwest National Laboratory Analytical Support Operations - IC Report PO Box 999, Richland, Washington 99352}

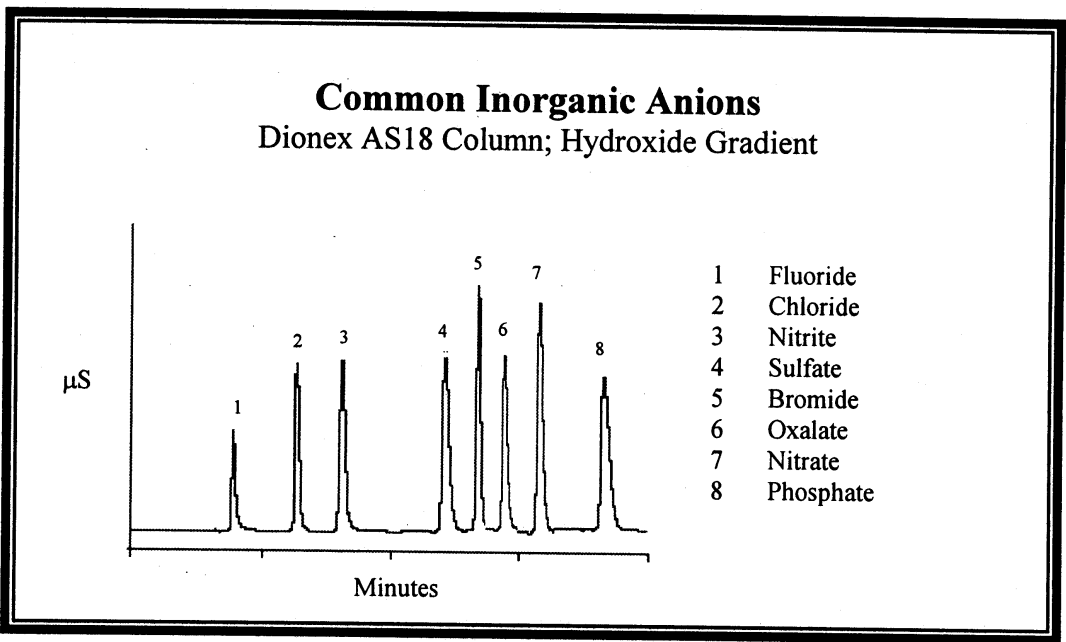

Client:

Project \#:

Charge Code:
R. Shimskey 52964

F99189
ASR \#:

\# Samples:
8176

5 liquids

*** RPL Numbers: 08-02059 through 08-02063***

Liquid Samples Only Reported

Rev. 1 - Revised Report - Corrected RPL sample number ID's on results page.

Procedure, Analysis, System, and Records Information

\begin{tabular}{|l|l|}
\hline Analysis Procedure & PNL-ALO-212, "Determination of Inorganic Anions by Ion Chromatography" \\
\hline Prep Procedure & Bench Dilution performed in lab 400 (MJS 7/24/08 and 7/25/08) \\
\hline Analyst & MJ Steele \\
\hline Analysis Dates & $07 / 25-26 / 2008$ \\
\hline Calibration Date & $5 / 8 / 08$ \\
\hline Cal/Ver Stds Prep Date & Cal 5/8/08; Ver 7/24/08 \\
\hline Excel Data File & Results ASR8176 Shimskey.xls \\
\hline \multirow{2}{*}{ M\&TE Numbers } & IC System (M\&TE) N830443 \\
\cline { 2 - 2 } & Balances: 360-06-01-031/1113052270 \\
\hline All Analysis Records & Chemical Measurement Center 98620: RIDS IC System File (IC-0168) \\
\hline
\end{tabular}
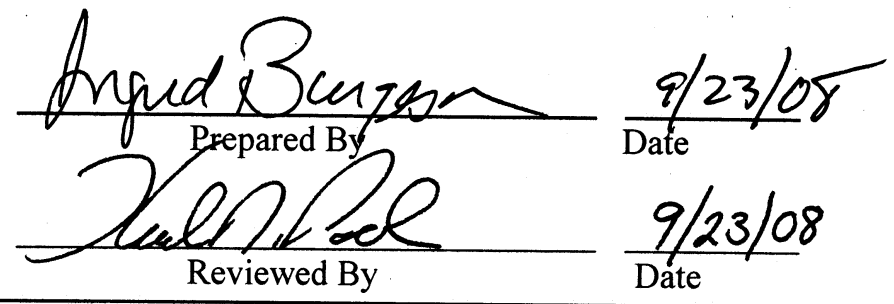


\section{IC Report-Rev. 1}

\section{Sample Results}

See Attachment: Direct Liquid Sample Results ASR 8176

\section{Sample Analysis/Results Discussion}

Five liquid samples were submitted to the ASO for analysis under ASR 8176. The analytes of interest are fluoride, chloride, nitrite, nitrate, oxalate, sulfate and phosphate. The samples were prepared for analysis using dilutions at the bench, which included the preparation of analytical spikes and sample replicates. The dilutions were prepared in deionized water and the water was analyzed as the process dilution sample. All sample results are reported as $\mu \mathrm{g} / \mathrm{mL}$.

The final analysis was performed using dilutions ranging from $100 \mathrm{x}$ to $\sim 10,000 \mathrm{x}$ to provide values within the calibration range. All results have been adjusted for all analytical dilutions. The preparation dilution blanks (water used to dilute samples at the IC workstation) are reported as analyzed, no dilution factors were applied to these samples. The estimated method detection limits (MDL) are provided, and are based on the estimated quantitation limit (EQL), which is one-tenth of the lowest calibration standard (adjusted for the dilutions used for reporting the results).

\section{Data Limitations}

None

\section{Quality Control Discussion}

The method performance is evaluated against the acceptance criteria established by Analytical Support Operations QA Plan ASO-QAP-001 and the client specified special instructions, RPP-WTP-QA-005 Rev 2, which has the same specification as the QA Plan.

Processing Blanks: (Dilution) Two process dilution blanks (deionized water) were analyzed with the sample set. There were no anions detected above the method detection limit (MDL). Thus, the processing blanks met the QA Plan acceptance criteria for all analytes of interest.

Duplicate (Precision): One sample was analyzed in duplicate (08-02259). The relative percent difference (RPD) ranged from $2 \%$ to $3 \%$ for all analytes of interest. Note: the replicate RPD is not calculated for results less than the EQL.

Processing Laboratory Control/Blank Spike (LCS/BS): The routine instrument blank spike was analyzed twice with the run and had a recovery range of $95 \%$ to $118 \%$ for the analytes of interest. These recoveries meet the QA Plan acceptance criteria of $80 \%$ to $120 \%$ recovery.

Matrix Spike: (Accuracy) None prepared. Sample did not undergo sample preparation; therefore, an analytical spike was prepared and analyzed.

Post Spike: (Accuracy) One sample was prepared as an analytical spike and analyzed (0802260). Sample 08-02260 was analyzed as a post spike using three separate dilutions. The recovery ranged from $95 \%$ to $109 \%$ for all analytes of interest, which meets the QA Plan matrix spike recovery acceptance criteria of $75 \%$ to $125 \%$. 


\section{IC Report-Rev. 1}

IC System QC Samples: Numerous calibration verification standards and calibration verification blanks were analyzed with each run day. For all data reported, the IC System QC bounding the sample analyses produced results for all analytes were within the acceptance criterion of the ASO's QA Plan (i.e., $90 \%$ to $110 \%$ recovery for verification standards and verification blank results $<\mathrm{EQL}$ or $<5 \%$ of reported sample result).

\section{Deviations from Procedure}

None

\section{General Comments}

- The reported "Final Results" have been corrected for all dilutions performed on the sample during processing or analysis.

- The MDL is set at the concentration of the lowest calibrations standard divided by 10 . The $\mathrm{EQL}$ is defined as the concentration of the lowest calibration standards times the sample dilution factors (processing and analysis) and assumes non-complex aqueous matrices. Matrix-specific MDLs or EQLs may be determined, if requested.

- Routine precision and bias are typically $\pm 15 \%$ or better for non-complex aqueous samples that are free of interference. 
WTP-RPT-169

$\underset{\overline{0}}{\overline{0}}$
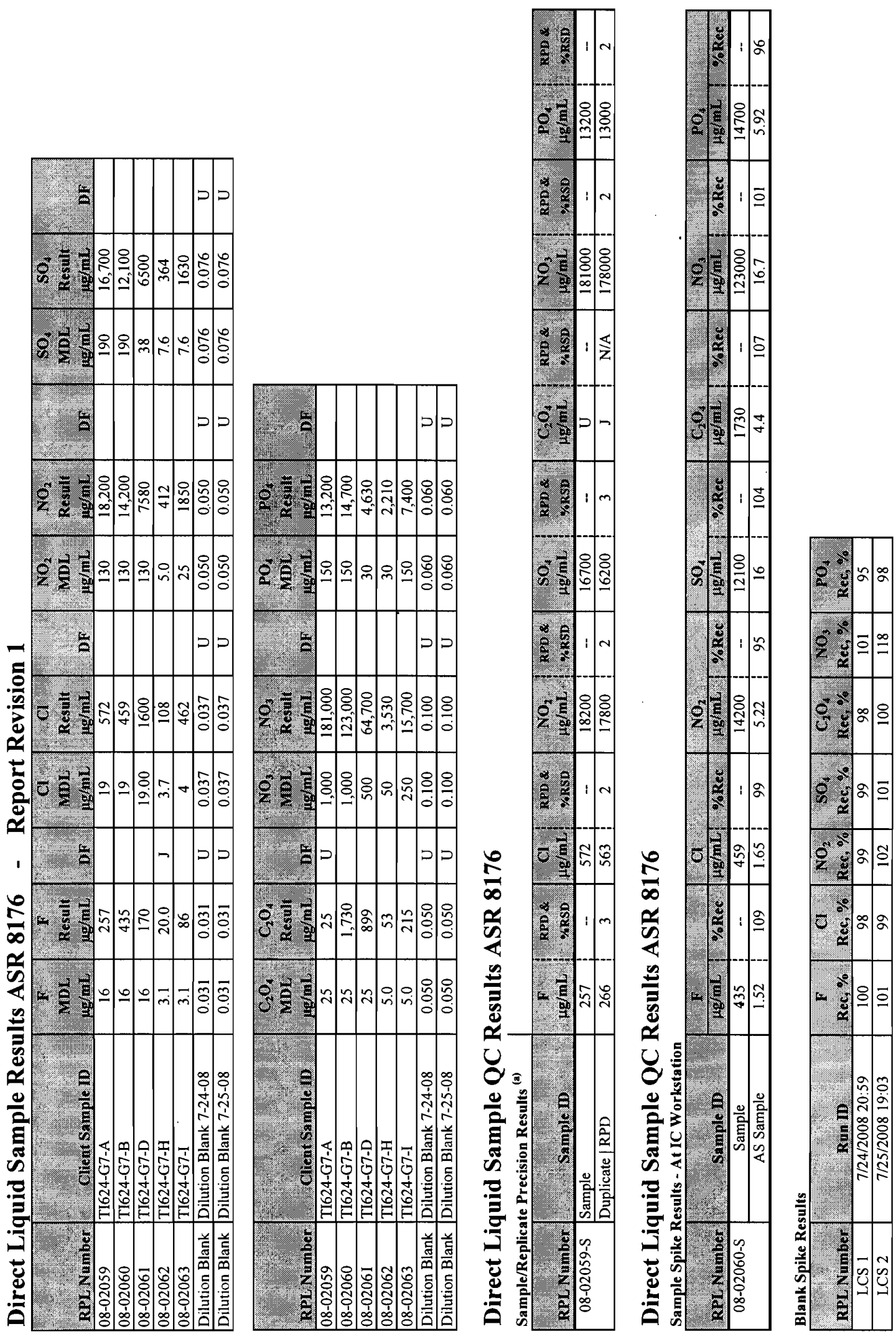

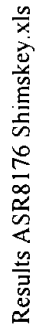

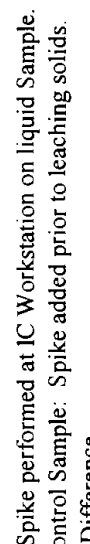

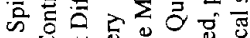

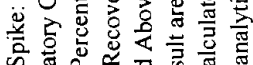

बु

สำ

र

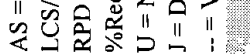




\section{Battelle - Pacific Northwest National Laboratory Analytical Support Operations - IC Report \\ PO Box 999, Richland, Washington 99352}

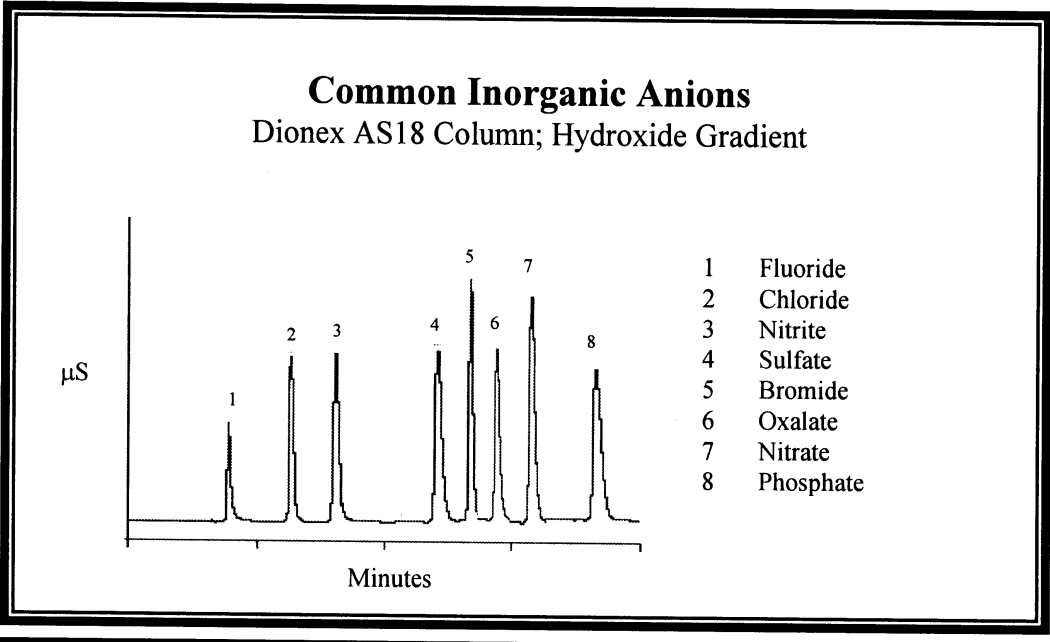

Client:

R. Shimskey

Project \#: 52964

Charge Code: $\quad$ F99189

ASR \#: $\quad 8176$

\# Samples: 3 Solids

\section{*** RPL Numbers: 08-02074 through 08-02076*** \\ Water Leached Solids Samples Only Reported}

\section{Procedure, Analysis, System, and Records Information}

\begin{tabular}{|l|l|}
\hline Analysis Procedure & PNL-ALO-212, "Determination of Inorganic Anions by Ion Chromatography" \\
\hline Prep Procedure & Bench Dilution performed in lab 400 (MJS 7/24/08 and 7/25/08) \\
\hline Analyst & MJ Steele \\
\hline Analysis Dates & $07 / 25-26 / 2008$ \\
\hline Calibration Date & $5 / 8 / 08$ \\
\hline Cal/Ver Stds Prep Date & Cal 5/8/08; Ver 7/24/08 \\
\hline Excel Data File & Results ASR8176 Shimskey.xls \\
\hline \multirow{2}{*}{ M\&TE Numbers } & IC System (M\&TE) N830443 \\
\cline { 2 - 2 } & Balances: $360-06-01-031 / 1113052270$ \\
\hline All Analysis Records & Chemical Measurement Center 98620: RIDS IC System File (IC-0168) \\
\hline
\end{tabular}

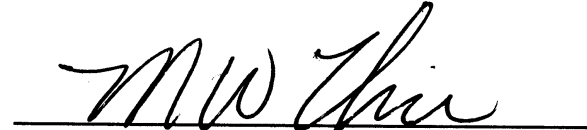

Ppepared By

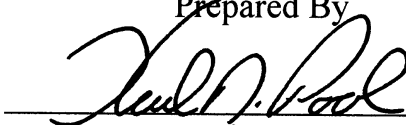

Reviewed By

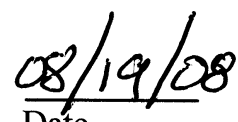

Date

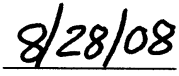

Date 


\section{IC Report}

\section{Sample Results}

See Attachment: Water Leached Solids Results ASR 8176

\section{Sample Analysis/Results Discussion}

Three solid/slurry samples were submitted to the ASO for analysis under ASR 8176. The specified analytes of are fluoride, nitrite, nitrate, sulfate, oxalate and phosphate; however, chloride has also been reported. The samples were prepared for IC analysis by drying the solids/slurry and then leaching the dry solids (from $0.3 \mathrm{~g}$ to $1.4 \mathrm{~g}$ slurry to $10 \mathrm{~mL}$ of deionized water), which included the preparation of a matix spike and sample duplicate. Following leaching, the samples were further diluted to bring each analyte within the calibration range. The dilutions were prepared in deionized water. Both the deionized water used to leach the solids/slurries and to make further dilutions were analyzed as a process sample. All sample results are reported as $\mu \mathrm{g} / \mathrm{g}$; the leach deionized water samples (referred to a the process blank, PB) has been adjusted for each sample leach factor and reported with each sample.

After screening the samples, the final analysis was performed using additional dilution factors ranging from $\sim 20$ to 2100 . All sample results have been adjusted for all leaching and analytical dilution factors. The estimated method detection limits (MDL) are provided for each analyte of interest measured and the MDLs have been adjusted for all analytical dilutions. The MDLs are set at one-tenth the lowest calibration standard, which is defined as the estimated quantitation limit (EQL).

\section{Data Limitations}

None

\section{Quality Control Discussion}

The method performance is evaluated against the acceptance criteria established by Analytical Support Operations QA Plan ASO-QAP-001 and the client specified special instructions, RPPWTP-QA-005 Rev 2, which has the same specification as the QA Plan.

Dilution Blank: (Analytical Dilution) Two dilution blanks (deionized water) were analyzed with the sample set. There were no anions detected above the method detection limit (MDL). The processing blank meets the QA Plan acceptance criteria for all analytes of interest.

Process Blank: (Leach Dilution) A process blank (deionized water subjected to the same handling as the leached solid/slurry samples) was analyzed with the sample set. Only fluoride and chloride were detected in the process leach blank, but were below the EQL; thus meeting the QA Plan acceptance criteria for all analytes of interest.

Duplicate (Precision): Sample 08-02074 was analyzed in duplicate. The relative percent difference is reported for all analytes which were measured at or above the EQL. The reported RPDs ranged from 2 to $13 \%$ for all analytes of interest, which meets the Project acceptance criteria (Table 5 of ASR) of $<25 \%$. 


\section{IC Report}

Processing Laboratory Control Sample/Blank Spike (LCS/BS): The leaching process LCS/blank spike was analyzed with the data set and had a recoveries ranging from $92 \%$ to $108 \%$ for the analytes of interest. These recoveries meet the Project acceptance criteria (Table 4 of ASR) of $80 \%$ to $120 \%$ recovery.

Matrix Spike: (Accuracy) A matrix spike was prepared for Sample 08-02076. However, no recoveries are reported since concentrations of all analytes of interest are greater than five times the (added) spike concentration. Post spikes were performed to evaluate accuracy.

Post Spike: (Accuracy) Multiple post spikes (i.e., standard added after leaching) were prepared for sample 08-02076 and analyzed. Sample 08-02076 was diluted by 40, 400 and 1,400 in order to obtain spikes concentrations at least $20 \%$ greater than measured sample concentration. The recovery range was from $94 \%$ to $102 \%$ for all analytes of interest, which meets the QA Plan post spike recovery acceptance criteria of $75 \%$ to $125 \%$.

IC System QC Samples: Numerous calibration verification standards and calibration verification blanks were analyzed with each run day. For all data reported, the IC System QC bounding the sample analyses produced results for all analytes were within the acceptance criterion of the ASO's QA Plan (i.e., $90 \%$ to $110 \%$ recovery for verification standards and verification blank results $<\mathrm{EQL}$ or $<5 \%$ of reported sample result).

\section{Deviations from Procedure}

None

\section{General Comments}

- The reported "Final Results" have been corrected for all dilutions performed on the sample during processing or analysis.

- The MDL is set at the concentration of the lowest calibrations standard divided by 10 . The EQL is defined as the concentration of the lowest calibration standards times the sample dilution factors (processing and analysis) and assumes non-complex aqueous matrices. Matrix-specific MDLs or EQLs may be determined, if requested.

- Routine precision and bias are typically $\pm 15 \%$ or better for non-complex aqueous samples that are free of interference. 


\begin{tabular}{|c|c|c|c|c|c|c|c|c|c|c|c|c|c|c|}
\hline & & & & & & . & 8176 & & & & & & & \\
\hline \multirow[b]{2}{*}{ RPI Number } & \multirow[b]{2}{*}{ Client Sample ID } & \multirow[b]{2}{*}{$\begin{array}{l}\text { Leach } \\
\text { Dilution }\end{array}$} & \multicolumn{3}{|c|}{$F$} & \multicolumn{3}{|c|}{$\mathrm{Cl}$} & \multicolumn{3}{|c|}{$\mathrm{NO}_{2}$} & \multicolumn{3}{|c|}{$\mathrm{SO}_{4}$} \\
\hline & & & \begin{tabular}{|c|}
$\mathbf{M D L}$ \\
$\mu \mathrm{g} / \mathrm{g}$
\end{tabular} & $\begin{array}{c}\text { Resulf } \\
\text { Mg/g }\end{array}$ & DF & $\begin{array}{l}\mathrm{MDL} \\
\mu \mathrm{g} / \mathrm{g}\end{array}$ & $\begin{array}{c}\text { Result } \\
\mu \mathrm{g} / \mathrm{g}\end{array}$ & DF & $\begin{array}{c}\mathrm{MDL} \\
\mu \mathrm{g} / \mathrm{g}\end{array}$ & \begin{tabular}{|c|} 
Resulf \\
$\mathrm{ug} / \mathrm{g}$
\end{tabular} & DF & $\begin{array}{c}\text { MDI } \\
\mu \mathrm{g} / \mathrm{g}\end{array}$ & $\begin{array}{c}\text { Resuitt } \\
\text { Hg/g/g }\end{array}$ & DF \\
\hline $08-02074-103-\mathrm{S}$ & TI624-G7-6 & 21.2 & 130 & 678 & $\mathrm{~J}$ & 160 & 615 & $\mathrm{~J}$ & 210 & 19,100 & & 320 & \begin{tabular}{|l|}
16,200 \\
\end{tabular} & \\
\hline 08-02074-103-PB & Water Leach PB @2074 Dil. & 21.2 & 130 & 545 & $\mathbf{J}$ & 160 & 951 & $\mathrm{~J}$ & 210 & 210 & $\bar{U}$ & 320 & 320 & $\bar{U}$ \\
\hline $08-02075-103-\mathrm{S}$ & TI624-G7-9 & 7.3 & 45 & 759 & & 54 & 2,980 & & 73 & 14,500 & & 110 & 12,000 & \\
\hline $08-02074-103-\mathrm{PB}$ & Water Leach PB @2075 Dil. & 7.3 & 45 & 189 & $\mathrm{~J}$ & 54 & 324 & $\mathbf{J}$ & 73 & 73 & $\mathrm{U}$ & 110 & 110 & $\mathrm{U}$ \\
\hline $08-02076-103-\mathrm{S}$ & TI624-G7-12 & 29.8 & 18 & 456 & & 22 & 2,040 & & 300 & 13,300 & & 45 & 7,720 & \\
\hline \multirow{2}{*}{$08-02074-103-\mathrm{PB}$} & Water Leach PB @2076 Dil. & 29.8 & 18 & 77 & $\mathrm{~J}$ & 22 & 133 & $\mathbf{J}$ & 300 & 300 & $\mathrm{U}$ & 45 & 45 & $\mathrm{U}$ \\
\hline & & & $\mu \mathrm{g} / \mathrm{mL}$ & $\mu \mathrm{g} / \mathrm{mI}$ & $\overline{\text { DF }}$ & $\mu \mathrm{g} / \mathrm{mL}$ & $\mu \mathrm{gmi}$ & DF & $\mu \mathrm{g} / \mathrm{mL}$ & $\mu \mathrm{g} / \mathrm{mI}$ & $\overline{D F}$ & $\mu \mathrm{g} / \mathrm{mL}$ & $\mu \mathrm{g} / \mathrm{mL}$ & $\mathrm{DF}$ \\
\hline 08-02074-103-PB & Water Leach Process Blank & 1.0 & 0.031 & 0.130 & $\mathrm{~J}$ & 0.037 & 0.220 & $\mathbf{J}$ & 0.050 & 0.050 & $\mathrm{U}$ & 0.076 & 0.076 & $\mathrm{U}$ \\
\hline 072408 Dilution Blank & Dilution Blank 7-24 \& 7-25 & 1.0 & 0.031 & 0.031 & $\mathrm{U}$ & 0.037 & 0.037 & $\mathrm{U}$ & 0.050 & 0.050 & $\mathrm{U}$ & 0.076 & 0.076 & $\mathrm{U}$ \\
\hline \multirow{2}{*}{$\begin{array}{l}\text { RPL Number } \\
\text { RL }\end{array}$} & & \multirow[b]{2}{*}{$\begin{array}{l}\text { Leach } \\
\text { Dilutior }\end{array}$} & \multicolumn{2}{|r|}{$\mathrm{C}_{2} \mathrm{O}_{4}$} & & \multicolumn{3}{|c|}{$\mathrm{NO}_{3}$} & \multicolumn{3}{|c|}{$\mathrm{PO}_{4}$} & & & \\
\hline & & & \begin{tabular}{|c|}
$\mathbf{M D L}$ \\
$\mu \mathrm{g} / \mathrm{g}$
\end{tabular} & $\begin{array}{r}\text { Resuit } \\
\mu \mathrm{g} / \mathrm{g}\end{array}$ & DF & $\begin{array}{c}\text { MDL } \\
\mu \mathrm{g} / \mathrm{g}\end{array}$ & $\begin{array}{c}\text { Resuit } \\
\mu \mathrm{g} / \mathrm{g}\end{array}$ & DF & $\begin{array}{c}\mathrm{MDL} \\
\mu \mathrm{g} / \mathrm{g}\end{array}$ & $\begin{array}{c}\text { Resulf } \\
\mu \mathrm{g} / \mathrm{g}\end{array}$ & DF & & & \\
\hline $08-02074-103-\mathrm{S}$ & TI624-G7-6 & 21.2 & 210 & 2,820 & & 1,500 & 155,000 & & 250 & 45,200 & & & & \\
\hline 08-02074-103-PB & Water Leach PB @2074 Dil. & 21.2 & 210 & 210 & $\bar{U}$ & 1,500 & 1,500 & $\overline{\mathrm{U}}$ & 250 & 250 & $\mathrm{U}$ & & & \\
\hline $08-02075-103-\mathrm{S}$ & TI624-G7-9 & 7.3 & 73 & 2,640 & & 510 & 115,000 & & 310 & 66,100 & & & & \\
\hline $08-02074-103-\mathrm{PB}$ & Water Leach PB @2075 Dil. & 7.3 & 73 & 73 & $\overline{\mathrm{U}}$ & 510 & 510 & $\mathrm{U}$ & 310 & 310 & $\overline{\mathrm{U}}$ & & & \\
\hline $08-02076-103-S$ & T1624-G7-12 & 29.8 & 30 & 1,580 & & 600 & 70,300 & & 360 & 35,200 & & & & \\
\hline \multirow[t]{2}{*}{$08-0207 \overline{4-103-P B}$} & Water Leach PB @2076 Dil. & 29.8 & 30 & 30 & $\overline{\mathrm{U}}$ & 600 & 600 & $\mathrm{U}$ & $3 \overline{60}$ & \begin{tabular}{|l|}
360 \\
\end{tabular} & $\overline{\mathrm{U}}$ & & & \\
\hline & & & $\mu \mathrm{g} / \mathrm{mL}$ & $\mu \mathrm{g} / \mathrm{mL}$ & DF & $\mu \mathrm{g} / \mathrm{mL}$ & $\mu \mathrm{g} / \mathrm{mL}$ & DF & $\mu \mathrm{g} / \mathrm{mI}$ & $\mu \mathrm{g} / \mathrm{mI}$ & DF & & & \\
\hline 08-02074-103-PB & Water Leach Process Blank @1 & 1.0 & 0.050 & 0.050 & $\overline{\mathrm{U}}$ & 0.10 & 0.10 & $\mathrm{U}$ & 0.060 & 0.060 & $\mathrm{U}$ & & & \\
\hline 072408 Dilution Blank & Dilution Blank 7-24 \& 7-25 & 1.0 & 0.050 & 0.050 & $\mathrm{U}$ & 0.10 & 0.10 & $\bar{U}$ & 0.060 & 0.060 & $\mathrm{U}$ & & & \\
\hline
\end{tabular}

\section{Water Leached Solids QC Results -- ASR 8176}

Sample/Replicate Precision Results ${ }^{(2)}$

\begin{tabular}{|c|c|c|c|c|c|c|c|c|c|c|c|c|c|c|c|}
\hline & Sample/Duplicate & \multicolumn{2}{|c|}{ F } & \multicolumn{2}{|c|}{ Cl } & \multicolumn{2}{|c|}{$\mathrm{NO}_{2}$} & \multirow{2}{*}{\multicolumn{2}{|c|}{$\frac{\mathrm{SO}_{4}}{\mu \mathrm{g} / \mathrm{g} / \% \mathrm{RSD}}$}} & \multicolumn{2}{|c|}{$\mathrm{C}_{2} \mathrm{O}_{4}$} & \multicolumn{2}{|c|}{$\mathrm{NO}_{3}$} & \multicolumn{2}{|c|}{$\mathrm{PO}_{4}$} \\
\hline RPL Number & Designation & $\mu \mathrm{g} / \mathrm{g}$ & \%RSD & $\mu \mathrm{g} / \mathrm{g}$ & $\%$ RSD & $\mu \mathrm{g} / \mathrm{g}$ & $\%$ RSD & & & $\mu g / g$ & \%RSD & $\mu \mathrm{g} / \mathrm{g}$ & \%RSD & $\mu \mathrm{g} / \mathrm{g}$ & \%RSD \\
\hline 08-02074-103-D & Duplicate & $\mathrm{J}$ & $n / a$ & $\mathrm{~J}$ & $n / a$ & 18,600 & 2 & 15,500 & 4 & 2,650 & 6 & 149,000 & 4 & 39,800 & 13 \\
\hline
\end{tabular}

Sample Spike Results - Prior to Water Leach and at IC Workstation ${ }^{(a)}$

\begin{tabular}{|c|c|c|c|c|c|c|c|c|c|c|c|c|c|c|c|}
\hline \multirow{2}{*}{ RPL Number } & \multirow{2}{*}{$\begin{array}{l}\text { Sample/Spike } \\
\text { Designation }\end{array}$} & \multicolumn{2}{|c|}{$\mathbf{F}:-1$} & \multicolumn{2}{|c|}{$\mathrm{Cl}$} & \multicolumn{2}{|c|}{$\mathrm{NO}_{2}$} & \multicolumn{2}{|c|}{$\mathrm{SO}_{4}$} & \multirow{2}{*}{\multicolumn{2}{|c|}{\begin{tabular}{|c|}
$\mathrm{C}_{2} \mathrm{O}_{4}$ \\
$1 \mathrm{~g} / \mathrm{mL}$ \\
$\% \mathrm{Rec}$ \\
\end{tabular}}} & \multicolumn{2}{|c|}{$\mathrm{NO}_{3}$} & \multicolumn{2}{|c|}{$\mathbf{P O}$} \\
\hline & & $1 \mathrm{~g} / \mathrm{mL}$ & \%Ree & Hg/mL & $\%$ Recl & Hg/mL/ & $\% \operatorname{Rec}$ & $\mu \mathrm{g} / \mathrm{mL}$ & \%Red & & & $\mu \mathrm{g} / \mathrm{mL}$ & $\%$ Rec & Hg/mul & \%Rer \\
\hline \multicolumn{16}{|c|}{ LCS/BS- Leached } \\
\hline \multirow{2}{*}{$\begin{array}{l}\text { 072508 Dilution Blank } \\
\text { 08-02074-103-BS-IC }\end{array}$} & Dilution Blank & $\mathrm{U}$ & -- & $\mathrm{U}$ & \begin{tabular}{l|l}
-- & \\
\end{tabular} & U & -- & $\mathrm{U}$ & -- & $\mathrm{U}$ & -- & $\mathrm{U}$ & - & $\mathrm{U}$ & -- \\
\hline & LCS Sample & 5.1 & 105 & 6.2 & 105 & 7.7 & 100 & 11.7 & 101 & 7.6 & 99 & 13.9 & 103 & 9.5 & 99 \\
\hline \multirow{2}{*}{$\begin{array}{l}\text { 072508 Dilution Blank } \\
\text { 08-02074-103-BS-IC(20) }\end{array}$} & Dilution Blank & $\mathrm{U}$ & -- & $\mathrm{U}$ & -- & $\mathrm{U}$ & -- & $\mathrm{U}$ & $\cdots$ & $\mathrm{U}$ & -- & $\mathrm{U}$ & -- & $\mathrm{U}$ & -- \\
\hline & LCS Sample & 5.1 & 105 & 6.3 & \begin{tabular}{|l|l|}
108 \\
\end{tabular} & \begin{tabular}{|l|}
7.7 \\
\end{tabular} & 100 & 12 & 104 & 7.1 & 92 & $\overline{14}$ & 104 & 8.9 & 93 \\
\hline \multicolumn{16}{|c|}{ Matrix Spike - Leached } \\
\hline \multirow{2}{*}{$\begin{array}{l}08-02076-103-\mathrm{S} \\
08-02076-103-\mathrm{MS}\end{array}$} & Sample & $15 . \overline{3}$ & \begin{tabular}{l|l}
-- & \\
\end{tabular} & 68.4 & \begin{tabular}{|l|}
-- \\
\end{tabular} & 447 & -- & 259 & -- & 53.1 & $\because$ & 2,360 & -- & $\mathrm{I}, 180$ & -- \\
\hline & MS Sample & 24.2 & \begin{tabular}{|l|l}
$\mathrm{n} / \mathrm{a}$ \\
\end{tabular} & 94.2 & \begin{tabular}{|l|}
$\mathbf{n} / \mathbf{a}$ \\
\end{tabular} & \begin{tabular}{|l|l|}
588 & \\
\end{tabular} & $\mathrm{n} / \mathrm{a}$ & 352 & $\mathrm{n} / \mathrm{a}$ & 88 & $\mathrm{n} / \mathrm{a}$ & 2,930 & $\mathrm{n} / \mathrm{a}$ & 1,440 & $\mathrm{n} / \mathrm{a}$ \\
\hline \multicolumn{16}{|c|}{ Analytical Post Spike - After Leaching } \\
\hline \multirow[t]{2}{*}{$08-02076-103-S$} & Sample & $15 . \overline{3}$ & \begin{tabular}{|l|}
- \\
\end{tabular} & 68.4 & \begin{tabular}{|l|l|}
-- & \\
\end{tabular} & $4 \overline{47}$ & -- & 259 & -- & 53.1 & -- & 2,360 & -- & 1,180 & -- \\
\hline & PS (Sample @40x Dilution) & 1.32 & 94 & 2.92 & 101 & $\mathrm{o} / \mathrm{r}$ & $\mathrm{n} / \mathrm{a}$ & 10.1 & 97 & 3.79 & 99 & $0 / \mathrm{r}$ & $\mathrm{n} / \mathrm{a}$ & $\mathrm{o} / \mathrm{r}$ & $n / a$ \\
\hline \multirow[t]{2}{*}{$08-02076-103-S$} & Sample & 15.3 & -- & 68.4 & +- & 447 & -- & 259 & -- & 53.1 & -- & 2,360 & -- & 1,180 & $-\sim$ \\
\hline & PS (Sample@400x Dilution) & 1.06 & 102 & 1.34 & 97 & 3.54 & 97 & 4.33 & 98 & 2.64 & 100 & 10.3 & 101 & 6.01 & 98 \\
\hline \multirow[t]{2}{*}{ 08-02076-J03-S } & Sample & 15.3 & -- & 68.4 & -- & 447 & -- & 259 & -- & 53.1 & -- & 2,360 & -- & 1,180 & $-\cdot$ \\
\hline & PS (Sample @1400x Dilution) & 1.03 & 102 & 1.22 & 98 & 2.76 & 98 & $3 . \overline{88}$ & 98 & 2.53 & 100 & 6.06 & 100 & 3.84 & 96 \\
\hline \multicolumn{16}{|l|}{ LCS Results - IC System } \\
\hline RPL Number & Run ID & $\begin{array}{c}F \\
\% \text { Rec }\end{array}$ & $\begin{array}{r}\text { CI } \\
\% \text { Rec }\end{array}$ & $\begin{array}{l}\mathrm{NO}_{2} \\
\% \mathrm{Rec}\end{array}$ & \begin{tabular}{|c|}
$\mathrm{SO}_{4}$ \\
$\% \mathrm{Rec}$ \\
\end{tabular} & $\begin{array}{l}\mathrm{C}_{2} \mathrm{O}_{4} \\
\% \text { Rec }\end{array}$ & $\begin{array}{l}\mathrm{NO}_{3} \\
\% \mathrm{Rec} \\
\end{array}$ & $\begin{array}{c}\mathrm{PO}_{4} \\
\% \mathrm{Rec} \\
\end{array}$ & & & & & & & \\
\hline LCS & $7 / 24 / 200820: 59$ & 100 & 98 & 99 & 99 & 98 & 101 & 95 & & & & & & & \\
\hline LCS & $7 / 25 / 200819: 03$ & 101 & 99 & 102 & 101 & 100 & 118 & 98 & & & & & & & \\
\hline
\end{tabular}

D = Duplicate; S = Sample; DF = Data Flag; \%Rec = Percent Recovery; RPD = Relative Percent Difference' o/r $=0$ over range; $\mathrm{n} / \mathrm{a}=\mathrm{not}$ applicable

LCS/BS = Laboratory Control Sample/Blank Spike: Standard processed through entire cycle ... including water leaching.

LCS = Laboratory Control Sample (Standard analyzed at IC Workstation)

MS = Matrix Spike: Sample spiked with standard solution and processed through entire cycle ... including water leaching.

PS = Analytical Post Spike: Spike performed at IC Workstation on same sample as MS prepared from.

$U=$ Data Flag for Not Detected Above Method Detection Limit

$\mathrm{J}=$ Data Flag for Detected, Result are Qualitative: Result $>$ MDL but $<$ EQL (estimated quantitation limit)

-- = Value Not Calculated, place holder for blank cell

(a) \%RPD not calculated (i.e., n/a) if either result is $<\mathrm{EQL}$; \% Rec not calculated (i.e., n/a) if sample or AS over-range, or spike is $<25 \%$ of sample concentration 


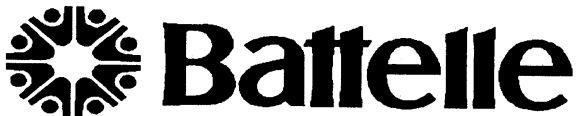 \\ ... Putting Technology To Work}

Client: $\quad$ Rick Shimskey

Subject: Hydroxide Analyses for:

ASR: $\quad 8176 \quad$ Rev-0

Sample ID. $\quad 08-02059 \quad$ thru

\begin{tabular}{rl|} 
Report Date: & $7 / 3 / 2008$ \\
Analysis Date: & $7 / 1 / 2008$ \\
\hline
\end{tabular}

CUF Group 7 (TPB Sludge) / 241-AY-102

Waste Treatability Study

Procedure: RPG-CMC-228-Rev 1

Direct sample aliquots of CUF Group 7 (TPB Sludge) / 241-AY-102 Waste Treatability Study samples (see above assigned RPL Sample \#'s), 13 samples total were analyzed in duplicate for the base constituents content following procedure RPG-CMC-228, and using a Brinkman 636 Auto-Titrator. The titrant used was $0.1016 \mathrm{M} \mathrm{HCl}$ and the base standard, $0.1118 \mathrm{M} \mathrm{NaOH}$ was used for QC verification standards and matrix spike. -- See Chemrec_139 pdf imbedded in the result report.

The hydroxide Standard recovery was $98 \%$, well within the allowed $\pm 20 \%$ recovery range. Although not required in this ASR, 2 matrix spike were analyzed with recoveries of $99 \%$ and $89 \%$. No hydroxide was detected in the reagent blank.

The initial pH is reported on attached Report Summary along with the free hydroxide molarities at an average $\mathrm{pH}$ of 10 to 11 . These results showed excellent Relative Percent Deviation (RPD) for the first inflection point, all $<7 \%$, well within $\pm 20 \%$ allowed range. A 2 nd inflection point around $\mathrm{pH} 7-8$, indicating final hydroxide molarity or carbonate also showed very good RPD's, well within $\pm 20 \%$ allowed range. All samples also indicated a third inflection point, probably bicarbonate, around $\mathrm{pH} 4-5$, and again all RPD's were within \pm $20 \%$ allowed range.

The best estimate of the MDL for this method is obtained from the reagent blank which did not show any inflection points and is consistent with a value of 0 within our measurement sensitivity. All samples molarities were well above the MDL $(0.1 \mathrm{M})$ for this analysis. The results are accepted based on the QC data meeting the acceptance criteria as specified in the ASR.

Following is the report summary, the sample results calculated from the raw data, and the record file for the standardized acid and base used. The sample fractions provided were consumed in the analysis process. Copies of the titration curves are available upon request.

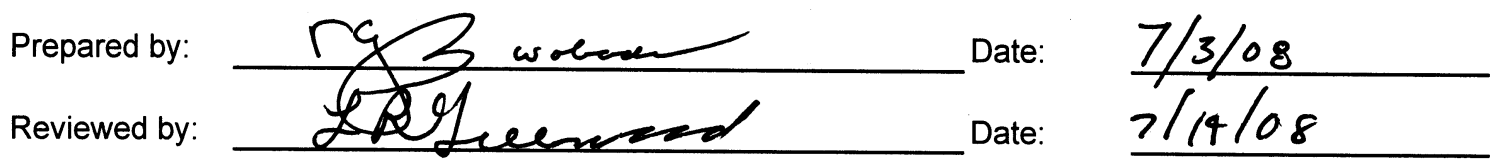


Battelle Pacific Northwest Laboratory

Radiochemical Processing Group-325 Building

Chemical Measurements Center

Hydroxide and Alkalinity Determination

Procedure: RPG-CMC-228-Rev 1
ASR \# $\mathbf{8 1 7 6}$

WP\# F99189

Equip \# WB76843

\section{Report Summary for ASR \# -- 8176}

Revision \# Rev-0

\begin{tabular}{rr|} 
Report Date: & $7 / 3 / 2008$ \\
Analysis Date: & $7 / 1 / 2008$ \\
\hline
\end{tabular}

Concentration, moles / Liter

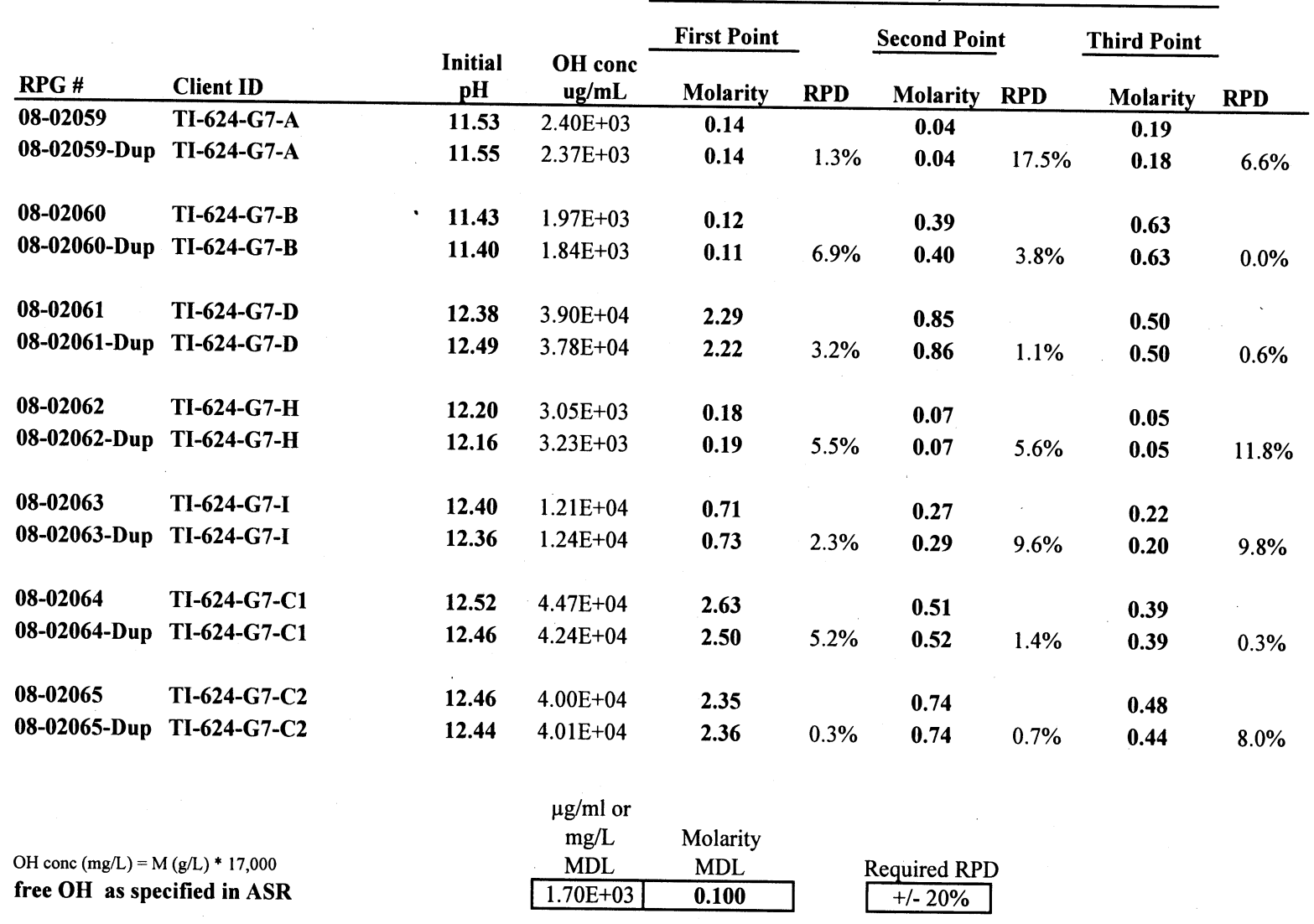

Reag. Blk.1

0

Allowed Recovery Range

Standard 1

12.56

$97.6 \%$

$+/-20 \%$

12.47

$98.6 \%$
$+/-20 \%$

Note: Results are presented for the first, second, and third inflection points on the titration curves, as applicable. The first inflection point is generally associated with the free hydroxide concentration. The second inflection point generally represents total hydroxide, or carbonate or a combination of aluminate and carbonate. The third inflection point is usually indicative of bicarbonate or other weak acids or possibly the continued protonation of alumina.

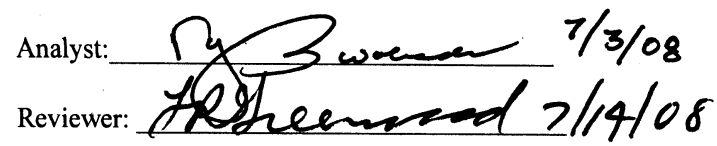


Battelle Pacific Northwest Laboratory

Radiochemical Processing Group-325 Building

Chemical Measurements Center

Hydroxide and Alkalinity Determination

Procedure: RPG-CMC-228-Rev 1

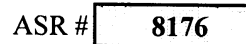

WP\# F99189

Equip \# WB76843

$$
\begin{array}{r}
\text { Report Summary for ASR \# -- } 8176 \\
\text { Revision \# Rev-0 }
\end{array}
$$

\begin{tabular}{rr|}
$r$ Report Date: & $7 / 3 / 2008$ \\
Analysis Date: & $7 / 1 / 2008$ \\
\hline
\end{tabular}

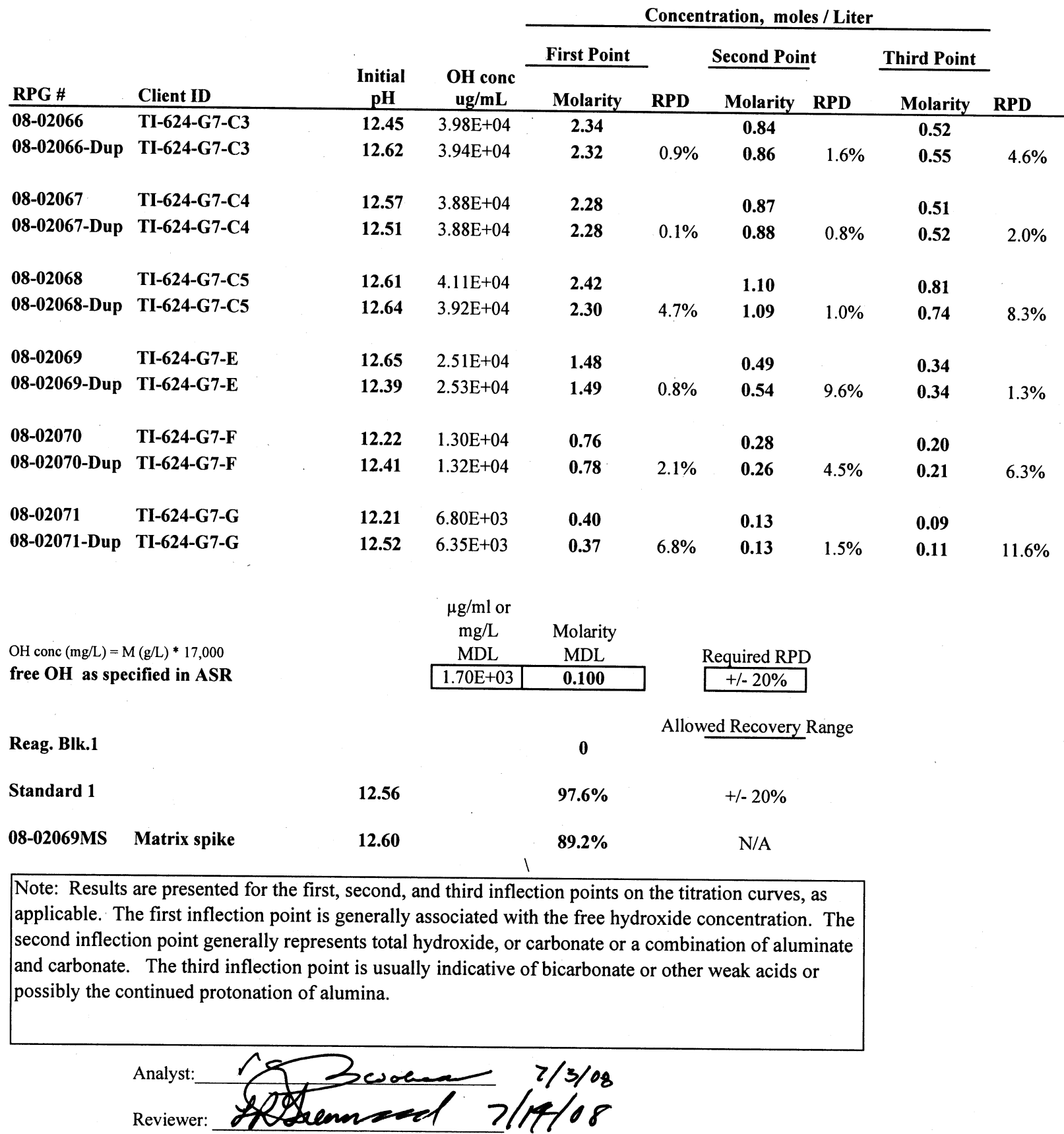




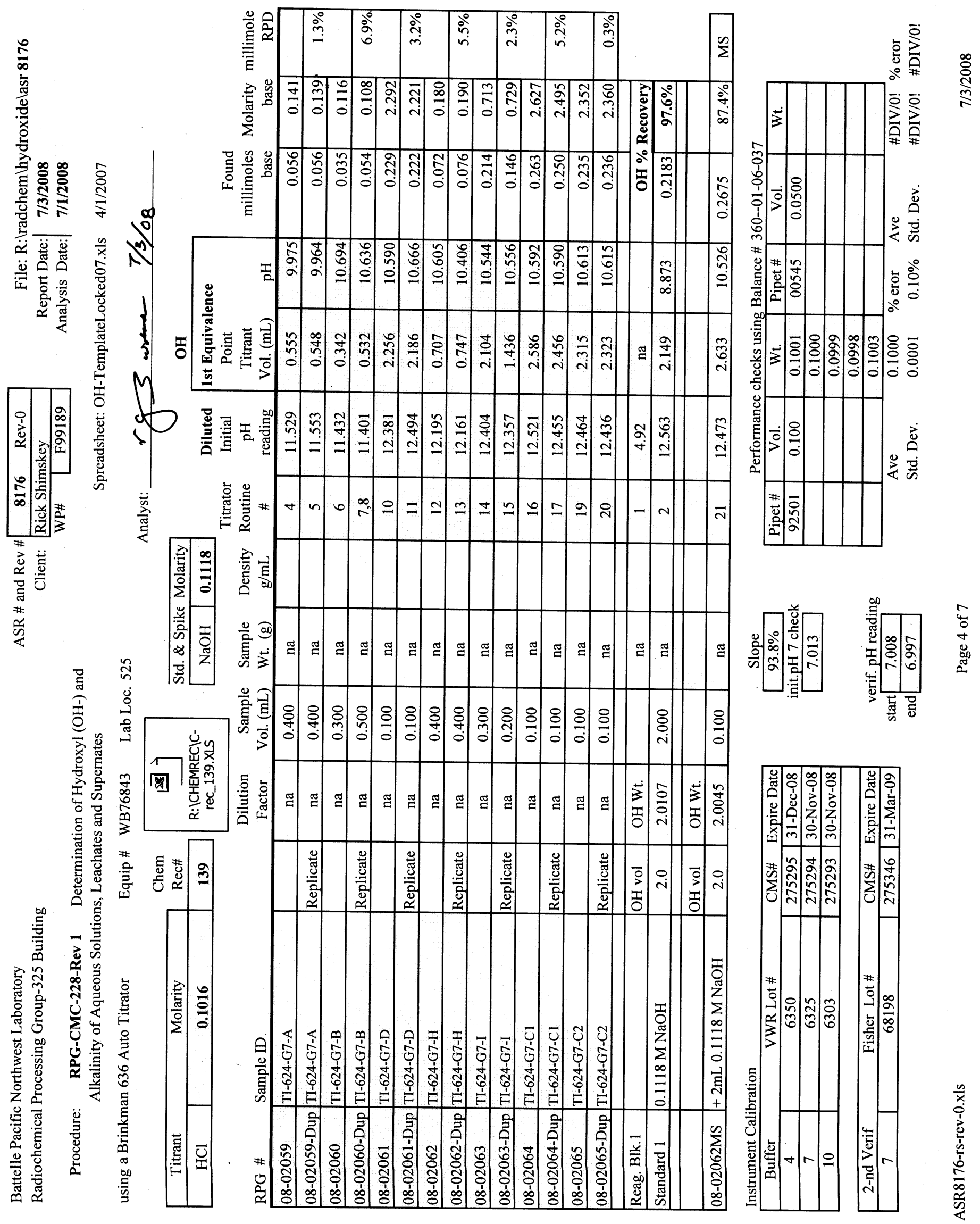




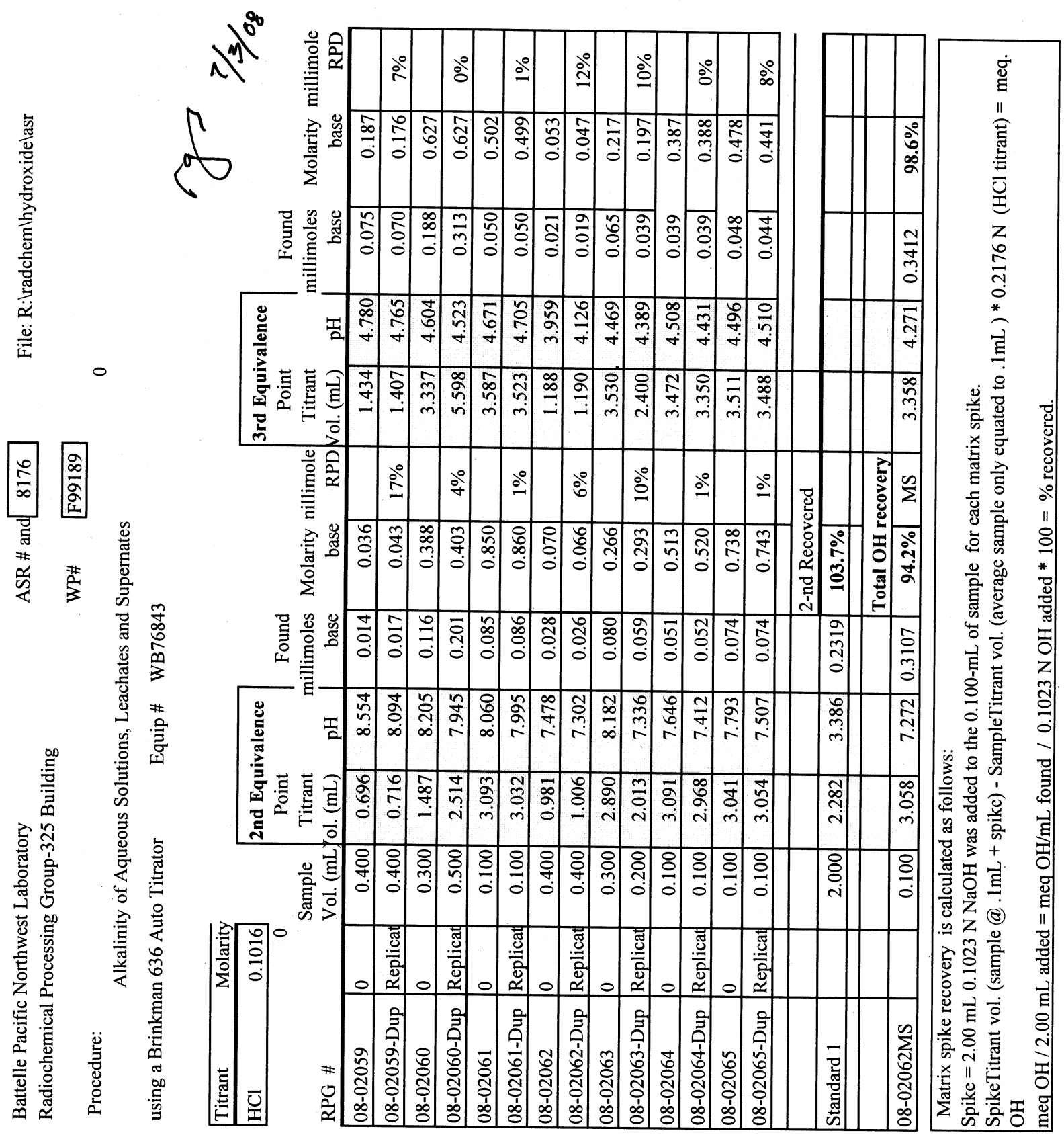




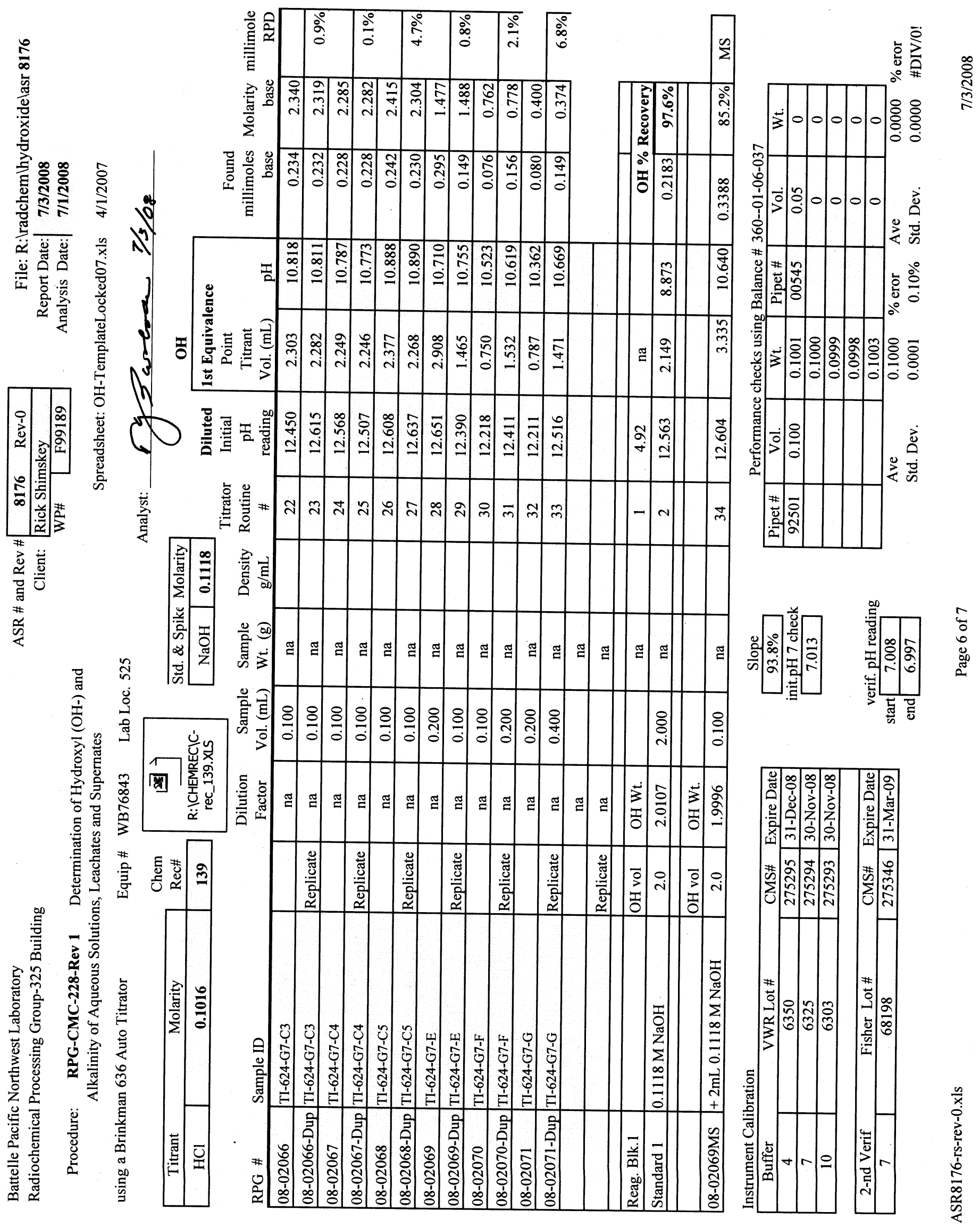



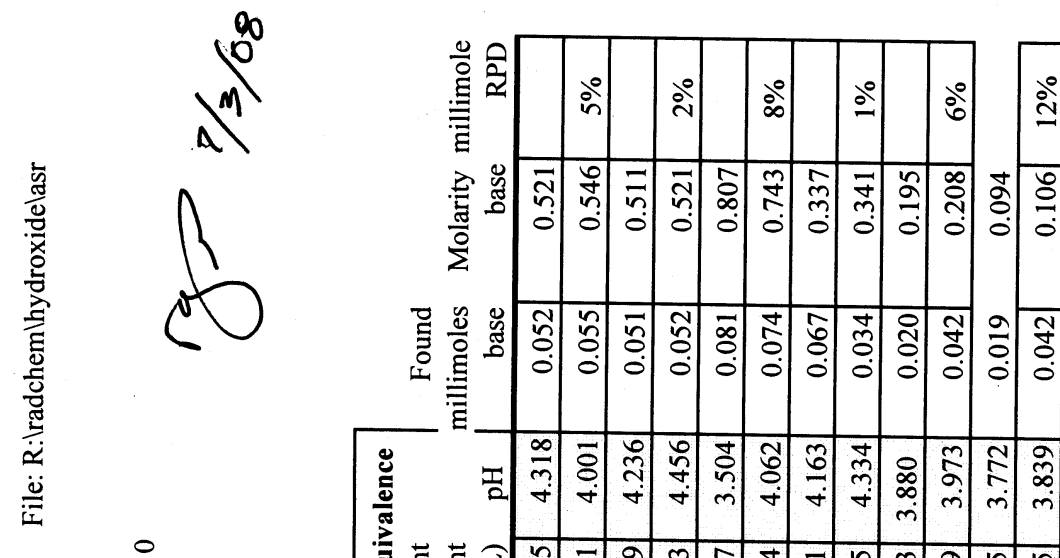

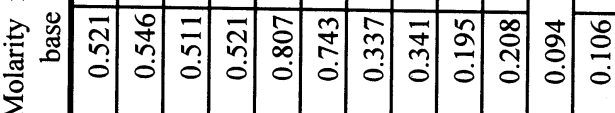
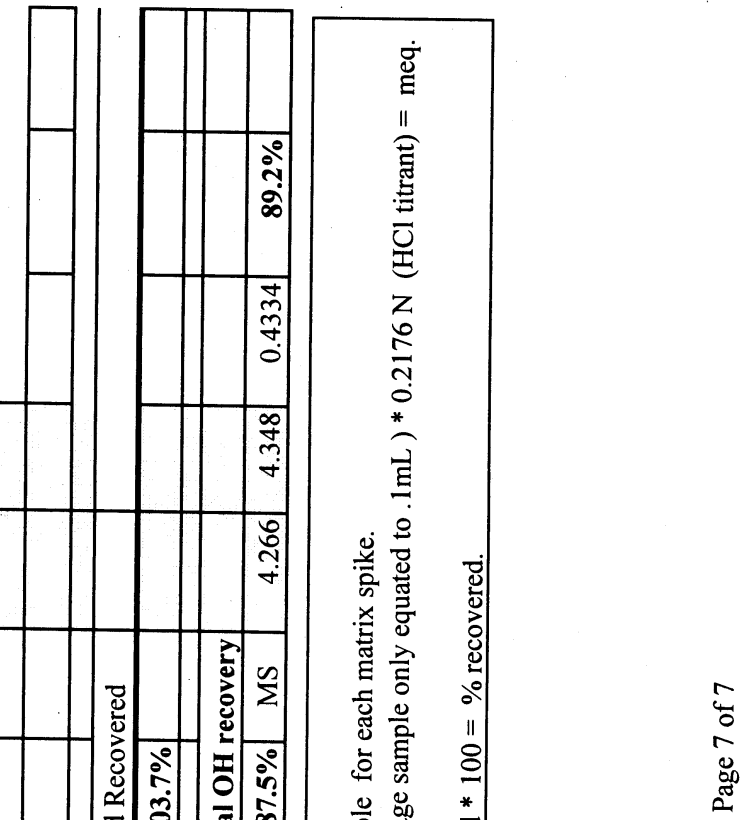

这

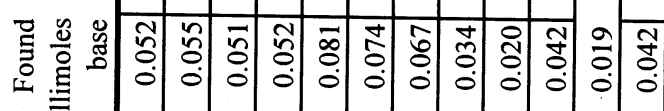

1
0
0
0
0
0

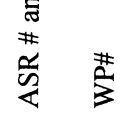

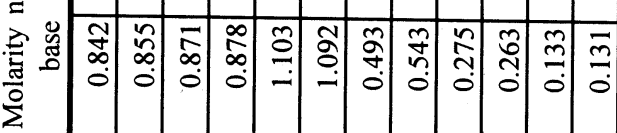

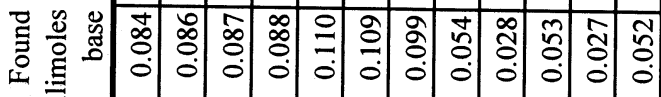

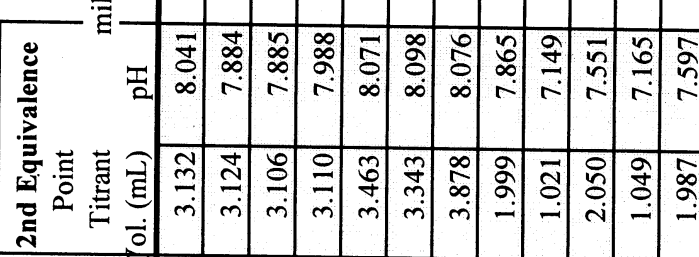

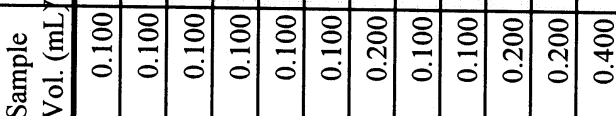

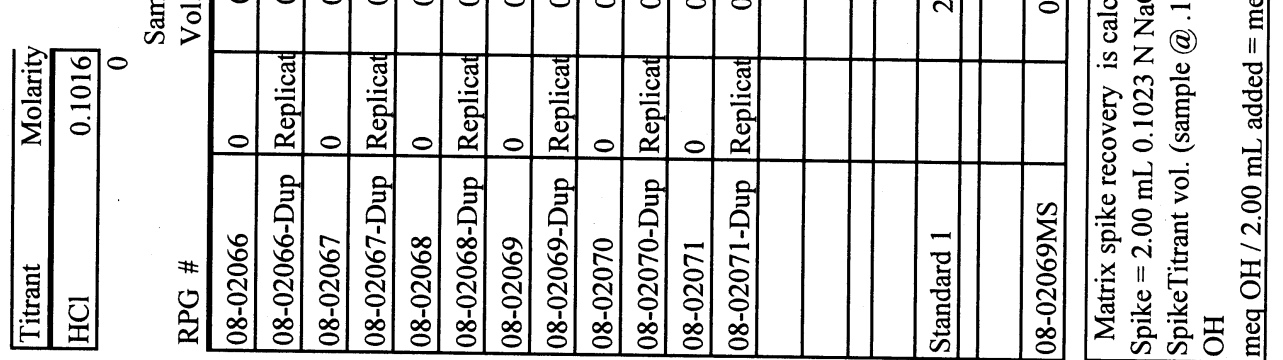

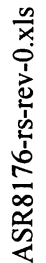



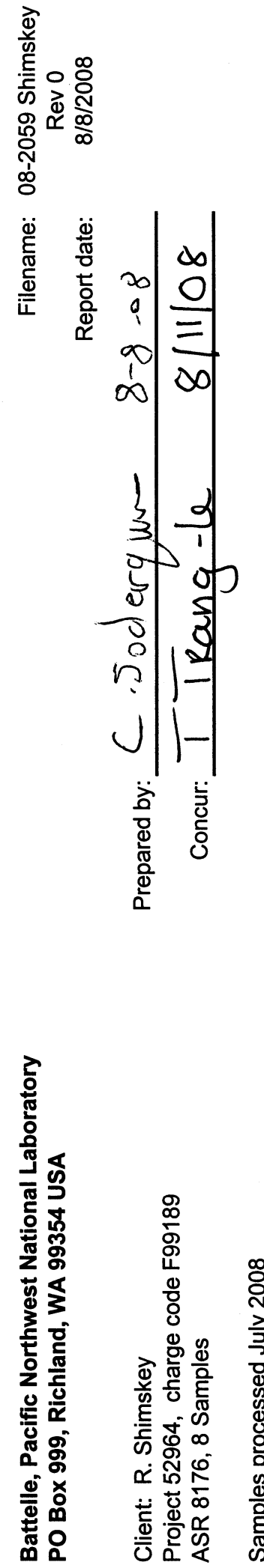

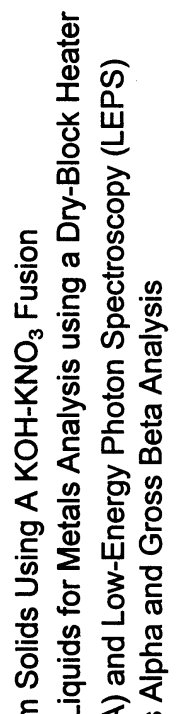

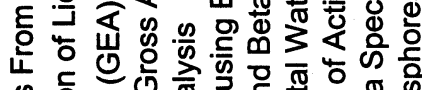

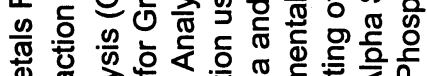

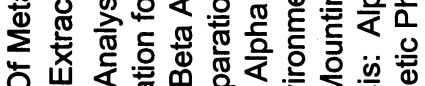

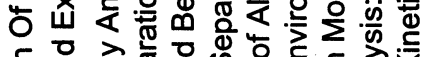

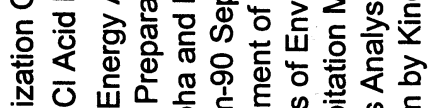
승 우

冬 旁

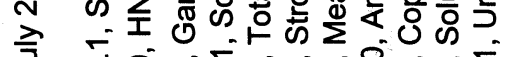

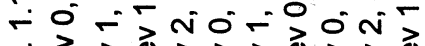

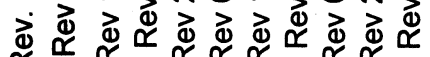
นึ ¿̇ं 安施 $\sum_{0} \sum_{0} \sum_{0} \sum_{0} \sum_{0} \sum_{0} \sum_{0} \sum_{0} \sum_{0}$ 光

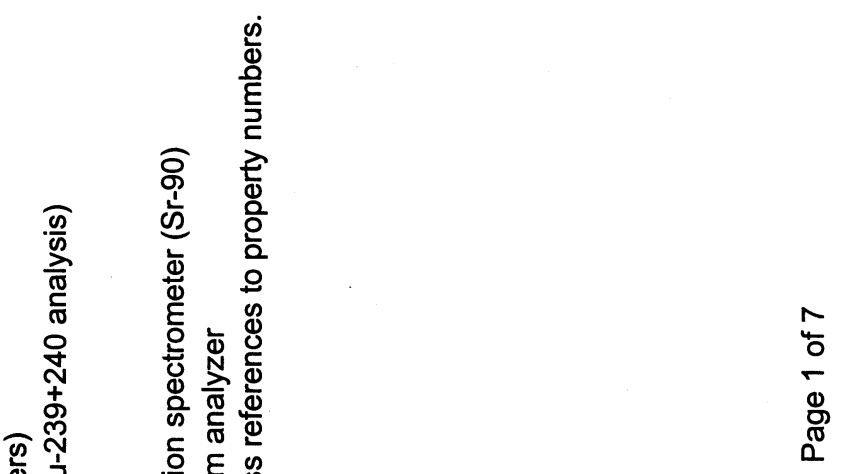

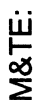

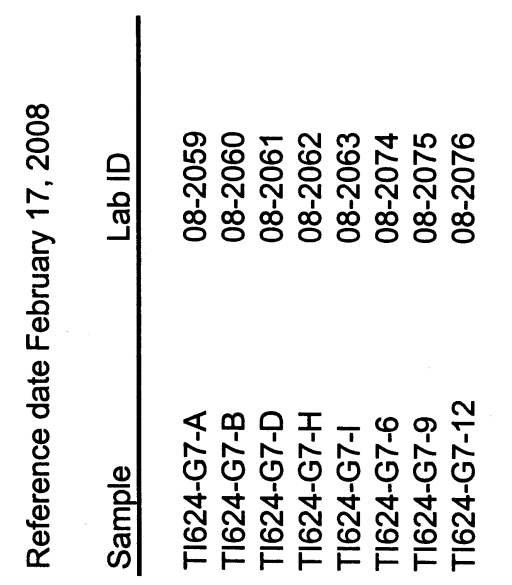


Battelle, Pacific Northwest National Laboratory

Richland, WA

Radiochemical Sciences and Engineering Group filename $\quad 08-2059$ Shimskey

$8 / 8 / 2008$

Client: R. Shimskey

ASR 8176

\section{The Samples}

These samples originated in the hot cells and arrived in the analytical lab in June 2008. The samples required analysis of metals by ICPOES, hydroxide, anions, and several radionuclides. Only the radiochemistry data is reported here; the inorganic analytes are reported separately.

\section{Sample Preparation}

The aqueous samples were digested in dilute nitric acid (procedure RPG-CMC-128) in a laboratory fume hood. The solid samples were fused with potassium hydroxide (procedure PNL-ALO-115) in a hot cell.

\section{Quality Control Results}

All of the quality control results fell well within the limits prescribed by the project.

All of the requested detection limits were met except for Eu-155 and Am-241 in the aqueous samples, where the Compton background from high Cs-137 activity raised the detection limit for Eu155 and Am-241. The hot cell blank results are small compared to the accompanying samples. All pairs of duplicates agree closely. All of the spike recoveries fell within the limits prescribed by the project, and within expected uncertainty.

\section{Gamma Emitters (procedure RPG-CMC-450)}

Gamma emitters were measured by counting aliquots of the acid digestions and potassium hydroxide fusions. All gamma emitters that were detected were reported, except for potassium-40. Eu-152 was found in the solid samples and is included on the report, even though it was not explicitely requested by the Project. Because no sample preparation or separation is done for gamma counting, no spikes are prepared.

\section{Gross Alpha and Gross Beta (procedures RPG-CMC-4001 and -408)}

To measure gross alpha, a small volume of each sample solution (the acid digestion or fusion solution) was dried onto a steel disk and counted on a Ludlum solid scintillation alpha counter.

To measure gross beta, a small volume of each sample solution was evaporated onto a planchet and counted on a gas proportional counter . Nearly all the activity is beta, not alpha, and crosstalk corrections were not necessary. Solids loading on the counting planchets was too small to affect the data. 
Battelle, Pacific Northwest National Laboratory Richland, WA Radiochemical Sciences and Engineering Group filename $\quad 08-2059$ Shimskey $8 / 8 / 2008$

Client: R. Shimskey

ASR 8176

All but one of the aqueous samples have too little alpha to measure accurately by gross alpha counting. The sum of Pu-239+240, Pu-238, and Am-241 is a more accurate and sensitive estimate of the gross alpha activity of these samples. (Uranium contributes only a small part of the alpha activity.) Only a small amount of the fusion solution can be evaporated onto a counting disk without compromising the accuracy from mass loading.

The gross beta activity agrees reasonably well with the sum of Cs-137, Sr-90, and Y-90.

Strontium-90 (procedures RPG-CMC-476 and -474)

Strontium was chemically separated from the acid digestion preparations, then measured by liquid scintillation.

Plutonium (procedures RPG-CMC-4017, -496, and -422)

Plutonium was separated from the sample solutions by anion exchange in hydrochloric acid, then mounted for alpha spectroscopy by coprecipitation, then measured using alpha spectrometry.

Uranium (procedures RPG-CMC-4017 and -4014)

Uranium was chemically separated from the samples by anion exchange in hydrochloric acid, then measured by kinetic phosphorescence. All of the samples have easily measurable uranium, well above the blanks.

Raw aqueous sample, not the acid digestion, was used for uranium analysis. No uranium concentration is given for the acid digestion blank because the acid digestion was not used for uranium analysis. 


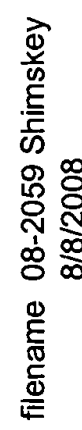

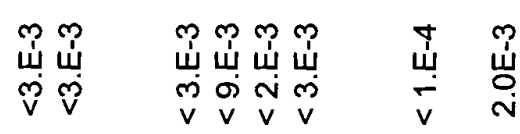

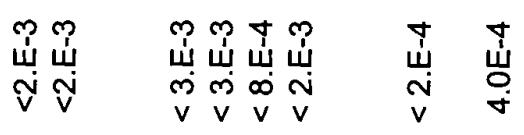

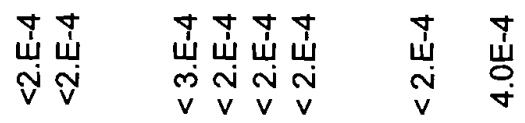

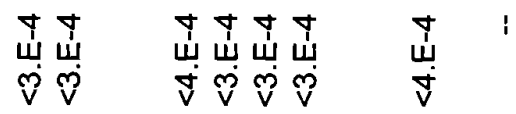
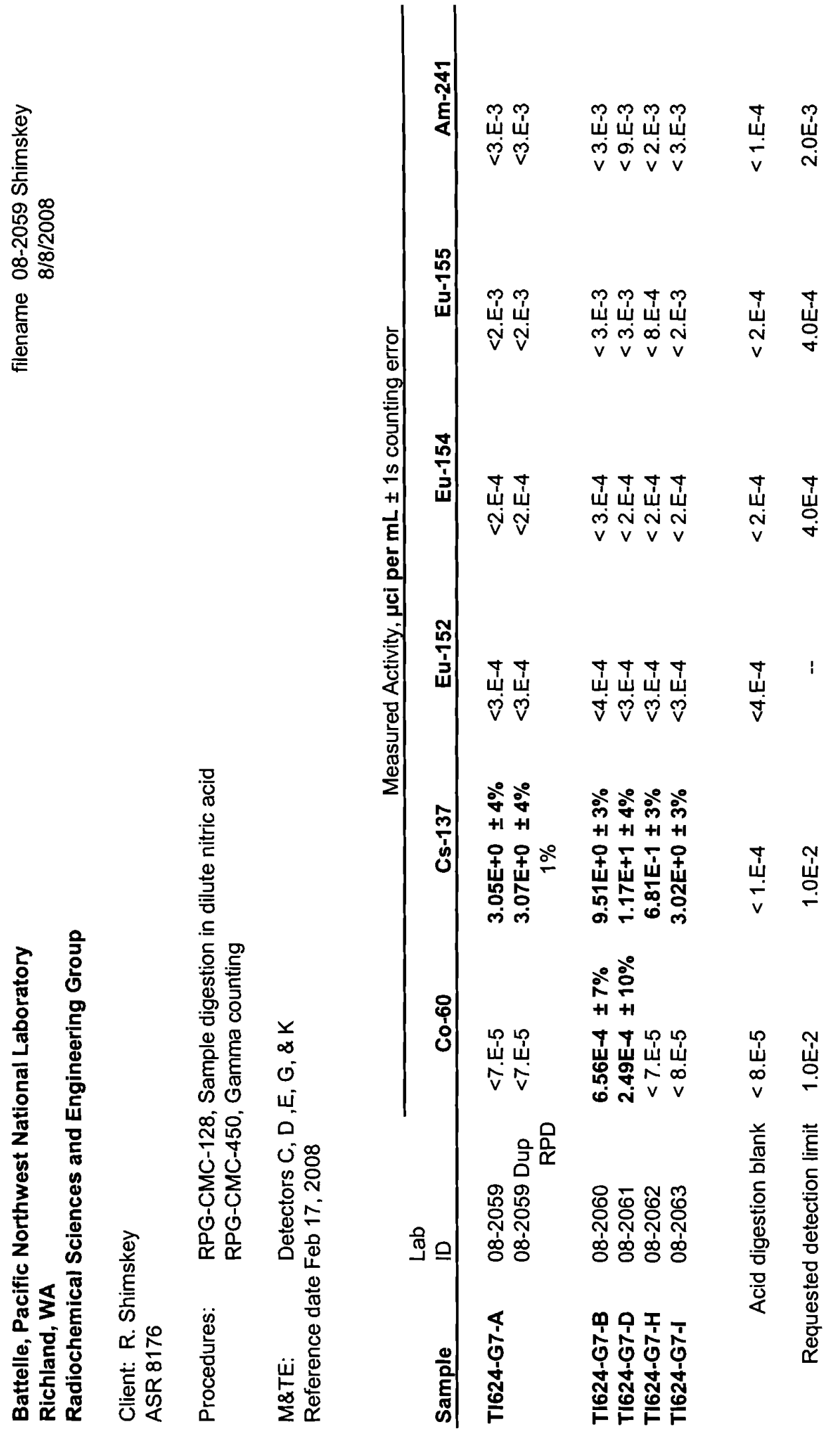

L 100740

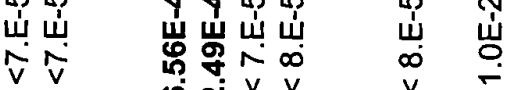

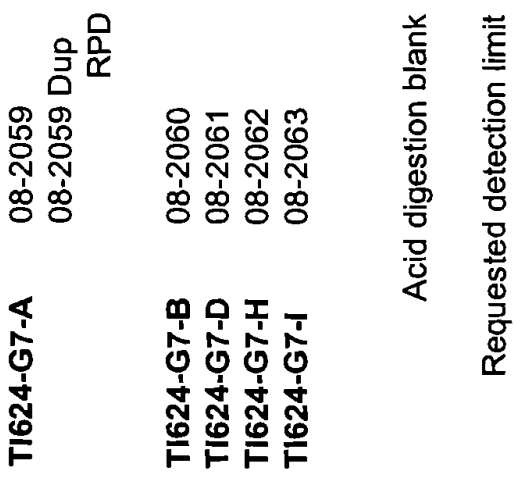




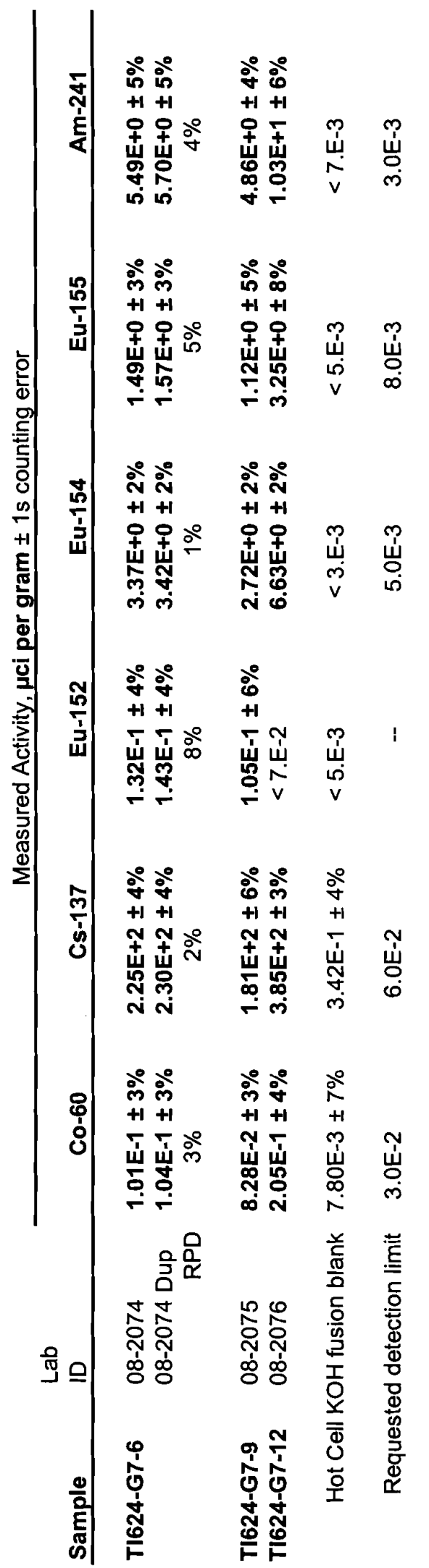



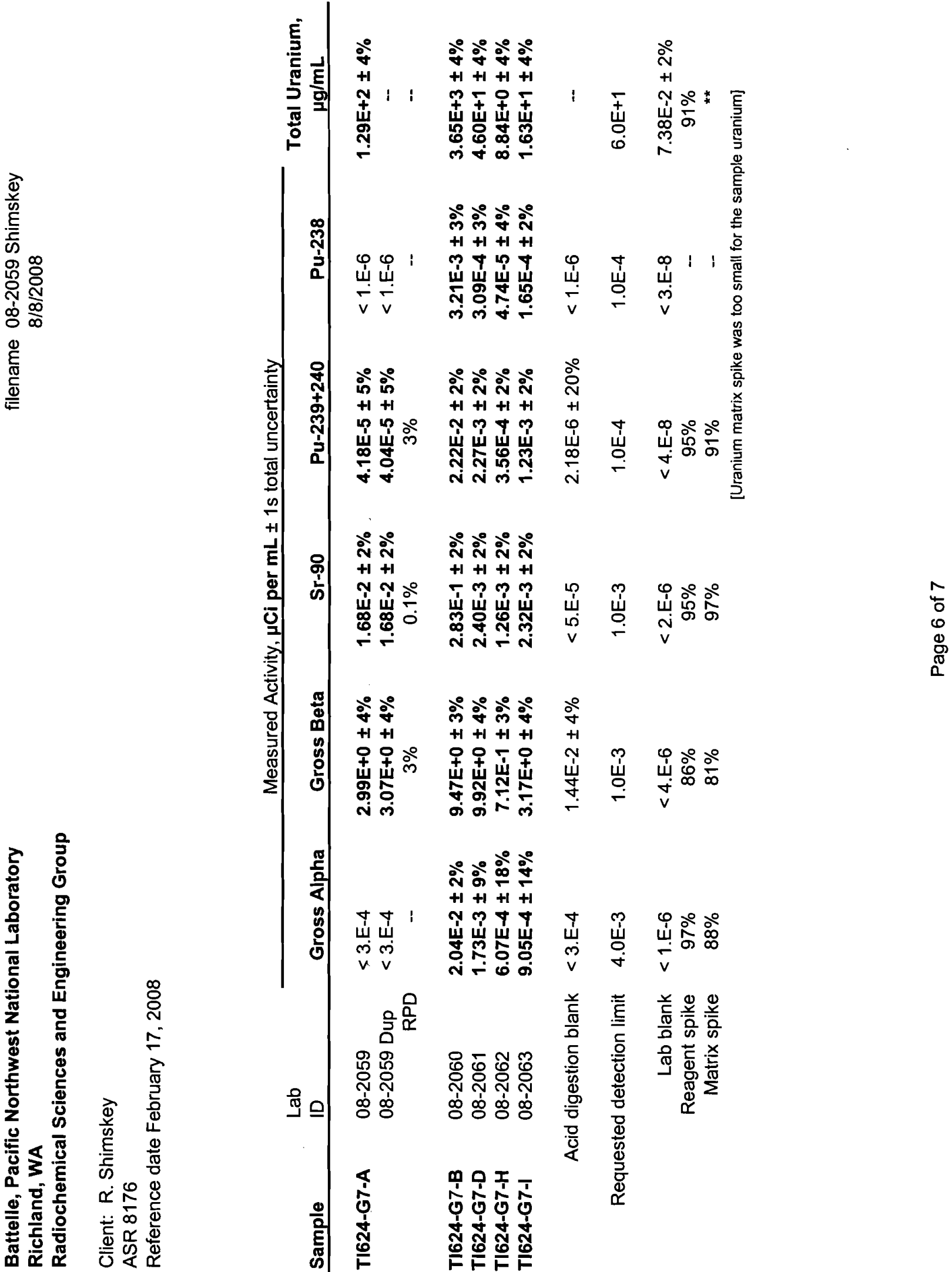

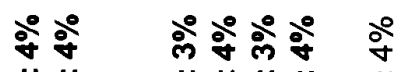

$+1+1+1+1+1+1$

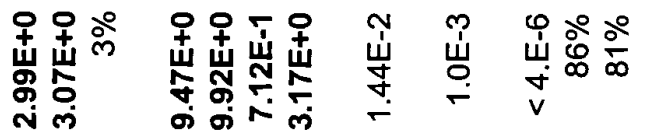

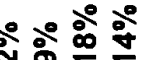

$+1+1+1+1$

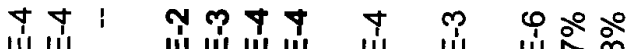

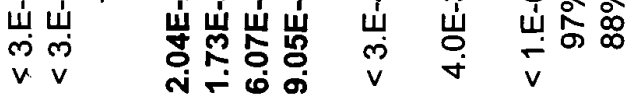

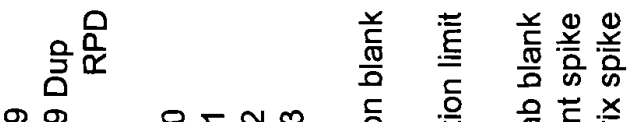

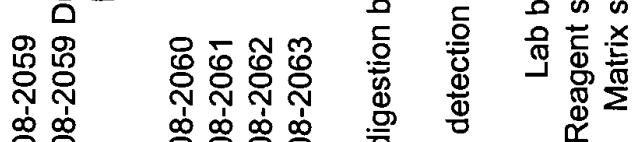

모 으

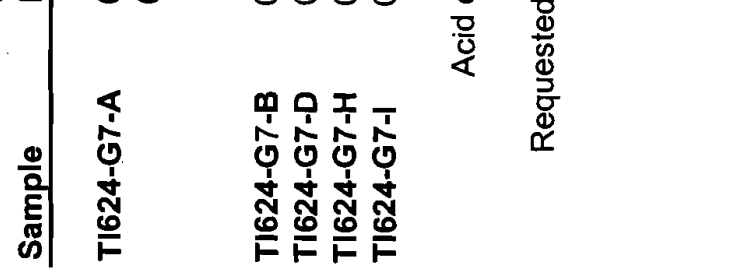




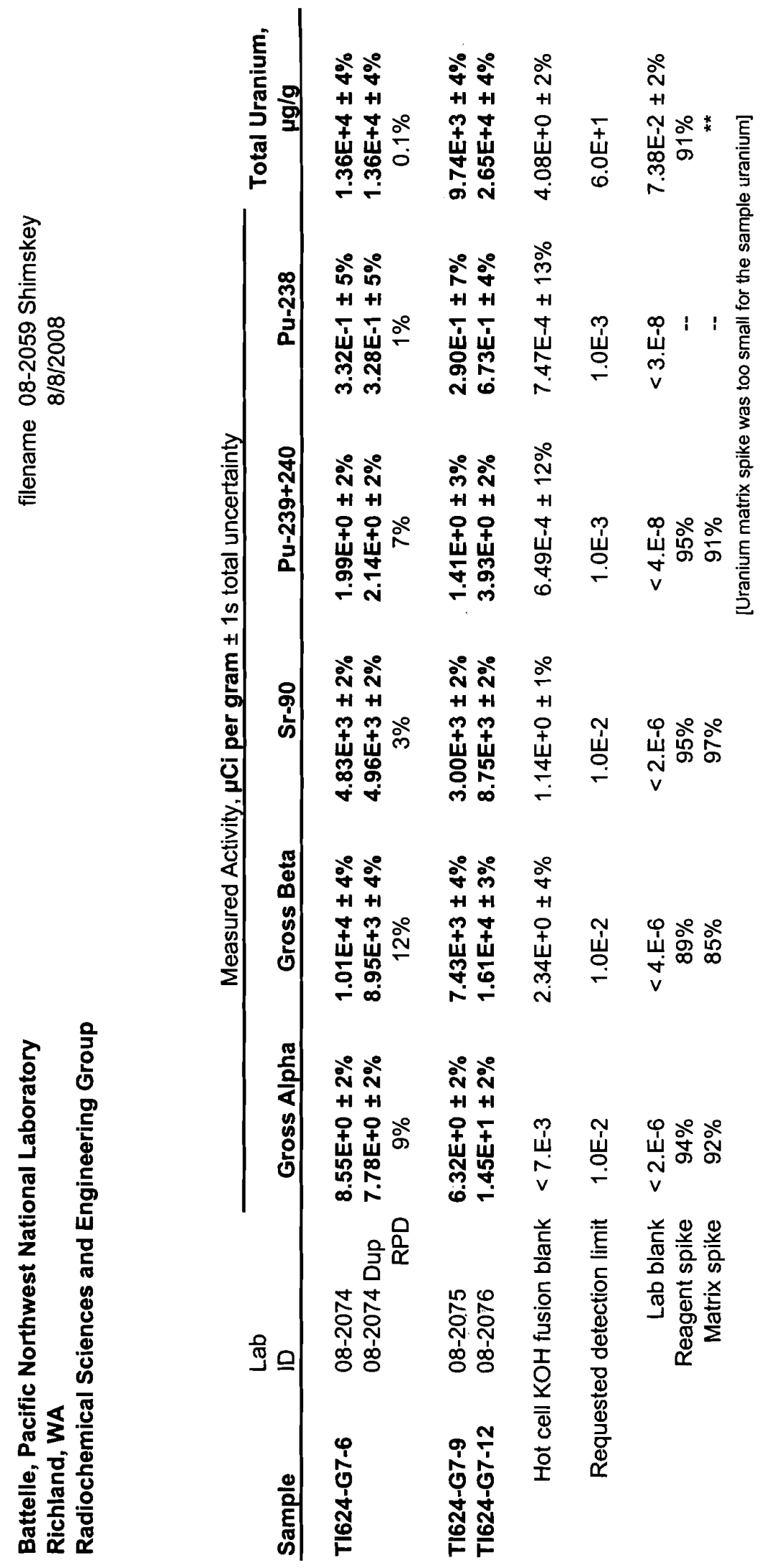


怘

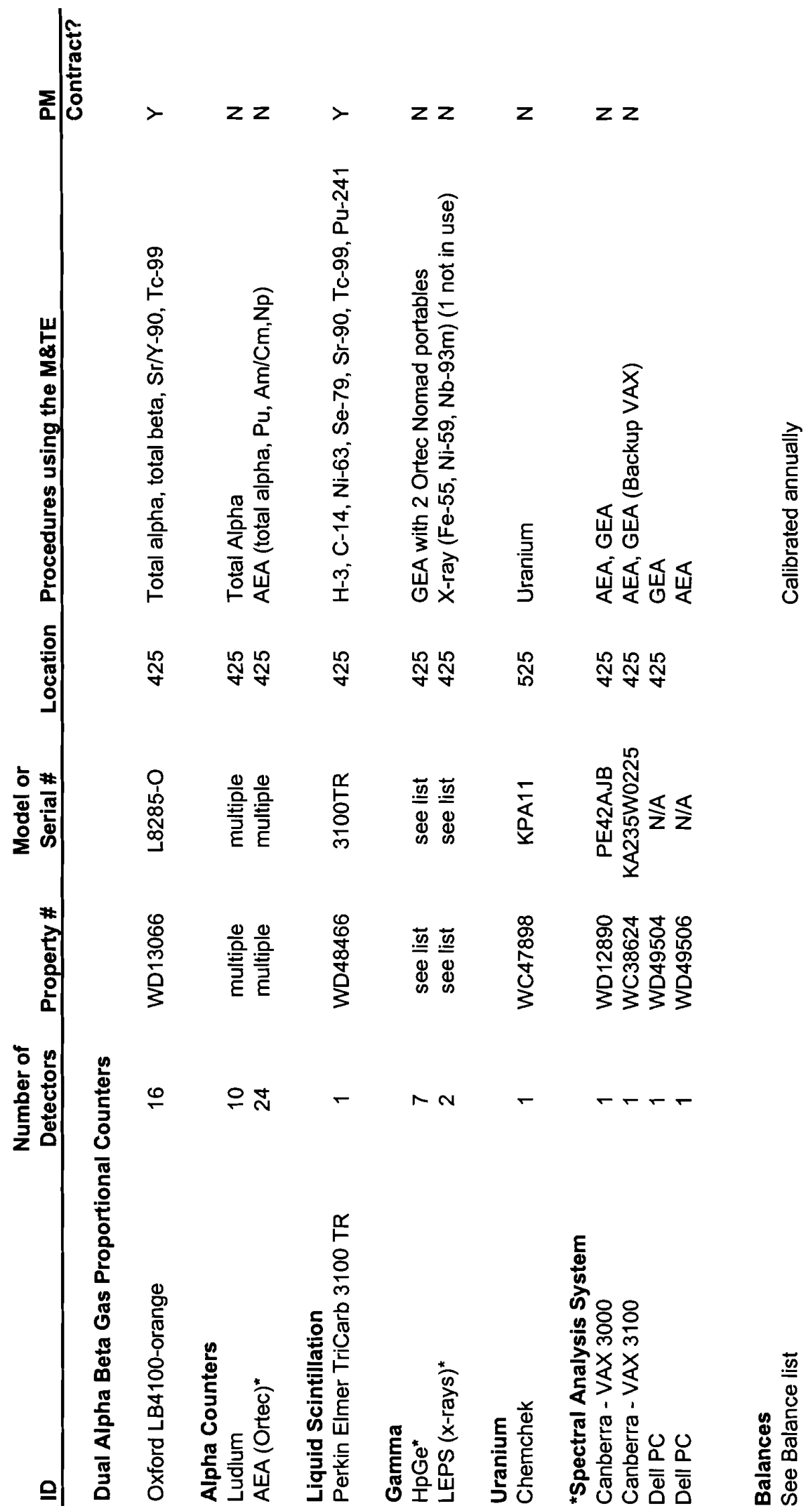


Appendix K

\section{Group 7 CUF Concurrence Letter}


Appendix K: Group 7 CUF Concurrence Letter 


\section{Pacific Northwest \\ National Laboratory}

Operated by Battelle for the

U.S. Department of Energy

April 22, 2008

Mr. Haukur R. Hazen

WTP/RPP-MOA-PNNL-00216

Bechtel National Inc.

2435 Stevens Center Place, MSIN: H4-02

Richland WA 99352

Dear Mr. Hazen:

Subcontract NO. 24590-QL-HC9-WA49-00001 - Project 53019 (WA\#2007-019)

Request Approval for Recommendation for Feed Composition, Bench-Scale Testing, and CUF Testing for Group 7

The purpose of this letter is to seek concurrence with the recommendation for feed composition, bench-scale testing, and CUF testing as required in Section 6.4 Item 2.0 in Test Plan TP-RPP-WTP467, Characterization and Small Scale Testing of Hanford W astes to Support the Development and Demonstration of Leaching and Ultrafiltration Pretreatment Processes

\section{Recommendations for Filtration, and Caustic Leaching Test Matrix in the CUF for Group 7 Sample}

This test will cover the cross flow filtration and caustic leaching test for Group 7 (TBP sludge) composite tank waste slurry, blended with tank wastes samples from 241-AY-102. Accordingly, this work addresses the determination of filtration and leaching behavior at the bench-scale using the CUF system as described in TP-RPP-WTP-467. As the test plan allows, additional material may be added to a homogenized sample group for CUF testing if the total mass of the homogenized waste sample is not large enough to process by itself. Initial characterization of the Group 7 homogenized sample estimates that there are $\sim 200$ grams of un-dissolved solids present -- a minimum of 300 grams are required to produced a waste slurry at $20 \mathrm{wt} \%$ un-dissolved solids (UDS). It is proposed that archived tank waste samples from 241-AY-102 be added to the Group 7 during processing to increase the solid level of the slurry. The AY-102 samples are similar in composition and are estimated to have 200 grams of insoluble solids in the waste samples available. While the aluminum levels in both wastes are relatively small, the insoluble fraction of phosphate present in the Group 7 waste is high enough to justify performing a caustic leach. The proposed test sequence is summarized in the scheme shown in Figure 1. 
Mr. Haukur R. Hazen

April 22, 2008

Page 2

\section{Initial Test Matrix:}

The initial filtration testing, low solids test matrix shown in Table 1, will be conducted with the Group 7 homogenized sample alone diluted to an estimated $4 \mathrm{wt} \%$ UDS. The inventory consists of 1.3-1.4L of the waste slurry at an un-dissolved solids concentration of $10 \mathrm{wt} \%$. To dilute the waste slurry to $4 \mathrm{wt} \%$ UDS, a supernatant simulant will be added to give a total slurry volume of $\sim 3.5 \mathrm{~L}$. The supernatant simulant will be made to mimic the composition of the $\sim 4 \mathrm{M} \mathrm{Na}$ supernatant of Group 7 waste. While the sodium concentration of the simulant is lower than prototypic concentration of $5 \mathrm{M}$, it is more desirable to use a simulant based on the composition of the supernatant that is at equilibrium already with the waste. This will avoid precipitating species from the entrained supernatant and will allow for the formulation of a stable supernatant simulant. However, because the waste is caustic deficient, the free hydroxide of the simulant supernatant will be increased to $0.3 \mathrm{M}$.

\section{Dewatering:}

All dewatering and filtration testing will be conducted at $25 \pm 5^{\circ} \mathrm{C}$. Dewatering parameters will be conducted at the median target of the filtration testing, which is a transmembrane pressure (TMP) of $40 \mathrm{psi}$ and an axial velocity (AV) of $13 \mathrm{ft} / \mathrm{s}$.

Dewatering will be done on the initial $\sim 4 \mathrm{wt} \%$ Group 7 slurry to a target of $\sim 10 \mathrm{wt} \%$ UDS. Once the waste slurry is back at its original concentration, the AY-102 archive samples (1750 ml slurry (a) 3.4M Na) will be added to the slurry reservoir. The AY-102 slurry samples are estimated to have the same un-dissolved solids concentration of $10 \mathrm{wt} \%$ UDS, so no other adjustments to the combined slurry will be made. The combined slurry $(\sim 3.2 \mathrm{~L})$ will then be dewatered to $\sim 1.4 \mathrm{~L}$, or to the minimum volume possible. The target solids concentration of slurry at a final volume of $1.4 \mathrm{~L}$ is $22 \mathrm{wt} \%$ UDS.

The combined dewatered supernatant will be at a sodium concentration of approximately $3.7 \mathrm{M}$ $\mathrm{Na}$ and a free hydroxide concentration of $0.4 \mathrm{M}$. Figure 2 provides a summary of sodium molarity during dewatering for the first five years of operating the Waste Treatment Plant. Inspection of this figure indicates that $3.7 \mathrm{M} \mathrm{Na}$ is within the range of conditions expected to be seen during the initial dewatering of slurry and bounds approximately $30 \%$ of the batches.

After dewatering the combined waste slurry, a high solids filtration test matrix, shown in Table 1 , will be conducted. If the slurry is unable to be pumped adequately through the system to run the test matrix, the slurry may be diluted with dewatered permeate as required. 
Mr. Haukur R. Hazen

April 22, 2008

Page 3
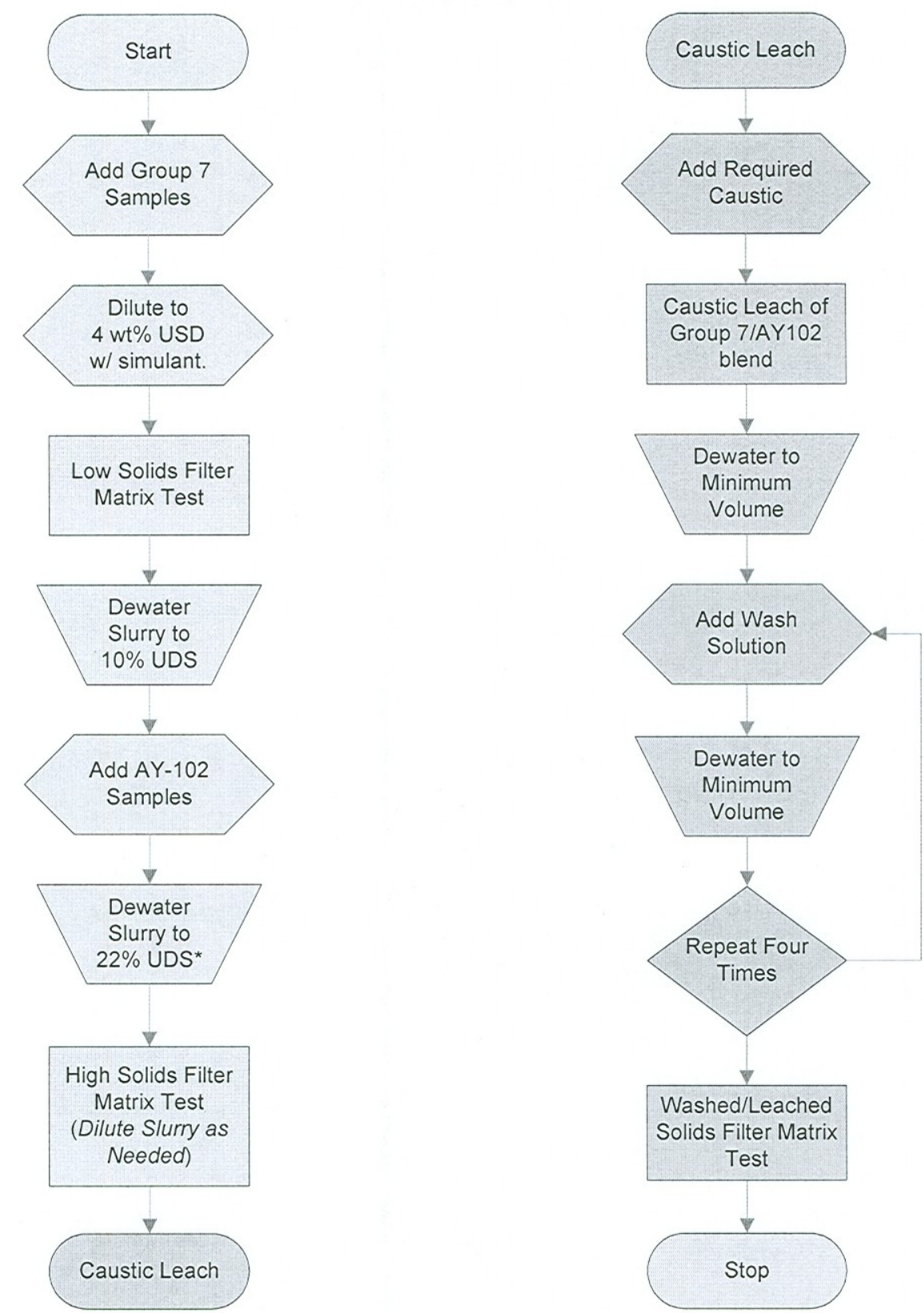

* Concentration value is target

Figure 1: Proposed Test Scheme for Composite Group 7 / AY-102 CUF Test 
Mr. Haukur R. Hazen

April 22, 2008

Page 4

Fraction of batches bounded by the sodium molarity during initial dewatering

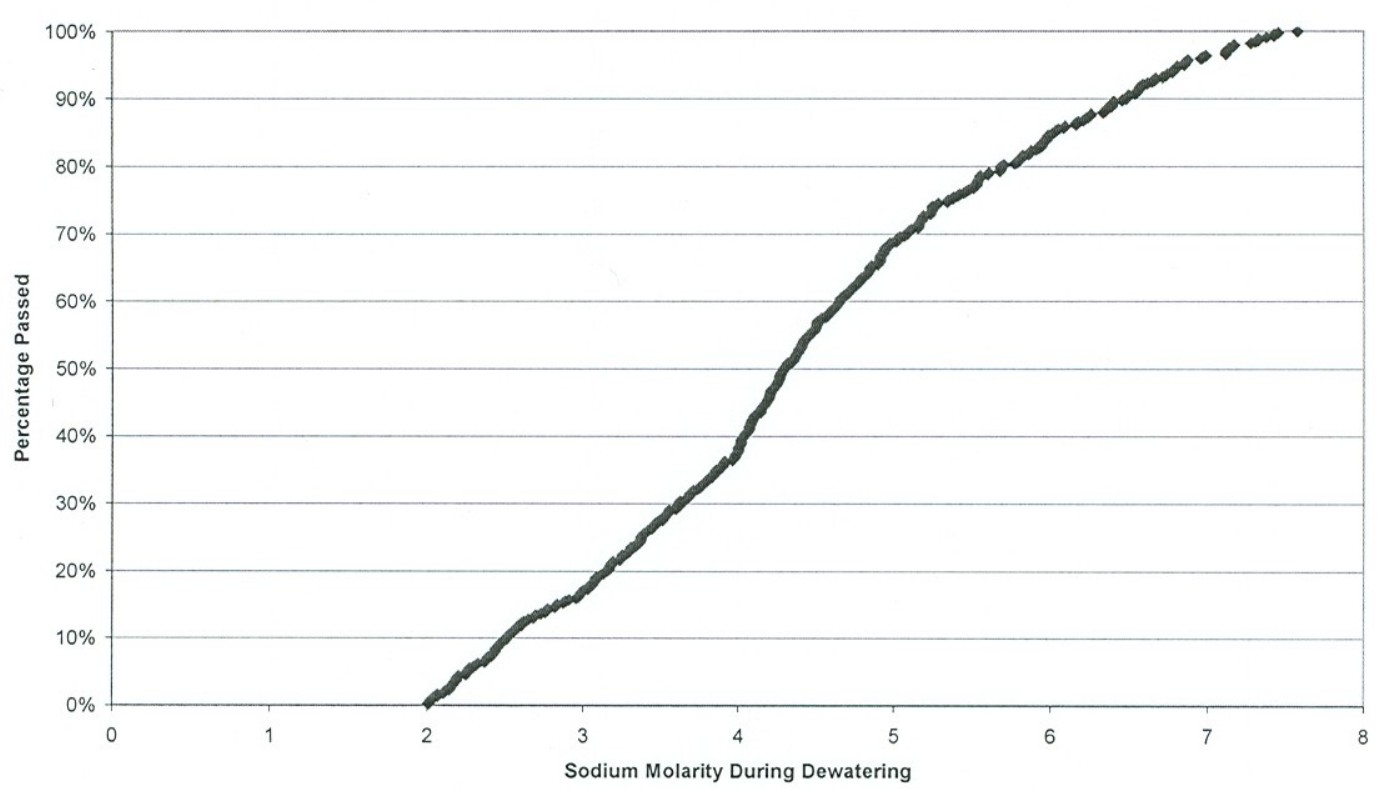

Figure 2. Projected WTP sodium molarity during initial dewatering.

\section{Dewater Process Steps (more details provided in this section)}

- First prepare the low-solids slurry by combining a supernatant simulant with the Group 7 slurry, to provide $\sim 3.5 \mathrm{~L}$ of slurry at a target of $\sim 4 \mathrm{wt} \%$ UDS and $4 \mathrm{M}$ sodium.

- Conduct low solids filtration test matrix, 
Mr. Haukur R. Hazen

April 22, 2008

Page 5

Table 1.

- Dewater to target of $10 \mathrm{wt} \%$ UDS or as low volume as possible to generate a dewatering data from the Group 7 waste.

- Add the archive AY-102 samples to the dewatered Group 7 waste slurry.

- Dewater to target of $22 \mathrm{wt} \%$ UDS or as low volume as possible to generate a detailed dewater curve.

- Conduct a high solids matrix test as shown in Table 1. (If rheology, air entrainment or temperature control does not allow operation at $22 \mathrm{wt} \%$, permeate will be added back such that the test matrix could be carried out.) 
Mr. Haukur R. Hazen

April 22, 2008

Page 6

Table 1. Filtration Test Matrix

\begin{tabular}{|c|c|c|c|}
\hline Test number & $\begin{array}{c}\text { Duration } \\
\text { (hours) }\end{array}$ & $\begin{array}{c}\text { Target TMP* } \\
(\mathbf{p s i})\end{array}$ & $\begin{array}{c}\text { Target Axial Velocity* } \\
(\mathrm{ft} / \mathbf{s})\end{array}$ \\
\hline 1 & 3 & 40 & 13 \\
\hline 2 & 1 & 30 & 11 \\
\hline 3 & 1 & 30 & 15 \\
\hline 4 & 1 & 50 & 11 \\
\hline 5 & 1 & 50 & 13 \\
\hline 6 & 1 & 40 & 9 \\
\hline 7 & 1 & 40 & 17 (or max) \\
\hline 8 & 1 & 40 & 13 \\
\hline 9 & 1 & 20 & 13 \\
\hline 10 & 1 & 60 & condit \\
\hline 11 & 1 & 40 & may \\
\hline
\end{tabular}

* Actual conditions may vary based upon slurry volume and rheology. All conditions may not be obtainable.

\section{Leaching}

Caustic leach conditions for the blended waste slurry are proposed below based on a slurry volume of $\sim 1.4 \mathrm{~L}$ at $\sim 22 \mathrm{wt} \%$ UDS, expected aluminum solid concentration, and leach factors of $100 \%$ dissolution of aluminum:

Add 1.4 $\mathrm{L}$ of $5.3 \mathrm{M} \mathrm{NaOH}$ (adjust as needed for $\mathrm{Al}$ solubility at $25^{\circ} \mathrm{C}$ ), leach for 8 hours at $60^{\circ} \mathrm{C}$, and add water as needed during the caustic leach lost by evaporation to maintain a constant volume.

The final sodium concentration is expected to be $\sim 4.5 \mathrm{M}$. Examining Figure 3, a summary of the sodium molarity during caustic leaching for the first 5 years of WTP operation, shows that leaching at $\sim 4.5 \mathrm{M}$ sodium is at the lower end of the expected operating envelope. Because the aluminum present in the waste is relatively small ( $\sim 5 \%$ aluminum in the combined solids), the required quantity of caustic to be added is lower as well. However, the main goal of the caustic leach is to dissolve the phosphate present in the Group 7 that is insoluble otherwise. 
Fraction of batches bounded by the sodium molarity during caustic leaching

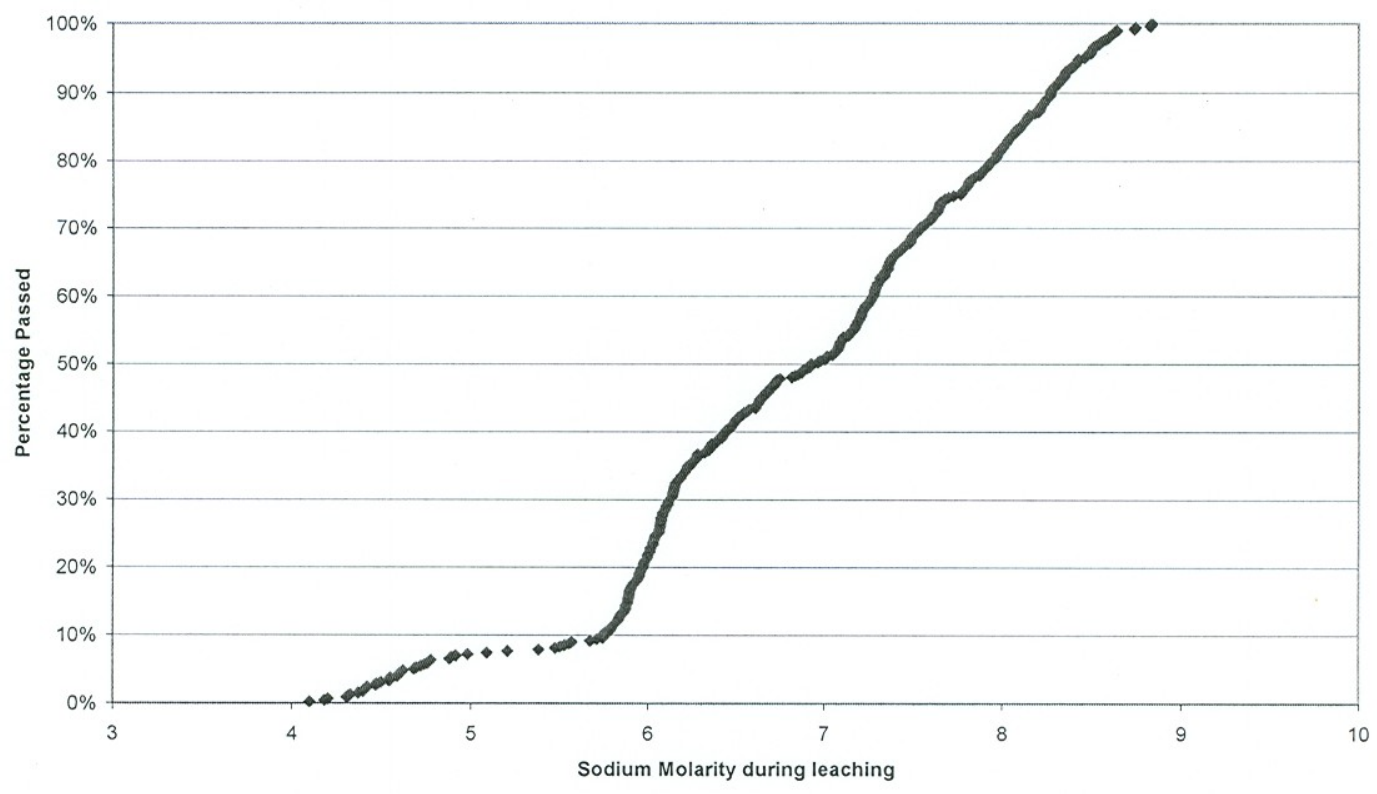

Figure 3. Projected WTP sodium molarity during caustic leaching.

\section{Caustic Leaching Process Steps (more details provided in this section)}

- Retrieve all solids from CUF and isolate in slurry feed reservoir for leaching.

- Assuming $1.4 \mathrm{~L}$ of $20 \mathrm{wt} \%$ UDS at $3.7 \mathrm{M}$ sodium, add $1.4 \mathrm{~L}$ of $5.3 \mathrm{M} \mathrm{NaOH}$. (These leaching conditions have been estimated to produce a solution saturated with $\mathrm{Al}$ at $25^{\circ} \mathrm{C}$ at the conclusion of the leaching process.)

- Based on kinetic studies of phosphate dissolution while caustic leaching, there is no need to heat the batch beyond $60^{\circ} \mathrm{C}$ while caustic leaching. Aluminum dissolution is not an objective for the caustic leaching of the Group 7/AY-102 waste. The process, which deviates from historic WTP baseline process conditions, is as follows:

$\circ$ Heat from $25^{\circ} \mathrm{C}$ to $60^{\circ} \mathrm{C}$ in 2.5 hours.

- Leach for $8 \mathrm{~h}$ at $60(+5 /-10)^{\circ} \mathrm{C}$.

- Cool from $60^{\circ} \mathrm{C}$ to $25^{\circ} \mathrm{C}$ in 5.6 hours.

\section{Post Caustic Leach Dewater Process Steps}

- Dewater leached solids at $25^{\circ} \mathrm{C}, \mathrm{TMP}=40 \mathrm{psi}$, and $\mathrm{AV}=13 \mathrm{ft} / \mathrm{s}$.

- Dewater to a target of $\sim 1.3 \mathrm{~L}$ or to minimum operating volume of CUF ( $20 \mathrm{wt} \%$ undissolved solids assuming aluminum is all gibbsite and 100\% $\mathrm{Al}$ dissolution). 
Mr. Haukur R. Hazen

April 22, 2008

Page 8

\section{Post Caustic Leach Washing Process Steps (if necessary)}

- Four equal volume washes of the dewatered leached slurry will occur at caustic levels high enough to ensure that the solubility of $\mathrm{Al}$ is maintains in the leached slurry permeate and the dewatered wash solutions.

- Wash 1: $\sim 1.2 \mathrm{~L}$ solution of $0.5 \mathrm{M} \mathrm{NaOH}$ solution is added. Slurry is dewatered to a target of $\sim 1.2 \mathrm{~L}$ or to minimum operating volume of CUF.

- Wash 2: 1.2L solution of $0.1 \mathrm{M} \mathrm{NaOH}$ solution is added. Slurry is dewatered to a target of $\sim 1.2 \mathrm{~L}$ or to minimum operating volume of CUF.

- Wash 3: 1.2L solution of $0.05 \mathrm{M} \mathrm{NaOH}$ solution is added. Slurry is dewatered to a target of $\sim 1.2 \mathrm{~L}$ or to minimum operating volume of CUF.

- Wash 4: 1.2L solution of $0.01 \mathrm{M} \mathrm{NaOH}$ solution is added. Slurry is dewatered to a target of $\sim 1.2 \mathrm{~L}$ or to minimum operating volume of CUF.

- After the fourth rinse, perform a final filter test matrix on the washed solids, as outlined in Table 1.

- Drain slurry from CUF and retain for potential use, only dispose at the guidance of the client.

- Clean CUF and determine clean water $(0.01 \mathrm{M} \mathrm{NaOH})$ flux.

\section{Sample Plan}

The sample collection and analysis plan will be implemented as defined in the test plan.

If you have any questions, please contact Reid Peterson on 376-5340.

Sincerely,

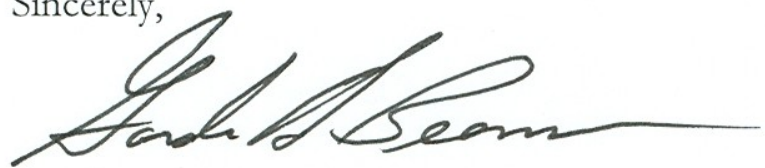

Gordon H. Beeman, Manager

RPP-WTP Support Program

GHB: $\mathrm{c}^{2}$

cc: $\quad$ RA Peterson (PNNL)

RW Shimskey (PNNL)

PS Sundar (BNI)

Project File/LB 
From: Gilbert, Robert A (Rob) [Robert_A_Rob_Gilbert@RL.gov]

Sent: Thursday, April 03, 2008 1:34 PM

To: Barnes, Steven M; Sundar, Parameshwaran S

Cc: Peterson, Reid A

Subject: FW: Request for Approval on Group 7 Parametric Test Matrix

Steve,

ORP concurs with the Group 7 parametric test matrix. Several typos are noted in Keith's message below.

Thanks

Rob Gilbert

From: Sandroni, Keith E

Sent: Thursday, April 03, 2008 8:51 AM

To: Gilbert, Robert A (Rob)

Subject: RE: Request for Approval on Group 7 Parametric Test Matrix

Rob,

I only found minor typos in the Group 7 approval. The first paragraph of recommendations states "Group 1" when, I'm assuming, it should be group 7 . Also, "volume" is misspelled in requirement $2 \mathrm{~d}$. I don't have any issues with the actual test matrix.

Keith

From: Gilbert, Robert A (Rob)

Sent: Wednesday, April 02, 2008 8:58 AM

To: Sandroni, Keith E

Subject: FW: Request for Approval on Group 7 Parametric Test Matrix

I mportance: High

Updated matrix for review.

From: Sundar, Parameshwaran S [mailto:pssundar@bechtel.com]

Sent: Wednesday, April 02, 2008 8:55 AM

To: Gilbert, Robert A (Rob)

Cc: Barnes, Steven M; Peterson, Reid A

Subject: Request for Approval on Group 7 Parametric Test Matrix

I mportance: High

ROB:

I am attaching the revised subject request for approval from PNNL for the Group 7 parametric test matrix. As you may recall we have reviewed this at yesterday's weekly meeting. The revised request incorporates the agreed to additional tests.

Please review the attached and approve, it acceptable to ORP by COB Thursday, April 3, 2008.

Regards,

SUNDAR

<<Group 7 Parametric Test Matrix Request for Approval -040208.doc>> 
From: Peterson, Reid A [reid.peterson@pnl.gov]

Sent: Monday, April 28, 2008 1:27 PM

To: Sundar, Parameshwaran S

Subject: FW: Formal Concurrence Letter to BNI for Group 7 CUF Test

Attachments: Group 7 Test Concurrence Request from WTP final RAG Comments.doc fyi

Reid

From: Gilbert, Robert A (Rob)

Sent: Monday, April 21, 2008 1:24 PM

To: Barnes, Steven M

Cc: Peterson, Reid A; Bang, Ricky

Subject: RE: Formal Concurrence Letter to BNI for Group 7 CUF Test

Steve,

ORP concurs with the subject Group 7 CUF test proposal with one change as marked in the attached file. The change does not alter the test but corrects misstatements of the test parameter basis.

Thanks

Rob Gilbert

From: Barnes, Steven M [mailto:smbarnes@bechtel.com]

Sent: Thursday, April 17, 2008 9:25 AM

To: Gilbert, Robert A (Rob)

Cc: Peterson, Reid A

Subject: FW: Formal Concurrence Letter to BNI for Group 7 CUF Test

Rob,

Please provide any comments you have on the specific tests to be performed with group 7 wastes as we have discussed in our weekly meetings.

Thank you Steve

From: Peterson, Reid A [mailto:reid.peterson@pnl.gov]

Sent: Wednesday, April 16, 2008 12:58 PM

To: Sundar, Parameshwaran S

Cc: Barnes, Steven M

Subject: FW: Formal Concurrence Letter to BNI for Group 7 CUF Test

Here is the Group 7 concurrence letter.

Reid

From: Shimskey, Rick W

Sent: Wednesday, April 16, 2008 12:56 PM 
To: Charron, Chrissy E

Cc: Peterson, Reid A

Subject: Formal Concurrence Letter to BNI for Group 7 CUF Test

Chrissy,

Please format the attached word document into a formal concurrence letter to BNI.

Subcontract NO. 24590 QL HC9 WA49-00001 - Project 53019 (WA\#2007-019)

Thanks,

Rick

<<Group 7 Test Concurrence Request from WTP.final.doc >> 
PNNL-18119

WTP-RPT-169, Rev. 0

\section{Distribution}

No. of

Copies

\section{ONSITE}

4 Bechtel National, Inc.

WTP R\&T Docs (2) H4-02

P. S. Sundar H4-02

S. Barnes H4-02

15 Pacific Northwest National Laboratory

M. K. Edwards (2) P7-25

J. M. Billing P7-25

E. C. Buck P7-27

R. C. Daniel P7-22

S. K. Fiskum P7-25

D. E. Kurath K3-52

G. J. Lumetta P7-25

L. M. Peurrung K9-09

R. A. Peterson P7-22

R. L. Russell K6-24

R. W. Shimskey P7-25

L. A. Snow P7-25

Information Release P8-55

Project File K3-52 